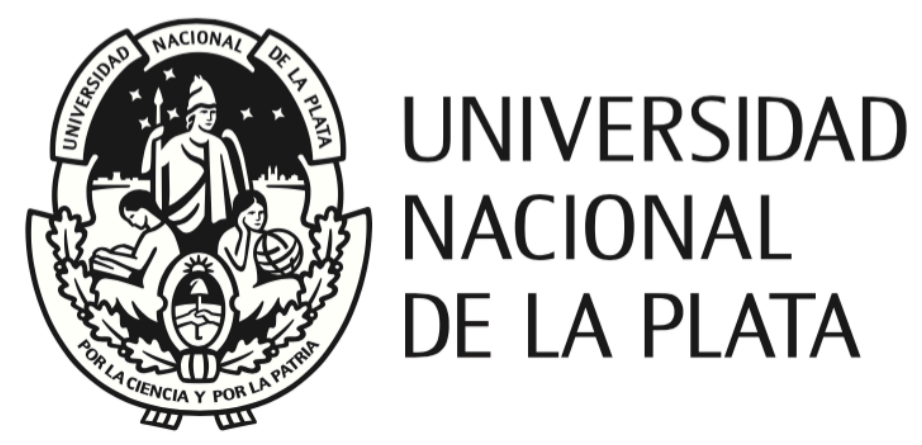

FACULTAD DE INFORMATICA

\title{
Interacción e interactividad en el trabajo colaborativo mediado por tecnología informática
}

Metodología de seguimiento en escenarios educativos

Tesista: Prof. Mgter. María Alejandra Zangara

Directora: Dra. Cecilia Sanz

Tesis presentada para obtener el grado de Doctor en Ciencias Informáticas 
"La cosa más humana sobre nosotros es la tecnología"

Herbert Marshall McLuhan 


\section{Indice de Contenidos}

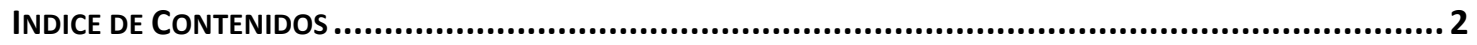

INDICE DE FIGURAS

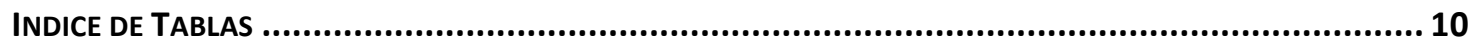

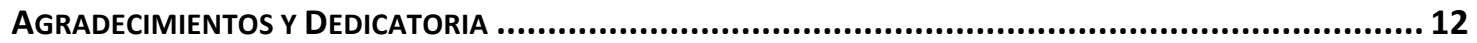

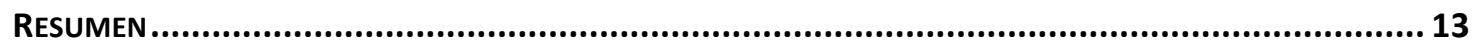

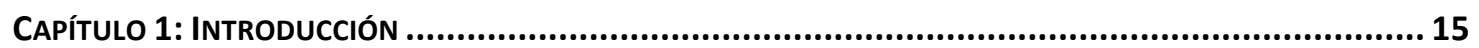

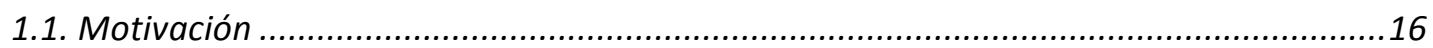

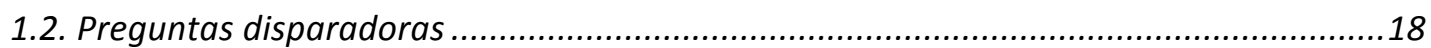

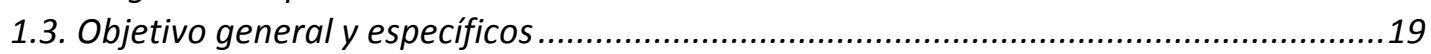

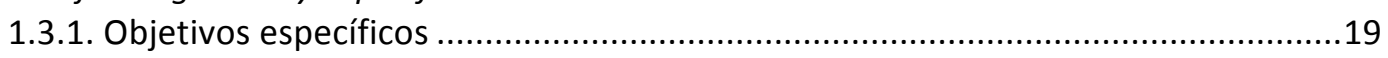

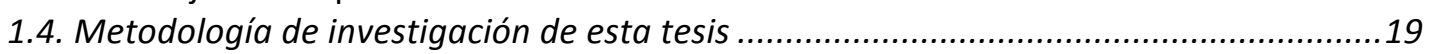

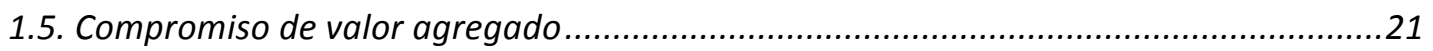

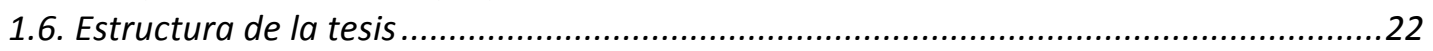

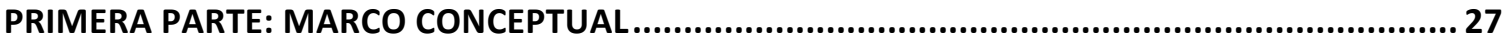

CAPÍTULO 2: INTERACCIÓN E INTERACTIVIDAD EN LA EDUCACIÓN MEDIADA ......................................... 28

2.1. El modelo de Distancia Transaccional en la educación a distancia ................................29

2.1.1. Componentes del modelo de Distancia Transaccional .........................................29

2.1.1.1. Estructura de la propuesta de enseñanza .......................................................

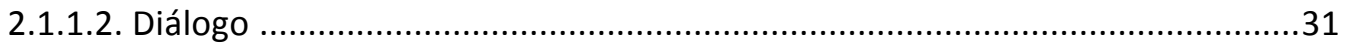

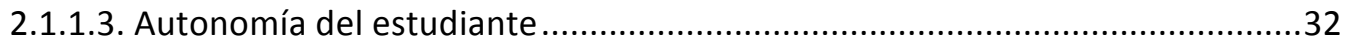

2.2. Relaciones conceptuales entre interacción e interactividad .........................................36

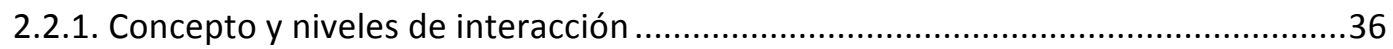

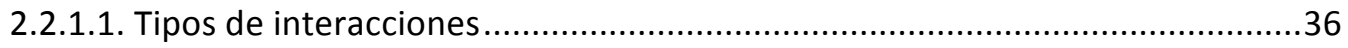

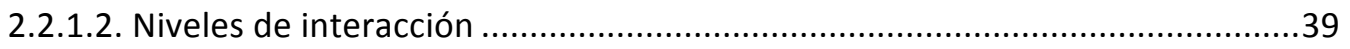

2.2.1.3. Interacción Persona-Ordenador (IPO) ........................................................4

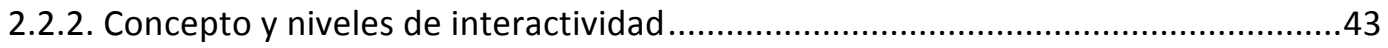

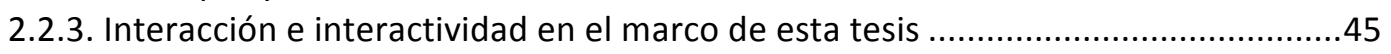

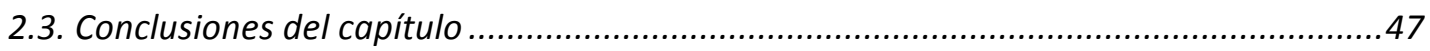

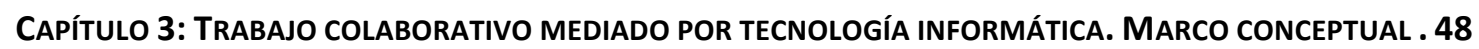

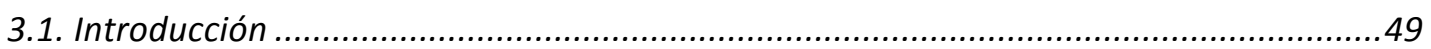

3.2. Trabajo en grupos como antecedente del trabajo colaborativo ....................................49

3.2.1. Del objeto discreto al colectivo: la tensión individuo-grupo y su relación con la

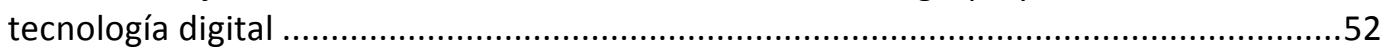

3.2.2. Grupos de aprendizaje como un tipo especial de grupo ....................................54

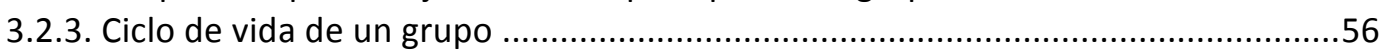

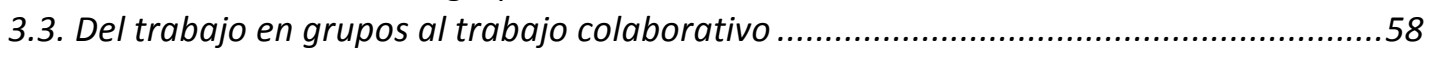

3.3.1. Definición de trabajo colaborativo en escenarios educativos ................................58

3.3.2. Diferencias entre trabajo colaborativo y otros tipos de trabajo grupal ..................60

3.3.3. Diferencias entre trabajo colaborativo y cooperativo ..........................................62

3.4. La enseñanza orientada a grupos como objeto de la Didáctica.....................................63

3.4.1. Una propuesta de enseñanza para grupos colaborativos.....................................64 
CAPÍtULO 4: ANTECEDENTES EN RELACIÓN A LA VALORACIÓN DEL TRABAJO COLABORATIVO MEDIADO POR TECNOLOGÍA INFORMÁTICA

4.1. Valoración, seguimiento, evaluación. ¿Para qué? ¿Para quiénes? ..............................69

4.1.1. Diferencias conceptuales: evaluación, seguimiento, valoración ............................70

4.1.2. Actores de la situación educativa impactados por esta información ......................71

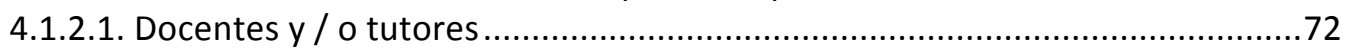

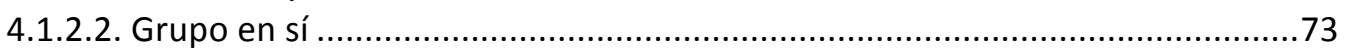

4.1.2.3. Diseñadores de ambientes colaborativos y herramientas .............................74

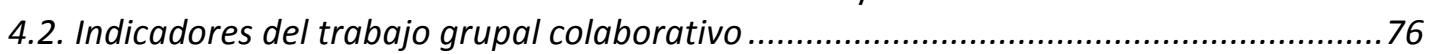

4.2.1. Indicadores del aporte individual al grupo ..........................................................76

4.2.1.1. Síntesis de indicadores desde la perspectiva individual y su contribución al

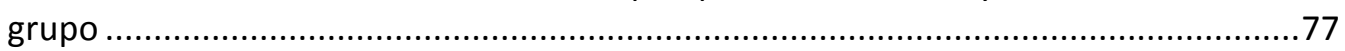

4.2.2. Indicadores que la tecnología permite visibilizar: cómo el grupo construye ..........79

4.2.3. Análisis de la conexión semántica en el trabajo colaborativo. Argumentación como

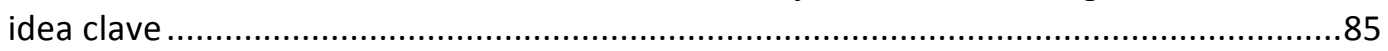

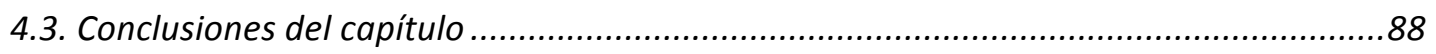

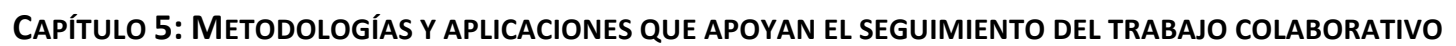

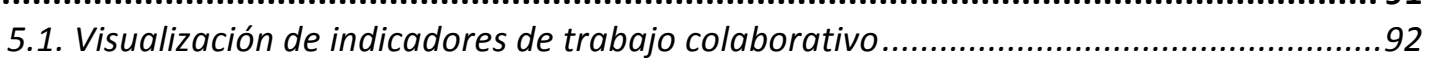

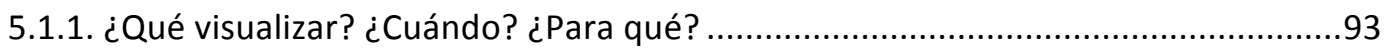

5.2. Herramientas de visualización del trabajo colaborativo ..............................................94

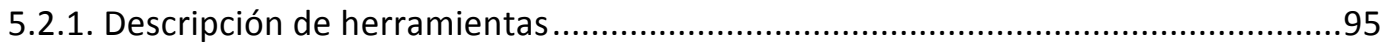

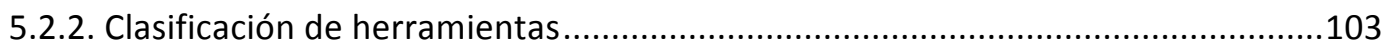

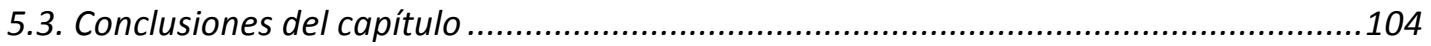

EPÍlOGo: MAPA DE COMPONENTES DEL TRABAJo ColabORATIVo SEGÚN DISCIPLINAS ......................... 106

SEGUNDA PARTE: APORTES DE ESTA TESIS Y SU VALIDACIÓN ............................................ 108

Capítulo 6: Presentación de la metodología de seguimiento y Valoración del tRabajo

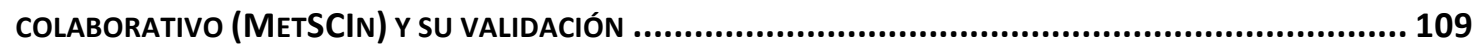

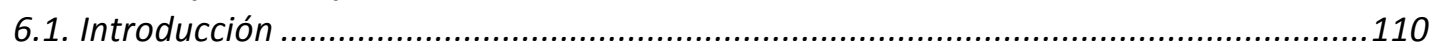

6.2. Área de vacancia para la presentación de la metodología de seguimiento del trabajo

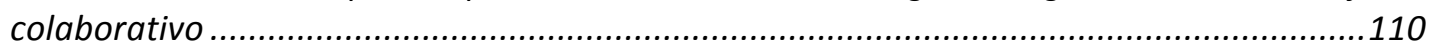

6.2.1. Componentes de una metodología ..............................................................111

6.2.2. Componentes de la metodología de seguimiento del trabajo colaborativo mediado por tecnología informática MetSCIn .........................................................................111

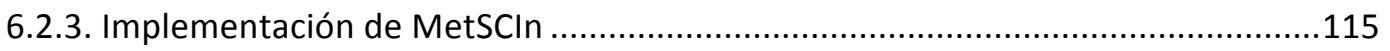

6.3. Matriz de indicadores de seguimiento del trabajo colaborativo................................116

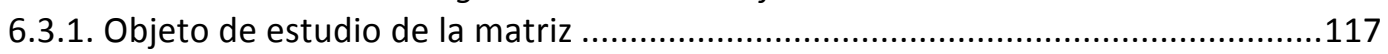

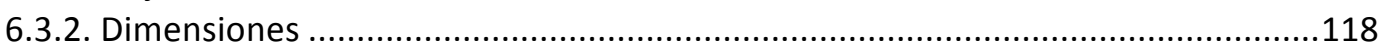

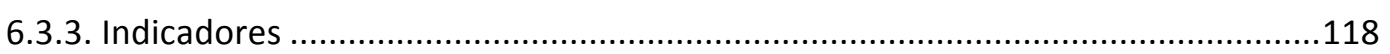

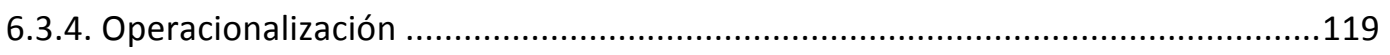

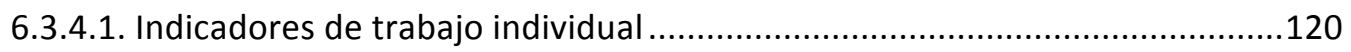

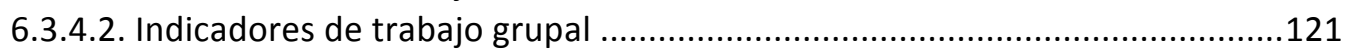

6.4. Instrumentos diseñados ad hoc como parte de MetSCIn ...........................................123 
6.4.1. Indagación sobre autorregulación ............................................................123

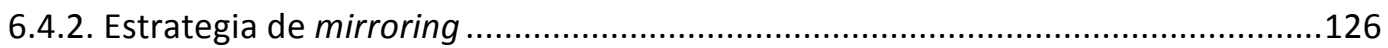

6.4.2.1. Concepto de mirroring ....................................................................127

6.4.2.2. Comunicación de la estrategia de mirroring en MetSCIn ............................127

6.4.2.3. Estructura propuesta para la presentación de información de mirroring en MetSCIn

6.4.2.4. Indagación del impacto del mirroring en el trabajo colaborativo en MetSCIn

6.5. Etapas de construcción de la metodología..............................................................136

6.6. Posibilidades de aplicación de la metodología MetSCIn. Uso modular........................137

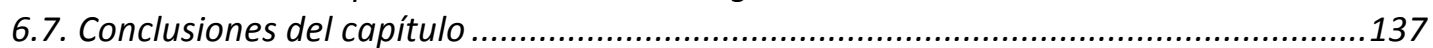

CAPítUlo 7: JUICIO DE EXPERTOS COMO VALIDACIÓN DE LA MATRIZ DE INDICADORES DE SEGUIMIENTO.. 139

7.1. Introducción ............................................................................................ 140

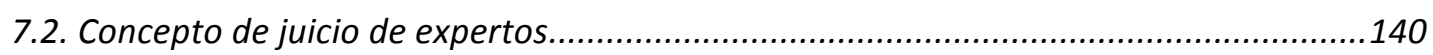

7.3. Concepto de experto ........................................................................................ 142

7.4. Consideraciones sobre la cantidad de expertos recomendada ..................................143

7.5. Evaluación de la validez de la matriz de indicadores mediante el juicio de expertos...143

7.6. Metodología implementada ..................................................................... 144

7.6.1. Selección de expertos por cada dimensión del tema ........................................145

7.6.1.1. Biograma de los expertos seleccionados................................................146

7.6.2. Instrumento aplicado en el juicio de expertos ................................................147

7.6.3. Comunicación y seguimiento metodológico del juicio de expertos .....................150

7.6.4. Análisis de resultados del juicio de expertos .................................................151

7.6.4.1. Análisis del factor $\mathrm{K}$ (grado de expertise manifestado por los expertos) ......151

7.6.4.2. Análisis de la concordancia de respuesta por ítem y sección del instrumento

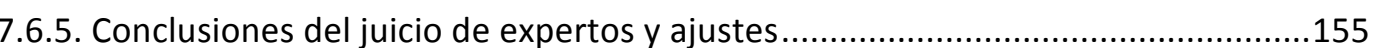

7.7. Versión final de la matriz de indicadores ........................................................... 157

7.8. Conclusiones del capítulo .................................................................... 158

Capítulo 8: Estudio de CASO como IMPLEMENTACIÓn DE METSCIN ....................................... 159

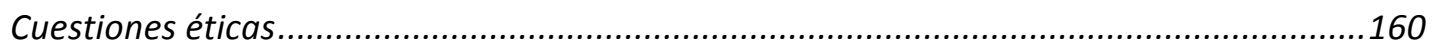

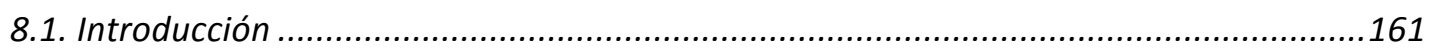

I. Concepto y JustificAción MEtodológiCA DEL ESTUdio de CASO.......................................... 161

8.2. Definición de la metodología de estudio de caso ...................................................161

8.3. Consideraciones sobre la recolección y análisis de la información en el estudio de caso

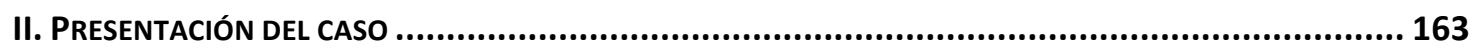

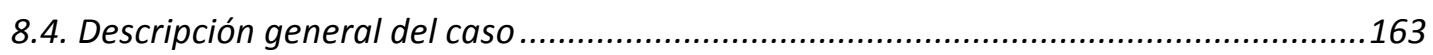

8.4.1. Presentación de la e-actividad de escritura colaborativa ...................................164

8.5. Constitución de los grupos de estudio contrastados ................................................167

8.6. Indicadores e instrumentos de MetSCIn para el estudio de caso ................................168

III. RESUltadoS ............................................................................................. 169

8.7. Conformación del grupo de estudio ............................................................... 170

8.7.1. Otros datos de interés .................................................................................172

8.8. Resultados de la encuesta de autorregulación. Hallazgos por categoría de habilidades 


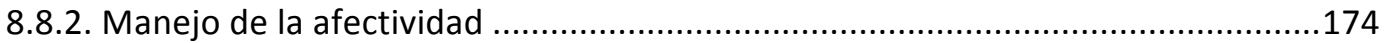

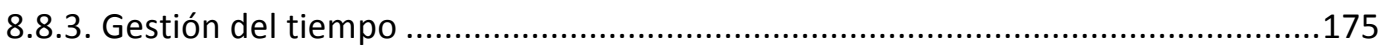

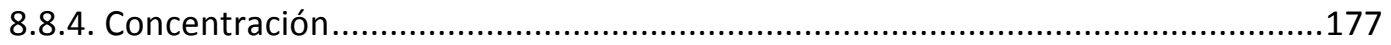

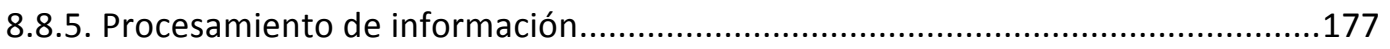

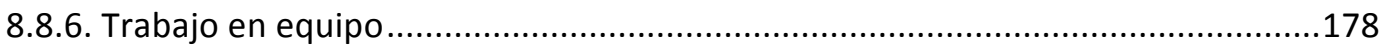

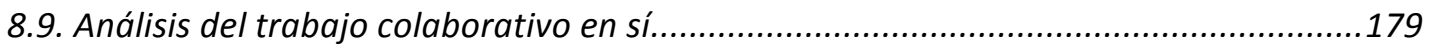

8.9.1. Dimensión individual de la colaboración. Densidad y calidad de interacción.

Cohortes contrastadas. .180

8.9.1.1. Densidad de interacción. Cantidad de mensajes durante toda la tarea y por

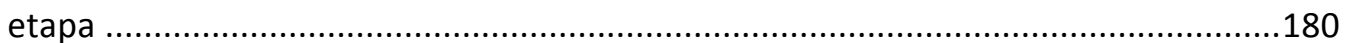
8.9.1.2. Densidad de interacción. Componentes de los mensajes según su tipo en la

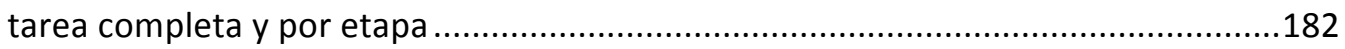

8.9.1.3. Dimensión individual de la colaboración. Comentarios ................................183

8.9.2. Dimensión grupal de la colaboración. Cohortes contrastadas .............................184

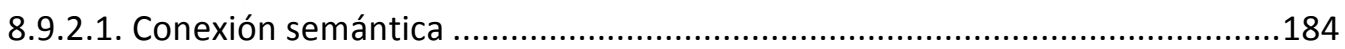

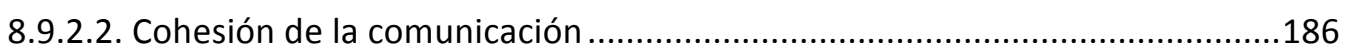

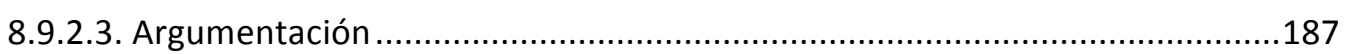

8.9.2.4. Dimensión grupal de la colaboración. Comentarios......................................189

8.10. Impacto de la estrategia de mirroring en la cohorte 2016......................................190

8.10.1. Frecuencia de acceso al sitio de información de mirroring ................................191

8.10.2. Acceso a la información sobre el tiempo restante para la entrega del trabajo..191

8.10.3. Información a la que se accedió según su autoría ..............................................192

8.10.4. Formato de información a la que se accedió .....................................................194

8.10.5. Decisiones de trabajo grupal resultantes del conocimiento de la información del

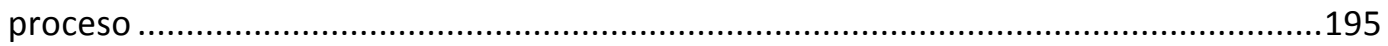

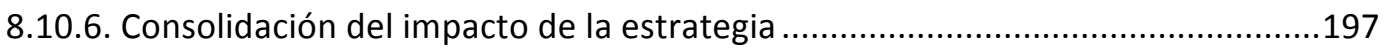

8.11. Discusión sobre la eficacia de MetSCIn a partir de los resultados obtenidos..............199

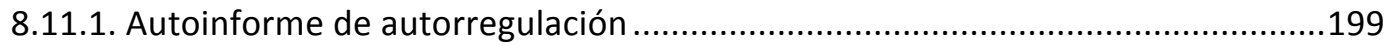

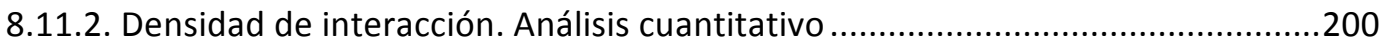

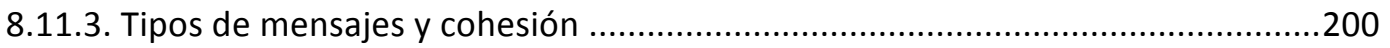

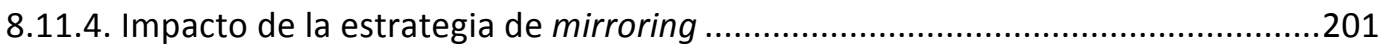

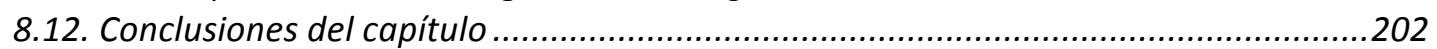

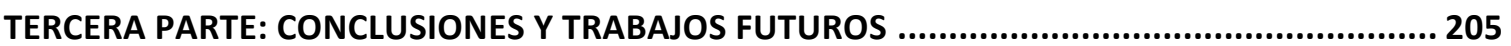

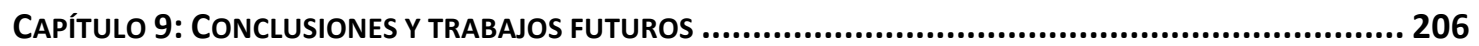

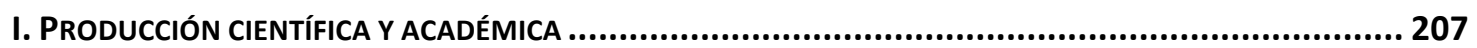

9.1. Producción científica y académica en relación con la tesis .......................................207

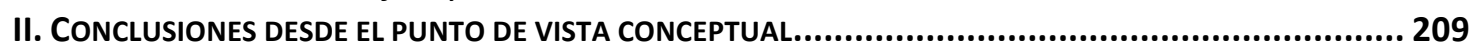

9.2. Conceptualización de interacción-interactividad ......................................................209

9.3. Componentes del trabajo colaborativo. Vinculaciones ..............................................209

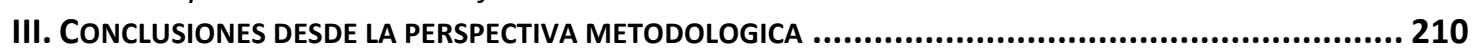

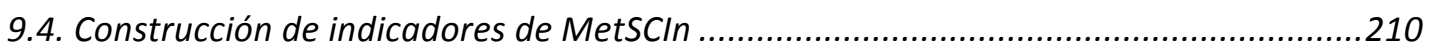

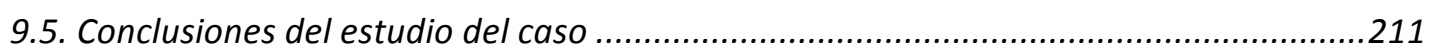

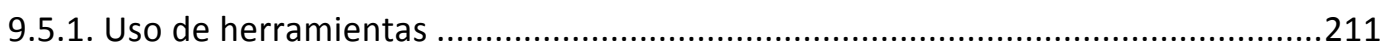

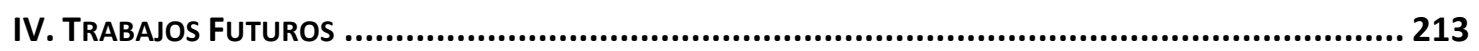

9.6. Avance en el campo de la interacción-interactividad...............................................213

9.7. Autorregulación individual como pilar de la enseñanza y del seguimiento grupal ......214

9.7.1. Derivaciones de la autorregulación para la enseñanza ........................................214 
9.7.2. Relación entre la autorregulación individual y grupal

9.8. Implementación de MetSCIn con vistas al análisis de su confiabilidad ........................214

9.9. Prototipo de una herramienta de mirroring sobre IDEAS..........................................214

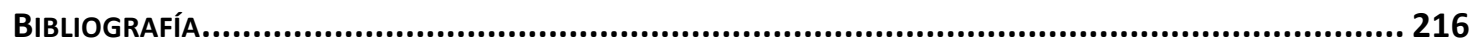

ANEXOS

ANEXO 1: COMUNICACIÓN Y PROTOCOLO DEL AUTOINFORME SOBRE HABILIDADES DE AUTORREGULACIÓN

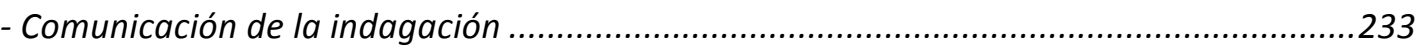

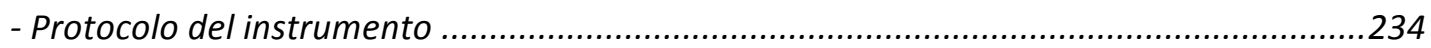

ANEXO 2: COMUNICACIÓN E INSTRUMENTO DE INDAGACIÓN DE IMPACTO DE LA ESTRATEGIA DE MIRRORING

- Comunicación de la estrategia de mirroring en MetSCIn...............................................242

- Indagación del impacto del mirroring en el trabajo colaborativo en MetSCIn .................243

ANEXo 3: COMUNICACIÓN E INSTRUMENTO DE INDAGACIÓN DEL JUICIO DE EXPERTOS ........................ 249

- Comunicación de la estrategia de juicio de expertos ....................................................249

- Instrumento de indagación del juicio de expertos .................................................250

ANEXO 4: RESULTADOS DEL ESTUDIO DE CASO POR COHORTE Y POR GRUPO .................................. 257

- Conformación de los grupos de trabajo .............................................................257

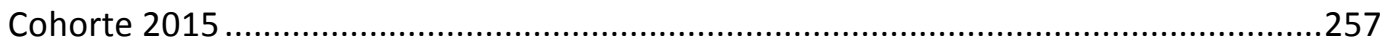

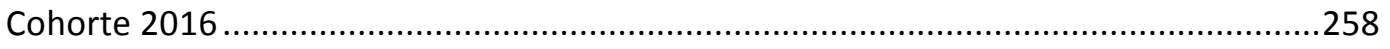

- Dimensión individual de la colaboración. Densidad y calidad de la interacción por grupo

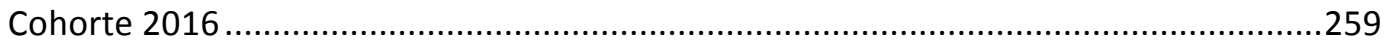

- Dimensión grupal. Conexión semántica ............................................................261

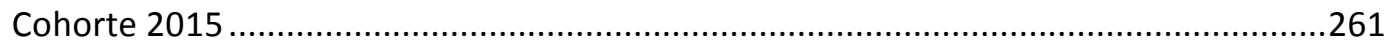

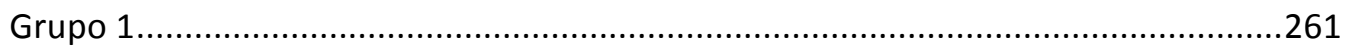

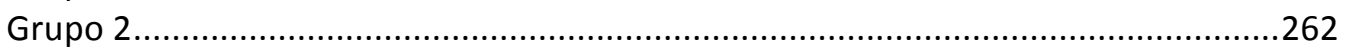

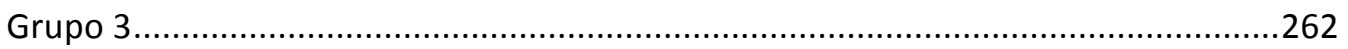

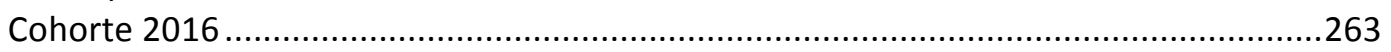

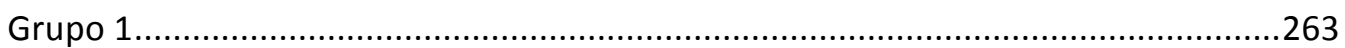

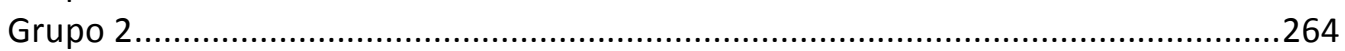

ANEXO 5: SITIOS DE INTERÉS CONSTRUÍDOS ESPECIALMENTE PARA ESTA TESIS ...................................266

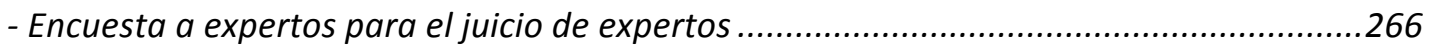

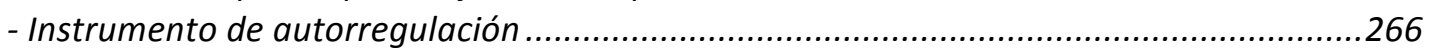

- Sitio de seguimiento del trabajo colaborativo para mirroring (en Googlesites)................266

- Instrumento de indagación de impacto de la estrategia de mirroring ..............................266

- Análisis de las estrategias de argumentación en un tópico completo, mediado por la herramienta foro. Ambas cohortes.... 266 


\section{Indice de Figuras}

Figura 1: Disciplinas que iluminan el objeto de estudio de esta tesis. Modelo propio ............................. 18

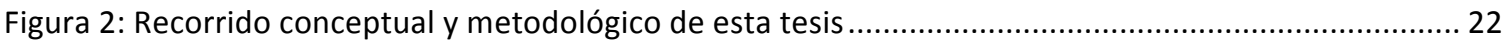

Figura 3: Relación entre las preguntas fundamentales de la tesis y los capítulos................................... 26

Figura 4: Modelo tridimensional de Distancia Transaccional (Traducido de Shearer, 2013) ...................... 30

Figura 5: Izquierda: Modelo telegráfico (Shannon y Weaver, 1950). Derecha: Modelo orquestal de la

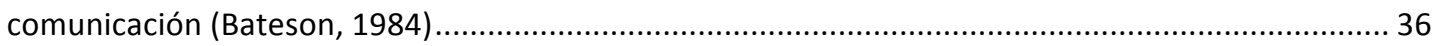

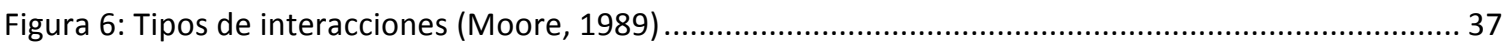

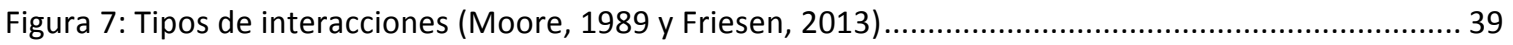

Figura 8: Interactividad como nivel superior del aprendizaje activo (Chi, 2009) ................................... 40

Figura 9: Niveles de interactividad (Williams et al., 1998) ..................................................................... 44

Figura 10: Concepto de interacción e interactividad en el marco de esta tesis .........................................46

Figura 11: Comparación entre los abordajes de cognición tradicional y cognición distribuida (Preece et al.,

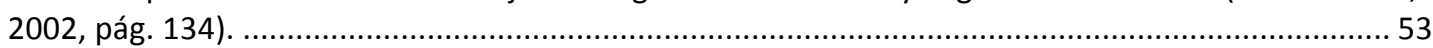

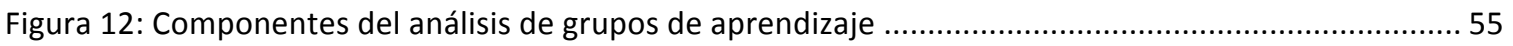

Figura 13: Componentes del concepto de cohesión de un grupo ........................................................5 56

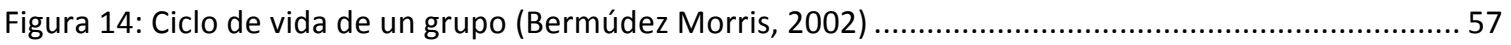

Figura 15: Gráfico de dinámicas de producción grupal no colaborativas (Libedinksky et al., 2011) ............ 61

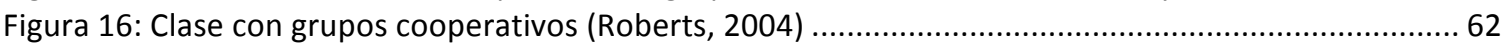

Figura 17: Trabajo cooperativo-colaborativo según la intervención del profesor (Correa, 2013) ...............63

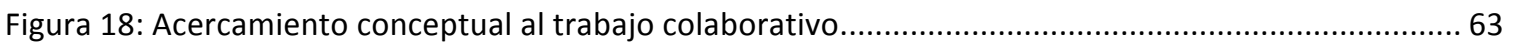

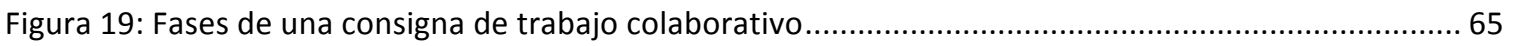

Figura 20: La evaluación en el modelo de enseñanza. Modelo propio ....................................................69

Figura 21: Vinculación entre los conceptos de evaluación, seguimiento y valoración. Modelo propio........ 71

Figura 22: Actores impactados por la información de entornos virtuales colaborativo con tecnología informática (Tomado y modificado de Dimitrakopoulou et al., 2006).............................................. 72

Figura 23: Estructura de una actividad colaborativa en un ambiente mediado por tecnología informática

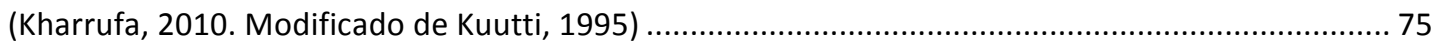

Figura 24: Presentación del concepto de CSCL en sus inicios (Nardi, 1996)........................................... 79

Figura 25: Doble dimensión del concepto de interdependencia positiva (Driscoll \& Vergara, 1997) .......... 84

Figura 26: Modelo de argumentación de Toulmin (en Karbach, 1987). Primera aproximación .................. 86

Figura 27: Modelo de argumentación de Toulmin (en Karbach, 1987, pág. 81) ..................................... 87

Figura 28: Modelo de argumentación de Toulmin (en Karbach, 1987, pág. 83). Completo......................... 88

Figura 29: Estudios sobre trabajo colaborativo con tecnología informática reseñados en la tesis...............89 89

Figura 30: Qué, para qué, para quiénes y cuándo visualizar indicadores de colaboración ......................... 94

Figura 31: Radar de participación, según Big Five (Tomado de Kay et al., 2006) .................................... 96

Figura 32 Redes de interacción en dos herramientas y con diferentes densidad y relaciones, según Big Five

(Tomado de Kay et al., 2006) .................................................................................................. 96

Figura 33: Wattle Tree. Eventos colaborativos por persona, día, tipo y magnitud (Tomado de Kay et al.,

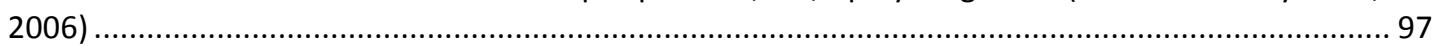

Figura 34: Home de Co-Lab (En van Joolingen et al., pág. 673) .............................................................. 98

Figura 35: Visualización de un diálogo por palabra clave en iBee (Tomado de Mochizuki et al., 2005) ...... 99

Figura 36: Visualización de un diálogo según desempeño individual en la herramienta ITree (Tomado de Dimitrakopoulou, et al., 2006).

Figura 37: Visualización de la tarea modelada y los componentes asociados al trabajo colaborativo en ModellingSpace (Tomado de Avouris et al., 2004)

Figura 38: Visualización de la colaboración en la interface de Narcissus. Vista del grupo (Tomado de Upton \& Kay, 2009)

Figura 39: Visualización de la construcción colaborativa en Synergo (Tomado de Avorius et al., 2004, Agosto)

Figura 40: Mapa conceptual de componentes del trabajo colaborativo según disciplinas. Modelo propio 
Figura 41: Comparación de los paradigmas cuanti y cualitativo. (Cook \& Reichardt, 1979, pág. 5 ) ......... 113

Figura 42: Componentes de la metodología MetSCIn presentada en esta tesis .................................. 115

Figura 43: Etapas de implementación de MetSCIn............................................................................... 116

Figura 44: Matriz de indicadores de colaboración de MetSCIn .......................................................... 117

Figura 45: Portada del autoinforme de autorregulación en GoogleForm ............................................. 126

Figura 46: Indagación sobre motivación. Dos ítems.............................................................................. 126

Figura 47: Información del tiempo restante para resolver la actividad colaborativa. Reloj en formato

"cuenta regresiva" ................................................................................................................... 130

Figura 48: Información de los indicadores de MetSCIn en la estrategia de mirroring ............................ 131

Figura 49: Grafo de relaciones en la información de mirroring ............................................................ 131

Figura 50: Etapas de la construcción de la metodología, según modelo RUP (Kruchten, 1996 en Díaz-Antón

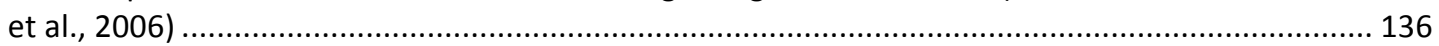

Figura 51: Comunicación con los expertos y seguimiento del proceso ..................................................... 150

Figura 52: Pérdida muestral según las etapas del juicio de expertos ................................................. 151

Figura 53: Factor de concordancia Kc de la sección 2. Grado de competencia experta............................ 152

Figura 54: Concordancia de la sección 2. Concepto de Trabajo Colaborativo......................................... 153

Figura 55: Concordancia de la sección 3. Indicadores de la dimensión individual del Trabajo Colaborativo

Figura 56: Concordancia de la sección 4. Indicadores de la dimensión grupal del Trabajo Colaborativo .. 154

Figura 57: Concordancia de la sección 5. Matriz completa de indicadores............................................. 155

Figura 58: Aportes cualitativos a la matriz de indicadores de seguimiento de trabajo colaborativo

proporcionados por los expertos ......................................................................................... 156

Figura 59: Matriz de indicadores de colaboración. Versión final. En color grisáceo se marcan los agregados

luego del juicio de expertos .................................................................................................... 157

Figura 60. Ejemplo de consigna individual del trabajo colaborativo en el estudio de caso ....................... 165

Figura 61. Ejemplo de consigna grupal del trabajo colaborativo en el estudio de caso............................. 165

Figura 62: Criterios de evaluación del producto de la actividad de escritura colaborativa....................... 167

Figura 63: Estructura del estudio de caso de esta tesis..................................................................... 168

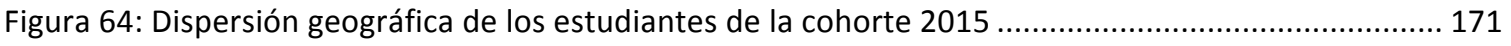

Figura 65: Dispersión geográfica de los estudiantes de la cohorte 2016 ............................................. 171

Figura 66: Componentes del concepto de trabajo colaborativo en las respuestas de la encuesta inicial. Ambas cohortes

Figura 67: Por qué la tecnología digital puede favorecer el trabajo colaborativo. Justificación. Ambas cohortes.

Figura 68: Nivel motivacional en relación con la visualización de la meta a alcanzar ............................... 173

Figura 69: Nivel motivacional en relación con la identificación de compañero/as experto/as.................. 174

Figura 70: Manejo de la afectividad en la tensión proceso-resultado ................................................ 174

Figura 71: Manejo de la afectividad en relación con la posibilidad de cometer errores............................ 175

Figura 72: Gestión del tiempo. Planificación de las actividades diarias .................................................... 176

Figura 73: Gestión del tiempo. Tendencia a procrastinar .............................................................. 176

Figura 74: Procesamiento de información. Eficiencia de las estrategias de búsqueda ........................... 177

Figura 75: Procesamiento de información. Interacción vicaria ......................................................... 178

Figura 76: Trabajo en equipo. Conocimiento previo. Grupalidad ..................................................... 178

Figura 77: Trabajo en equipo. Tensión entre las tareas invidual y grupal ............................................ 179

Figura 78: Densidad de interacción en la tarea completa. Ambas cohortes ........................................... 180

Figura 79: Densidad de interacción por etapa. Ambas cohortes........................................................... 181

Figura 80: Densidad de interacción por tipo de mensaje en la tarea completa. Ambas cohortes ............. 182

Figura 81: Densidad de interacción por tipo de mensaje por etapa. Ambas cohortes ............................ 183

Figura 82: Interface de la mensajería de WebUNLP. Títulos de los mensajes con información irrelevante

Figura 83: Tópicos o unidades semánticas abordadas en el trabajo colaborativo por etapas. Ambas cohortes. Presentación gráfica.................................................................................................. 186

Figura 84: Cohesión de la comunicación. Ambas cohortes .................................................................. 187

Figura 85: Argumentación según componentes. Ambas cohortes..................................................... 189 
Figura 86: Frecuencia de acceso al sitio de información de mirroring 191

Figura 87: Acceso a la información sobre el tiempo restante para la entrega del trabajo (reloj en formato

"cuenta regresiva")

Figura 88: Acceso a la información de indicadores individuales y/o grupales ........................................ 193

Figura 89: Acceso a la información según autoría (individual o grupal) ................................................. 194

Figura 90: Acceso a la información según formato ................................................................................ 195

Figura 91: Decisiones tomadas a partir de la información del mirroring ................................................ 196

Figura 92: Decisiones tomadas a partir de la información del mirroring. Corte según tipo de decisiones 196

Figura 93: Opiniones sobre la utilidad del mirroring ....................................................................... 197

Figura 94: Opinión final sobre el impacto del mirroring ................................................................. 198

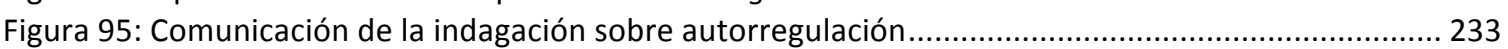

Figura 96: Comunicación inicial de la estrategia de mirroring ............................................................... 242

Figura 97: Comunicación semanal de la estrategia de mirroring ....................................................... 242

Figura 98: Comunicación final de la estrategia de mirroring ........................................................... 243

Figura 99: Comunicación inicial del juicio de expertos. Grupal ....................................................... 249

Figura 100: Segunda comunicación del juicio de expertos. Individual ................................................. 250

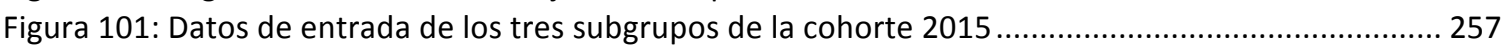

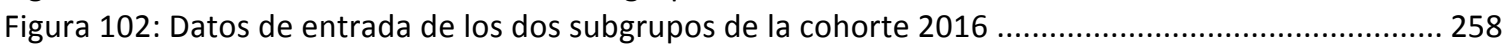

Figura 103: Densidad de interacción por etapa. Cohorte 2015 .............................................................. 258

Figura 104: Mensajes por etapa y por tipo. Cohorte 2015 ............................................................ 259

Figura 105: Densidad de interacción por etapa. Cohorte 2016 ............................................................ 260

Figura 106: Mensajes por etapa y por tipo. Cohorte 2016 ............................................................... 260

Figura 107: Mapa de tópicos. Conexión semántica. Grupo 1. Cohorte 2015 ......................................... 261

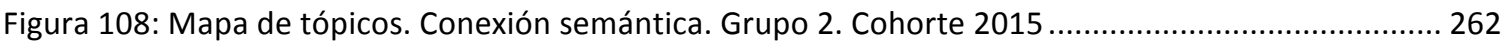

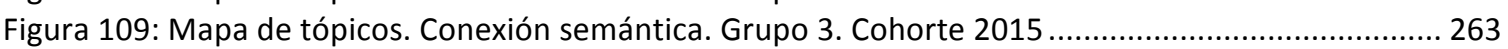

Figura 110: Mapa de tópicos. Conexión semántica. Grupo 1. Cohorte 2016 ............................................. 263

Figura 111: Mapa de tópicos. Conexión semántica. Grupo 2. Cohorte 2016 ........................................ 264

Figura 112: Tópicos trabajados por semana en la información de mirroring del grupo 2 de la cohorte 2016 


\section{Indice de Tablas}

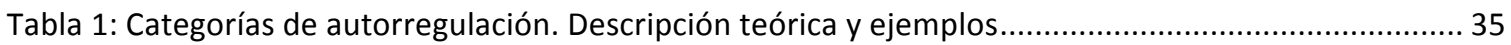

Tabla 2: Niveles de interacción/colaboración (Adaptado de Kahn \& Mentzer, 1996) ............................... 41

Tabla 3: Tipos de agrupamientos (Tomado y modificado de Anzieu \& Martin, 1968) ............................... 51

Tabla 4: Conceptualizaciones de trabajo colaborativo (Pérez, 2007) ...................................................59

Tabla 5: Trabajo colaborativo en comparación con otras formas de trabajo grupal ................................61

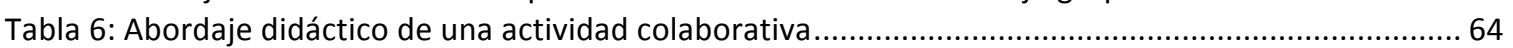

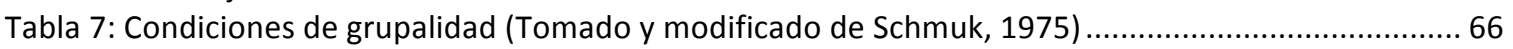

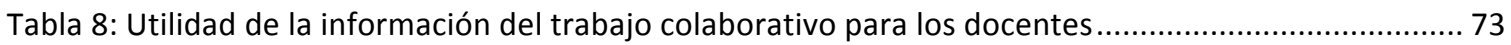

Tabla 9: Utilidad de la información del trabajo colaborativo para el individuo y el grupo ......................... 74

Tabla 10: Tipos de mensajes. Integración de indicadores en el aporte de cada miembro al trabajo

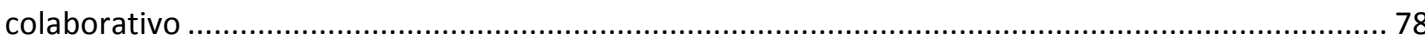

Tabla 11: Reseña de investigaciones de trabajo colaborativo con tecnología informática. Base del estudio extraída de Dimitrakopoulou et al., 2006 y actualizada con reseñas propias de esta tesis................. 83

Tabla 12: Presentación de herramientas de visualización del trabajo colaborativo en el modelo mirroringmetacognitive-guiding. (Tomado de Jermann et al., 2001 y Soller et al. , 2005). Modelo propio...... 95

Tabla 13: Presentación de herramientas que apoyan el seguimiento del trabajo colaborativo ................ 103

Tabla 14: Gradiente de presentación de herramientas en el gradiente: contenido-mirroring-metacognitiveguiding-entorno digital colaborativo. Modelo propio ............................................................. 104

Tabla 15: Lista de palabras clave para cada categoría de mensajes. Los que están entre corchetes corresponden al contenido de la tarea especifica.

Tabla 16: Ejemplo de análisis del componente de argumentación, a partir de un corpus de mensajes del estudio de caso

Tabla 17: Relación entre categorías e ítems del autoinforme de autorregulación ................................. 125

Tabla 18: Indicadores del trabajo individual y grupal del mirroring .................................................... 128

Tabla 19: Cronograma de actualización semanal de información del mirroring ...................................... 129

Tabla 20: Información de la home del sitio de mirroring ........................................................................... 129

Tabla 21: Estructura de la e-encuesta que indaga el impacto del mirroring en MetSCIn .......................... 132

Tabla 22: Cantidad de ítems total y por cada sección del instrumento de indagación post mirroring ...... 133

Tabla 23: Descripción de la estrategia de indagación de impacto del mirroring ..................................... 135

Tabla 24: Calidad del instrumento de evaluación mediante el juicio de expertos en el método de agregación individual (Extraído de Corral, 2009, pág. 233) ........................................................ 141

Tabla 25: Componentes de la evaluación de la validez de indicadores mediante el juicio de expertos .... 144

Tabla 26: Descripción de los pasos metodológicos del juicio de expertos ................................................ 145

Tabla 27: Biograma de los expertos seleccionados .......................................................................... 146

Tabla 28: Instrumento de indagación de Juicio de Expertos. Análisis del coeficiente de competencia experta -factor K- en su componente de conocimiento Kc.

Tabla 29: Componentes de la matriz validados en el formulario de juicio de expertos por sección del instrumento

Tabla 30: Cantidad de ítems total y por cada sección del instrumento de indagación del juicio de experto

Tabla 31: Respuestas por ítem y por sección. Tabla de datos ........................................................ 153

Tabla 32: Decisiones metodológicas de la recolección de datos en el estudio de caso ............................ 162

Tabla 33: Competencias a desarrollar en el seminario de Educación a Distancia .................................... 163

Tabla 34: Operacionalización de indicadores de MetSCIn en el estudio de caso .................................... 169

Tabla 35: Composición de ambas cohortes según profesiones.......................................................... 170

Tabla 36: Composición de ambas cohortes según lugar de residencia ................................................ 171

Tabla 37: Cantidad de días por etapa en el trabajo colaborativo............................................................ 180

Tabla 38: Media de densidad de interacción en la tarea completa. Ambas cohortes.............................. 181

Tabla 39: Media de densidad de interacción por etapa. Ambas cohortes ............................................. 181

Tabla 40: Media de densidad de interacción por tipo de mensaje en la tarea completa. Ambas cohortes 
Tabla 41: Unidades semánticas abordadas en el trabajo colaborativo, por etapas. Ambas cohortes ....... 185 Tabla 42: Componentes de argumentación por participante. Tópico "Escritura colaborativa”. Cohorte 2015 188

Tabla 43: Componentes de argumentación por participante. Tópico “Escritura colaborativa”. Cohorte 2016

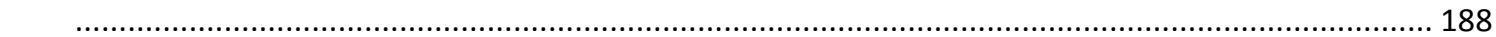

Tabla 44: Media de componentes de argumentación por mensaje. Ambas cohortes ............................. 189

Tabla 45: Promedio de mensajes por etapa y por grupo. Cohorte 2015............................................. 259

Tabla 46: Promedio de mensajes por tipo, por etapa y por grupo. Cohorte 2015 ................................. 259

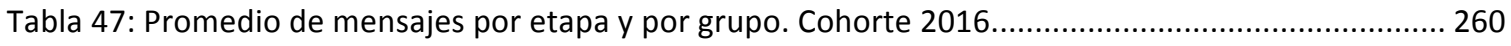

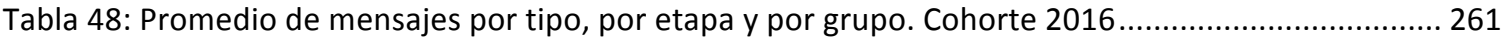




\section{Agradecimientos y Dedicatoria}

"En su niñez leyó un diccionario enciclopédico completo. ¿Por qué? Enfermo, debía estar en cama un tiempo y su situación económica no le ofrecía otra cosa para leer. Esa pasión por el conocimiento mueve al mundo".

\section{Agradecimientos}

A las autoridades y compañeros de la Facultad de Informática, por la preocupación permanente por la formación de sus docentes y la creación de condiciones para llevarla adelante.

A la Dra. Cecilia Sanz, admirada colega y gran compañera en la Maestría en "Tecnología Informática aplicada en Educación". Experta y cuidadosa directora de esta tesis.

A los colegas que colaboraron con gran compromiso en el juicio de expertos que fundamentó parte de la estrategia que aquí se presenta.

A los docentes, estudiantes de la "Maestría en Tecnología Informática aplicada en Educación”, por la confianza depositada en nosotros y el estímulo permanente para ir por más.

\section{Dedicatoria}

A mi mamá, incondicional, siempre.

A Rodolfo, mi amor. 


\section{Resumen}

El estudio de los escenarios de enseñanza y aprendizaje mediados por tecnología digital se asemeja a mirar a través de un caleidoscopio. Cada cristal ofrece una óptica diferente. Cada disciplina que observa este fenómeno muestra una cara algo desconocida, un aspecto quizás inexplorado. La sensación es la de pisar arenas resbaladizas, viscosas, cada vez más profundas: cuánto más se avanza, más camino hay por delante. En ese camino transita esta tesis.

El objeto de estudio aborda el análisis y el seguimiento de la interacción e interactividad en el trabajo colaborativo mediado por tecnología informática. La literatura proveniente de la Psicología y la Didáctica ha estudiado y escrito sobre este fenómeno desde el propio nacimiento de la Tecnología Educativa, en la década del '70. En las aulas presenciales es posible observar "en vivo" y analizar cómo las personas se comunican en pos de lograr algo juntas. En este sentido, la Didáctica de Grupos se ha convertido en un eje fundamental de la enseñanza. Con la tecnología digital y la posibilidad agregada de documentar eventos e información para su posterior recuperación, estos estudios se han enriquecido al punto de poder reconstruir las formas de interacción e interactividad de un grupo colaborativo en una situación de enseñanza mediada.

En esta tesis se propone echar luz sobre algunos temas que resultan de interés, tanto para la Ciencia Informática como para la Tecnología Educativa y la Didáctica. Se ofrecerá un marco conceptual comprensivo acerca de las relaciones epistemológicas entre los conceptos de interacción e interactividad, desde una mirada interdisciplinar. Asimismo, respecto del trabajo colaborativo, se lo ubicará conceptualmente, diferenciándolo de otras formas de trabajo grupal y de cooperación que no llegan al estadio de la colaboración.

El aporte sustancial de la tesis se vincula con el seguimiento del trabajo colaborativo mediado por tecnología informática. En este sentido, se ofrece un metodología completa (que se ha llamado por su acrónimo MetSCIn) que puede ayudar a estudiantes, docentes y desarrolladores de software a analizar, e incluso reconstruir, las etapas y eventos que conllevan a un grupo a logros colectivos. En el diseño de esta metodología se ha documentado el estado del arte de los indicadores con los cuales se ha estudiado el trabajo colaborativo desde diversas disciplinas. Se han comparado investigaciones en este tema para componer, como parte de MetSCin, una matriz de indicadores integrados en una doble dimensión de estudio: el aporte de los individuos al trabajo grupal y la construcción colaborativa propiamente dicha. El estudio de caso donde se ha probado la metodología completa se ha llevado adelante en una e-actividad de escritura colaborativa, con estudiantes del seminario de "Educación a Distancia" de la Maestría en "Tecnología Informática aplicada en Educación", que se dicta en la Facultad de Informática de la Universidad Nacional de La Plata.

En el estudio de caso se ha trabajado con dos cohortes completas contrastadas (2015 y 2016). En la segunda cohorte se ha implementado la metodología MetSCIn completa. Se ha realizado, como parte de esta metodología, una intervención didáctica denominada mirroring que consiste en la visilibización semanal del seguimiento de los indicadores del proceso colaborativo a disposición de todos los integrantes del grupo. Una vez finalizado ese trabajo, se ha evaluado su impacto.

Los resultados permiten comprobar que la metodología ha mostrado eficacia en el seguimiento del trabajo colaborativo, al permitir realizar una cuidadosa descripción y 
recuperación del proceso de trabajo en el estudio de caso. La matriz de indicadores de colaboración que forma parte de MetSCIn fue sometida al juicio de expertos y resultó válida y confiable a partir de las respuestas obtenidas. Finalmente, los resultados alcanzados en la indagación de impacto posterior a la implementación de la estrategia de mirroring refuerzan la idea de que el grupo se beneficia a partir del conocimiento sobre cómo se está desarrollando su proceso colaborativo $\mathrm{y}$, aún más, indican que se profundiza la conciencia que cada integrante tiene de su propia tarea y de la de sus compañeros.

Asimismo, esta tesis ha permitido avanzar hacia trabajos futuros en cada una de las áreas de incumbencia, que se describen al final de este informe. 


\section{Capítulo 1: Introducción}

Este primer capítulo de la tesis aborda los siguientes temas:

1.1. Motivación

1.2. Preguntas disparadoras

1.3. Objetivo general y específicos

1.3.1. Objetivos específicos

1.4. Metodología de investigación de esta tesis

1.5. Compromiso de valor agregado

1.6. Estructura de la tesis 


\subsection{Motivación}

Los fenómenos de interacción e interactividad resultan centrales a la hora de analizar las actividades humanas. Más aún si se consideran estas actividades en espacios colaborativos, con fines educativos, y mediadas por tecnología informática. Estos conceptos resultan esenciales en los espacios de enseñanza, que se ven resignificados por las nuevas tecnologías digitales.

Etimológicamente, según la Real Academia Española ${ }^{1}$, interacción es "la acción que se ejerce recíprocamente entre dos o más grupos, personas u otros agentes o la influencia recíproca de varias entidades (fuerzas, objetos, personas). En un sistema, la interacción entre distintos elementos sería uno de los factores principales que explicarían la emergencia de nuevas propiedades".

En el campo de la enseñanza y el aprendizaje es posible traducir algunas de estas ideas y atribuir al término interacción la propiedad de aquellos escenarios donde se discuten ideas, se analizan casos, se presentan informaciones, etc., sean estos espacios sincrónicos o asincrónicos. Los espacios de interacción, desde este marco, están definidos por la relación con otra persona o personas, sean estos docentes, ayudantes, tutores, otros alumnos, etc. Siempre se interacciona con otras personas, en espacios físicos presenciales (aula) o mediados tecnológicamente, presencialmente o a distancia. En este último caso, en tiempos sincrónicos o asincrónicos. Dentro de este marco se ubica lo que Moore (1972, 1983, 1990 y otros) definen como el componente de diálogo en su concepto de Distancia Transaccional.

El fenómeno de la interactividad ha sido foco de variados estudios en el campo de la educación a distancia. Keegan presenta, dentro de su definición de educación a distancia, el componente de individualización "para que el estudiante pueda beneficiarse del diálogo, lo que distingue a la educación a distancia de otros usos de la tecnología en educación ya que permite individualizar la enseñanza al adaptarla a las características idiosincrásicas de cada estudiante" (Keegan en Simonson, Smaldino, Albrigh \& Zvacek, 2006, págs. 34-35). Moore agrega el componente de autonomía del estudiante como un requerimiento necesario para sacar un buen provecho de esta individualización. Define a la autonomía en términos de: "la medida en la que el estudiante de una propuesta de educación a distancia pueda determinar o elegir los objetivos, los recursos y los procedimientos de evaluación" (Moore en Fainholc, 1999, pág. 63). Siguiendo esta línea, un dispositivo o un software se calificaría como interactivo cuando la persona que lo usa puede tomar decisiones de recorrido de acceso a información o modificar su comportamiento de alguna manera, o la forma en que le presenta la información. En este sentido, los programas y videojuegos digitales serían interactivos per se, ya que la elección de caminos alternativos y canales de acceso a la información son, en general, intrínsecos a su diseño.

La interactividad, hace también referencia al diseño de la propuesta didáctica de los materiales de autoinstrucción (Díaz Barriga, 2005). Una propuesta educativa o material didáctico interactivo le debería permitir al estudiante:

- Encontrar lo que necesita (en términos de contenidos y actividades) según sus necesidades.

- Seguir un camino de recorrido idiosincrásico.

- Identificar formas en la presentación de los contenidos más relacionadas con su estilo de aprender (abordajes más textuales, gráficos, visuales, auditivos, audiovisuales, etc.).

- Vincular situaciones, actividades o planteos respecto de lo que tiene que aprender más relacionados con su realidad y sus posibilidades de transferencia.

\footnotetext{
${ }^{1}$ En: http://dle.rae.es/. Consultado en Noviembre de 2017.
} 
- Recibir información de retorno (no sólo correctiva sino explicativa) de cada una de las actividades y ejercicios propuestos.

- Hallar orientaciones que fomenten su metacognición.

En el campo de la tecnología informática, los términos interactividad e interacción muchas veces se usan indistintamente e, incluso, como sinónimos. Es más, se utiliza la palabra interacción para nombrar lo que se acaba de presentar como interactividad. En este sentido, un aporte de esta tesis será la demarcación del campo y las definiciones de interacción e interactividad a la luz de diferentes disciplinas, en pos de construir una definición propia de la interdisciplinariedad.

En la Ciencia Informática se describen paradigmas y estilos de interacción. Los paradigmas de interacción representan una abstracción de todos los posibles estilos de interacción, organizados en grupos con características similares. Según Preece, un estilo de interacción se reconoce como "el término genérico que agrupa las diferentes maneras en que los usuarios se comunican o interaccionan con el computador" (Preece, 1994, pág. 60). Se retomará este tema en el capítulo 2 , en el que se profundizarán los conceptos de interacción e interactividad desde diferentes perspectivas.

A las tensiones epistemológicas sobre las definiciones de interacción e interactividad producto de una permanente construcción interdisciplinar, habría que agregar el problema de la intervención didáctica en el diseño e implementación de espacios donde la interacción e interactividad se ponen en juego con vistas al logro de aprendizajes. Esta tesis instala como espacio el campo del trabajo colaborativo, concepto que también es abordado desde diferentes perspectivas. Una disciplina de fundamental importancia en el estudio de la enseñanza en general y del trabajo colaborativo en particular es la Psicología Educacional. Esta disciplina se ha ocupado del estudio de la persona, ya sea de su comportamiento observable o de su organización cognitiva interna, siempre en su relación con el medio socialmente construido. Así, se visualiza un recorrido disciplinar que transita desde el estudio del individuo en solitario a la consideración del contexto y de allí al grupo.

El trabajo colaborativo está constituido por personas, integradas a un contexto, trabajando en forma grupal y colaborativa (definiciones que se abordarán en los capítulos del marco conceptual) y mediadas por herramientas y/o entornos construidos por tecnología informática. El componente tecnológico ha ido sumando e integrando nuevas posibilidades de entender, reconstruir y valorar el trabajo colaborativo.

Entonces, esta tesis abreva en disciplinas diferentes, que deben catalizarse para enfocar un problema complejo: la interacción e interactividad en el trabajo colaborativo mediado por tecnología informática. Son varios los puntos de mira que deben ser articulados para enfocar este objeto. Estas disciplinas se presentan organizadas en la figura 1. 


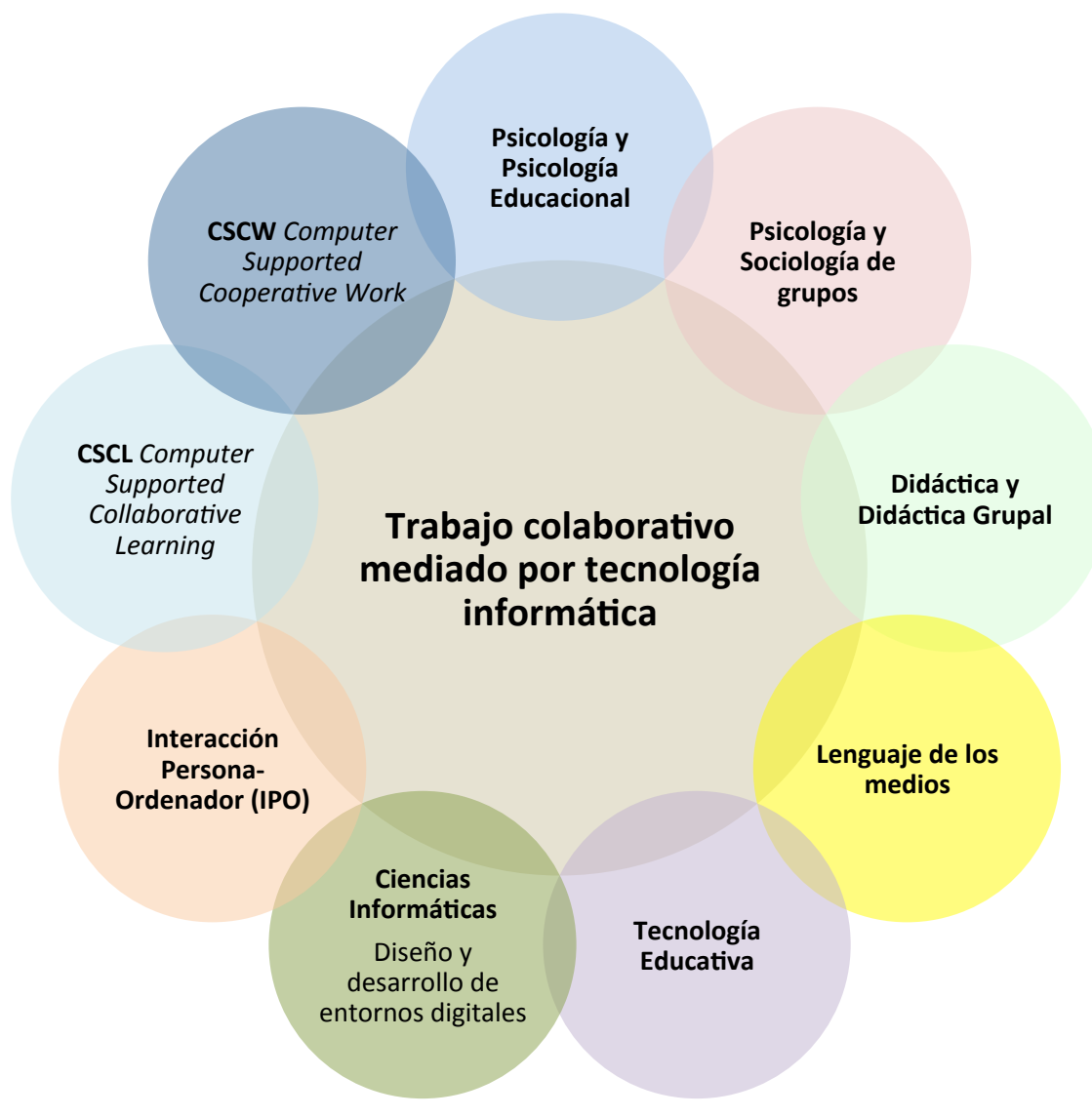

Figura 1: Disciplinas que iluminan el objeto de estudio de esta tesis. Modelo propio

\subsection{Preguntas disparadoras}

En función del conocimiento aportado por las disciplinas mencionadas, sus intersecciones en función de iluminar el objeto de estudio de esta tesis y sus áreas de vacancia, surgen las preguntas disparadoras de este trabajo. Se presentarán en tres perspectivas: conceptual, metodológica y desde la información que visibiliza del trabajo colaborativo y su impacto.

Desde el punto de vista conceptual, es de interés comprender ¿cómo se entiende la interacción e interactividad en el trabajo colaborativo en la enseñanza? ¿cómo actúan las personas y cómo intervienen las herramientas?

Desde el punto de vista metodológico, esta tesis se propone comprender el trabajo colaborativo. Entonces, resulta de interés averiguar ¿qué componentes intervienen en el trabajo colaborativo, cómo se relacionan y cómo es posible estudiarlos?. Además, focalizando el seguimiento de este tipo de procesos en escenarios educativos, las peguntas que guiaron este trabajo se formularon de la siguiente forma: ¿existen metodologías para identificar, describir y valorar la interacción y la interactividad en el trabajo colaborativo? ¿qué aspectos miran de la interacción? ¿y de la interactividad? ¿qué indicadores se utilizan para analizar la construcción colaborativa? ¿existen herramientas que faciliten este seguimiento?

Finalmente, desde el punto de vista del seguimiento y valoración del trabajo colaborativo, resultó de interés investigar ¿qué información del proceso colaborativo se visibiliza en las 
investigaciones en este tema? y ¿qué impacto tiene en el proceso y producto del grupo el conocimiento de su desempeño online?

Estas preguntas resultaron una guía a la hora de relevar las diferentes fuentes bibliográficas y webiográficas, como así también para construir los objetivos y definir la estructura de este trabajo.

\subsection{Objetivo general y específicos}

El objetivo general de este trabajo es desarrollar una metodología que permita identificar y analizar los fenómenos de interacción e interactividad en procesos colaborativos mediados por tecnología informática.

\subsubsection{Objetivos específicos}

- Diferenciar conceptualmente los fenómenos de interacción e interactividad desde el punto de vista epistemológico y en su relación con la enseñanza.

- Compilar el estado del arte de estos fenómenos en su definición y en su vinculación con la tecnología informática.

- Describir antecedentes de metodologías e indicadores de seguimiento de trabajo colaborativo en los campos educativo y tecnológico.

- Clasificar y analizar las herramientas informáticas utilizadas para realizar el seguimiento del trabajo colaborativo.

- Desarrollar una metodología que permita analizar fenómenos de interacción e interactividad en un proceso colaborativo mediado por tecnología informática, de manera tal de definir las variables a atender, así como también los criterios e indicadores que permitirán evaluar este tipo de procesos.

- Validar la metodología a partir del estudio de caso, de manera tal de analizar el alcance del aporte de este tesis y las mejoras a realizar.

\subsection{Metodología de investigación de esta tesis}

Para el logro de estos objetivos, en esta tesis se proponen dos tipos de investigación: teórica/documental en la primera parte y estudio de caso, en la segunda. En el marco conceptual se llevará adelante una investigación bibliográfica sobre dos aspectos centrales de este trabajo. En referencia a los conceptos de interacción e interactividad, se integrarán visiones sociopsicológicas y comunicacionales, con vistas a su uso en espacios educativos. Asimismo, se plantea un recorrido por los modelos de comunicación humana y paradigmas y estilos de interacción trabajados en la disciplina informática. Como finalización de este trabajo, se propone una visión integradora de los conceptos de interacción e interactividad y sus relaciones. En cuanto al concepto de trabajo colaborativo, se presenta un recorrido por los conceptos de trabajo cooperativo y colaborativo y su empleo en espacios de educación de adultos, mediados por tecnología informática. Para articular estos conceptos en el espacio educativo, se tomará la teoría de Distancia Transaccional del Dr. Michael Moore, que aborda las dimensiones de diálogo estructura - autonomía del estudiante para comprender los fenómenos de la enseñanza en espacios sincrónicos y asincrónicos mediados por tecnología informática (Shearer en Moore, 2013).

Para la investigación documental se revisaron textos completos de abordaje de la enseñanza y el aprendizaje y la didáctica individual y grupal. Se revisitaron fuentes primarias de la Psicología del Aprendizaje: desde la teoría de la Gestalt de Köhler de 1929, la teoría de la instrucción personalizada de Skinner en 1938, la teoría de Vygotsky de 1962 y teorías cognitivas 
que tuvieron visibilidad desde 1960 en adelante. Asimismo, los textos fundantes de la disciplina Tecnología Educativa desde 1970 a la actualidad. En cuanto a trabajo grupal y colaborativo, se revisaron autores correspondientes a la didáctica grupal (Anzieu, 1967) y al trabajo cooperativo y colaborativo (desde el año 2000 en adelante). Se utilizaron las siguientes palabras clave para la búsqueda bibliográfica: trabajo grupal, didáctica grupal, trabajo en grupo, trabajo cooperativo, trabajo colaborativo, aprendizaje grupal, aprendizaje cooperativo, aprendizaje colaborativo. Específicamente en las Ciencias Informáticas, los campos analizados correspondieron a CSCW (Computer Supported Colaborative Work) y CSCL (Computer Supported Collaborative Learning). Se trabajó tanto con revistas arbitradas como con actas de conferencias de congresos nacionales e internacionales. En este caso, se utilizaron como fuente sólo los artículos completos, no los resúmenes. En cuanto a las revistas se trabajó con las siguientes: Dialnet, Redalyc, Springer, IEEE, ACM, Archivos de Ciencias de la Educación (Revista de la Facultad de Humanidades y Ciencias de la Educación, UNLP), Journal of Distance Education, NAER, Computers \& Education y TE\&ET. Además de la búsqueda por palabra o concepto clave, fue importante seguir las referencias indicadas en los textos de los autores fundantes. Esto resultó de gran utilidad en la construcción del estado del arte de las investigaciones de seguimiento del trabajo colaborativo del capítulo 4. En cuanto al análisis de las herramientas informáticas del capítulo 5, se buscaron las herramientas que se referenciaban en el estado del arte de las investigaciones e indicadores consignadas en el capítulo 4. Se siguieron, en ese caso, las referencias de cada reporte de investigación. Los idiomas revisados fueron español e inglés.

Haciendo un análisis de la bibliografía referenciada en este trabajo respecto de sus años de publicación, se observa que hay un $15 \%$ de la bibliografía que fue publicada con anterioridad al año 1980; un $25 \%$ entre 1981 y 2000 ; un $22 \%$ hasta el 2005 ; un $18 \%$ hasta el 2010 y un $16 \%$ hasta el 2015. Además, hay un $4 \%$ de la bibliografía referenciada que ha sido publicada entre 1920 y 1960. La explicación que se ha encontrado para esta distribución tiene que ver con los objetivos de modelización conceptual de esta tesis y la necesidad de buscar el marco en el que abrevan los modelos utilizados hoy. Precisamente, el 4\% de obras de las cuatro primeras décadas del siglo pasado (hasta 1960) se han referenciado en los capítulos 2 y 3, al explicar las teorías atómicas del conductismo, el pasaje a la teoría del campo social de Lewin, las primeras concepciones de grupo, la teoría interaccionista de Lev Vygotsky y el modelo telegráfico de la comunicación. En los intervalos que van desde 1981 al 2000 y del 2001 al 2010 se publicaron la mayoría de los fundamentos teóricos de esta tesis en cuanto a concepto de grupo y trabajo colaborativo, interacción e interactividad y los modelos iniciales de interacción personaordenador (IPO). Respecto de los softwares de seguimiento del trabajo colaborativo en los que se centra el capítulo 5, la literatura referencia obras de la década de 2000 a 2010 en la creación de prototipos y herramientas de mirroring, metacognitive y guiding systems. A partir del 2011, las publicaciones, si bien refieren a modelos teóricos escritos con anterioridad, los resignifican a partir de nuevas herramientas que, a su vez, organizan según IPO nuevos modelos de interacción. Se ve claramente esta tendencia en la aparición de hardware y software de interacción tangible, computación afectiva $\mathrm{y}$, en el caso del trabajo colaborativo en particular, nuevos entornos digitales colaborativos. En el caso del software de análisis y visualización del trabajo colaborativo, se utilizan modelos de visualización anteriores (tablas cuanti y cualitativas, radares para mostrar interacción, visualizadores propios de la sociometría y del análisis de redes sociales) para aplicarlos a las nuevas herramientas: tabletops y sistemas de computación afectiva. Una posible explicación podría ser: las herramientas cambian, los modelos permanecen, revisitados y resignificados.

Luego, la tesis se encamina hacia la construcción de una metodología que permita identificar y analizar los fenómenos de interacción e interactividad en procesos colaborativos mediados por tecnología informática. En el inicio de esta búsqueda, se presenta el estado del arte de los indicadores con los que se ha estudiado el trabajo colaborativo. Se elabora una metodología propia (MetSCIn), que incluye la integración de indicadores en una matriz. Parte de la metodología, la matriz de indicadores, es sometida a la validación mediante juicio de expertos. 
Finalmente se lleva adelante un estudio de caso. El caso se enmarca en la Maestría en "Tecnología Informática aplicada en Educación" de la Facultad de Informática de la Universidad Nacional de La Plata, en el seminario de "Educación a Distancia". Se trabaja con dos grupos de estudiantes de esta asignatura, de dos años correlativos (2015 y 2016). Con estos estudiantes se lleva adelante una indagación acerca de habilidades de autorregulación para el estudio, componente significativo en las actividades colaborativas, y se realiza la valoración y seguimiento del desempeño individual y colectivo en la resolución de una e-actividad de escritura colaborativa a partir de la utilización de MetSCIn. La metodología de investigación de este trabajo se presenta en detalle en la segunda parte: "Aportes de esta tesis y su validación", en los capítulos 6 a 8 . A partir de este estudio de caso en el que se pone en juego la metodología propuesta, y se analizan las debilidades y fortalezas encontradas en relación a su implementación en una situación de enseñanza específica.

\subsection{Compromiso de valor agregado}

En esta tesis se compromete agregado de valor en los siguientes campos:

\section{Desde el punto de vista conceptual}

a. Presenta una conceptualización de los fenómenos de interacción e interactividad desde una óptica interdisciplinar.

b. Ofrece una discriminación conceptual entre trabajo grupal y colaborativo y una definición propia de este último concepto.

c. Integra estas miradas en un mapa de los componentes del trabajo colaborativo y sus relaciones multidimensionales y complejas.

d. Describe un modelo de análisis de diferentes softwares que permiten hacer seguimiento del trabajo colaborativo.

\section{Desde el punto de vista metodológico}

e. Construye una metodología de seguimiento del trabajo colaborativo. Como componente de esta metodología se presenta una matriz de indicadores que posibilita la valoración del trabajo colaborativo mediado por tecnología informática. Esta matriz es sometida al juicio de expertos, como una estrategia para la validación de su diseño lógico y confiabilidad.

f. Aplica la metodología en un estudio de caso, estudiando sus fortalezas y debilidades.

g. Analiza el impacto de una estrategia de mirroring, que se propone como parte de la metodología antes construida. Se presenta la visualización de resultados de proceso colaborativo online. Como parte del estudio de caso se avanza, en la muestra de la segunda cohorte, en la visibilización de indicadores de seguimiento colaborativo mediante una estrategia de mirroring. Por medio de esta estrategia, los integrantes de los grupos bajo estudio reciben información online del proceso y resultado de su colaboración. El impacto que el conocimiento de esta información ha producido en cada grupo en particular y en el grupo en general, es otro aporte de esta tesis. 


\subsection{Estructura de la tesis}

En la figura 2 puede visualizarse el recorrido de esta tesis en función de sus compromisos de valor agregado. En el marco conceptual se desarrollan los temas centrales: interaccióninteractividad y trabajo colaborativo. Como se ha dicho, estos temas se enmarcan en la teoría de la Distancia Transaccional del Dr. Michael Moore (1972, 1983, 1990 y otros). Una vez desarrollados los temas teóricos, se avanza hacia la construcción de una metodología de seguimiento, como parte de la cual se construye una matriz de indicadores. Esa matriz es sometida al juicio de expertos. Una vez que se obtienen los resultados del juicio de expertos y se resignifica la matriz, se aplica la metodología construida en un caso de estudio, para analizar sus fortalezas y debilidades. Al mismo tiempo, se contrastan dos cohortes completas de estudiantes de postgrado, con la intervención didáctica de una estrategia de mirroring (que forma parte de la metodología MetSCIn propuesta en la tesis) en la segunda cohorte, de manera tal de medir su impacto.

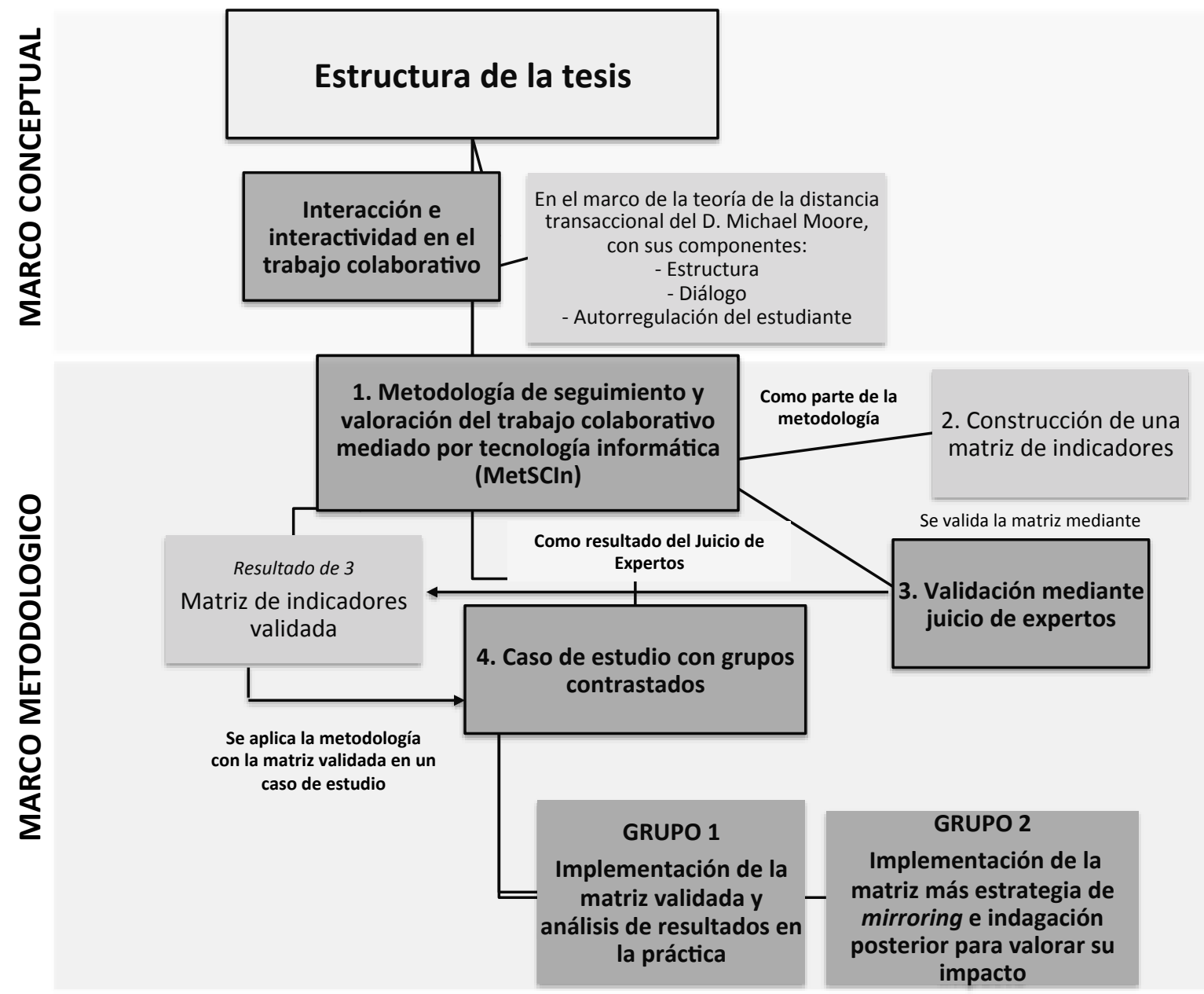

Figura 2: Recorrido conceptual y metodológico de esta tesis

Se presenta a continuación la estructura de la tesis, con los capítulos que constituyen este trabajo y una breve descripción de cada uno. Este trabajo se inicia con un capítulo de introducción (este capítulo) y tres partes, cada una de las cuales tiene capítulos y, dentro de los capítulos, secciones o apartados numerados en forma correlativa ${ }^{2}$. En los capítulos 8 y 9 , por la cantidad de apartados que se abordan, se los organiza en bloques, que están indicados con números romanos.

\footnotetext{
${ }^{2}$ Se mencionarán de manera indistinta.
} 
Se presenta la compilación de la bibliografía utilizada con formato APA. La bibliografía referenciada en cada capítulo se presenta en el capítulo de "Bibliografía" al final del trabajo.

Se incluyen cinco anexos. El primero complementa la presentación detallada del estudio de caso con la estrategia de comunicación y el protocolo de la e-encuesta utilizada para indagar las habilidades de autorregulación como parte de MetSCIn. El segundo hace lo propio con la estrategia de mirroring. El tercer anexo pertenece a la estrategia de comunicación e instrumento utilizado en el juicio de expertos. En el cuarto anexo se presentan los resultados de la implementación de MetSCIn al interior de cada una de las cohortes de estudiantes. El quinto anexo presenta los sitios de interés construidos especialmente para esta tesis que están referenciados a lo largo del corpus, con sus direcciones web. La estructura general de la tesis se presenta a continuación.

\section{Capítulo 1: Introducción}

\section{PRIMERA PARTE: MARCO CONCEPTUAL}

\begin{tabular}{|l|}
\hline Capítulo 2: Interacción e \\
interactividad en la \\
educación mediada
\end{tabular}

\section{Capítulo 3: Trabajo colaborativo mediado por tecnología informática. Marco conceptual}

\section{Capítulo 4: Antecedentes en relación a la valoración del colaborativo mediado por tecnología informática}

\section{Capítulo 5: Metodologías y aplicaciones que apoyan el seguimiento del trabajo colaborativo}

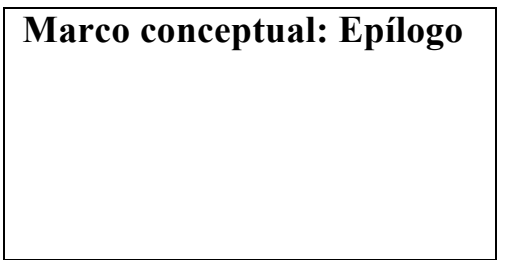
tesis. estudiante. años.
Se presentan la motivación, los objetivos y la estructura de la

Se describen los abordajes conceptuales de la interacción e interactividad en el marco de la teoría de la Distancia Transaccional del Dr. Michael Moore, con sus tres componentes: estructura, diálogo y autorregulación del

Se valoran los tipos de interacciones y su resignificación a la luz de la mediación tecnológica. Se presentan modelos que trabajan sobre grados o niveles de interacción e interactividad.

Se presenta el tránsito de los modelos atómicos, basados en la concepción de la persona en solitario a los modelos contextuales, grupales y de ahí a los modelos colaborativos. Se entrama con el rol de la tecnología informática en los últimos

Se presenta una metodología didáctica de trabajo colaborativo, diseñada en fases de trabajo.

Se expone el estado del arte en el seguimiento y valoración del trabajo colaborativo desde la Psicología, la Didáctica y la interdisciplina de CSCL.

Se presentan estudios comparados de metodologías e indicadores de trabajo colaborativo.

Se analiza la visualización de información en el trabajo colaborativo según diferentes criterios: momentos (antesdurante-después); tipo de información y forma de presentación de esta información. Se comparan softwares disponibles, presentados bajo una categorización conceptual propia, según su objetivo: mostrar información, comparar con los objetivos esperados y/o guiar al grupo.

Se avanza hacia un mapa del trabajo colaborativo en entornos educativos. Este mapa identifica y relaciona todos los elementos intervinientes en el trabajo colaborativo mediado por tecnología informática, tomando como eje la figura 1. Se describen, además, los diferentes tipos de relaciones que existen entre estos componentes. 


\section{SEGUNDA PARTE: APORTES DE ESTA TESIS Y SU VALIDACIÓN}

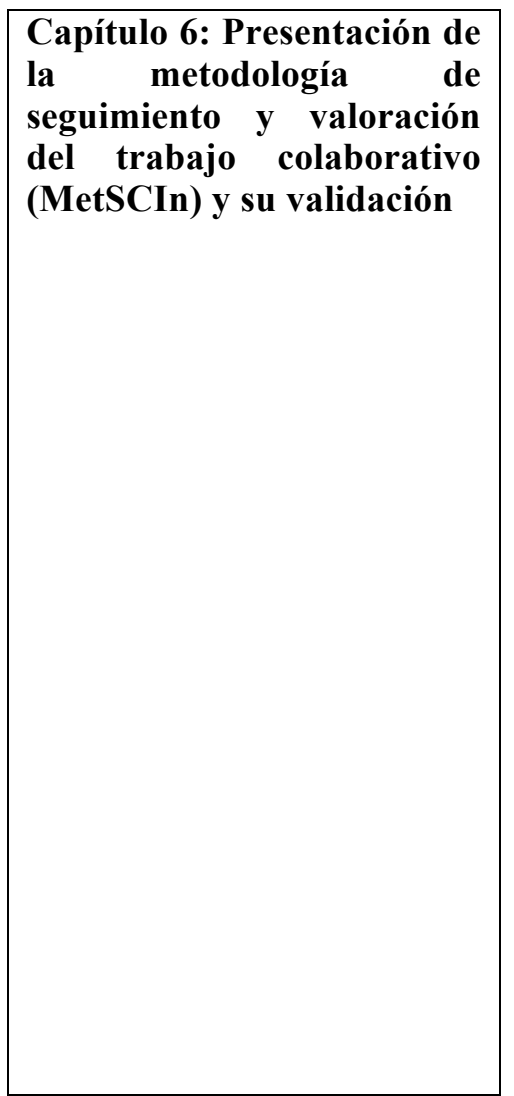

Capítulo 7: Juicio de Expertos como validación de la matriz de indicadores de seguimiento

Capítulo 8: Estudio de caso como implementación de MetSCIn
En concordancia con el objetivo general de la tesis, este capítulo presenta la metodología para identificar, analizar y comparar los fenómenos de interacción e interactividad en procesos colaborativos mediados por tecnología informática. Se retoma el estado del arte del marco conceptual y se presenta y describe la metodología construida para el seguimiento del trabajo colaborativo. Mediante el uso de un acrónimo, se ha denominado a esta metodología MetSCIn.

Como integrante de esta metodología, se describe la matriz de indicadores, con sus componentes: objeto, dimensiones, indicadores y operacionalización.

Se describen los instrumentos diseñados ad hoc como componentes de esta metodología:

a. Auto informe, en formato e, sobre autorregulación, como condición de entrada para la formación de grupos, conocimiento de perfiles individuales y estrategias de grupalidad.

b. Estrategia de mirroring y su impacto en el trabajo colaborativo.

En el anexo 1 se presenta la estrategia de comunicación propuesta y el protocolo del auto informe sobre habilidades de autorregulación.

En el anexo 2 se presenta la estrategia de comunicación propuesta y el instrumento de indagación de impacto del mirroring.

Se describe el concepto de juicio de expertos y la metodología usada como estrategia de validación de la matriz de indicadores de seguimiento del trabajo colaborativo. Se incluye: la constitución del grupo de expertos, el instrumento utilizado, los resultados obtenidos y la resignificación de la matriz a partir de estos resultados. En el anexo 3 se presenta la estrategia de comunicación y el instrumento de indagación utilizado en del juicio de expertos.

La metodología presentada se somete al trabajo empírico a través de un estudio de caso. En este capítulo se describe conceptualmente la metodología de estudio de caso en general y de grupos contrastados en particular. Se introduce el estudio de caso, en el seminario de "Educación a Distancia" de la Maestría en "Tecnología Informática aplicada en Educación". Se describen los dos grupos de trabajo bajo análisis en cuanto a su constitución y características y se presentan los resultados, en cada una de las etapas y según cada uno de los instrumentos descriptos.

a. Conformación del grupo de estudio. Información de entrada de los estudiantes de las cohortes 2015 y 2016.

b. Hallazgos del auto informe de autorregulación. Ambas cohortes en forma comparada.

c. Contrastación del trabajo colaborativo en los grupos de las cohortes 2015 y 2016, según MetSCIn. 


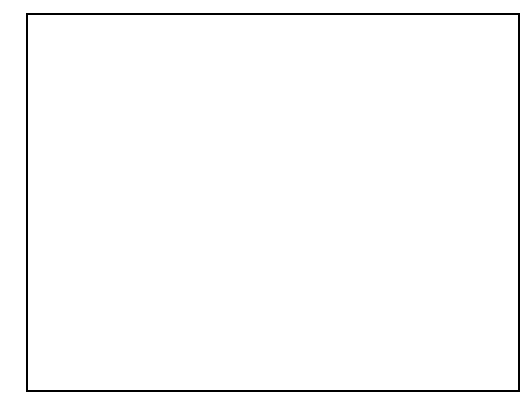

d. Impacto de la estrategia de mirroring, en la cohorte de estudiantes 2016.

En el apartado final se presenta la discusión de los resultados obtenidos a partir de MetSCIn para justificar su eficacia en el seguimiento del trabajo colaborativo mediado por tecnología informática en escenarios educativos.

El anexo 4 incluye la información detallada del trabajo colaborativo: los resultados del análisis cuantitativo y cualitativo al interior de cada grupo de cada cohorte.

\section{TERCERA PARTE: CONCLUSIONES Y TRABAJOS FUTUROS}

\section{Capítulo 9: Conclusiones y} trabajos futuros

\section{BIBLIOGRAFIA}

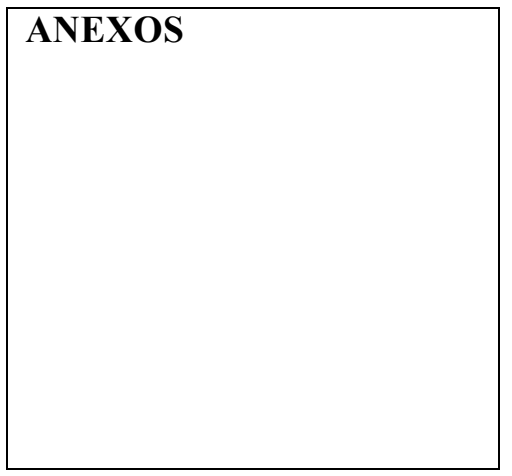

Se presentan las conclusiones, en función de cada uno de los puntos comprometidos en el agregado de valor de la tesis y se ofrecen perspectivas de trabajo futuro para cada tema clave.

Se enumera alfabéticamente la bibliografía de la tesis, referenciada en cada uno de los capítulos.

Se presentan los cinco anexos de esta tesis:

Anexo 1: Comunicación y protocolo del auto informe sobre habilidades de autorregulación.

Anexo 2: Comunicación e instrumento de indagación de impacto de la estrategia de mirroring.

Anexo 3: Comunicación e instrumento utilizado en del Juicio de Expertos.

Anexo 4: Resultados del estudio de caso por cohorte y por grupo.

Anexo 5: Sitios de interés construidos especialmente para esta tesis.

Cada capítulo inicia con una lista de temas a tratar, que actúa como organizador anticipante. Se cierra con una conclusión del capítulo con un doble objetivo: reforzar las ideas del capítulo y enlazar con el siguiente.

La relación entre las preguntas fundamentales de esta tesis presentadas y su abordaje en los capítulos puede verse en la figura 3 . 

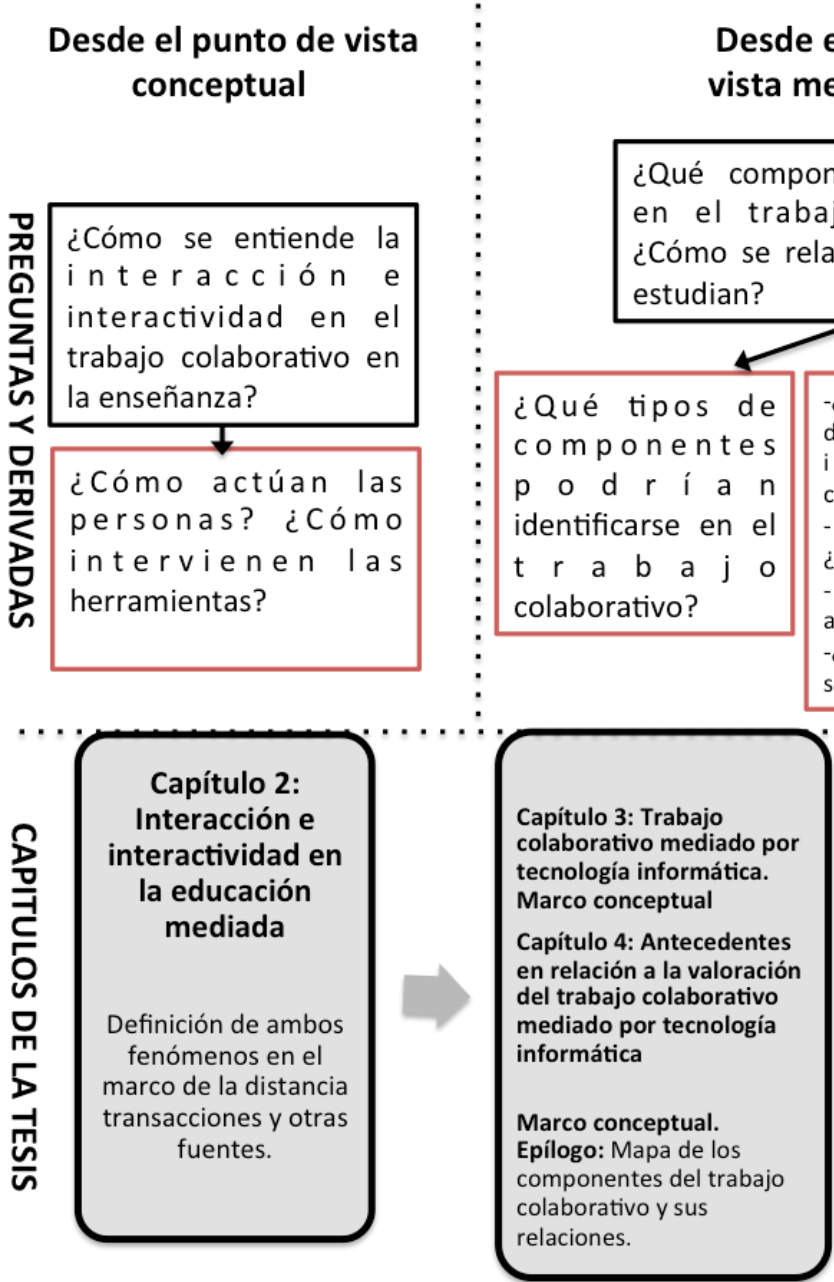

Figura 3: Relación entre las preguntas fundamentales de la tesis y los capítulos

¿Qué componentes intervienen en el trabajo colaborativo? ¿Cómo se relacionan? ¿Cómo se estudian?
¿Qué tipos de componentes p o d r í a $n$ identificarse en el t $r$ a b a j o colaborativo?

Existen metodologías para identificar, describir y valorar la interacción y la interactividad en el trabajo colaborativo?

- ¿Qué aspectos miran de la interacción?

¿Qué indicadores se utilizan para analizar la construcción colaborativa? -¿Existen herramientas que faciliten este seguimiento? ¿Y de la interactividad?

Desde el punto de vista del seguimiento y valoración del trabajo colaborativo

¿Qué información visibiliza, sobre el proceso colaborativo, la matriz de indicadores construida?

¿Qué impacto tiene en el proceso y producto d e l gru po e I conocimiento de su desempeño online?

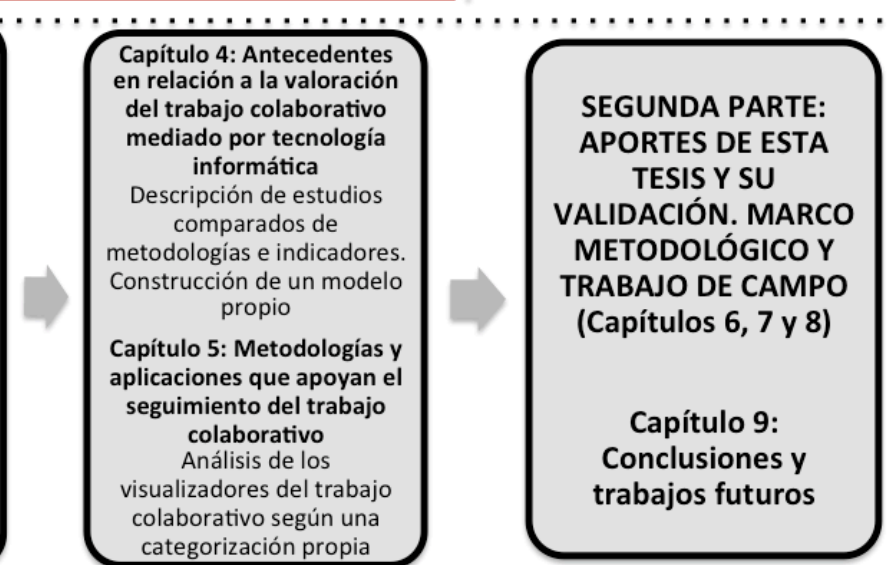




\section{Primera parte: Marco conceptual}




\section{Capítulo 2: Interacción e interactividad en la educación mediada}

El recorrido conceptual propuesto para este capítulo es el siguiente:

2.1. El modelo de Distancia Transaccional en la educación a distancia

2.1.1. Componentes del modelo de Distancia Transaccional

2.1.1.1. Estructura de la propuesta de enseñanza

2.1.1.2. Diálogo

2.1.1.3. Autonomía del estudiante

2.2. Relaciones conceptuales entre interacción e interactividad

2.2.1. Concepto y niveles de interacción

2.2.1.1. Tipos de interacciones

2.2.1.2. Niveles de interacción

2.2.1.3. Interacción Persona-Ordenador (IPO)

2.2.2. Concepto y niveles de interactividad

2.2.3. Interacción e interactividad en el marco de esta tesis

2.3. Conclusiones del capítulo 


\subsection{El modelo de Distancia Transaccional en la educación a distancia}

La educación a distancia ha sido revisitada a lo largo de su historia, a la luz de las miradas rupturistas en las de dimensiones tiempo y espacio en la enseñanza (Moore 1972, 1973 y 1975; Keegan 1980 y 1990; Tiffin \& Rajasingham, 1995). Enriquecida por la propia historia de la Tecnología Educativa, con el devenir de las innovaciones tecnológicas y sus aplicaciones en el campo educativo, la educación a distancia pasó de ser "el abandono de la comunicación interpersonal cara a cara, reemplazada por otro tipo de comunicación más impersonal, mecánica o electrónica" (Keegan, 1980 y 1990) a ser conceptualizada como un modelo tridimensional, en el que se conjugan las variables de estructura didáctica, comunicación multimedia y multidireccional y autonomía del estudiante (Moore, 1972, 1973, 1975 y otros).

Como antecedente resulta interesante analizar cómo se ha modificado el concepto de distancia, como así también el concepto de diálogo y de estudio independiente en la propia génesis de la enseñanza mediada. Algunos autores como Delling (1975), citado en Sewart, Keegan \& Holmberg, 1983), plantea el estudio a distancia como un fenómeno cercano a la autodidaxia, como una decisión del estudiante respecto de cuándo, cuánto, cómo y dónde aprender. A esta capacidad del estudiante hace referencia Wedemeyer (1973), más cercano a la filosofía no directivista de Carl Rogers (1986), quien plantea el estudio independiente sobre un ideal de democracia y una filosofía basada en la libertad e igualdad de oportunidades. Con referencia a la Didáctica de la educación a distancia, Peters (1971) plantea el modelo de industrialización, con énfasis en el diseño de cursos y materiales a gran escala, con probada eficiencia y para gran cantidad de personas. Su entendimiento del fenómeno estaba en relación con la producción industrial de bienes (Peters, 1971 en Sewart et al., 1983). Quien menciona el tema del diálogo es Holmberg $\left(1985^{3}\right)$, que describe a la educación a distancia como una conversación didáctica mediatizada. El estudio a distancia, según su visión, es un estudio independiente, pero en el que el estudiante no está solo, su trabajo se ve enriquecido por los tutores, otros estudiantes y la estructura administrativa que da soporte al curso (Holmberg en Clark \& Moore, 1989).

Finalmente, el modelo que concilia estas partes, las ubica en tensión y permite entender la real complejidad de la enseñanza y el aprendizaje a distancia, es el modelo de Distancia Transaccional de Michael Moore. Sewart et al. (1983) ubican al modelo de Moore como integración de las teorías de la industrialización de Peters, la comunicación-interacción grupal de Holmberg y las teorías de autonomía e independencia del estudiante de Wedemeyer (Sewart et al., 1983, pág. 65). Este modelo comienza a delinearse en las primeras presentaciones de Moore en los años 1972 y 1973. Moore muestra su trabajo junto a Charles Wedemeyer en la Universidad de Wisconsin, presentando a la educación a distancia como una "familia de métodos de enseñanza en los que la conducta instruccional se desarrolla con independencia del comportamiento de los estudiantes" (Moore, 1972, pág. 36). El concepto de distancia radica, entonces, en la separación de docentes y estudiantes y en la dimensión de autonomía que es requisito para que el aprendizaje exista. Toma las dimensiones de diálogo, estructura y autonomía del estudiante para comprender los fenómenos de la enseñanza en espacios sincrónicos y asincrónicos. Supera, así, la concepción geográfica de la distancia: ya no se estudia a distancia porque se está lejos de las instituciones que imparten propuestas educativas, sino que se estudia en un espacio mediado, con diálogo, estructura didáctica y el requisito de autorregulación necesario para la autoadministración de la propuesta de enseñanza.

\subsubsection{Componentes del modelo de Distancia Transaccional}

\footnotetext{
${ }^{3}$ Su obra fue originalmente escrita en alemán. El año 1985 es la fecha de la primera traducción al idioma ingles.
} 
El modelo de Distancia Transaccional permite comprender la enseñanza mediada como un espacio de comunicación, en el que la distancia geográfica de los docentes y los alumnos no es un elemento fundamental a la hora de planificar e implementar una propuesta. Moore describe tres elementos que se redefinen en los espacios de educación mediada con tecnología informática:

- Estructura de la propuesta de enseñanza, como espacio de prefiguración, de diseño en los niveles de curso, materiales, actividades y evaluación. Según Moore "estas variables acerca de la enseñanza y el diseño instruccional derivan del análisis de los programas de educación a distancia y son usadas para ordenar, organizar y clasificar la gran variedad de prácticas que han constituido y constituyen el campo de la educación a distancia en la actualidad" (Moore, 1990, pág. 124).

- Diálogo, como elemento transaccional de interacción entre personas. Se manifiesta en el sistema de atención a los estudiantes, que se incluye en toda propuesta de educación a distancia que atienda a su calidad. La función del diálogo es escuchar, acompañar, orientar, estimular, anticipar (problemas y sus soluciones) y, muchas veces, también evaluar y acreditar.

- Autonomía del estudiante, como competencia metacognitiva de autorregulación que le permite al estudiante, entre otras acciones, hacer un uso óptimo de la estructura y el diálogo presentes en la propuesta de enseñanza.

En este modelo la distancia es entendida como el espacio de interacción e interactividad que opera dentro de la distancia física. Ofrece, entonces, otra dimensión del concepto de educación a distancia, vinculado con las mediaciones que ocurren en la enseñanza y aprendizaje. Este tipo de distancia, mediada o transaccional, mejora cualitativamente cuanto mejor esté pensando el diseño de la propuesta, mejor sea la calidad del diálogo y/o más desarrollado esté el nivel de autonomía o autorregulación del estudiante.

Gráficamente puede verse en un espacio tridimensional que muestra cómo la estructura y el diálogo se manejan en tensión con la autonomía. Por ejemplo, en el caso de estudiantes con menor autonomía, es necesario crear espacios de mayor estructura (que expliciten todos los componentes de la enseñanza) o diálogo con el docente y/o compañeros (que completen los espacios de duda o dirijan al estudiante en los momentos en los que la dirección interna no funcione). La figura 4 muestra cómo se interrelacionan los tres elementos mencionados en el modelo de Shearer (en Moore, 2013).

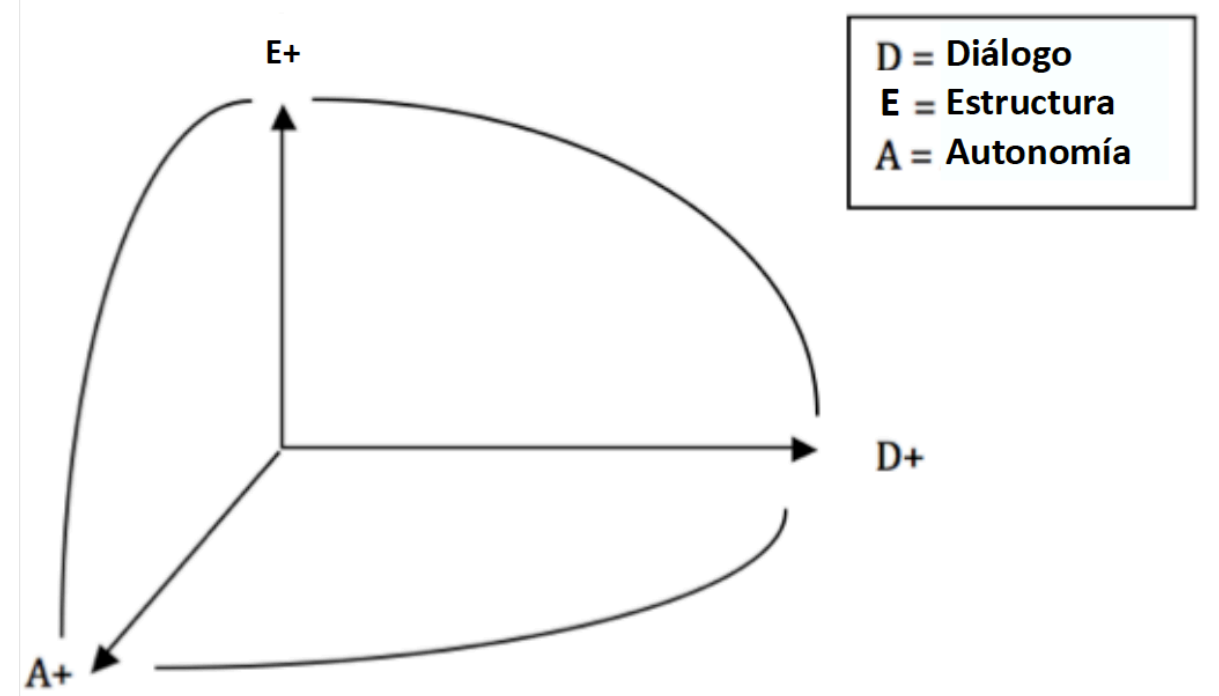

Figura 4: Modelo tridimensional de Distancia Transaccional (Traducido de Shearer, 2013) 
El aspecto del diseño se vincula con la interactividad, sus características y sus grados. El componente del diálogo se vincula con la interacción. Ambos se abordarán en este mismo capítulo, en próximas secciones. La autorregulación, que también se trabajará más adelante en este mismo capítulo, es un elemento central en la consideración del trabajo colaborativo. En las secciones siguientes se explicará, con mayor profundidad y retomando diversas fuentes, cada uno de los componentes de la teoría de Distancia Transaccional.

\subsubsection{Estructura de la propuesta de enseñanza}

Este componente trata sobre el diseño. El diseño supone, a la vez, una actividad simbólica proyectiva y un profundo conocimiento de la realidad. Siguiendo a Ciapuscio (1996) es como "soñar, con los pies sobre la tierra". El diseño es proyectivo porque piensa un escenario deseado. A la vez, necesita un profundo conocimiento de la realidad, ya que debe generar un puente de estrategias viables para ser llevadas la práctica en un contexto real: modificar la situación inicial $\mathrm{y}$, en lo posible, llevarla a la situación proyectada. Se encuentra, entonces, en un punto intermedio entre la teoría y la realidad y representa un instrumento de profunda transformación.

Así, el diseño de la enseñanza a distancia implica prefigurar y organizar estrategias para presentar los contenidos temáticos, posibilitar la práctica y evaluar los logros en términos de cambio conceptual o de competencias deseados en los estudiantes. Representa un eje central en la enseñanza a distancia. Según Shearer "en el diseño de la estructura didáctica de una propuesta de educación a distancia, los diseñadores establecen ritmos, secuencias, requerimientos de interacción y de tecnología que permiten revisar la idea de que la educación a distancia se produzca en cualquier momento y en cualquier lugar". (Shearer en Moore, 2013, pág. 25).

Con el cambio de medios que se ha generado en este último siglo (en cuanto a su soporte y lenguaje), y la proyección geométrica de estos cambios en la actualidad y hacia el futuro, el diseño de estrategias para enseñar a distancia se ha enriquecido. Se combinan entornos de enseñanza y aprendizaje, escenarios de simulación (laboratorios, entornos virtuales inmersivos, etc.) a la vez que estrategias didácticas que deben transformarse en experiencias de aprendizaje significativas para los estudiantes. Ya en 2003, Chacón presentaba una idea clave del diseño atendiendo al cambio de escenarios digitales con esta frase: "un problema común cuando se enfrenta la tarea de mediar la instrucción de la clase o de diseñar materiales instruccionales a distancia es cómo transformar las experiencias de aprendizaje en experiencias igualmente significativas en un ambiente virtual" (Chacón, 2003, pág. 16).

El tema del diseño se vincula con el fenómeno de la interactividad. Se volverá sobre este tema en la sección 2.2.2. "Concepto y niveles de interactividad".

\subsubsection{Diálogo}

El diálogo es una forma de comunicación pedagógica, tal vez la más reveladora de las acciones educativas. La educación es comunicación y la comunicación se manifiesta a través del diálogo. Freire (en Moreno, 1999) identifica al diálogo como un fenómeno humano que muestra la esencia del hombre: acción y reflexión. Edith Litwin resignifica la pregunta docente como disparador del diálogo. En su obra El oficio de enseñar plantea una serie de interesantes preguntas de investigación respecto de las configuraciones didácticas que se visibilizan en una clase presencial y le dedica un espacio especial a la relación entre la clase expositiva y la clase dialogada (Litwin, E., 2008, pág. 80). Presenta a la clase expositiva como una estrategia sumamente válida para la acción docente, que requiere y necesita de un cuidadoso análisis epistemológico de la disciplina a enseñar y de una no menos cuidadosa organización y transposición didáctica. Se reserva, así, un lugar de preponderancia para el diálogo. El diálogo 
visto como una herramienta docente para favorecer los procesos comprensivos y de integración. Dice: "en las explicaciones que las y los docentes despliegan en sus clases, más de una vez realizan preguntas para ayudar a la comprensión o para reconocer si los estudiantes comprenden. Otras veces, las preguntas son verdaderos desafios cognitivos, invitaciones para que se cuestionen y se desplieguen los interrogantes más atrevidos o más provocativos".

El tema del diálogo en la enseñanza es también objeto de estudio para Burbules (1999) quien plantea que el diálogo es inherente a la construcción de comunidades de aprendizaje. Define, entonces, cuatro tipos de diálogo: como conversación, como debate, como indagación y como enseñanza, cada uno con sus objetivos didácticos, su estructura interna y sus recomendaciones para generarlo y sostenerlo en la clase entendida como comunidad.

Bain (2011) realiza un interesante estudio, una especie de benchmarking para identificar qué hacen los mejores profesores que dejan huella en sus estudiantes (lo que Litwin denomina "clases memorables"). Al final de su estudio intenta configurar una especie de perfil, a partir de las buenas prácticas en las que encuentra cierta regularidad entre los docentes referidos por sus entrevistados. El diálogo es una de ellas. Según Bain, los docentes deben poseer una caja de herramientas, en las que debe haber diferentes tipos de preguntas y diálogos posibles, para manejar la tensión propia de la observación, análisis, intervención y evaluación, que acompaña el ciclo de vida de una clase.

También se retoma la importancia del diálogo en la enseñanza en artículos más actuales, vinculados con el diseño y performance de los cursos online. Se valora la interacción como uno de los ejes del diseño de este tipo de cursos. Como ejemplo, Jaggars \& Xu presentan al diálogo como "la medida en que maestro y estudiante participan en una interacción constructiva que construye el conocimiento del alumno ${ }^{4 »}$ (Jaggars \& Xu, 2016, pág. 271).

La teoría de la Distancia Transaccional, entonces, retoma la importancia del diálogo en la presencialidad y en la teoría de la conversación didáctica mediatizada de Holmberg y ayuda a dimensionar otras cuestiones asociadas al valor estratégico del diálogo en una propuesta de enseñanza mediada: ¿quiénes dialogan? ¿sólo los alumnos con los docentes? ¿y los alumnos entre sí? ¿y los docentes entre sí? ¿cuánto se dialoga? ¿cada cuánto tiempo se intercambian mensajes? ¿cómo se dialoga? ¿cómo es el diálogo con el contenido? ¿por qué medios y lenguajes se produce este diálogo?. Y aún más: ¿qué peso tiene el componente de diálogo en la propuesta de enseñanza en general? y ¿para qué tipo de autorregulación está pensando ese diálogo? ¿es coherente con los estudiantes reales que acceden a la propuesta de enseñanza?

El tema del diálogo en la enseñanza a distancia ha sido, y es, objeto de constantes investigaciones. La posibilidad de documentar y recuperar las transacciones-diálogos que ocurren en un espacio de tecnología informática ha hecho posible que este tema se pueda desentramar y resignificar en cada curso o aula virtual donde haya un docente dispuesto a deconstruir su práctica para construir algo superador. Se retomará este tema, en línea con las investigaciones de Moore y otros, en la sección 2.2.1.1. "Tipos de interacciones".

\subsubsection{Autonomía del estudiante}

Moore toma de Wedemeyer la idea de la independencia del estudiante. Este es el origen del componente de autonomía presente en el modelo de Distancia Transaccional . La autonomía del estudiante puede ser identificada con la autorregulación. Se trata de un proceso autodirigido a través del cual los aprendices transforman sus capacidades cognitivas y afectivas en habilidades académicas, puestas al servicio del logro de sus objetivos de aprendizaje. Es multidimensional e

\footnotetext{
${ }^{4}$ Traducción de la frase original: "Dialogue is the extent to which teacher and student engage in constructive interaction that builds the student's knowledge”. (Jaggars \& Xu, 2016, pág. 271).
} 
implica componentes personales (cognitivos y emocionales), de comportamiento y contextuales (Zimmerman, 1989, 1998, 2000, 2001).

Wedemeyer (1973) presenta ciertas características que debe cumplir el estudiante y que, en su modelo, relacionan a la educación a distancia con el estudio independiente. El estudiante debe ser capaz de funcionar en cualquier lugar en el que haya estudiantes (aunque sea un solo estudiante) con independencia de si hay profesores presentes en el mismo lugar y en el mismo momento y debe tener conciencia de la responsabilidad sobre su aprendizaje. Por otro lado, la propuesta debe ofrecer a los estudiantes un amplio abanico de cursos, formatos y metodologías; utilizar de manera apropiada todos los medios y métodos de enseñanza que han demostrado ser efectivos; combinar medios y métodos de manera que cada tema se enseñe de la mejor manera posible conocida; conservar y mejorar las oportunidades de adaptación a las diferencias individuales; evaluar el rendimiento del estudiante, no levantando barreras relacionadas con el lugar, el ritmo, el método o la secuencia de estudio del alumno y permitir que los estudiantes inicien el proceso, se detengan para recapitular y volver a comenzar y aprendan según su propio ritmo.

El tema de la autorregulación en el aprendizaje ha sido ampliamente estudiado desde diferentes perspectivas que tuvieron su origen en la instalación de las teorías cognitivas y constructivas como explicación del aprendizaje. Como se mencionó párrafos arriba, se trata de un proceso que implica diversos componentes, tanto de la afectividad como del intelecto. En la bibliografía se ha descripto este tema complejo según diferentes abordajes:

- Según momentos del proceso de autorregulación. Zimmerman, 1989, 1998, 2000, 2001: Bandura, 1986, 1997.

- Según categorías de pensamiento y conducta, que permitirían identificar los componentes de este proceso Pintrich (1991); Entwistle \& Briggs, 1988; Seifert \& O'Keefe, 2001; Simons, Dewitte \& Lens, 2004; Torre Puente, 2007.

Diversos autores (Zimmerman, 1989, 1998, 2000, 2001; Bandura, 1986, 1997) coinciden en identificar tres momentos fundamentales:

a) el momento de premeditación, que hace referencia a los procesos y a las creencias que influyen y que preceden a los esfuerzos por aprender y preparar el terreno para el aprendizaje. En este momento sobresale el valor del conocimiento de los objetivos a lograr en el proceso del aprender, la utilidad de los aprendizajes y la prefiguración del logro (que la persona pueda imaginarse en el final del proceso, con el resultado obtenido).

b) el momento de ejecución o control voluntario, que se da en los procesos que tienen lugar mientras el estudiante lleva a la práctica su planificación y afectan en la concentración y la ejecución. En este momento interjuegan el contexto de la enseñanza (institucional, tecnológico), los docentes y los compañeros.

c) el momento de la autorreflexión, que son los procesos que tienen lugar tras el esfuerzo por aprender y que influyen sobre lo que se está aprendiendo. Tienen influencia en la premeditación de los futuros procesos de aprendizaje que cierran el círculo de autorregulación. Se podría relacionar este último momento con el concepto de metacognición (Flavell, 1971).

Otros autores, como Pintrich (1991), identifican y describen los componentes de la autorregulación según áreas de pensamiento que impactan en las acciones necesarias para alcanzar los objetivos de aprendizaje. Mencionan cuatro áreas: cognitiva, motivacional, conductual y contextual. En cada una de estas áreas se organiza la actividad en dirección a la tarea a cumplir y el objetivo a lograr. El área cognitiva contiene un aspecto de contenido y otro 
lógico-formal (la metacognición). En este sentido, en el área cognitiva se organizan tres componentes: a. información y anticipación del objetivo a alcanzar; b. activación del contenido previo relevante y c. organización del repertorio de estrategias metacognitivas que ya se hayan utilizado, exitosamente, en el pasado. El análisis del objetivo a alcanzar abarca el tipo de actividades que el logro del objetivo requiere. La internalización del objetivo interpela a la estructura cognitiva de tal forma que el contenido relevante se dispone naturalmente para ser usado en la consecución del nuevo objetivo. En cuanto al aspecto metacognitivo, cobra importancia la forma en la que se han aprendido los conocimientos previos, la profundidad con la que se han estudiado, el nivel de dificultad, etc. Dos de las estrategias metacognitivas más interesantes y eficientes que presentan estos autores son: judgements of learning (JOLs), que son estrategias de comprensión del contenido (vinculado con su organización lógica) y feeling of knowing (FOK), que es el sentimiento o sensación de saber. La persona comienza a construir desde sus conocimientos previos una zona de conocimiento extendida que va aumentando cuantitativa y cualitativamente a medida que avanza la actividad cognitiva y metacognitiva, hasta que se genera la sensación de saber y poder hacer una tarea que antes no hubiera podido enfrentarse con la sensación de terminarla exitosamente. En el área motivacional está incluida la regulación del aspecto motivacional. Así como un estudiante regula sus estrategias cognitivas y metacogitivas, podría regular el componente afectivo y motivacional. Un elemento que orienta el aspecto motivacional es el logro del objetivo cumplido y la prefiguración de la situación deseada (examen aprobado, carrera terminada, vacaciones post logro, etc.). Un componente central de este aspecto es el easy of learning (EOL). Esto es el análisis, en términos cognitivos y metacognitivos, de la dificultad de la tarea encomendada. El área conductual es el aspecto de la autorregulación que organiza lo que la persona hace en términos de organizar su estudio y alcanzar el objetivo. Las actividades principales de esta área son: el planeamiento, el manejo del tiempo y recursos, la organización del esfuerzo (por niveles, por ejemplo), los tiempos de trabajo y descanso, las alertas en la organización de tareas, etc. Finalmente, en el área contextual se concentran las tareas de percepción y manejo del contexto. Incluyen percepción de la tarea a realizar y de las condiciones del contexto para que esa tarea sea llevada adelante, en términos de los recursos que se ponen a disposición (tiempo, recursos, fuentes de consulta, otros alumnos expertos que puedan ayudar, etc.). También incluye la re negociación de las condiciones iniciales, si no resultan propicias para el trabajo: negociar la fecha de entrega o las condiciones de entrega o el nivel de dificultad. También podría incluir dejar la tarea inconclusa o, incluso, abandonar la actividad completa.

Se registran instrumentos diversos que indagan en las habilidades de autonomía o autorregulación (Entwistle \& Briggs en Crooks, 1988; Zimmerman, 1998; Seifert \& O’Keefe, 2001; Simons, Dewitte \& Lens, 2004; Torre Puente, 2007). También, los aspectos motivacionales y éticos (Morales Vallejo, 2006) y hasta la diferencia de escala y rendimiento en las habilidades de estudio según la perspectiva de género (Mehrabian, 1968; Riveiro, Nieto \& Veiga, 2004). Como puede verse en la literatura sobre este tema, hay aspectos o variables diversos que conforman la autorregulación y hasta unos influyen sobre otros en situaciones determinadas. Existe consenso en las habilidades que conforman la autorregulación y que podrían organizarse según las siguientes categorías:
a. Motivación - Sostenimiento de la motivación
b. Manejo de la afectividad
c. Gestión del tiempo
d. Concentración
e. Habilidades de procesamiento de información
f. Trabajo en equipo

Se ofrece una breve descripción teórica y ejemplificación de cada una de estas categorías de análisis en la tabla 1. 


\begin{tabular}{|c|c|}
\hline CATEGORIA & DESCRIPCION y EJEMPLOS \\
\hline $\begin{array}{l}\text { a. Motivación - } \\
\text { Sostenimiento de la } \\
\text { motivación }\end{array}$ & $\begin{array}{l}\text { Implica estar motivado ante una nueva tarea por aprender y sostener su } \\
\text { motivación durante el proceso de logro del objetivo previsto. Debería: } \\
\text { - Vislumbrar la meta desde el inicio. } \\
\text { - Tener idea de pasos intermedios y pequeños éxitos que conducirán al } \\
\text { logro del objetivo. } \\
\text { - Terminar lo que inicia. } \\
\text { - Buscar formas de mantener el interés. } \\
\text { - Enfrentar y superar los obstáculos. } \\
\text { - Saber cómo y a quién pedirle ayuda. } \\
\text { - Ser consciente de las dificultades que se tienen durante el estudio y } \\
\text { planificar cómo superarlas. }\end{array}$ \\
\hline $\begin{array}{l}\text { b. Manejo de la } \\
\text { afectividad }\end{array}$ & $\begin{array}{l}\text { La afectividad es un tema central en el aprendizaje. El proceso de } \\
\text { aprender demuestra una valoración hacia lo que se aprende. Implica } \\
\text { moverse hacia un objetivo que se valoriza como importante. En este } \\
\text { sentido, la demostración de esta categoría debería cumplir con: } \\
\text { - Avanzar, pese a sentirse perdido por momentos. } \\
\text { - Valorar el proceso más que el resultado. } \\
\text { - Animarse a cometer errores. } \\
\text { - Buscar formas de animarse: pensar que otros compañeros/as están } \\
\text { - Recorriendo el mismo camino. } \\
\text { - Buscar un equilibrio entre descanso y estudio. }\end{array}$ \\
\hline c. Gestión del tiempo & $\begin{array}{l}\text { El manejo del tiempo es central en la organización de cualquier tarea, } \\
\text { individual o social. Lo es también en la planificación del aprendizaje. Esta } \\
\text { tarea tiene un desafío adicional: hacer coincidir esa auto-planificación con } \\
\text { los eventos (externos) de la enseñanza: encuentros, entrega de ejercicios, } \\
\text { exámenes, organización del calendario académico, etc. El estudiante que } \\
\text { sepa administrar su tiempo de estudio debería estar en condiciones de: } \\
\text { - Planificar como primera tarea, entendiendo que la planificación macro } \\
\text { es una tarea más, quizás la más importante. } \\
\text { - Organizar cuánto tiempo demanda una tarea (pensar cuánto me llevó } \\
\text { la última vez). } \\
\text { - Intentar no procrastinar (o aplazar las obligaciones) } \\
\text { recorriendo el mismo camino. }\end{array}$ \\
\hline d. Concentración & $\begin{array}{l}\text { Tener habilidades de concentración significa: } \\
\text { - Organizarse, en función del tiempo y material disponible. Plantearse } \\
\text { objetivos intermedios y finales. } \\
\text { - Buscar un lugar acorde para el estudio en cuanto a luz, orden, limpieza, } \\
\text { silencio. } \\
\text { - Otorgar la importancia requerida a las tareas de repaso. }\end{array}$ \\
\hline f. Trabajo en equipo & $\begin{array}{l}\text { Está compuesta por: la motivación por el trabajo en equipo, los aportes } \\
\text { individuales en pos de la construcción del mensaje grupal, las habilidades } \\
\text { para el manejo de conflictos, la importancia que de la planificación, la } \\
\text { implementación de lo planificado y el uso de la tecnología como } \\
\text { mediadora. }\end{array}$ \\
\hline
\end{tabular}

Tabla 1: Categorías de autorregulación. Descripción teórica y ejemplos

En el capítulo 6 se describe detalladamente la vinculación de este tema con la metodología MetSCIn y su abordaje. 


\subsection{Relaciones conceptuales entre interacción e interactividad}

Este tema resulta central en el capítulo y es uno de los compromisos de agregado de valor mencionado en el capítulo 1 de este trabajo. Para cumplir con este objetivo se ha decidido comenzar por la definición de interacción e interactividad, y posteriormente construir un modelo integrado, en el marco de la enseñanza mediada con tecnología informática.

\subsubsection{Concepto y niveles de interacción}

García Aretio (2011) en una entrevista brindada a una revista argentina especializada en educación, identifica a la educación con la comunicación y a ésta con la interacción. Dice: "si la educación es algo, es comunicación, es diálogo, sea éste síncrono o asíncrono, vertical u horizontal. La interacción, por tanto, es elemento definitorio del hacer educativo. Y decimos más, interacción sea con los otros (docente-estudiante, estudiante-estudiante, docente-docente), sea con los contenidos (contenidos-estudiante, contenidos-docente), sea con los recursos tecnológicos que median el contenido o sea con el resto de la sociedad". (García Aretio, 2011, pág. 2).

\subsubsection{Tipos de interacciones}

Si la interacción es comunicación, para el estudio de las interacciones es necesario remontarse a la teoría de comunicación. Como presenta Wiener en 1950 (en Winkin, 1984) el modelo telegráfico de la comunicación "es una cuestión de un intercambio de mensajes entre el hombre y las máquinas, entre las máquinas y el hombre, y entre la máquina y la máquina". Este modelo, bajo la metáfora del telégrafo, entiende a la comunicación como un sistema de intercambio de mensajes, en el que emisor y receptor únicamente necesitan compartir el código y el canal. Como contraposición a este modelo, en su artículo "El telégrafo y la orquesta" (Winkin, 1984), Gregory Bateson propone un modelo multisensorial, mutidireccional y polisémico, en el que la comunicación actúa como una orquesta: cada instrumento sabe y presta atención a su parte, pero funciona, además, como componente de algo mayor, que lo incluye y resignifica. Podrían compararse topológicamente estos modelos, en cuanto a la forma que tiene la comunicación entre personas según se muestra en la figura 5 .

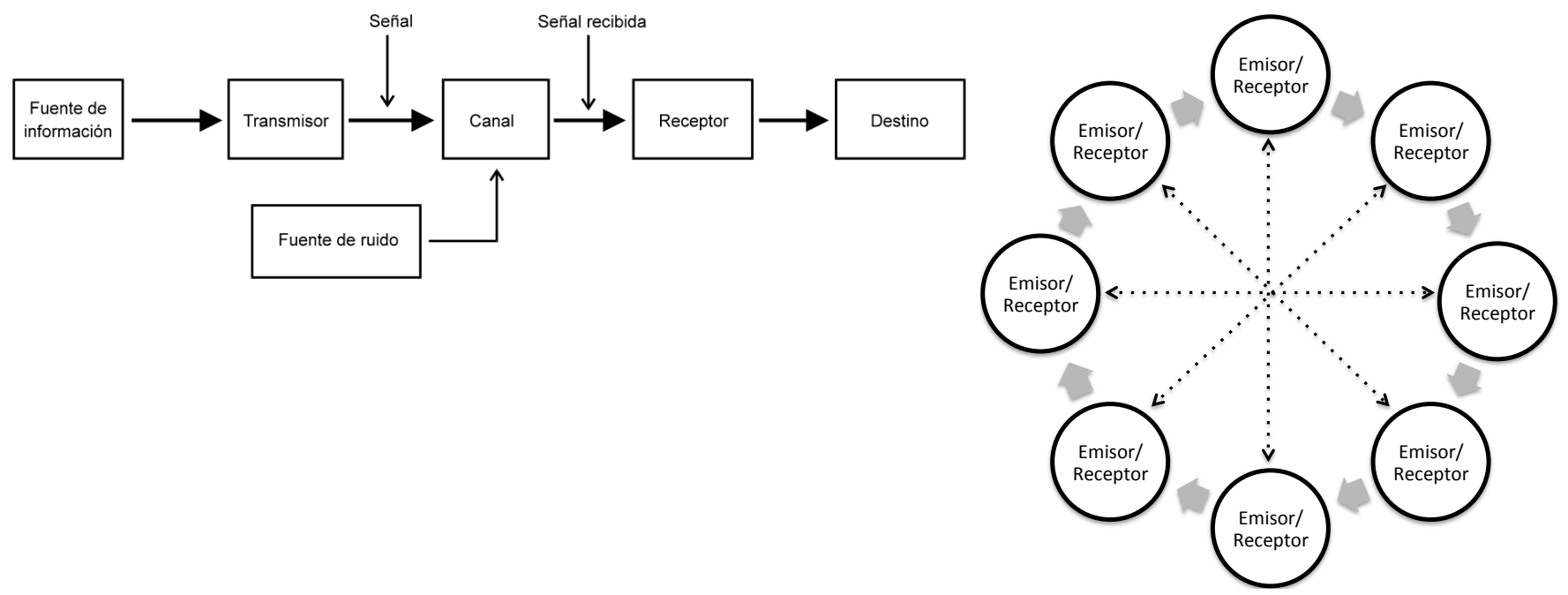

Figura 5: Izquierda: Modelo telegráfico (Shannon y Weaver, 1950). Derecha: Modelo orquestal de la comunicación (Bateson, 1984) 
Tan vinculada está la interacción a la comunicación, que el enfoque que subyace a los modelos orquestales de comunicación lleva el nombre de enfoque interaccional (Bateson en Winkin, 1984). Llevando estas ideas al campo de la enseñanza podría decirse que entender las interacciones en una situación educativa implica comprender el aula (física o virtual) como un sistema bajo alguna de estas metáforas: o es un telégrafo (Shannon \& Wiener) o es una orquesta (Bateson). Fainholc otorga gran importancia a esta idea en su trabajo: "La interactividad en la educación a distancia". Dice: "la interacción implica un proceso de comunicación, que no es lineal entre un estímulo y una respuesta, sino un proceso donde los interlocutores ocupan alternativamente una y otra posición, recreando todos los elementos que se implican en una comunicación. Tanto presencialmente como a distancia, la comunicación incluye mensajes simbólicos implícitos, reacciones de retorno, percepciones portadoras de significado, etc., donde los motivos y las transacciones interpersonales replantean las estrategias de pensamiento, emoción y acción”. (Fainholc, 1999, pág. 60).

Además, la irrupción de la tecnología informática ha ayudado a pasar del telégrafo a la orquesta, al permitir visibilizar los rastros de las comunicaciones en educación a distancia. En este tránsito, Moore (1989) describe tres formas de interacción en educación a distancia: entre estudiantes y docentes, entre los estudiantes entre sí y entre los estudiantes y el contenido. Esto representa una primera versión del modelo de interacción en la Distancia Transaccional, que se grafica en la figura 6 .

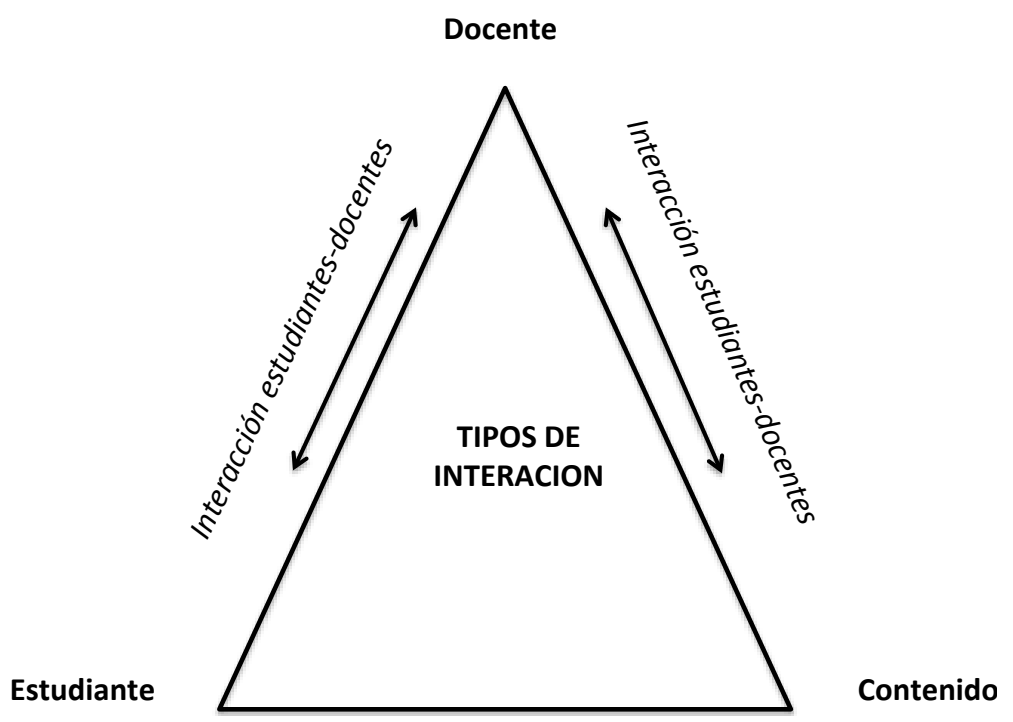

Figura 6: Tipos de interacciones (Moore, 1989)

Friesen (2013) agrega dos tipos más de interacciones a este primer modelo: interacciones entre docentes y entre docentes y contenido. Hillman, Willis \& Gunawardena hablan de la interacción entre el estudiante y la interface. La definen como "el proceso de manejo de herramientas para cumplir una tarea. Se focaliza en el acceso, competencias y actitudes necesarias para que la tarea (de aprendizaje) sea exitosa" (Hillman, Willis \& Gunawardena, 1994, pág. 76). Todas las formas de interacción en un contexto de educación a distancia son, por definición, formas tecnológicamente mediadas de interacción.

Friesen presenta otra forma de interacción que resulta sumamente interesante a la luz de la tecnología informática. Retoma a Sutton (2000) quien, sobre la base de conocimientos de Fulford \& Zhang (1993) y Kruh \& Murphy (1990), postula una nueva forma de interacción que denomina "interacción vicaria". En la educación a distancia, como en el aprendizaje en el aula, no todos los estudiantes interaccionan directamente entre sí o con el profesor durante las clases o, incluso, en un curso entero. Sin embargo, pueden interaccionar vicariamente. Sutton define la interacción 
vicaria como algo que ocurre "cuando un estudiante procesa activamente ambos lados de una interacción directa entre los otros dos estudiantes o entre otro estudiante y el instructor, sin dejar rastros visibles en la herramienta mediadora". (Sutton, 2000, pág. 354). O sea, conoce, entiende, procesa. Interactúa, pero no deja rastros de ese aprendizaje. Un ejemplo típico de este tipo de interacción se da en los espacios colaborativos: el estudiante está atento, lee, procesa cognitivamente, pero no participa. El análisis de este tipo de interacción, resulta un tema central a la hora de valorar el trabajo colaborativo con tecnología informática. Se volverá sobre este tema en la segunda parte de esta tesis, en el abordaje del estudio de caso.

Se contaría entonces, con los siguientes tipos de interacción en la educación a distancia:

- Estudiante-docente

- Estudiante-estudiante

- Estudiante-contenido

- Docente-contenido

- Docente-docente

Se profundiza en cada una de ella a continuación.

La interacción estudiante-docente ha sido muy estudiada desde la perspectiva docente. El profesional reflexivo de Shön (1998) postula un docente con competencias de reflexión "de" y "en" la práctica, donde el tipo y modo de esta interacción forma parte de la resignificación del propio rol docente: el docente actúa y reflexiona sobre esa acción. Asimismo, se han estudiado muchos de los beneficios pedagógicos de la interacción estudiante-docente, especialmente las relacionadas con la motivación (Wlodkowski, 1985) y la retroalimentación (Laurillard, 1997; 2000). Estas potencialidades de los buenos docentes se ven como igualmente relevantes en contextos presenciales y de educación a distancia.

La interacción estudiante-estudiante ha sido la más ampliamente investigada por la literatura especializada, en relación con el trabajo en grupos y la actividad colaborativa. Como Brown \& Duguid afirman: "convertirse en miembro de una comunidad y participar en sus prácticas, permite no sólo adquirir y hacer uso de sus conocimientos e información, sino participar de su crecimiento" (Brown \& Duguid, 2000, pág. 126). Dentro de este tipo de interacción, coinciden Collinson (2000) y Arango (2003) en tres formas de diálogo: diálogos sociales, caracterizados por la informalidad y la necesidad de compartir asuntos de carácter personal; diálogos argumentativos, nacidos desde las lógicas individuales y caracterizados por la defensa de puntos de vista personales, no necesariamente confrontados con los de los demás; y diálogos pragmáticos, en los cuales se pone en juego el conocimiento de todos para construir, desde distintas miradas y significados de un mismo hecho.

Retomando a Clark (2000) en la interacción estudiante-contenido se debe identificar que, en los contextos educativos, existen dos niveles de esta interacción: a.- la interacción con el lenguaje o atributos de los medios de comunicación que apoyan la enseñanza y b.- el diseño instruccional y tecnológico que el docente o diseñadores hayan decidido para ese medio. El estudiante interactúa con el medio a través del diseño instruccional, que actúa como catalizador. Algunas de estas características se retomarán en la construcción conceptual del modelo interacción - interactividad.

En cuanto a la interacción docente-contenido, también es un eje de la formación docente. Aquí se reconoce una tensión entre la conceptualización del docente como autor o diseñador de materiales instruccionales vs. el docente como buscador experto de materiales diseñados por otros. Hay especialistas que apuestan al docente diseñador (Mayer, 1999 y 2003) y otros que prefieren que el docente adquiera estrategias de búsqueda y reutilización de materiales existentes. 
En esta línea, una de las competencias del buen docente de Bain (2011) es la búsqueda, reutilización y evaluación de materiales educativos existentes. El docente actúa como rediseñador y revitalizador de esos materiales, al utilizarlos en un contexto de enseñanza diferente.

Finalmente, la interacción docente-docente escala a la dimensión de la comunidad de práctica. El concepto de comunidad de práctica fue introducido por Etienne Wenger en 2001, para identificar a "un grupo de personas que se reúnen de manera informal para compartir su experiencia y pasión por una empresa común" (Wenger, 2001, pág. 22). Estos espacios, muchas veces generados y robustecidos institucionalmente, resultan pilares del fortalecimiento de la educación a distancia en dos dimensiones: hacia adentro de las instituciones, creando comunidades de práctica entre sus docentes, y hacia fuera, en el crecimiento de la disciplina y la interdisciplina.

Los tipos de interacciones descriptas, con sus características y fuentes principales se sintetizan en la figura 7.

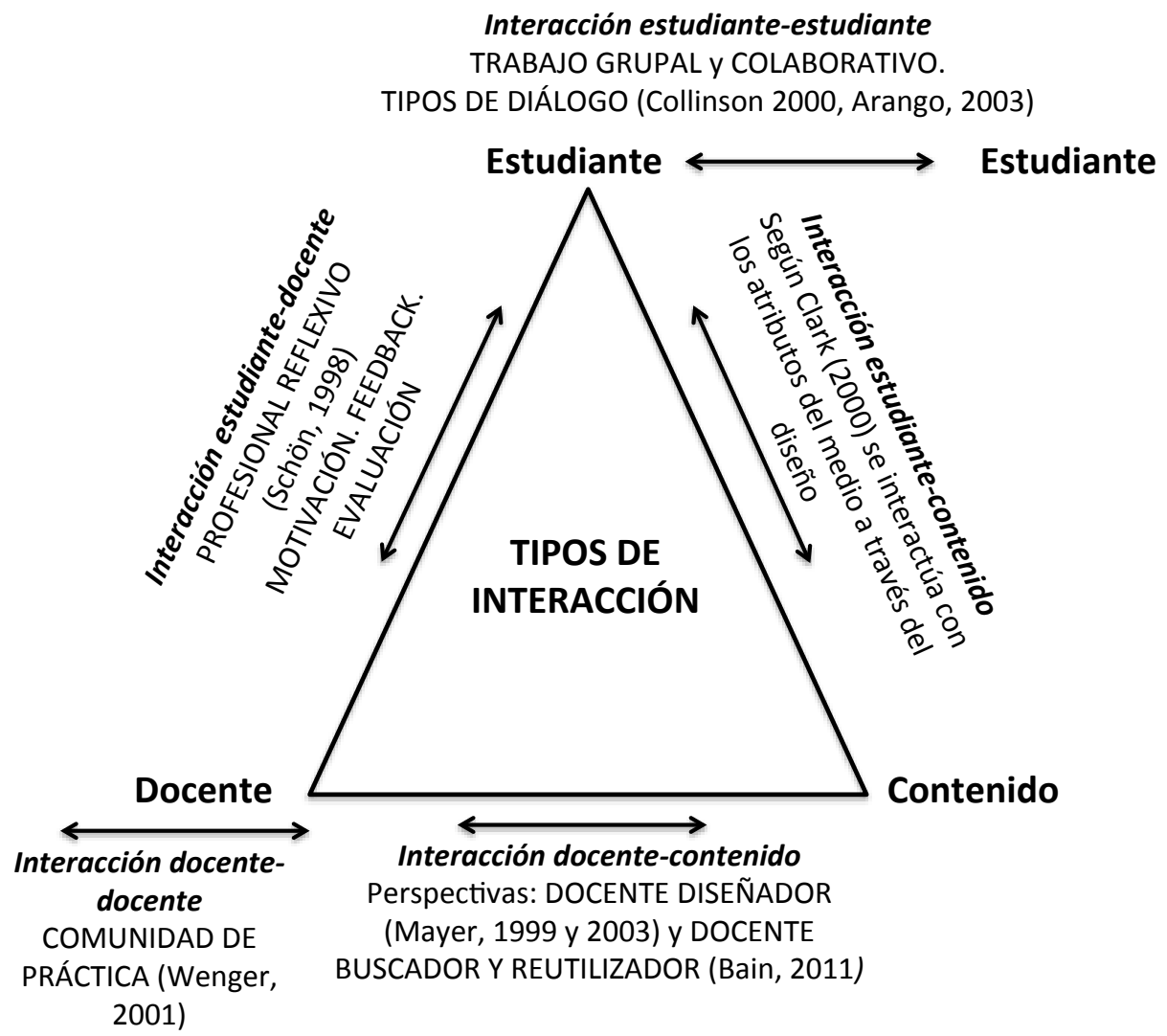

Figura 7: Tipos de interacciones (Moore, 1989 y Friesen, 2013)

\subsubsection{Niveles de interacción}

En el análisis de los niveles de interacción se han encontrado en la literatura dos modelos que vale la pena destacar y contraponer.

Un primer modelo presenta la interacción desde la perspectiva individual. Conlleva a definir a la interacción como la habilidad de autorregulación de más alto nivel. Esto permitiría pasar del aprendizaje activo al aprendizaje interactivo. Siguiendo la idea del interaccionismo social 
vygotskyano (Vygotsky, Hanfmann \& Vakar, 1962) el aprendizaje con otros y de otros sería un estadio superior de la autorregulación o autonomía. Molina, Beristaín, Tamés, Moska, Ramírez \& Romo (2012), como parte de una investigación sobre el tema del Centro de Desarrollo e Innovación Educativa del Instituto Tecnológico de Monterrey, describen las características que llevarían a un estudiante a un estadio superior de actividad y autorregulación. Molina et al. (2012) retoman y revisitan el concepto de aprendizaje interactivo de Chi (2009). Este autor lo describe en un interesante artículo bajo el título "Active-Constructive-Interactive: A Conceptual Framework for Differentiating Learning Activities", donde aparecen ideas tanto de interacción como de interactividad, en una muestra más de las interrelaciones entre estos conceptos. En este caso, se considera al aprendizaje interactivo como relativo a la interacción, ya que en el artículo de referencia se menciona la palabra interacción (interaction) y no interactividad (interactivity). Siguiendo esta idea, Chi (2009) lo grafica según aparece en la figura 8. El estudiante debería, entonces, pasar de un rol de escucha pasiva al involucramiento activo en las actividades de aprendizaje (lecturas, discusiones, reflexiones, etc.); involucrarse en procesos del pensamiento de orden superior tales como análisis, síntesis y evaluación; aprender en el diálogo y en la interacción con el contenido; desarrollar competencias asociadas a estas actividades; y solicitar y aceptar retroalimentación inmediata del profesor y de sus compañeros.

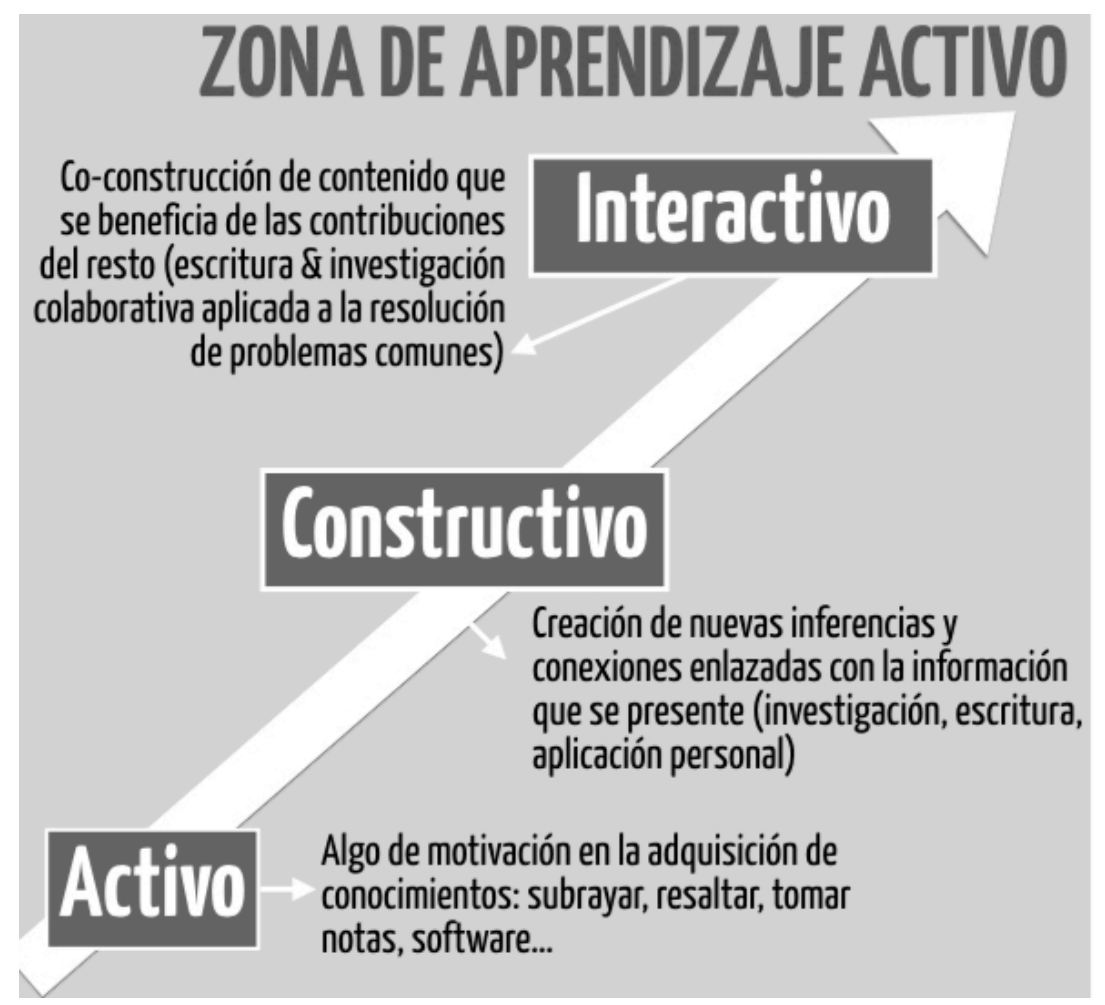

Figura 8: Interactividad como nivel superior del aprendizaje activo (Chi, 2009)

Otra perspectiva es pensar a la interacción como una cualidad de un grupo. En el trabajo de Spermon, Schouten \& van den Hoven (2014) se describe una experiencia de trabajo colaborativo con niños mediado por una mesa de interacción tangible. En ese artículo se hace mención al concepto de niveles de colaboración (tomado de Kahn \& Mentzer, 1996) que resulta ilustrativo para comenzar a integrar el concepto de interacción, interactividad y trabajo colaborativo. Si bien el trabajo de Kahn \& Mentzer (1996) se enmarca en una cadena de producción fabril, y hace referencia explícita a la integración de departamentos en esa cadena logística de producción, los conceptos podrían transferirse en el sentido que sigue. Los autores identifican interacción con comunicación (similar a García Aretio, Moore y Friesen), pero además definen un segundo y tercer nivel, en el vínculo entre interacción y colaboración. El segundo nivel, construido sobre la base de la comunicación, es la transacción, definida como el 
intercambio de artefactos físicos o simbólicos (bienes físicos o mensajes). El tercer nivel es la generación de comunidad, a partir de la comunicación y las transacciones, que genera identidad a partir del intercambio permanente de artefactos simbólicos y materiales (entre los que estarían procedimientos, protocolos de comunicación, etc.). En este marco se definen cuatro niveles de interacción/colaboración que se listan a continuación (de menor a mayor):

Nivel 1: baja interacción, baja colaboración;

Nivel 2: alta interacción, baja colaboración;

Nivel 3: baja interacción, alta colaboración;

Nivel 4: alta interacción, alta colaboración.

Se muestran algunos ejemplos propios en la tabla 2, extrapolados al ámbito de la enseñanza con tecnología informática.

\begin{tabular}{|c|c|c|}
\hline Alta interacción & $\begin{array}{l}\text { NIVEL } 2 \\
\text { - Protocolos de comunicación } \\
\text { compartidos } \\
\text { - Baja incertidumbre } \\
\text { - Alto compromiso }\end{array}$ & $\begin{array}{l}\text { NIVEL } 4 \\
\text { - Producción compleja } \\
\text { - Materiales compartidos en } \\
\text { repositorios públicos } \\
\text { - Eficacia (logro del objetivo) y } \\
\text { eficiencia (buen manejo del } \\
\text { tiempo) } \\
\text { - } \text { Alto compromiso }\end{array}$ \\
\hline \multirow[t]{2}{*}{ Baja interacción } & $\begin{array}{l}\text { NIVEL } 1 \\
\text { - } \quad \text { Intervención de terceros } \\
\text { (docente) } \\
\text { - } \\
\text { - } \\
\text { - Bajo compromiso incertidumbre }\end{array}$ & $\begin{array}{l}\text { NIVEL } 3 \\
\text { - Trabajo a corto plazo, con } \\
\text { buenos resultados } \\
\text { - Relativa sustentabilidad de } \\
\text { procesos de trabajo } \\
\text { - Rotación }\end{array}$ \\
\hline & Baja colaboración & Alta colaboración \\
\hline
\end{tabular}

Tabla 2: Niveles de interacción/colaboración (Adaptado de Kahn \& Mentzer, 1996)

\subsubsection{Interacción Persona-Ordenador (IPO)}

Desde las Ciencias de la Computación se habla de paradigmas y estilos de interacción. Preece (1994) lo define de una manera general, diciendo que un estilo de interacción es " $e l$ término genérico que agrupa las diferentes maneras en que los usuarios se comunican o interaccionan con el computador". Heim (2008) enuncia que un paradigma es un "modelo o patrón de interacción que abarca todos los aspectos de la interacción, incluyendo el físico, virtual, perceptivo y cognitivo".

Una visión general de los paradigmas de interacción es presentada por Manresa-Yee, Abásolo, Sansó \& Vénere (2011). Proponen los siguientes:

La computadora de escritorio: la interacción se realiza normalmente aislado del entorno, el usuario básicamente interactúa con una computadora de mesa o escritorio, de manipulación directa a través de los periféricos de entrada y salida.

La realidad virtual: es una simulación por ordenador en la que se emplea el grafismo para crear un mundo que parece realista. Además este mundo no es estático sino dinámico y responde a las órdenes del usuario (gestos, voces, etc.). Su clave es la interactividad en tiempo real (respuesta inmediata) y el sentimiento de inmersión, al participar de lo que se desarrolla en la pantalla a través de sus diferentes sentidos. 
La computación ubicua: el término se debe a Mark Weiser (1991). Según su visión, las computadoras deberían desaparecer del medio e integrarse al contexto de las personas. Como parte de este proceso, deben invisiblemente mejorar el mundo que ya existe en lugar de crear uno mundo artificial alrededor de los usuarios. Así, Weiser propone extender la capacidad computacional al entorno del usuario, permitiendo que la información esté presente en todas partes en forma de pequeños dispositivos muy diversos. El diseño y localización de estos dispositivos deben ser ideados especialmente para la tarea objeto de interacción. La computación, por tanto, deja de estar localizada en un único punto para pasar a diluirse en el entorno.

La realidad aumentada: se trata de una tecnología que aumenta o mejora la visión que el usuario tiene del mundo real con información adicional sintetizada mediante un modelo computarizado. La persona puede interactuar con el mundo real, que está aumentado por la información sintetizada por el ordenador. Según la definición que presentó Ronald Azuma en 1997 (en Moralejo, Sanz, Pesado \& Baldassarri Santalucía, 2014) un sistema de realidad aumentada debe cumplir con tres requerimientos: combina la realidad y lo virtual, es interactivo en tiempo real y las imágenes son registradas en espacios 3D.

En su trabajo de 2002, Preece, Rogers \& Sharp actualizan estos paradigmas. A los ya mencionados, agregan y definen los siguientes:

- Pervasive Computer (integración perfecta de la computadora al ambiente)

- Wearable Computing (computación usable o para llevar en el cuerpo)

- Interfaces tangibles (o interacción tangible)

- Computación afectiva

El modelo de pervasive computer está en algún punto vinculado con la idea de Weiser de computación ubicua. En este sentido Weiser (en Preece et al., 2002) se refiere a que la tecnología se ha diseñado para integrarse perfectamente al mundo físico del usuario, para cumplir con la idea de extensión de las capacidades humanas. En esta línea, el modelo de pervasive computer apuesta a una tecnología inteligente, cuyo software libere al usuario de tareas rutinarias o de baja carga cognitiva: cuando está lista una comida, por ejemplo. La idea es que casi cualquier dispositivo, desde ropa hasta herramientas y automóviles pueden estar conectados inteligentemente para liberar al usuario de tareas rutinarias y hacer su vida más fácil. En este sentido, combina las tecnologías de red con la informática inalámbrica, reconocimiento de voz y la inteligencia artificial: todos avances del conocimiento informático que permiten crear este tipo de ambientes. Según Weiser (1991) la computación ubicua no producirá nada fundamentalmente nuevo, pero al hacer todo más rápido y fácil, con menos tensión y esfuerzo, correrá los límites de lo que es realmente posible ${ }^{5}$.

Wearable Computing es, según la presentación de Preece et al. (2002) la computación usable. Muchas de las ideas detrás de la computación ubicua han inspirado a otros investigadores a desarrollar tecnologías que forman parte del medio ambiente: ropa, joyería, anteojos, zapatos. Todos estos objetos han sido desarrollados para proporcionar información al usuario, mientras está desarrollando sus actividades en el mundo físico. Las aplicaciones incluyen diarios automáticos que mantienen al usuario al día sobre lo que está sucediendo y lo que tienen que hacer; guías turísticas que ofrecen información relevante al caminar en una exposición, etc. (Rhodes, Minar, \& Weaver, 1999).

Otro desarrollo que ha evolucionado a partir de la computación ubicua son las interfaces tangibles (Ishii \& Ullmer, 1997). El enfoque de este paradigma es la integración de herramientas

\footnotetext{
${ }^{5}$ Traducción y adaptación de la frase original: "Ubiquitous computing will produce nothing fundamentally new, but by making everything faster and easier to do, with less strain and fewer mental gymnastics, it will transform what is apparently possible" (Weiser, 1991 en Preece et al. 2002, pág. 62).
} 
computacionales en el medio ambiente físico; la búsqueda de formas para combinar la información digital con los objetos físicos y superficies (por ejemplo, mesas, u otros muebles) que permiten a las personas llevar a cabo sus actividades cotidianas. Ejemplos de este tipo de interacción podrían ser libros físicos integrados con información digital, tarjetas de felicitación que muestren una animación digital cuando se abren, mesas interactivas que puedan ser usadas con objetos físicos (para un juego grupal, por ejemplo) y registren información de desempeño, etc.

En la computación afectiva, que Preece et al. (2002) denominan entornos atentos y computación transparente, se busca anticipar lo que el usuario quiere hacer. En lugar de que los usuarios tengan el control sobre el hardware y el software y decidan cuál es el próximo paso, esta carga es desplazada hacia la computadora en función del análisis de sentimientos y la detección de emociones. En este sentido, el modo de interacción es mucho más implícito, ya que las interfaces responden a las expresiones del usuario y a sus gestos. Son entornos ricos en sensores que se utilizan para detectar el estado actual de la persona y sus necesidades. Por ejemplo, el sistema informático podría contar con un tutor electrónico inteligente poniendo a disposición del estudiante ayudas metacognitivas, si se detectan en el estudiante gestos de estar confundido en algún tema de estudio.

Es interesante ver que estas investigaciones tratan de generar confort y naturalidad en tres escenarios principales: la casa, el lugar de trabajo y lo que las personas usan para actividades recreativas (viajes, museos) y deportivas.

Relacionando estos conceptos con el término interacción, es notable que en las Ciencias Informáticas, los modelos y estilos de interacción incluyen tanto la relación con los artefactos físicos (hardware) como simbólicos (software) y conocimiento (mindware). En el análisis de esta tesis, la relación con los componentes de hardware y software de la tecnología estaría relacionada con la interactividad. En la sección final de este capítulo se unirán ambas visiones en un concepto integrador.

\subsubsection{Concepto y niveles de interactividad}

En la introducción de este trabajo se mencionó a Keegan (1996) quien señala el peso que se ha dado a la interactividad en el campo de la educación a distancia. Diversos autores (Fainholc, 1999; Moore, 1972 y 1989; Coll \& Onrubia 1994; Hillman, Willis \& Gunawardena, 1994; Fainholc, 1999; Mena, Rodríguez \& Diez, 2005) coinciden en que la interactividad pedagógica es la relación que establece una persona con un material de estudio, que le permite "hacerlo propio". Así, los materiales interactivos generan una acción participativa en los sujetos que los usan. Podría desagregarse el significado de interactividad en las siguientes ideas:

- Es la posibilidad que se le da al estudiante a través de los materiales tecnológicos y de las situaciones de enseñanza de elegir el camino más significativo.

- Se enriquece a través del diálogo permanente entre el estudiante y el material (tipo de interacción mencionado por Moore, 1972 y retomado por Friesen, 2013). La permanente devolución de información que el material de instrucción debe brindar al estudiante acerca de su desempeño le permitirá monitorear las estrategias que utiliza para aprender, esto significa trabajar con habilidades no sólo cognitivas sino metacognitivas.

- Los grados de interactividad dependen del tipo de actividades que se le presentan y las estrategias cognitivas y metacognitivas que se pongan en juego para resolverlas. 
En cuanto a los niveles de interactividad, es un tema tratado en el ámbito de la educación a distancia. Un modelo muy reconocido y citado por los autores significativos en este tema se presenta en la figura 9.

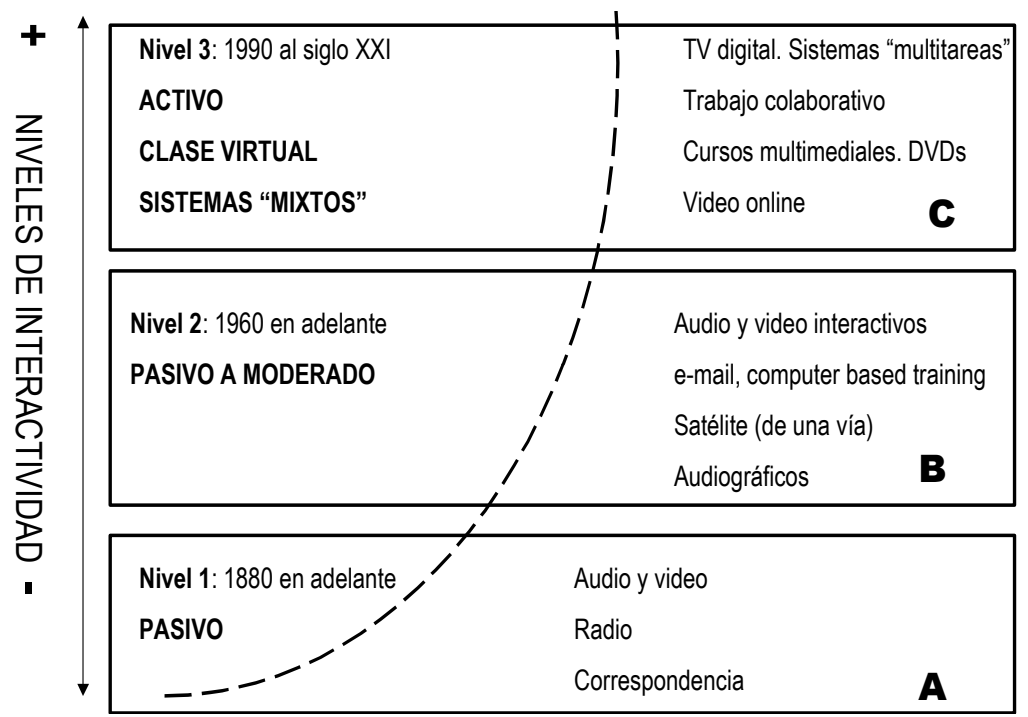

Figura 9: Niveles de interactividad (Williams et al., 1998)

Los autores (Williams, Paprock \& Covington, 1998) sostienen que el cambio de soporte mediacional en la estrategia de enseñanza y de comunicación (del material impreso a la computadora y de ahí a la comunicación de doble vía mediante las nuevas tecnologías informáticas) supone niveles crecientes de interactividad. Definen tres niveles de interactividad pedagógica, según la tecnología de soporte utilizada en los materiales, que se describen a continuación

Nivel de interactividad 1 (A): la estrategia de enseñanza a distancia está soportada en tecnologías como materiales impresos, audio y videocassettes. Según los autores del modelo, este nivel 1 se considera como un "aprendizaje a distancia pasivo", ya que no existe interacción en tiempo real entre el alumno y el tutor. La comunicación es "uno a uno" y los niveles de respuesta y feedback son asincrónicos.

Nivel de interactividad 2 (B): la estrategia de enseñanza a distancia está soportada en tecnologías digitales como videoconferencias (con interacción remota sincrónica o diferida), CBT (Computer Based Training), CDs, e-mails, etc. Se considera como un nivel que atraviesa desde el nivel anterior (pasivo) hacia una "interactividad moderada". La tecnología utilizada en esta etapa permite:

- Transmitir mensajes en forma simultánea entre emisor y receptor (comunicación sincrónica).

- Recibir feedback a distancia inmediatamente.

Nivel de interactividad 3 (C): estos entornos combinan la tecnología de la clase virtual con todos los elementos tecnológicos descriptos en los niveles anteriores, expandidos a su vez por las posibilidades de internet. Se considera un nivel de "alta interactividad" ya que las posibilidades de la tecnología utilizada permiten:

- La comunicación "uno a uno", "uno a muchos" o "muchos a muchos" en forma sincrónica o asincrónica. 
- La personalización de las opciones de entrada y navegación por los contenidos (hipertextual o navegacionalmente).

- La utilización de recursos multimedia.

- El uso de simulaciones.

- La ejercitación con niveles de complejidad crecientes y la obtención de feedback inmediato.

- El seguimiento de todas las tareas realizadas por docentes u alumnos.

- La acumulación de información compartida.

Si bien este artículo tiene algunos años, el sistema que está detrás de la definición de niveles de interactividad resulta útil aún en la actualidad: los niveles de interactividad aumentan cuánto más puede la persona modificar el mensaje que recibe del medio tecnológico y alcanzar una experiencia más personalizada.

\subsubsection{Interacción e interactividad en el marco de esta tesis}

En el camino de construir un marco conceptual que albergue posturas humanistas y computacionales, se retomarán las principales ideas vertidas hasta aquí. Desde el punto de vista educativo, interacción e interactividad se han definido según la siguiente línea (Mena et al. 2005): "la interacción y la interactividad son condiciones básicas de un buen ambiente para aprender. La primera hace referencia a la comunicación entre los actores del proceso de aprendizaje, mientras que la interactividad tiene que ver con la relación entre quien aprende y el contenido, soportado por alguna tecnología" Los espacios de interacción, desde este marco, se definen por la relación con otra persona o personas, en espacios físicos presenciales (aula) o mediados con tecnología informática y, en este último caso, con tiempos sincrónicos o asincrónicos. Alude al componente de diálogo didáctico, en el marco de la teoría de Distancia Transaccional (Moore 1972, 1983, 1990 y otros). La interactividad está relacionada con el diseño y relación con los materiales de enseñanza.

En el campo de las Ciencias Informáticas, la disciplina conocida como Interacción persona ordenador (IPO) es la que se ocupa de estas conceptualizaciones. Según Abascal González (2000), en la disciplina aparecen conceptos propios de los procesos tecnológicos (vinculados con la interacción e interactividad) como son los conceptos de diseño centrado en el usuario, usabilidad, accesibilidad, etc. Son varios los autores vinculados al área de Interacción PersonaOrdenador que utilizan los términos interactividad e interacción sin distinción e, incluso, como sinónimos.

Por lo tanto, y en afán de generar un marco conceptual que permita operar sobre la realidad y explicar los aportes realizados, se define el concepto de interacción y las relaciones conceptuales en su interior. Se entiende a la interacción como una matriz de diálogos, conformada por un entramado de voces, de personas y mensajes mediados por los lenguajes de diversas tecnologías. Cada mensaje modifica, y se ve modificado por los demás, y el resultado es un discurso enriquecido y enriquecedor. En esta categoría están las interacciones estudiantedocente, estudiante-estudiante y docente-docente presentadas por Moore y Friesen (2013). La interacción aparece, entonces, de dos formas:

1. entre personas, cara a cara, mediada por el lenguaje como tecnología invisible y fundamental;

2. entre personas, a través del uso de tecnología informática que media esta interacción. 
En este segundo caso:

a) se usa una aplicación informática que permita la comunicación con el otro (foros, chat, videoconferencia, mensajes, entre otros), o

b) se usa una aplicación informática que permita llevar adelante una actividad o tarea específica. En esa situación, si bien la interacción pareciera darse sólo con la computadora, se está mediando alguna vinculación con otras personas (docentes, tutores, administrativos, etc.).

El concepto de interacción hace referencia al primer tipo de diálogo mencionado en el párrafo anterior (personas cara a cara). El segundo tipo de interacción presenta dos posibilidades. El escenario a (personas interactuando a través de una herramienta informática) se considera interacción, pero con un grado (dado por el uso de la herramienta) de interactividad. El escenario b se define como interactividad. En esta última categoría están las interacciones estudiantecontenido, docente-contenido (Friesen, 2013) y la categoría de Hillman, Willis \& Gunawardena (1994) estudiante-interface. La interactividad hace referencia a la versatilidad de un software para que las decisiones del usuario cambien su rumbo. Representa el control que la persona ejerce sobre el programa y la versatilidad que éste presente, desde su diseño, para acomodarse a las decisiones de la persona que lo usa. En síntesis, la interactividad es un subconjunto de la interacción, en aquellas relaciones donde la tecnología artefactual y simbólica aparece como mediadora. Gráficamente se presenta en la figura 10.

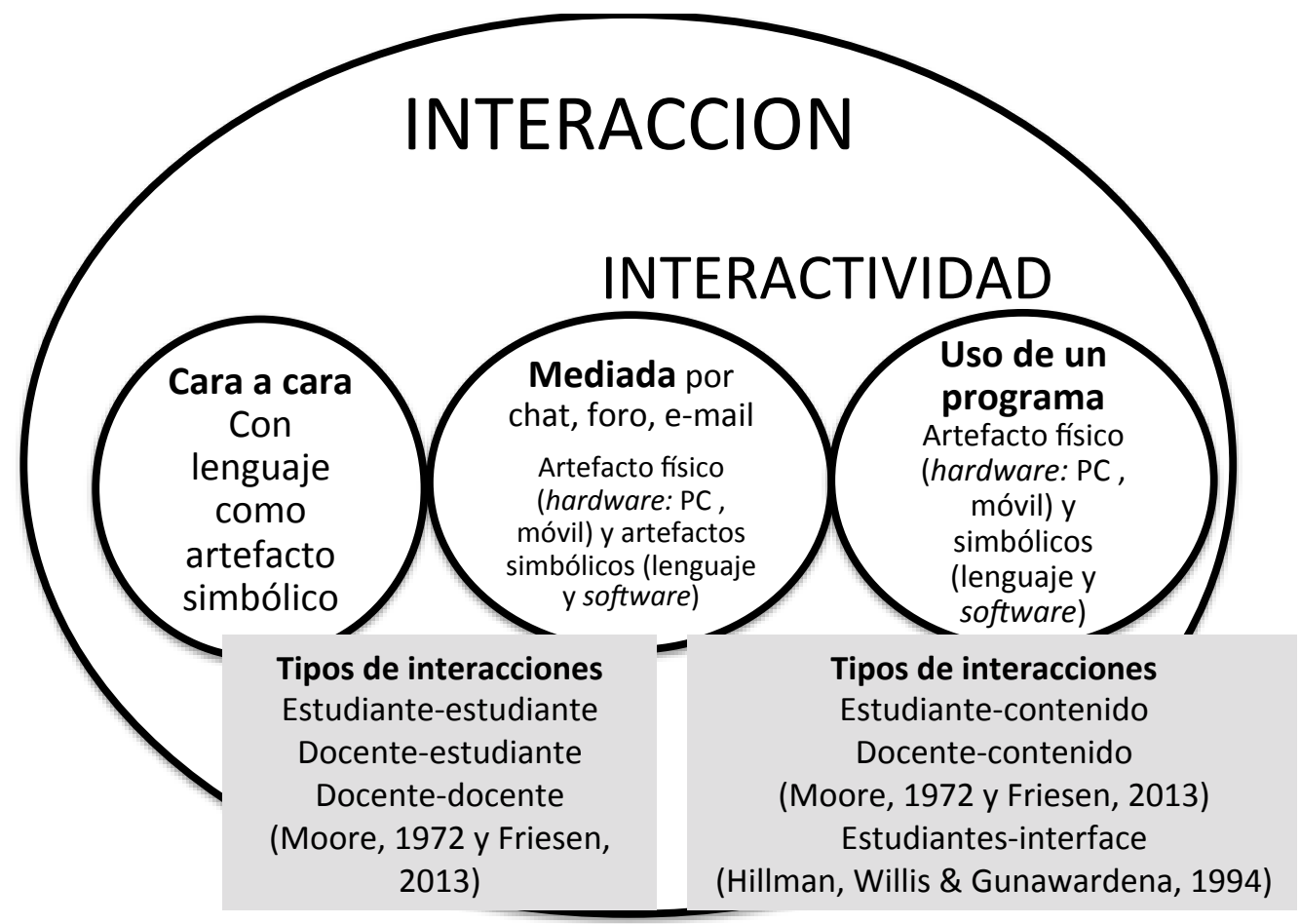

Figura 10: Concepto de interacción e interactividad en el marco de esta tesis 


\subsection{Conclusiones del capítulo}

Este capítulo corresponde a la primera parte de la tesis. Junto a los capítulos 3, 4, 5 y Epílogo componen la sección donde se presenta el marco conceptual que da sustento al trabajo.

En este capítulo se ha focalizado el tema de interacción e interactividad, instalándolo en espacios específicos:

- en primer lugar, se ha definido el escenario educativo: la interacción e interactividad se focalizan en este trabajo en relación con la enseñanza y el aprendizaje.

- en segundo lugar, se las estudia en relación con la tecnología informática como espacio, herramienta y contexto de mediación.

- en tercer lugar, por considerarse una teoría suficientemente comprensiva y fecunda en su potencial explicativo, se las ha instalado en el modelo de Distancia Transaccional de Michael Moore, que no solamente permite explicar estos fenómenos en la enseñanza a distancia, sino que permite comprender las situaciones mediadas cualquier grado de hibridación de la enseñanza.

Se ha descripto la Distancia Transaccional, con sus tres componentes: estructura (de enseñanza), diálogo y autonomía o autorregulación del estudiante. Luego se ha profundizado en el concepto de interacción, tomando posturas comunicacionales y didácticas y la proveniente de la disciplina Interacción Persona Ordenador (IPO). Se describieron los tipos de interacciones según diferentes autores, complementándose unos con otros, y se avanzó hacia un modelo de niveles de interacción, tomando dos posturas diferentes: una perspectiva que mira a la interacción como capacidad individual y la otra desde una perspectiva grupal en su integración con interactividad y colaboración.

Con el concepto de interactividad se siguió la misma línea: se profundizó en su definición y se describió un modelo que define grados de interactividad en la educación a distancia.

Finalmente, y en línea con uno de los agregados de valor comprometidos en este trabajo, se definió un marco integrador de interacción e interactividad. Se concluyó que el diálogo es la base de la interacción (y, por lo tanto de la enseñanza y el aprendizaje) y puede estar mediada por objetos simbólicos (lenguaje, software) o físicos (computadoras u otros artefactos). En el caso de la mediación por una aplicación y, por consiguiente, con un soporte artefactual, se la define como interactividad.

Además, se han relacionado estas definiciones con los tipos de interacción que presenta la literatura. Según Moore (1989) existe interacción entre el estudiante y el docente, entre los estudiantes entre sí y entre el estudiante y el contenido. Si estas interacciones están mediadas por herramientas digitales, también se agregaría la característica de interactividad. Según Friesen (2013), existe interacción entre los docentes y entre el docente y el contenido. Según Hillman, Willis \& Gunawardena (1994) existe interacción entre el estudiante y la interface.

En síntesis, la interactividad es interacción mediada por una herramienta y una aplicación: cuánto más pueda la persona modificar de esa aplicación, mayor será el grado de interactividad que ésta muestre. En las situaciones de interactividad también hay interacción (mediada por la aplicación) con los diseñadores, desarrolladores y equipo que está detrás de cada aplicación informática.

Esta tesis se propone estudiar estos fenómenos en el marco del trabajo colaborativo. En el capítulo siguiente se avanzará en la definición de trabajo grupal y colaborativo en escenarios educativos mediados con tecnología informática. 


\section{Capítulo 3: Trabajo colaborativo mediado por tecnología informática. Marco conceptual}

El recorrido conceptual propuesto para este capítulo es el siguiente:

3.1. Introducción

3.2. Trabajo en grupos como antecedente del trabajo colaborativo

3.2.1. Del objeto discreto al colectivo: la tensión individuo-grupo

3.2.2. Grupos de aprendizaje como un tipo especial de grupo

3.2.3. Ciclo de vida de un grupo

3.3. Del trabajo en grupos al trabajo colaborativo

3.3.1. Definición de trabajo colaborativo en escenarios educativos

3.3.2. Diferencias entre trabajo colaborativo y otros tipos de trabajo grupal

3.3.3. Diferencias entre trabajo colaborativo y cooperativo

3.4. La enseñanza orientada a grupos como objeto de la Didáctica

3.4.1. Una propuesta de enseñanza para grupos colaborativos

3.5. Conclusiones del capítulo 


\subsection{Introducción}

El trabajo en grupo tiene en su base un entramado de competencias conceptuales, habilidades $\mathrm{y}$ destrezas físicas y, como componente subjetivo, cuestiones emocionales.

En la literatura hay obras que expresan con maestría lo que significa armar y trabajar en grupo. En Argentina, el cuento "Instrucciones para elegir en un picado" de Crónicas del Angel Gris, de Alejandro Dolina (1996, pág. 256) lo muestra claramente:

"Cuando un grupo de amigos no enrolados en ningún equipo, se reúnen para jugar, tiene lugar una emocionante ceremonia destinada a establecer quiénes integrarán los dos bandos.

Generalmente dos jugadores se enfrentan en un sorteo o pisada y luego cada uno de ellos elige alternadamente a cada uno de sus compañeros.

Se supone que los más diestros serán elegidos en los primeros turnos, quedando para el final los troncos.

Pocos han reparado en el contenido dramático de estos lances. El hombre que está esperando ser elegido vive una situación que rara vez se da en la vida: sabrá de un modo brutaly exacto en qué medida lo aceptan o lo rechazan. Sin eufemismos, conocerá su verdadera posición en el grupo [...]

Manuel Mandeb, que casi siempre oficiaba de elector, observó que sus decisiones no siempre recaían sobre los más hábiles. En un principio se creyó poseedor de vaya a saber qué sutilezas de orden técnico, que le hacian preferir compañeros que reunían ... ciertas cualidades.

Pero un día comprendió que lo que en verdad deseaba, era jugar con sus amigos más queridos. Por eso elegía siempre a los que estaban más cerca de su corazón, aunque no fueran los más capaces.

El criterio de Mandeb parece apenas sentimental, pero es también estratégico: uno juega mejor con sus amigos. Ellos serán generosos, lo ayudarán, lo comprenderán, lo alentarán y lo perdonarán.

Un equipo de hombres (y mujeres) que se respetan y se quieren es invencible. [...]”.

Si bien este extracto literario tiene licencias precisamente por su género, presenta algunas tensiones propias del trabajo grupal, que coinciden con la literatura especializada en este tema. Se podrían mencionar: la tensión entre el individuo como objeto discreto y el grupo como colectivo, el sostenimiento de la identidad dentro del grupo, las condiciones de grupalidad (Schmuk \& Schmuk, 1975) y la mixtura de competencias conceptuales y afectivas necesarias para fortalecer las redes de trabajo grupal. capítulo.

De estas cuestiones, y la consecución de estos temas en el trabajo colaborativo, se trata este

\subsection{Trabajo en grupos como antecedente del trabajo colaborativo}

Las teorías de trabajo en grupo se han alimentado de varias corrientes. Por un lado, a principios del siglo pasado, en 1910, la Gestalt supera el atomismo y aboga por el concepto de totalidad. Esta teoría nació en el campo de la percepción como categoría psicológica (Köhler, Wertheimer \& Riezler, 1944) y se ha extendido a otros campos. Algunas de las llamadas Leyes de 
la Gestalt permiten comprobar la idea de conjunto desde sus cimientos. Por ejemplo, la Ley de Proximidad proclama que "cuando las partes de una totalidad reciben un mismo estímulo, se unen formando grupos en el sentido de la mínima distancia"; o la Ley de la Buena Forma, que advierte que "las partes de una figura que tiene buena forma indican una dirección o destino común y forman con claridad unidades autónomas en el conjunto".

Por otro lado, el pasaje de la percepción individual al concepto colectivo se vio influenciado por la Teoría del Campo Vital (Lewin, 1935) quien también contribuyó a la teoría gestáltica y profundizó en la relación entre el individuo y el grupo. Su Teoría del Campo Vital comprende al comportamiento humano como dependiente de dos supuestos básicos: a) cada individuo actúa en un determinado entorno y su comportamiento se ve influenciado por la totalidad de los hechos que afectan dicho entorno; $\mathrm{y} b$ ) esos hechos configuran un campo de fuerzas dinámico que puede denominarse "campo psicológico". Este campo psicológico constituye para el individuo su ambiente vital. Con la idea de "campo de fuerzas" se postula que las personas, situaciones y objetos tienen valencias que confluyen en cada campo vital y lo determinan. La valencia de un elemento del campo psicológico es positiva cuando dicho elemento puede satisfacer alguna necesidad del sujeto. Por el contrario, es negativa cuando puede causarle daño o perjuicio. Los objetos, situaciones o personas que asumen valencia positiva atraen al individuo, ya que generan una fuerza que lo/la impulsa hacia ese elemento; los de valencia negativa le causan repulsión y alejamiento. Esta teoría intenta componer un modelo químico y matemático del comportamiento humano y llega, incluso, a modelizar qué tipo de comportamientos podría adoptar una persona en función de la relación con su campo de fuerzas, en cada ambiente y tiempo particular. Si bien la base de la teoría de Lewin sigue siendo el comportamiento previsible a partir de un campo de fuerzas determinado, se supera la concepción atómica, sostenida por las miradas conductistas de la Psicología del Aprendizaje y trasladadas luego al campo de la Educación, a partir de la Teoría de Instrucción Programada (Watson, 1913; Skinner, 1938 y 1953; Thorndike, 1910). Se sitúa al individuo en el contexto que lo circunda y comienza a pensarse el proceso interno de respuesta (más tarde, de construcción) en ese contexto. La Teoría del Campo Vital ha valorizado el contexto, en tanto ambiente que interviene en los procesos individuales y ha favorecido la transición del pensamiento desde el individuo solo, o "solista" como lo llamó más tarde Gavriel Salomon (Salomon, 2001, pág. 154) hacia el grupo de pares que lo rodea y con quienes comparte experiencias.

Si bien Lev Vygotsky había desarrollado, antes de los años '30, su teoría del interaccionismo social con el concepto clave de "Zona de Desarrollo Próximo" (Vygotsky, 1962), su trabajo en la antigua Unión Soviética, fuera de los límites del mundo académico de ese momento, dentro de otra composición y comunicación del mundo, puso sus ideas fuera de órbita. Su obra fue descubierta y divulgada por los medios académicos del mundo occidental en la década de 1960 y 1970. Fue en ese momento, con la traducción al idioma inglés de su paradigmática obra "Pensamiento y lenguaje" (Vygotsky, 1962) cuando este autor se establece como referencia indiscutible dentro del mundo de la Psicología y la Educación, con vinculación específica a los grupos de trabajo y aprendizaje.

Con estos antecedentes, desde la Psicología y la Educación comienza a pensarse en el individuo en contexto y en el grupo como reunión de personas en confluencia de tiempo y espacio. La pregunta que sigue sería ¿qué es un grupo? Se debe recurrir, entonces, a la Sociología, en la rama que se ocupa de la Sociología de Grupos, para diferenciar simples reuniones de personas del concepto de grupo propiamente dicho. Luego, es posible adentrarse en los diferentes tipos de grupos.

La conformación de grupos podría pensarse como un gradiente que iría de menor a mayor integración en base a los componentes que ya comienzan a delinearse como fundantes de un grupo:

- Objetivos/fines comunes. 
- Identidad compartida.

- Estructura interna necesaria para su funcionamiento.

- Tareas comunes.

- Conciencia de grupo (característica asociada a la metacognición grupal).

- Sostenimiento en el tiempo de cada uno de estos componentes.

Así, habría una línea conceptual imaginaria que se inicia en las reuniones denominadas muchedumbre, donde los elementos identitarios y el sostenimiento en el tiempo son bajos hasta los diferentes tipos de grupos. En el extremo superior de este gradiente se ubicaría el grupo.

Siguiendo la línea histórica, en 1968, Anzieu \& Martin se destacaron por la instalación de criterios que permitían componer diferentes tipos de grupos. Según esta idea, podría caracterizarse a diferentes reuniones de personas en función de: la cantidad de individuos que la componen, los objetivos comunes, su estructura, su conciencia de grupalidad, y las tareas comunes que comparten. Así, comienza a utilizarse una primera taxonomía en la que se incluye a la muchedumbre, agrupamiento, banda y grupo primario. Se presentan estas características en la tabla 3.

\begin{tabular}{|c|c|c|c|c|c|c|}
\hline $\begin{array}{c}\text { Tipo de } \\
\text { reuniones }\end{array}$ & $\begin{array}{c}\text { Cantidad } \\
\text { de } \\
\text { individuos }\end{array}$ & $\begin{array}{c}\text { Objetivos } \\
\text { comunes } \\
\text { y estructura } \\
\text { interna }\end{array}$ & $\begin{array}{l}\text { Identidad } \\
\text { compartida }\end{array}$ & $\begin{array}{l}\text { Conciencia } \\
\text { de grupo }\end{array}$ & $\begin{array}{c}\text { Tareas } \\
\text { comunes }\end{array}$ & Ejemplo \\
\hline Muchedumbre & $\begin{array}{l}\text { Grande } \\
\text { (miles) }\end{array}$ & Muy débil & $\begin{array}{l}\text { Emociones } \\
\text { por contagio }\end{array}$ & Escasa & $\begin{array}{l}\text { Indiferencia } \\
\text { o acciones } \\
\text { espontáneas } \\
\text { poco } \\
\text { importantes } \\
\text { para el grupo }\end{array}$ & $\begin{array}{l}\text { Manifestación } \\
\text { en una plaza } \\
\text { Recitales } \\
\text { Asistentes a } \\
\text { espectáculos } \\
\text { deportivos }\end{array}$ \\
\hline Agrupamiento & Mediana & Mediana & $\begin{array}{l}\text { Pequeña o } \\
\text { mediana }\end{array}$ & $\begin{array}{l}\text { Relaciones } \\
\text { humanas } \\
\text { superficiales }\end{array}$ & $\begin{array}{l}\text { Escasa a } \\
\text { mediana }\end{array}$ & $\begin{array}{l}\text { Cola de un } \\
\text { banco o } \\
\text { negocio } \\
\text { Reuniones } \\
\text { de padres en } \\
\text { un colegio }\end{array}$ \\
\hline Banda & Pequeña & $\begin{array}{l}\text { Mediana a } \\
\text { débil }\end{array}$ & $\begin{array}{c}\text { Empatía / } \\
\text { Semejantes }\end{array}$ & Mediana & $\begin{array}{c}\text { Espontánea } \\
\text { poco } \\
\text { importante } \\
\text { para el } \\
\text { grupo }\end{array}$ & $\begin{array}{l}\text { Bandas de } \\
\text { adolescentes }\end{array}$ \\
\hline $\begin{array}{c}\text { Grupo } \\
\text { primario }\end{array}$ & Pequeña & Alta & Rica & Elevada & $\begin{array}{c}\text { Importantes } \\
\text { permanentes } \\
y \\
\text { planificadas }\end{array}$ & $\begin{array}{l}\text { Familia } \\
\text { Grupos de } \\
\text { trabajo }\end{array}$ \\
\hline
\end{tabular}

Tabla 3: Tipos de agrupamientos (Tomado y modificado de Anzieu \& Martin, 1968) 
En esta línea se ubica a los grupos de aprendizaje dentro de los grupos primarios. Un grupo primario podría definirse como un conjunto de personas cuya relación está basada en la afectividad, el compromiso y la solidaridad. Son grupos reducidos y la interacción es permanente. En una primera definición, el concepto incluye la idea de relación cara a cara. Esto ha cambiado con el advenimiento de la tecnología digital, como se verá en capítulos posteriores de esta tesis. Los sujetos que conforman los grupos primarios no son intercambiables, es decir, cuando uno se va, la relación deja de existir con ese integrante.

\subsubsection{Del objeto discreto al colectivo: la tensión individuo-grupo y su relación con la tecnología digital}

En cuanto a los componentes epistemológicos necesarios para estudiar en grupo, Fernández (1989) presenta tres vertientes: la primera considera al grupo como más que la suma de sus partes. Esto remite a la teoría de Lewin y a la Gestalt, ya presentadas. El segundo aborda la estructura, las invariantes del grupo, los aspectos formales y organizacionales. El tercero intenta desentramar el tránsito del objeto discreto al objeto colectivo y trabaja, entonces, en dos dimensiones: la del individuo y la del grupo. En las dos primeras vertientes el objeto de estudio es el grupo en sí, como un objeto único y la preocupación está centrada en delimitarlo, recortarlo y estudiarlo en lo que es y hace. En la tercera variante, en la que estaría incluida la tensión individuo-grupo, se analizan los entrecruzamientos propios de la comunicación grupal. Entonces, el campo de "lo grupal" se resignifica como un campo atravesado por la tensiones de los individuos más las propias del grupo. A decir de Marta Souto: "se piensa en Lo Uno y Lo Múltiple al mismo tiempo" (Souto, 1993, pág. 54).

Desde la Psicología, la idea de cognición distribuida sostiene que el "conocimiento se construye socialmente por medio de esfuerzos cooperativos dirigidos a metas compartidas, o de diálogos y cuestionamientos que nacen de las diferencias que existen entre las perspectivas de las personas" (Pea en Salomon, 2001, pág. 77). Aprender en grupo supone que, a través de una serie de interacciones, se enriquece la actividad cognitiva a partir de la confrontación de ideas con otros, ya sea por la generación de un conflicto o por la simple presentación de las propias ideas a los pares.

Preece et al. (2002) evalúan como insatisfactorios los abordajes de la cognición como fenómeno individual, al no considerar la interacción con otros y el manejo de artefactos (tanto de tecnología simbólica como artefactual ${ }^{6}$ ) como representaciones externas de conocimiento en actividades cognitivas diarias. Presentan la idea de Hutchins de cognición distribuida (en Preece, et al. 2002) como una nueva conceptualización de las actividades humanas. La figura 11 muestra la comparación entre los abordajes de cognición individual y cognición distribuida que estos autores aportan a la discusión.

\footnotetext{
${ }^{6}$ Una definición apropiada podría ser la aportada por Simon (1969) para quien "el objeto de estudio de la disciplina tecnológica son los objetos artificiales, tanto los duros o artefactuales como los blandos o gestionales" (en Ciapuscio, 1996, pág. 35).
} 


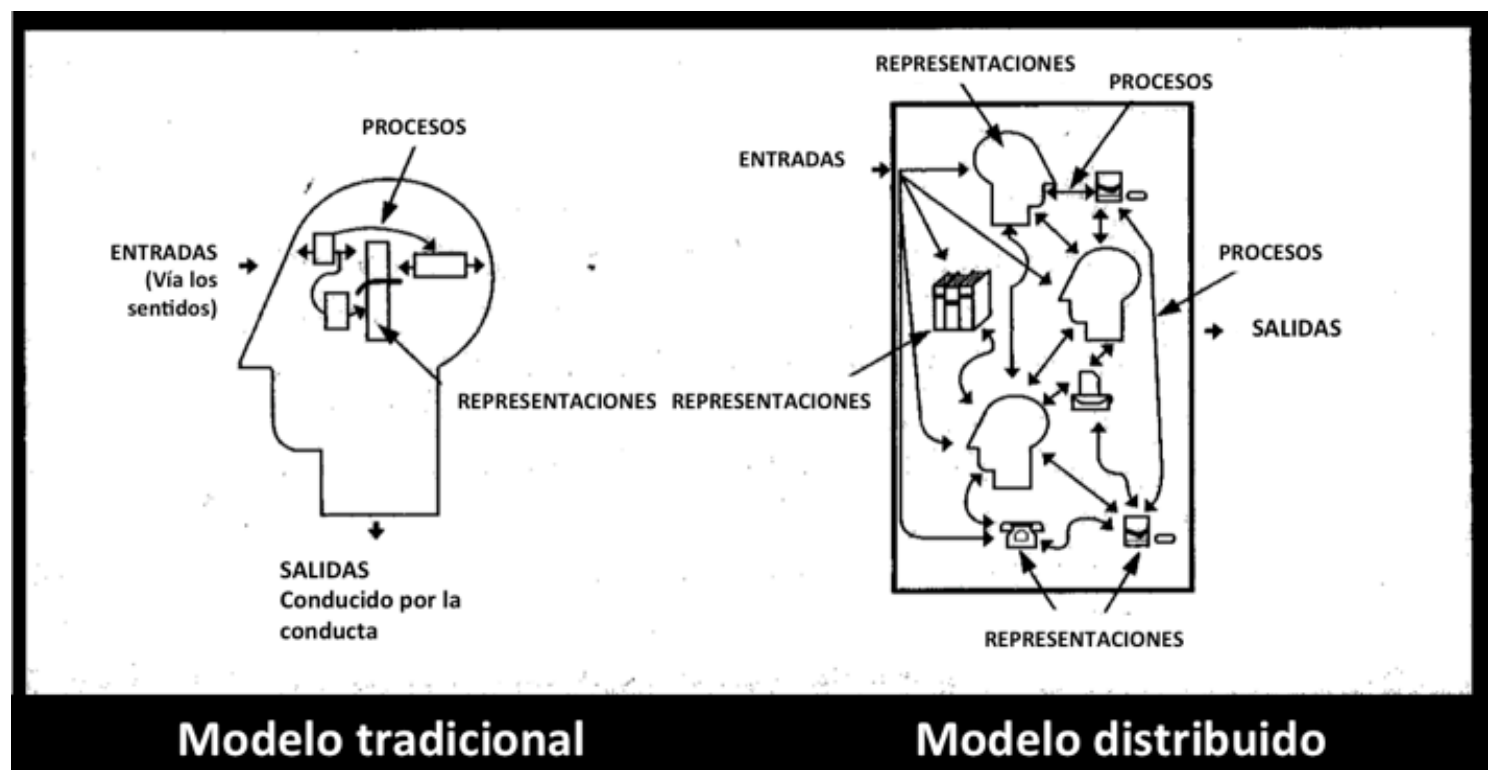

Figura 11: Comparación entre los abordajes de cognición tradicional y cognición distribuida (Preece et al., 2002, pág. 134).

En la figura anterior puede visualizarse que la cognición se estudia como un sistema, en el que se conjugan diferentes representaciones mentales, externalizadas a través de sistemas tecnológicos simbólicos (lenguaje oral, textual o gráfico). En la perspectiva de la cognición distribuida (Rogers \& Ellis, 1994; Norman, 1993; Halverson, 2002; Nardi, 1996) la unidad principal de análisis es el sistema funcional, que consiste en la integración entre las personas y los recursos utilizados, y su relación entre sí dentro del ambiente de trabajo o estudio. Según Kharrufa (2010) esta unidad de análisis se supone dentro de un contexto, y su estudio se enfoca en las relaciones funcionales de los elementos que intervienen. Incluso, siguiendo a Pea (Salomon, 2001, pág.75) la cognición humana puede considerarse distribuida más allá del propio individuo $\mathrm{y}$ en distintos sentidos: incluyendo a otras personas y apoyándose en medios simbólicos, en el entorno y en los artefactos. En otras palabras, las personas colaboran en un sistema de cognición, en el que externalizan su conocimiento a través de representaciones tecnológicas simbólicas y construyen conocimiento grupal que termina residiendo en este sistema. La construcción de conocimiento a través de una herramienta de foro, por ejemplo, podría ser un buen ejemplo de cómo se construye conocimiento distribuido.

La idea de extensión de las capacidades humanas a través de la tecnología había sido presentada por McLuhan, al atribuir a los medios la capacidad de aumentar la posibilidad de las personas de conocer y aprehender la realidad (McLuhan, 1972). En 1992, Gavriel Salomon habla de efectos "de" y "con" la tecnología. Dice: "la diferencia entre los dos tipos de efectos se ve reflejado en el caso de un experto operador de un ábaco. Por un lado, la persona demuestra una mayor habilidad aritmética mientras trabaja con el ábaco -(el efecto CON el ábaco)-. Luego es posible que demuestre una mayor capacidad matemática cuando hace sus cálculos sin el ábaco, una consecuencia de la interiorización de los procedimientos facilitados inicialmente por el ábaco-(el efecto DE la herramienta)-" (Salomon, 1992, págs. 17-18).

Esto significa que la interactividad con las herramientas, y/o la interacción con los pares en una tarea grupal, genera una huella cognitiva duradera o "residuo cognitivo" (Salomon, 2001; Litwin, 2005) más allá del momento de uso de la herramienta o interacción con otros. Podría traducirse como una competencia cognitiva disponible para ser transferida a otras situaciones, con la idea de que la transferencia "está vinculada con el uso de las competencias o habilidades aprendidas en un contexto diferente al contexto de aprendizaje". (Libedinsky, 2016). 
Si se analiza la tensión individuo-grupo desde el punto de vista de la herramienta tecnológica, la visión parece ser más "optimista". Aparece la idea de la "dinámica relacional" de los grupos en las redes digitales. Según los analistas, esto ha permitido la aparición de "otro tipo de producto y proceso de interacción" (Pisani \& Piotet, 2008). En la definición de esta idea, los autores apuntan a dos hipótesis. La primera es la presentada por James Surowiecki (2005) en "La Sabiduría de las Multitudes". Describe el fenómeno del pensamiento colectivo como epónimo de esta época y lo define como de un "truismo matemático", ya que esta sabiduría permitiría conocer la media de opiniones, gustos y juicios diferentes sólo por estar participando de una especie de comunidad de miles. Nótese que este fenómeno de comunidad, en cierto sentido organizada e inteligente, defiere bastante de los estudios franceses del siglo pasado que dotaban a las muchedumbres de un bajo grado de sentido de pertenencia y organización (véase el concepto de muchedumbre en la tabla 2). Si bien no es la única causa a la que se le atribuye el cambio de la concepción de las multitudes, la existencia de tecnología que posibilita alta conectividad parece ser un motor importante en este cambio de visión. Por otro lado, como segunda hipótesis, el advenimiento del concepto de Web 2.0 ( $\mathrm{O}^{\prime}$ Reilly, 2006) postula la organización de grandes masas de personas en dos aspectos: la creación de contenido bottom up y el aprovechamiento de la inteligencia colectiva para realizar cambios sociales más rápida y efectivamente. Más detalles de estas ideas, innovadoras en su momento, pueden leerse aún en su blog ${ }^{8}$.

Por último, para cerrar esta visión optimista que los expertos presentan respecto de la tensión individuo-grupo en las redes actuales vinculadas con tecnología digital, resta considerar la idea de Pisani \& Piotet (2008) acerca de que se podría pasar de la sabiduría de las muchedumbres a la inteligencia colectiva, creando espacios en los cuales mucha gente piense junta. Esta idea coincide con la idea de cognición distribuida, devenida de la Psicología Cognitiva, presentada en párrafos anteriores. O sea que, tanto desde las miradas humanísticas como tecnológicas se postula el pasaje del individuo al grupo y aún a las multitudes de una forma orgánica e inteligente. Al parecer, la tecnología podría realizar aportes en este sentido. En el capítulo 4 de esta tesis se profundizará la relación entre el trabajo colaborativo y la tecnología digital.

\subsubsection{Grupos de aprendizaje como un tipo especial de grupo}

Para definir este concepto, se retoma a Marta Souto, quien define a un grupo de aprendizaje como: "una estructura formada por personas que interactúan, en un espacio y tiempo común, para lograr ciertos y determinados aprendizajes en los individuos (alumnos), a través de su participación en el grupo. Dichos aprendizajes, que se expresan en los objetivos del grupo, son conocidos y sistemáticamente buscados por el grupo a través de la interacción de sus miembros." (Souto, 1987, pág. 55).

Es visible que en los grupos de aprendizaje, los componentes fundantes de un grupo se mejoran y organizan en pos del logro del objetivo común. Así, los componentes de organización y conciencia de grupo se ven fortalecidos.

Los grupos de aprendizaje deben ser considerados dentro del escenario didáctico en el cual se crean, fortalecen y trabajan. Entonces, se entrelazan tres abordajes de características epistemológicas diferentes, pero afluentes de la misma situación didáctica (véase la figura 12):

- El proceso de aprendizaje: en este sentido, las primeras líneas de didáctica grupal consideraban el aprendizaje individual de cada miembro como el objeto de estudio. Con la consideración de los ambientes de tecnología informática como escenarios de

\footnotetext{
${ }^{7}$ Literalmente sería "desde abajo hacia arriba". Podría considerarse como producción descentralizada de contenidos, en este caso.

${ }^{8}$ O Reilly, Tim "Harnesing Collective Intelligence" http://www.oreilly.com/pub/a/web2/archive/what-is-web-20.html (Consultado en Noviembre de 2017).
} 
la construcción grupal han aparecido ideas innovadoras, como la cognición distribuida o la inteligencia grupal, que consideran un aspecto no presente en el trabajo grupal con tecnología no informática: la penetración de la tecnología "inteligente" en la "inteligencia colectiva" de los grupos de aprendizaje.

- El proceso de enseñanza: el abordaje es la Didáctica, como teoría de la enseñanza que reseña los elementos constitutivos de una situación de enseñanza. Desde los objetivos, actividades, métodos, materiales, manejo del tiempo y evaluación puestos a disposición para que los integrantes del grupo y el grupo como unidad mayor, aprendan.

- El proceso de dinámica grupal: el objeto de estudio es el propio grupo, en su devenir desde su construcción o primer contacto, pasando por las etapas de trabajo (que serán revisadas en próximas secciones de este capítulo) hasta su disolución.

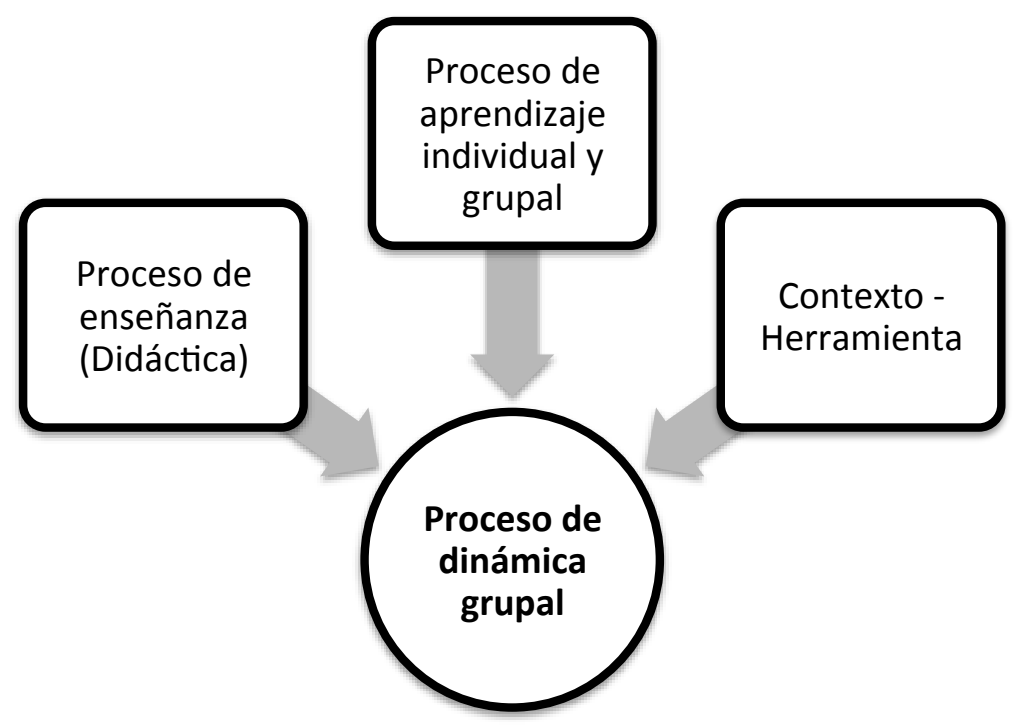

Figura 12: Componentes del análisis de grupos de aprendizaje

Para algunos autores este tipo de grupos de aprendizaje con alta integración y funcionalidad deberían trasladarse a la categoría de "equipo", bajo esta concepción "Un equipo de trabajo está compuesto por personas que se reúnen alrededor de una tarea. A diferencia de los grupos espontáneos, familiares o de amigos que esencialmente se reúnen por motivos y necesidades personales, los equipos están convocados alrededor de un objetivo común. Los equipos son las unidades fundamentales que permiten el logro de las metas que se propone una institución" (De Bono, 1988, pág. 47). Los componentes o características que hacen funcionar a un equipo hablan de su cohesión como tal (Johnson \& Johnson, 1997) y son los siguientes: interdependencia, identidad e interacción. Se muestran en la figura 13. 


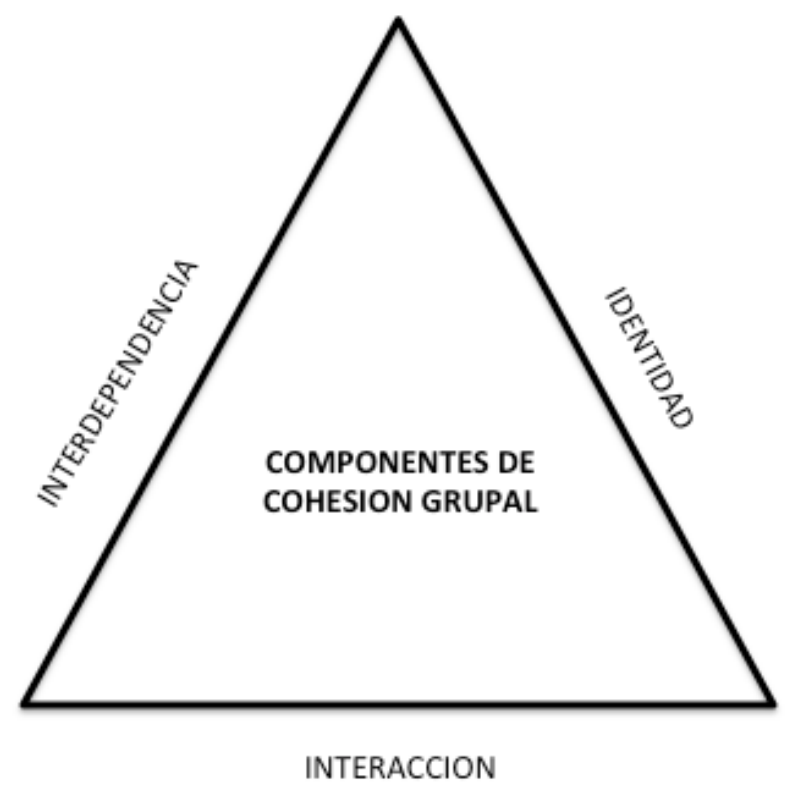

Figura 13: Componentes del concepto de cohesión de un grupo

- Interdependencia: es importante que los miembros reconozcan que se necesitan unos a otros. Ese reconocimiento y necesidad aportará a la factibilidad en el logro de los objetivos propuestos. Este concepto tiene especial importancia en le definición de "lo colaborativo". Así, Salomon, Perkins \& Globerson plantearon que "la interdependencia genuina del aprendizaje colaborativo depende del uso de recursos compartidos con actividades compartidas, con contraposición de opiniones, consenso de conocimientos alcanzados y roles diferenciados y complementarios". (Salomon et al. 1992, pág. 17).

- Identidad: es importante que el equipo tenga una identidad propia que lo defina y le dé coherencia y consistencia. Además de su singularidad, los integrantes se reconocen como parte del equipo, piensan en términos de "nosotros" y están orgullosos de ello.

- Interacción: como consecuencia de los dos componentes anteriores, en el equipo se genera interacción entre sus miembros: la interdependencia se materializa por medio de la interacción y esto fortalece la identidad. Aquí radica el motor del equipo.

Como puede apreciarse, estos componentes de un equipo pueden asimilarse a las características mencionadas párrafos arriba como referidas a los grupos con funcionamiento más "aceitado". Es por esta razón que, en las páginas de estas tesis se considerarán grupo y equipo como sinónimos. Esto es: un grupo con buen funcionamiento dirigido a metas comunes y con alto nivel de identidad será, entonces, un equipo.

\subsubsection{Ciclo de vida de un grupo}

Un grupo no se constituye en el momento en el que sus integrantes se encuentran o se comunican por primera vez. Por el contrario, el "ser un equipo" es una cualidad, una característica que un conjunto de personas va adquiriendo en el tiempo, a través del paso por sucesivas etapas. Bermúdez Morris (2002) presenta y sintetiza aportes diversos en relación con las etapas en la conformación de la vida de un grupo. Existe coincidencia en las etapas que se presentan en la figura 14. 


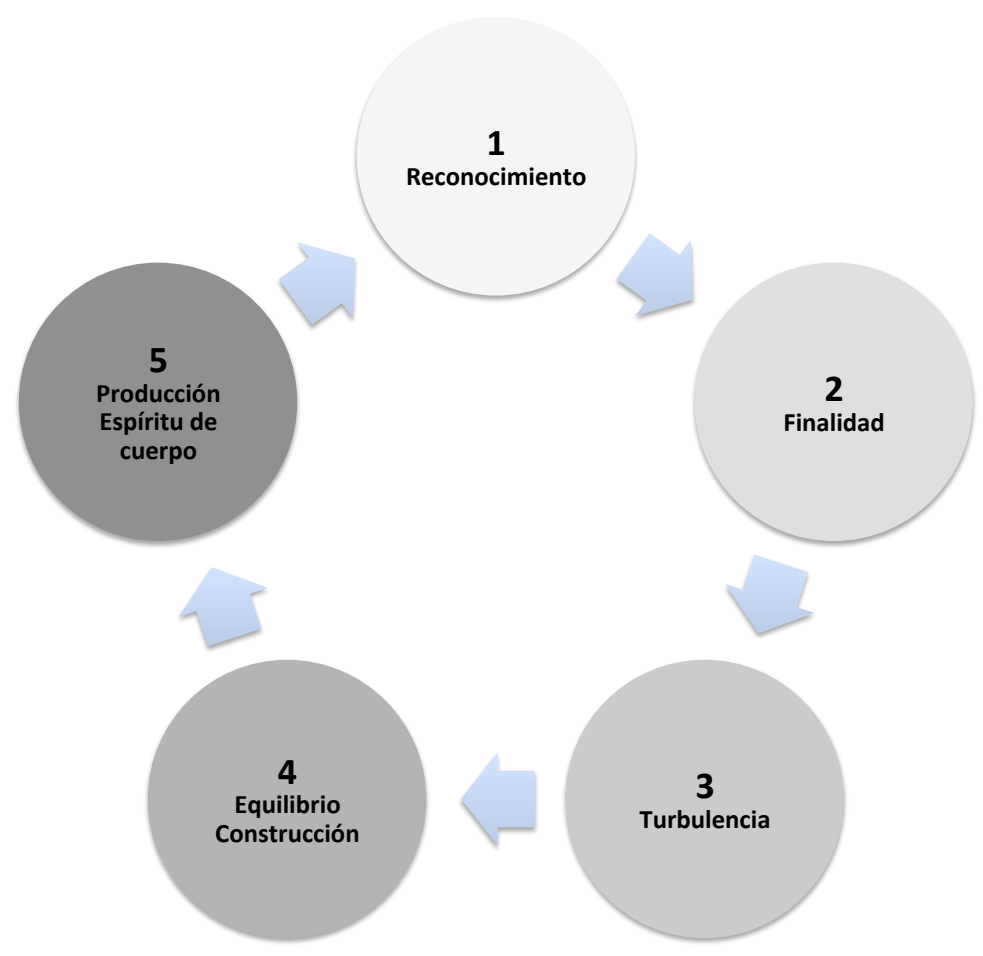

Figura 14: Ciclo de vida de un grupo (Bermúdez Morris, 2002)

La etapa de reconocimiento es la primera. Aquí el grupo se conforma y, por lo tanto, no es esperable ningún logro respecto del objetivo de la tarea final, que le da sentido al grupo. La conformación y construcción de la identidad es una tarea en sí misma en esta etapa. Es una etapa de investigación en la que cada individuo explora el terreno, tratando de verse a sí mismo como integrante. Desde el punto de vista de la emocionalidad, esta etapa puede incluir tanto sentimientos de optimismo como sentimientos contrarios y hasta ansiedad. En cuanto a la tarea encomendada, es una etapa de definición; se intenta determinar las necesidades de información del grupo, mediante el reconocimiento de la información que aporta cada miembro. Aquí el reconocimiento es la clave, que deviene en el nombre de la etapa. Pasado el reconocimiento, llega la etapa de definición de la finalidad: su razón de ser juntos. Es clave que todos los integrantes del grupo tengan la misma idea de finalidad; esto hace que la explicitación de la meta u objetivo se convierta en una tarea central de esta etapa. La etapa de turbulencia es la más difícil: ha comenzado la tarea y puede generarse impaciencia y otros sentimientos y actitudes que no favorezcan la tarea en conjunto. Los miembros del grupo tratan de manifestarse a partir de su experiencia y saberes personales y hasta pueden resistirse a la colaboración. Se pueden dar discusiones, conformar subgrupos, cuestionamientos, tensión, etc. Hasta puede existir competencia por lograr la atención e influir en la acción conjunta. Es vital superar esta etapa para conformar un grupo y llegar al objetivo final: la tarea resuelta, desde el producto, y la cohesión grupal, como proceso. Luego del desequilibrio de la etapa anterior, se sucede la etapa de equilibrio: retorna la calma y comienza el trabajo. Los participantes pueden hacer críticas constructivas, sentir alivio porque la tarea está encaminada, se genera confianza y apoyo entre los miembros y se establecen o se reformulan las reglas que estaban establecidas, tal vez enriquecidas por la superación de la etapa de turbulencia. La energía se canaliza hacia el proyecto: por lo tanto los objetivos compartidos y la tarea vuelve a cohesionar al grupo. Esto caracteriza a la etapa de equilibrio. Finalmente, la etapa de producción está basada en la sinergia, la producción y el apego. Aparecen situaciones de unidad, aceptación mutua y alta cohesión. Cada miembro del equipo cumple un rol y tiene una función definida. Comienzan a diagnosticar, generar propuestas e implementar soluciones. Se aceptan las diferencias grupales, los integrantes se sienten satisfechos funcionando como unidad. ¡El equipo está en marcha! 


\subsection{Del trabajo en grupos al trabajo colaborativo}

La literatura referida al trabajo en grupos, o en equipos, proveniente de la Psicología, la Sociología y la Didáctica coloca a los grupos de aprendizaje en un nivel alto de productividad, autorregulación y autopercepción de su entidad como colectivo. El marco teórico que se ha construido interdisciplinariamente a partir del advenimiento de la tecnología digital como espacio transaccional del trabajo de un grupo también le ha otorgado a los grupos de aprendizaje en entornos tecnológicos un alto grado de funcionamiento. Así, Benkler \& Nissenbaum (2006) introducen el término "trabajo colaborativo" para hacer referencia a este alto grado de funcionamiento de un grupo de personas tras un objetivo común. Se asocia, en un inicio, a iniciativas de "bien común" sostenidas en las ideas de inteligencia colectiva (Salomon, 2001) o sabiduría de multitudes (Surowiecki, 2005), pero en la actualidad el término trabajo colaborativo se refiere también a grupos pequeños y se ha trasladado al trabajo grupal en escenarios educativos.

\subsubsection{Definición de trabajo colaborativo en escenarios educativos}

Una aclaración que debe hacerse es que, en el marco de esta tesis, se usará la definición de trabajo colaborativo y no aprendizaje colaborativo. Si bien muchos autores lo mencionan como sinónimos, y hasta existe cierto acuerdo sobre la idea de que los grupos aprenden al mismo tiempo que sus individuos aprenden, se seguirá en este tema a Litwin $(2000,2001)$ en la convicción de que el aprendizaje es un fenómeno interno, idiosincrático, de construcción y reconstrucción permanente en estructuras superadoras. Es el trabajo colaborativo la experiencia que posibilita el aprendizaje, tanto de los integrantes de un grupo como del grupo como unidad. Esto no califica como colaborativo al aprendizaje, sino al trabajo que posibilita que estas dos dimensiones del aprendizaje tengan lugar.

Hecha la aclaración, se comenzará el itinerario de definición de trabajo colaborativo en escenarios educativos. Este tipo de trabajo busca propiciar espacios en los cuales se dé el desarrollo de habilidades individuales y grupales a partir de consignas específicas que busquen la colaboración y el intercambio de información y estrategias entre los integrantes de un grupo de trabajo. Deviene de las prácticas tradicionales de trabajo grupal y apuesta, efectivamente, a las ideas de interacción, interactividad y conocimiento compartido. Necesita tanto de estrategias de planificación en la tarea conjunta como de construcción afectiva que permitan que el conocimiento compartido circule, se asiente y permanezca.

El término trabajo colaborativo se utiliza como una especie de paraguas terminológico para cubrir aquellas actividades que implican la colaboración dentro de un contexto educativo. Siguiendo a Dillenbourg (1999) un primer acercamiento a este concepto podría ser: "el aprendizaje colaborativo es una situación en la que dos o más personas aprenden o intentan aprender algo juntas". Avanzando en las definiciones, Pérez (2007) presenta una posible línea de conceptualización de este proceso en su aparición en la escena educativa. Se presentan compiladas en la tabla 4.

\begin{tabular}{|l|l|}
\hline \multicolumn{1}{|c|}{ Autores } & \multicolumn{1}{c|}{ Conceptualizaciones } \\
\hline $\begin{array}{l}\text { Panitz \& } \\
\text { Panitz, }\end{array}$ & $\begin{array}{l}\text { Proceso de interacción cuya premisa básica es la construcción del consenso. Se } \\
\text { comparte la autoridad entre todos y se acepta la responsabilidad de las } \\
\text { acciones del grupo. }\end{array}$ \\
\hline $\begin{array}{l}\text { Guitert y } \\
\text { Simérez, }\end{array}$ & $\begin{array}{l}\text { Proceso en el que cada individuo aprende más de lo que aprendería por sí solo, } \\
\text { fruto de la interacción de los integrantes del equipo. El trabajo colaborativo se } \\
\text { da cuando existe una reciprocidad entre un conjunto de individuos que saben } \\
\text { diferenciar y contrastar sus puntos de vista, de tal manera que lleguen a } \\
\text { generar un proceso de construcción de conocimiento. }\end{array}$ \\
\hline
\end{tabular}




\begin{tabular}{|l|l|}
\hline \multicolumn{1}{|c|}{ Autores } & \multicolumn{1}{c|}{ Conceptualizaciones } \\
\hline $\mathbf{2 0 0 0}$ & $\begin{array}{l}\text { Proceso en el que las partes se comprometen a aprender algo juntas. Lo que } \\
\text { debe ser aprendido sólo puede conseguirse si el trabajo en grupo es realizado } \\
\text { en colaboración. Es el grupo el que decide cómo realizar la tarea, qué } \\
\text { procedimientos adoptar, cómo dividir el trabajo o tareas a realizar. La } \\
\text { comunicación y la negociación son claves en este proceso. }\end{array}$ \\
\hline $\begin{array}{l}\text { Salinas, } \\
\mathbf{2 0 0 0}\end{array}$ & $\begin{array}{l}\text { Proceso en el que resulta fundamental el análisis de la interacción profesor- } \\
\text { estudiante y estudiante-estudiante; por cuanto el trabajo busca el logro de } \\
\text { metas de tipo académico y también mejora las propias relaciones sociales. }\end{array}$ \\
\hline $\mathbf{2 0 0 4}$ & $\begin{array}{l}\text { Conjunto de métodos de instrucción y entrenamiento apoyados con } \\
\text { estrategias para propiciar el desarrollo de habilidades mixtas (aprendizaje y } \\
\text { desarrollo personal y social), donde cada miembro del grupo es responsable } \\
\text { tanto de su aprendizaje como del de los demás miembros del grupo. }\end{array}$ \\
\hline
\end{tabular}

Tabla 4: Conceptualizaciones de trabajo colaborativo (Pérez, 2007)

Del análisis de las definiciones anteriores surgen elementos comunes, algunos de los cuales ya aparecían en las primeras definiciones de trabajo en grupo y que fortalecen la idea de colaboración:

- El individuo aprende más y mejor en estos procesos de lo que podría hacerlo solo/a. Por eso, la idea de interacción aparece íntimamente vinculada con la colaboración.

- En la interacción se fortalecen las dimensiones social y afectiva de los miembros del grupo.

- Cobran importancia las competencias de planificación.

- Dentro de la dimensión afectiva, el compromiso del trabajo propio, y del trabajo con otros, asoma como central.

Reforzando la idea de compromiso en el trabajo colaborativo, Driscoll \& Vergara (1997) mencionan los siguientes componentes:

1) responsabilidad individual: todos los miembros son responsables de su desempeño individual dentro del grupo.

2) interdependencia positiva: los miembros del grupo deben depender los unos de los otros para lograr la meta común.

3) habilidades de colaboración: las habilidades necesarias para que el grupo funcione en forma efectiva, como el trabajo en equipo, liderazgo y solución de conflictos.

4) interacción promotora: los miembros del grupo interactúan para desarrollar relaciones interpersonales y establecer estrategias efectivas de aprendizaje.

5) proceso de grupo: el grupo reflexiona en forma periódica y evalúa su funcionamiento, efectuando los cambios necesarios para incrementar su efectividad.

Se presenta una definición propia de trabajo colaborativo como un tipo especial de trabajo en grupo que promueve el desarrollo de habilidades de aprendizaje, personales y sociales, en el que cada miembro expresa compromiso tanto con su propio aprendizaje como con el de los demás miembros de su grupo. Son elementos básicos la interdependencia positiva, la interacción, la contribución individual y las habilidades personales y de grupo. Este tipo de actividades puede ser mediada por herramientas tecnológicas digitales. En los espacios colaborativos online, existen factores claves como el establecimiento de protocolos y sesiones de comunicación tanto sincrónicas como asincrónicas. 
Desde el punto de vista de la metodología didáctica de diseño e implementación, se propone que este tipo de trabajo sea considerado en fases (Sanz, Zangara, \& Manresa-Yee, 2012):

- una fase individual, para que cada miembro del grupo tenga una actividad y espacio individual para organizar el conocimiento/tarea que aportará al grupo,

- luego una fase (con sub fases) de trabajo grupal colaborativo y

- una última fase de cierre de proceso y autoevaluación (individual y grupal) en términos de la producción y proceso de trabajo grupal.

Se presentará esta metodología en detalle en la sección final de este capítulo (apartado 3.4.1. "Una propuesta de enseñanza para grupos colaborativos").

\subsubsection{Diferencias entre trabajo colaborativo y otros tipos de trabajo grupal}

El trabajo colaborativo representa un estadio superior del trabajo grupal, en términos de su organización, compromiso y autorregulación. Se diferencia, entonces, de otras formas de trabajo grupal que no cumplen con estas condiciones.

Otros tipos de trabajos grupales pueden revisarse en el texto de Libedinsky, Manso, Pérez, Light \& Garzón (2011). Las autoras establecen cinco dinámicas en las que se puede presentar la colaboración en los proyectos y en las actividades con TIC. Si bien todas implican trabajar en forma conjunta en el logro de una meta común, no pueden considerarse trabajo colaborativo. Estas dinámicas se describen a continuación y se grafican sus diferencias en la figura 15.

- Dinámica de Producción Conjunta: los participantes trabajan en simultáneo en la misma tarea, estudiando un asunto común durante un periodo de tiempo acordado, para obtener un producto compartido. Aunque hacia el interior se distribuyan las tareas, todos son responsables del producto final.

- Dinámica de Producción Secuenciada: cada participante debe realizar una instancia del trabajo, pero la dinámica es secuenciada ya que hasta que el primer participante no cumple su paso, el siguiente no puede realizar su tarea. Cada instancia es requisito para que el compañero pueda avanzar. Es fundamental que todos los integrantes tengan claro el objetivo del producto final.

- Dinámica de Producción Complementaria: cada participante produce una porción del total y entre todos desarrollan el producto final. El producto final es impensado inicialmente por cada uno de los participantes.

- Dinámica de Producción Mosaico: todos los participantes aportan datos sobre una base dada. La colaboración cobra sentido solo en la medida en que se habilita una instancia en la que se utilizan los datos recopilados para realizar un análisis o como insumo para desarrollar una nueva tarea.

- Dinámica de Producción en Espejo: cada uno de los participantes describe o investiga un tema respetando la forma establecida. Al finalizar, ambas producciones se comparan y se realizan devoluciones constructivas al trabajo del compañero. 
Dinámica de producción conjunta

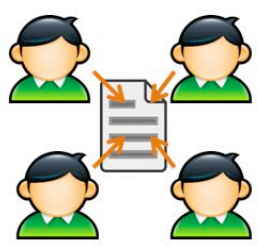

Dinámica de producción secuenciada

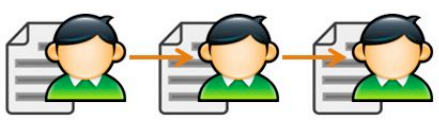

Dinámica de producción complementaria
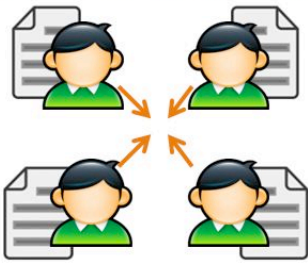

Dinámica espejo

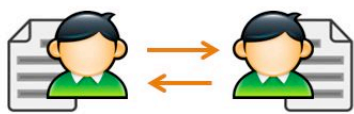

Figura 15: Gráfico de dinámicas de producción grupal no colaborativas (Libedinksky et al., 2011)

¿Cuál es la diferencia entre el trabajo colaborativo y las instancias anteriormente descriptas de trabajo en grupo? Se presentan sus diferencias conceptuales, construidas según elaboración propia de esta tesis, en la tabla 5. Como resultado puede verse que el trabajo colaborativo enriquece otras formas de trabajo grupal.

\begin{tabular}{|c|c|c|}
\hline Concepto & Idea clave & Diferencia con trabajo colaborativo \\
\hline $\begin{array}{l}\text { Producción } \\
\text { Conjunta }\end{array}$ & $\begin{array}{l}\text { Los participantes } \\
\text { trabajan en } \\
\text { simultáneo. Todos son } \\
\text { responsables }\end{array}$ & $\begin{array}{l}\text { La concepción aquí presentada de trabajo } \\
\text { colaborativo cumple con estas dos condiciones. } \\
\text { Según la metodología que se postula aquí, el } \\
\text { trabajo en simultáneo se daría con información } \\
\text { individual y única, para luego componer el } \\
\text { trabajo en grupo, orientado con una consigna } \\
\text { específica que apunta a la construcción. Por lo } \\
\text { que la producción conjunta podría estar asociada } \\
\text { a una parte de la concepción de trabajo } \\
\text { colaborativo propuesta. }\end{array}$ \\
\hline $\begin{array}{l}\text { Producción } \\
\text { Secuenciada }\end{array}$ & $\begin{array}{l}\text { Los participantes } \\
\text { trabajan según una } \\
\text { secuencia definida (por } \\
\text { la consigna) }\end{array}$ & $\begin{array}{l}\text { Todos los participantes trabajan de forma } \\
\text { simultánea en la consigna individual y luego } \\
\text { construyen en la consigna grupal. No hay } \\
\text { secuencia, salvo que el grupo decida hacerlo así } \\
\text { en la etapa de autorregulación grupal. }\end{array}$ \\
\hline $\begin{array}{l}\text { Producción } \\
\text { Complemen- } \\
\text { Taria }\end{array}$ & $\begin{array}{l}\text { Todos los participantes } \\
\text { se complementan para } \\
\text { la producción final. }\end{array}$ & $\begin{array}{l}\text { Cumple con una parte del trabajo colaborativo, } \\
\text { ya que la información individual se complementa } \\
\text { en la producción de la consigna grupal. }\end{array}$ \\
\hline $\begin{array}{l}\text { Producción } \\
\text { Mosaico }\end{array}$ & $\begin{array}{l}\text { Todos los participantes } \\
\text { aportan información o } \\
\text { trabajo para una nueva } \\
\text { producción }\end{array}$ & $\begin{array}{l}\text { Esta idea forma parte definitivamente del trabajo } \\
\text { colaborativo, ya que la construcción final debe } \\
\text { ser resultado de la complementariedad de } \\
\text { acciones y conocimientos. Según la metodología } \\
\text { que se presenta en este capítulo, el mosaico } \\
\text { podría darse luego de una etapa de } \\
\text { investigación/desarrollo de una producción } \\
\text { individual. }\end{array}$ \\
\hline $\begin{array}{l}\text { Producción en } \\
\text { Espejo }\end{array}$ & $\begin{array}{l}\text { Trabajo de a pares de } \\
\text { contrastación de } \\
\text { producciones } \\
\text { individuales. }\end{array}$ & $\begin{array}{l}\text { Podría ser una de las etapas del trabajo grupal, si } \\
\text { el grupo lo decide. El trabajo colaborativo es más } \\
\text { que eso: debe llegar a una producción grupal } \\
\text { consensuada en proceso y producto. }\end{array}$ \\
\hline
\end{tabular}




\subsubsection{Diferencias entre trabajo colaborativo y cooperativo}

Los trabajos cooperativo y colaborativo tienen varias cuestiones en común. En el contexto de la enseñanza se asimilan en que: ambos trabajan con grupos, ambos especifican tareas a esos grupos, en ambas posiciones los grupos deben compartir información y comparar sus procesos de trabajo y las conclusiones del trabajo se pueden compartir en plenario.

Si bien existe la tendencia de considerar al trabajo cooperativo y colaborativo como sinónimos, en la profundización de ambos conceptos aparecen sus diferencias. Se presentaron en secciones anteriores diversas conceptualizaciones de trabajo colaborativo que hacían foco en la planificación, la interdependencia, la identificación y, como síntesis, la autorregulación. Pero muchos grupos que trabajan integradamente y hasta llegan a lograr sus objetivos de manera eficiente, no llegan a cumplir con estos estándares. ¿Se puede decir, en ese caso, que no trabajan en grupo? Seguramente no. Es más, tal vez utilicen una, varias o todas las dinámicas presentadas en la subsección anterior. ¿Es posible aseverar, entonces, que no llegan a un grado de colaboración en su trabajo colectivo? Tampoco se podría arriesgarse esa respuesta, ya que seguramente el aprendizaje tanto individual como grupal haya tenido lugar en esta hipotética experiencia. ¿Cuál sería entonces la cuestión? Pensar a la colaboración como un estadio mayor de autorregulación en el que el grupo pase por todas las etapas que se describieron en la sección 1.3 (Véase: "Ciclo de vida de un grupo") sin ayuda externa. Si la situación está planteada en términos didácticos, la fuente de ayuda externa por antonomasia es el docente.

Así, Millis (Roberts, 2004) afirma que el aprendizaje cooperativo es un "término genérico utilizado para describir una situación en la que los estudiantes trabajan juntos en grupos pequeños para ayudarse a aprender entre si"; mientras que Johnson \& Johnson (2001) lo definen como "el uso educativo de los grupos pequeños para que los estudiantes trabajan juntos en pos de maximizar su propia y el aprendizaje de los demás".

Roberts (2004) presenta el siguiente esquema, que aparece en la figura 16, de una posible clase con grupos trabajando cooperativamente.

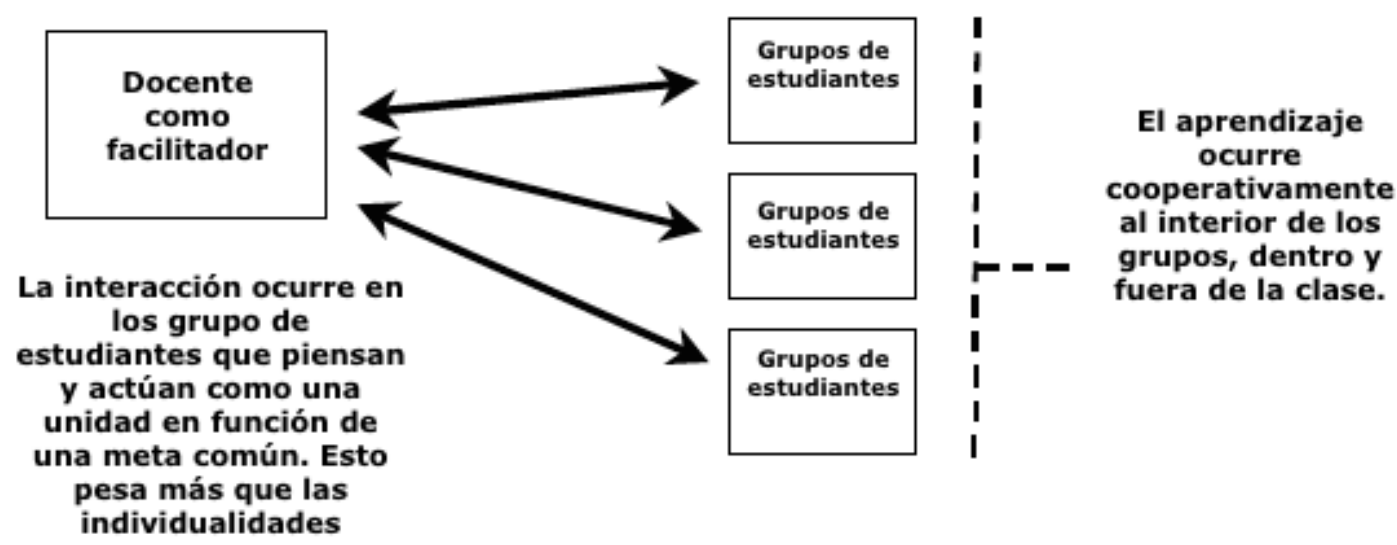

Figura 16: Clase con grupos cooperativos (Roberts, 2004)

De este esquema surge la principal diferencia que podría establecerse en la dinámica cooperación - colaboración, que estaría en el continuum dependencia (del docente) autorregulación (del grupo). En el trabajo cooperativo, los estudiantes trabajan en grupo, aplican dinámicas de trabajo colectivo, pero para transitar sus etapas, obtener el sentido de identidad, evaluar sus producciones y obtener la sensación de tarea cumplida, necesitan del espejo constante del docente. No se cumpliría cabalmente, entonces, la idea completa de trabajo colaborativo en la que las partes se comprometen a aprender algo juntos que sólo puede conseguirse si el trabajo del 
grupo es realizado en colaboración y donde es el grupo el que decide cómo realizar la tarea, qué procedimientos adoptar, cómo dividir el trabajo, etc.

La intervención docente en el interior del trabajo grupal es la variable en este caso, que varía de acuerdo con la necesidad del grupo: cuánto más colaborativo sea, menor intervención docente se requerirá. Según Correa (2013) podría considerarse un gradiente que se grafica en la figura 17.

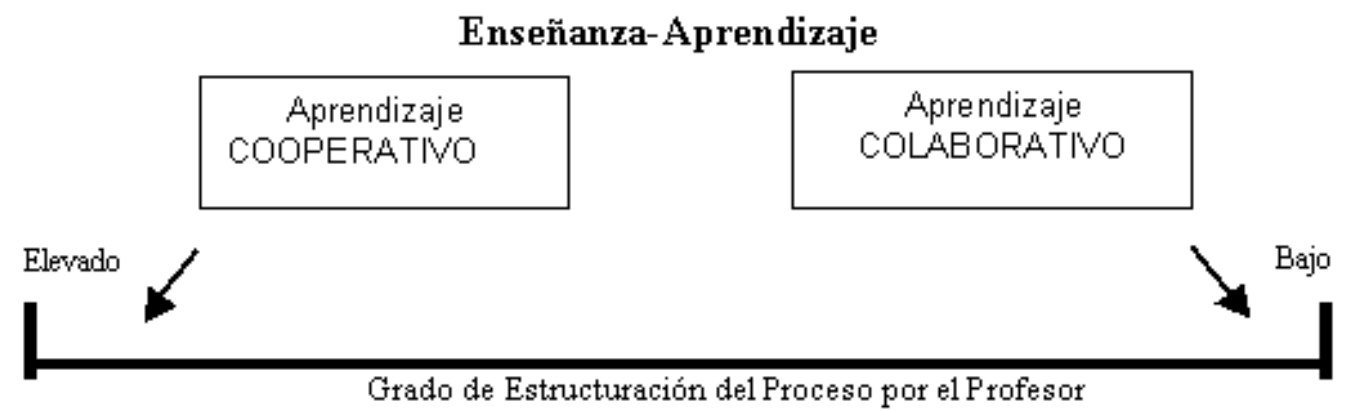

Figura 17: Trabajo cooperativo-colaborativo según la intervención del profesor (Correa, 2013)

De acuerdo con Panitz (1997) una posible distinción sería identificar a la colaboración como una filosofía de interacción y hasta de estilo de vida personal, mientras que la cooperación es una estructura de interacción diseñada para facilitar el cumplimiento de un producto final o meta.

Antes de pasar al aspecto didáctico-metodológico se presenta, en la figura 18, un esquema de acercamiento al concepto y funcionamiento de un grupo colaborativo. Se considera la metáfora gráfica de completar los requisitos que se han definido para grupos de trabajo colaborativo.

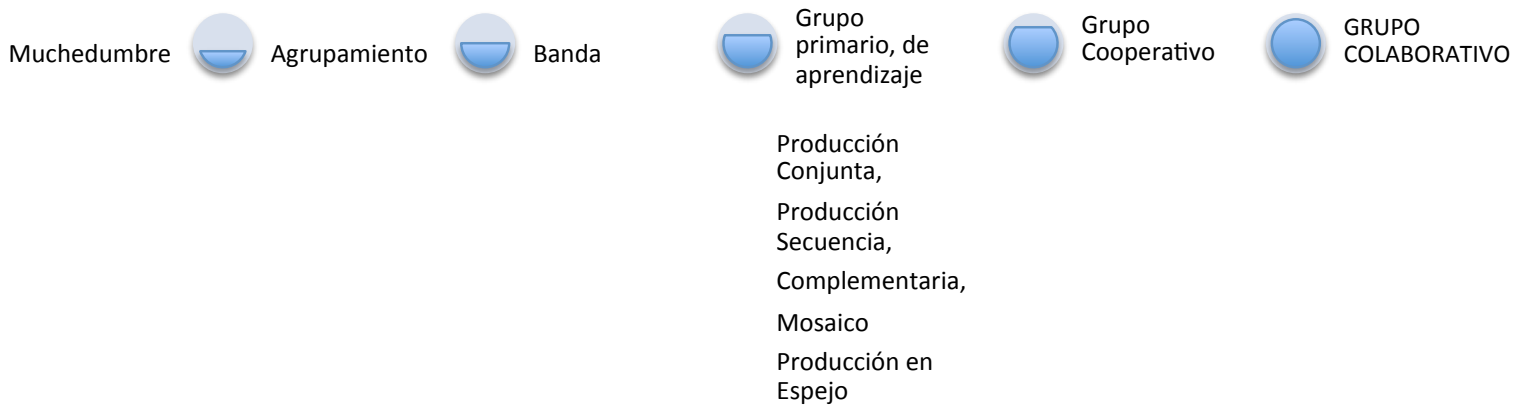

Figura 18: Acercamiento conceptual al trabajo colaborativo

\subsection{La enseñanza orientada a grupos como objeto de la Didáctica}

En el campo de la Didáctica, la enseñanza orientada a grupos ha modificado la perspectiva del sujeto que aprende. Se ha pasado de lo discreto al conjunto, de las problemáticas de la persona sola al colectivo y al trabajo grupal. Se piensa "lo grupal" como atravesamientos múltiples. Dentro del marco social, político e institucional se inscribe la problemática del contexto de enseñanza. Además aparecen las variantes del aula con el componente de la tecnología digital. Se concibe la problemática del grupo como entramado de voces y relaciones, compuesto por individuos igualmente complejos en su interioridad. Se hace necesario, entonces, pensar en la interdisciplinariedad para comprender fenómenos cada vez más transversales. 
Los grupos aparecen como "nudos constituidos por múltiples hilos de unidades disciplinarias que se enlazan en el pensar en lo grupal" (Souto, 1996, pág. 54) o como "proceso desencadenado por cruces y anudamientos deseantes entre miembros singulares" (Souto, 1996, pág. 55). Esto significa que se desiste que abordar, desde el punto de vista de la enseñanza, al grupo como objeto discreto y único y se entiende como un entramado ("dispositivo" diría Souto, 1996) de voces diferentes que actúa como una unidad en un tiempo y espacios determinados enfocados hacia objetivos comunes.

La complejidad del abordaje didáctico de la enseñanza en grupos existe y comienza en la propia dificultad para definir el concepto y los tipos de grupos. Parte de esta problemática ha ocupado este capítulo. ¿Por qué, entonces, el trabajo en grupos es un objeto de interés para la Didáctica, a pesar de las dificultades para su abordaje? Una posible respuesta parece estar en sus ventajas. Los beneficios de la colaboración para el aprendizaje se han establecido largamente en la literatura (Chickering \& Gamson, 1996; Dillenbourg, 1999; Stahl, 2006). El segundo principio de Chickering \& Gamson establece que "el aprendizaje aumenta cuando se trata más de un esfuerzo de equipo que de una carrera en solitario. El buen aprendizaje, al igual que un buen trabajo, es colaborativo y social, no competitivo y aislado. En funcionamiento con otros, a menudo, aumenta la participación en el aprendizaje. Compartir las propias ideas y responder a las reacciones de los demás agudiza el pensamiento y profundiza la comprensión"9 (Chickering \& Gamson, 1987, pág. 3). El trabajo grupal colaborativo conlleva una serie de ventajas en diferentes dimensiones del aprendizaje. Con respecto a la ejecución de tareas grupales es posible mencionar que promueve el logro de objetivos cualitativamente más ricos ya que reúne propuestas y soluciones de varias personas del grupo; facilita la valoración del conocimiento de los miembros de un grupo; incentiva el desarrollo del pensamiento crítico y la apertura mental y fortalece el sentimiento de solidaridad y respeto mutuo, basado en los resultados del trabajo. Asimismo, contribuye a aumentar el aprendizaje de cada integrante debido a que se enriquece la experiencia de aprender, la motivación y el compromiso. La satisfacción por el trabajo del grupo pasa a ser el foco, basada en el trabajo de cada integrante. Puede contribuir, también, a la disminución del sentimiento de aislamiento y el temor a la crítica.

\subsubsection{Una propuesta de enseñanza para grupos colaborativos}

En la definición de trabajo colaborativo presentada en este trabajo de tesis se hizo alusión a su tratamiento didáctico específico. Este tratamiento fue desarrollado y probado en el Seminario de "Educación a Distancia" de la Maestría en Tecnología Informática aplicada en Educación. Se presentará en detalle en este apartado. Los pasos considerados en esta metodología están compilados en la tabla 6.

\begin{tabular}{|l|}
\hline \multicolumn{1}{|c|}{ Pasos de la metodología de enseñanza para grupos colaborativos } \\
\hline 1. Determinación de los objetivos didácticos de la actividad de trabajo colaborativo. \\
2. Diseño de la consigna en sus fases individual y grupal. \\
3. Armado de grupos, según criterios que apunten a su grupalidad. \\
4. Tareas del docente en cada etapa. \\
5. Autoevaluación del trabajo individual y grupal. \\
6. Cierre del trabajo final de cada grupo. Análisis. Devolución a los estudiantes. \\
Tabla 6: Abordaje didáctico de una actividad colaborativa
\end{tabular}

\footnotetext{
9 "Learning is enhanced when it is more like a team effort than a solo race. Good learning, like good work, is collaborative and social, not competitive and isolated. Working with others often increases involvement in learning. Sharing one's own ideas and responding to others 'reactions sharpens thinking and deepens understanding". (Chickering \& Gamson, 1987, pág. 3).
} 
A continuación se detallan las decisiones de cada una de las etapas mencionadas de manera general. En el capítulo 8 se detallan las decisiones particulares y la consigna con la que se trabajó en el estudio de caso.

1. Determinación de los objetivos didácticos de la actividad de trabajo colaborativo: en esta etapa se analizan qué objetivos se persiguen con la realización del trabajo colaborativo y se toman decisiones metodológicas iniciales. Básicamente cuáles serán sus fases y qué relación habrá entre el trabajo individual y grupal. Se evalúa, además, qué momento del proceso de enseñanza es apropiado para realizar este trabajo y también su duración.

2. Diseño de la consigna: en esta etapa se debe diseñar una consigna que permita desarrollar los objetivos planteados. En este aspecto, la consigna debe considerar la definición de trabajo colaborativo que se adopte y sus componentes: objetivos, conformación de los grupos, metodología (en fases), tareas en cada una, tiempos y criterios de evaluación. La figura 19 describe las fases de una consigna de trabajo colaborativo.

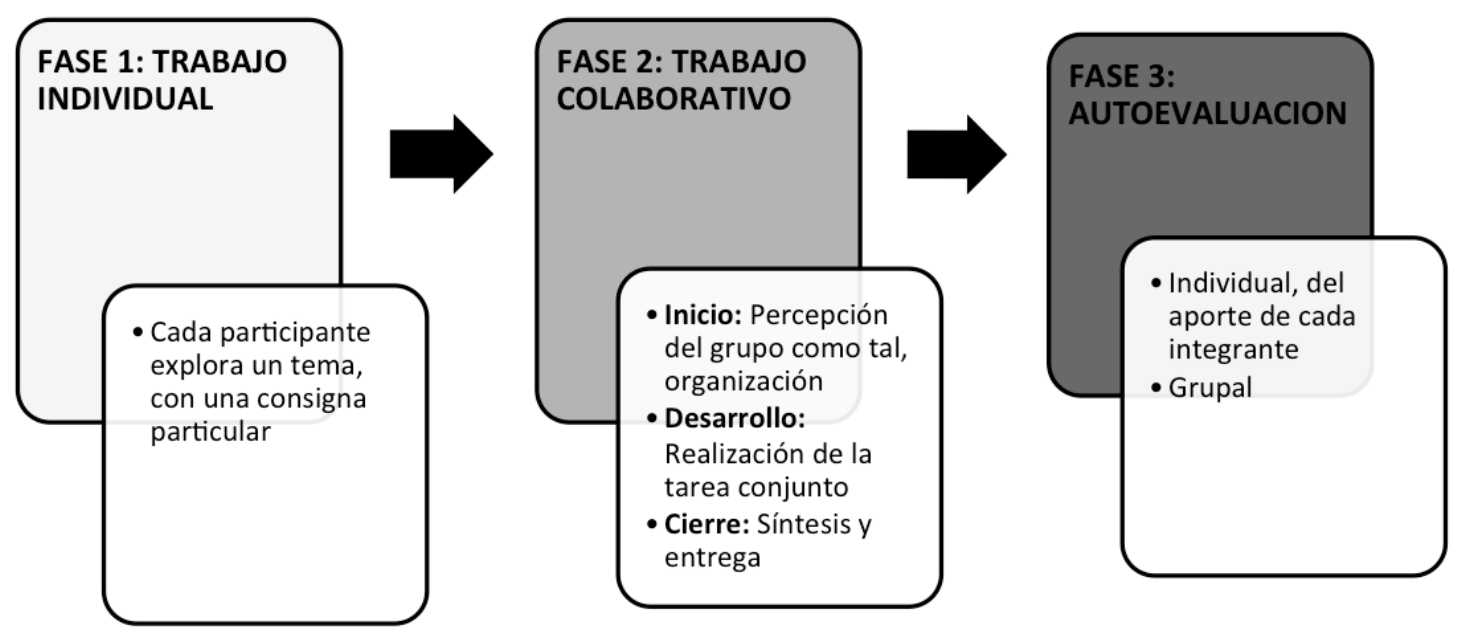

Figura 19: Fases de una consigna de trabajo colaborativo

- La primera fase considera un espacio y tiempo de trabajo individual. De esta forma, cada estudiante dispone de un espacio para preparar su aporte al trabajo grupal posterior. Esta primera fase debe ser diseñada con el fin de que cada alumno construya un punto de vista sobre un tema específico o sobre el problema que se debe resolver colaborativamente.

- La segunda fase aborda el trabajo colaborativo en equipo, donde se debe llegar a un objetivo, teniendo cada uno una visión previa de algún aspecto del problema a analizar conjuntamente. Esta fase tiene sub fases (inicio de la tarea-desarrollo-cierre y entrega del producto del grupo), en las que el grupo deberá transitar por los siguientes momentos:

- Interpretación / apropiación de la consigna.

- Búsqueda de un coordinador, si lo creyesen necesario.

- Negociación de acuerdos y establecimiento y concientización de puntos de desacuerdo.

- Identificación del proceso de solución.

- Determinación de estándares de calidad tanto en el proceso de solución como en el producto resultante de cada paso y final. 
- La tercera fase se corresponde con la auto-evaluación. La idea clave es el análisis del desempeño individual y grupal en cuanto al producto final y a la colaboración.

3. Armado de grupos: es un aspecto fundamental, basado en la característica de grupalidad. La grupalidad representa la potencialidad de un conjunto de personas de convertirse en un grupo (Schmuk, 1975). En esta condición aparecen competencias individuales, que los docentes podrán analizar de cada uno de sus estudiantes, y la mirada proyectiva de cómo esas personas funcionarán en un colectivo. Schmuk marca algunas condiciones a tener en cuenta, en las perspectivas presente (individual) y futura (de grupo). En ambas perspectivas, considera las competencias vinculadas a la tarea (lo que el individuo debe hacer, tanto en su tarea individual como grupal) y las características socio-emocionales. Estas condiciones se describen en la tabla 7.

\begin{tabular}{|c|c|c|}
\hline & Tarea & Socio-emocional \\
\hline Perspectiva individual & $\begin{array}{l}\text { Lectura comprensiva } \\
\text { Aceptación y comprensión de } \\
\text { consignas } \\
\text { Buena expresión escrita } \\
\text { Autorregulación }\end{array}$ & $\begin{array}{l}\text { Aceptación (propia y de los } \\
\text { compañeros) } \\
\text { Solidaridad } \\
\text { Capacidad de soporte a los } \\
\text { compañeros } \\
\text { Capacidad de liderazgo (potencial) }\end{array}$ \\
\hline Perspectiva de grupo & $\begin{array}{l}\text { Capacidad (potencial) para: } \\
\text { - trabajar con otros } \\
\text { - presentar otros puntos de vista } \\
\text { - encontrar los pequeños éxitos en } \\
\text { el proceso que permitan continuar } \\
\text { con el trabajo }\end{array}$ & $\begin{array}{l}\text { Capacidad para mantener una } \\
\text { discusión, llevarla adelante y } \\
\text { cerrarla }\end{array}$ \\
\hline
\end{tabular}

Tabla 7: Condiciones de grupalidad (Tomado y modificado de Schmuk, 1975)

La grupalidad no implica necesariamente simetría (aspecto considerado por Gross, 2007), ya que los individuos diferentes pueden enriquecer al grupo, siempre que sus competencias puedan funcionar complementariamente en el trabajo grupal futuro. En el capítulo 8, en la presentación del estudio de caso, se hará referencia a la interdisciplinariedad como un componente no simétrico y de alta grupalidad en la formación de grupos en el seminario de "Educación a Distancia" de la Maestría en "Tecnología Informática aplicada en Educación".

4. Tareas del docente en cada fase: Las intervenciones del docente en el trabajo colaborativo resultan del tipo "laparoscópicas", en general a solicitud del grupo y planificadas de manera tal de acompañar el trabajo al ritmo y de la forma en la que el grupo se organice. Sus tareas varían, de acuerdo con las fases de trabajo presentadas anteriormente en este apartado:

- En la fase de trabajo individual: representa una fuente de consulta para los participantes en la búsqueda de material inicial, por ejemplo, acerca de: qué tipo de material buscar, dónde buscarlo (fuentes), cómo catalogarlo, dónde subirlo en el entorno virtual que sirva de marco al curso, etc.

- Durante la fase de trabajo en equipo: debe estar atento a las posibles dudas: alcance de la producción colaborativa (en tiempo y forma), herramientas, tiempos, tareas de cada integrante del equipo, qué hacer con los alumnos que no habían participado, etc.

- En la evaluación: realiza el seguimiento de cada entrega, tanto de las evaluaciones individuales como las grupales. Asimismo, oficia como fuente de consulta para el completamiento de los instrumentos.

5. Auto-evaluación del trabajo individual y grupal: la tarea consiste en definir la metodología de evaluación (el circuito de comunicación de entrega de los instrumentos de 
evaluación individual y grupal y las herramientas seleccionadas) y la construcción de los instrumentos.

6. Cierre del trabajo final de cada grupo. Análisis y devolución a los estudiantes: en esta etapa se organiza la entrega de cada trabajo final. Deberá implementarse el formato y circuito de entrega diseñado y comunicado a los estudiantes desde el inicio. Respecto de la devolución, será doble: a) de calidad de producto, en qué forma responde a la consigna y b) de calidad del trabajo colaborativo, cuánto demuestra la participación y cohesión grupal.

\subsection{Conclusiones del capítulo}

En este capítulo se ha transitado un camino que se inició con el individuo, siguió con el grupo como objeto de estudio y arribó a la conceptualización de trabajo colaborativo.

Se comenzó presentado la relación individuo-grupo desde una perspectiva psicológica. Se describió la tensión de pasar del abordaje individual al tratamiento didáctico de "lo grupal" y de ahí al grupo funcionando colaborativamente.

Se definió, entonces, al trabajo colaborativo como un tipo especial, máximo, de trabajo grupal. Se diferenciaron formas de trabajo en grupo no colaborativas, así como se marcó la distancia entre trabajo colaborativo y cooperativo. Las estrategias de autorregulación al interior del grupo y el rol de coordinación (del docente) por fuera del grupo fueron el centro de esta diferenciación.

Luego se avanzó hacia el grupo colaborativo como objeto de enseñanza y se presentó una metodología, en fases de trabajo, creada, implementada y probada en el seminario de "Educación a Distancia" de la Maestría en "Tecnología Informática aplicada en Educación". Se describió el proceso de planificación didáctica (metodología utilizada para buscar alcanzar el trabajo colaborativo entre los estudiantes): desde la definición de objetivos y la conformación de los grupos, atendiendo a un criterio de grupalidad, hasta la evaluación del producto final y seguimiento del proceso.

En el siguiente capítulo se aborda el tema del estudio del trabajo colaborativo mediado por tecnología informática. Se relevan indicadores de diversos estudios y autores, para avanzar en la composición de un modelo propio. 


\section{Capítulo 4: Antecedentes en relación a la valoración del trabajo colaborativo mediado por tecnología informática}

Un dia Hansel le dijo a Gretel, "tiremos estas migas de pan, así podemos encontrar juntos el camino a casa, ya que perder nuestro camino sería lo peor que nos puede pasar" Extraído de Hänsel und Gretel. Cuento de hadas alemán recogido por los hermanos Grimm, 1893.

Para describir un proceso de trabajo con miras a su mejoramiento resulta fundamental conocer los pasos que lo componen. Sobre esta problemática trabaja este capítulo. El recorrido conceptual propuesto es el siguiente:

4.1. Valoración, seguimiento, evaluación. ¿Para qué? ¿Para quiénes?

4.1.1. Diferencias conceptuales: evaluación, seguimiento, valoración

4.1.2. Actores de la situación educativa impactados por esta información

4.1.2.1. Docentes y / o tutores

4.1.2.2. Grupo en sí

4.1.2.3. Diseñadores de ambientes colaborativos y herramientas

4.2. Indicadores del trabajo grupal colaborativo

4.2.1. Indicadores del aporte individual al grupo

4.2.1.1 Síntesis de indicadores desde la perspectiva individual y su contribución al grupo

4.2.2. Indicadores que la tecnología permite visibilizar: cómo el grupo construye

4.2.3. Análisis de la conexión semántica en el trabajo colaborativo. Argumentación como idea clave

4.3. Conclusiones del capítulo 


\subsection{Valoración, seguimiento, evaluación. ¿Para qué? ¿Para quiénes?}

Como el valor agregado de esta tesis es aportar herramientas conceptuales y metodológicas en el seguimiento del trabajo colaborativo en escenarios educativos, se comenzará retomando un modelo de enseñanza para instalar allí las tareas de seguimiento y evaluación en las que se focalizarán en las siguientes páginas.

Todos los modelos se instalan en un escenario teórico, de alto nivel de abstracción. Sus componentes dependen de la óptica con la que se tiña la mirada de análisis. Según Gimeno Sacristán (1981, págs. 95-96): "un modelo es una representación de la realidad que supone un alejamiento o distanciamiento de la misma. Es una representación conceptual, simbólica, y por lo tanto indirecta que, al ser necesariamente esquemática, se convierte en una representación parcial y selectiva de aspectos de la realidad, focalizando la atención en lo que se considera importante [...] el modelo se identifica con una especie de esquema interpretativo [...] el modelo es un esquema mediador entre la realidad y el pensamiento". Un modelo es un esquema interpretativo de la realidad, en la cual cada autor selecciona los componentes que considera relevantes y elige, de la red de relaciones posibles, aquéllas que sean más pertinentes a sus necesidades de explicitación e interpretación de la realidad. Por lo tanto, cada modelo resulta acotado a un contexto témporo-espacial y cultural. Siempre es provisional.

El concepto de modelo aparece en los textos de las Ciencias de la Educación referidos a Pedagogía y Didáctica $\mathrm{y}$, fundamentalmente, en el discurso pedagógico actual para definir esquemas interpretativos acerca de los elementos intervinientes y la trama de relaciones posibles en toda situación educativa.

En la figura 20 se presenta un modelo interpretativo propio de los elementos constitutivos de la situación de enseñanza, enmarcando las tareas de seguimiento y evaluación. Cada círculo representa las etapas propias de la planificación didáctica (planificación, implementación o puesta en acto y resultados). En las flechas que unen las etapas están demarcadas las tareas propias de cada etapa. En los recuadros de abajo aparecen los tipos de evaluación en cada etapa y, finalmente, el circuito de retroalimentación que producen los resultados obtenidos.
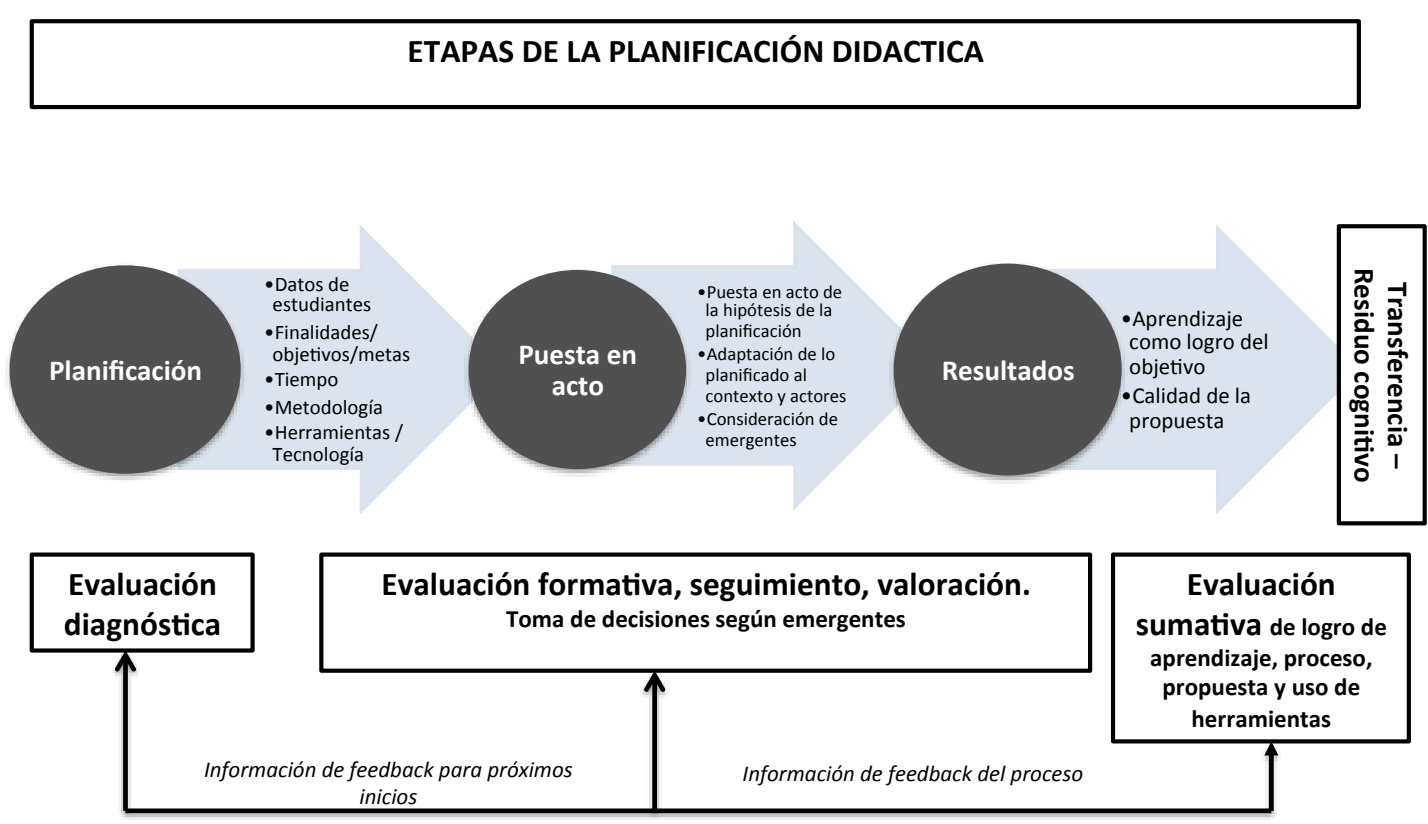

Figura 20: La evaluación en el modelo de enseñanza. Modelo propio 
En el modelo anterior, como en la mayoría de los modelos de enseñanza relevados (Pansza, Juárez \& Oviedo, 1986; Zabalza, 1987; Hernández, 1989; Gimeno Sacristán, 1986; Gimeno Sacristán \& Pérez Gómez, 1989 y 1995; Tiffin \& Rajasingham, 1995) la evaluación aparece como una de las funciones propias e inherentes a la enseñanza. Si el contexto de esa enseñanza está instalado en los escenarios tecnológico digitales resulta imprescindible trasladar la evaluación a estos escenarios.

\subsubsection{Diferencias conceptuales: evaluación, seguimiento, valoración}

Es necesario comprender las diferencias entre estos conceptos para ubicar la metodología de seguimiento del trabajo colaborativo mediado por tecnología informática que aquí se propone en el marco de la acción docente y del trabajo en grupo. Existe una relación conceptual de inclusión entre los conceptos de evaluación, valoración y seguimiento. Se presentan sus conceptualizaciones y relaciones a continuación.

Según Gimeno Sacristán "evaluar hace referencia a cualquier proceso por medio del que alguna o varias características de un alumno, de un grupo de estudiantes, de un ambiente educativo, de objetivos educativos, de materiales, profesores, programas, etc., recibe la atención del que evalúa, se analizan y se valoran sus características y condiciones en función de unos criterios o puntos de referencia para emitir un juicio que sea relevante para la educación" (Gimeno Sacristán, 1995, pág. 339). Desde el concepto se definen sus pasos. Según Bertoni, Poggi \& Teobaldo son:

- relevamiento de información (observaciones, documentos, producciones, otros);

- análisis de los datos según marcos de referencia;

- elaboración de conclusiones, expresadas como juicios de valor o en datos cuantitativos;

- comunicación a los actores involucrados;

- toma de decisiones para intervenir en los procesos y resultados obtenidos del proceso evaluativo. (Bertoni, Poggi \& Teobaldo, 1997, pág.18)

La evaluación, como proceso esencial de la enseñanza, ha sufrido, y aún sufre, de una ambigüedad tal que permite ser vista como un "Jano moderno". Al decir de Ardroino \& Berger "con un doble perfil: un lado muestra un perfil filosófico, en la medida en que toda evaluación plantea el problema del valor, del sentido y de la significación de aquello que se evalúa (lo que requiere de un tratamiento cualitativo); el otro lado muestra un perfil técnico, ya que la evaluación constituye un dispositivo compuesto por métodos, técnicas e instrumentos empleados para dar cuenta y rendir cuenta (de manera cuantitativa) de los resultados obtenidos. Ese perfil se asocia con la noción de control y medición". (Ardroino \& Berger en Bertoni et al., 1997, pág. 25). Como en la metáfora de Jano sus dos caras aparecen, en tensión, en el momento de evaluar. Algunos autores plantean que estas dos caras se han terminado hibridando en modelos mixtos (Popham, 1974; Stufflebean \& Shinkfield, 1987; Cook \& Reichardt, 1979).

El paradigma cuantitativo hace énfasis exclusivo en los resultados de la enseñanza, se mide la situación inicial (pre-test), luego de un período de enseñanza se miden los conocimientos adquiridos y se comprueba la eficacia de la intervención didáctica bajo evaluación (programa, clase, actividad didáctica, software educativo, etc.). Estas mediciones requieren la operacionalización de las variables y resaltan sólo la conducta observable de los alumnos, descuidando otros aspectos, no siempre previsibles. Por eso, requiere de un estricto control de las variables en el aula. Por otro lado, el paradigma cualitativo (que, según las perspectivas de hibridación puede ser visto como complementario al cuantitativo) se sostiene en la 
interpretación, como categoría propia de la subjetividad. En una actividad como la enseñanza, en la que intervienen personas y sus producciones (métodos, modelos, tecnologías), la evaluación se propone comprender y valorar. Al no considerar solamente los resultados, la evaluación es una actividad continua de observación, documentación e interpretación, que se complementa con la comunicación de la información del proceso a los actores involucrados.. El énfasis se traslada de los productos a los procesos, de la evaluación sumativa a la evaluación formativa (Scriven, 1967 en Stufflebean \& Shinkfield, 1987). La evaluación cualitativa se interesa en la acción didáctica, para su formulación y reformulación. En este marco, la evaluación implica el seguimiento y la valoración. La tarea de seguimiento consiste en la recopilación de información a medida que se avanza en la implementación de una situación de enseñanza determinada y la valoración supone el análisis de esta información en función de estándares predefinidos. En la figura 21 se definen y vinculan, en un modelo propio, los tres conceptos.

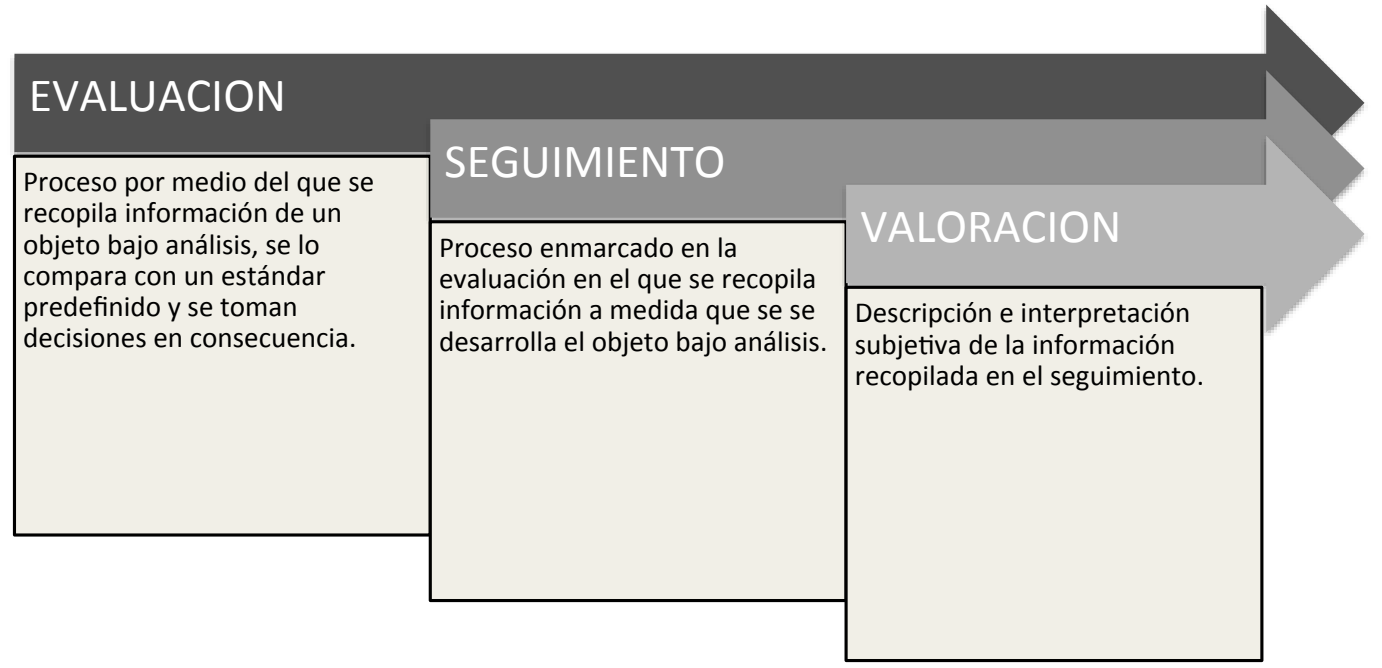

Figura 21: Vinculación entre los conceptos de evaluación, seguimiento y valoración. Modelo propio

\subsubsection{Actores de la situación educativa impactados por esta información}

La evaluación tiene un componente estratégico: la comunicación de resultados, tanto formativos como sumativos. En esto se basa la toma de decisiones posterior. En el libro La evaluación: campo de controversias y paradojas o un nuevo lugar para la buena enseñanza (Camilloni, Celman, Litwin \& Palou de Maté, 2000, pág. 11), Litwin presenta cabalmente el tema de la evaluación como un campo de controversias, con énfasis en las decisiones que se habilitan a partir de la información que arroja. Tanto, que se cuestiona acerca del rol de la evaluación en la nueva agenda de la Didáctica: tema central, periférico o borde. Plantea esta pregunta por la paradoja del insuficiente tratamiento del tema de la evaluación en la literatura especializada, a pesar de su alta valoración y reconocimiento. Retoma de Bruner (1997) la idea de que la construcción de un objeto es perspectivista, o sea "toma la forma de la perspectiva con la que se lo mire". Esta perspectiva, en un objeto tan complejo como una estrategia de enseñanza, le da una importancia fundamental a la comunicación, ya que la evaluación tomaría la forma de un proceso de diálogo, comprensión y mejora continua (Santos Guerra, 1993). 
Cabe preguntarse, entonces ¿a quiénes les sería de utilidad el resultado del seguimiento del trabajo colaborativo mediado por tecnología digital?. Básicamente, se encuentran tres actores, componentes de la situación educativa mediada, que mejorarían su actividad con esta información: a.- el o los docentes, para contar con más información enriquecida que les permita optimizar las decisiones previas para el diseño de la experiencia, la planificación de la intervención en el trabajo grupal y las propias estrategias de intervención; b.- al propio grupo, para poder tomar decisiones de proceso que hagan más eficiente y valiosa la tarea y c.- a los diseñadores y desarrolladores de las herramientas tecnológicas, para mejorar el entorno en el que las actividades colaborativas se encuentran inmersas. Se muestran, en la figura 22, el tipo de información recuperada, las disciplinas que echan luz para su interpretación y los actores que toman decisiones a partir de la información obtenida (tomado y modificado de Dimitrakopoulou, Petrou, Martínez, Marcos, Vassilis Kollias, et al., 2006).

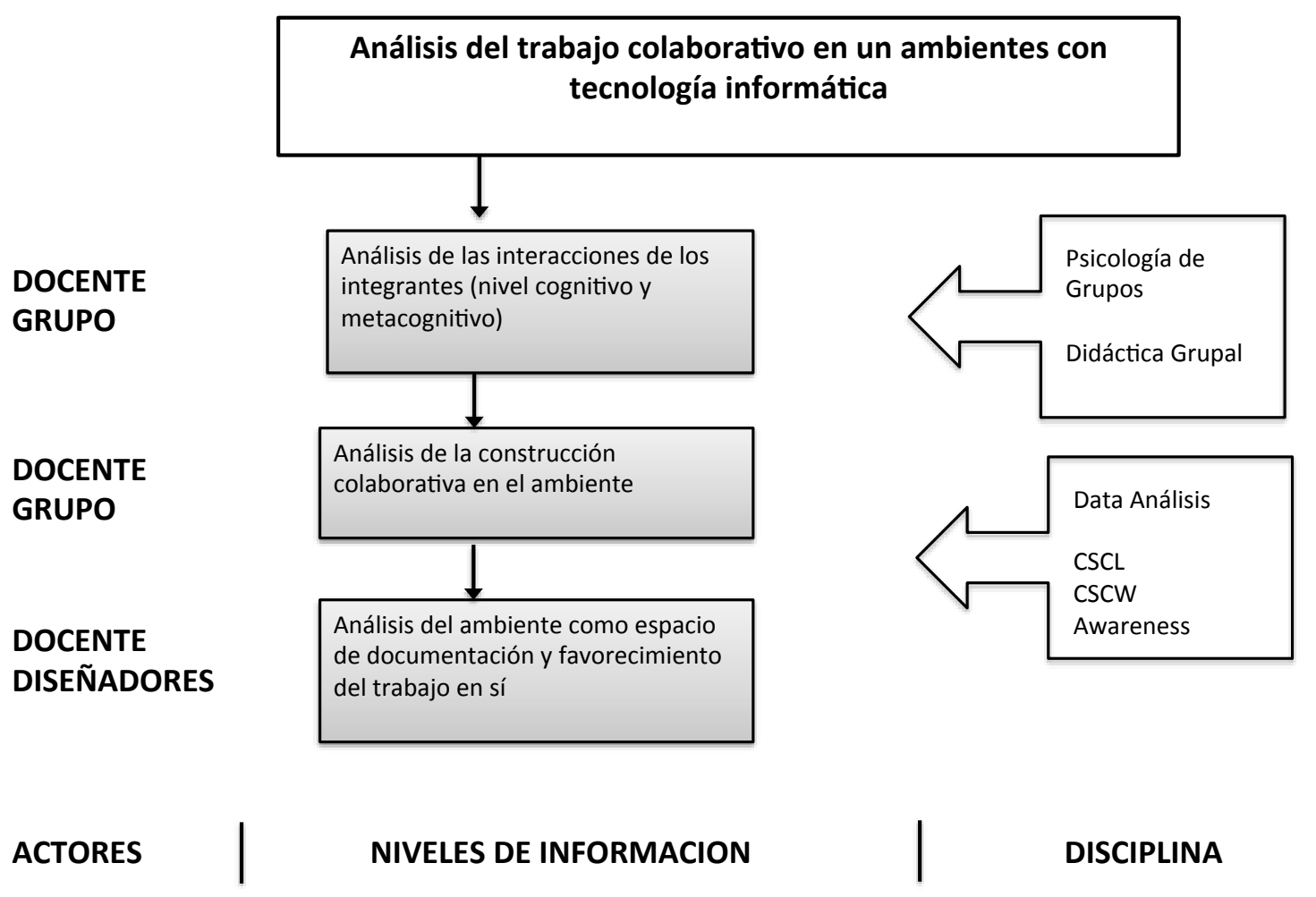

Figura 22: Actores impactados por la información de entornos virtuales colaborativo con tecnología informática (Tomado y modificado de Dimitrakopoulou et al., 2006)

\subsubsection{Docentes y / o tutores}

Vale comenzar aclarando que, a los efectos de esta subsección, serán equivalentes los roles de docente y tutor. Si bien la literatura sobre Educación a Distancia marca diferencias respecto de la experticia en el contenido a enseñar, las competencias de comunicación y hasta el manejo de las herramientas tecnológicas, se hará foco en este caso en la tarea que los unifica: las estrategias de atención a los estudiantes.

Para los docentes resulta valiosa toda información que pueda recuperarse del proceso de aprendizaje generado a partir de su propuesta de enseñanza. Según Constantino (2010), la enseñanza efectiva implica una recreación o reconstrucción del conocimiento, en cualquiera de sus formas. Esto se produce en la interacción comunicativa didáctica, y un campo propicio para su realización son los escenarios virtuales. 
Entonces, la información recolectada acerca de la interacción en los escenarios colaborativos tecnológicos podría permitirle a los docentes tomar decisiones en variados campos, según se presentan en la tabla 8 .

\begin{tabular}{|c|c|}
\hline $\begin{array}{l}\text { CAMPOS DE } \\
\text { DECISIONES }\end{array}$ & DECISIONES POSIBLES EN ESCENARIOS COLABORATIVOS \\
\hline $\begin{array}{l}\text { Diseño de la } \\
\text { propuesta de } \\
\text { enseñanza }\end{array}$ & $\begin{array}{l}\text { - Mejorar la presentación de la consigna y sus etapas. } \\
\text { - Adecuar los tiempos de trabajo de cada etapa. } \\
\text { - } \text { Adecuar los estándares de evaluación iniciales (diagnóstico). } \\
\text { - Mejorar la conformación de grupos - características de la } \\
\text { grupalidad requerida para el trabajo. }\end{array}$ \\
\hline $\begin{array}{c}\text { Implementación de la } \\
\text { propuesta }\end{array}$ & $\begin{array}{l}\text { - Reconocer los tipos de alumnos (Horton, 2000) y su modelo de } \\
\text { interacción y uso de la herramienta. } \\
\text { - Identificar los tipos de interacción (en particular la interacción } \\
\text { vicaria, que es compleja de visualizar con métodos } \\
\text { cuantitativos). } \\
\text { - Refinar el diálogo, en el caso de que el grupo se encuentre en } \\
\text { una turbulencia de la cual no pueda salir solo. } \\
\text { - Decidir la intervención }{ }^{10} \text { ante problemas suscitados en los } \\
\text { grupos, en cuanto a: } \\
\text { O Momento; } \\
\text { O Privacidad: Público (a todo el grupo o a toda la clase) o } \\
\text { privado a la/s persona/s involucrada/s; } \\
\text { Área de intervención. Contenido, planificación del } \\
\text { trabajo grupal, emocionalidad }\end{array}$ \\
\hline Evaluación & $\begin{array}{l}\text { - Refinar las estrategias de evaluación. } \\
\text { - Evaluar a grupos o estudiantes en forma personalizada } \\
\text { (respecto de contenidos, estrategias o tiempos). } \\
\text { - Diseñar actividades remediales }{ }^{11} \text {. }\end{array}$ \\
\hline
\end{tabular}

Tabla 8: Utilidad de la información del trabajo colaborativo para los docentes

\subsubsection{Grupo en sí}

Se deberá volver en este punto sobre la dimensión individuo-grupo ya tratada en el capítulo 3. En el caso del individuo, disponer de un modelo que le permita visualizar cómo está resultando el trabajo colaborativo podría favorecer su proceso de autoevaluación formativa y de heteroevaluación formativa también, sobre sus compañeros. Algunos de estos temas han sido presentados en el capítulo 2, en el componente de autorregulación de la teoría de Distancia Transaccional (Moore, 1972). Además, le permitiría volver sobre las etapas del trabajo y su cumplimiento en el tiempo. En la tabla 9 se presentan los puntos fundamentales de este aporte, en forma de preguntas disparadoras para los integrantes del grupo, retomando los componentes constitutivos de un grupo que se han expuesto en el capítulo 3 de esta tesis.

\footnotetext{
${ }^{10}$ Se entiende el concepto de intervención didáctica como la acción proactiva docente con la forma de estrategia, método, procedimiento, etc. que se propone resolver un problema, mejorar un aspecto de la experiencia de aprendizaje o realizar una innovación en su propuesta de enseñanza. (Extraido y modificado de Ramírez \& Noguera, 1999).

${ }^{11}$ Una actividad remedial es una actividad que sirve para que un estudiante o grupo de estudiantes dispongan de una instancia de recuperación de una competencia no lograda mediante la actividad original. Por lo tanto, tiene que ser diseñada con objetivo equivalente a la actividad inicial. (Extraído y modificado de Penzo, Fernández, García, Gros, Pagès, Roca \& Vendrell, 2010).
} 


\begin{tabular}{|c|c|c|}
\hline \multirow{2}{*}{$\begin{array}{c}\text { AREAS DE } \\
\text { PLANIFICACION }\end{array}$} & \multicolumn{2}{|c|}{ PREGUNTAS DISPARADORAS EN LOS NIVELES INDIVIDUO Y GRUPO } \\
\hline & Individuo & Grupo \\
\hline Planificación & $\begin{array}{l}\text { ¿Tuve injerencia en la planificación del } \\
\text { trabajo colaborativo? }\end{array}$ & $\begin{array}{l}\text { ¿Hay una correcta planificación del } \\
\text { trabajo colaborativo, considerando sus } \\
\text { fases? }\end{array}$ \\
\hline $\begin{array}{l}\text { Presentación e } \\
\text { intercambio de } \\
\text { información }\end{array}$ & $\begin{array}{l}\text { ¿Pude presentar mi punto de vista de } \\
\text { manera eficiente? } \\
\text { ¿Tengo feedback de que he sido } \\
\text { comprendido? } \\
\text { ¿Tengo la suficiente experticia } \\
\text { (comunicacional y de uso de la } \\
\text { herramienta/s como para } \\
\text { comunicarme? }\end{array}$ & $\begin{array}{l}\text { ¿Todas las líneas temáticas necesarias } \\
\text { para resolver el problema han sido } \\
\text { consideradas? } \\
\text { ¿Es equivalente el desarrollo de todas } \\
\text { ellas? }\end{array}$ \\
\hline $\begin{array}{l}\text { Coordinación/ } \\
\text { Roles }\end{array}$ & $\begin{array}{l}\text { ¿Estoy cumpliendo el rol que mejor me } \\
\text { hace sentir y para el que creo que } \\
\text { tengo mejores competencias? }\end{array}$ & $\begin{array}{l}\text { ¿Qué roles se están cumpliendo y qué } \\
\text { falta? } \\
\text { ¿Cómo se muestran mis compañeros } \\
\text { en el trabajo en grupo? ¿Qué roles } \\
\text { aparecen? (Horton, 2010) }\end{array}$ \\
\hline Tiempo & $\begin{array}{l}\text { ¿Estoy haciendo un buen uso del } \\
\text { tiempo? }\end{array}$ & $\begin{array}{l}\text { ¿Se está cumpliendo con los tiempos } \\
\text { planificados? }\end{array}$ \\
\hline Compromiso & $\begin{array}{l}\text { ¿Muestro un nivel de compromiso } \\
\text { adecuado a la tarea? }\end{array}$ & $\begin{array}{l}\text { ¿Todos los miembros del grupo } \\
\text { muestran un nivel de compromiso } \\
\text { equivalente? }\end{array}$ \\
\hline
\end{tabular}

Tabla 9: Utilidad de la información del trabajo colaborativo para el individuo y el grupo

\subsubsection{Diseñadores de ambientes colaborativos y herramientas}

Existe consenso respecto de la posibilidad de la tecnología digital de facilitar tanto la mediación como el registro de los eventos del proceso de construcción colaborativa, para su recuperación posterior. De esta forma, la experiencia de colaboración terminaría beneficiando a todas las partes: estudiantes, docentes y diseñadores. (Murcia, 2004; Roschelle, Pea, Gordin \& Means, 2001).

La mediación tecnológica no sólo origina cambios en la forma cómo se estructura la organización de la enseñanza, sino que también reporta beneficios en el aprendizaje de los estudiantes. Estos últimos pueden resumirse en: a.- habilidades de alto orden de pensamiento crítico (Roschelle et al., 2001), b.- autonomía en el aprendizaje y colaboraciones más efectivas (Tatar, Roschelle, Vahey \& Penuel, 2003) y c.- habilidades sociales personales y de grupo (Lucero, Chiarani \& Pianucci, 2003).

Las herramientas tecnológicas permiten visibilizar transacciones entre los individuos de un grupo que, antes de la tecnología digital, quedaban invisibilizadas. Como en un telar, es posible volver sobre cada hilo y hacer una y otra vez el recorrido de principio a fin, no sólo en solitario sino en su vinculación con los demás. Si bien no es sencillo graficar esta complejidad, un esquema posible se presenta en la figura 23, tomada de Kharrufa (2010). 


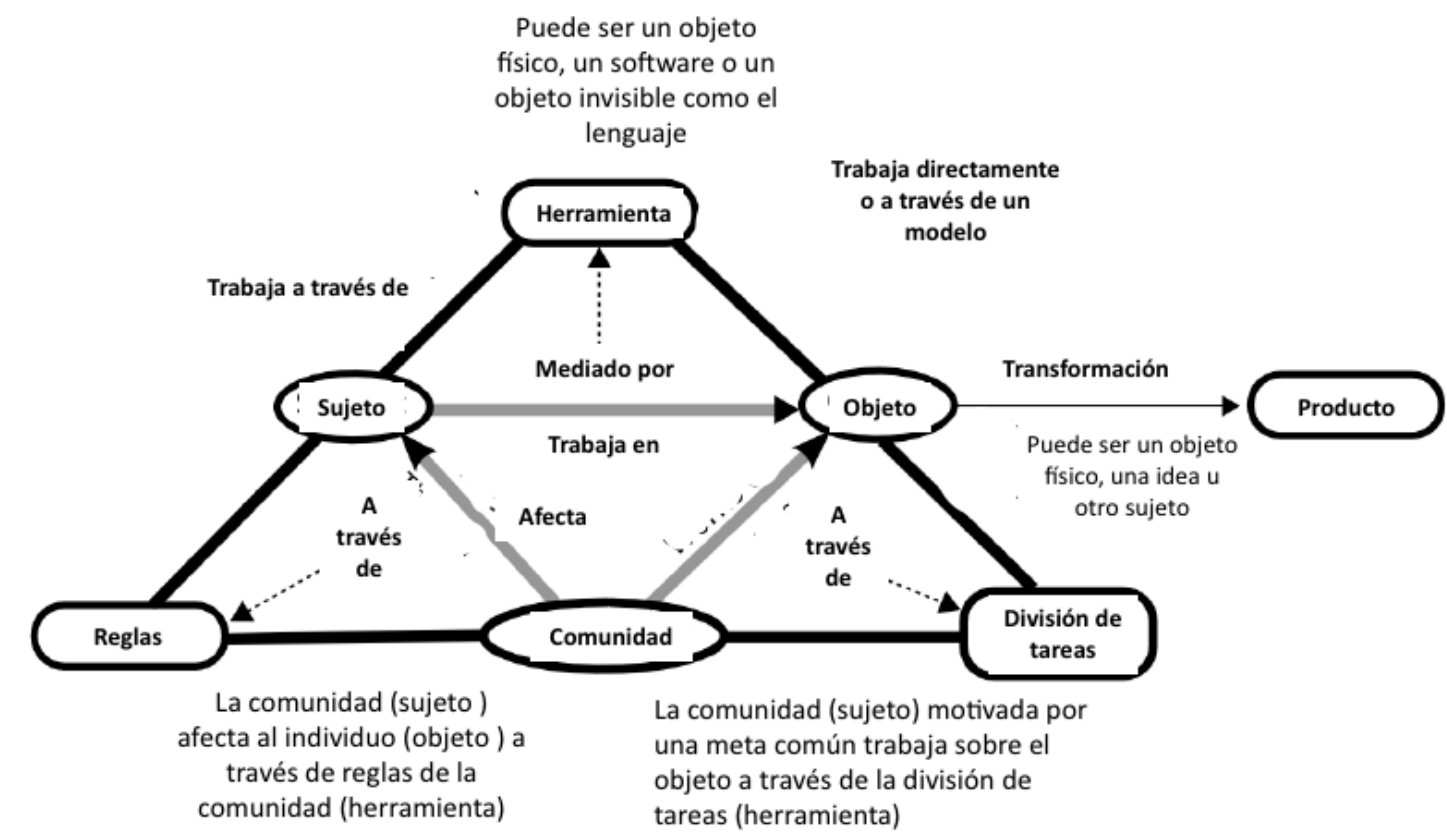

Figura 23: Estructura de una actividad colaborativa en un ambiente mediado por tecnología informática (Kharrufa, 2010. Modificado de Kuutti, 1995)

Este esquema muestra cómo funcionan los sujetos en solitario, trabajando con las herramientas y tareas propias, cómo trabaja la comunidad, que establece reglas orientadas a metas comunes para funcionar, y cómo se produce la división de tareas, mediadas por las herramientas, para arribar a un producto en común.

Para delinear la importancia y utilidad que tiene para los diseñadores la obtención de información del proceso colaborativo, se retomará el aporte de Dimitrakopoulou et al. (2006, pág. 49) relacionado con lo que la autora denomina nivel de asistencia del software, entendido como el impacto que tiene el diseño del software en el trabajo colaborativo. Una tensión entre cuánto el grupo puede modificar la aplicación o el software y/o cuánto el software puede modificar el trabajo del grupo. Este nivel de asistencia podría implementarse en:

- Presentación y sostenimiento de la tarea.

- Pistas cognitivas (qué sigue en la realización de la tarea) y metacognitivas (cómo organizar la tarea en general y el próximo paso en particular).

- Logros: cuántos, cuáles y en qué tiempo.

- Relación con la planificación: tareas pendientes y tiempo disponible.

- Manejo del tiempo.

- Performance (cuánto se ha realizado de lo esperado por la propuesta de trabajo y por el entorno) según estándares predefinidos.

En línea con el concepto de nivel de asistencia de Dimitrakopoulou se instala otro tema clave en el diseño de ambientes colaborativos: el group awareness. El término awareness podría entenderse como conciencia del grupo al ser informado [por la herramienta] acerca de su desempeño (Gross, Stary \& Totter en Bodemer, 2011). En el campo educativo, las experiencias de awareness han tomado como modelo las relaciones docente-alumno y alumno-alumno de los ambientes de enseñanza cara a cara, sumado a la idea de reduced context cues (reducción de señales del contexto). Esta expresión hace alusión a las diferencias de conciencia (o de posibilidades de generar conciencia) que tiene a su favor un buen docente presencial, respecto de 
un ambiente de tecnología digital (Kiesler, Siegel \& McGuire, 1984 en Bodemer, 2011). A simple vista se podría acordar con la idea de las enormes posibilidades de la comunicación cara a cara, aunque los ambientes de tecnología informática guardan ventajas propias respecto del awareness en el aprendizaje en general, y en el trabajo colaborativo en particular. Estas ventajas estarían vinculadas con su capacidad para registrar, guardar y organizar información para su recuperación posterior y su las posibilidades de lenguaje multimedial, entre otras.

\subsection{Indicadores del trabajo grupal colaborativo}

En este apartado se toman en cuenta dos categorías de indicadores, coincidentes con las miradas teóricas acerca de la conformación de un grupo colaborativo: el aporte de cada individuo y la construcción del grupo como entidad colectiva indisoluble.

\subsubsection{Indicadores del aporte individual al grupo}

Diversos autores han trabajado en la definición, descripción y operacionalización de indicadores para describir, valorar e intentar mejorar el trabajo colaborativo.

Gunawardena, Lowe \& Anderson (1997) e Ingram \& Hathorn (2004) aparecen entre los principales referentes en este tema. Las dimensiones de análisis citadas en sus principales trabajos podrían ser clasificadas de la siguiente forma:

- Estructural

- Social

- Intervenciones del docente o tutor

- Intervenciones de los alumnos

- Intervenciones del grupo

La dimensión estructural está referida a la sintaxis, la semántica, la argumentación como unidad comunicativa. Esta dimensión se abordará más adelante con el aporte de Baker (en Spermon, Schouten \& van den Hoven, 2014) bajo la denominación de grounding. En el caso de trabajo colaborativo mediado por tecnología informática, esta dimensión incluye el conocimiento de la herramienta. En la dimensión social, se integran las reglas que rigen la comunicación: la cantidad y tipos de mensajes que se intercambien entre los miembros de un grupo. Las intervenciones del docente o tutor pueden clasificarse en:

- Intervenciones de organización: tienen la finalidad de manejar los tiempos asignados a cada actividad, así como informar/acordar sobre los espacios habilitados para la interacción.

- Intervenciones de información: utilizadas para exponer contenidos conceptuales, presentar las tareas a realizar, o bien proporcionar información acerca de aspectos administrativos del curso.

- Intervenciones de feedback: tienen por finalidad proporcionar la retroalimentación, a causa de alguna consulta o de una tarea entregada.

- Intervenciones afectivas: utilizadas para dinamizar el debate, fomentando las intervenciones de los alumnos.

Las intervenciones de los alumnos pueden ser, muchas veces, reflejo de las intervenciones del docente. Podrían ser: 
- Intervenciones en respuesta al profesor;

- Intervenciones para efectuar aportes espontáneos;

- Intervenciones de pedido de información sobre alguna cuestión concreta;

- Intervenciones para solicitar ayuda;

- Intervenciones para suscitar la participación de los compañeros;

- Intervenciones para responder al planteo de un compañero.

Finalmente, las intervenciones del grupo son las que realmente soportan el trabajo colaborativo:

- Intervenciones de organización para realizar la tarea;

- Intervenciones de avance en la elaboración de una respuesta;

- Intervenciones de aceptación de la respuesta elaborada por el grupo;

- Intervenciones de socialización.

Bacino, Massa \& Zangara (2015) retoman los trabajos de Casanova Uribe (2008) y Beaufait, Lavin \& Tomei (2008) y construyen indicadores para el concepto de interdependencia positiva presentado por Driscoll \& Vergara, A. (1997) (se puede volver sobre estos conceptos en el capítulo 3 de esta tesis). Los indicadores que se definen son:

- Contribuye: se relaciona con el compromiso individual para la resolución del problema común.

- Propone: se refiere al aporte realizado con la intención de organizar el trabajo conjunto.

- Solicita: hace referencia al requerimiento o solicitud de aporte que realiza un integrante del grupo para con los otros miembros del grupo.

- Consulta: demanda de información, aclaración, opinión o asesoramiento de un miembro del grupo hacia los otros, relacionada con la resolución del problema o con la organización de las tareas grupales.

- Aclara: la aclaración puede producirse ante una consulta efectuada por otro u otros miembros del grupo o por intervención directa con el fin de especificar conceptos o planteos realizados.

Esta perspectiva de análisis posibilitaría entender cuánto y de qué forma cada miembro de un grupo aporta para la construcción grupal. Estos indicadores no permitirían, todavía, avanzar hacia cómo se construye la colaboración.

\subsubsection{Síntesis de indicadores desde la perspectiva individual y su contribución al grupo}

Como cierre de esta sección se presenta una integración de indicadores para la perspectiva individuo-grupo que incluye:

- La propia definición de trabajo colaborativo y sus etapas

- Las categorías de Gunawardena, et al. (1997) e Ingram \& Hathorn (2004) en las dimensiones estructural y social. Se consideran los tipos de mensajes como referidos a la organización, al contenido y a la afectividad. 
- Los indicadores construidos por Bacino et al. (2015) sobre el concepto de interdependencia positiva de Driscoll \& Vergara.

Se presenta la integración de indicadores propios en la tabla 10.

\begin{tabular}{|c|c|c|c|c|}
\hline \multirow{2}{*}{\multicolumn{2}{|c|}{$\begin{array}{l}\text { FASES DEL } \\
\text { TRABAJO }\end{array}$}} & \multicolumn{3}{|c|}{ INDICADORES (por tipo de mensaje) } \\
\hline & & REFERIDO A LA ORGANIZACION & $\begin{array}{c}\text { REFERIDO AL } \\
\text { CONTENIDO } \\
\end{array}$ & $\begin{array}{l}\text { REFERIDO A LA } \\
\text { AFECTIVIDAD }\end{array}$ \\
\hline \multicolumn{2}{|c|}{$\begin{array}{l}\text { TRABAJO } \\
\text { INDIVIDUAL }\end{array}$} & Pregunta por la consigna & Comparte & $\begin{array}{l}\text { Muestra } \\
\text { contento/descontento }\end{array}$ \\
\hline \multirow{12}{*}{ 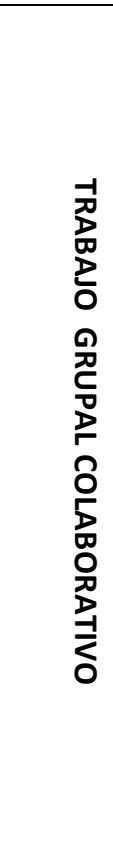 } & \multirow{4}{*}{$\frac{\bar{\Sigma}}{\overline{0}}$} & Organiza tareas & \multirow[t]{4}{*}{ Repasa la consigna } & Busca acuerdos \\
\hline & & Organiza responsables & & Motiva \\
\hline & & \multirow[t]{2}{*}{ Organiza tiempos } & & Anima a que se expresen \\
\hline & & & & $\begin{array}{l}\text { Se refiere al grupo } \\
\text { usando pronombres } \\
\text { inclusivos }\end{array}$ \\
\hline & \multirow{8}{*}{$\begin{array}{l}\text { 员 } \\
\text { D } \\
\text { 艿 } \\
0 \\
\frac{0}{0}\end{array}$} & Reorganiza tareas & Pregunta & Anima \\
\hline & & Reorganiza tiempos & $\begin{array}{l}\text { Comparte lo que hizo o } \\
\text { sabe }\end{array}$ & Felicita \\
\hline & & Reorganiza responsables & Pide aclaraciones & $\begin{array}{l}\text { Explica por qué se ha } \\
\text { llegado a un punto } \\
\text { (buscando mediar) }\end{array}$ \\
\hline & & $\begin{array}{l}\text { Documenta los avances del } \\
\text { grupo }\end{array}$ & Aclara & $\begin{array}{l}\text { Toma en cuenta quiénes } \\
\text { no participaron }\end{array}$ \\
\hline & & $\begin{array}{l}\text { Hace síntesis parciales para } \\
\text { avanzar }\end{array}$ & $\begin{array}{l}\text { Pone lo hecho a } \\
\text { consideración de todos }\end{array}$ & \multirow[t]{4}{*}{ Agradece } \\
\hline & & $\begin{array}{l}\text { Retoma el hilo de la } \\
\text { planificación acordada }\end{array}$ & \multirow[t]{3}{*}{ Presenta otra opinión } & \\
\hline & & Planifica el siguiente paso. & & \\
\hline & & Busca estrategias de ayuda & & \\
\hline & \multirow{6}{*}{ 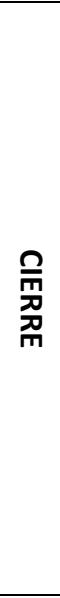 } & Busca consenso: voto & $\begin{array}{l}\text { Cierra las ideas. Incluye } \\
\text { las de todos en ideas } \\
\text { inclusoras }\end{array}$ & $\begin{array}{l}\text { Recuerda los pasos } \\
\text { exitosos del trabajo }\end{array}$ \\
\hline & & Busca consenso: mayoría & $\begin{array}{l}\text { Trabaja para completar } \\
\text { lo que falta (temas, } \\
\text { gráficos, diccionario), } \\
\text { etc. }\end{array}$ & $\begin{array}{l}\text { Retoma lo que cada uno } \\
\text { hizo }\end{array}$ \\
\hline & & $\begin{array}{l}\text { Busca consenso por tiempo } \\
\text { (Hasta tal momento hay tiempo } \\
\text { para) }\end{array}$ & $\begin{array}{l}\text { Recupera el formato de } \\
\text { la entrega. Lo compara } \\
\text { con lo hecho. }\end{array}$ & $\begin{array}{l}\text { Toma y hace tomar } \\
\text { conciencia del esfuerzo } \\
\text { que llevaron adelante }\end{array}$ \\
\hline & & $\begin{array}{l}\text { Recuerda la consigna, con su } \\
\text { formato y su fecha de entrega }\end{array}$ & Propone repasar & $\begin{array}{l}\text { Da ánimo en el manejo } \\
\text { del tiempo: ¡Falta poco! }\end{array}$ \\
\hline & & Organiza el repaso & Revisa antes de & Avisa que se entregó. Da \\
\hline & & Prepara la entrega y la realiza & entregar & idea de tarea cumplida \\
\hline \multirow{2}{*}{\multicolumn{2}{|c|}{$\begin{array}{l}\text { FASES DEL } \\
\text { TRABAJO }\end{array}$}} & \multicolumn{3}{|c|}{ INDICADORES (por tipo de mensaje) } \\
\hline & & REFERIDO A LA ORGANIZACION & $\begin{array}{l}\text { REFERIDO AL } \\
\text { CONTENIDO }\end{array}$ & $\begin{array}{c}\text { REFERIDO A LA } \\
\text { AFECTIVIDAD } \\
\end{array}$ \\
\hline \multirow{2}{*}{\multicolumn{2}{|c|}{$\begin{array}{l}\text { CIERRE DE } \\
\text { PROCESO Y } \\
\text { AUTOEVALUA- } \\
\text { CION }\end{array}$}} & $\begin{array}{l}\text { Describe lo trabajado por el } \\
\text { grupo }\end{array}$ & & $\begin{array}{l}\text { Da idea y mensaje de } \\
\text { tarea cumplida }\end{array}$ \\
\hline & & $\begin{array}{l}\text { Analiza qué hizo cada uno y } \\
\text { cómo }\end{array}$ & & Felicita \\
\hline
\end{tabular}

Tabla 10: Tipos de mensajes. Integración de indicadores en el aporte de cada miembro al trabajo 


\subsubsection{Indicadores que la tecnología permite visibilizar: cómo el grupo construye}

La tecnología convierte en visible, documentable y repetible el trazo de la actividad grupal que quedaría invisible e inasible, sobre todo en los escenarios asincrónicos de comunicación. La disciplina que se ha ocupado de este estudio en el trabajo colaborativo es la denominada CSCL (Computer-Supported Collaborative Learning). Se trata de un área interdisciplinaria, que incluye la Tecnología Educativa, Psicología de la Educación, la Sociología, la Psicología Cognitiva y la Psicología Social. Además, integra las miradas sustantivas de la tecnología como espacio y lenguaje (Simon, 1969; Quintanilla, 1988; Pinch \& Bijker (1984); Latour, 1992; Ciapuscio, 1996; Fainholc, 1990 y 2010) y el propio desarrollo de software para el trabajo colaborativo. Un aporte interesante acerca de sus aplicaciones en educación puede encontrarse en la retrospectiva de Goodyear, Jones \& Thompson (2014).

Según Cabrera Murcia "el marco metodológico del CSCL permite entender la actividad [colaborativa] que se genera en esta forma de trabajo, como interdependiente de los otros elementos que se requieren para que exista actividad. Tanto la comunidad (los otros) como las herramientas (computador) son fuentes que el estudiante (agente) coordina durante el desarrollo de la actividad (objetivo). Su acción y la de los otros, se ve modificada por las reglas y los roles que emergen en la interacción. Finalmente como las relaciones que se establecen son bidireccionales, el resultado pueda transformarse en una nueva actividad o en un nuevo artefacto" (Cabrera Murcia, 2004, pág. 3). Nardi (1996) clarifica lo explicitado mediante la representación gráfica que de la figura 24.

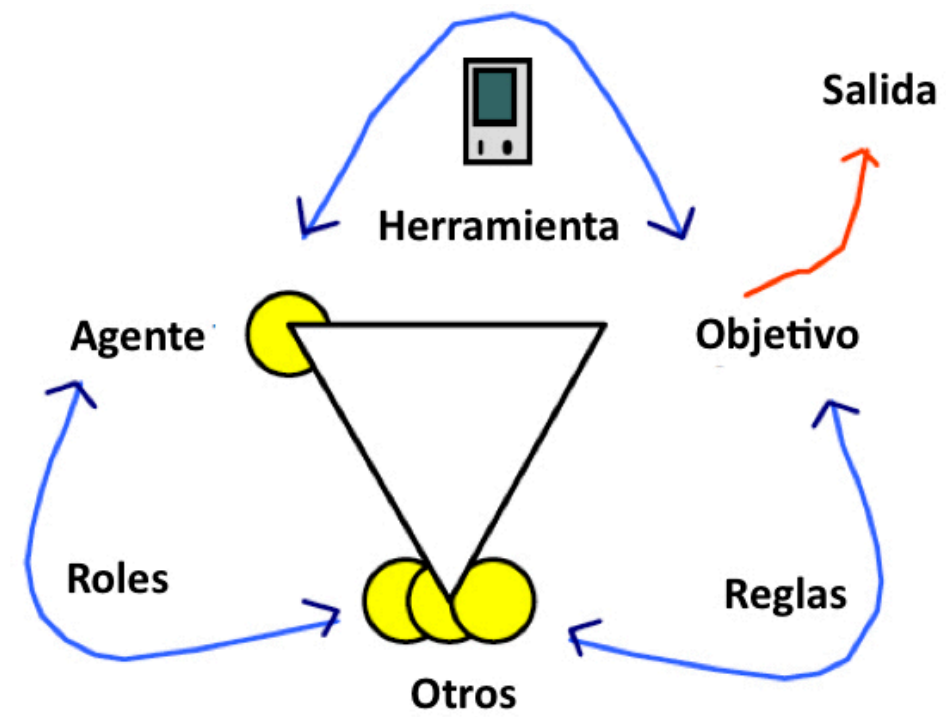

Figura 24: Presentación del concepto de CSCL en sus inicios (Nardi, 1996)

En la tabla 11 se reseñan las principales investigaciones que la literatura presenta respecto de la colaboración en entornos tecnológicos, las metodologías de seguimiento y los indicadores utilizados. Se presenta, en orden cronológico descendente, la siguiente información: la fuente de información, los autores de la misma, las condiciones experimentales, los indicadores y, en algunos casos, el uso de la información posterior. La base del estudio fue extraída de Dimitrakopoulou et al., 2006 y actualizada con reseñas propias de esta tesis. 


\begin{tabular}{|c|c|c|c|c|}
\hline $\begin{array}{c}\text { Fuente/ } \\
\text { Investigación }\end{array}$ & $\begin{array}{c}\text { Condiciones } \\
\text { experimentales }\end{array}$ & Metodología & Indicadores & $\begin{array}{c}\text { Conclusiones / Trabajos } \\
\text { posteriores }\end{array}$ \\
\hline $\begin{array}{l}\text { Restrepo, C.; } \\
\text { Jiménez, L.; Hurtado, } \\
\text { J.; Collazos, C. } \\
\text { Grupo IDIS } \\
\text { Colombia } \\
(2017)\end{array}$ & $\begin{array}{l}\text { Se propone coAVISPA, } \\
\text { una herramienta para } \\
\text { medir y visualizar } \\
\text { aspectos colaborativos a } \\
\text { través de la } \\
\text { identificación de } \\
\text { patrones de } \\
\text { colaboración en } \\
\text { modelos de procesos de } \\
\text { desarrollo de software. }\end{array}$ & 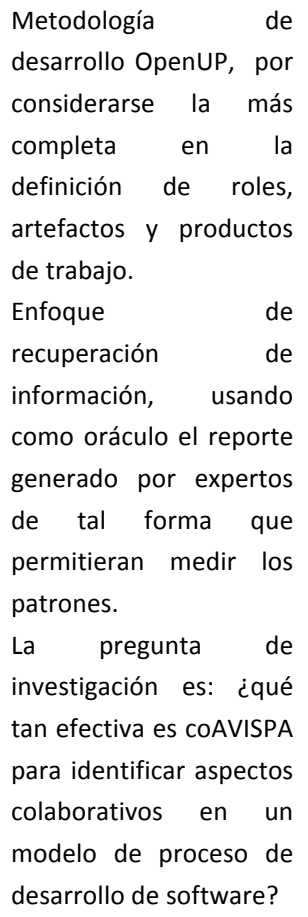 & $\begin{array}{c}\text { Patrones de Identificación } \\
\text { de Aspectos Colaborativos } \\
\text { - Patrón Estrella: } \\
\text { - Patrón } \\
\text { - Divergencia: } \\
\text { Patrón Isla }\end{array}$ & $\begin{array}{l}\text { Se recupera información } \\
\text { de la colaboración } \\
\text { opiniones de los expertos } \\
\text { en el uso de coAVISPA y se } \\
\text { concluye la efectividad y } \\
\text { por tanto de la capacidad } \\
\text { de coAVISPA para } \\
\text { identificar puntos } \\
\text { sensibles a la colaboración }\end{array}$ \\
\hline $\begin{array}{l}\text { Charczuk, N., } \\
\text { Rodríguez, D., \& } \\
\text { García Martínez, R. } \\
\text { (2015) }\end{array}$ & $\begin{array}{l}\text { Cuatro alumnos que } \\
\text { trabajan en grupo por } \\
\text { mensajes de correo } \\
\text { electrónico. }\end{array}$ & $\begin{array}{l}\text { Análisis de interacciones } \\
\text { por correo electrónico. }\end{array}$ & $\begin{array}{l}\text { Matriz de interacciones en } \\
\text { base a los indicadores de } \\
\text { interacción de los } \\
\text { participantes y roles o } \\
\text { status. }\end{array}$ & $\begin{array}{l}\text { Continúa el trabajo } \\
\text { probando las métricas con } \\
\text { grupos más numerosos. }\end{array}$ \\
\hline $\begin{array}{l}\text { Spermon, M., } \\
\text { Schouten, I., \& van } \\
\text { den Hoven, E. (2014) }\end{array}$ & $\begin{array}{l}\text { CASO 1: Juego para } \\
\text { niños en una tabletop } \\
\text { (Totti game). } \\
\text { CASO 2: Juego para } \\
\text { niños filmados durante } 6 \\
\text { sesiones. }\end{array}$ & $\begin{array}{l}\text { Observación no } \\
\text { participante. } \\
\text { Análisis de significado de } \\
\text { las sesiones filmadas. }\end{array}$ & $\begin{array}{l}\text { CASO 1: Grados de } \\
\text { colaboración de Kahn \& } \\
\text { Mentzer: acciones e } \\
\text { intercambio de } \\
\text { información. } \\
\text { CASO 2: Gestos } \\
\text { cooperativos de Morris et } \\
\text { al.: interacciones verbales } \\
\text { y gestuales. }\end{array}$ & $\begin{array}{l}\text { El diseño de ambos juegos } \\
\text { requería diferentes grados } \\
\text { de colaboración. Se } \\
\text { demostró que en diseño } \\
\text { de los juegos influyó en la } \\
\text { colaboración observada. O } \\
\text { sea que el diseño de la } \\
\text { actividad y el escenario es } \\
\text { un elemento interviniente } \\
\text { importante en la } \\
\text { colaboración resultante. }\end{array}$ \\
\hline
\end{tabular}




\begin{tabular}{|c|c|c|c|c|}
\hline $\begin{array}{c}\text { Fuente/ } \\
\text { Investigación }\end{array}$ & $\begin{array}{c}\text { Condiciones } \\
\text { experimentales }\end{array}$ & Metodología & Indicadores & $\begin{array}{c}\text { Conclusiones /Trabajos } \\
\text { posteriores }\end{array}$ \\
\hline $\begin{array}{l}\text { Martínez Maldonado, } \\
\text { R. (2014). }\end{array}$ & $\begin{array}{l}\text { Estudiantes trabajan en } \\
\text { mapas conceptuales } \\
\text { colaborativos usando } \\
\text { tabletops. }\end{array}$ & $\begin{array}{l}\text { Estudio de casos de } \\
\text { pequeños grupos ( } 3 \\
\text { personas) trabajando } \\
\text { frente a la tabletop. }\end{array}$ & $\begin{array}{l}\text { - Cantidad y distribución } \\
\text { de participación. } \\
\text { - Sinergia entre el habla y } \\
\text { el tacto. } \\
\text { - Trabajo en paralelo y en } \\
\text { turnos. } \\
\text { - Progreso de la tarea. } \\
\text { - Nivel de colaboración. } \\
\text { - Uso de los artefactos. }\end{array}$ & $\begin{array}{l}\text { Los estudios demuestran } \\
\text { que el análisis de la } \\
\text { información recogida de } \\
\text { las interacciones según } \\
\text { indicadores resulta un } \\
\text { elemento de interés para } \\
\text { la intervención docente }\end{array}$ \\
\hline $\begin{array}{l}\text { Álvarez Ferrando, A., } \\
\text { Kuz, A., \& Falco, M. } \\
\text { (2013) }\end{array}$ & $\begin{array}{l}\text { Grupo de séptimo año } \\
\text { de la educación } \\
\text { secundaria técnica, de la } \\
\text { ETT № 5, de La Plata. } \\
\text { Actividad de foro vía } \\
\text { Moodle para determinar } \\
\text { requerimientos del } \\
\text { Sistema de } \\
\text { Estacionamiento } \\
\text { Medido de la Ciudad de } \\
\text { La Plata. }\end{array}$ & $\begin{array}{l}\text { Análisis de grupo } \\
\text { completo, para } \\
\text { determinar clima del } \\
\text { aula mediante ARS } \\
\text { (Análisis de Redes } \\
\text { Sociales). }\end{array}$ & $\begin{array}{l}\text { Indicadores de clima del } \\
\text { aula: } \\
\text {-Grado de centralidad. } \\
\text {-Grado de intermediación. } \\
\text {-Comunidades } \\
\text { (o grupos). } \\
\text {-Fuerza de los vínculos. }\end{array}$ & $\begin{array}{l}\text { Las herramientas de ARS } \\
\text { brindan una contribución } \\
\text { importante, ya que } \\
\text { permite representar } \\
\text { interacciones. Se seguirán } \\
\text { realizando estudios con } \\
\text { alumnos de PostGrado. }\end{array}$ \\
\hline Cenich, G. (2007) & $\begin{array}{l}\text { Alumnos del } \\
\text { Profesorado } \\
\text { en Informática de la } \\
\text { Universidad Nacional del } \\
\text { Centro (Argentina). Se } \\
\text { analizó la colaboración } \\
\text { en una actividad de foro. }\end{array}$ & $\begin{array}{l}\text { Actividad en foro y chat. } \\
\text { Registro de } \\
\text { los mensajes publicados } \\
\text { por todos los miembros } \\
\text { del grupo. }\end{array}$ & $\begin{array}{l}\text { Modelo de Gunawardena } \\
\text { et al. (1997) } \\
\text { "Interaction analysis } \\
\text { model" } \\
\text { 1. Comparte. } \\
\text { 2. Explora. } \\
\text { 3. Negocia. } \\
\text { 4.Evalua. } \\
\text { 5. Acuerda. }\end{array}$ & $\begin{array}{l}\text { Diferencias de reflexión de } \\
\text { mensajes entre foro y chat } \\
\text { (producidas por la } \\
\text { sincronía - asincronía) } \\
\text { Relación entre la actividad } \\
\text { colaborativa y el tipo de } \\
\text { consigna. }\end{array}$ \\
\hline $\begin{array}{l}\text { Cenich y Santos } \\
(2006)\end{array}$ & $\begin{array}{l}\text { Alumnos del } \\
\text { Profesorado en } \\
\text { Informática de la } \\
\text { Universidad Nacional del } \\
\text { Centro (Argentina). }\end{array}$ & $\begin{array}{l}\text { Actividad en un foro en } \\
\text { el marco de la } \\
\text { asignatura "Didáctica de } \\
\text { la Informática II" en la } \\
\text { elaboración de una } \\
\text { propuesta educativa } \\
\text { grupal }\end{array}$ & $\begin{array}{l}\text { - Nivel de participación: } \\
\text { cantidad de mensajes } \\
\text { - Identificación de aportes } \\
\text { individuales: consultar al } \\
\text { grupo, compartir } \\
\text { interpretaciones, } \\
\text { argumentar, acordar, } \\
\text { presentar alternativas, } \\
\text { presentar síntesis de lo } \\
\text { acordado, evaluar el } \\
\text { avance del trabajo, } \\
\text { formular propuesta de } \\
\text { trabajo } \\
\text {-Cohesión grupal }\end{array}$ & $\begin{array}{l}\text { Mayor nivel de } \\
\text { participación, más aportes } \\
\text { individuales y cohesión } \\
\text { grupal a medida que se } \\
\text { visualiza el logro del } \\
\text { objetivo final. }\end{array}$ \\
\hline $\begin{array}{l}\text { Weinberger, A., \& } \\
\text { Fischer, F. (2006). }\end{array}$ & $\begin{array}{l}\text { Seis estudiantes que } \\
\text { trabajaron } \\
\text { colaborativamente en } \\
\text { estudios experimentales } \\
\text { en Alemania. }\end{array}$ & $\begin{array}{l}\text { Análisis del discurso en } \\
\text { base al muestreo y } \\
\text { segmentación de los } \\
\text { corpus discursivos. } \\
\text { Categorías de } \\
\text { argumentación, según } \\
\text { niveles de granularidad. } \\
\text { Relaciones en cadenas } \\
\text { de argumentos. }\end{array}$ & $\begin{array}{l}\text { Enfoque multidimensional } \\
\text { para analizar el } \\
\text { conocimiento } \\
\text { argumentativo, en } 3 \\
\text { dimensiones: análisis } \\
\text { cuantitativo de la } \\
\text { participación, } \\
\text { argumentación individual y } \\
\text { construcción } \\
\text { argumentativa grupal. }\end{array}$ & $\begin{array}{l}\text { Base subjetiva en el } \\
\text { análisis de contenido } \\
\text { requerido para la } \\
\text { argumentación. } \\
\text { Importancia central de la } \\
\text { recuperación de } \\
\text { información digital en el } \\
\text { análisis de contenido. }\end{array}$ \\
\hline
\end{tabular}




\begin{tabular}{|c|c|c|c|c|}
\hline $\begin{array}{c}\text { Fuente/ } \\
\text { Investigación }\end{array}$ & $\begin{array}{c}\text { Condiciones } \\
\text { experimentales }\end{array}$ & Metodología & Indicadores & $\begin{array}{c}\text { Conclusiones /Trabajos } \\
\text { posteriores }\end{array}$ \\
\hline $\begin{array}{l}\text { Nakahara, } \\
\text { Kazaru, Shinichi, } \\
\text { Yamauchi (2005) }\end{array}$ & $\begin{array}{l}\text { Estudiantes de la } \\
\text { Universidad de Tokyo. }\end{array}$ & $\begin{array}{l}\text { Grupo experimental y } \\
\text { grupo control } \\
\text { Cuestionarios } \\
\text { Información subjetiva } \\
\text { mediante el software } \\
\text { ITree. }\end{array}$ & $\begin{array}{l}\text { Nivel de participación en } \\
\text { un foro. }\end{array}$ & $\begin{array}{l}\text { Los estudiantes se } \\
\text { preocupaban por lo } \\
\text { extenso del árbol del foro } \\
\text { (porque demostraba que } \\
\text { el indicador funcionaba } \\
\text { bien). Menos } \\
\text { preocupación por el } \\
\text { contenido. }\end{array}$ \\
\hline $\begin{array}{l}\text { Vassileva, Cheng, } \\
\text { Sun, \& Han, } \\
(2005)\end{array}$ & $\begin{array}{l}\text { Estudiantes del curso de } \\
\text { "Etica y Tecnología". } \\
\text { Nivel de grado . } 10 \\
\text { semanas. }\end{array}$ & $\begin{array}{l}\text { Encuestas de opinión. } \\
\text { Visualización de } \\
\text { performance (usando la } \\
\text { herramienta Comtella). } \\
\text { Recompensa por buenas } \\
\text { intervenciones se } \\
\text { introdujo luego de } 6 \\
\text { semanas. }\end{array}$ & Nivel de participación. & $\begin{array}{l}\text { Los estudiantes se } \\
\text { preocupaban por el } \\
\text { tamaño del círculo (que } \\
\text { mostraba el indicador). }\end{array}$ \\
\hline $\begin{array}{l}\text { Zumbach, } \\
\text { Schönemann, \& } \\
\text { Reimann, (2005) }\end{array}$ & $\begin{array}{l}\text { Estudiantes } \\
\text { universitarios conversan } \\
\text { en un escenario de } \\
\text { enseñanza sobre la } \\
\text { depresión y la anorexia } \\
\text { nerviosa por } 1 \text { hora y } \\
\text { media. }\end{array}$ & $\begin{array}{l}\text { Trabajo en parejas. Se } \\
\text { administra pre y post } \\
\text { test de conocimiento, } \\
\text { clima de la conversación } \\
\text { y respuestas individuales } \\
\text { a las preguntas. }\end{array}$ & $\begin{array}{lll}\text { Seguimiento de la } \\
\text { colaboración (por el } \\
\text { experimentador). }\end{array}$ & $\begin{array}{l}\text { La colaboración en parejas } \\
\text { mejoró los desempeños } \\
\text { individuales. }\end{array}$ \\
\hline $\begin{array}{l}\text { Mochizuki, Kato, } \\
\text { Hisamatsu, } \\
\text { Yaegashi, } \\
\text { Fujitani, Nagata, } \\
\text { Nakahara, } \\
\text { Nishimori, \& } \\
\text { Suzuki (2005) }\end{array}$ & $\begin{array}{l}\text { Futuros profesores que } \\
\text { prepararon sus } \\
\text { portfolios usaron el } \\
\text { software i-Bee. Esto } \\
\text { ocurrió de } 15 \text { a 30' } \\
\text { minutos al comienzo y al } \\
\text { final de } 7 \text { de cada } 10 \\
\text { clases de práctica. }\end{array}$ & $\begin{array}{l}\text { Videos de los } \\
\text { estudiantes trabajando, } \\
\text { mientras documentaban } \\
\text { sus ideas. Fueron } \\
\text { analizados los mensajes } \\
\text { escritos. }\end{array}$ & $\begin{array}{l}\text { Relación entre los } \\
\text { estudiantes y palabras } \\
\text { clave en los mensajes } \\
\text { online. }\end{array}$ & $\begin{array}{l}\text { I-Bee ayudó a los } \\
\text { estudiantes a visualizar los } \\
\text { temas de discusión y } \\
\text { quienes participaban en } \\
\text { ellos. }\end{array}$ \\
\hline $\begin{array}{l}\text { Vizcaino, A. } \\
\text { (2005) }\end{array}$ & $\begin{array}{l}\text { Los estudiantes } \\
\text { trabajaron en clase con } \\
\text { el programa HabiPro } \\
\text { (software de Inteligencia } \\
\text { Artificial) por el cual } \\
\text { guiaban a un estudiante } \\
\text { simulado. }\end{array}$ & $\begin{array}{l}\text { Dos pares de alumnos. } \\
\text { Uno con un estudiante } \\
\text { simulado y otro sin. }\end{array}$ & $\begin{array}{l}\text { Detección de estudiantes } \\
\text { pasivos por combinación } \\
\text { de criterios (Nro. de } \\
\text { aportes, Nro. palabras, } \\
\text { comparación del } \\
\text { rendimiento individual y } \\
\text { grupal y conversaciones } \\
\text { "off topic" (por palabra } \\
\text { clave). }\end{array}$ & $\begin{array}{l}\text { Los alumnos respondieron } \\
\text { a los comentarios del } \\
\text { estudiante simulado. }\end{array}$ \\
\hline
\end{tabular}




\begin{tabular}{|c|c|c|c|c|}
\hline $\begin{array}{c}\text { Fuente/ } \\
\text { Investigación }\end{array}$ & $\begin{array}{c}\text { Condiciones } \\
\text { experimentales }\end{array}$ & Metodología & Indicadores & $\begin{array}{c}\text { Conclusiones /Trabajos } \\
\text { posteriores }\end{array}$ \\
\hline $\begin{array}{l}\text { Van Joolingen, } \\
\text { W.R., De Jong, T., } \\
\text { Lazonder, A.W., } \\
\text { Savelsbergh, E.R. } \\
\text { \& Manlove, S. } \\
\text { (2005) }\end{array}$ & $\begin{array}{l}\text { Estudiantes secundarios } \\
\text { (de } 16 \text { a } 18 \text { años) } \\
\text { trabajaron en el } \\
\text { ambiente digital } \\
\text { colaborativo Co-Lab en } 3 \\
\text { sesiones de } 3 \text { horas en } \\
\text { total. }\end{array}$ & $\begin{array}{l}\text { Grupo experimental y } \\
\text { control, con diferentes } \\
\text { visualizaciones de la } \\
\text { herramienta. } \\
\text { El grupo control tuvo } \\
\text { acceso al Process } \\
\text { Coordinator, } \\
\text { herramienta de } \\
\text { administración sin } \\
\text { contenidos. El grupo } \\
\text { experimental tuvo } \\
\text { acceso a la herramienta } \\
\text { completa, con jerarquía } \\
\text { de objetivos, y pistas de } \\
\text { cada paso de la } \\
\text { resolución del problema. }\end{array}$ & $\begin{array}{l}\text { Visualización de la } \\
\text { planificación compartida. }\end{array}$ & $\begin{array}{l}\text { La herramienta Process } \\
\text { Coordinator se usó } \\
\text { durante la colaboración. } \\
\text { Los estudiantes pudieron } \\
\text { usar el feedback acerca de } \\
\text { su planificación para } \\
\text { mejorar el proceso. }\end{array}$ \\
\hline $\begin{array}{l}\text { Ogata \& Yano } \\
(2004)\end{array}$ & $\begin{array}{l}\text { Estudiantes japoneses } \\
\text { de grado y postgrado, en } \\
\text { una clase de inglés usan } \\
\text { dispositivos móviles con } \\
\text { el software CLUE. }\end{array}$ & $\begin{array}{l}\text { Estudiantes divididos en } \\
\text { dos grupos: unos usaron } \\
\text { CLUE y otros sólo el } \\
\text { material de la clase. La } \\
\text { evaluación consistió en } \\
\text { un cuestionario sobre } \\
\text { CLUE. }\end{array}$ & $\begin{array}{l}\text { Para un grupo: } \\
\text { representación de } \\
\text { conocimiento de } \\
\text { expresiones precisas en } \\
\text { inglés. Para el otro, cuán } \\
\text { cerca estuvieron de esa } \\
\text { precisión. }\end{array}$ & \\
\hline Jerman, (2004) & $\begin{array}{l}\text { Estudiantes de escuelas } \\
\text { secundarias trabajaron } \\
\text { con simuladores de } \\
\text { tráfico en laboratorios. }\end{array}$ & $\begin{array}{l}\text { Grupo experimental y } \\
\text { control. } \\
\text { Interacciones en } \\
\text { términos de diálogo y } \\
\text { acciones compartidas en } \\
\text { el espacio común. }\end{array}$ & $\begin{array}{l}\text { Nivel de participación en la } \\
\text { discusión y aportes a la } \\
\text { resolución del problema } \\
\text { (considerando o no la } \\
\text { evaluación contenida en la } \\
\text { consigna). }\end{array}$ & $\begin{array}{l}\text { Mejoró el indicador del } \\
\text { diálogo porque los } \\
\text { estudiantes dispusieron de } \\
\text { la información de la } \\
\text { consigna. Pero este } \\
\text { diálogo no afectó la } \\
\text { resolución del problema. }\end{array}$ \\
\hline $\begin{array}{l}\text { Zumbach, Hillers, } \\
\text { \& Reimann, } \\
\text { (2003) }\end{array}$ & $\begin{array}{l}\text { Estudiantes diseñan } \\
\text { cursos online sobre } \\
\text { diseño instruccional } \\
\text { para una compañía } \\
\text { ficticia usando la } \\
\text { plataforma Lotus Notes, } \\
\text { por dos semanas. }\end{array}$ & $\begin{array}{l}\text { Grupos contrastados. } \\
\text { Armados al azar, con } \\
\text { diferentes estrategias } \\
\text { (con y sin historias). Fue } \\
\text { administrada pre y post } \\
\text { test de conocimiento. }\end{array}$ & $\begin{array}{l}\text { Los alumnos que } \\
\text { interactuaron con historia } \\
\text { presentaron mejor } \\
\text { motivación y rendimiento. }\end{array}$ & $\begin{array}{l}\text { Las diferentes estrategias } \\
\text { de trabajo y el modo de } \\
\text { recibir feedback estaba } \\
\text { relacionado con la } \\
\text { motivación y } \\
\text { rendimiento. }\end{array}$ \\
\hline $\begin{array}{l}\text { Baker, Quignard, } \\
\text { Lund, \& Sejourne } \\
\text { (2003) }\end{array}$ & $\begin{array}{l}\text { Estudiantes de escuelas } \\
\text { secundarias trabajan con } \\
\text { el software DREW para } \\
\text { construir argumentos en } \\
\text { torno a un problema. }\end{array}$ & $\begin{array}{l}\text { Grupo experimental y } \\
\text { control. Se contrastan } \\
\text { los argumentos } \\
\text { construidos. }\end{array}$ & $\begin{array}{l}\text { Visualización de conflictos } \\
\text { en la argumentación. }\end{array}$ & $\begin{array}{l}\text { No se obtuvo información } \\
\text { significativa acerca de la } \\
\text { construcción de los } \\
\text { argumentos. }\end{array}$ \\
\hline $\begin{array}{l}\text { Zumbach, } \\
\text { Muehlenbrock, } \\
\text { Jansen, Reimann, } \\
\text { \& Hoppe, (2002) }\end{array}$ & $\begin{array}{l}\text { Discusión rápida. } \\
\text { (espacio compartido } \\
\text { para resolver un } \\
\text { problema abierto) } \\
\text { Cada persona está en } \\
\text { una sala diferente. } \\
\text { Duración de la } \\
\text { experiencia: } 2 \text { horas. }\end{array}$ & $\begin{array}{l}\text { Condiciones } \\
\text { controladas. Análisis del } \\
\text { contenido con el } \\
\text { método de pre y post } \\
\text { test. }\end{array}$ & $\begin{array}{l}\text { Motivación del grupo a } \\
\text { través del análisis de las } \\
\text { motivaciones individuales } \\
\text { (a través de auto } \\
\text { evaluación). }\end{array}$ & $\begin{array}{l}\text { Se incrementó el } \\
\text { comportamiento } \\
\text { interactivo, pero el post } \\
\text { test no mostró mejor } \\
\text { rendimiento. }\end{array}$ \\
\hline
\end{tabular}

Tabla 11: Reseña de investigaciones de trabajo colaborativo con tecnología informática. Base del estudio extraída de Dimitrakopoulou et al., 2006 y actualizada con reseñas propias de esta tesis 
Estas investigaciones muestran que la cualidad de documentar y recuperar los eventos de colaboración que ofrece la tecnología informática ha posibilitado construir indicadores basados en la historia de las interacciones a lo largo de un período de tiempo determinado. Asimismo, el advenimiento de nuevas herramientas, como las tabletops en las investigaciones de Spermon et al. (2014) y Martínez Maldonado (2014) recuperan los indicadores de los escenarios sincrónico presenciales, como los gestos y la sinergia entre el habla y el tacto. Los trabajos de Charczuk et al.; Martínez Maldonado; Alvarez Ferrando et al.; Zumbach et al. en 2005 y 2006 muestran cómo puede reconstruirse la tarea colaborativa de un grupo en entornos virtuales de enseñanza y aprendizaje o en entornos creados ad hoc para la colaboración. Los trabajos de Weinberger \& Fischer (2006) y sus referencias a modelos de argumentación como el de S. Toulmin (en Karbach, 1987) y el análisis de mensajes según granularidad (en Chi, 1997) que muestran la importancia de analizar, desde el punto de vista semántico, corpus de mensajes en función de su entrelazamiento en cadenas argumentativas.

Los indicadores expuestos en estos estudios podrían ser integrados a los presentados anteriormente en esta tesis (Véase sección 4.2.1. "Indicadores del aporte individual al grupo") para completar la perspectiva del análisis grupal. Así, el concepto de interdependencia positiva de Driscoll \& Vergara (1997) presentado en el capítulo 3 podría verse desde otro ángulo, como patrón de participación e interacción del grupo como un objeto único, no únicamente como suma de las participaciones de sus miembros.

Para ahondar en esta idea resulta pertinente retomar los estudios de Baker (en Spermon et al., 2014) quienes sostienen que para aprender en colaboración se necesita algún tipo de entendimiento compartido, que los investigadores denominan grounding. Describen dos niveles de este entendimiento: pragmático y semántico. El nivel de entendimiento pragmático busca describir la evolución cultural del lenguaje para comprenderlo desde un paradigma experimental que permita modelizarlo y operar sobre él. Los estudios de Konno, Morita \& Hashimoto (2012) presentan un estado del arte sobre esta cuestión. Este aspecto está relacionado con el aprender a colaborar desde el punto de vista de la estructura del lenguaje y la comunicación. El nivel semántico se refiere a la consecución de un entendimiento mutuo desde el punto de vista del significado de lo que se dice o escribe. Esto se denomina conexión semántica y será uno de los indicadores considerados en el trabajo de campo de la segunda parte. Las investigaciones de Stahl, Koschmann \& Suthers (2006) reafirman esta concepción, al presentar a la colaboración como un proceso de construcción de significados compartidos. El logro de aprendizaje colaborativo implica fenómenos como la negociación y el intercambio de significado.

Tomando en cuenta el concepto vertido anteriormente sobre interdependencia positiva y la nueva perspectiva presentada en los dos párrafos anteriores, se arribaría a una doble dimensión, que puede ser visualizada tal como se presenta en la figura 25.

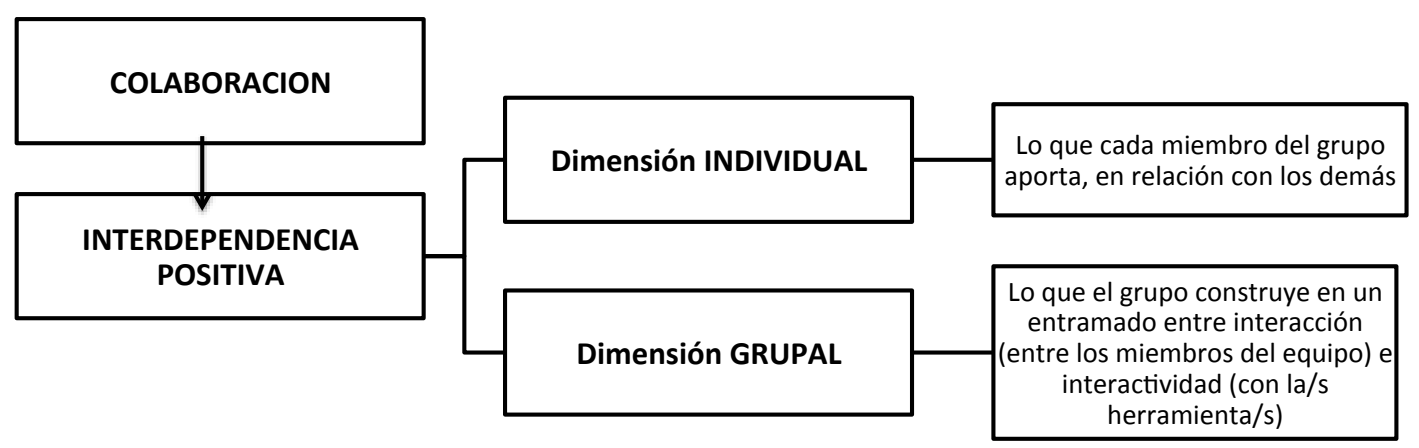

Figura 25: Doble dimensión del concepto de interdependencia positiva (Driscoll \& Vergara, 1997) 


\subsubsection{Análisis de la conexión semántica en el trabajo colaborativo. Argumentación como idea clave}

En la construcción de indicadores para el estudio de la interdependencia positiva deben tomarse en cuenta ambas dimensiones del concepto: la individual y la grupal. Desde el punto de vista del aporte de cada miembro, podrían servir los indicadores presentados en la tabla 10.

En cuanto a la construcción colaborativa propiamente dicha en espacios tecnológicos, se debe recurrir al campo de CSCL, ya que la construcción colaborativa puede ser revisitada a partir de la visibilización y documentación que posibilita la tecnología. Los indicadores posibles (muchos de los cuales aparecen en la tabla 10) podrían ser integrados en la idea de conexión semántica (Baker en Spermon et al., 2014), que se relaciona con el concepto de construcción de significados a través de cadenas de sentido de Stahl et al. (2006) y que podrían operacionalizarse a partir del mapa conceptual de los temas abordados por el grupo.

El concepto y presentación gráfica de los mapas conceptuales se basan en el trabajo de Joseph D. Novak (1990) a partir de la teoría cognitiva de Robert Ausubel. Su idea original ha sido ofrecer una representación del conocimiento construido por una persona (o grupo de personas) a través de un mapa que muestra los conceptos, sus nombres o etiquetas, las jerarquías entre ellos y sus relaciones. En el trabajo colaborativo, el uso de mapas conceptuales permitiría verificar, también, la cohesión de la comunicación (Reyes \& Tchounikine en Dimitrakopoulou et al., 2006) en tanto difusión de la información en el grupo: cuanto más cohesionada, mejor fluye la información entre todos los miembros del grupo.

Para definir las cadenas de significado se retoma la idea de los patrones de comunicación (Mason, 1992) y el análisis de contenido (Cáceres, 2008). Para construir estas cadenas es necesario analizar los mensajes que los miembros de un grupo intercambian en los siguientes términos:

- Objetivo y contenido;

- Relación con la tarea en sí;

- Función dentro de la cadena de comunicación: abre un tema, desarrolla o cierra;

- Componentes emocionales;

- Palabras clave;

- Puntos de gramática (los signos de puntuación, pronombres inclusive);

- Cierre del mensaje con acuerdos finales (compromisos, promesas).

Este tipo de análisis permite entender las cadenas de significado en el marco de la comunicación del grupo en los entornos digitales colaborativos. A través de estas cadenas es posible identificar cómo se generan y comparten conocimientos. En la tabla 11 se incluye esta perspectiva en los trabajos de Cenich, 2007; Cenich \& Santos, 2006; Weinberger \& Fischer, 2006; Mochizuki et al., 2005 y Baker, 2003. Siguiendo el estudio de Weinberger \& Fischer (2006) podría analizarse la composición de las cadenas de significado en dos dimensiones, a las que Chi (1997) denomina granularidad de los mensajes, con los siguientes componentes:

- Macro mensaje: tipo de mensaje, título, partes del mensaje (inicio, desarrollo, final) cantidad de palabras totales, cantidad de ideas transmitidas, palabras clave, etc.

- Argumentación de la idea clave del mensaje. Esta idea sigue la línea teórica de los autores del arguin to learn que comprenden la construcción del aprendizaje a partir de las líneas argumentales que aparecen dentro del mensaje macro. En esta línea se describe a la argumentación como una competencia experta, relacionado tanto con 
el conocimiento sobre un tema específico, como con la estructura de metaconocimiento que permite explorar forma más apropiada de transmitir ese conocimiento y construir en base a decir de los demás. Se instalan en esta línea autores como Blanco, Cuello, González \& Penco, 2016; Felton, Garcia-Mila, Villarroel \& Gilabert, 2015; Yanacon Atia \& Costaguta, 2013; Andriessen, Baker \& Suthers, 2013; Jonassen \& Kim, 2010; Weinberger, \& Fischer, 2006; Chi, 1997; Karbach, J., 1987; Fulford \& Zhang, 1993.

La argumentación es una competencia a la vez cognitiva y metacognitiva. En ambos niveles resulta una competencia experta. Está ligada, a la vez, con el conocimiento de un área, que se construye a lo largo de la vida de trabajo o académica en una disciplina o disciplinas (competencia cognitiva) y con la posibilidad de construir estructuras formales de que permitan sostener una postura (competencia metacognitiva). La argumentación entre personas expertas permite saldar las posibles diferencias por la existencia de una base común de conocimiento. Molina \& Padilla explican lógicamente la construcción argumentativa de la siguiente forma: "la argumentación constituye una herramienta epistémica para construir conocimientos, que se torna una herramienta didáctica que permite aprender contenidos y desarrollar pensamiento crítico, implica socializarse con las prácticas de una comunidad determinada y sólo a través de la práctica, como actores activos, los estudiantes podrán apropiarse de estos conocimientos" (Molina \& Padilla, 2013, pág. 559). Es, por esta razón, una competencia individual por la que una persona construye argumentos que se entraman con otros en una línea de discusión o intercambio.

El modelo inicial de argumentación seleccionado para esta tesis corresponde al filósofo Stephen Toulmin quien, en 1958, presenta un modelo de argumentación basado en los siguientes componentes (ver figura 26):

- Argumento (Claim): punto de partida. Argumento inicial. Puede ser una afirmación, premisa o idea.

- Evidencia (Ground): datos empíricos o evidencia que fundamentan el argumento inicial.

- Garantía (Warrant): vincula la evidencia a la idea inicial y ofrece mayor fundamento.

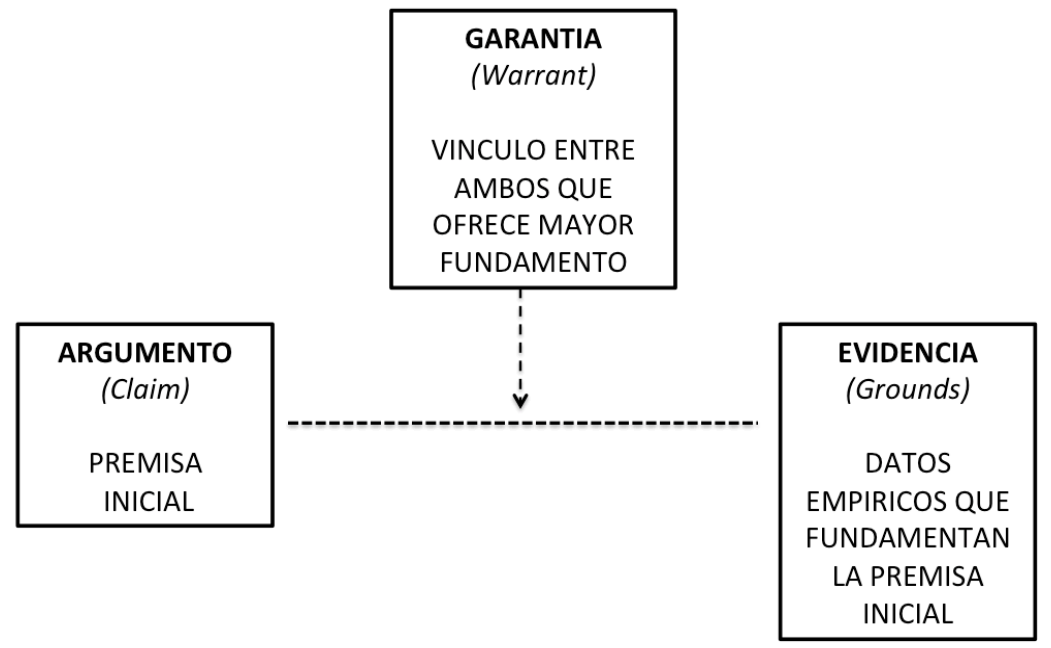

Figura 26: Modelo de argumentación de Toulmin (en Karbach, 1987). Primera aproximación

La idea que sustenta el modelo es que el razonamiento argumentativo es una construcción individual, refinada a partir de la interacción entre argumentos y contra-argumentos, con su 
soporte empírico y valorativo. Así, el modelo completo, se describe a continuación y se presenta un ejemplo en la figura 27.

- Argumento (Claim): punto de partida. Argumento inicial. Puede ser una afirmación, premisa o idea.

- Evidencia (Ground): datos empíricos o evidencia que fundamentan el argumento inicial.

- Garantía (Warrant): vincula la evidencia a la idea inicial y ofrece mayor fundamento.

- Respaldo (Backing): establece la confiabilidad y relevancia de la garantía.

- Calificador (Qualifier): construcciones lingüísticas modeladoras que permiten atenuar una afirmación. Cuando está presente, modifica el argumento a través de la forma en la que está presentado.

- Refutaciones (Rebuttal): condiciones de refutación que pueden menguar la eficacia de los argumentos y refutan la afirmación inicial.

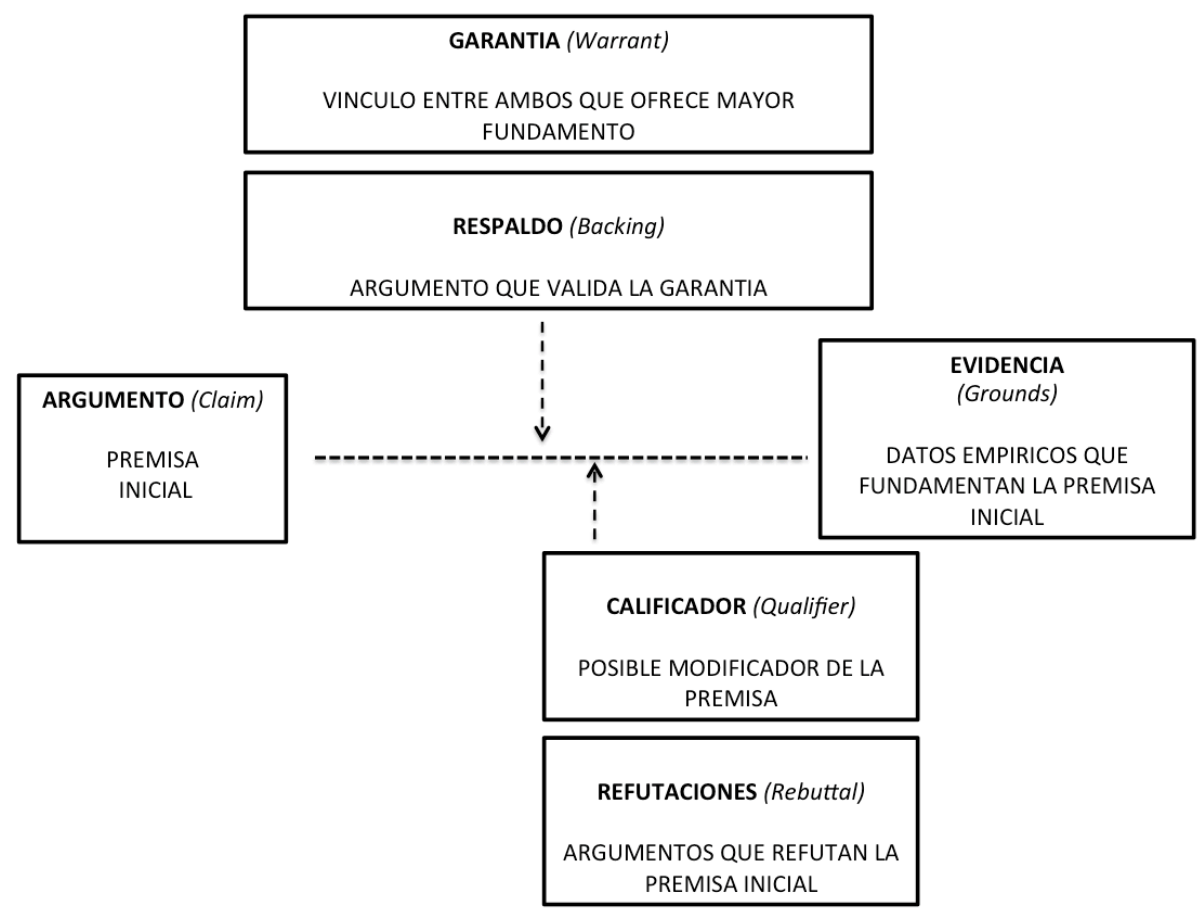

Figura 27: Modelo de argumentación de Toulmin (en Karbach, 1987, pág. 81)

Karbach (1987) presenta el modelo completo mediante un ejemplo" Sus componentes se presentan en la figura 28. 


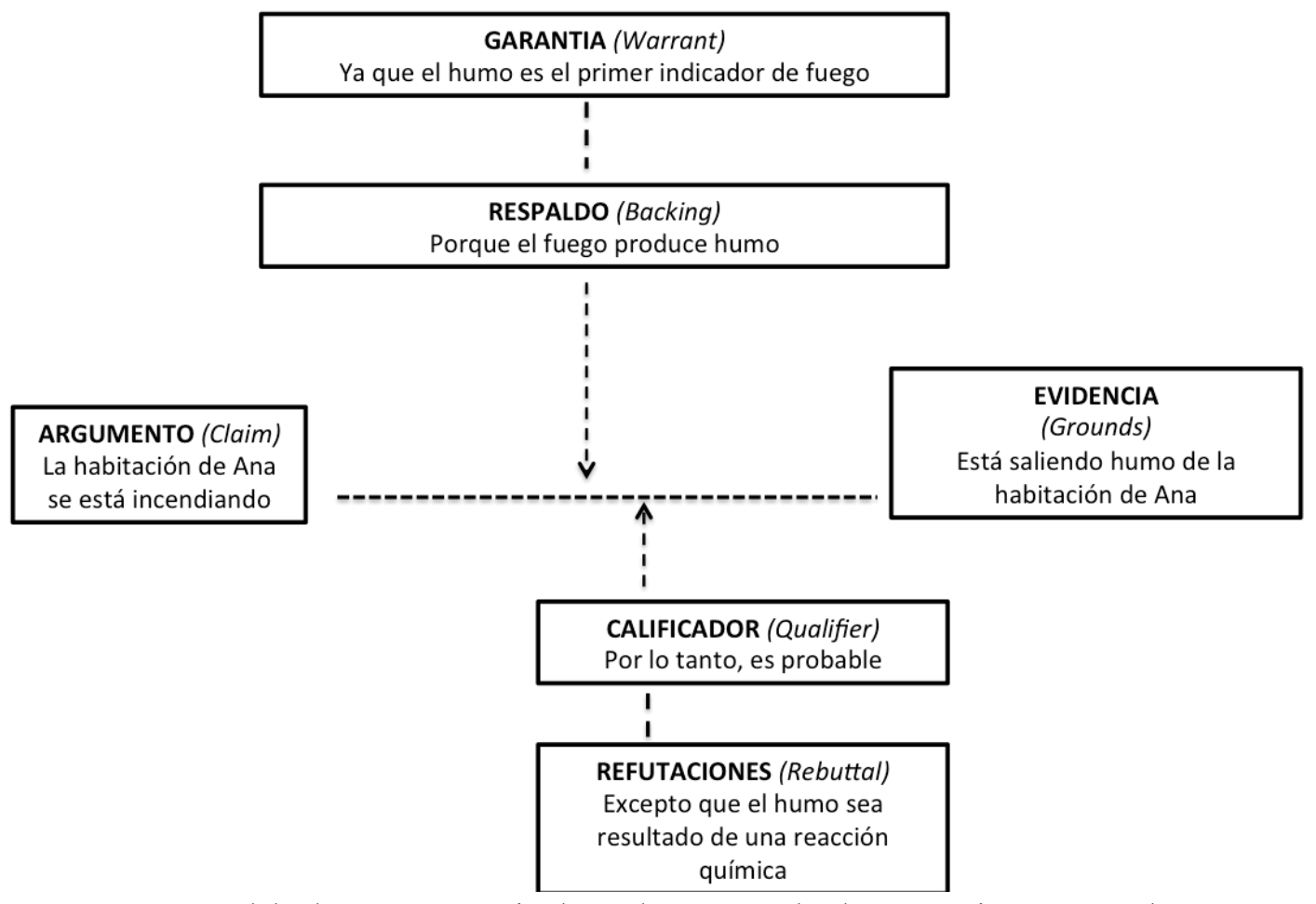

Figura 28: Modelo de argumentación de Toulmin (en Karbach, 1987, pág. 83). Completo

Este modelo se utilizará de referencia para analizar los componentes de los mensajes en términos de su construcción argumentativa. Se volverá sobre este tema en los capítulos 6 y 8 .

\subsection{Conclusiones del capítulo}

En este capítulo se presentó el tema del seguimiento del trabajo colaborativo. Se comenzó con una definición conceptual, bajo el paraguas de la evaluación, de los términos seguimiento y valoración. Se llegó a un modelo que los integra en tanto la valoración implica la opinión subjetiva de un hecho, que permite su seguimiento, con vistas a la evaluación formativa y final.

El siguiente tema fue describir para quién y para qué se puede valorar el trabajo colaborativo. Se definieron tres grupos de beneficiarios: el propio grupo, los coordinadores (docentes, en el caso de trabajo colaborativo en espacios de enseñanza) y los diseñadores y desarrolladores de entornos informáticos que alojan grupos que trabajan colaborativamente.

El modelo de valoración propuesto tuvo dos ejes. El tema de los indicadores se presentó mediante un relevamiento de experiencias que se ubican en la gradiente cooperacióncolaboración, desde el año 2002 hasta la actualidad, en diferentes escenarios, con niveles de destinatarios diversos (desde niños hasta adultos) y con diferentes herramientas tecnológicas. Se relevaron y consignaron 19 trabajos sintetizados en la tabla 11 de este capítulo. Algunas experiencias presentan herramientas desagregadas para mediar el trabajo colaborativo: correo electrónico, foro, chat, NetMeeting, HabiPro (software de Inteligencia Artificial); otras utilizan los softwares de seguimiento del trabajo colaborativo; otras se realizan inmersas en entornos virtuales de enseñanza y aprendizaje (por ejemplo, Moodle) o entornos colaborativos, como MODELLING y CLUE. En la figura 29 se presenta una síntesis de los tipos de investigaciones reseñadas: su escenario (presencial o a distancia), las herramientas que utilizan y los tipos de indicadores de interacción y/o interactividad que reseñan en su estudio. 


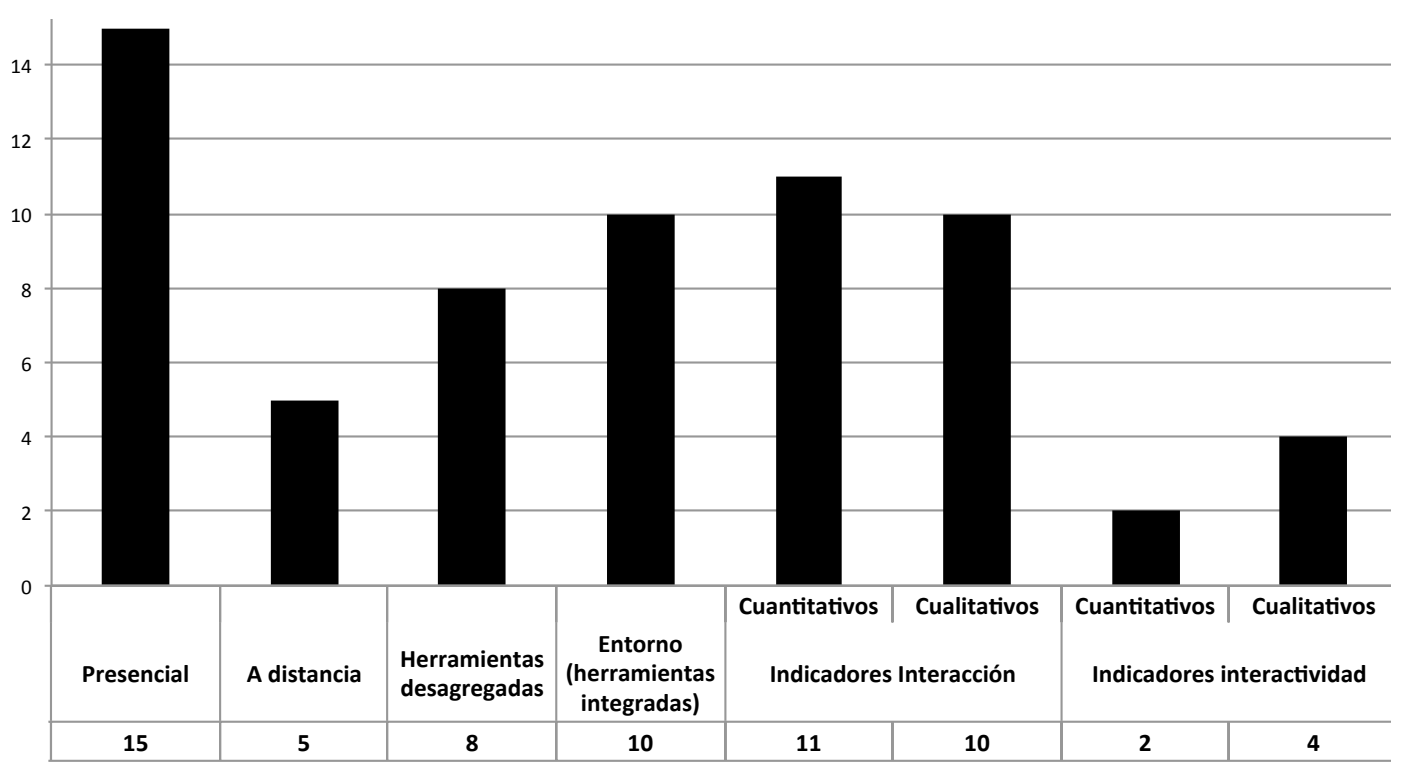

Figura 29: Estudios sobre trabajo colaborativo con tecnología informática reseñados en la tesis

Como puede verse en el análisis del gráfico, hay una considerable variedad de escenarios y herramientas. Respecto de los indicadores, la mayoría de los estudios se enfocan en la interacción, concentrándose en la densidad de mensajes que se intercambian a través de las herramientas o de manera verbal, mediante observación no participante, en las sesiones de trabajo presencial. En cuanto al análisis cualitativo de la interacción, se consideran los mapas de sentido y la construcción de soluciones a los problemas planteados. Se han relevado experiencias interesantes en la mejora de la habilidad de argumentación mediante el uso del software Drew (Corbel, 2003) y la graficación de conversaciones usando palabra clave con iBee (Mochizuki et al., 2005). Respecto del estudio de la interactividad, en el estado del arte relevado los estudios se basan en el manejo de contenidos con simulaciones a través de entornos como CoLab, el uso de tabletops, y software como HabiPro y Wizard of $\mathrm{Oz}$ (de inteligencia artificial). Aunque se debe aclarar que las experiencias desarrolladas con Co-Lab, HabiPro y Wizard of Oz no estudian la actividad colaborativa en sí, sino que se concentran en el manejo del contenido por parte del grupo.

Este análisis de la literatura permitiría concluir en que no ha habido un cambio significativo en los indicadores que se valoran para el estudio del trabajo cooperativo-colaborativo a lo largo de los años. Están presentes los indicadores cuantitativos de densidad de comunicación en general y con los cortes por etapa (en los trabajos que se consideran etapas en la resolución de la tarea colaborativa). En cuanto a los cualitativos, los mapas de tópicos, con cortes de off topic y off task son mayoría. También resulta significativo el diseño de consignas orientadas a la acción, que predefinen etapas y modelos de resolución exitosa. En ese marco, se orienta el análisis de conexión semántica. En síntesis: los escenarios y las herramientas varían. Los tipos de consigna y los indicadores que iluminan los estudios tienden a permanecer invariantes.

Lo que si representa un valor agregado es la posibilidad que ofrecen las herramientas informáticas para favorecer un seguimiento cuidadoso de los eventos de colaboración. En este sentido, en este capítulo se definieron dos categorías de indicadores: los que contribuyen a visualizar el aporte de cada individuo al trabajo grupal y aquéllos que permiten desentrañar la construcción. En este últimos, tiene un rol específico la tecnología informática y la posibilidad de documentar-recuperar eventos significativos de colaboración. En este escenario, se describieron los indicadores de análisis semántico de la colaboración: a) conexión semántica; b) cohesión de la comunicación y c) argumentación, tomando en cuenta la granularidad de los mensajes, a partir del modelo de Stephen Toulmin (en Karbach, 1987). 
El capítulo siguiente presenta un estado del arte de las aplicaciones informáticas de seguimiento y documentación del trabajo colaborativo. Al final de esta primera parte, como epílogo, se presenta un mapa integrador de las dimensiones abordadas en este marco conceptual. 


\section{Capítulo 5: Metodologías y aplicaciones que apoyan el seguimiento del trabajo colaborativo}

El abordaje teórico de esta tesis se ha iniciado con los conceptos de interacción e interactividad y se ha enfocado el trabajo colaborativo como objeto de estudio. En el capítulo anterior se han determinado metodologías e indicadores que podrían dar cuenta del seguimiento de este tipo de trabajo, desde la perspectiva interdisciplinaria. El presente capítulo ofrece un estado del arte de herramientas informáticas de seguimiento y documentación del trabajo colaborativo. El recorrido propuesto es el siguiente:

5.1. Visualización de indicadores de trabajo colaborativo

5.1.1. ¿Qué visualizar? ¿Cuándo? ¿Para qué?

5.2. Herramientas de visualización del trabajo colaborativo

5.2.1. Descripción de las herramientas

5.2.2. Clasificación de las herramientas

5.3. Conclusiones del capítulo 


\subsection{Visualización de indicadores de trabajo colaborativo}

Hay coincidencia acerca de la importancia que brinda al trabajo grupal el conocimiento de su desempeño por parte de todos los involucrados en el grupo (Mühlenbrock \& Hoppe, 1999; Jermann, Soller \& Müehlenbrock, 2001; Barros, Verdejo, Read \& Mizoguchi, 2002; Avouris, Dimitracopoulou \& Komis, 2003; Martínez, Kay \& Yacef, 2011; Fessakis \& Dimitracopoulou, 2003). Bodemer \& Dehler (2011) describen tres tipos de awareness que pueden considerarse cruciales para el aprendizaje colaborativo:

- información pública sobre lo que los integrantes del grupo efectivamente hacen (mencionada también por Janssen, Erkens \& Kirschner, 2011);

- información cognitiva acerca del background de conocimientos previos y/o habilidades de autorregulación para el aprendizaje de cada miembro (también reconocida por Dehler, Bodemer, Butler \& Hesse, 2011; Sangin, Molinari, Nüssli \& Dillenbourg, 2011);

- información social sobre el funcionamiento del grupo según la percepción de los colaboradores (por ejemplo, Phielix, Prins, Kirschner, Erkens \& Jaspers, 2011).

En un ambiente digital para el trabajo colaborativo hay dos tipos de tareas: qué hay que hacer (determinado por la consigna) y qué hace cada integrante del grupo (proceso de trabajo colaborativo). Los awareness, entonces, están relacionados con qué hace cada miembro del grupo en función de la meta común. Siguiendo a Dourish \& Bellotti (1992), pueden encontrarse dos tipos de awareness, según cómo se organice el ambiente de trabajo:

Awareness activo: cuanto más organizado sea el ambiente, los roles del trabajo colaborativo están perfectamente delineados. Se reduce la incertidumbre y aumenta el awareness, ya que parte de la funcionalidad del sistema es indicar qué hizo cada uno. En este sentido, es fundamental el log del sistema, según los permisos y restricciones respecto de lo que cada rol puede hacer o no.

Awareness pasivo: si el ambiente digital no está tan organizado (o se usan ambientes desagregados, como en el estudio de caso de esta tesis), puede haber awareness respecto de:

- tareas sucesivas o simultáneas;

- qué información se comparte y cómo;

- configuración de roles: en función de la coordinación del grupo y en función de la organización de la tarea;

- tiempos: síncrono y/o asíncrono;

- tareas vinculadas a la forma y tareas vinculadas al contenido;

- protocolos de comunicación definidos y utilizados por el grupo;

- etc.

En este capítulo se avanza sobre qué información es importante visualizar, cómo, en qué formato y cuándo. Se presenta también el estado de arte de las herramientas existentes, categorizadas según una taxonomía propia. En los capítulos 6 y 8 se retomará el tema del concepto y estrategia de una de las metodologías descriptas aquí: el mirroring. 


\subsection{1. ¿Qué visualizar? ¿Cuándo? ¿Para qué?}

Erickson, Smith, Kellogg, Laff, Richards et al. (1999) realizan un interesante análisis, en "Social Translucence: An Approach to Designing Systems that Support Social Processes", acerca de la importancia que tiene para cada persona en su vida cotidiana, las decisiones y experiencias de los demás. Ya en 1999, estos autores introdujeron la idea de que los sistemas informáticos que soportan estas actividades pueden hacerlas visibles $\mathrm{y}$, por ende, ayudar a visibilizar estas relaciones. Crearon así el concepto social translucence (algo así como "translucidez social") como una propiedad de los sistemas informáticos que puede ayudar a la comunicación, mostrando aspectos cuantitativos simples de la participación de los usuarios en una tarea compartida. Este enfoque se basa en tres propiedades (Erickson \& Kellogg, 2000). La primera, la visibilidad, se refiere a la idea de que los usuarios pueden enfocar su atención en la información social que se presenta en forma de cifras o gráficos; la segunda, la conciencia, considera el impacto de la información de la actividad de los otros sobre la actividad de cada miembro y las reglas colectivas de trabajo y convivencia; por último, la responsabilidad se refiere a los procesos de autorregulación individual que pueden ocurrir como resultado de la conciencia del usuario sobre sus propias acciones o las de los demás. Estas ideas pioneras fueron continuadas por diversos autores en la construcción de sistemas de visibilización del desempeño de grupos de trabajo: tanto pequeños grupos, como grupos sociales y hasta redes.

En relación con grupos pequeños se retoma el trabajo de Dimitracopoulou (2005, pág. 119) quien cita a Jerman (2001) y Soller, Martínez, Jermann \& Muehlenbrock (2005) y avanza sobre el concepto de mirroring. Lo define como "sistemas que reflejan las interacciones de un grupo". Estos sistemas muestran indicadores de interacción y serán caracterizados más adelante en este capítulo. Existen otros que no sólo ofrecen una descripción de los eventos de interacción, sino que los presentan según indicadores predefinidos y en comparación con estándares esperados. Estas visualizaciones incluyen un conjunto de indicadores que representan el estado de la interacción, junto a un conjunto de valores y parámetros deseados para estos indicadores. Existen diferentes tipos de visualizaciones: gráficos de barra y circulares, mapas de temas de un foro (indicando dispersión de tópicos y tareas) e, incluso, desarrollo colectivo de mapas conceptuales (Martínez Maldonado, 2014). Según la hipótesis de Dimitracopoulou, y en concordancia con los trabajos citados al inicio de este capítulo, esta información podría favorecer tanto el trabajo del grupo en sí como el de los coordinadores que lo supervisan y orientan. Las estructuras de visualización, con representaciones adecuadas, pueden ayudar a los estudiantes en el desarrollo metacognitivo y, posteriormente, en la regulación de la actividad de colaboración.

En referencia a cuándo visualizar el trabajo del grupo, se profundizará el tema en la presentación de las herramientas existentes, más adelante en este capítulo (sección 5.2.1. "Descripción de las herramientas"). En cada herramienta se toman decisiones respecto de qué información se muestra en función de qué indicador, cómo y cuándo. Una vez que el grupo comenzó su trabajo colaborativo, es complejo determinar momentos dentro de la actividad para mostrar su avance. Además, la posibilidad de mostrar desempeño y avance en relación con los indicadores está en estrecha relación con el escenario de la actividad colaborativa: presencial, a distancia y, sobre todo, el manejo del tiempo: sincrónico o asincrónico. En la literatura se encuentra con más frecuencia la visualización de indicadores ex post facto o post mortem, luego de que el trabajo grupal finaliza. Sin embargo, es posible y deseable que las herramientas definan ventanas de tiempo (Manuel Castells en Burge, Campbell \& Gibson, 2011) para hacer un corte, abstracto, en el trabajo y mostrar su rumbo y relación con lo esperado.

\footnotetext{
${ }^{12}$ Los autores hablan de translucidez y no de transparencia, ya que hacen intervenir la tensión público-privado en el manejo de la información de un grupo. Por eso, la circulación de la información no convierte al sistema en transparente.
} 
Como respuesta a las preguntas que dan título a esta sección, la problemática de la visualización del trabajo colaborativo mediado por tecnología informática podría presentarse como se presenta en la figura 30.

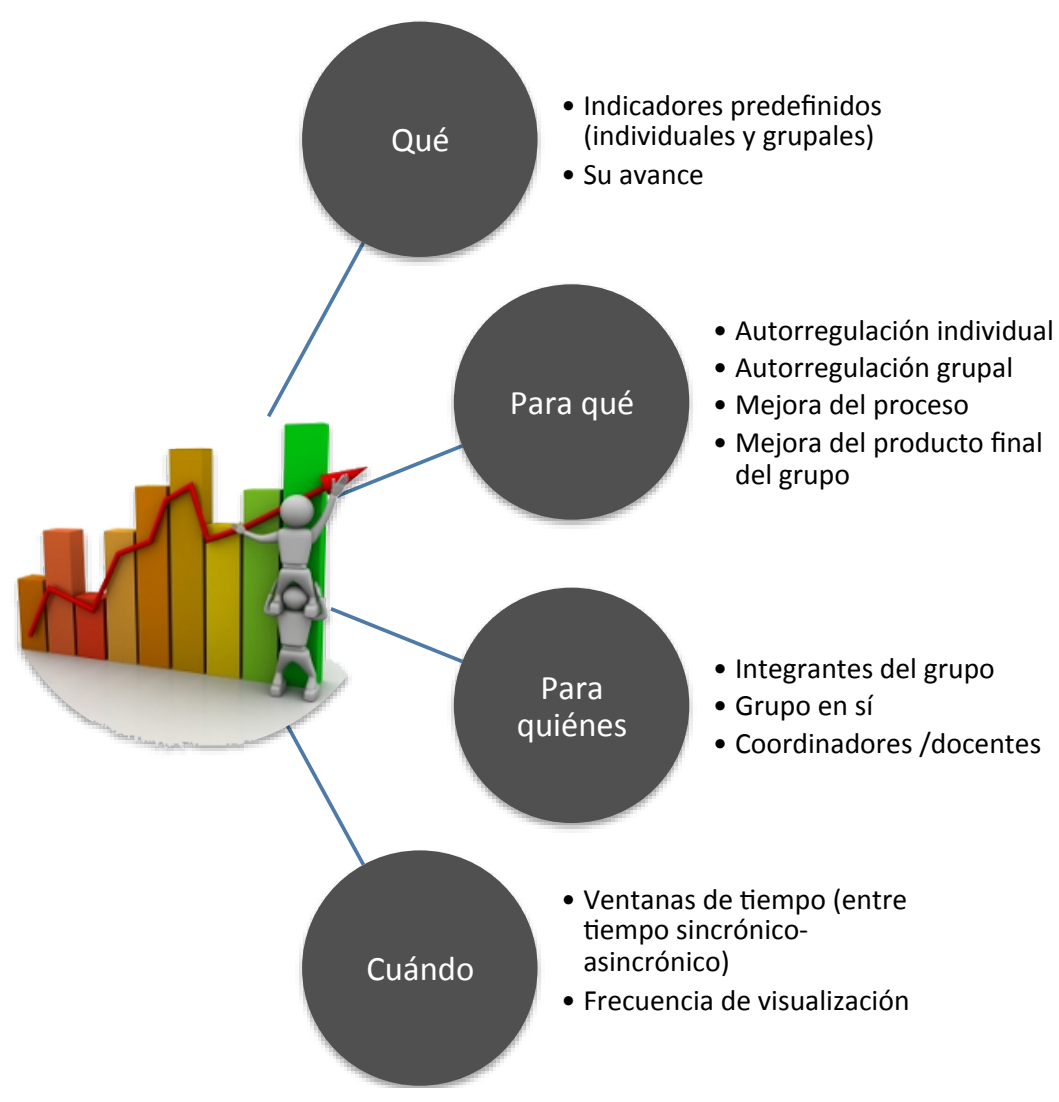

Figura 30: Qué, para qué, para quiénes y cuándo visualizar indicadores de colaboración

\subsection{Herramientas de visualización del trabajo colaborativo}

En esta sección se describen las herramientas de visualización del trabajo colaborativo mediado por tecnología informática relevadas. Para enmarcar esta presentación, se toma el modelo de visualización-seguimiento presentado por Jermann et al. (2001) y Soller et al. (2005). La idea central es pasar del mirroring (visualización) al guiding (seguimiento con valor agregado por parte del docente o coordinador). Las tres categorías de herramientas que ofrece este modelo se presentan en la tabla 12 .

\begin{tabular}{|c|l|}
\hline TIPO DE HERRAMIENTAS & \multicolumn{1}{c|}{ CARACTERISTICAS } \\
\hline $\begin{array}{c}\text { Herramientas de espejo } \\
\text { (Mirroring Tools) }\end{array}$ & $\begin{array}{l}\text { Incluye herramientas que reflejan automáticamente la actividad de los } \\
\text { integrantes de un grupo de trabajo. Son visualizaciones gráficas de las } \\
\text { acciones de cada uno en las herramientas objeto de seguimiento. Se } \\
\text { supone que la visualización per se podría ser de utilidad para mejorar } \\
\text { los procesos de trabajo. }\end{array}$ \\
\hline $\begin{array}{c}\text { Herramientas } \\
\text { metacognitivas }\end{array}$ & $\begin{array}{l}\text { Incluye a la anterior de mirroring, pero muestra información acerca } \\
\text { del desvío del desarrollo de los indicadores respecto de lo deseado. } \\
\text { (Metacognitive Tools) } \\
\text { los integrantes del grupo, dispersión de temas, manejo ineficiente del }\end{array}$ \\
\hline
\end{tabular}




\begin{tabular}{|c|l|}
\hline & tiempo, control de las herramientas en manos de pocas personas, etc. \\
\hline TIPO DE HERRAMIENTAS & \multicolumn{1}{|c|}{ CARACTERISTICAS } \\
\hline $\begin{array}{c}\text { Herramientas de guía } \\
\text { (Guiding Systems) }\end{array}$ & $\begin{array}{l}\text { Incluye a las dos anteriores y agrega un espacio para la guía e } \\
\text { intervención del docente. }\end{array}$ \\
\hline
\end{tabular}

Tabla 12: Presentación de herramientas de visualización del trabajo colaborativo en el modelo mirroring metacognitive- guiding. (Tomado de Jermann et al., 2001 y Soller et al. , 2005). Modelo propio

\subsubsection{Descripción de herramientas}

Se describen a continuación las herramientas informáticas relevadas en la literatura, en función de la reseña de investigaciones presentada en el capítulo anterior y consignada en la tabla 11. A continuación se ordena alfabéticamente su descripción y luego se las presenta en forma comparada en la tabla 13, con la siguiente estructura:

- país de creación;

- tipo de software (web, de escritorio, móvil);

- tipo de licencia;

- descripción básica de sus funcionalidades,

- Awareness (tipos);

- cuándo (inicio, durante, después del proceso colaborativo);

- posibilidad de intervención del docente.

1. Aroma. La sigla significa Abstract Representation Of Presence Supporting Mutual Awareness. Se conoce en el año 1997, a través de las investigaciones de Pedersen \& Sokoler. Se trata de un entorno virtual que se enfoca en generar un sistema de awareness permanente. Se vincula al concepto de social translucence.

2. Babble. Se desarrolla a partir de investigaciones de Erickson, Smith, Kellogg, Laff, Richards, \& Bradner en 1999. Se trata de un visualizador de conversaciones en el que es posible identificar quiénes están hablando de qué tema. Rápidamente la interface muestra quiénes están off topic.

3. Big Five. Herramientas de visualización que se corresponden con la teoría de grupos BIG FIVE. Kay, Maisonneuve, Yacef \& Reimann (2006) crearon un set de herramientas de visualización específicas del trabajo colaborativo en entornos informáticos que se corresponde con el marco teórico presentado por Albert Bandura (1997), dentro de la teoría de la construcción social (Social Cognitive Theory, SCT). Este marco identifica las cinco capacidades que definen el trabajo grupal: 1. capacidad de simbolización; 2. capacidad de prefiguración y planificación; 3. aprendizaje vicario; 4. autorregulación; 5. autorreflexión. Se las conoce como big five. Las herramientas de Kay et al. (2006) permiten visualizar las cinco capacidades que, según Bandura, definen un trabajo en grupo. Las herramientas de visualización principales creadas por este grupo de investigadores son:

3.a. Radar de actividad. Consiste en un círculo, que representa el rango de participación de cada miembro en función de un estándar de comparación, que puede ser el promedio del grupo en el pasado, un estándar predefinido o la actividad de un integrante del grupo. Este estándar aparece en el punto medio del círculo. Se ve como aparece en la figura 31. Como puede observarse, cuanto más alejado del círculo central, más lejos del estándar esperado. 


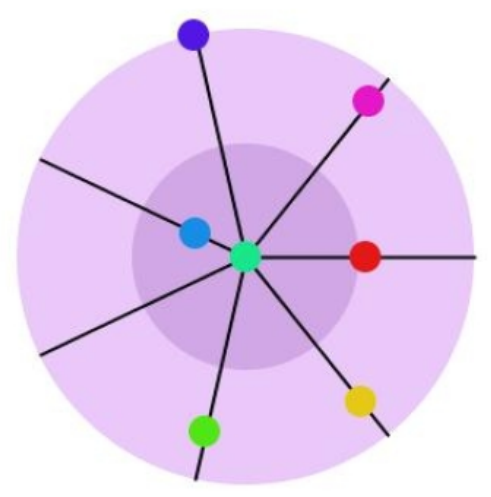

Figura 31: Radar de participación, según Big Five (Tomado de Kay et al., 2006)

3.b. Red de interacción. Esta representación está basada en el Análisis de Redes sociales (ARS) y cuantifica las relaciones entre los actores, con el objeto de crear redes gráficas que representen esas relaciones como un todo. Hay tres elementos básicos que conforman una red: actores, límites y relaciones. Los actores están representados con puntos y las relaciones con líneas que los unen. El límite de la red debe guardar lógica con la relación que constituye esa red, ya que es el tipo de relación el que determina qué sujetos participan de ella y cómo. Los sujetos se ven con puntos y el grosor de la línea muestra la cantidad de interacciones existentes entre los sujetos. Se ve en la figura 32.
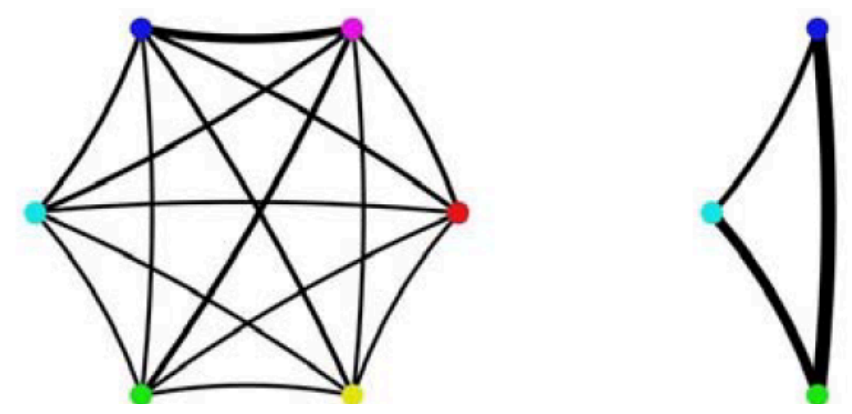

Figura 32 Redes de interacción en dos herramientas y con diferentes densidad y relaciones, según Big Five (Tomado de Kay et al., 2006)

3.c. Wattle Tree. El nombre de esta herramienta se debe a una planta australiana nativa (árbol de acacias), con flores redondas de color amarillo y dorado, similar a la visualización de eventos que muestra su interface, que se muestra en la figura 33. Cada línea indica una persona del grupo; en el eje vertical se consigna el número de día de trabajo y la fecha; en las líneas de cada individuo se integran las participaciones en cada herramienta estudiada por color y tamaño de la contribución (medido por la cantidad de contribuciones y su longitud). Cada intervención es considerada como un ticket que se suma a la cuenta de la persona que la realizó. Por ejemplo la actividad de la wiki se muestra en amarillo. Las "hojas" en verde muestran si una persona abrió, desarrolló o cerró una línea de colaboración mediante un ticket. 


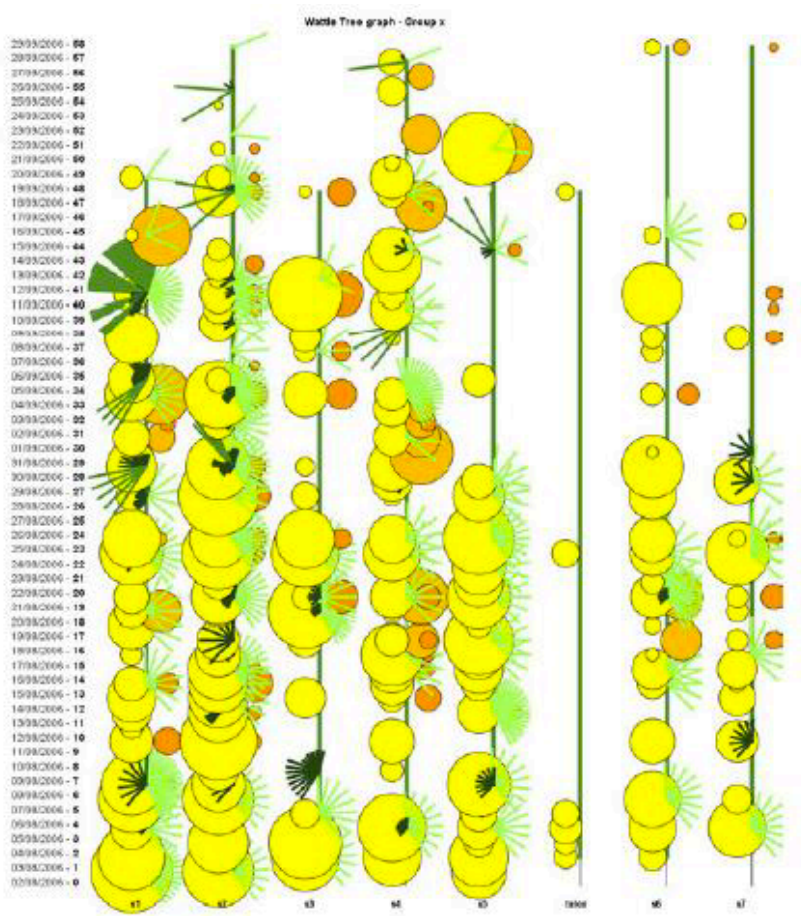

Figura 33: Wattle Tree. Eventos colaborativos por persona, día, tipo y magnitud (Tomado de Kay et al., 2006)

4. Co-Lab. Colaborative Laboratories for Europe. Se trata de un proyecto del $5^{\circ}$ Programa Marco de la Unión Europea. Es un entorno web cuyo objetivo es desarrollar en los estudiantes conocimientos flexibles en áreas científicas y aptitudes para recolectar, sintetizar y modelizar información. Actualmente es posible trabajar en las temáticas de: administración del agua, efecto invernadero, mecánica y electricidad. Se lo presenta como "un entorno de aprendizaje colaborativo en el que los grupos de estudiantes pueden experimentar a través de simulaciones y laboratorios remotos" (van Joolingen, de Jong, Lazonder, Savelsbergh \& Manlove, 2005). Es un entorno que favorece el trabajo colaborativo y se lo ha utilizado en experiencias de aula presencial y en el trabajo a distancia. Incluye un espacio para comunicación sincrónica y asincrónica por el cual los usuarios pueden mantener una colaboración en línea. Incluye, además, espacios de trabajo con el contenido y manejo de modelos individuales, de a pares y en grupos. Puede verse la interface de entrada a Co-Lab en la figura 34. 


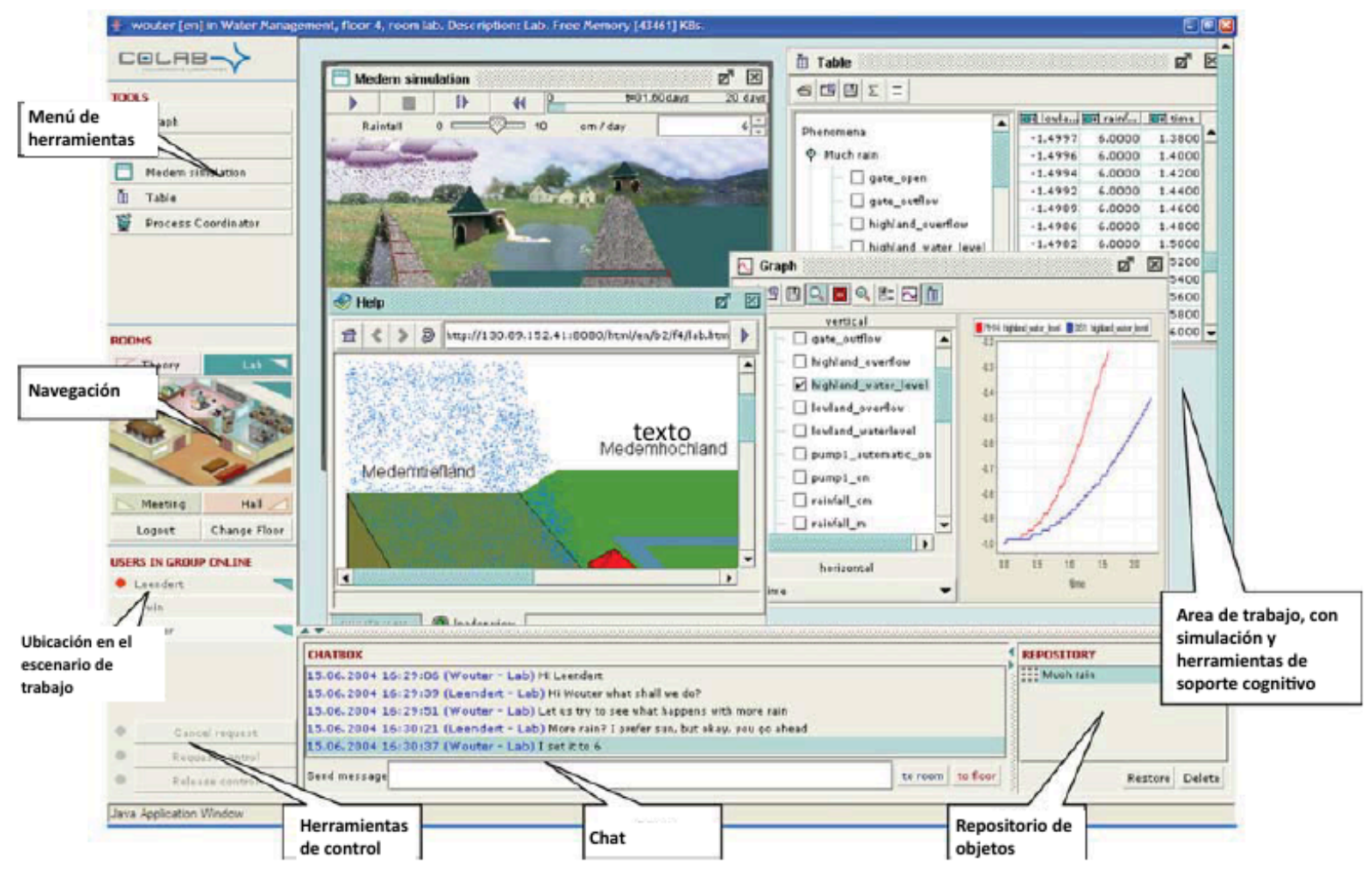

Figura 34: Home de Co-Lab (En van Joolingen et al., pág. 673)

5. CLUE. Ogata \& Yano (2004) lo presentan como un entorno colaborativo de computación ubicua. De allí procede su nombre: Collaborative Learning supported system in Ubiquitous compuer Environmets. La información que recoge y presenta se basa en awareness acerca de quién está haciendo qué, dónde y cuándo. Ofrece información compilada acerca de qué visiones se están informando sobre un mismo tema, quiénes presentan las mismas dudas y quiénes están disponibles para ayudarlos (en expertise y cercanía). Además, ofrece un mapa de awareness (knowledge awareness map) con el que los estudiantes pueden ver todos los indicadores que el sistema está recopilando juntos.

6. Comtella. Se trata de un repositorio para el intercambio de documentos académicos desarrollado en el laboratorio MADMAC en la Universidad de Saskatchewan, Canadá. Como este tipo de espacios requiere de una masa crítica de participación, Comtella incluye un mecanismo de recompensa, a partir de la inclusión de documentos y evaluación y recomendación de documentos y usuarios. Esta herramienta permite la visualización de rankings de usuarios.

7. Drew. Dialogical Reasoning Educational Web tool. Según Corbel, Jaillon, Serpaggi, Baker, Quignard, et al. 2003) se trata de una herramienta web que muestra gráficamente el mapa de tópicos que se genera en un sistema de argumentación. Se enmarca en el proyecto SCALE de la Comunidad Europea, enfocado al aprendizaje colaborativo para la argumentación a través de internet en la enseñanza secundaria (Apprentissage Collaboratif par l'Argumentation à travers Internet dans l'Enseignement Secondaire). Sus herramientas están diseñadas para ayudar a los estudiantes a desarrollar, refinar y ampliar su conocimiento argumentativo en un campo determinado. El profesor tiene un rol definido en el software para visualizar lo que sucede, agregar tareas y participantes. 
8. iBee. Bulletin Board Enrollee Envisioner. Creado y presentado por Mochizuki, Kato, Yaegashi, Nagata, Nishimori, et al., 2005) iBee es un software bajo el modelo de tablón de anuncios, que funciona como un plug in en un entorno virtual de enseñanza y aprendizaje. Sus principales características incluyen: 1.la visualización de la relación entre palabras clave y los alumnos en tiempo real; 2.la visualización de una trayectoria de conversación en un tiempo determinado; 3.la visualización de los últimos niveles de participación de los alumnos y de la frecuencia de uso de palabras clave, y 4.la ubicación de los mensajes según palabras clave, representados con la metáfora de flores y abejas, para que el estudiante pueda acceder a ellas mediante un click. La interface mostrada por los autores en el trabajo referido al tema es la que aparece en la figura 35. Las flechas, los círculos y las referencias se han incluido con el propósito de explicar la herramienta.

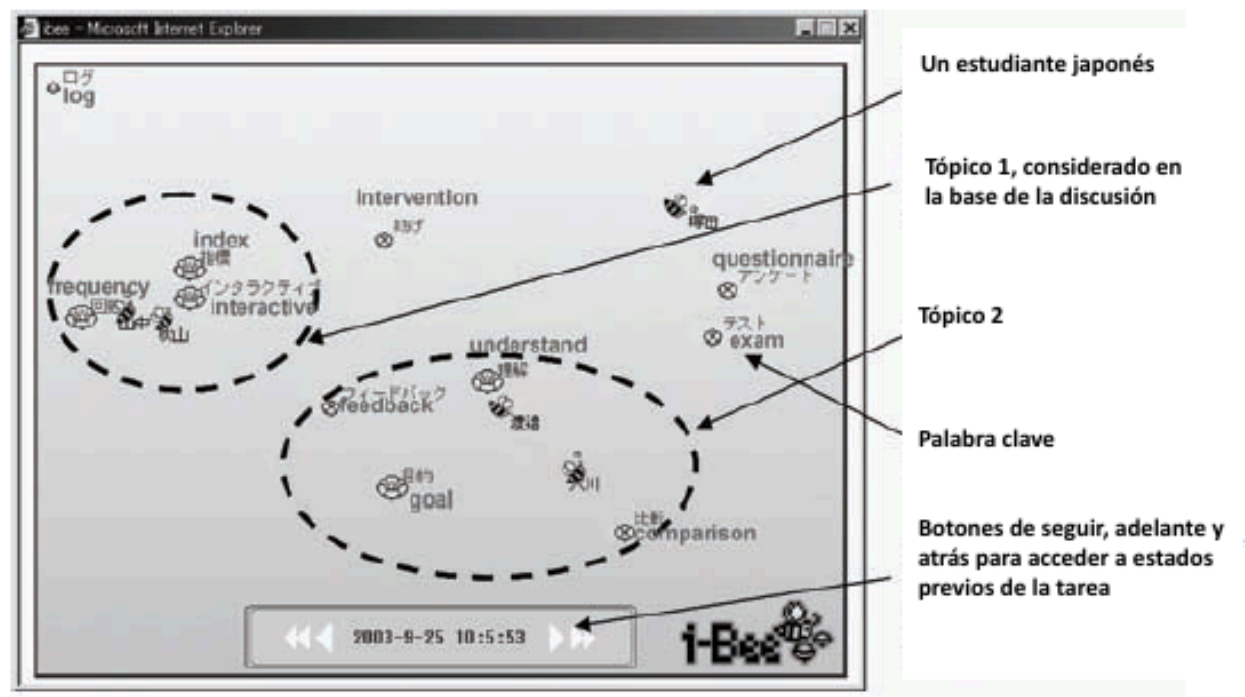

Figura 35: Visualización de un diálogo por palabra clave en iBee (Tomado de Mochizuki et al., 2005)

9. I-Tree. Bratitsis \& Dimitracopoulou (2006) analizan esta herramienta (desarrollada e introducida por Nakahara, Hisamatsu, Yaegashi \& Yamauchi, 2003 y 2005) que permite la visualización de conversaciones en teléfonos celulares a través de la metáfora del árbol. La información que ofrece al usuario es sólo relativa a su desempeño y la apariencia del árbol está condicionada por éste. Tiene la siguiente correspondencia: el tronco y las ramas del árbol obedecen a la cantidad de mensajes enviados, el volumen y color de las hojas se corresponden con los mensajes leídos, las frutas indican la cantidad de mensajes que han sido respondidos y la apariencia del cielo marca el status de la conversación completa: cuánto más respuestas se hayan recibido en relación con los mensajes totales, más oscuro es el color azul del cielo. Una muestra de la interface es la que aparece en la figura 36. 


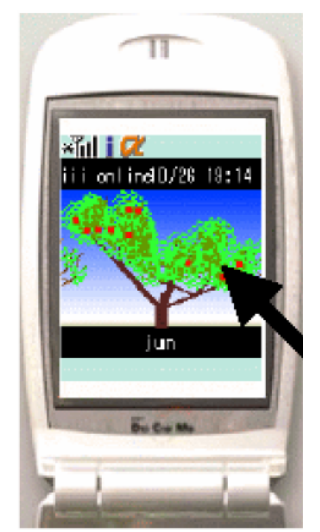

Figura 36: Visualización de un diálogo según desempeño individual en la herramienta ITree (Tomado de Dimitrakopoulou, et al., 2006)

10. ModellingSpace. Fue presentado por Avouris et al., en 2004. Se trata de un ambiente digital de aprendizaje que permite la colaboración y, en particular, se enfoca en la coordinación y la comunicación durante la resolución de un problema. Sus principales componentes son: 1.el entorno de modelado del problema; 2.las herramientas de análisis y de supervisión; 3.el repositorio común y 4.el espacio comunitario de apoyo. Su interface se muestra en la figura 37.

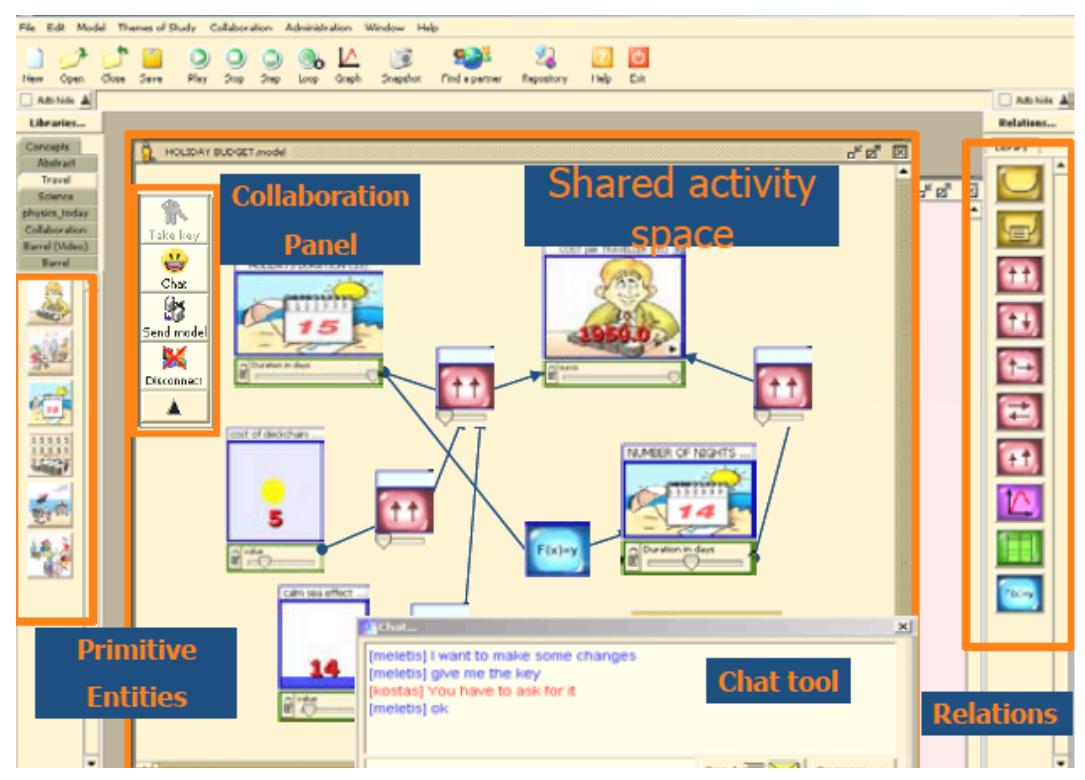

Figura 37: Visualización de la tarea modelada y los componentes asociados al trabajo colaborativo en Modellingspace (Tomado de Avouris et al., 2004)

11. Narcissus. Según Upton \& Kay (2009) este software permite a los grupos evaluar su trabajo colectivo, cotejando sus contribuciones en relación con los planes, y ayudándolos a identificar problemas. Debe estar vinculado con un entorno de enseñanza y aprendizaje. Presenta algunas características superadoras de los modelos que aparecen descriptos en esta sección: 1. permite documentar el trabajo de los estudiantes en varias herramientas, 2. puede ser controlado por el usuario y 3. ofrece diferentes vistas: la del usuario, la del grupo, la del proyecto y la de cada intervención (también identificado con tickets que representan eventos de interacción). Su interface, con el análisis de la información que documenta, compila y muestra este software aparece en la figura 38. En la figura se presenta la vista del grupo, que es la vista predeterminada. Se muestran 20 días de actividad (indicados en la columna de la izquierda). Cada línea 
corresponde a un miembro del grupo. En el panel de la derecha se muestra, en color, los eventos de cada herramienta en forma de tickets: en morado los aportes en la wiki, en azul los aportes al repositorio y en verde los tickets. La barra gris indica que no hay actividad.

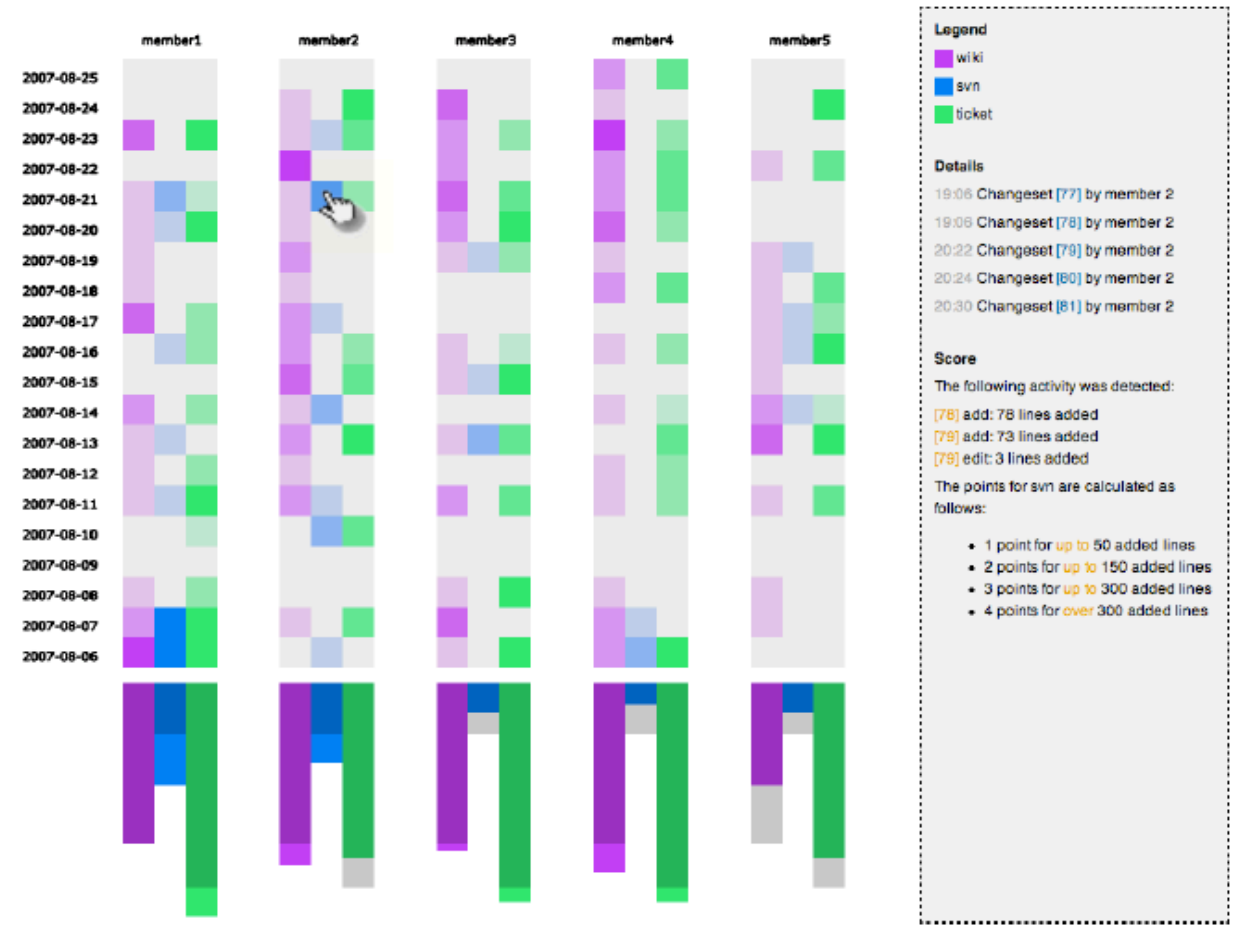

Figura 38: Visualización de la colaboración en la interface de Narcissus. Vista del grupo (Tomado de Upton \& Kay, 2009)

12. Synergo. Avouris et al., (2004 Agosto) presentan un entorno de modelado colaborativo que muestra la construcción de conocimiento a partir de diagramas de flujo, mapas conceptuales, flujo de datos, etc. Para el manejo de la comunicación y la coordinación, proporciona una herramienta de chat y posibilita el mecanismo de control de palabra. El análisis de la colaboración se realiza ex post facto. Construye para esto dos indicadores: el indicador de "factor de colaboración" y la "evolución de la actividad de actores". Su interface se ve como aparece en la figura 39.
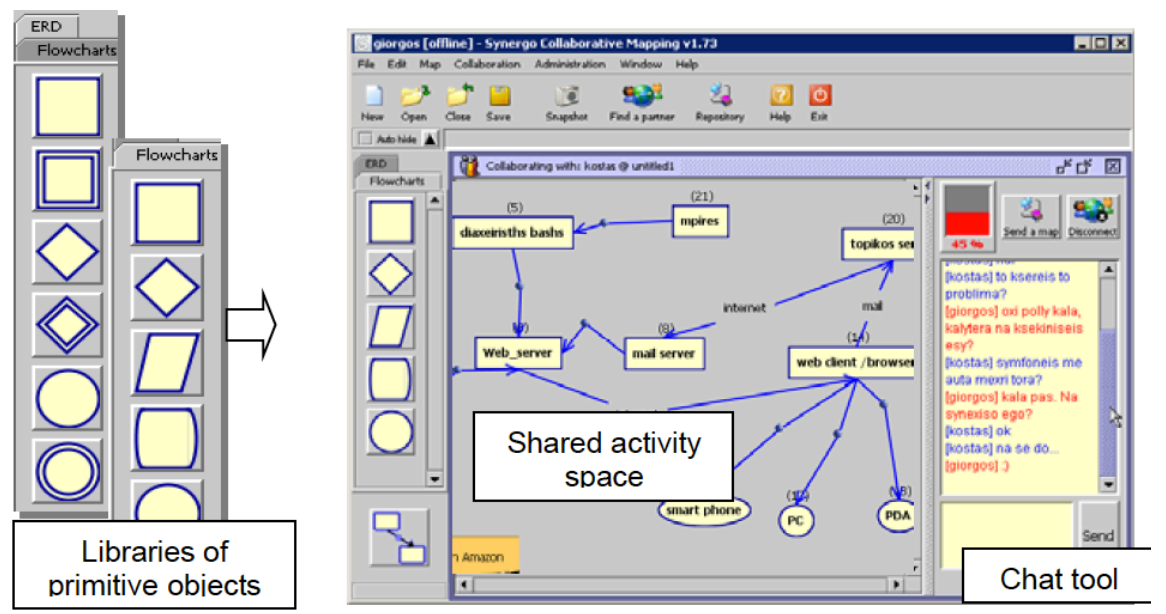

Figura 39: Visualización de la construcción colaborativa en Synergo (Tomado de Avorius et al., 2004, Agosto) 
En la tabla 13 se presentan las herramientas descriptas según los criterios mencionados al inicio de esta sección. Cabe aclarar que, como la totalidad de las herramientas son propietarias, el análisis se convirtió en meta análisis, ya que se hizo a partir de la referencia de los artículos que las mencionan.

\begin{tabular}{|c|c|c|c|c|c|c|c|}
\hline Herramienta & País & $\begin{array}{c}\text { Tipo de } \\
\text { software }\end{array}$ & $\begin{array}{l}\text { Tipo de } \\
\text { licencia }\end{array}$ & Funcionalidades & Awareness & Cuándo & $\begin{array}{l}\text { Interven- } \\
\text { ción } \\
\text { Docente }\end{array}$ \\
\hline $\begin{array}{l}\text { AROMA } \\
\text { Pedersen \& } \\
\text { Sokoler } \\
\text { (1997) }\end{array}$ & USA & Web & Propietario & $\begin{array}{l}\text { Ofrece } \\
\text { visibilidad del } \\
\text { trabajo } \\
\text { conjunto en un } \\
\text { ambiente físico }\end{array}$ & Si. & Durante & No \\
\hline $\begin{array}{l}\text { BABBLE } \\
\text { Erickson et } \\
\text { al. } \\
\text { (1999) }\end{array}$ & USA & $\begin{array}{l}\text { Cliente } \\
\text { servidor }\end{array}$ & Propietario & $\begin{array}{l}\text { Analiza de } \\
\text { información } \\
\text { textual }\end{array}$ & $\begin{array}{l}\text { SI. Sobre } \\
\text { contenido, } \\
\text { relación social y } \\
\text { actividades }\end{array}$ & Durante & No \\
\hline \multicolumn{8}{|c|}{ BIG FIVE Kay et al. (2006) } \\
\hline $\begin{array}{l}\text { RADAR DE } \\
\text { ACTIVIDAD }\end{array}$ & Australia & Web & Propietario & $\begin{array}{l}\text { Muestra grados } \\
\text { de participación } \\
\text { según estándar } \\
\text { predefinido }\end{array}$ & $\begin{array}{l}\text { Si. Participación } \\
\text { según estándar }\end{array}$ & $\begin{array}{l}\text { Antes/ } \\
\text { Durante }\end{array}$ & $\begin{array}{l}\text { Si. Define } \\
\text { el estándar }\end{array}$ \\
\hline $\begin{array}{l}\text { RED DE } \\
\text { INTERACCION }\end{array}$ & Australia & Web & Propietario & $\begin{array}{l}\text { Muestra grados } \\
\text { de participación } \\
\text { según estándar } \\
\text { predefinido }\end{array}$ & $\begin{array}{l}\text { Si. Relaciones } \\
\text { según ARS: } \\
\text { actores, límites } \\
\text { y relaciones }\end{array}$ & Durante & No \\
\hline WATTLE TREE & Australia & Web & Propietario & $\begin{array}{l}\text { Muestra grados } \\
\text { de participación } \\
\text { según estándar } \\
\text { predefinido }\end{array}$ & $\begin{array}{l}\text { Si. } \\
\text { Conversaciones } \\
\text { en el tiempo. }\end{array}$ & Durante & No \\
\hline $\begin{array}{l}\text { CO LAB } \\
\text { van } \\
\text { Joolingen et } \\
\text { al. } \\
(2005)\end{array}$ & $\begin{array}{l}\text { Unión } \\
\text { Europea }\end{array}$ & Web & Propietario & $\begin{array}{l}\text { Entorno de } \\
\text { trabajo } \\
\text { colaborativo } \\
\text { con panel de } \\
\text { control según } \\
\text { herramientas }\end{array}$ & $\mathrm{Si}$ & Durante & No \\
\hline $\begin{array}{l}\text { CLUE } \\
\text { Ogata \& } \\
\text { Yano } \\
(2004)\end{array}$ & Japón & & Propietario & $\begin{array}{l}\text { Información de } \\
\text { trabajo } \\
\text { colaborativo } \\
\text { ubicuo }\end{array}$ & $\begin{array}{l}\text { Si. } \\
\text { Tópicos } \\
\text { Preguntas } \\
\text { Expertos } \\
\text { disponibles }\end{array}$ & Durante & No \\
\hline $\begin{array}{l}\text { COMTELLA } \\
\text { Vassileva et } \\
\text { al. } \\
(2005)\end{array}$ & Canadá & Web & Propietario & $\begin{array}{l}\text { Repositorio de } \\
\text { documentos } \\
\text { con ranking de } \\
\text { usuarios y } \\
\text { preferencias }\end{array}$ & $\begin{array}{l}\text { Si. } \\
\text { Ranking de } \\
\text { usuarios } \\
\text { Recomendación } \\
\text { Aporte de } \\
\text { documentos }\end{array}$ & $\begin{array}{l}\text { Antes } \\
\text { Durante }\end{array}$ & No \\
\hline
\end{tabular}




\begin{tabular}{|c|c|c|c|c|c|c|c|}
\hline Herramienta & País & $\begin{array}{c}\text { Tipo de } \\
\text { software }\end{array}$ & $\begin{array}{l}\text { Tipo de } \\
\text { licencia }\end{array}$ & Funcionalidades & Awareness & Cuándo & $\begin{array}{l}\text { Interven- } \\
\text { ción } \\
\text { Docente }\end{array}$ \\
\hline $\begin{array}{l}\text { Drew } \\
\text { Corbel et al. } \\
(2003)\end{array}$ & $\begin{array}{l}\text { Unión } \\
\text { Europea }\end{array}$ & Web & Propietario & $\begin{array}{l}\text { Muestra } \\
\text { gráficamente el } \\
\text { mapa de } \\
\text { tópicos que se } \\
\text { genera en un } \\
\text { sistema de } \\
\text { argumentación }\end{array}$ & $\begin{array}{l}\text { Si } \\
\text { Mapa de } \\
\text { tópicos }\end{array}$ & Durante & $\begin{array}{l}\text { Si. } \\
\text { Agrega tareas } \\
y \\
\text { participantes }\end{array}$ \\
\hline $\begin{array}{l}\text { I Bee } \\
\text { Mochizuki et } \\
\text { al. } \\
(2005)\end{array}$ & Japón & $\begin{array}{l}\text { Plug in } \\
\text { en un } \\
\text { entorno } \\
\text { virtual }\end{array}$ & Propietario & $\begin{array}{l}\text { Muestra una } \\
\text { conversación } \\
\text { online }\end{array}$ & $\begin{array}{l}\text { Si } \\
\text { Tópicos } \\
\text { Participantes }\end{array}$ & Durante & No \\
\hline $\begin{array}{l}\text { I Tree } \\
\text { Nakahara et } \\
\text { al. } \\
\text { (2003 / } \\
2005)\end{array}$ & Japón & Móvil & Propietario & $\begin{array}{l}\text { Muestra } \\
\text { gráficamente } \\
\text { una } \\
\text { conversación } \\
\text { online }\end{array}$ & $\begin{array}{l}\text { Si } \\
\text { Cantidad de } \\
\text { mensajes } \\
\text { enviados, } \\
\text { mensajes leídos, } \\
\text { mensajes } \\
\text { respondidos y } \\
\text { status de la } \\
\text { conversación } \\
\text { completa }\end{array}$ & Durante & No \\
\hline $\begin{array}{l}\text { Modelling } \\
\text { Space } \\
\text { Avouris et al. } \\
(2004)\end{array}$ & USA & Web & Propietario & $\begin{array}{l}\text { Comunicación } \\
\text { grupal durante } \\
\text { la resolución de } \\
\text { un problema }\end{array}$ & Si & Durante & $\mathrm{Si}$ \\
\hline $\begin{array}{l}\text { Narcissus } \\
\text { Upton \& Kay } \\
(2009)\end{array}$ & USA & Web & Propietario & $\begin{array}{l}\text { Eventos en un } \\
\text { grupo } \\
\text { colaborativo } \\
\text { según } \\
\text { herramientas }\end{array}$ & $\begin{array}{l}\text { Si } \\
\text { Vista de grupo, } \\
\text { proyecto, } \\
\text { tickets } \\
\text { Cantidad de } \\
\text { eventos por } \\
\text { participante } \\
\text { según una línea } \\
\text { de tiempo, en } \\
\text { código de color }\end{array}$ & Durante & $\begin{array}{l}\text { Si. Define } \\
\text { estándares }\end{array}$ \\
\hline $\begin{array}{l}\text { Synergo } \\
\text { Avouris et al. } \\
(2004)\end{array}$ & USA & Web & Propietario & $\begin{array}{l}\text { Análisis de una } \\
\text { conversación }\end{array}$ & $\begin{array}{l}\text { Si } \\
\text { Grado de } \\
\text { colaboración } \\
\text { Evolución de la } \\
\text { actividad de los } \\
\text { actores }\end{array}$ & Después & No \\
\hline
\end{tabular}

Tabla 13: Presentación de herramientas que apoyan el seguimiento del trabajo colaborativo

\subsubsection{Clasificación de herramientas}

Se presenta aquí una clasificación de las herramientas anteriores, propia de esta tesis. Las categorías para esta clasificación se han construido tomando como base los tipos de herramientas descriptos en la sección 5.2. "Herramientas de visualización del trabajo colaborativo". Además, se ha incluido una primera categoría de herramientas colaborativas que se enfocan únicamente en 
el tratamiento del contenido o problema a resolver, sin analizar la colaboración en sí. La última escala del modelo de categorización se corresponde con los entornos digitales colaborativos. Se clasifica, entonces, a las herramientas en un continuum que inicia en los entornos focalizados en el contenido y finaliza en los entornos digitales de colaboración. Las categorías de este modelo son:

- herramientas/entornos colaborativos focalizadas en el contenido;

- herramientas de mirroring;

- herramientas metacognitivas;

- guiding Systems;

- entornos digitales colaborativos.

Ambos extremos del gradiente toman la forma de entornos digitales, con integración de las herramientas. Las herramientas de mirroring, metacognición y guiding son herramientas informáticas desagregadas, que funcionan tomando información de otras herramientas o con la información generada por los participantes de un grupo, por ejemplo, dentro de un entorno virtual de enseñanza y aprendizaje. Se presenta en la tabla 14.

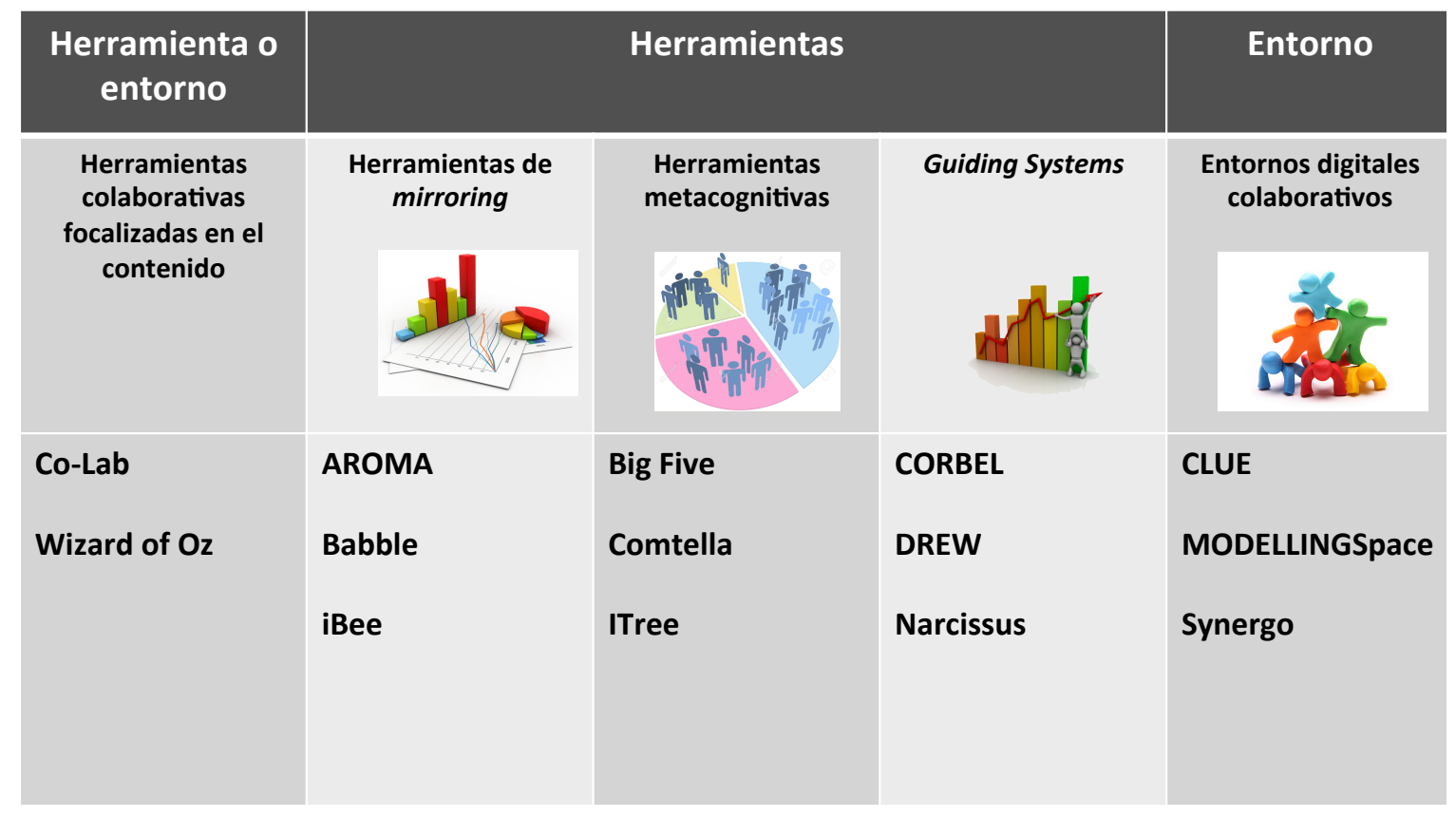

Tabla 14: Gradiente de presentación de herramientas en el gradiente: contenido-mirroring-metacognitiveguiding-entorno digital colaborativo. Modelo propio

\subsection{Conclusiones del capítulo}

En este capítulo se volvió sobre el tema instalado en el capítulo anterior: qué información podría mostrarse acerca de la colaboración, cuándo se podría visualizar y a quién podría servirle. Se ha descripto el estado del arte de las herramientas de visualización de la tarea colaborativa clasificadas según una gradiente que se compone de la siguiente forma:

- herramientas/entornos colaborativos focalizadas en el contenido; 
- herramientas de mirroring;

- herramientas metacognitivas;

- guiding Systems;

- entornos digitales colaborativos.

Este capítulo completa el marco conceptual de la tesis. En el cierre de esta primera parte -Epílogo- se presenta un mapa conceptual de los componentes del trabajo colaborativo según las disciplinas de abordaje presentadas en el capítulo 1: "Introducción". 


\section{Epílogo: Mapa de componentes del trabajo colaborativo según disciplinas}

Para la construcción de este mapa se han tomado las siguientes líneas:

- Está basado en la perspectiva disciplinar presentada en la figura 1, que aparece en la Introducción: "Disciplinas que iluminan el objeto de estudio de esta tesis. Modelo propio".

- Retoma los marcos teóricos vistos, tanto en general (la teoría de la Distancia Transaccional de Michael Moore), como los marcos que iluminan cada uno de los temas: autorregulación, didáctica grupal, modelos de comunicación, indicadores de valoración del trabajo colaborativo desde las perspectivas individual y grupal, etc.

- Está construido por capas o categorías, que se corresponden con las disciplinas intervinientes, intentando integrar los componentes psicológicos, didácticos y tecnológicos que se articulan en el diseño, implementación, evaluación y seguimiento de una actividad colaborativa mediada por tecnología informática en entornos presenciales o de educación a distancia, en ambientes con alta disposición tecnológica. [Cada categoría está marcada en negrita en el mapa].

- Intenta funcionar como un mapa anticipador de los elementos intervinientes, y un check list de temas básicos.

Leyendo el siguiente código QR, con un software específico en un dispositivo móvil con acceso a Internet, se podrá acceder al mapa completo. El mismo mapa se presenta en la siguiente página, en la figura 40.

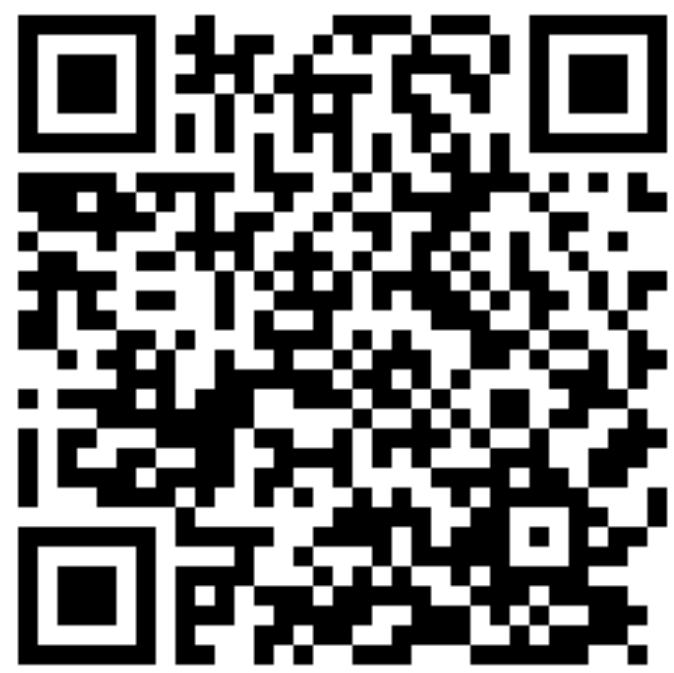


Figura 40: Mapa conceptual de componentes del trabajo colaborativo según disciplinas. Modelo propio 


\section{Segunda parte: Aportes de esta tesis y su} validación 


\section{Capítulo 6: Presentación de la metodología de seguimiento y valoración del trabajo colaborativo (MetSCIn) y su validación}

El recorrido conceptual propuesto para este capítulo es el siguiente:

6.1. Introducción

6.2. Área de vacancia para la presentación de la metodología de seguimiento del trabajo colaborativo

6.2.1. Componentes de una metodología

6.2.2. Componentes de la metodología de seguimiento del trabajo colaborativo mediado por tecnología informática MetSCIn

6.2.3. Implementación de MetSCIn

6.3. Matriz de indicadores de seguimiento del trabajo colaborativo

6.3.1. Objeto de estudio de la matriz

6.3.2. Dimensiones

6.3.3. Indicadores

6.3.4. Operacionalización

6.3.4.1. Indicadores de trabajo individual

6.3.4.2. Indicadores de trabajo grupal

6.4. Instrumentos diseñados $a d$ hoc como parte de MetSCIn

6.4.1. Indagación sobre autorregulación

6.4.2. Estrategia de mirroring

6.4.2.1. Concepto de mirroring

6.4.2.2. Comunicación de la estrategia de mirroring en MetSCIn

6.4.2.3. Estructura propuesta para la presentación de información de mirroring en MetSCIn

6.4.3. Indagación del impacto del mirroring en el trabajo colaborativo en MetSCIn

6.5. Etapas de construcción de la metodología

6.6. Posibilidades de aplicación de la metodología MetSCIn. Uso modular

6.7. Conclusiones del capítulo 


\subsection{Introducción}

Esta segunda parte representa el eje central de la tesis. En los tres capítulos que la componen se describe el recorrido metodológico que se ha seguido para construir cada uno de los aportes de valor agregado y se explica cómo se ha procedido a su validación.

Se propone aquí una metodología de análisis de un constructo teórico, intangible, con aristas que entraman en disciplinas humanísticas e informáticas como es el trabajo colaborativo. En la primera parte, marco conceptual, se ha dado cuenta de los conceptos asociados a este tema, y se ha ofrecido un mapa -construido por enfoque disciplinar- que posibilita un acercamiento a su complejidad.

En concordancia con el objetivo general de la tesis, este capítulo presenta la metodología de seguimiento y valoración de actividades colaborativas mediadas por tecnología informática. Se retoma el estado del arte del marco conceptual y se presenta y describe la metodología. Como componente de esta metodología, se presenta la matriz de indicadores.

En la figura 2 presentada en el capítulo 1, se anticipa el marco metodológico. Se presenta con la siguiente secuencia: 1. definición de la metodología de seguimiento de trabajo colaborativo; 2. construcción de la matriz de indicadores de seguimiento como parte de esta metodología; 3. validación de la matriz de indicadores a través del juicio de expertos; y 4. implementación de la metodología (con la matriz validada) en el estudio de caso con grupos contrastados. Esta secuencia se retoma en los tres capítulos de esta segunda parte. En el capítulo 6 (este capítulo) se presenta la metodología completa; en el capítulo 7 se avanza en la explicación del procedimiento de evaluación de la matriz de indicadores mediante el juicio de expertos y sus resultados y en el capítulo 8 se presenta la descripción del estudio de caso en el que se aplicó la metodología completa y sus resultados.

\section{2. Área de vacancia para la presentación de la metodología de seguimiento del trabajo colaborativo}

Algunas de las preguntas que dieron origen a este trabajo estuvieron relacionadas con la existencia y validación de metodologías de seguimiento del trabajo colaborativo mediado por tecnología informática, que dieran cuenta de los fenómenos de interacción e interactividad. En la figura 3, presentada en el capítulo 1 de esta tesis, se formulaban de la siguiente forma:

- ¿Existen metodologías para identificar, describir y valorar la interacción y la interactividad en el trabajo colaborativo?

- ¿Qué aspectos miran de la interacción? ¿Y de la interactividad?

- ¿Qué indicadores se utilizan para analizar la construcción colaborativa?

Luego de recorrer el marco conceptual y establecer el estado del arte de las metodologías e indicadores de seguimiento, se consideró que existe aún un área de vacancia en referencia a las metodologías de seguimiento del trabajo colaborativo y a la construcción de sus indicadores desde la perspectiva interdisciplinar. Esta situación habilita, entonces, la presentación de un aporte original, en términos de la construcción de una metodología completa, que analice el trabajo colaborativo considerando sus etapas e incluya indicadores desde las perspectivas humanística e informática, individual y grupal.

La metodología aquí presentada permitiría responder a las preguntas anteriores y avanzaría sobre la última de las preguntas de la Introducción. Esta última cuestión se trata de: ¿existen herramientas que faciliten este seguimiento?. En este sentido, el capítulo 5 presenta un estado 
del arte de las herramientas de seguimiento del trabajo colaborativo bajo la clasificación de mirroring - metacognitive - guiding. Conforme se fue avanzando en la investigación bibliográfica y la exploración de herramientas fueron surgiendo nuevas preguntas, que refinaron las iniciales. Se sumó, entonces, una nueva pregunta que la metodología propuesta también trata de atender: ¿cómo funciona un grupo colaborativo desde las dimensiones individual y grupal si sus miembros van conociendo su desempeño en tiempo real y online?

La estrategia que subyace a esta pregunta se conoce con el nombre de mirroring y fue presentada conceptualmente en el capítulo 5. Para responder a esta nueva pregunta, subsidiaria de las iniciales, se diseñó un componente metodológico, que toma la forma de intervención didáctica específica, y crea un contexto que permite atenderla. Así, la metodología aquí propuesta incluye un componente que analiza la construcción colaborativa con una estrategia de mirroring, seguida por la indagación de su impacto. Esta estrategia, además de formar parte de la metodología descripta en este capítulo, fue implementada en el estudio de caso que se describe en el capítulo 8 de esta tesis. Como se verá más adelante, permitió extraer conclusiones específicas en el estudio de la cohorte de estudiantes 2016.

\subsubsection{Componentes de una metodología}

Para la presentación de la metodología se tuvieron en cuenta antecedentes de modelos metodológicos referidos a la ingeniería de software en general y a la apropiación de estos modelos en contextos educativos, en particular. Así, la estructura con la que se presenta la metodología tiene dos fuentes principales:

En cuanto a sus componentes: el modelo de presentación de metodologías ágiles en el diseño de software, basado en los trabajos de Canós, Letelier \& Penadés (2003).

En cuanto a sus etapas (presentadas en la sección 5.5: "Etapas de construcción de la metodología"), los estudios de Díaz-Antón, Pérez, Grimmán \& Mendoza (2006), quienes se basaron en la metodología Rational Unified Process (RUP) de desarrollo de software del área de la ingeniería y la adaptaron a la construcción de software educativo.

\subsubsection{Componentes de la metodología de seguimiento del trabajo colaborativo mediado por tecnología informática MetSCIn}

La metodología propuesta en esta tesis tiene como objetivo realizar el seguimiento y valoración del trabajo colaborativo mediado por tecnología informática. Con estas palabras se forma el acrónimo que le da el nombre: MetSCIn (Metodología de Seguimiento del Trabajo Colaborativo mediado por Tecnología Informática). Se ha construido considerando los siguientes componentes:

- Objeto (con sus dimensiones de análisis)

- Etapas

- Actores

- Modelo teórico subyacente

- Indicadores

- Espacios de construcción colaborativa y seguimiento del trabajo, según etapas

- Instrumentos 
- Tecnología involucrada

El objeto es el qué de la metodología. En este caso, el trabajo colaborativo mediado por tecnología informática configura el objeto de la metodología de seguimiento. Siguiendo los trabajos de Driscoll \& Vergara (1997) se llegó a la conclusión de que este objeto tiene dos dimensiones o perspectivas de análisis: individual y grupal.

Es posible considerar que existen metodologías que funcionan por aproximaciones sucesivas a su objeto de estudio. Esto consolida el cuándo de la metodología y, a su vez, organiza la tarea de los involucrados en su implementación. En este caso, las etapas de la metodología didáctica de trabajo colaborativo (presentadas en el capítulo 3) funcionan como organizadoras de las etapas metodológicas de su estudio. Esta metodología contempla un análisis del trabajo individual (coincidente con la etapa individual del trabajo colaborativo) y un análisis individual y grupal de lo construido durante el trabajo en grupo (fase colaborativa en sí). La tarea de análisis semántico de las comunicaciones del grupo debe realizarse una vez que la actividad ha finalizado (o en el momento post mortem de la actividad). En el caso de la implementación de la estrategia de mirroring, la tarea de seguimiento y publicación de la información se debe llevar adelante al mismo tiempo en que la actividad se está desarrollando. Además, considera un análisis de las condiciones de entrada de los participantes de la actividad a través de la indagación de la autopercepción sobre habilidades de autorregulación para el estudio y trabajo en equipo. En la sección 6.2.3. "Implementación de MetSCIn" se volverá sobre este tema con mayor detalle.

Los actores son quiénes implementan la metodología. Por la perspectiva necesaria para el análisis, debería ser implementada por un investigador (vinculado o no con la propuesta didáctica) y/o por los docentes que lleven adelante la actividad de trabajo colaborativo, posicionándose en el rol de investigadores. Si la estrategia incluye un modelo de intervención didáctica de mirroring, debería ser llevado adelante por un docente o tutor, con gran vinculación con la propuesta, para realizar la intervención dentro de ese contexto.

El tema de los modelos teóricos subyacentes está relacionado con la (¿falsa?) antinomia entre los modelos cuanti y cualitativos. Una comparación puede verse en la figura 41, según el trabajo editado por Cook \& Reichardt. 


\begin{tabular}{|c|c|}
\hline Aboga por el empleo de los métodos cualitativos & Aboga por el empleo de los métodos cuantitativos \\
\hline $\begin{array}{l}\text { Fenomenologismo y verstehen (comprensión) "interesado } \\
\text { en comprender la conducta humana desde el propio marco } \\
\text { de referencia de quien actúa". }\end{array}$ & $\begin{array}{l}\text { Positivismo lógico; "busca los hechos o causas de los } \\
\text { fenómenos sociales, prestando escasa atención los estados } \\
\text { subjetivos de la individuos"* }\end{array}$ \\
\hline Observación naturalista y sin control & Medición penetrante y controlada \\
\hline Subjetivo & Objetivo \\
\hline Próximo a los datos; perspectiva "desde dentro". & Al margen de los datos; perspectiva" desde fuera". \\
\hline $\begin{array}{l}\text { Fundamentado en la realidad, orientado a los } \\
\text { descubrimientos, exploratorio, expansionista, descriptivo } \\
\text { e inductivo }\end{array}$ & $\begin{array}{l}\text { No fundamentado en la realidad, orientado a la } \\
\text { comprobación confirmatorio, reduccionista, interencial e } \\
\text { hipotético. }\end{array}$ \\
\hline Orientado al proceso. & Orientado al resultado. \\
\hline Válido: datos "reales", "ricos" y "profundos. & Fiable: datas "sólidos" y repetibles. \\
\hline No generalizable: estudios de casos aislados. & Generalizable: estudios de casos múltiples. \\
\hline Holista & Particularista \\
\hline Asume una realidad dinámica & Asume una realidad estable \\
\hline
\end{tabular}

Figura 41: Comparación de los paradigmas cuanti y cualitativo. (Cook \& Reichardt, 1979, pág. 5 )

Autores reconocidos en el campo de la investigación en general y de la investigación educativa en particular (Cook \& Reichardt, 1979; Cohen \& Manion, 2002; Cohen, \& Swerdlik, 2001; Monje Álvarez, 2011; Rockwell, 1980; Salinas, 2012) proponen la integración y complementación de estos modelos. En palabras de Cook \& Reichardt "el empleo conjunto de los métodos posibilitaría atender a las múltiples necesidades de la investigación [...] Algunas adaptaciones útiles pueden suponer un maridaje creativo de los métodos cualitativos y de los cuantitativos, como, por ejemplo, el empleo de experimentos aleatorios con observadores participantes" (Cook \& Reichardt, 1979, pág. 12). La metodología aquí propuesta combina la perspectiva cuantitativa con la cualitativa. En la selección de indicadores se toma en cuenta tanto información objetiva - paradigma cuantitativo- como algunas interpretaciones de la realidad desde contextos particulares -paradigma cualitativo-.

El componente central de esta metodología está constituido por una matriz de indicadores que considera el estado del arte descripto en la primera parte de este trabajo. Incluye las dimensiones individual y grupal, y cada uno de los espacios de construcción en la operacionalización de estos indicadores. Se volverá sobre este tema en la sección siguiente.

Como espacios de construcción colaborativa se considera el espacio de construcción de cada una de las herramientas disponibles para la tarea colaborativa. Deben considerarse los espacios tecnológicos que la consigna didáctica haya puesto a disposición para el trabajo colaborativo y los que cada grupo haya decidido usar: mensajes electrónicos (e-mails), foro, wiki, videoconferencia, bitácora, grupos de WhatsApp, espacios de trabajo colaborativo en Google, sistemas tipo groupware o los que se haya decidido habilitar. Estos espacios podrían estar concentrados en un entorno virtual de enseñanza y aprendizaje o desagregados, en diferentes herramientas. La metodología funcionaría de la misma forma, siempre que el evaluador/investigador tenga acceso al contenido producido en cada uno de estos espacios.

Atendiendo a la integración de modelos teóricos, los instrumentos utilizados abrevan en ambos paradigmas. Al decir de Cook \& Reichardt "el conocimiento cualitativo puede 
beneficiarse del conocimiento cuantitativo. Incluso los investigadores más introspectivos y de orientación más subjetiva no pueden prescindir del hecho de contar elementos o de emplear conceptos cuantitativos como "más grande que" y "menos que". La medición cuantitativa puede corregir la observación cualitativa, al tiempo que se basa en ésta y un hallazgo cuantitativo puede estimular una ulterior indagación cualitativa" (Cook \& Reichardt, 1979, pág. 13). Así, la metodología propone integrar técnicas de análisis cuantitativo de la densidad de interacción, combinadas con el análisis cualitativo de la calidad de interacción. Para el análisis cuantitativo, la metodología propone considerar:

a. Cantidad de mensajes enviados durante todo el tiempo de la tarea.

b. Cantidad de mensajes enviados por cada miembro de cada grupo.

c. Promedio de mensajes enviados (número de mensajes en relación con el número de días de trabajo).

d. Cantidad de mensajes enviados en cada etapa de la resolución de la tarea y su promedio.

e. Comparación entre grupos.

Cabe aclarar que la consideración de las etapas del trabajo está fuertemente ligada a la consigna y al modo de trabajo de cada grupo. Según la definición de trabajo colaborativo de esta tesis, hay dos etapas pre definidas: etapa individual y etapa colaborativa propiamente dicha. El seguimiento detallado y organizado de la tarea grupal permite definir sub etapas al interior de la actividad colaborativa propiamente dicha. Al menos, tres: inicio-desarrollo y cierre.

En relación con el análisis cualitativo, se realiza a través de la interpretación de las intervenciones individuales. Entonces, se analizan:

a. Cantidad de mensajes según su tipo: organización, contenido, afectividad.

b. Cantidad de mensajes por tipo y por etapa.

La matriz de indicadores, que se describe en el apartado siguiente, ofrece orientaciones para estos dos tipos de análisis.

En cuanto a la tecnología involucrada, tanto el trabajo en sí (el QUÉ de esta metodología) como la metodología de seguimiento propiamente dicha se enmarcan en entornos digitales. Por esto, las herramientas utilizadas para indagar en el trabajo colaborativo son digitales. La metodología MetSCIn propone dos encuestas en formato electrónico y un sitio online de seguimiento que posibilita la estrategia de mirroring.

La figura 42 muestra la metodología, con sus componentes y una descripción sintética de cada uno de ellos. 


\begin{tabular}{|c|c|}
\hline \multicolumn{2}{|r|}{ Componentes de la metodología propuesta } \\
\hline Objeto & $\begin{array}{l}\text { Trabajo colaborativo mediado por tecnología informática } \\
\text { Dimensiones: individual y grupal }\end{array}$ \\
\hline Etapas & $\begin{array}{l}\text { Trabajo individual } \\
\text { Trabajo grupal } \\
\text { "Post Mortem" (una vez terminada la actividad) } \\
\text { Mirroring según tipo de awareness (activo o pasivo). Durante la actividad + impacto post } \\
\text { mortem }\end{array}$ \\
\hline Actores & $\begin{array}{l}\text { Docente - investigador } \\
\text { Tutor (para mirroring) }\end{array}$ \\
\hline $\begin{array}{l}\text { Modelo teórico } \\
\text { subyacente }\end{array}$ & $\begin{array}{l}\text { Modelos cuantitativos: Mide densidad de interacción } \\
\text { Modelos cualitativos: Analiza calidad de interacción }\end{array}$ \\
\hline Indicadores & Matriz de indicadores \\
\hline $\begin{array}{l}\text { Espacios de } \\
\text { seguimiento }\end{array}$ & $\begin{array}{l}\text { Mensajes electrónicos (dentro o fuera de un EVEA) } \\
\text { Foros } \\
\text { Wikis } \\
\text { Blogs } \\
\text { Videoconferencia } \\
\text { Documentos de GoogleDocs } \\
\text { Diarios de bitácora }\end{array}$ \\
\hline Instrumentos & $\begin{array}{l}\text { Medición } \\
\text { Interpretación. } \\
\text { Comunicación de seguimiento y mirroring } \\
\text { Indagación. E-encuestas } \\
\quad \bullet \text { Autorregulación } \\
\quad \text { Impacto del mirroring }\end{array}$ \\
\hline Tecnología & $\begin{array}{l}\text { Las herramientas que generan los espacios de seguimientos mencionados. } \\
\text { Las herramientas que median los instrumentos mencionados. }\end{array}$ \\
\hline
\end{tabular}

Figura 42: Componentes de la metodología MetSCIn presentada en esta tesis

\subsubsection{Implementación de MetSCIn}

La metodología aquí presentada fue diseñada para ser implementada en etapas, de acuerdo a las consideraciones didácticas acerca del trabajo colaborativo que se han presentado en el marco conceptual de este trabajo. Estas etapas permitirían seguir el trabajo colaborativo propiamente dicho, con sus correspondientes sub etapas. Así, hay instrumentos que deberán ser aplicados antes de la tarea, incluso para constituir los grupos de trabajo bajo condiciones de grupalidad; otros en la etapa individual del trabajo; otros durante la etapa colaborativa (con sus sub etapas: inicio, desarrollo y cierre) y otros al finalizar la actividad, luego de cerrar la tarea o post mortem.

En la figura 43 se presentan los instrumentos mencionados y las consideraciones metodológicas trabajadas de acuerdo a las etapas de implementación. 


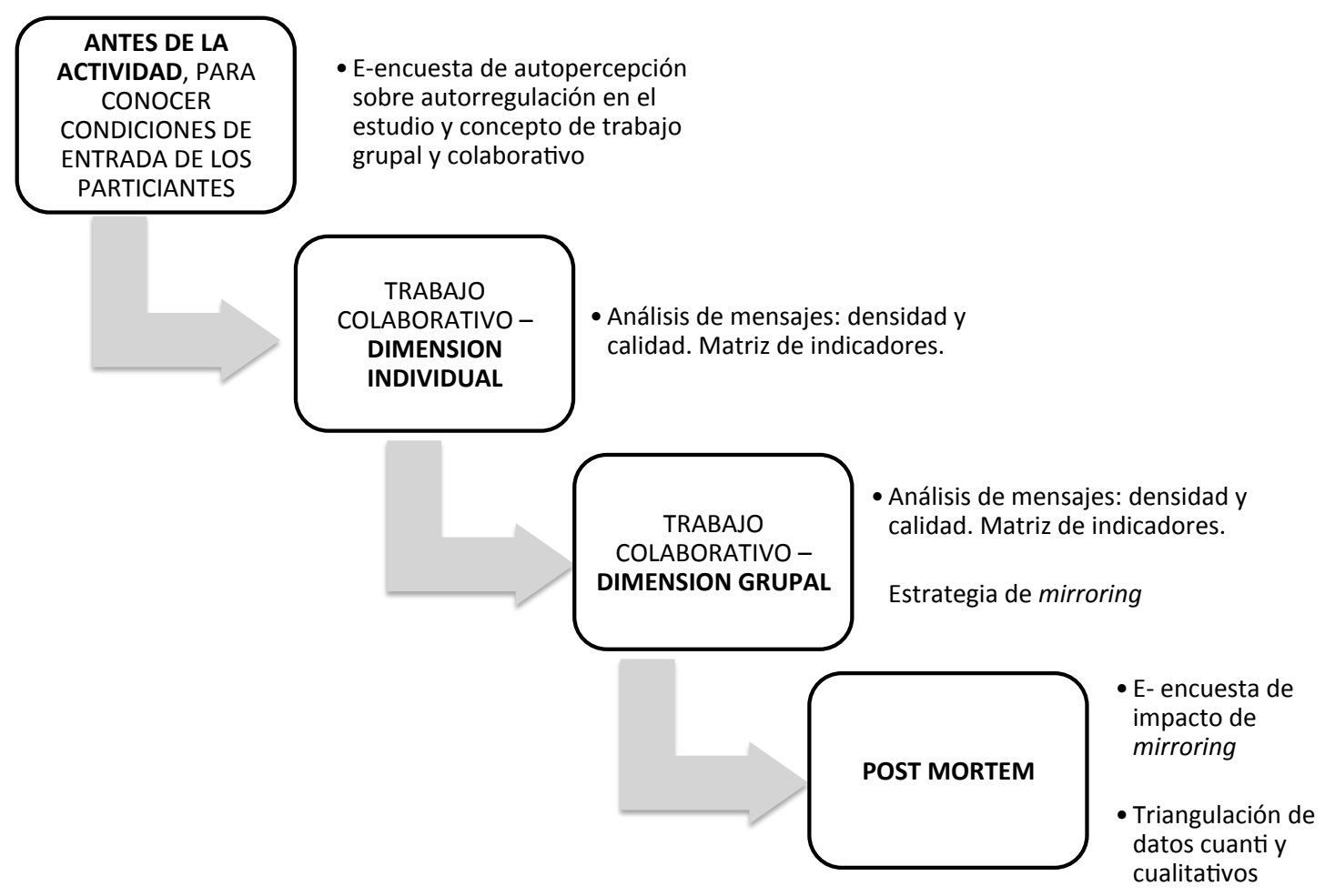

Figura 43: Etapas de implementación de MetSCIn

\subsection{Matriz de indicadores de seguimiento del trabajo colaborativo}

Un componente clave de MetSCIn, que funciona como un faro, iluminando qué mirar a cada paso y qué elementos del trabajo individual y grupal considerar es la matriz de indicadores de colaboración. En el capítulo 4 se ha presentado el sustrato conceptual que subyace al análisis del trabajo colaborativo y el estado del arte que da cuenta de cómo se ha desagregado su estudio en indicadores, según las diferentes disciplinas y marcos de análisis y experimentación. Un modelo que comprenda el trabajo colaborativo podría verse, entonces, desde dos puntos de vista complementarios: desde el punto de vista comunicacional y educativo y desde la interpretación de la información recogida por las herramientas tecnológicas utilizadas. En un modelo que organice esta información sería posible entender ambos aspectos, cada uno con su propio significado. Desde el punto de vista psicológico-educativo se ofrecería información sobre el desempeño de cada miembro del grupo. Entretanto, las herramientas tecnológicas podrían reflejar la interdependencia que es necesaria en cualquier grupo de trabajo colaborativo.

Como ideas clave del capítulo 4 se han mencionado:

- Las dimensiones individual y grupal del concepto de interdependencia positiva de Driscoll \& Vergara, 1997.

- El concepto de entendimiento compartido o grounding, de Baker (en Spermon et al., 2014), que podría relacionarse con el concepto de granularidad de los mensajes (Chi, 1997).

- El modelo de argumentación de Toulmin (en Karbach, 1987).

- El concepto de conexión semántica en Stahl et al., 2006. 
- La idea de cohesión de la comunicación de Reyes \& Tchounikine (en Dimitrakopoulou et al., 2006).

Conciliando estos indicadores y sus marcos de referencia en un modelo integrador que, a la vez, tenga potencialidad descriptiva y explicativa, se ha llegado a la siguiente matriz de indicadores de colaboración. Este modelo considera la integración del concepto de interdependencia positiva con sus dimensiones, los indicadores para su estudio y la operacionalización en los eventos de colaboración. Se presenta la matriz en la figura 44. Esta matriz corresponde a la versión final, enriquecida por el resultado de la evaluación del juicio de expertos. Se describirá en detalle este procedimiento en el capítulo siguiente.

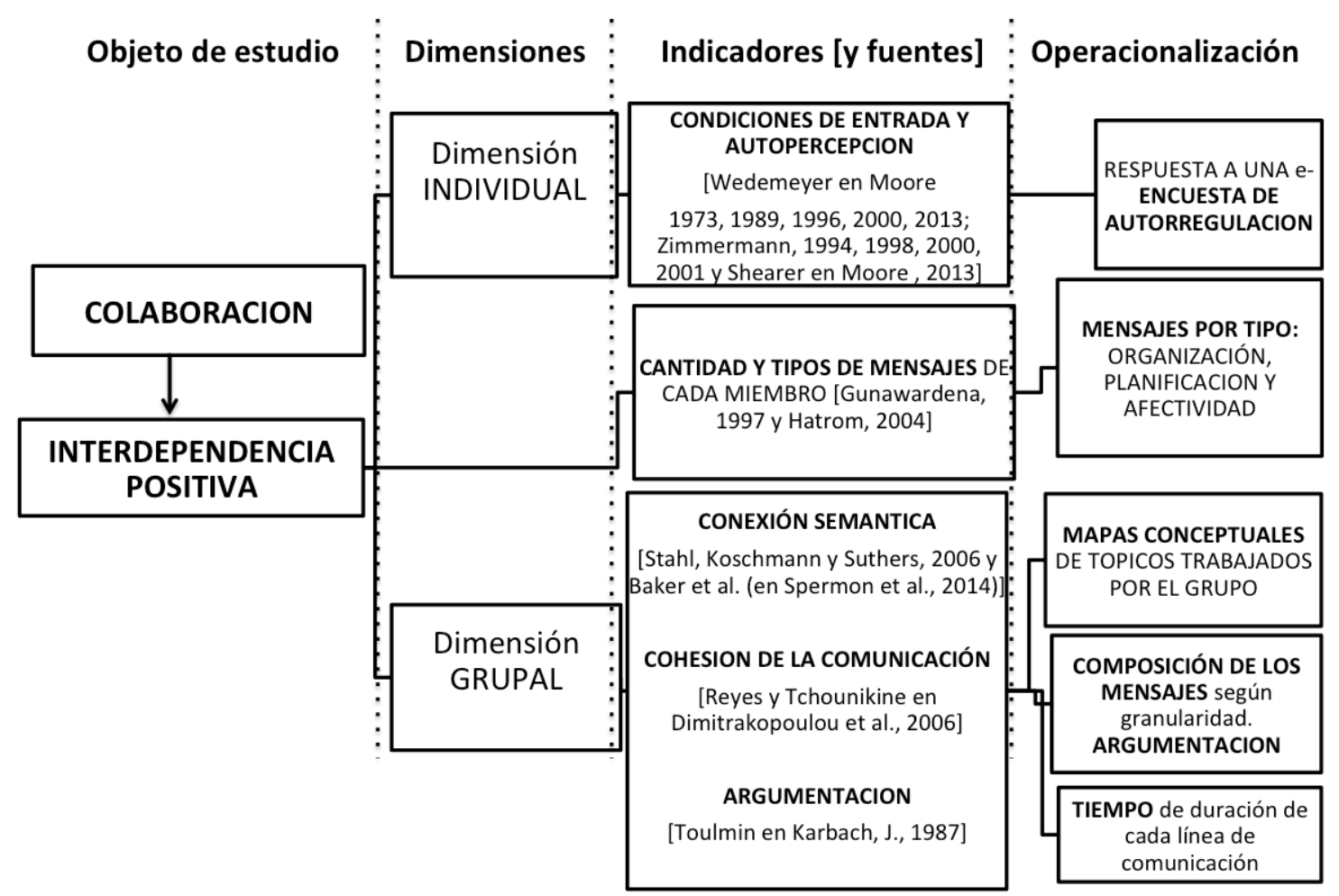

Figura 44: Matriz de indicadores de colaboración de MetSCIn

Esta matriz cuenta con cuatro componentes metodológicos:

- Objeto de estudio

- Dimensiones

- Indicadores

- Operacionalización

En la próxima subsección se explica cada uno de estos componentes.

\subsubsection{Objeto de estudio de la matriz}

Como se ha dicho, el objeto de estudio es la forma en la que se define el fenómeno de interés. En la matriz se han definido dos componentes que forman parte sustantiva de este estudio: la colaboración y la interdependencia positiva. En los capítulos 3 y 4 del marco conceptual se ha seguido la línea de Driscoll \& Vergara (1997) quienes consideran a la interdependencia positiva como uno de los elementos clave de la colaboración. Esto significa que 
los miembros de un grupo se necesitan unos a otros para poder llevar adelante la tarea. Si se retoman los grados de trabajo grupal y colaborativo de Manso et. al (2011) presentados en el capítulo 3, puede observarse que el trabajo colaborativo es el estadío más desarrollado del trabajo grupal, en el que todos los integrantes deben desarrollar su tarea en pos de dos logros: en cuanto al contenido propio de la tarea y en lo referente a la organización de la tarea grupal. La interdependencia es, entonces, sinónimo de colaboración. Por lo tanto, la matriz se enfoca en descomponer este concepto en sus dimensiones para alcanzar su análisis, seguimiento y posterior validación.

\subsubsection{Dimensiones}

En cuanto a las dimensiones de la interdependencia positiva, se sigue a Driscoll \& Vergara (1997) y a Gunawardena et al. (1997) en la idea de las dimensiones individual y grupal como capas del trabajo colaborativo. Esta fue una de las preocupaciones que guió la construcción de la metodología en general, y de la matriz en particular. Cómo discriminar, a partir del seguimiento y la observación del trabajo, ambas dimensiones: hasta dónde se trabaja individualmente y dónde comienza el trabajo sinérgico del grupo (puede verse conceptualmente este tema en el apartado 3.2.1. "Del objeto discreto al colectivo: la tensión individuo-grupo y su relación con la tecnología digital). Se definen indicadores para cada una de las dimensiones.

\subsubsection{Indicadores}

La dimensión individual del trabajo colaborativo podría definirse como lo que cada uno de los integrantes del grupo hace en forma solitaria, a su propio ritmo y con sus habilidades cognitivas y metacognitivas (Driscoll \& Vergara, 1997). Los indicadores que se han construído para esta dimensión están basados en los tipos de mensaje que los integrantes de un grupo intercambian por medio de herramientas informáticas. En el capítulo 4 se presentó una integración conceptual de los indicadores descriptos por Gunawardena et al. (1997) e Ingram \& Hathorn (2004). Se construyeron en las siguientes categorías:

Mensajes de organización (Función metacognitiva). Relacionados con la forma en la que se lleva adelante la tarea: aclaraciones sobre la consigna, manejo del tiempo, organización de las sub tareas, división de roles en el grupo, responsables de cada tarea, indicadores de avance, eventos de comunicación grupal, herramientas a utilizar, estrategias de repaso y entrega de la tarea, etc.

Mensajes de contenido (Función cognitiva). Vinculados al contenido de la actividad que se debe hacer. Pertenecen a esta categoría los mensajes referidos a las fuentes de información, lecturas, manejo conceptual, relación entre conceptos, construcción del discurso grupal (generación de hipótesis, aceptación o rechazo de éstas), consistencia de la actividad completa y sus partes, existencia de todas las perspectivas de análisis, etc.

Mensajes de afectividad (Función afectiva). Vinculados a los componentes afectivos del aprendizaje: motivación, empatía, solidaridad, comprensión, ayuda, etc.

Además de los tipos de mensajes individuales, se incluyó en la matriz un componente central, tanto desde la teoría que da marco a esta tesis como desde la metodología de seguimiento presentada: la autorregulación en el aprendizaje (Wedemeyer en Moore 1973, 1989, 1996, 2000, 2013; Zimmermann, 1994, 1998, 2000, 2001 y Shearer en Moore, 2013). Se trata de un componente individual que oficia como requisito de entrada al trabajo grupal. Este tema fue presentado en el capítulo 2 y puede verse en el apartado 2.1.1.3. "Autonomía del estudiante". En este sentido, la metodología incluye la implementación de una e-encuesta de autopercepción 
sobre autorregulación, que será presentada más adelante en este capítulo y que se propone implementar previamente al inicio del trabajo colaborativo. Esta herramienta permitiría conocer de antemano algunas prácticas cognitivas y metacognitivas de los estudiantes, con vistas a favorecer estrategias de grupalidad.

En cuanto a la dimensión grupal, la matriz intenta discriminar los elementos que forman parte de la construcción colaborativa. Así, se integran los trabajos de distintos autores, de diferentes disciplinas, que contribuyen a entender esta construcción. Se retoman los estudios de Baker (en Spermon et al., 2014) quienes sostienen que para aprender en colaboración se necesita algún tipo de entendimiento compartido o grounding. En el marco del trabajo grupal, se define este nivel de entendimiento como el que permite que el grupo acuerde las cuestiones suficientes (de organización y contenido) para avanzar hacia el siguiente paso. Stahl et al. (2006) reafirman esta concepción, al presentar a la colaboración como un proceso de construcción de significados compartidos. A este concepto se asocia el de cadenas de sentido de Stahl (2006). El autor las presenta diciendo: "la creación de sentido no es únicamente la expresión de las representaciones mentales de los participantes individuales, es un logro interaccional" (Stahl, 2006, pág. 415). El logro de aprendizaje colaborativo implica fenómenos como la negociación y el intercambio de significado. Este indicador se definió en la matriz como conexión semántica.

La cohesión de la comunicación es el segundo de los indicadores grupales construidos en esta matriz. Se trata de otro aspecto de la construcción comunicativa que contribuye a su calidad. Se sigue a Reyes \& Tchounikine (en Dimitrakopoulou et al., 2006) y se considera tanto desde el punto de vista semántico (de qué habla el grupo) como pragmático (cuán eficiente es para orientarse al objetivo y proceder en consecuencia). Se toma el concepto de cohesión de estos autores entendido como la dispersión de información en el grupo. Esto significa cuán eficiente resulta el grupo para llegar, en cada línea de comunicación, a cada tema clave y tomar las decisiones correspondientes. En el siguiente apartado de "Operacionalización" se explicará cómo se ha abordado el análisis de este tema y su visualización.

El tercer indicador de la construcción grupal es el de la argumentación. Este componente formó parte del marco conceptual de esta tesis, y se incorporó finalmente como una categoría de indicador a partir del resultado del juicio de expertos, instancia en la que se confirmó su relevancia. Se tomó el modelo de argumentación presentado en el capítulo 4 (Toulmin en Karbach, 1987) que contiene los siguientes elementos:

- Argumento (Claim): Punto de partida. Argumento inicial. Puede ser una afirmación, premisa o idea.

- Evidencia (Ground): Datos empíricos o evidencia que fundamentan el argumento inicial.

- Garantía (Warrant): Vincula la evidencia a la idea inicial y ofrece mayor fundamento.

- Respaldo (Backing): Establece la confiabilidad y relevancia de la garantía.

- Calificador (Qualifier): Construcciones lingüísticas modeladoras que permiten atenuar una afirmación.

- Refutaciones (Rebuttal): Condiciones de refutación que pueden menguar la eficacia de los argumentos y refutan la afirmación inicial.

\subsubsection{Operacionalización}

Se presenta en este apartado la implementación empírica de cada uno de los indicadores. Según Cohen \& Manion (1987) la operacionalización permite convertir un concepto teórico en 
empírico, focalizar qué componentes de la realidad se deben analizar como correspondientes a cada idea teórica. Se refiere, entonces, a la unidad de análisis que permite visualizar el comportamiento y/o la variación de cada indicador. Por lo tanto, la matriz se completa con la operacionalización de cada indicador. Se describen a continuación.

\subsubsection{Indicadores de trabajo individual}

Estos indicadores se observan y analizan en base a dos componentes. La autopercepción sobre las estrategias de autorregulación como condición de entrada para la construcción colaborativa, que se trabaja a partir de la implementación de una encuesta en formato digital, que se propone administrar a los estudiantes antes del comienzo de la actividad colaborativa. Más adelante, en este capítulo, se presentará en detalle este instrumento y sus categorías de análisis. Durante el trabajo individual, que representa la primera etapa del trabajo colaborativo, la unidad de análisis está compuesta por los mensajes intercambiados y su tipología. Sobre el corpus de comunicación, se proponen dos tipos de análisis: cuantitativo y cualitativo. Como se mencionó en la presentación de la metodología, desde el punto de vista cuantitativo se considera la densidad de interacción. En cuanto al análisis cualitativo, se analiza la calidad de interacción.

Para analizar el contenido de los mensajes se retoma la tipología de mensajes presentada en el capítulo 4, en la tabla 10. Para identificar los tipos de mensaje se propone el método de análisis por unidades semánticas, retomando la propuesta de análisis de contenido en la que se siguió a Cáceres (2008). Se propone, entonces, el análisis de los intercambios de mensajes en los siguientes términos:

- objetivo y contenido (el título del aporte puede dar cuenta de este aspecto);

- relación con la tarea/etapa del trabajo;

- función dentro de la cadena de sentido: abre un tema, desarrolla o cierra (a-b-c);

- sujeto de la enunciación (quién escribe explícitamente);

- a quiénes va dirigido (cómo se refiere al grupo, uso de metáforas);

- componentes emocionales;

- coherencia y sentido del texto (dice lo que se propone decir);

- palabra/s clave (la metodología de análisis por unidades semánticas propone trabajar con una lista de palabras. Se presentan algunas en la tabla 11);

- puntos de gramática (los signos de puntuación, uso de pronombres inclusivos);

- fin del mensaje (compromisos, promesas).

Si bien el análisis de contenido es subjetivo, resulta de gran utilidad recurrir a una herramienta que auxilia en la detección de cada tipo de mensaje y su contenido. MetSCIn propone trabajar con una lista de palabras clave, en este sentido también se siguió a Cáceres (2008) que se corresponde con cada componente de los mensajes. Una estructura posible de lista de palabras clave se presenta en la tabla 15 . 


\begin{tabular}{|c|c|}
\hline CATEGORIA & PALABRA CLAVE \\
\hline $\begin{array}{l}\text { PLANIFICACION / } \\
\text { organización }\end{array}$ & $\begin{array}{l}\text { Organicémonos } \\
\text { Tiempo } \\
\text { Entrega } \\
\text { Consigna } \\
\text { Ocupaciones } \\
\text { Formato }\end{array}$ \\
\hline CONTENIDO & $\begin{array}{l}\text { Individual } \\
\text { Aporte } \\
\text { Autores } \\
\text { [Escritura colaborativa] } \\
\text { [Índice] } \\
\text { [Tapa] } \\
\text { [Contratapa] }\end{array}$ \\
\hline AFECTIVIDAD & $\begin{array}{l}\text { ¡Felicitaciones! } \\
\text { Gracias } \\
\text { Orgullo (orgulloso/orgullosa) } \\
\text { Felicitaciones } \\
\text { Satisfacción } \\
\text { ¡Al fin! } \\
\text { ¡Entregamos! } \\
\text { Signos de admiración } \\
\text { Signos de pregunta } \\
\text { Emoticones (escritos con el } \\
\text { teclado o los predefinidos en } \\
\text { Google) }\end{array}$ \\
\hline
\end{tabular}

Tabla 15: Lista de palabras clave para cada categoría de mensajes. Los que están entre corchetes corresponden al contenido de la tarea especifica.

En este punto corresponde hacer una aclaración: las palabras clave de las categorías de organización y afectividad pueden ser utilizadas con cierta independencia del tipo de trabajo colaborativo del que se trate (puede verse en el "Epílogo" del marco conceptual de este trabajo la cantidad de variables a considerar en la definición de la consigna del trabajo colaborativo, con las categorías de macro y micro estructura de la actividad). Las palabras clave de la categoría contenido están vinculadas a la micro tarea (el tipo de tarea de que se trate) y a la consigna específica. En la tabla anterior, entre corchetes, aparecen las palabras referidas al tipo de tarea colaborativa encomendada a los participantes que formaron parte del estudio de caso de esta tesis, que se trató de una actividad de escritura colaborativa. Entonces, la categoría "Contenido" deberá ajustarse: el investigador deberá incluir las palabras específicas del tipo de tarea indicada al grupo.

\subsubsection{Indicadores de trabajo grupal}

Para el análisis de la conexión semántica, y tal como se presenta en la matriz de indicadores, la unidad de análisis es el mapa conceptual de tópicos abordados por cada grupo. No se toman los mensajes unitarios (como en la dimensión individual) sino el entramado de construcción resultante de esa interacción. Allí se definen los temas estructurales de la comunicación que permiten avanzar con la tarea encomendada. Como se ha presentado en los componentes de la metodología, debe considerarse el contenido de los mensajes intercambiados a través: mensajes electrónicos (dentro o fuera de un EVEA), foros, wikis, blogs, videoconferencia y/o documentos de GoogleDocs (si los hubiera) donde se hayan alojado diálogos. Este tipo de 
análisis muestra los tópicos (o temas) en el marco de la comunicación del grupo. A través de estos tópicos es posible identificar cómo se generan y comparten conocimientos.

En la cohesión de la comunicación la unidad de análisis es, nuevamente, el mapa conceptual de tópicos de cada grupo. Allí se analizan las cadenas de comunicación en términos de tópicos vinculados directamente a la tarea a realizar y no vinculados (de dispersión). Cuánto más cohesionado es el grupo, más tópicos tendrán vinculación directa con la tarea y habrá menos tópicos de dispersión. Reyes \& Tchounikine (en Dimitrakopoulou et al., 2006) lo mencionan como "on" y "off topics" e Ingram \& Hathorn (en Roberts, 2004. Capítulo X, pág. 225) como "on" y "off task". En la metodología se toman como indicadores de cohesión grupal tanto los mensajes referidos a la planificación (task) como al contenido del trabajo (topics).

En el análisis de la argumentación se toman en cuenta los mensajes compartidos en los espacios de interacción según su granularidad (véase el capítulo 4, apartado 4.2.3. "Análisis de la conexión semántica en el trabajo colaborativo. Argumentación como idea clave"). El análisis de la argumentación requiere una minuciosa recopilación, lectura y análisis de un corpus completo de piezas de comunicación (mensajes). Este es el mecanismo utilizado y recomendado por los investigadores que se dedican a este tema (Weinberger \& Fischer, 2006; Felton, et al., 2015). MetSCIN propone como unidad de análisis el tratamiento de un tópico completo, para analizar las cadenas de mensajes en términos de entramado argumentativo, según el modelo de Stephen Toulmin. Como este análisis resulta subjetivo, se propone utilizar el mismo método que en los dos indicadores semánticos anteriores, de palabra clave y análisis de contenido (Cáceres, 2008).

En la tabla 16 se presenta un ejemplo de construcción de argumentos en el tópico "Escritura colaborativa" de la cohorte 2015.

\begin{tabular}{|c|c|c|c|}
\hline $\begin{array}{c}\text { FASE DE } \\
\text { ARGUMENTACION }\end{array}$ & $\begin{array}{l}\text { FUNCION EN LA } \\
\text { CADENA }\end{array}$ & $\begin{array}{c}\text { EJEMPLO DE MACRO } \\
\text { MENSAJE }\end{array}$ & $\begin{array}{l}\text { FRASE DEL MENSAJE/ } \\
\text { PALABRA CLAVE }\end{array}$ \\
\hline $\begin{array}{l}\text { Argumento } \\
\text { (Claim) }\end{array}$ & $\begin{array}{l}\text { Dar inicio a un } \\
\text { nuevo tema }\end{array}$ & $\begin{array}{l}\text { Título del mensaje: } \\
\text { Propuesta para el } \\
\text { índice }\end{array}$ & Propuesta / Índice \\
\hline $\begin{array}{l}\text { Evidencia } \\
\text { (Ground) }\end{array}$ & $\begin{array}{l}\text { Reforzar el primer } \\
\text { aporte }\end{array}$ & $\begin{array}{l}\text { Aporta evidencia del } \\
\text { aporte anterior }\end{array}$ & $\begin{array}{l}\text { "Viendo todos los } \\
\text { aportes individuales (da } \\
\text { idea de mapa general de } \\
\text { la actividad, asumiendo } \\
\text { que los demás } \\
\text { compañeros estaban } \\
\text { menos compenetrados } \\
\text { en el asunto) considero } \\
\text { que ese debe ser el } \\
\text { orden". }\end{array}$ \\
\hline $\begin{array}{l}\text { Garantía } \\
\text { (Warrant) }\end{array}$ & $\begin{array}{l}\text { Reafirmar el índice } \\
\text { del mensaje inicial }\end{array}$ & $\begin{array}{l}\text { No aporta (ya que } \\
\text { indica Re:) al título } \\
\text { anterior }\end{array}$ & $\begin{array}{l}\text { "Agregando a lo } \\
\text { aportado por [nombre } \\
\text { del compañero/a], este } \\
\text { sería mi aporte para el } \\
\text { índice". }\end{array}$ \\
\hline $\begin{array}{l}\text { Respaldo } \\
\text { (Backing) }\end{array}$ & $\begin{array}{l}\text { Agregar } \\
\text { aportes }\end{array}$ & $\begin{array}{l}\text { No aporta (ya que } \\
\text { indica Re:) al título } \\
\text { anterior }\end{array}$ & $\begin{array}{l}\text { "Ya hemos revisado los } \\
\text { temas a incluir y están } \\
\text { todos ubicados en el } \\
\text { índice, según jerarquía" }\end{array}$ \\
\hline $\begin{array}{l}\text { Calificador } \\
\text { (Qualifier) }\end{array}$ & $\begin{array}{l}\text { Modificar el } \\
\text { modelo del índice }\end{array}$ & $\begin{array}{l}\text { Título: “¿índice } \\
\text { forma de mapa?: }\end{array}$ & $\begin{array}{l}\text { "Si alguno/a puede } \\
\text { agregar algo diferente, } \\
\text { voy a estar agradecid@". }\end{array}$ \\
\hline
\end{tabular}




\begin{tabular}{|l|l|l|c|}
\hline \multicolumn{1}{|c|}{$\begin{array}{c}\text { FASE DE } \\
\text { ARGUMENTACION }\end{array}$} & \multicolumn{1}{|c|}{$\begin{array}{c}\text { FUNCION EN LA } \\
\text { CADENA }\end{array}$} & $\begin{array}{c}\text { EJEMPLO DE MACRO } \\
\text { MENSAJE }\end{array}$ & $\begin{array}{c}\text { FRASE DEL MENSAJE/ } \\
\text { PALABRA CLAVE }\end{array}$ \\
\hline $\begin{array}{l}\text { Refutaciones } \\
\text { (Rebuttal) }\end{array}$ & $\begin{array}{l}\text { Modificar el } \\
\text { modelo del índice }\end{array}$ & $\begin{array}{l}\text { No aporta (ya que } \\
\text { indica Re:) al título } \\
\text { anterior }\end{array}$ & $\begin{array}{l}\text { Si alguien tiene algo no } \\
\text { considerado, avise". }\end{array}$ \\
\hline
\end{tabular}

Tabla 16: Ejemplo de análisis del componente de argumentación, a partir de un corpus de mensajes del estudio de caso

\subsection{Instrumentos diseñados ad hoc como parte de MetSCIn}

La metodología presentada comprende dos instancias de indagación a los estudiantes con instrumentos específicos. En la dimensión individual, como información de entrada al trabajo colaborativo, incluye un autoinforme, en formato $e$, sobre autopercepción de estrategias de autorregulación en el aprendizaje y el trabajo en grupo. En la dimensión grupal incluye una estrategia de mirroring y su posterior indagación de impacto. En este apartado se presentan estos instrumentos. En el análisis de la actividad individual se presenta el autoinforme sobre autorregulación, como condición de entrada para la formación de grupos, conocimiento de perfiles individuales y estrategias de grupalidad. En el análisis de la construcción grupal se presenta la estrategia de mirroring que MetSCIn propone como visualización de indicadores online. Además, se agrega la estrategia de indagación del impacto del mirroring en el trabajo colaborativo, a través de una $e$-encuesta.

Como complemento de este capítulo, en el anexo 1 se presenta un ejemplo de la estrategia de comunicación propuesta y el protocolo del autoinforme sobre habilidades de autorregulación. En el anexo 2, la comunicación recomendada y el instrumento de indagación de impacto del mirroring. En el anexo 5, como parte de los sitios de interés construidos especialmente para esta tesis se incluye el acceso a los protocolos de la e-encuesta de autorregulación, el sitio de seguimiento de trabajo colaborativo para mirroring y el instrumento de indagación de impacto de esta estrategia.

\subsubsection{Indagación sobre autorregulación}

En línea con los componentes del modelo de Distancia Transaccional (presentados en el capítulo 2) se construyó, como parte de MetSCIn, un instrumento con formato autoinforme para indagar la percepción de las habilidades de autorregulación para el estudio de los estudiantes. Dentro de la metodología, este instrumento se utiliza para:

- Relevar ideas previas sobre trabajo colaborativo y en equipo. Esta información impacta en prácticas posteriores, ya que puede favorecer la grupalidad.

- Caracterizar a los estudiantes del grupo bajo estudio y disponer de un registro acerca del repertorio de sus habilidades de aprendizaje y de la percepción que tienen sobre sí mismos.

- Identificar algún grado de transferencia de estas habilidades en el análisis del trabajo grupal colaborativo.

Para la construcción del instrumento de autoinforme se revisaron y tradujeron los siguientes protocolos de la literatura:

- Pintrich, P. R. (1991). A manual for the use of the Motivated Strategies for Learning Questionnaire. Motivated Strategies for Learning Questionnaire (MSLQ). En: http://files.eric.ed.gov/fulltext/ED338122.pdf 
- Weinstein, C. \& Palmer, D. (1990). Learning and Study Strategies Inventory (LASSI).

En: http://www.jstor.org/stable/pdf/40032060.pdf?seq=1\#page scan tab_contents

- Cabanach, Valle, Gerpe, Rodríguez, Pineiro, \& Rosario (2009) Motivational Management Questionnaire

- Wayne Stain University Time Management Questionnaire.

- Pérez-Blasco, J.; García-Ros, R. \& Pérez-González, F. (2014). Guía para el manejo del estrés académico en la universidad. En: http://www.uv.es/iqdocent/recursos/Futura28.pdf

La construcción del instrumento se realizó ad hoc, ya que los instrumentos que se encontraron en la literatura adolecen de los siguientes problemas: a) indagan aspectos particulares de las habilidades de autorregulación: sólo los aspectos motivacionales, sólo el manejo del tiempo, sólo los aspectos afectivos, etc. La idea del instrumento es permitir que, a partir de una única indagación, el participante pueda informar acerca de todas las habilidades de autorregulación; b) no consideran las particularidades del contexto argentino (uso del tiempo, cantidad de horas de trabajo de un docente o profesional, uso de la tecnología en espacios públicos y medios de transporte, etc.; y c) muchas de las encuestas reconocidas en este tema no son de uso libre.

El instrumento toma la forma de autoinforme. Esta forma de indagación se define como un "método de recogida de datos en el que la fuente de información está basada en la introspección que el sujeto hace de sus propias competencias, conductas o habilidades. Significa la autopercepción de cómo actúa en la realidad" (tomado y modificado de Cohen \& Manion, 2002, pág. 48). La metodología propone que el instrumento se administre de la siguiente forma:

1er. momento. Debe informase a los participantes que será administrado este instrumento antes de iniciar la actividad colaborativa.

2do. momento. Se recomienda un mensaje público, mediante una herramienta tipo mensajería electrónica o foro, en el que se presente la estrategia de indagación, relacionando el instrumento con su objetivo: indagar estas habilidades para favorecer el trabajo colaborativo posterior. Un mensaje "tipo" aparece en el anexo 1.

3er. momento. Por su facilidad de uso y gratuidad, el instrumento está desarrollado en GoogleForm y se implementa mediante el envío del link al formulario, que puede incluirse en el mensaje del paso anterior.

4to. momento. Se recomienda realizar un cuidadoso seguimiento de su completamiento, enviando avisos a los alumnos que no lo completen en tiempo y forma (según el cronograma que se maneje). El seguimiento puede consistir en volver a enviar el mismo mensaje, o variaciones del mensaje, según los casos detectados. Se presentan en el anexo 1.

5to. momento. Recopilación y análisis de los resultados.

Para construir el instrumento se han operacionalizado las habilidades consideradas por la literatura especializada en este tema en las siguientes categorías de análisis, que fueron descriptas en el capítulo 2:

a. Motivación - Sostenimiento de la motivación

b. Manejo de la afectividad

c. Gestión del tiempo 

d. Concentración
e. Habilidades de procesamiento de información
f. Trabajo en equipo

Para cada categoría se redactó una cantidad diferente de situaciones cotidianas de estudio y trabajo, para que los indagados pudieran indicar con qué frecuencia realizaban o pensaban en las cuestiones indicadas. En la decisión de qué tareas o situaciones considerar se tuvieron en cuenta las recomendaciones de Merton \& Kendal (en Rubin, 2001), quienes señalan que se debería indagar acerca de vivencias subjetivas en cada situación particular ${ }^{13}$. La relación entre las categorías de habilidades y la cantidad de afirmaciones o ítems se muestra en la tabla 17.

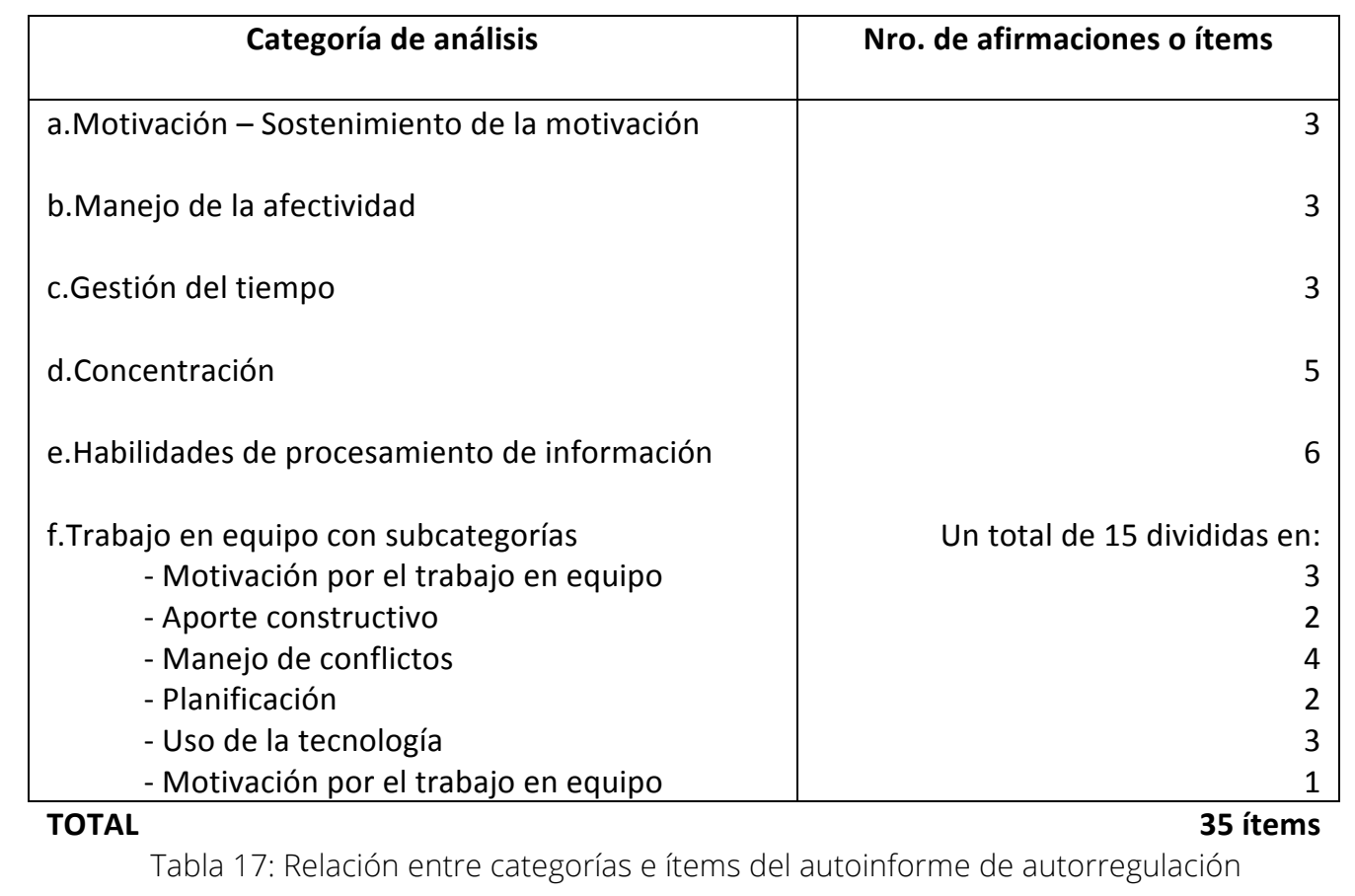

La redacción de estas situaciones tomó la forma de oraciones afirmativas, en sentido positivo. En su redacción se tuvo en cuenta reducir la determinación de algunas afirmaciones (significa no escribirlas de modo taxativo) para que la respuesta condiga con la realidad y no sea la respuesta esperada por el investigador. Este fenómeno se conoce como "efecto Hawthorne" (Manterola \& Otzen, 2015) y será retomado en las conclusiones de esta tesis. En cuanto a la escala, se utilizó una escala de frecuencia de 1-5, con las siguientes categorías de respuesta:

$$
\begin{aligned}
& 1 \text { (siempre); } \\
& 2 \text { (casi siempre); } \\
& 3 \text { (a veces); } \\
& 4 \text { (casi nunca) y } \\
& 5 \text { (nunca). }
\end{aligned}
$$

Se consignó un casillero más, donde se concebía la posibilidad de no responder (S/R).

\footnotetext{
${ }^{13}$ Si bien estas ideas son expresadas, en la bibliografia referenciada, respecto de la entrevista en profundidad, estas recomendaciones pueden ser consideradas en el diseño de un autoinforme.
} 
A continuación se presenta la portada del instrumento diseñado como parte de MetSCIn, en la figura 45 , y las dos primeras consignas referidas a la primera categoría de análisis: "Motivación y sostenimiento de la motivación", en la figura 46. El instrumento completo se presenta en el anexo 1.

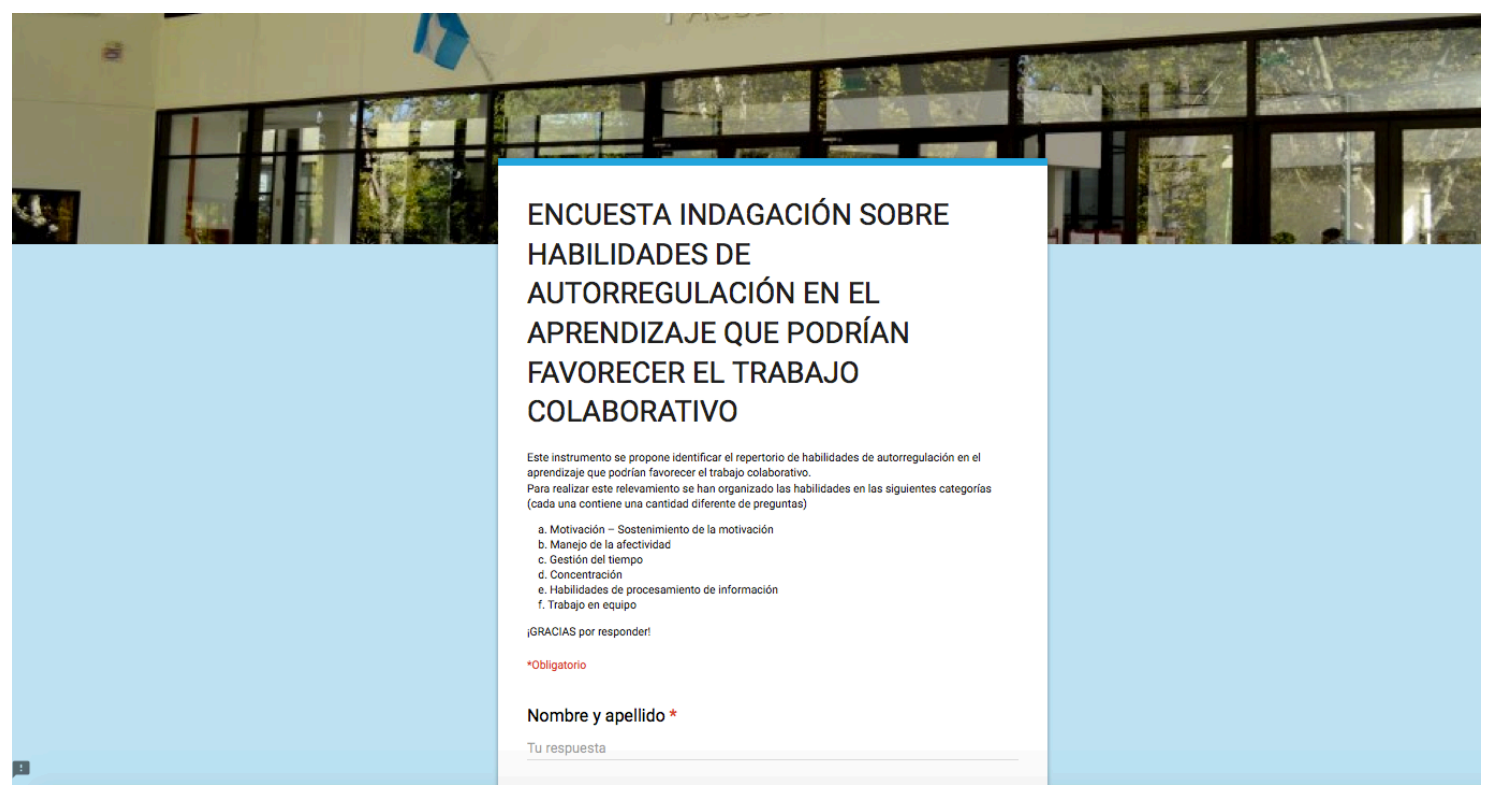

Figura 45: Portada del autoinforme de autorregulación en GoogleForm

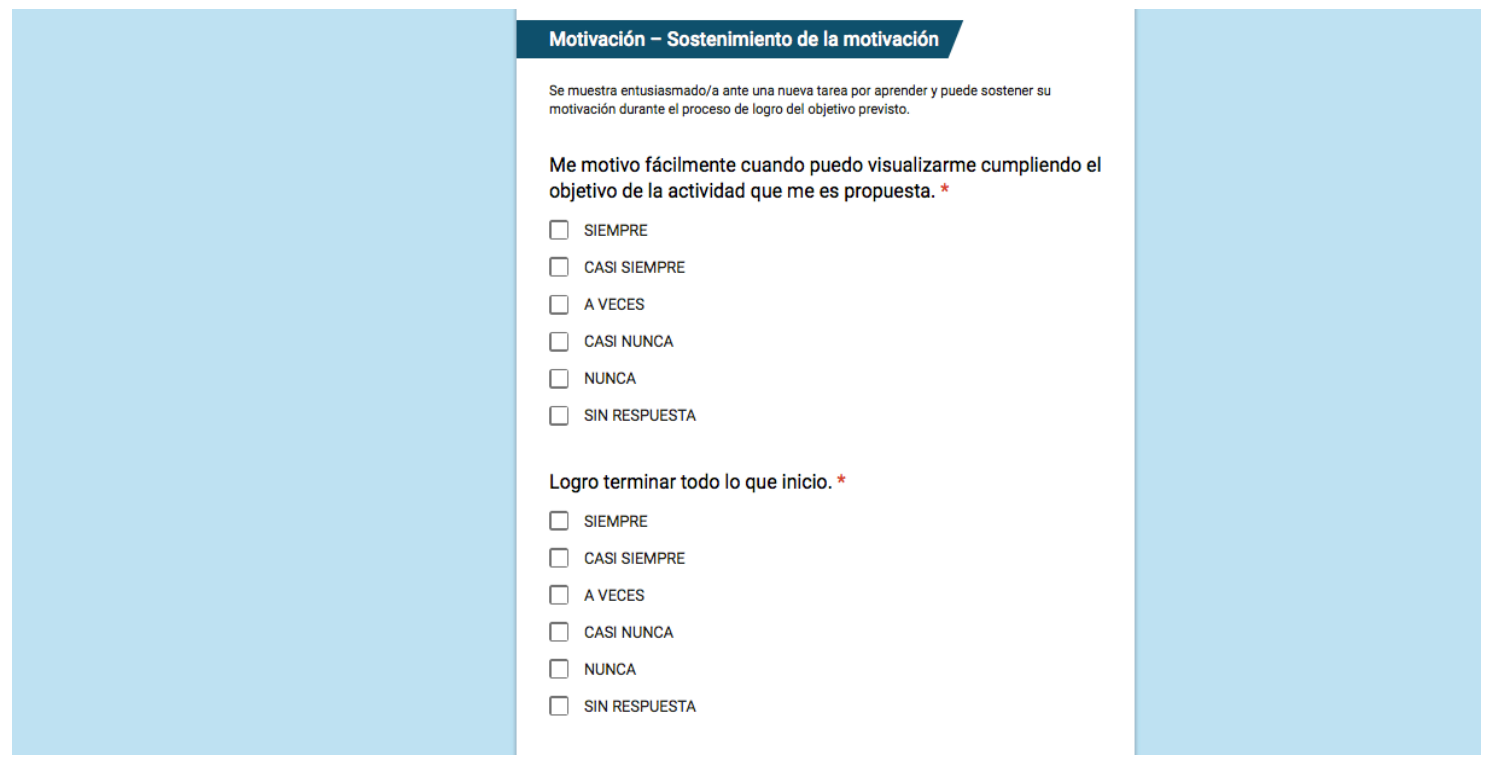

Figura 46: Indagación sobre motivación. Dos ítems

\subsubsection{Estrategia de mirroring}

Según la figura 42 presentada en este capítulo, esta estrategia forma parte de MetSCIn, en el seguimiento de la dimensión grupal durante la fase del trabajo colaborativo en sí. Representa una intervención didáctica que consiste en ofrecer un tablero de información sobre el proceso colaborativo en tiempo real, durante el trabajo colaborativo del grupo. Para presentar esta herramienta se revisitan, en los siguientes apartados, algunos de los conceptos introducidos en los capítulos 4 y 5 y se describe la estrategia propuesta dentro de MetSCIn. 


\subsubsection{Concepto de mirroring}

En el capítulo 5 de esta tesis se definió mirroring, siguiendo a Dimitracopoulou (2005, Mayo) quien cita a Jerman (2001) y Soller et al. (2005). Se presentó al mirroring como una estrategia que refleja la actividad de los integrantes de un grupo de trabajo. Se trata de comentarios de texto y visualizaciones gráficas de las acciones de cada uno de los integrantes de un grupo y del grupo como un todo, en cada una de las herramientas informáticas utilizadas. Según la hipótesis de Dimitracopoulou, esta información podría favorecer tanto el trabajo del grupo en sí como el de los coordinadores que lo supervisan y orientan y su intervención. Las estructuras de visualización, que proporcionan representaciones modeladas del trabajo del grupo, pueden ayudar a los estudiantes en el desarrollo metacognitivo y en la regulación de la actividad de colaboración.

Además, se citó a Dourish \& Bellotti (1992) en su presentación de tipos de awareness en relación con el formato de ambiente colaborativo donde el grupo trabaja. Si el ambiente es altamente estructurado, el awareness es activo y muestra las tareas y avances según permisos. Si la tarea colaborativa se lleva adelante en un ambiente desagregado (diferentes herramientas de la web, EVEAs, etc.) sin roles pautados de antemano, el mirroring toma la forma de shared feedback o awareness pasivo. Esto significa que los estudiantes trabajan según sus propios protocolos y el sistema de seguimiento muestrea estas actividades y les informa de sus avances, según las herramientas que utiliza. Esto significa que, en la implementación de la metodología MetSCin, deberá tomarse la mejor decisión de mirroring, que está vinculada con el tipo de ambiente donde se desarrolla la tarea colaborativa.

\subsubsection{Comunicación de la estrategia de mirroring en MetSCIn}

En el apartado 6.6. "Posibilidades de aplicación de la metodología MetSCIn. Uso modular" se presentará la característica modular de la metodología aquí propuesta, lo que posibilitaría utilizar uno, alguno/s o todos sus componentes. Si se decide utilizar mirroring, la tarea deberá iniciarse al mismo tiempo que el trabajo colaborativo en sí.

La primera actividad debe ser, entonces, comunicar a los participantes sobre la implementación de esta estrategia, indicando el trabajo que se llevará adelante y enfatizando el uso las herramientas puestas a disposición del grupo para hacer posible el seguimiento online. En el anexo 2 se puede acceder a mensajes "tipo" en la implementación del mirroring. Es recomendable que con la comunicación se adjunte un documento con la información del mapa de indicadores sobre los cuales se focalizará el seguimiento y el cronograma de presentación de la información. MetSCIn recomienda que se haga foco en los indicadores presentados en la tabla 18.

\begin{tabular}{|l|l|}
\hline \multicolumn{1}{|c|}{$\begin{array}{c}\text { Dimensiones/ } \\
\text { Categorías de } \\
\text { indicadores }\end{array}$} & Indicadores \\
\hline DIMENSION: APORTE INDIVIDUAL DE CADA MIEMBRO \\
\hline $\begin{array}{l}\text { Aporte de cada } \\
\text { miembro al } \\
\text { trabajo colaborativo }\end{array}$ & $\begin{array}{l}\text { Análisis cuantitativo } \\
\end{array}$ \\
& $\begin{array}{l}\text { Cantidad de mensajes intercambiados en cada etapa de } \\
\text { la resolución de la consigna. }\end{array}$ \\
& $\begin{array}{l}\text { Cantidad de mensajes en [herramientas puestas a } \\
\text { Aisposición para el trabajo colaborativo] }\end{array}$ \\
& Tipos de mensajes según categorías: Organización; \\
& Contenido; Afectividad \\
\hline
\end{tabular}




\begin{tabular}{|l|l|}
\hline $\begin{array}{c}\text { Dimensiones/ } \\
\text { Categorías de } \\
\text { indicadores }\end{array}$ & Indicadores \\
\hline DIMENSION: CONSTRUCCION COLABORATIVA PROPIAMENTE DICHA \\
\hline $\begin{array}{l}\text { Interdependencia } \\
\text { (Concepto grupal) }\end{array}$ & Mapa conceptual de tópicos. Temas y duración \\
\hline \multicolumn{2}{|c|}{ Tabla 18: Indicadores del trabajo individual y grupal del mirroring } \\
\hline
\end{tabular}

Además del mapa de indicadores, se recomienda adjuntar un cronograma que indique la frecuencia de publicación de la información de seguimiento. En cuanto a la publicación de esta información, se ofrecen las siguientes recomendaciones:

- Que la publicación sea semanal, para mantener un intervalo de tiempo estable que permita mostrar flujo de actividad suficiente para generar conciencia del trabajo individual y grupal.

- Que sea siempre el mismo día de la semana y a la misma hora, para facilitar una rutina en el acceso a la información.

- Que se establezca claramente, en la comunicación inicial del mirroring, que la información que se publica corresponde a lo generado hasta las 24hs. del día anterior a la publicación, y que lo se genere después de ese momento será consignado en la publicación de la semana siguiente.

- Que se atienda al gran flujo de trabajo que se genera durante el fin de semana. Si la metodología se utiliza en espacios de educación de personas adultas, se recomienda que se atienda a este hábito de trabajo reconocido en los cursos de grado y postgrado con estudiantes adultos.

- Que se alerte a los participantes de la habilitación de esta información por una doble vía: publicando la información en la herramienta decidida para este fin y enviando un mensaje público mediante la herramienta que se haya usado para la comunicación inicial, ya sea dentro del EVEA (si se usa uno) o por fuera. Algunos mensajes "tipo" se consignan en el anexo 2.

Se presenta un modelo de cronograma en la tabla 19. La frase que aparece entre corchetes deberá completarse con la información de las herramientas de comunicación y repositorios de documentos con los que cuente cada grupo y a los que el docente / investigador pueda acceder.

\begin{tabular}{|l|l|}
\hline \multicolumn{1}{|c|}{ Semanas } & \multicolumn{1}{c|}{ Publicación de información en el sitio según indicadores } \\
\hline Semana 1 & $\begin{array}{l}\text { Aporte individual de cada miembro } \\
\text { Trabajo individual: Cantidad y tipo de mensajes enviados por cada } \\
\text { integrante de los grupos vía [herramientas puestas a disposición para } \\
\text { el trabajo colaborativo] }\end{array}$ \\
& $\begin{array}{l}\text { Cantidad/ tipo de documentos compartidos en [herramientas puestas a } \\
\text { disposición para el trabajo colaborativo] }\end{array}$ \\
\hline
\end{tabular}




\begin{tabular}{|l|l|}
\hline \multicolumn{1}{|c|}{ Semanas } & \multicolumn{1}{c|}{ Publicación de información en el sitio según indicadores } \\
\hline Semana 2 & $\begin{array}{l}\text { Aporte individual de cada miembro } \\
\text { Idem semana 1 + cantidad de mensajes/actividad en cada } \\
\text { herramienta + análisis de quién envía/desarrolla/responde mensajes. }\end{array}$ \\
$\begin{array}{l}\text { Construcción colaborativa propiamente dicha } \\
\text { Mapa conceptual de tópicos / contenidos de la comunicación } \\
\text { grupal. }\end{array}$ \\
\hline Cohesión de la comunicación
\end{tabular}

\subsubsection{Estructura propuesta para la presentación de información de mirroring en MetSCIn}

Una posibilidad para materializar la información del proceso de trabajo colaborativo puede ser la utilización de un sitio de GoogleSites o similar o, incluso, se puede armar un sitio web ad hoc con algún sistema de gestión de contenidos.

Con independencia de la herramienta decidida para mostrar la información del mirroring, se recomienda que en el home se vuelva sobre la estrategia y su marco conceptual (información que también debería enviarse por una comunicación grupal, como se mencionó en los párrafos anteriores). Resulta de gran importancia que se refuerce esta simetría: que la herramienta de comunicación y el sitio de presentación de información refieran unívocamente a la misma idea. Así, el home del entorno donde se presente la información del mirroring debería presentar información breve, como se muestra en la tabla 20.

\begin{tabular}{|l|l|}
\hline \multicolumn{1}{|c|}{ INFORMACION } & \multicolumn{1}{|c|}{ DESCRIPCION } \\
\hline $\begin{array}{l}\text { ¿Qué es el } \\
\text { mirroring? }\end{array}$ & $\begin{array}{l}\text { Breve presentación del concepto, con sus fuentes teóricas, focalizando su } \\
\text { uso para mejorar el trabajo colaborativo. }\end{array}$ \\
\hline $\begin{array}{l}\text { ¿Qué impacto } \\
\text { puede tener } \\
\text { sobre el trabajo } \\
\text { de un grupo? }\end{array}$ & $\begin{array}{l}\text { Podría volver sobre la hipótesis de Dimitracopoulou (2005, Mayo) quien } \\
\text { consigna que la información que ofrece el mirroring, con } \\
\text { representaciones adecuadas, pueden ayudar a los estudiantes en el } \\
\text { desarrollo metacognitivo y, posteriormente, en la regulación de la } \\
\text { actividad de colaboración. }\end{array}$ \\
\hline $\begin{array}{l}\text { ¿Qué indicadores } \\
\text { se visualizarán? }\end{array}$ & Información de indicadores consolidada. \\
\hline $\begin{array}{l}\text { ¿Qué tipo de } \\
\text { información se } \\
\text { presentará? }\end{array}$ & $\begin{array}{l}\text { Formato de información (números, gráficos, textos) por cada tipo de } \\
\text { indicador. }\end{array}$ \\
\hline ¿Cuándo? & $\begin{array}{l}\text { Frecuencia de presentación de la información y de la cantidad de semanas } \\
\text { del trabajo colaborativo completo. }\end{array}$ \\
\hline ¿Dónde? & $\begin{array}{l}\text { Dónde y cómo se accede a la información de cada grupo, indicando el } \\
\text { nombre del link o la opción de acceso. }\end{array}$ \\
\hline ¿Quiénes? & $\begin{array}{l}\text { Permisos de acceso a la información del mirroring: si cada grupo podrá } \\
\text { ver sólo su información o todos los grupos podrán acceder a la } \\
\text { información completa. }\end{array}$ \\
\hline
\end{tabular}

Tabla 20: Información de la home del sitio de mirroring 
A continuación se presentan algunas estrategias de visualización de la información. En la figura 47 se muestra una forma para visibilizar la información del tiempo disponible en la resolución de la actividad colaborativa. Se usa una herramienta de reloj, en formato cuenta regresiva, para mostrar el tiempo restante para resolver la actividad. En la figura 48 se visualiza el formato de presentación de la información según los indicadores de la matriz de seguimiento. En el gráfico de barras se muestra la cantidad y calidad de mensajes según su tipo (contenido, organización, afectividad) por cada integrante del grupo. Debajo aparece un mapa de temas o tópicos, indicando tiempo de duración de cada uno, en semanas. Cada tópico está identificado con un color y está indicado en cada uno, la o las personas que trabajaron (con sus iniciales). En la figura 49 se muestra la relación entre tópicos e integrantes del grupo en el formato de grafo. Esta representación gráfica facilita el análisis de las participaciones e intercambios. En el trabajo de Roig Vila \& Rosales Statkus (2012) se referencia especialmente la importancia de la presentación gráfica y su influencia sobre la conciencia de la participación en ambientes colaborativos. En la estrategia de mirroring implementada, los grafos se construyen de acuerdo a las siguientes reglas: a.- están conformados por nodos: participantes y tópicos; b.- los nodos correspondientes a personas son etiquetados con las iniciales del nombre y los correspondientes a tópicos llevan el nombre del tema; c.- todos los nodos se representan con círculos coloreados; d.- las aristas que unen a cada persona con un tópico indican la relación del primero con el segundo; e.- el tamaño de los nodos aumenta conforme se incrementa la cantidad de aristas que salen o llegan a él y f.- el grosor de las aristas aumenta conforme se incrementa la participación de una persona con un tópico. Allí puede observarse qué tan lejos del mapa de tópicos está cada integrante del grupo y visibilizar la significatividad de la participación de cada uno.

Información del proceso de trabaio GRUPO 2>

Semana 5: Desde el 27 de Julio al 2 de Agosto Semana informada: De Miércoles a Martes

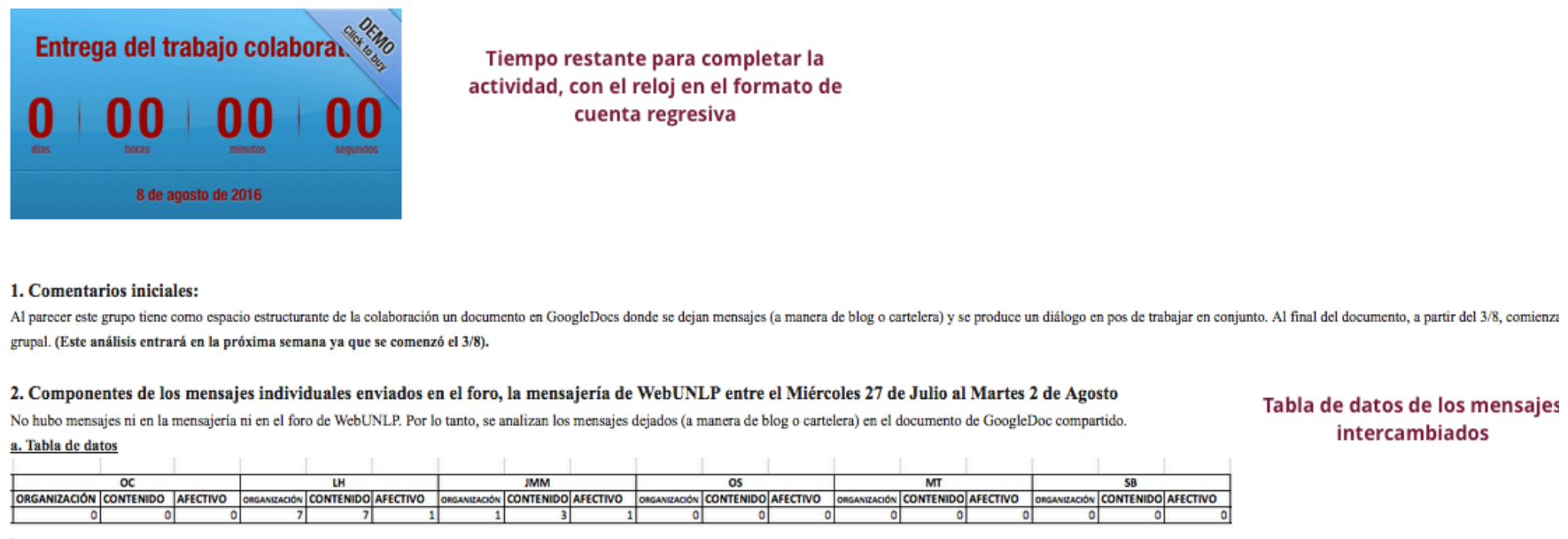

Figura 47: Información del tiempo restante para resolver la actividad colaborativa. Reloj en formato "cuenta regresiva" 


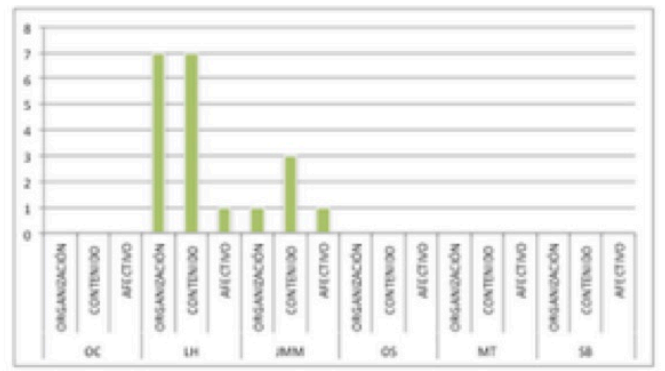

Gráfico de barras de los mensajes intercambiados

3. Temas abiertos

Linea de tiempo por semana de temas con las iniciales de quienes les inicinn y desarrollan

\begin{tabular}{|c|c|c|c|c|c|c|}
\hline $\begin{array}{l}\text { Compartit trabajos } \\
\text { individuales }\end{array}$ & IH & LH. 58 & $\begin{array}{l}\text { oc }=\text { LA } \\
\text { os }\end{array}$ & UH & $\begin{array}{l}\text { IH imas } \\
\text { (polatra } \\
\text { dove) }\end{array}$ & \\
\hline Biticon & MM - LH & $\mathbf{L H}-\mathbf{L H}$ & & & & \\
\hline $\begin{array}{l}\text { Planificasión del trabajo } \\
\text { colaborativo }\end{array}$ & & OS : IH & $\begin{array}{l}\text { OC-OS- } \\
\text { IH-NMM }\end{array}$ & os & Ін м⿻м & \\
\hline $\begin{array}{l}\text { Shuacibon de alumn@ } \\
\text { que dejóel } \\
\text { seminario }\end{array}$ & & & os & $\begin{array}{l}\text { UH } \\
\text { [Comparte } \\
\text { trabajol }\end{array}$ & & \\
\hline Aviso de vacaciones & & & os & & & \\
\hline Thito del Iibre & & & & & LH- $\mathrm{NMM}$ & \\
\hline \multirow[t]{3}{*}{ Orzanizacion del loro } & & & & & $\begin{array}{l}\text { JMM (de io } \\
\text { everala a lo } \\
\text { particudar) }\end{array}$ & \\
\hline & $\begin{array}{l}\text { Semana del } \\
29 / 6 \text { al } 5 / 7\end{array}$ & $\begin{array}{l}\text { Semana del } \\
\text { Gal } 12 / 7\end{array}$ & $\begin{array}{l}\text { Semana del } \\
13 \text { al } 19 / 7\end{array}$ & $\begin{array}{l}\text { Semana del } \\
20 \text { al } 26 / 7\end{array}$ & $\begin{array}{l}\text { Semana del } \\
2 / 7 / 7 \text { al } 2 / 8\end{array}$ & $\begin{array}{c}\text { Semana del } \\
3 \text { al } 8 / 7\end{array}$ \\
\hline & 1 & 2 & 3 & 4 & 5 & 6 \\
\hline
\end{tabular}

Temas por semanas (están indicadas en el eje de abscisas de la tabla. Cada tema tiene un color representativo y se extiende a lo largo de las semanas.

Si un tema no aparece más es porque se ha dejado de tratar o se ha cerrado (eso se indica en el mapa).

Las iniciales que aparecen en los cuadrantes corresponden a las iniciales de los estudiantes que han intervenido en el tratamiento de ese tema, en cada semana

Figura 48: Información de los indicadores de MetSCIn en la estrategia de mirroring

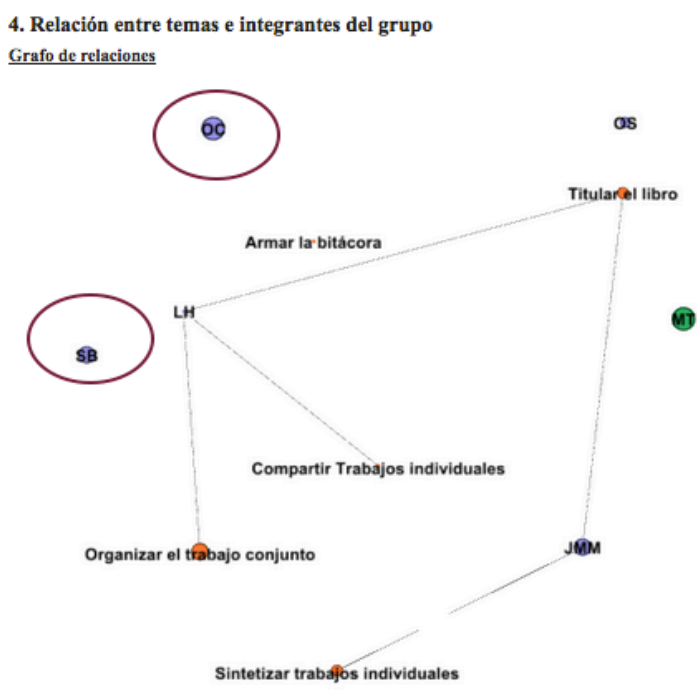

Grafo de relaciones que muestra qué temas se han compartido en esa semana y quiénes han trabajado en cada uno.

Los nodos que aparecen separados de la trama del grafo (marcados en la imagen) corresponden a participantes que no han tenido intervención en actividad alguna en la semana informada

5. Documentos compartidos en el repositorio de WebUNLP: No hay nuevos documentos compartidos, pero se menciona un repositorio en el documento de GoogleDocs compartido (al que no se tiene acceso).

6. Trabajo en el documento compartido en GoogleDocs: Se mencionaron las novedades en el punto 1 y, a partir de ahi se compuso el grafo de relaciones de esta semana.

7. Comentarios adicionales: Sin otras novedades

Figura 49: Grafo de relaciones en la información de mirroring 


\subsubsection{Indagación del impacto del mirroring en el trabajo colaborativo en MetSCIn}

Luego de las semanas de publicación de la información, en la semana inmediatamente posterior, la metodología propone la recopilación de opinión sobre el impacto de esta estrategia mediante la indagación individual y privada a los integrantes de todos los grupos bajo análisis. MetSCIn propone esta indagación mediante una e-encuesta. Este instrumento está compuesto por 5 secciones de información que se organizan según se indica en la tabla 21.

\begin{tabular}{|c|c|}
\hline SECCION & INFORMACION POR SECCION \\
\hline $\begin{array}{l}\text { SECCION 1: } \\
\text { Datos personales }\end{array}$ & Datos del estudiante y del grupo de pertenencia \\
\hline $\begin{array}{l}\text { SECCION 2: } \\
\text { Trabajo individual }\end{array}$ & $\begin{array}{l}\text { Información acerca de su aporte individual al trabajo colaborativo } \\
\text { - Comprensión de la consigna individual de la etapa } 1 \\
\text { - } \quad \text { Conocimiento previo del tema del aporte individual } \\
\text { - } \quad \text { Aporte de la tecnología para indagar la información y compartir } \\
\text { su aporte individual }\end{array}$ \\
\hline $\begin{array}{l}\text { SECCION 3: } \\
\text { Uso de } \\
\text { herramientas }\end{array}$ & $\begin{array}{l}\text { Uso de herramientas, en función de la siguiente lista [Herramientas que } \\
\text { se hayan utilizado en el trabajo]: } \\
\text { - } \quad \text { EVEA y sus herramientas } \\
\text { - } \text { Formulario de GoogleDocs } \\
\text { - } \text { Repositorios compartidos en Drive o Dropbox } \\
\text { - Guentas de e-mail particulares } \\
\text { - Mensajes de texto } \\
\text { - Videoconferencia mediante Skype o HangOut } \\
\text { - Llamadas telefónicas (teléfonos fijos o celulares) } \\
\text { - Grupos de Facebook } \\
\text { - Otras redes sociales } \\
\text { - Otras herramientas informáticas en general }\end{array}$ \\
\hline $\begin{array}{l}\text { SECCION 4: } \\
\text { Trabajo grupal }\end{array}$ & $\begin{array}{l}\text { Indagación acerca del trabajo colaborativo propiamente dicho, vinculado } \\
\text { con la consigna dada. Algunos componentes podrían ser: } \\
\text { - Coordinación } \\
\text { - Liderazgo } \\
\text { - Comunicación } \\
\text { - Organización del material de trabajo } \\
\text { - Negociación } \\
\end{array}$ \\
\hline $\begin{array}{l}\text { SECCION } 5 \text { Impacto } \\
\text { de la estrategia de } \\
\text { mirroring }\end{array}$ & $\begin{array}{l}\text { Opinión acerca de la estrategia de mirroring. Se indaga acerca de: } \\
\text { - } \quad \text { Frecuencia de consulta de la información } \\
\text { - Utilidad de la información } \\
\text { - Atención a indicadores individuales o grupales } \\
\text { - } \text { trabajaba en paralelo } \\
\text { - Información sobre el tiempo restante para entregar el trabajo } \\
\text { - Utilidad de la información según formato } \\
\text { - } \text { mecisiones que se modificaron en función de la información } \\
\text { Opinión general de la influencia de la información en el trabajo } \\
\text { del grupo }\end{array}$ \\
\hline
\end{tabular}

Tabla 21: Estructura de la e-encuesta que indaga el impacto del mirroring en MetSCIn 
Respecto de los tipos de ítems o preguntas, se incluyen preguntas de selección de opciones de tres tipos:

a)preguntas de selección de respuestas de opción múltiple, que se responden seleccionando la o las opciones que se corresponden con las acciones llevadas adelante en el trabajo colaborativo.

b)de dos opciones, que se utilizan en las secciones correspondientes al trabajo individual de la etapa 1 y al trabajo grupal. Ante cada tarea, se indican las opciones SI o NO, según se haya realizado, o no, esa tarea. Al final de cada una, se complementa la respuesta solicitada con una pregunta de completamiento que hace foco en la forma de trabajo;

c)en la sección de opinión sobre el impacto de la estrategia de mirroring, se propone combinar preguntas de selección de opción múltiple (en los tipos de información del sitio que hayan impactado en el trabajo, por ejemplo), de dos opciones (SI o NO se ha llevado adelante una tarea en específico) y de completamiento, para recabar información cualitativa.

En la tabla 22 se muestra la cantidad de ítems totales del instrumento y desagregados por cada sección.

\begin{tabular}{|c|c|c|c|c|}
\hline $\begin{array}{l}\text { SECCIONES DE } \\
\text { INDAGACION } \\
\text { DEL } \\
\text { INSTRUMENTO }\end{array}$ & DESCRIPCION & $\begin{array}{l}\text { CANTIDA } \\
\text { D DE } \\
\text { ITEMS }\end{array}$ & \multicolumn{2}{|c|}{ TIPO DE ITEM } \\
\hline & & & SELECCIÓN & CONSTRUCCION \\
\hline $\begin{array}{l}\text { SECCION 1: } \\
\text { Datos } \\
\text { personales }\end{array}$ & $\begin{array}{l}\text { Datos del estudiante y del } \\
\text { grupo de pertenencia }\end{array}$ & 2 & 1 & 1 \\
\hline $\begin{array}{l}\text { SECCION 2: } \\
\text { Trabajo } \\
\text { individual }\end{array}$ & $\begin{array}{l}\text { Información acerca de su } \\
\text { aporte individual al trabajo } \\
\text { colaborativo }\end{array}$ & 5 & 3 & 2 \\
\hline $\begin{array}{l}\text { SECCION 3: } \\
\text { Uso de } \\
\text { herramientas }\end{array}$ & Uso de las herramientas & 5 & 3 & 2 \\
\hline $\begin{array}{l}\text { SECCION 4: } \\
\text { Trabajo grupal }\end{array}$ & $\begin{array}{l}\text { Escritura colaborativa. División } \\
\text { y complementación de tareas y } \\
\text { responsables }\end{array}$ & 14 & 7 & 7 \\
\hline $\begin{array}{ll}\text { SECCION } & 5: \\
\text { Impacto de la } \\
\text { estrategia de } \\
\text { mirroring }\end{array}$ & $\begin{array}{l}\text { Opinión acerca de cómo influyó } \\
\text { en el proceso y producto del } \\
\text { grupo el conocer, con } \\
\text { actualización semanal, los } \\
\text { indicadores de trabajo } \\
\text { colaborativo que se pusieron a } \\
\text { disposición en el sitio de } \\
\text { Google. }\end{array}$ & 17 & 8 & 9 \\
\hline
\end{tabular}

Tabla 22: Cantidad de ítems total y por cada sección del instrumento de indagación post mirroring

\footnotetext{
${ }^{14}$ Se refiere a la actividad colaborativa del estudio de caso, que consistió en un trabajo de escritura colaborativa. Se verá con detalle en el capítulo 8.
} 
En referencia específicamente al impacto de la estrategia de mirroring, en la sección 5: "Impacto de la estrategia de mirroring" se indaga acerca de lo siguiente:

- Frecuencia de acceso al sitio de información de mirroring.

- Acceso a la información sobre el tiempo restante para la entrega del trabajo.

- Información a la que se accedió según su autoría.

- Formato de información a la que se accedió.

- Decisiones resultantes del conocimiento de la información del proceso en el trabajo del grupo.

- Pregunta final de consolidación del impacto de la estrategia.

Se describen estas consignas en la tabla 23.

\begin{tabular}{|c|c|c|c|}
\hline CATEGORIA & CONSIGNA & $\begin{array}{c}\text { CANTIDAD } \\
\text { DE ITEMS }\end{array}$ & ESCALA \\
\hline $\begin{array}{l}\text { Frecuencia de } \\
\text { acceso al sitio } \\
\text { de } \\
\text { información } \\
\text { de mirroring }\end{array}$ & $\begin{array}{l}\text { Consulta acerca de la frecuencia de acceso al sitio: } \\
\text { ¿Cuántas veces visualizó el sitio de información del } \\
\text { proceso colaborativo? }\end{array}$ & $\begin{array}{l}2 \\
\text { (Pregunta de } \\
\text { ensayo sobre } \\
\text { las razones) }\end{array}$ & $\begin{array}{l}\text { Escala } \\
\text { ordinal } \\
\text { NUNCA } \\
\text { DIARIAMENTE }\end{array}$ \\
\hline $\begin{array}{l}\text { Acceso a la } \\
\text { información } \\
\text { sobre el } \\
\text { tiempo } \\
\text { restante para } \\
\text { la entrega del } \\
\text { trabajo }\end{array}$ & $\begin{array}{l}\text { Información acerca de la importancia que el } \\
\text { estudiante le ha otorgado al reloj, en modo cuenta } \\
\text { regresiva, con la siguiente pregunta: ¿Qué } \\
\text { importancia le asignó a la información sobre el } \\
\text { tiempo restante para entregar el trabajo que } \\
\text { apareció en el sitio a partir de la segunda semana } \\
\text { (con el reloj en modo "cuenta regresiva")? }\end{array}$ & 1 & $\begin{array}{l}\text { Escala } \\
\text { ordinal } \\
\text { NINGUNA } \\
\text { MUCHA }\end{array}$ \\
\hline $\begin{array}{l}\text { Información a } \\
\text { la que se } \\
\text { accedió según } \\
\text { su autoría }\end{array}$ & $\begin{array}{l}\text { Consulta acerca del acceso a la información del sitio: } \\
\text { Una vez que comenzó a ver la información semanal: } \\
\text { ¿Le prestó más atención a: la información propia, la } \\
\text { información de lo producido por los compañeros de } \\
\text { su grupo o a la información de lo producido por el } \\
\text { otro grupo? Con las siguientes opciones: } \\
\text { - Información propia } \\
\text { - Información de los compañeros de mi grupo } \\
\text { - Información del otro grupo } \\
\text { - Todas las informaciones por igual } \\
\text { - Ninguna información me resulto de interés }\end{array}$ & $\begin{array}{c}2 \\
\text { (Pregunta de } \\
\text { ensayo sobre } \\
\text { las razones de } \\
\text { la consulta) }\end{array}$ & $\begin{array}{l}\text { Opciones de } \\
\text { respuesta }\end{array}$ \\
\hline $\begin{array}{l}\text { Formato de } \\
\text { información a } \\
\text { la que se } \\
\text { accedió }\end{array}$ & $\begin{array}{l}\text { Consulta acerca del formato de la información del } \\
\text { sitio que ha resultado más significativo. La pregunta } \\
\text { es: ¿Qué tipo de información le resultó de más } \\
\text { utilidad?, según las siguientes opciones: } \\
\text { - Textos } \\
\text { - Números } \\
\text { - Tablas de datos } \\
\text { - Gráficos de barras de Excel } \\
\text { - Grafos de trabajo grupal (Realizados con Gephi) } \\
\text { - Imágenes } \\
\text { - Todos los tipos de información por igual } \\
\text { - Ninguna información me resulto de interés }\end{array}$ & $\begin{array}{c}2 \\
\text { (Pregunta de } \\
\text { ensayo sobre } \\
\text { las razones de } \\
\text { la consulta) }\end{array}$ & $\begin{array}{l}\text { Opciones de } \\
\text { respuesta }\end{array}$ \\
\hline
\end{tabular}




\begin{tabular}{|c|c|c|c|}
\hline CATEGORIA & CONSIGNA & $\begin{array}{l}\text { CANTIDAD } \\
\text { DE ITEMS }\end{array}$ & ESCALA \\
\hline $\begin{array}{l}\text { Decisiones } \\
\text { resultantes } \\
\text { del } \\
\text { conocimiento } \\
\text { de la } \\
\text { información } \\
\text { del proceso } \\
\text { en el trabajo } \\
\text { del grupo }\end{array}$ & $\begin{array}{l}\text { Indagación sobre las decisiones que se hayan } \\
\text { tomado en función de la información mostrada en el } \\
\text { sitio. Se pregunta: ¿Qué decisiones se modificaron } \\
\text { en función de la información mostrada en el sitio? (se } \\
\text { dividen las opciones en tres aspectos: afectividad, } \\
\text { contenido, organización). Como se ha presentado en } \\
\text { el marco conceptual, se han clasificado estas } \\
\text { decisiones en tres categorías: afectividad, contenido, } \\
\text { organización. } \\
\text { - Organización: Manejo del tiempo: Planificación } \\
\text { /cronograma } \\
\text { - Organización: Armado de la bitácora } \\
\text { - Organización: Participación equilibrada de todos } \\
\text { los integrantes del grupo (todos intervienen) } \\
\text { - Organización: Aviso al grupo de disponibilidad } \\
\text { individual de tiempo (descanso, vacaciones de } \\
\text { invierno, por ejemplo) } \\
\text { - [Contenido: Incorporación de todos los temas] } \\
\text { - [Contenido: Tratamiento de todos los temas con la } \\
\text { misma importancia] } \\
\text { - [Contenido: Apertura y cierre de temas de forma } \\
\text { ordenada y rápida (se tratan todos y tratan de } \\
\text { cerrarse)] } \\
\text { - [Contenido: Mejora del producto del grupo] } \\
\text { - Afectividad: Motivación para que todos participen } \\
\text { trabajos individuales de la gente que dejó el } \\
\text { seminario) } \\
\text { - Afectividad: Atención de conflictos internos para } \\
\text { su parte }\end{array}$ & $\begin{array}{l}2 \\
\text { (Pregunta de } \\
\text { ensayo sobre } \\
\text { las razones de } \\
\text { la consulta) }\end{array}$ & $\begin{array}{l}\text { Opciones de } \\
\text { respuesta }\end{array}$ \\
\hline $\begin{array}{l}\text { Pregunta final } \\
\text { de } \\
\text { consolidación } \\
\text { del impacto } \\
\text { de la } \\
\text { estrategia }\end{array}$ & $\begin{array}{l}\text { Pregunta sobre el grado de influencia del mirroring } \\
\text { en el trabajo del grupo. Se formula de la siguiente } \\
\text { forma: En su opinión ¿cuánto influyó en el trabajo } \\
\text { colaborativo tener disponible la información del } \\
\text { proceso en forma semanal? }\end{array}$ & $\begin{array}{l}2 \\
\text { (Pregunta de } \\
\text { ensayo sobre } \\
\text { las razones de } \\
\text { la consulta) }\end{array}$ & $\begin{array}{l}\text { Escala } \\
\text { ordinal } \\
\text { NADA } \\
\text { MUCHO }\end{array}$ \\
\hline
\end{tabular}

Tabla 23: Descripción de la estrategia de indagación de impacto del mirroring

Resulta pertinente realizar una aclaración en este punto. En la sección "Decisiones resultantes del conocimiento de la información del proceso en el trabajo del grupo" de la tabla anterior se presentan opciones vinculadas con la organización, el contenido y la afectividad. Como ya se ha mencionado, los mensajes de organización y afectividad pueden guardar cierta independencia del tipo de trabajo colaborativo del que se trate. Los mensajes de la categoría contenido se vinculan a la micro tarea (el tipo de tarea de que se trate) y a la consigna específica. Por eso aparecen entre corchetes. El protocolo de indagación completo se encuentra en el anexo 2. 


\subsection{Etapas de construcción de la metodología}

Se ha descripto la metodología completa, con sus componentes. En este apartado se mencionan las etapas de su construcción. Se retoma el modelo RUP (Kruchten, 1996 en DíazAntón et al., 2006) que presenta las siguiente etapas: comienzo; elaboración; construcción y transición.

El comienzo definió los requerimientos de la metodología y su alcance. La lectura y apropiación del marco teórico de interacción, interactividad, trabajo grupal y colaborativo formaron parte de esta etapa. Asimismo, la construcción de las estrategias didácticas del trabajo colaborativo fue un insumo de peso para definir el alcance y los requerimientos con los que esta metodología debía cumplir.

En la fase de elaboración, se planificaron las actividades necesarias y los recursos requeridos, en función del alcance de la metodología. En este caso, comenzaron a definirse las etapas de la metodología y a delinearse los modelos subyacentes.

En la fase de construcción se definieron los productos que se implementaría en el estudio de caso: la matriz de indicadores y los instrumentos. La matriz fue validada mediante el juicio de expertos (se describirá en detalle en el capítulo siguiente) antes de la aplicación en el estudio del caso y los instrumentos fueron aplicados a grupos piloto (que no formaron parte del estudio de caso final).

La fase de transición es la utilización o implementación de la metodología. En el caso de esta tesis, fue implementada en el estudio de caso con grupos contrastados, que fueron estudiantes de los años 2015 y 2016.

El modelo es iterativo: esto significa que cada vez que se produce la transición (implementación) se mejoran los instrumentos y la metodología completa. La figura 50 muestra las etapas de trabajo en la construcción de esta metodología.

\begin{tabular}{|c|c|c|c|c|c|c|c|}
\hline $\begin{array}{l}\text { Análisis } \\
\text { teórico: Estudio } \\
\text { del campo, } \\
\text { metodologías } \\
\text { de } \\
\text { investigación } \\
\text { de indicadores }\end{array}$ & $\begin{array}{l}\text { Elaboración de } \\
\text { la metodología, } \\
\text { en función de } \\
\text { la secuencia } \\
\text { didáctica. } \\
\text { Construcción } \\
\text { de } \\
\text { instrumentos }\end{array}$ & $\begin{array}{l}\text { Prueba piloto } \\
\text { de los } \\
\text { instrumentos } \\
\text { Juicio de } \\
\text { expertos para } \\
\text { validación de la } \\
\text { matriz de } \\
\text { indicadores }\end{array}$ & $\begin{array}{l}\text { Implementación } \\
\text { de la } \\
\text { metodología en } \\
\text { el estudio de caso } \\
2015\end{array}$ & $\begin{array}{l}\text { Refinamient } \\
\text { o de la } \\
\text { metodología } \\
\text { con la } \\
\text { intervención } \\
\text { didáctica del } \\
\text { del mirroring }\end{array}$ & $\begin{array}{l}\text { Elaboración } \\
\text { metodología } \\
\text { completa }\end{array}$ & $\begin{array}{l}\text { Mejoramiento } \\
\text { de los } \\
\text { instrumentos }\end{array}$ & $\begin{array}{l}\text { Implementación } \\
\text { de la } \\
\text { metodología } \\
\text { completa en el } \\
\text { estudio de caso } \\
2016\end{array}$ \\
\hline & & \multicolumn{2}{|c|}{$\begin{array}{l}\text { a. Juicio de expertos para validar la } \\
\text { matriz de indicadores } \\
\text { b. e-encuesta sobre autorregulación }\end{array}$} & & & \multicolumn{2}{|c|}{$\begin{array}{l}\text { a. Juicio de expertos para validar la } \\
\text { matriz de indicadores } \\
\text { b. e-encuesta sobre autorregulación } \\
\text { c. Encuesta post mirroring }\end{array}$} \\
\hline
\end{tabular}

\begin{tabular}{|l|l|l|l|}
$\begin{array}{l}\text { COMIENZO } \\
\text { Fase } 1\end{array}$ & FASE 1 de & $\begin{array}{l}\text { COMIENZO } \\
\text { Fase } 2\end{array}$ & FASE 2 de \\
& $\begin{array}{l}\text { ELABORACION } \\
\text { CONSTRUCCION } \\
\text { TRANSICION }\end{array}$ & & $\begin{array}{l}\text { ELABORACION } \\
\text { CONSTRUCCION }\end{array}$ \\
\hline & & & TRANSICION \\
\hline
\end{tabular}

Figura 50: Etapas de la construcción de la metodología, según modelo RUP

(Kruchten, 1996 en Díaz-Antón et al., 2006) 


\subsection{Posibilidades de aplicación de la metodología MetSCIn. Uso modular}

Para el diseño de la metodología aquí presentada se ha pensado en una estructura modular. Esto significa que cada instrumento guarda cierta independencia de los otros. Por ejemplo, la e-encuesta de autopercepción sobre autorregulación podría ser utilizada como inicio de una tarea grupal que sea o no colaborativa; o incluso para conocer mejor a un grupo de estudiantes que no vaya a trabajar en el futuro en forma grupal o colaborativa. Sus resultados, siempre en el campo de la autopercepción, podrían ofrecer información significativa por fuera del uso de la metodología completa.

Lo mismo ocurre con la matriz de indicadores: el investigador podría decidir usar sólo la dimensión individual, la grupal o ambas. Dentro de la dimensión grupal, podría decidir considerar la conexión semántica, la cohesión y la argumentación, o sólo alguna/s de ellas.

Por último, la estrategia de mirroring necesita de algunas condiciones particulares de implementación. Por el esfuerzo requerido para realizar el seguimiento y la publicación de información en tiempo real y online, está determinada por la cantidad de participantes totales y de grupos de trabajo, la cantidad de semanas de trabajo, la cantidad de herramientas sincrónicas y asincrónicas que se incluyan, la cantidad de investigadores y el tipo de consigna. Si las condiciones resultan pertinentes podría implementarse con independencia del uso de la metodología completa, como espejo de un trabajo (grupal o colaborativo), que no haya sido estudiado con la matriz de indicadores completa. Hasta podrían usarse algunas de las preguntas incluidas en la e-encuesta de impacto de mirroring (las tres primeras secciones del instrumento presentado en la sección anterior), sin el uso de la estrategia de mirroring completa.

El diseño metodológico que posibilita una implementación modular es un tema de amplio estudio. Tanto en el campo educativo, referido al diseño curricular y la programación didáctica áulica, como en el campo tecnológico, en referencia a la programación. Fuentes de ambas disciplinas (en el campo de la Educación: García-Cano, 1988; en el campo de la Programación: Maldonado \& Chavarría, 1991) coinciden en las siguientes ventajas. Permite:

- Mayor flexibilidad.

- Mejoramiento del uso de la energía o esfuerzo de su implementación, ya que puede ser realizada en partes.

- Mayor potencia, para centrarse en el objetivo propuesto para cada componente independiente.

- Mayor versatilidad, ya que puede ser reutilizada y adaptada a diferentes contextos.

Con estas posibilidades in mente fue construida la metodología MetSCIn, aquí presentada.

\subsection{Conclusiones del capítulo}

Este capítulo inicia la segunda parte del trabajo: "Aportes de esta tesis y su validación". Introduce la descripción de los aportes comprometidos como valor agregado y describe y desarrolla su validación.

Al inicio se presenta la metodología de seguimiento y valoración del trabajo colaborativo MetSCIn, con sus componentes: objeto; etapas; actores; modelo teórico subyacente; indicadores; espacios de construcción colaborativa y seguimiento del trabajo; instrumentos y tecnología involucrada. 
A continuación se describe la matriz de indicadores de colaboración, que recupera el marco conceptual presentado en la primera parte de esta tesis. Se detalla cada indicador y su operacionalización en unidades de análisis. Se define qué aspecto del trabajo colaborativo se estudia: qué teoría lo sustenta, a partir de qué indicadores se lo analiza y cómo se operacionaliza en la práctica.

Además, se presentan dos instrumentos construidos ad hoc para esta metodología:

1. Relevamiento de las habilidades de autorregulación sobre el aprendizaje y el trabajo en grupo a través de un autoinforme en formato electrónico.

2. Estrategia de mirroring en el trabajo colaborativo y análisis de su impacto.

Tres anexos se vinculan con este capítulo: en el anexo 1 se presenta el modelo de comunicación y el protocolo del autoinforme sobre habilidades de autorregulación, en el anexo 2 , el modelo de comunicación y el instrumento de indagación de impacto post mirroring. En el anexo 5 se incluye la dirección web de los sitios de interés construidos especialmente para esta tesis: la e-encuesta de autorregulación, el sitio de mirroring y el protocolo de la evaluación de su impacto.

Finalmente, se describen las etapas de elaboración, refinamiento e implementación de la metodología: comienzo; elaboración; construcción y transición, en un modelo iterativo y la característica de uso y reutilización de MetSCIn como diseño modular.

La validación de la metodología construida para esta tesis se realizó en dos etapas. En una primera instancia, la matriz de indicadores de seguimiento de trabajo colaborativo se sometió a juicio de expertos. Como resultado, la matriz se validó y se vio enriquecida en algunos aspectos. Una vez validada la matriz por expertos reconocidos en el área y resignificada a partir de los resultados, se aplicó la metodología completa en un estudio de caso.

Los capítulos siguientes se dedican a presentar ambas estrategias en detalle. El capítulo 7 aborda la estrategia y resultados del juicio de expertos. En el capítulo 8 se avanza en la descripción del estudio de caso y los resultados obtenidos en cada cohorte en particular y en su contrastación. 


\section{Capítulo 7: Juicio de expertos como validación de la matriz de indicadores de seguimiento}

El recorrido conceptual propuesto para este capítulo es el siguiente:

7.1. Introducción

7.2. Concepto de juicio de expertos

7.3. Concepto de experto

7.4. Consideraciones sobre la cantidad de expertos recomendada

7.5. Evaluación de la validez de la matriz de indicadores mediante el juicio de expertos

7.6. Metodología implementada

7.6.1. Selección de expertos por cada dimensión del tema

7.6.1.1. Biograma de los expertos seleccionados

7.6.2. Instrumento aplicado en el juicio de expertos

7.6.3. Comunicación y seguimiento metodológico del juicio de expertos

7.6.4. Análisis de resultados del juicio de expertos

7.6.4.1 Análisis del factor K (grado de expertise manifestado por los expertos).

7.6.4.2. Análisis de la concordancia de respuesta por ítem y sección del instrumento

7.6.5. Conclusiones del juicio de expertos y ajustes

7.7. Versión final de la matriz de indicadores

7.8. Conclusiones del capítulo 


\subsection{Introducción}

Un componente central de la metodología MetSCIn es la matriz de indicadores de colaboración, en la que se han integrado y operacionalizado los indicadores compilados en el marco conceptual. Esa matriz ha sido validada a través de la metodología del juicio de expertos.

En este capítulo se describirá la justificación y la metodología completa que se ha seguido en esta evaluación. Se avanza en la presentación de la misma, se describe cada una de sus fases, sus resultados y la resignificación de la matriz, a partir de los comentarios de los expertos.

\subsection{Concepto de juicio de expertos}

El juicio de expertos consiste en solicitar, a una serie de personas, la emisión de un juicio hacia un objeto, instrumento, material, o su opinión respecto a un aspecto concreto de un objeto sometido a evaluación (Maldonado Mahauad; Sanz \& Fernández Pampillón, 2014; Cabero Almenara \& Cejudo, 2013). En el contexto de cambios y subjetividades que se presentan en los entornos educativos con uso de tecnología digital, resulta un mecanismo de gran utilidad, ya que permite evaluar opiniones acerca de objetos simbólicos, invisibles (como metodologías, matrices de análisis, modelos de trabajo, etc.) con anterioridad a su aplicación (Ferrando, Ibáñez \& Martín, 1996). Esto permite obtener una opinión calificada que, si bien no asegura el éxito del objeto de la evaluación en un caso concreto, anticipa algunos escenarios temidos en tanto amenazas teóricas o metodológicas.

Existen diversas formas de consultar a los expertos. Se presentan a continuación las características de cada una y la justificación de la estrategia seleccionada para este estudio. Siguiendo a Cabero Almenara \& Cejudo (2013) y Corral (2009) pueden presentarse de la siguiente forma:

a) Agregación individual de los expertos. Consiste en obtener la información de manera individual de cada uno de los expertos -por una encuesta o entrevista individual, por ejemplo- sin que ellos se encuentren en contacto presencial o virtual. En este tipo de método, resulta fundamental la calidad del instrumento de indagación construido o seleccionado. Corral (2009) ofrece el un mapa de indicadores de calidad para controlar que el instrumento permita cumplir con el objetivo de la evaluación. Se presentan en la tabla 24. 


\begin{tabular}{|c|c|c|c|c|c|c|c|c|c|c|c|}
\hline \multirow{3}{*}{ ITEM } & \multicolumn{10}{|c|}{ CRITERIOS A EVALUAR } & \multirow{3}{*}{$\begin{array}{l}\text { Observaciones } \\
\text { (si debe } \\
\text { eliminarse o } \\
\text { modificarse un } \\
\text { item por favor } \\
\text { indique) }\end{array}$} \\
\hline & \multicolumn{2}{|c|}{$\begin{array}{l}\text { Claridad } \\
\text { en la } \\
\text { redacción }\end{array}$} & \multicolumn{2}{|c|}{$\begin{array}{l}\text { Coherencia } \\
\text { interna }\end{array}$} & \multicolumn{2}{|c|}{$\begin{array}{l}\text { Inducción } \\
\text { a la } \\
\text { respuesta } \\
\text { (Sesgo) }\end{array}$} & \multicolumn{2}{|c|}{$\begin{array}{c}\text { Lenguaje } \\
\text { adecuado } \\
\text { con el } \\
\text { nivel del } \\
\text { informante } \\
\end{array}$} & \multicolumn{2}{|c|}{$\begin{array}{l}\text { Mide } \\
\text { lo que } \\
\text { pretende }\end{array}$} & \\
\hline & Si & No & $\mathrm{Si}$ & No & $\mathrm{Si}$ & No & Si & No & $\mathrm{Si}$ & No & \\
\hline 1 & & & & & & & & & & & \\
\hline 2 & & & & & & & & & & & \\
\hline 3 & & & & & & & & & & & \\
\hline$\ldots$. & & & & & & & & & & & \\
\hline $\mathbf{n}$ & & & & & & & & & & & \\
\hline \multicolumn{9}{|c|}{ Aspectos Generales } & Sì & No & 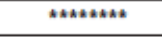 \\
\hline \multicolumn{9}{|c|}{$\begin{array}{l}\text { El instrumento contiene instrucciones claras y precisas } \\
\text { para responder el cuestionario }\end{array}$} & & & \\
\hline \multicolumn{12}{|c|}{$\begin{array}{l}\text { Los ítemes permiten el logro del objetivo de la } \\
\text { investigación }\end{array}$} \\
\hline \multicolumn{12}{|c|}{$\begin{array}{l}\text { Los ítemes están distribuidos en forma lógica y } \\
\text { secuencial }\end{array}$} \\
\hline \multicolumn{9}{|c|}{$\begin{array}{l}\text { El número de ítemes es suficiente para recoger la } \\
\text { información. En caso de ser negativa su respuesta, } \\
\text { sugiera los ítemes a añadir }\end{array}$} & & & \\
\hline \multicolumn{12}{|c|}{$\begin{array}{ll}\text { VALIDEZ } \\
\end{array}$} \\
\hline & & ICA & & & & & & NO A & LIC & BLE & \\
\hline \multicolumn{12}{|c|}{ APLICABLE ATENDIENDO A LAS OBSERVACIONES } \\
\hline \multicolumn{7}{|c|}{ Validado por: } & \multicolumn{4}{|c|}{ C.I.: } & Fecha: \\
\hline \multicolumn{7}{|c|}{ Firma: } & \multicolumn{4}{|c|}{ Teléfono: } & e-mail: \\
\hline \multicolumn{12}{|c|}{$\begin{array}{l}\text { Nota. Modificado de Formato de la Facultad de Odontología de la Universidad de } \\
\text { Carabobo (2007). }\end{array}$} \\
\hline
\end{tabular}

Tabla 24: Calidad del instrumento de evaluación mediante el juicio de expertos en el método de agregación individual (Extraído de Corral, 2009, pág. 233)

b) Método Delphi. Se asemeja al anterior, en cuanto se recoge la opinión de los expertos de forma individual y privada. Luego, antes de las conclusiones, se agrega una instancia de devolución de los resultados parciales compilados al conjunto de expertos, para su revisión y acuerdo final.

c) Técnica grupal nominal. En este método los expertos aportan la información de manera individual y después, de forma grupal y presencial, se llega a un acuerdo.

d) Método de consenso. En forma grupal y sincrónicamente, los expertos seleccionados llegan a conseguir un acuerdo. Puede implementarse presencial o virtualmente.

Avanzando hacia el análisis de la efectividad en la aplicación de esta estrategia (esto significa un análisis de costo-beneficio, tomando en consideración tiempo y dinero), el juicio de expertos resulta altamente eficiente, ya que no presenta una gran demanda de requisitos técnicos y humanos para su ejecución. Si bien dos de las cuatro estrategias antes descriptas exigen la reunión sincrónica (presencial o virtual) de los expertos, los dos primeros métodos permiten la consulta virtual a expertos en forma simultánea a través de una entrevista o un formulario electrónico. Este mecanismo resulta eficiente y de gran cobertura. Por esta razón, se ha seleccionado para este trabajo el método a) Agregación individual de los expertos. En este sentido, los autores (Corral, 2009; Escobar-Pérez \& Cuervo-Martínez, 2008) coinciden en que la construcción del instrumento de indagación se convierte en una herramienta clave, ya que no habría otra interacción con los expertos más que el envío y recepción del instrumento completo. Se volverá sobre el detalle de la aplicación de esta estrategia y sus resultados en los siguientes apartados de este capítulo. 


\subsection{Concepto de experto}

Entre las primeras consideraciones se hace necesario conceptualizar qué es un experto. Cabero \& Barroso (2013) retoman a Mengual (2011) y definen como experto tanto al individuo como al grupo de personas que son capaces de proporcionar valoraciones confiables sobre un problema en cuestión y, al mismo tiempo, hacer recomendaciones en función de un máximo de competencia. Es importante también la consideración de los pares, quienes otorgan a un profesional el lugar de experto. Ese es el aspecto mencionado por Rojas, Carrillo \& Flores (2012, pág. 18) quienes dicen que "un experto puede caracterizarse como tal en función de variadas dimensiones, tales como sus cualidades académicas, años de experiencia en el trabajo, consenso entre pares y evaluación basada en alguna tarea o dominio de conocimiento en su área". Además, desde la perspectiva metacognitiva, un experto es reconocido también por la organización cognitiva que posee de sus conocimientos, competencias y experiencias y la forma en que es capaz de juzgar un objeto que pone en juego esas capacidades. Así lo expresan Palacios $\&$ Villar, quienes aseguran que se considera experto a quien posee un "profundo conocimiento $o$ es capaz de una práctica altamente calificada en un campo particular de estudio o de labor y, además, se distingue por la representación formal de ese conocimiento en categorías conceptuales que le permiten operar con él y tomar decisiones para sí y para otros" (Palacios \& Villar, 1996, pág. 230).

En síntesis, los expertos se reconocen por las siguientes características (tomado y adaptado de Escobar-Pérez \& Cuervo-Martínez, 2008):

\section{Conocimientos y competencias}

- Emisión de juicios y toma de decisiones. Puede analizarse en este caso: grado académico, investigaciones, publicaciones, posición, experiencia, premios obtenidos, etc.

- Reputación en la comunidad académica.

- Habitualidad de respuesta a encuestas e instrumentos de indagación, digitales en este caso.

\section{Experiencia}

- Experiencia en la enseñanza e investigación (resulta de gran importancia en este tema en particular).

\section{Condiciones personales y predisposición}

- Objetividad (no estar vinculado/a con la construcción del instrumento objeto del análisis ni en la investigación completa).

- Confianza en sí mismo/a y adaptabilidad a la forma de trabajo de la metodología de juicio de expertos implementada.

- Grado de compromiso con la indagación y el trabajo futuro. Cumplimiento de los tiempos de completamiento del instrumento de indagación.

- Toma de decisiones en situaciones de estrés. 


\subsection{Consideraciones sobre la cantidad de expertos recomendada}

Otro tema central es la cantidad de expertos a convocar. Diversos estudios ofrecen diferentes miradas de este tema. Cabero \& Barroso (2013) realizan una revisión bibliográfica que presenta diferentes posturas: Malla \& Zabala (1978) sugieren que el número de expertos debe oscilar entre 15 y 20; Gordon (1994) los sitúa entre 15 y 35; Landeta (2002) indica que este número debe estar comprendido entre 7 y 30; para García \& Fernández (2008) el intervalo debe situarse entre 15 y 25; Witkin \& Altschuld (1995) no señalan un número concreto, pero sí indican que debe ser menor a 50. Un estudio numérico completo es presentado por García \& Fernández (2008, pág. 48), quienes relacionan el número de expertos con la tarea a realizar. Sus conclusiones indican que sobre un número mayor a 7 expertos, los resultados de la consulta no varían significativamente.

En la aplicación del juicio de expertos en situaciones educativas, como es este caso, Cabero \& Barroso (2013) presentan algunos criterios para la selección del número de expertos, que han sido tenidos en cuenta en este trabajo. Mencionan:

- La oportunidad de contactar una cantidad suficiente de expertos, con reconocidas competencias sobre la temática analizada.

- La posibilidad real de comprometer a los expertos.

- El compromiso mostrado por estos expertos hacia el tipo de tarea encomendada, en anteriores situaciones similares.

- El volumen de trabajo que los expertos sean capaces de manejar.

- El momento del año en el que se los contacta y el tiempo total destinado a la consulta.

- La rapidez con que se deban ofrecer resultados preliminares, sobre todo en estudios de varios pasos de circulación de información, para evitar la desmotivación en la participación en el estudio.

- La consideración de la pérdida muestral.

Para este trabajo se contactaron 10 expertos y, pérdida muestral mediante, terminaron respondiendo 7. Según los estándares presentados por García \& Fernández (2008) es un número aceptable, dado el objetivo y la especificidad de la consulta.

\subsection{Evaluación de la validez de la matriz de indicadores mediante el juicio de expertos}

El juicio de expertos se puso en práctica para medir la validez de la matriz de indicadores que se construyó, como parte de MetSCIn, a partir del relevamiento teórico. Los autores abordados coinciden en que es un método valioso para medir validez teórica de un conjunto de indicadores. Según Mayaute (1988) la validez indica la capacidad de un instrumento para medir lo que se pretende, se refiere al grado de confianza que se tiene de que la medición corresponde a la realidad del fenómeno que se está midiendo. Coincide con esta idea Corral (2009) quien presenta la validez de un instrumento como la determinación del grado en el que mide lo que pretende medir. Para esta consulta, se ha desagregado la validez de la matriz en los componentes que se presentan en la tabla 25 . 


\begin{tabular}{|l|l|}
\hline $\begin{array}{l}\text { SUBCOMPONENTE DE } \\
\text { VALIDEZ }\end{array}$ & \multicolumn{1}{c|}{ DESCRIPCION } \\
\hline $\begin{array}{l}\text { CONSISTENCIA } \\
\text { CONCEPTUAL }\end{array}$ & $\begin{array}{l}\text { Hay acuerdo en la comunidad científica en que el } \\
\text { trabajo colaborativo responde a la definición } \\
\text { construida para esta tesis y las dimensiones son } \\
\text { acertadas. }\end{array}$ \\
\hline $\begin{array}{l}\text { VALIDEZ DE } \\
\text { INDICADORES }\end{array}$ & $\begin{array}{l}\text { Hay acuerdo en que los indicadores seleccionados } \\
\text { describen/valoran el trabajo colaborativo desde las } \\
\text { dimensiones individual y grupal. }\end{array}$ \\
\hline $\begin{array}{l}\text { SUFICIENCIA DE } \\
\text { INDICADORES }\end{array}$ & $\begin{array}{l}\text { Hay acuerdo en que los indicadores seleccionados } \\
\text { son suficientes. Con estos alcanza para valorar este } \\
\text { proceso. }\end{array}$ \\
\hline $\begin{array}{l}\text { CLARIDAD DE LA } \\
\text { OPERACIONALIZACION }\end{array}$ & $\begin{array}{l}\text { Hay acuerdo en que la operacionalización es clara y } \\
\text { permite visualizar los indicadores definidos. }\end{array}$ \\
\hline
\end{tabular}

Tabla 25: Componentes de la evaluación de la validez de indicadores mediante el juicio de expertos

\subsection{Metodología implementada}

Los autores consultados (Santos, 2014; Cabero \& Cejudo, 2013; Cabero \& Barros, 2013; Escobar-Pérez \& Cuervo-Martínez 2008; García \& Fernández, 2008) coinciden en la siguiente secuencia de pasos metodológicos para llevar adelante esta evaluación:

1. Definir el objeto a evaluar (Qué).

2. Definir el objetivo de la evaluación por juicio de expertos (Para qué).

3. Definir el método de juicio de expertos a utilizar (Presentados en el apartado 7.2. "Concepto de Juicio de Expertos"), según análisis de ventajas y debilidades de cada uno para el logro del objetivo final.

4. Construir el instrumento de indagación. Someter el instrumento a una prueba piloto según criterios de calidad (Presentados en la tabla 24: "Calidad del instrumento de evaluación mediante el juicio de expertos, en el método de agregación individual").

5. Seleccionar a los expertos (Quiénes).

6. Comunicar a los expertos la metodología de indagación.

7. Implementar el instrumento.

8. Hacer seguimiento de su completamiento.

9. Realizar análisis de las respuestas.

10. Implementar los ajustes en función de las respuestas obtenidas.

11. Comunicar a los expertos los resultados de la evaluación.

En la tabla 26 se explicita cada uno de los pasos metodológicos en este trabajo. 


\begin{tabular}{|c|c|}
\hline PASOS & DESCRIPCION \\
\hline 1. Definir el objeto a evaluar & $\begin{array}{l}\text { Matriz de indicadores para la valoración del trabajo } \\
\text { colaborativo construida para esta tesis. }\end{array}$ \\
\hline $\begin{array}{l}\text { 2. Definir el objetivo de la } \\
\text { evaluación de expertos }\end{array}$ & $\begin{array}{l}\text { Evaluar la validez de contenido de este instrumento, } \\
\text { con los siguientes subcomponentes: } \\
\text { - Consistencia conceptual } \\
\text { - Validez de indicadores } \\
\text { - Suficiencia de indicadores } \\
\text { - Claridad de la operacionalización }\end{array}$ \\
\hline $\begin{array}{l}\text { 3. Definir el método de juicio de } \\
\text { expertos a utilizar }\end{array}$ & $\begin{array}{l}\text { Se ha seleccionado la agregación individual de los } \\
\text { expertos, considerando el objetivo de la indagación y la } \\
\text { eficacia tiempo-recursos (materiales y humanos) } \\
\text { necesarios. }\end{array}$ \\
\hline $\begin{array}{l}\text { 4. Construir el instrumento de } \\
\text { indagación }\end{array}$ & $\begin{array}{l}\text { Desarrollado en la sección 7.6.2. "Instrumento aplicado } \\
\text { en el juicio de expertos". }\end{array}$ \\
\hline 5. Seleccionar a los expertos ${ }^{15}$ & $\begin{array}{l}\text { Desarrollado en la sección 7.6.1. "Selección de expertos } \\
\text { por cada dimensión del tema". }\end{array}$ \\
\hline $\begin{array}{l}\text { 6. Comunicar a los expertos las } \\
\text { características de la indagación }\end{array}$ & $\begin{array}{l}\text { Desarrollado en la sección 7.6.3. "Comunicación y } \\
\text { seguimiento metodológico del Juicio de expertos". }\end{array}$ \\
\hline 7. Implementar el instrumento & $\begin{array}{l}\text { Desarrollado en la sección 7.6.3. "Comunicación y } \\
\text { seguimiento metodológico del juicio de expertos". }\end{array}$ \\
\hline $\begin{array}{l}\text { 8. Hacer seguimiento de su } \\
\text { completamiento }\end{array}$ & $\begin{array}{l}\text { Desarrollado en la sección 7.6.3. "Comunicación y } \\
\text { seguimiento metodológico del juicio de expertos" }\end{array}$ \\
\hline $\begin{array}{l}\text { 9. Realizar análisis de las } \\
\text { respuestas }\end{array}$ & $\begin{array}{l}\text { Desarrollado en la sección 7.6.4. "Análisis de resultados } \\
\text { del juicio de expertos". }\end{array}$ \\
\hline $\begin{array}{l}\text { 10. Implementar los ajustes en } \\
\text { función de las respuestas } \\
\text { obtenidas }\end{array}$ & $\begin{array}{l}\text { Desarrollado en la sección 7.6.5. "Conclusiones del } \\
\text { juicio de expertos y ajustes". }\end{array}$ \\
\hline $\begin{array}{l}\text { 11. Comunicar a los expertos los } \\
\text { resultados de la evaluación }\end{array}$ & $\begin{array}{l}\text { Al finalizar el trabajo de indagación y análisis de } \\
\text { resultados se informa a los expertos acerca del proceso } \\
\text { completo. }\end{array}$ \\
\hline
\end{tabular}

Tabla 26: Descripción de los pasos metodológicos del juicio de expertos

\subsubsection{Selección de expertos por cada dimensión del tema}

Maldonado Mahauad et al. (2014) recopilan la bibliografía sobre este tema y presentan dos formatos para la selección de jueces: el biograma y el coeficiente de competencia experta. El biograma consiste en elaborar una biografía del experto, incorporando diversos aspectos: formación de grado y postgrado, años de experiencia profesional -en general en la disciplina o disciplinas y en el tema del juicio de expertos en particular-, formación académica, lugar de trabajo, experiencia en investigación, experiencia como experto en diversos juicios, etc. En función del conocimiento acerca del experto, se decide sobre su adecuación y la pertinencia de su inclusión en la muestra de expertos. El coeficiente de competencia experta, conocido como Factor K (Cabero \& Cejudo 2013; Cabero \& Barroso, 2013) se obtiene a partir de la autovaloración realizada por la persona para determinar su competencia experta en la materia. Tiene dos subcomponentes: Kc es el "coeficiente de conocimiento" o información que tiene el experto

\footnotetext{
${ }^{15}$ Los pasos 4 y 5 pueden darse en el orden contrario o, incluso, superponerse en el tiempo.
} 
acerca del tema o problema planteado y su propia valoración como experto; y Ka es el denominado "coeficiente de argumentación" o fundamentación de los criterios de los expertos.

En este trabajo se han tomado en cuenta dos formatos para la selección de los expertos: el biograma y el coeficiente Kc, ya que se ha dedicado la primera sección del instrumento de indagación a este objetivo. No se ha optado por la valoración del coeficiente Ka. Sin embargo, algunos de los expertos consultados han fundamentado su opinión en las preguntas de ensayo incorporadas en el instrumento y, en un caso, un experto envió una justificación complementaria vía e-mail. Estas respuestas han sido consideradas cualitativamente en la resignificación de la matriz de indicadores.

Los expertos seleccionados fueron considerados atendiendo al constructo multidimensional que significa el trabajo colaborativo mediado por tecnología informática. Así, se consideraron expertos en las siguientes temáticas:

- Perspectiva de comunicación, educación y el trabajo grupal: 4 expertos.

- Perspectiva de herramientas informáticas y entornos de groupware: 3 expertos.

- Perspectiva de construcción colaborativa mediada por tecnología digital: 3 expertos.

\subsubsection{Biograma de los expertos seleccionados}

La tabla 27 presenta esta información según la estructura descripta en el apartado anterior.

\begin{tabular}{|c|c|c|c|c|}
\hline & $\begin{array}{l}\text { Formación } \\
\text { académica }\end{array}$ & $\begin{array}{c}\text { Area de experiencia } \\
\text { profesional }\end{array}$ & $\begin{array}{c}\text { Inserción } \\
\text { institucional }\end{array}$ & Cargo \\
\hline Experto 1 & $\begin{array}{l}\text { Psicólo@ } \\
\text { educacional (Dra.) }\end{array}$ & Educación & UBA - UNLP & $\begin{array}{l}\text { Docente / } \\
\text { Investigador }\end{array}$ \\
\hline Experto 2 & Ingenierx. Magister & Educación & $\begin{array}{l}\text { Universidad Nacional } \\
\text { del Centro (UNICEN) }\end{array}$ & $\begin{array}{l}\text { Docente / } \\
\text { Investigador }\end{array}$ \\
\hline Experto 3 & Lic. En Educación. & $\begin{array}{l}\text { TICs y Educación } \\
\text { Didáctica }\end{array}$ & $\begin{array}{l}\text { UBA- USAL- } \\
\text { Universidad de Luján }\end{array}$ & $\begin{array}{l}\text { Docente / } \\
\text { Investigador }\end{array}$ \\
\hline Experto 4 & Dr. En Informática & $\begin{array}{l}\text { Interacción tangible para } \\
\text { niños } \\
\text { Trabajo colaborativo }\end{array}$ & $\begin{array}{l}\text { Universidad de } \\
\text { Zaragoza }\end{array}$ & $\begin{array}{l}\text { Docente / } \\
\text { Investigador }\end{array}$ \\
\hline Experto 5 & $\begin{array}{l}\text { Magister en } \\
\text { Ingeniería de } \\
\text { Software }\end{array}$ & Groupware & UNLP & $\begin{array}{l}\text { Docente / } \\
\text { Investigador }\end{array}$ \\
\hline Experto 6 & $\begin{array}{l}\text { Dr. en Ciencias } \\
\text { Informáticas. }\end{array}$ & $\begin{array}{l}\text { Educación y tecnología. } \\
\text { Computación afectiva }\end{array}$ & $\begin{array}{l}\text { Universidad de } \\
\text { Zaragoza } \\
\text { UNLP }\end{array}$ & $\begin{array}{l}\text { Docente / } \\
\text { Investigador }\end{array}$ \\
\hline Experto 7 & Ingenier@ & $\begin{array}{l}\text { Ingeniería del } \\
\text { conocimiento. Trabajo } \\
\text { colaborativo }\end{array}$ & $\begin{array}{l}\text { Universidad de Lanús } \\
\text { UNLP }\end{array}$ & $\begin{array}{l}\text { Docente / } \\
\text { Investigador }\end{array}$ \\
\hline Experto 8 & $\begin{array}{l}\text { Doctor en Física y } \\
\text { Profesor en } \\
\text { Matemática y Física }\end{array}$ & $\begin{array}{l}\text { Trabajo colaborativo y } \\
\text { tecnología informática }\end{array}$ & UNICEN & $\begin{array}{l}\text { Docente / } \\
\text { Investigador }\end{array}$ \\
\hline Experto 9 & $\begin{array}{l}\text { Dr. En Ciencias } \\
\text { Informáticas }\end{array}$ & $\begin{array}{l}\text { TICs y educación. Nuevos } \\
\text { lenguajes (RA) - Trabajo } \\
\text { colaborativo }\end{array}$ & UNLP - UNICEN & $\begin{array}{l}\text { Docente / } \\
\text { Investigador }\end{array}$ \\
\hline Experto 10 & Lic. En Informática & $\begin{array}{l}\text { Trabajo colaborativo en } \\
\text { Ed. Integacción tangible }\end{array}$ & UNLP & $\begin{array}{l}\text { Docente / } \\
\text { Investigador }\end{array}$ \\
\hline
\end{tabular}

Tabla 27: Biograma de los expertos seleccionados 


\subsubsection{Instrumento aplicado en el juicio de expertos}

El instrumento tomó la forma de encuesta de opinión en formato digital. Se administró en forma remota mediante un formulario en Google Formularios (se darán más detalles del procedimiento de comunicación y seguimiento en la sección siguiente). El instrumento de indagación construido para este fin consideró las siguientes secciones:

SECCION 1: Datos básicos. Se requirió información complementaria al biograma. Se solicitó la siguiente información: nombre y apellido; formación académica (título de grado y postgrado); área de experiencia profesional; institución donde trabaja (institución donde trabaja más tiempo de la semana); cargo que desempeña en dicha institución.

Análisis del coeficiente de competencia experta factor $K$ (en su componente de conocimiento Kc). En esta sección del formulario, cada experto tuvo la oportunidad de autoevaluar su expertise en el tema, indicando en qué grado se considera experto. Las preguntas del instrumento que atendieron a este componente se presentan en la tabla 28.

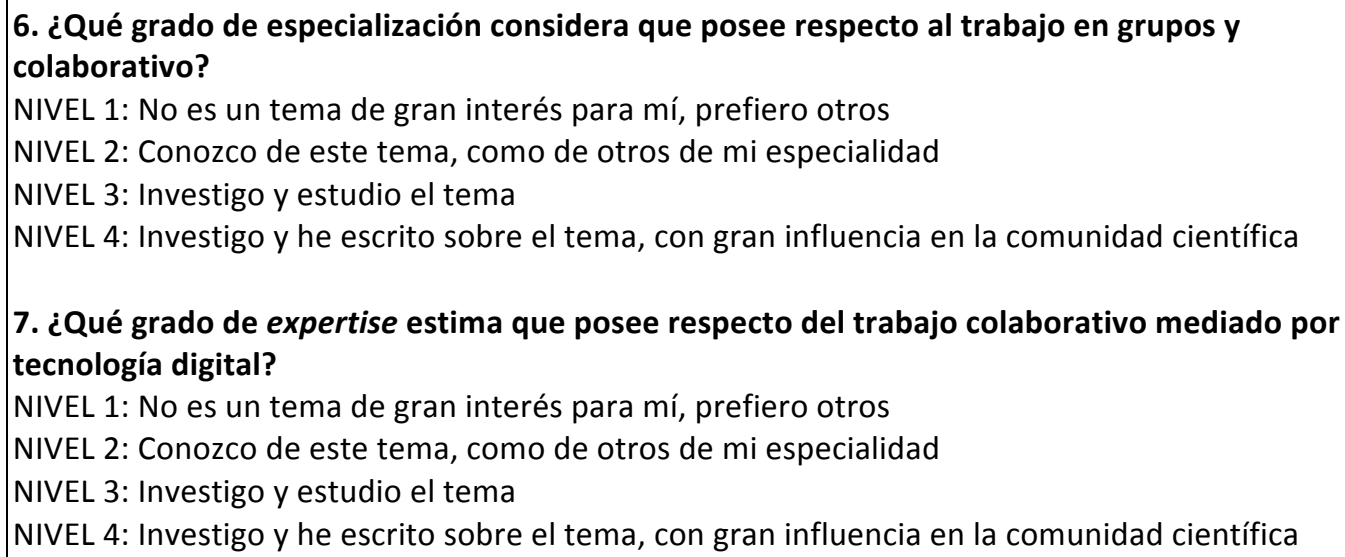

SECCION 2: Conceptos básicos: Se indagaron opiniones acerca de los conceptos asociados a trabajo cooperativo y colaborativo. Mediante tres preguntas, se indagó el concepto de trabajo colaborativo y sus componentes conceptuales, específicamente el concepto de interdependencia positiva y sus dimensiones.

SECCION 3: Análisis de la dimensión individual: Se requirió opinión sobre los indicadores construidos para el análisis de la dimensión individual del componente de interdependencia positiva en el trabajo colaborativo.

SECCION 4: Análisis de la dimensión grupal: Se solicitó opinión sobre los indicadores construidos para el análisis de la dimensión grupal del componente interdependencia positiva en el trabajo colaborativo.

SECCION 5: Matriz completa y su operacionalización: Se buscó reconstruir la matriz y avanzar sobre la operacionalización de estos indicadores. Esto significó indagar acerca de qué documentos de los producidos por un grupo colaborativo deben ser analizados para encontrar la información requerida por esta matriz.

SECCION FINAL: Agradecimiento y despedida. 
En la tabla 29 se indica en qué sección del instrumento de indagación se presenta cada subcomponente de componente de validez descripto.

\begin{tabular}{|c|c|}
\hline SUBCOMPONENTE DE VALIDEZ & SECCIONES DEL INSTRUMENTO DE INDAGACION \\
\hline CONSISTENCIA CONCEPTUAL & $\begin{array}{l}\text { SECCION 2. Opinión sobre el concepto de trabajo } \\
\text { colaborativo y sus componentes }\end{array}$ \\
\hline VALIDEZ DE INDICADORES & $\begin{array}{l}\text { SECCION 3. Análisis de la dimensión individual - } \\
\text { indicadores } \\
\text { SECCION 4. Análisis de la dimensión grupal - } \\
\text { indicadores }\end{array}$ \\
\hline SUFICIENCIA DE INDICADORES & $\begin{array}{l}\text { SECCION 3. Análisis de la dimensión individual - } \\
\text { indicadores } \\
\text { SECCION 4. Análisis de la dimensión grupal - } \\
\text { indicadores }\end{array}$ \\
\hline $\begin{array}{c}\text { CLARIDAD DE LA } \\
\text { OPERACIONALIZACION }\end{array}$ & SECCION 5. Matriz completa de indicadores \\
\hline
\end{tabular}

Tabla 29: Componentes de la matriz validados en el formulario de juicio de expertos por sección del instrumento

Respecto de los tipos de ítems o preguntas, se incluyeron preguntas cerradas, que se respondían indicando el grado de acuerdo con cada uno de los enunciados. Al final de cada sección se incluyó un set de dos preguntas, para registrar alguna opinión que no hubiera sido considerada y su argumentación por parte del experto. Esto conlleva a registrar el factor Ka, que es el denominado "coeficiente de argumentación". Si bien este coeficiente no se utilizó para analizar la condición de los expertos, se incluyeron sus comentarios en la resignificación de la matriz como resultado de esta instancia de evaluación.

Se muestra a continuación, como un ejemplo, el tipo de preguntas incluidas al final de la sección 3. Este set de preguntas se repetían al final de las secciones 4 y 5.

14. ¿Considera que hay algún otro indicador de la producción individual que no se haya considerado?

\section{$\mathrm{SI} / \mathrm{NO}$}

14a. Si respondió "SI" en la pregunta anterior, por favor indique cuál/es (y, si es posible, la fuente de información)

[Se podía responder, debajo de la consigna, en un espacio de construcción de respuesta en el formulario electrónico]

En la tabla 30 se muestra la cantidad de ítems totales del instrumento y desagregados por cada subcomponente y sección. 


\begin{tabular}{|c|c|c|c|c|}
\hline $\begin{array}{l}\text { SUBCOMPONENTE DE } \\
\text { VALIDEZ }\end{array}$ & \multirow{2}{*}{$\begin{array}{l}\text { SECCIONES DEL } \\
\text { INSTRUMENTO DE } \\
\text { INDAGACION }\end{array}$} & \multirow{2}{*}{$\begin{array}{l}\text { CANTIDAD DE } \\
\text { ITEMS POR } \\
\text { SECCION } \\
\end{array}$} & \multicolumn{2}{|c|}{ TIPO DE ITEMS } \\
\hline & & & $\begin{array}{l}\text { SELECION DE } \\
\text { RESPUESTA }\end{array}$ & $\begin{array}{l}\text { CONSTRUCIO } \\
\text { N DE } \\
\text { RESPUESTA }\end{array}$ \\
\hline \multicolumn{2}{|c|}{$\begin{array}{l}\text { DATOS BASICOS Y FACTOR DE COMPETENCIA EXPERTA } \\
\text { (Kc) }\end{array}$} & 7 (1 al 7) & 2 & 5 \\
\hline $\begin{array}{l}\text { CONSISTENCIA } \\
\text { CONCEPTUAL }\end{array}$ & $\begin{array}{l}\text { SECCION 2. Opinión sobre el } \\
\text { concepto de trabajo } \\
\text { colaborativo y sus componentes }\end{array}$ & 3 (8 al 10) & 3 & \\
\hline \multirow[t]{2}{*}{$\begin{array}{l}\text { VALIDEZ Y } \\
\text { SUFICIENCIA DE } \\
\text { INDICADORES }\end{array}$} & $\begin{array}{c}\text { SECCION 3. Análisis de la } \\
\text { dimensión individual - } \\
\text { indicadores }\end{array}$ & $\begin{array}{c}5(11 \text { al } 14 \text { y } \\
14 a)\end{array}$ & 4 & 1 \\
\hline & $\begin{array}{c}\text { SECCION 4. Análisis de la } \\
\text { dimensión grupal - indicadores }\end{array}$ & $\begin{array}{c}6(15 \text { al } 19 y \\
19 a)\end{array}$ & 5 & 1 \\
\hline $\begin{array}{l}\text { CLARIDAD DE LA } \\
\text { OPERACIONALIZA- } \\
\text { CION }\end{array}$ & $\begin{array}{l}\text { SECCION 5. Matriz completa de } \\
\text { indicadores }\end{array}$ & $\begin{array}{c}4(20 \text { al } 22 \text { y } \\
22 a)\end{array}$ & 3 & 1 \\
\hline
\end{tabular}

Tabla 30: Cantidad de ítems total y por cada sección del instrumento de indagación del juicio de experto

En cuanto a la escala, se utilizó una de las llamadas "tipo Likert"16. Es muy utilizada en Ciencias Sociales, para requerir opinión en términos de grado de acuerdo o desacuerdo, de gusto o disgusto, de aceptación o rechazo, etc. Según Monje Álvarez (2011), su diseño se inicia con una afirmación, que debe ser presentada de la forma más objetiva, exhaustiva, completa y clara posible, a la que se le agrega una escala que mide tanto el grado positivo, como neutral y negativo de cada enunciado. Esto le otorga confiabilidad a la escala (Malbrán, 2013).

GRADO 1: Completo desacuerdo.

GRADO 2: Algo en desacuerdo.

GRADO 3: Ni acuerdo ni desacuerdo.

GRADO 4: Algo de acuerdo.

GRADO 5: Completo acuerdo.

Se trata de una escala de grado de acuerdo, que puede ordenarse según las características de una escala ordinal. Por esta razón, habría correlación entre los dos últimos grados (4 y 5) y las respuestas deseadas, en tanto representan acuerdo con cada enunciado. En el anexo 3 se presenta el instrumento completo y en el anexo 5 se incluye la dirección del formulario de indagación a los expertos en GoogleForm.

Antes de su aplicación en el juicio de expertos, este instrumento fue sometido a una prueba piloto (con expertos de un perfil similar a los incluidos en la muestra, pero que no habían sido seleccionados para constituirla) para verificar el cumplimiento de los criterios presentados en la tabla 21. En dicha prueba piloto se evaluó la estructura del instrumento, en cuanto a la claridad y suficiencia de los indicadores sometidos a evaluación y la claridad de las consignas. Asimismo, antes de comenzar la comunicación se hizo una prueba de completamiento, para poner a consideración la escala seleccionada y verificar su potencialidad para arrojar resultados que

\footnotetext{
${ }^{16}$ La escala de Likert lleva su nombre por Rensis Likert, quien publicó un informe donde describía su uso en el año 1932.
} 
pudieran ser comunicables y permitieran validar la matriz de indicadores. El instrumento y la escala validados y modificados fueron, luego implementados en la indagación.

\subsubsection{Comunicación y seguimiento metodológico del juicio de expertos}

El circuito de comunicación y seguimiento que se implementó se muestra en la figura 51.

\begin{tabular}{|c|c|c|c|c|}
\hline PASO 1 & PASO 2 & PASO 3 & PASO 4 & PASO 5 \\
\hline $\begin{array}{l}\text { Aviso vía mail } \\
\text { de la } \\
\text { conformación } \\
\text { del comité de } \\
\text { expertos, } \\
\text { indicando } \\
\text { tiempos de } \\
\text { trabajo (envío } \\
\text { del instrumento } \\
\text { y respuesta } \\
\text { esperada) }\end{array}$ & $\begin{array}{l}\text { Envío del } \\
\text { instrumento (Vía } \\
\text { Google } \\
\text { Formularios) } \\
\text { - Pedido de } \\
\text { información para } \\
\text { el biograma } \\
\text { - Consulta sobre la } \\
\text { validez de los } \\
\text { indicadores } \\
\text { construidos para } \\
\text { seguimiento del } \\
\text { trabajo } \\
\text { colaborativo }\end{array}$ & $\begin{array}{l}\text { Seguimiento del } \\
\text { tiempo } \\
\text { estimado: } \\
\text { recuerdo para } \\
\text { que lo } \\
\text { completen }\end{array}$ & $\begin{array}{c}\text { Agradecimiento } \\
\text { por la } \\
\text { conformación } \\
\text { del Comité }\end{array}$ & $\begin{array}{l}\text { Envío de } \\
\text { conclusiones } \\
\text { post análisis de } \\
\text { resultados }\end{array}$ \\
\hline
\end{tabular}

Figura 51: Comunicación con los expertos y seguimiento del proceso

Se inició con el paso 1, mediante una invitación a participar de la evaluación, indicando objetivo del trabajo, pasos siguientes y tiempo estimado que debían dedicarle al tema. El mail de invitación fue enviado a todo el grupo de expertos seleccionado, con copia oculta a cada uno. En el anexo 3 se consigna el texto de la invitación. A partir de ese momento, la comunicación fue privada e individual con cada experto. En el paso 2, se envió el link al instrumento y se recordó el tiempo estimado para la realización del trabajo. El mensaje también aparece en el anexo 3.

Los pasos 3 y 4 del circuito de comunicación fueron personalizados, en respuesta a las diferentes situaciones que presentaron los expertos, que fueron las siguientes:

- no respondieron al primer mail;

- respondieron, pero no aceptaron participar del juicio de expertos;

- aceptaron, pero al recibir el formulario reconocieron que no podían responder a las preguntas;

- aceptaron y recibieron la información, pero nunca ingresaron al formulario para responderlo.

Entonces, considerando que se convocó a 10 expertos y terminaron respondiendo 7, la pérdida muestral fue del $30 \%$. Se produjo en las etapas que se muestran en la figura 52. 


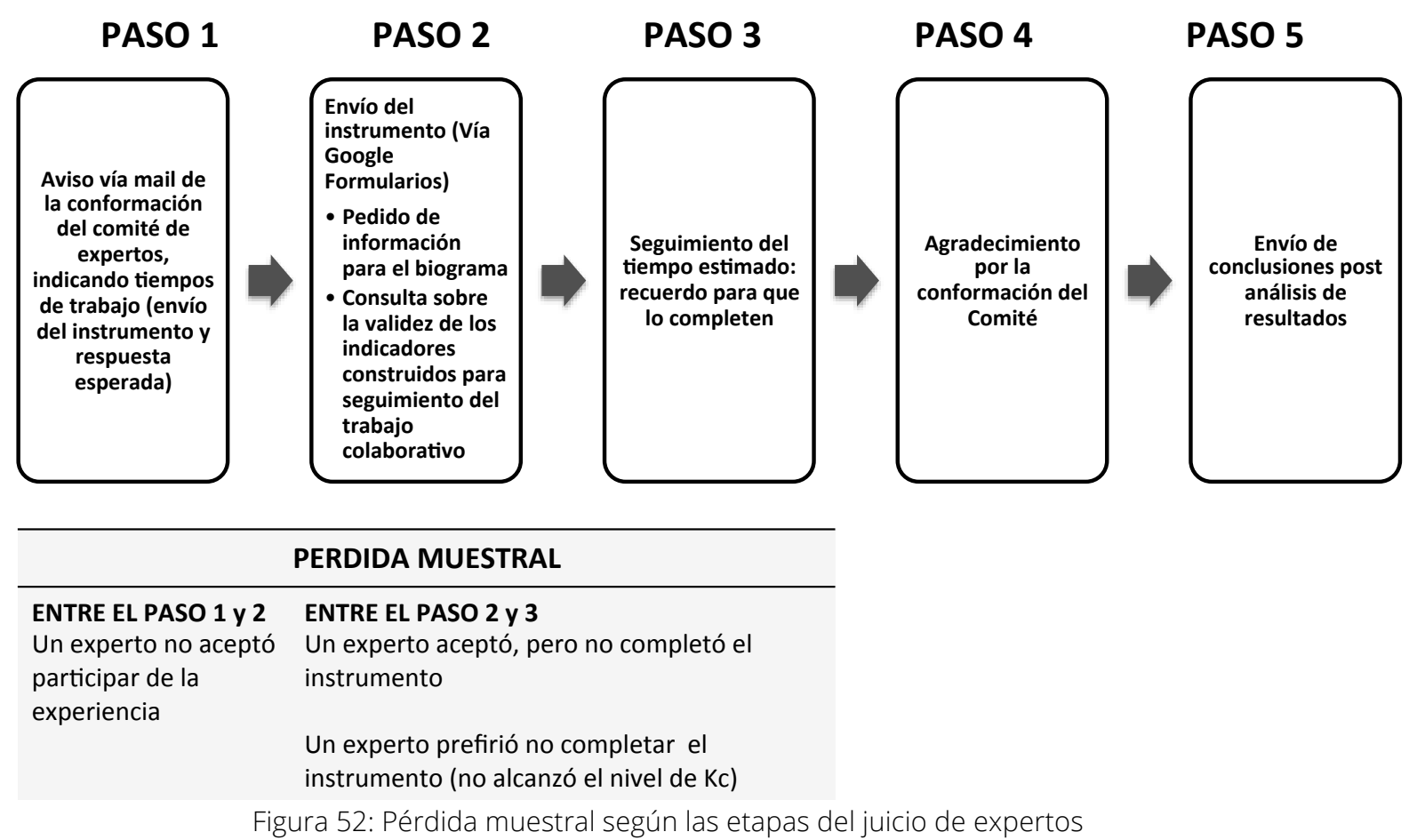

\subsubsection{Análisis de resultados del juicio de expertos}

Este punto resulta fundamental, ya que es imprescindible establecer el grado de acuerdo de los jueces respecto del tema en cuestión. Siguiendo a Maldonado Mahauad (2014) una aproximación inicial es calcular el porcentaje de acuerdo. Este valor se denomina factor de concordancia. Una medida de acuerdo alta indica consenso en el proceso de clasificación o asignación de puntajes entre los evaluadores. En el análisis de este trabajo se presenta la concordancia por ítem y sección, estableciendo una media de la concordancia en cada ítem y en cada sección. La presentación de los resultados se divide en dos partes:

- El análisis del factor de concordancia K, en su componente Kc (indagado en la primera sección del instrumento).

- El análisis de las secciones 2 a 5, por ítem y compilado por sección.

\subsubsection{Análisis del factor $\mathrm{K}$ (grado de expertise manifestado por los expertos). Sección 2}

Los resultados arrojados por las preguntas de valoración del coeficiente de competencia experta fueron los siguientes:

NIVEL 2: Conozco de este tema, como de otros de mi especialidad (14\%)

NIVEL 3: Investigo y estudio el tema (57\%)

NIVEL 4: Investigo y he escrito sobre el tema, con gran influencia en la comunidad científica (29\%). Gráficamente se presenta en la figura 53. 


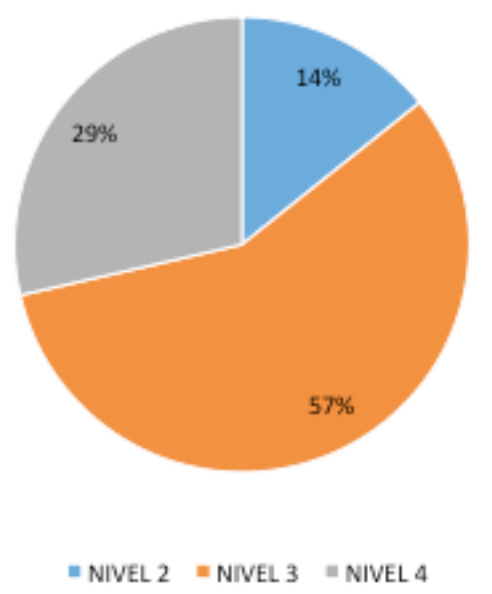

Figura 53: Factor de concordancia Kc de la sección 2. Grado de competencia experta

Teniendo en cuenta la especificidad del tema, se considera adecuado que un $57 \%$ de los indagados se considere conocedor y un $29 \%$ se vea como experto.

\subsubsection{Análisis de la concordancia de respuesta por ítem y sección del instrumento}

En la tabla de datos (tabla 31) se presentan las respuestas obtenidas, divididas por ítem y compiladas por sección. Asimismo, se presenta la media de opiniones, calculada utilizando la escala de grado de acuerdo (con su correspondencia numérica de 1 a 5) presentada en la sección 7.6.2. "Instrumento aplicado en el juicio de expertos".

\begin{tabular}{|c|c|c|c|c|c|c|c|c|c|}
\hline \multirow[t]{2}{*}{$\begin{array}{c}\text { SUBCOMPONENTE DE } \\
\text { VALIDEZ } \\
\end{array}$} & \multirow[t]{2}{*}{ SECCION / ITEM } & \multicolumn{7}{|c|}{$\begin{array}{c}\text { Respuestas de los expertos (nivel de acuerdo } \\
\text { en la escala Likert) }\end{array}$} & \multirow[t]{2}{*}{ Media } \\
\hline & & E1 & E2 & E3 & E4 & E5 & E6 & E7 & \\
\hline $\begin{array}{l}\text { Datos de los } \\
\text { expertos }\end{array}$ & $\begin{array}{l}\text { Información de biograma y coeficiente de } \\
\text { competencia experta (Subcomponente Kc) }\end{array}$ & \multicolumn{8}{|c|}{$\begin{array}{l}\text { Información utilizada para componer el biograma y } \\
\text { completar el coeficiente de expertise }\end{array}$} \\
\hline \multirow{4}{*}{$\begin{array}{l}\text { CONSISTENCIA } \\
\text { CONCEPTUAL }\end{array}$} & \multicolumn{8}{|l|}{ SECCION 2: Concepto de trabajo colaborativo } & 4.61 \\
\hline & Ítem 8: Definición de trabajo colaborativo & 5 & 4 & 5 & 5 & 5 & 4 & 5 & 4.71 \\
\hline & $\begin{array}{l}\text { Ítem 9: Concepto del interdependencia } \\
\text { positiva }\end{array}$ & 5 & 3 & 5 & 5 & 5 & 5 & 4 & 4.57 \\
\hline & $\begin{array}{l}\text { Ítem 10: Dimensiones individual y grupal } \\
\text { de la interdependencia positiva }\end{array}$ & 5 & 4 & 5 & 5 & 5 & 4 & 4 & 4.57 \\
\hline \multirow{6}{*}{$\begin{array}{l}\text { VALIDEZ Y } \\
\text { SUFICIENCIA DE } \\
\text { INDICADORES }\end{array}$} & \multicolumn{8}{|c|}{ SECCION 3. Análisis de la dimensión individual - indicadores } & 4.52 \\
\hline & Ítem 11: Composición de los mensajes & 5 & 3 & 5 & 5 & 5 & 5 & 5 & 4.71 \\
\hline & $\begin{array}{l}\text { Ítem 12. Indicadores de la dimensión } \\
\text { individual de la interdependencia positiva }\end{array}$ & 2 & 4 & 5 & 4 & 4 & 4 & 5 & 4.57 \\
\hline & $\begin{array}{l}\text { Ítem 13: Análisis de los mensajes como } \\
\text { indicadores de interdependencia positiva } \\
\text { individual }\end{array}$ & 3 & 4 & 5 & 5 & 5 & 4 & 4 & 4.28 \\
\hline & $\begin{array}{l}\text { Ítem 14: Consideración de otros } \\
\text { indicadores }\end{array}$ & NO & $\mathrm{SI}$ & $\mathrm{SI}$ & NO & NO & NO & NO & \\
\hline & Ítem 14 a: Justificación & \multicolumn{8}{|c|}{ Espacio de completamiento de texto de justificación } \\
\hline
\end{tabular}




\begin{tabular}{|c|c|c|c|c|c|c|c|c|c|}
\hline \multirow[t]{2}{*}{$\begin{array}{l}\text { SUBCOMPONENTE DE } \\
\text { VALIDEZ } \\
\end{array}$} & \multirow[t]{2}{*}{ SECCION / ITEM } & \multicolumn{7}{|c|}{$\begin{array}{c}\text { Respuestas de los expertos (nivel de acuerdo } \\
\text { en la escala Likert) }\end{array}$} & \multirow[t]{2}{*}{ Media } \\
\hline & & E1 & E2 & E3 & E4 & E5 & E6 & E7 & \\
\hline & \multicolumn{8}{|c|}{ SECCION 4. Análisis de la dimensión grupal - indicadores } & 4.38 \\
\hline & $\begin{array}{l}\text { Ítem 15: Concepto de grounding como } \\
\text { componente de construcción colaborativa }\end{array}$ & 5 & 4 & 5 & 5 & 5 & 5 & 4 & 4.71 \\
\hline & $\begin{array}{l}\text { Ítem 16: Concepto de cohesión como } \\
\text { componente de construcción colaborativa }\end{array}$ & 5 & 3 & 5 & 5 & 4 & 4 & 5 & 4.42 \\
\hline & $\begin{array}{l}\text { Ítem 17: Análisis de conversaciones } \\
\text { grupales como indicadores de grounding y } \\
\text { cohesión }\end{array}$ & 3 & 3 & 5 & 5 & 4 & 4 & 5 & 4.14 \\
\hline & Ítem 18: Mapa de indicadores compilados & 4 & 3 & 5 & 5 & 4 & 4 & 5 & 4.28 \\
\hline & $\begin{array}{l}\text { Ítem 19: Consideración de otros } \\
\text { indicadores }\end{array}$ & NO & NO & SI & NO & SI & NO & NO & \\
\hline & Ítem 19 a: Justificación & \multicolumn{8}{|c|}{ Espacio de completamiento de texto de justificación } \\
\hline CLARIDAD DE LA & \multicolumn{8}{|l|}{ SECCION 5. Matriz completa de indicadores } & 4.14 \\
\hline \multirow[t]{4}{*}{$\begin{array}{l}\text { OPERACIONALI- } \\
\text { ZACION }\end{array}$} & $\begin{array}{l}\text { Ítem 20: Concepto de trabajo colaborativo } \\
\text { con indicadores integrados }\end{array}$ & 3 & 4 & 5 & 4 & 4 & 5 & 4 & 4.14 \\
\hline & $\begin{array}{l}\text { Ítem 21: Operacionalización de } \\
\text { indicadores (con mapa) }\end{array}$ & 3 & 3 & 5 & 4 & 4 & 5 & 5 & 4.14 \\
\hline & $\begin{array}{l}\text { Ítem 22: Consideración de otros } \\
\text { indicadores }\end{array}$ & NO & NO & $\mathrm{SI}$ & SI & SI & NO & $\mathrm{SI}$ & \\
\hline & Ítem 22 a: Justificación & \multicolumn{8}{|c|}{ Espacio de completamiento de texto de justificación } \\
\hline
\end{tabular}

Tabla 31: Respuestas por ítem y por sección. Tabla de datos

Para proporcionar una mejor visión de esta concordancia se presenta, en las figuras 54 a 57, la concordancia de cada sección, considerando las respuestas de los siete expertos en cada uno de los ítems que conforman cada una de las secciones. En el epígrafe de cada figura se repite la media de concordancia que se ha presentado en la tabla 31.
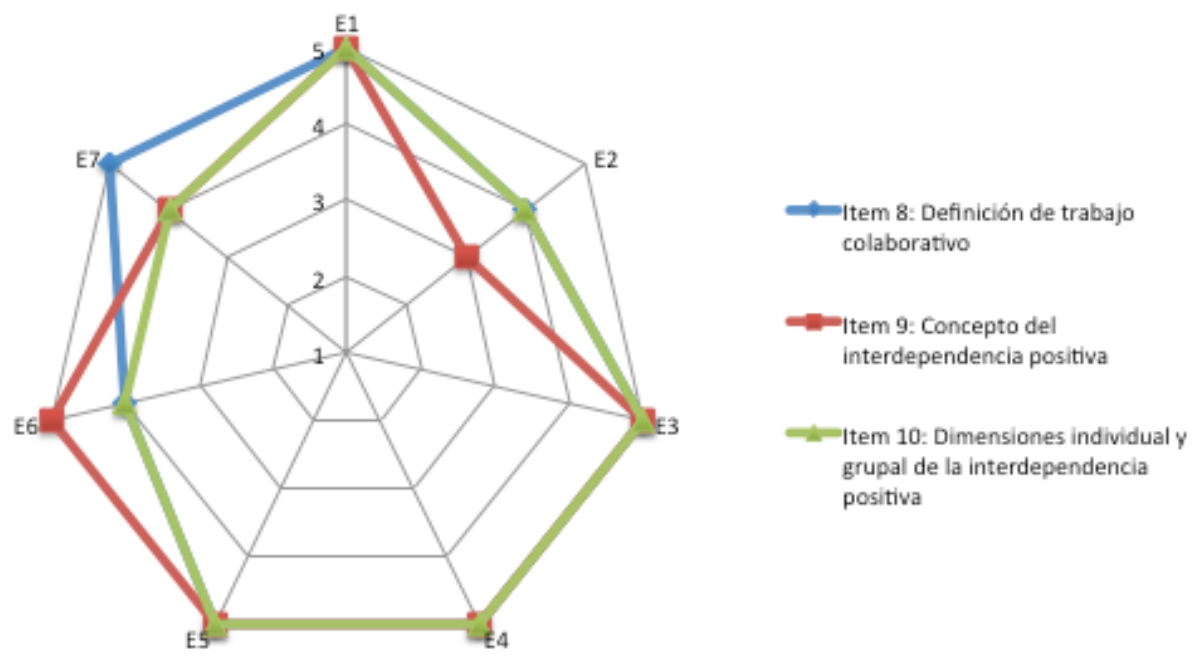

Figura 54: Concordancia de la sección 2. Concepto de Trabajo Colaborativo. Media: 4.61 

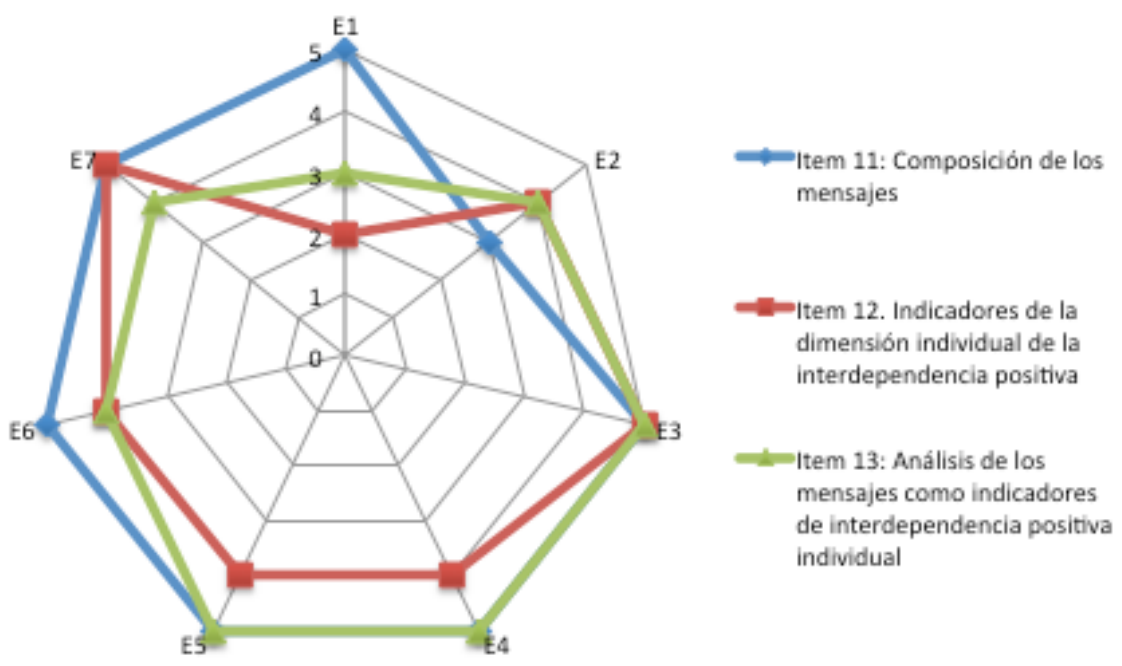

Figura 55: Concordancia de la sección 3. Indicadores de la dimensión individual del Trabajo Colaborativo. Media: 4.52

En la figura 55 se visualiza que uno de los expertos marcó la opción 2 ("algo en desacuerdo") de la escala en el ítem acerca de los indicadores de la dimensión individual del trabajo colaborativo (ítem 12). En esta misma sección del formulario, al final, se recogen sugerencias y su justificación. En este espacio, el experto ofreció un nuevo indicador que explica su opinión en este ítem y que fue tenido en cuenta para construir la matriz final. Se profundizará este agregado en la sección 7.6.5. "Conclusiones del juicio de expertos y ajustes".
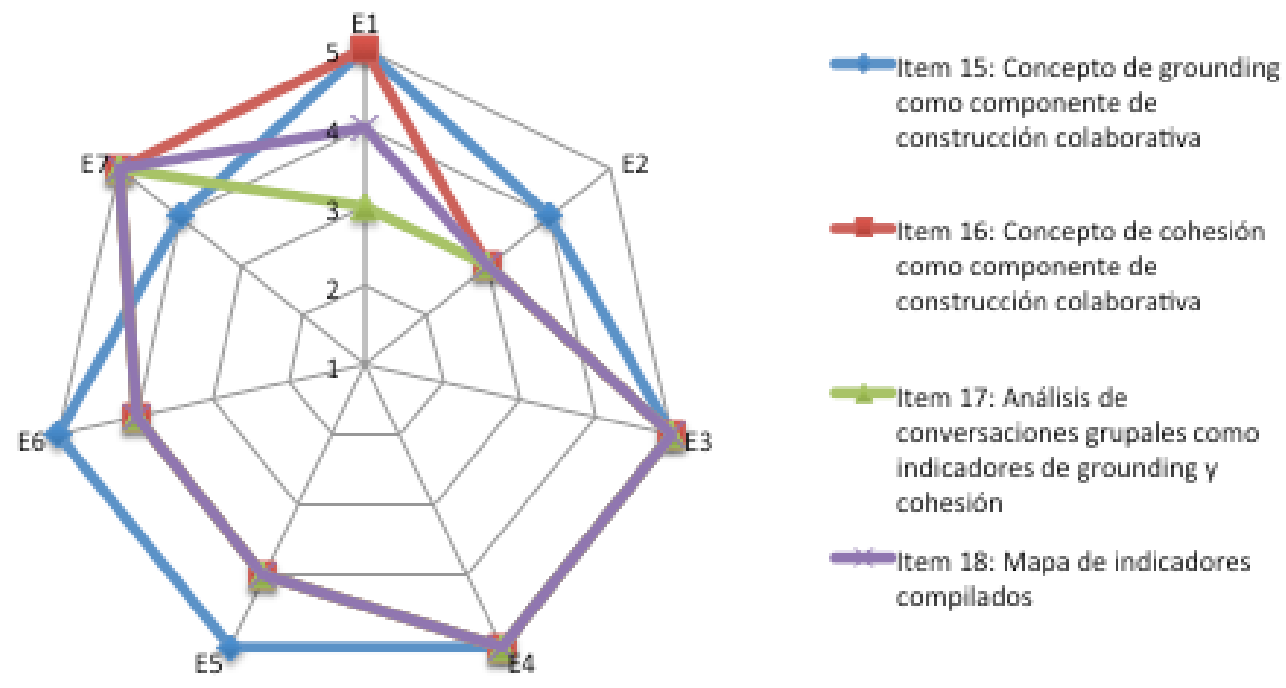

Figura 56: Concordancia de la sección 4. Indicadores de la dimensión grupal del Trabajo Colaborativo. Media: 4,38

En la figura 56 se muestra que en la sección 4 ocurre algo similar a la sección 3, ya que dos expertos hicieron aportes sobre indicadores de dimensión grupal. Eso explica las dos respuestas de grado 3 que se visualizan. Se profundizará este agregado en la sección siguiente: 7.6.5. "Conclusiones del juicio de expertos y ajustes".

Finalmente, en la figura 57 se presenta la concordancia de respuestas sobre la matriz completa de indicadores y su operacionlización. 


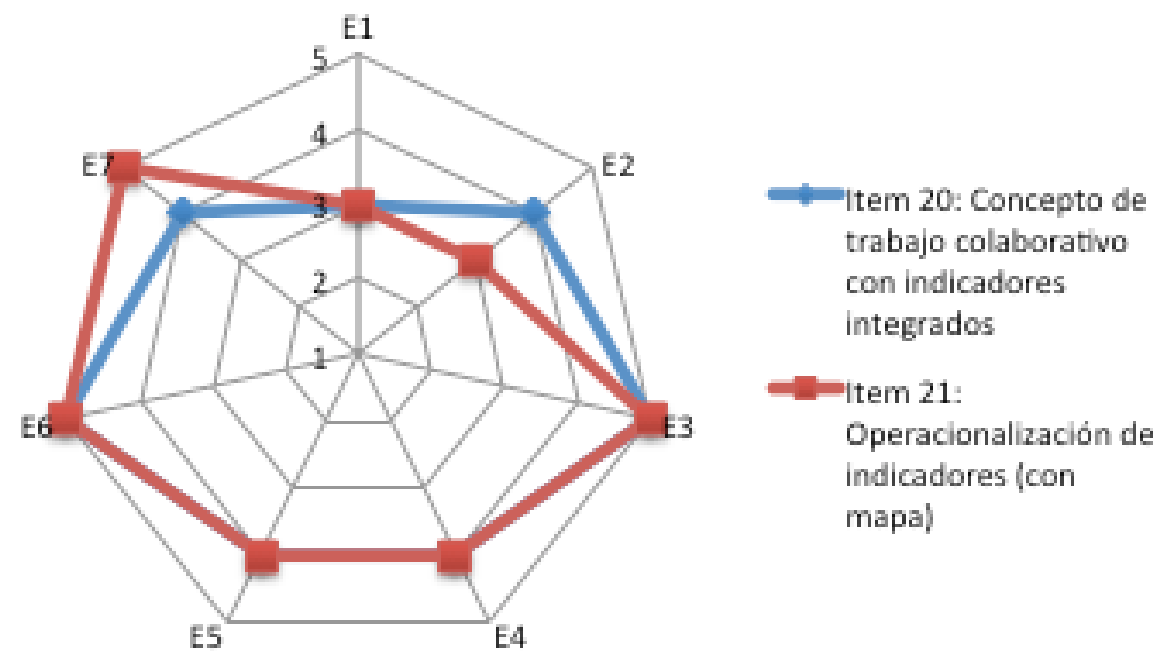

Figura 57: Concordancia de la sección 5. Matriz completa de indicadores. Media: 4,14

\subsubsection{Conclusiones del juicio de expertos y ajustes}

En esta sección se recuperan las respuestas cualitativas de los expertos que condujeron a la resignificación y enriquecimiento de la matriz.

Las medias de concordancia superan el grado 4 de la escala ("Algo de acuerdo"). No obstante la concordancia significativa, la matriz se vio resignificada y mejorada con los aportes de los expertos en las preguntas abiertas de las secciones 3,4 y 5 .

Las categorías de los aportes cualitativos ofrecidos por los expertos se presentan en la figura 58. Se refirieron a las tres categorías que aparecen en la figura. Uno de los expert@s consultados hizo mención a la perspectiva de la autopercepción individual sobre la autorregulación en el aprendizaje como factor inicial de la construcción colaborativa. Otro de los expert@s propuso descomponer el indicador de cohesión grupal en sub indicadores y tres expert@s mencionaron el componente del diálogo y la argumentación para agregar a la matriz (incluso facilitando bibliografía sobre el tema, oportunamente revisada). 


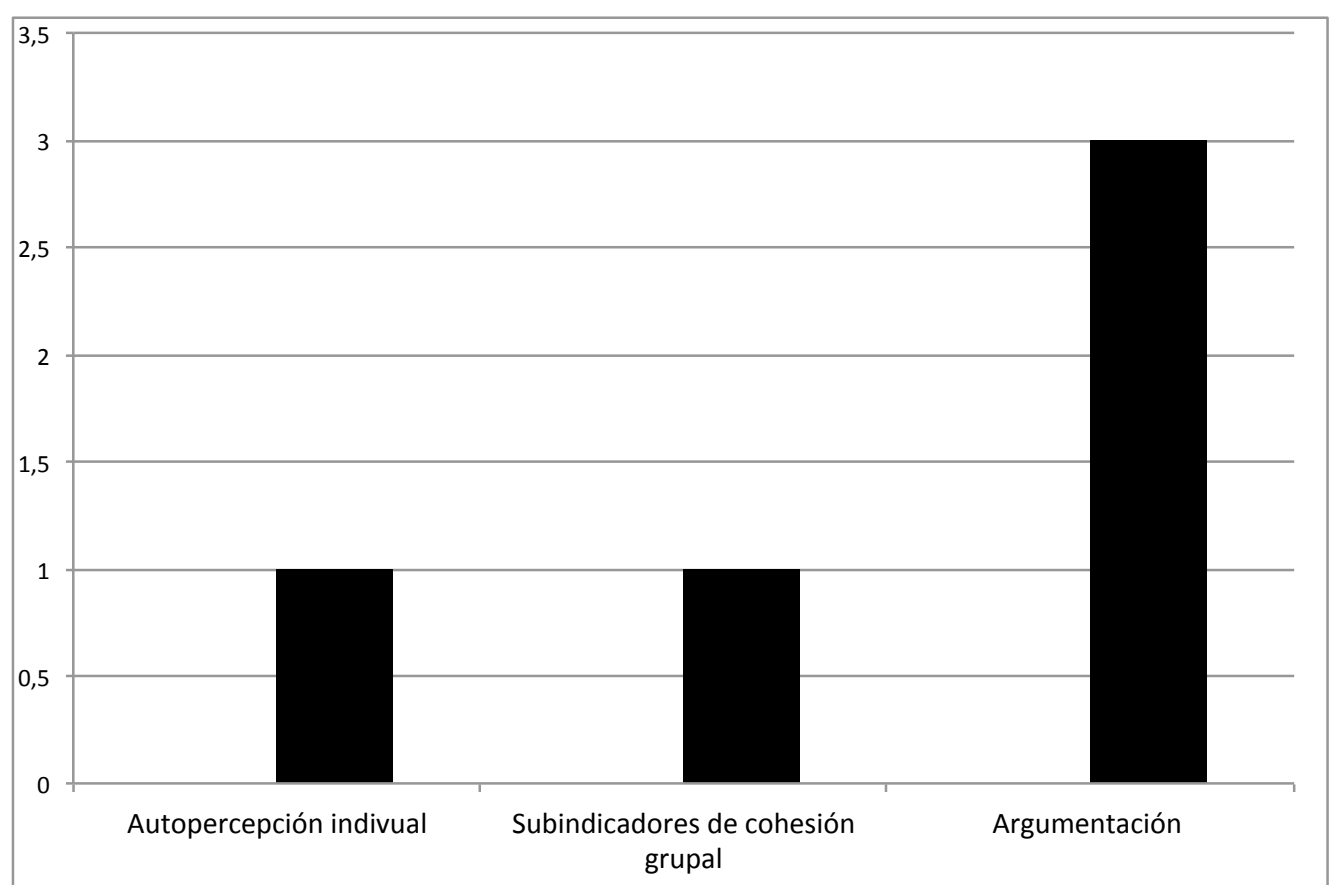

Figura 58: Aportes cualitativos a la matriz de indicadores de seguimiento de trabajo colaborativo proporcionados por los expertos

Como consecuencia del juicio de expertos descripto en este capítulo, se validó la composición y los indicadores de la matriz y se completaron algunos aspectos, ya presentados en la metodología MetSCIn completa y en la matriz descripta en el capítulo anterior. A continuación se presentan los componentes de la matriz que pudieron ser confirmados a partir del juicio de expertos:

- El concepto de trabajo colaborativo como un espacio de construcción con dos dimensiones: individual y grupal. Sus elementos básicos son la interdependencia positiva, la interacción, la contribución individual y la construcción grupal.

- El concepto de interdependencia positiva construido en el marco teórico, y tomado de Salomon, Perkins \& Globerson, 1992.

- La doble dimensión del concepto de interdependencia positiva, individual (lo que cada miembro aporta) y grupal (lo que el grupo construye en su interacción y mediante las herramientas tecnológicas).

- La interdependencia desde la perspectiva individual, considerando cantidad y tipos de mensajes que se intercambian.

- El concepto de cohesión de la comunicación como un indicador de la construcción grupal: "la cohesión de la comunicación representa la difusión de la información en el grupo: cuanto más cohesionada, mejor fluye la información entre todos los miembros del grupo". (Reyes \& Tchounikine en Dimitrakopoulou et al., 2006, pág. 46).

- La cohesión de la comunicación con dos componentes: cantidad y tiempo de temas trabajados en el grupo y análisis de los mapas conceptuales como indicadores de los temas que se compartes y construyen.

- La construcción de la matriz completa.

A partir de esta evaluación, y tomando en cuenta los aspectos mencionados y argumentados por los expertos, se realizó una resignificación de la matriz, dentro del marco de la distancia 
transaccional de Michael Moore, que había servido como marco inicial para presentar la enseñanza en entornos que utilizan tecnología informática en el marco conceptual de esta tesis. Este marco de estudio permitió integrar los elementos que ya formaban parte de la matriz, con los aportes que resultaron significativos y fueron aportados por los expertos.

En la siguiente sección, la última de este capítulo, se presenta la nueva matriz con su marco de operacionalización.

\subsection{Versión final de la matriz de indicadores}

En la matriz final, que se construyó a partir del juicio de expertos, tuvo dos agregados fundamentales:

Desde la perspectiva de la dimensión individual, se integró a la matriz un estudio de las condiciones de entrada al trabajo colaborativo según la autopercepción de los estudiantes en sus hábitos de estudio y sus ideas previas sobre el trabajo colaborativo. En el capítulo anterior, correspondiente a la metodología MetSCIn completa, se presentó el instrumento utilizado. En el capítulo 8 se describirán los resultados de su implementación en un estudio de caso.

En la dimensión grupal, como uno de los indicadores de la construcción se incluyó el componente de la argumentación, tomando el modelo de argumentación de Toulmin, S. ya presentado en el marco conceptual de este trabajo.

La matriz completa, a partir de la validación de los expertos se presenta a continuación en la figura 59. Se han marcado, en el gráfico, los componentes agregados en la dimensión correspondiente.

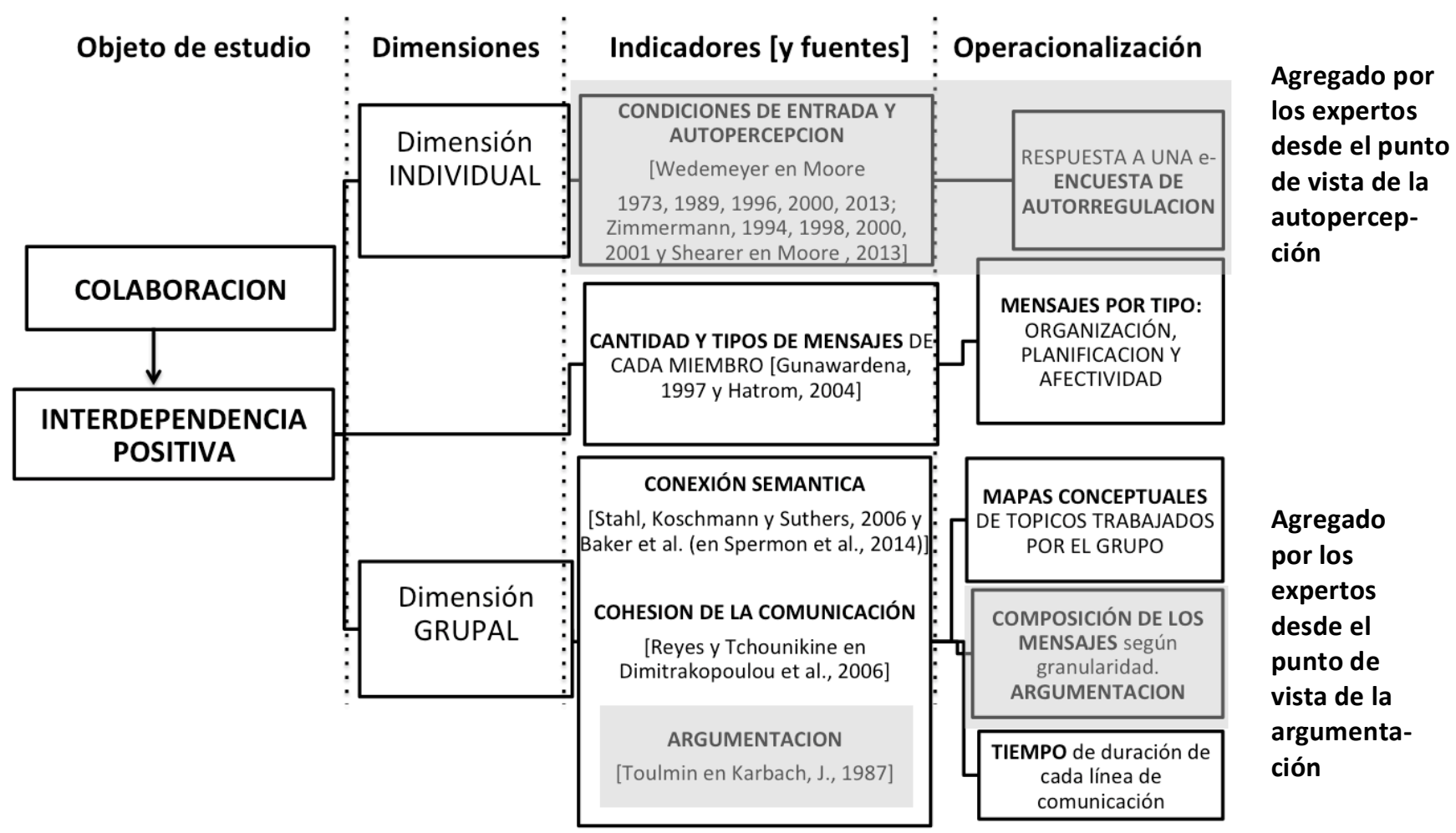

Figura 59: Matriz de indicadores de colaboración. Versión final. En color grisáceo se marcan los agregados luego del juicio de expertos 


\subsection{Conclusiones del capítulo}

Este capítulo presenta la evaluación de la matriz de indicadores de seguimiento del trabajo colaborativo mediado por tecnología informática que integra la metodología MetSCIn, descripta en el capítulo anterior.

La matriz de indicadores fue sometida a juicio de expertos, lo que permitió comprobar su validez lógica y resignificarla previa su etapa de transición (implementación). Se ha presentado en este capítulo la justificación de la elección de esta estrategia de validación y su descripción metodológica: la constitución del grupo de expertos, el instrumento utilizado, los resultados obtenidos y la resignificación de la matriz a partir de estos resultados.

Así, en el último apartado de este capítulo se ha arribado a una matriz enriquecida, a partir de la validación de la matriz inicial y de dos aportes cualitativos mencionados por los expert@s. Uno de estos aportes, la indagación sobre estrategias de autorregulación para el estudio, se vincula con las ideas de la teoría de la distancia transaccional, que ha servido de marco general a la primera parte de esta tesis. Se ha incluido, entonces, el componente de indagación sobre autorregulación como primera parte de la metodología y de la matriz. El otro agregado hace referencia a la argumentación, como competencia experta que enriquece la construcción colaborativa. Se visibiliza en el indicador de argumentación incluido en la matriz final.

La metodología MetSCIn, en su versión final, se implementó luego en un estudio de caso. En el capítulo siguiente se presenta la justificación teórica de la selección del estudio de caso como metodología de contrastación de MetSCIn. En el trabajo con el caso, se tomaron dos grupos diferentes de estudiantes, cuyos resultados se contrastaron a partir de una intervención didáctica particular (mirroring) en el segundo grupo. 


\section{Capítulo 8: Estudio de caso como implementación de Metscin}

Este capítulo aborda el estudio de caso de la tesis, en el que se aplica la metodología descripta en los capítulos anteriores. El recorrido conceptual propuesto consta de tres bloques: concepto y justificación metodológica del estudio de caso, presentación del caso y resultados. Se incluyen los siguientes apartados.

\subsection{Introducción}

\section{CONCEPTO Y JUSTIFICACION METODOLOGICA DEL ESTUDIO DE CASO}

8.2. Definición de la metodología de estudio de caso

8.3. Consideraciones sobre la recolección y análisis de la información en el estudio de caso

\section{PRESENTACION DEL CASO}

\subsection{Descripción general del caso}

8.4.1. Presentación de la e-actividad de escritura colaborativa

8.5. Constitución de los grupos de estudio

8.6. Indicadores e instrumentos de MetSCIn para el estudio de caso

\section{RESULTADOS}

8.7. Conformación de los grupos de estudio

\subsubsection{Otros datos de interés}

8.8. Resultados comparados de la encuesta de autorregulación. Hallazgos por categoría de habilidades

\subsubsection{Motivación}

8.8.2. Manejo de la afectividad

\subsubsection{Gestión del tiempo}

\subsubsection{Concentración}

8.8.5. Procesamiento de información

\subsubsection{Trabajo en equipo}

8.9. Análisis del trabajo colaborativo en sí

8.9.1. Dimensión individual de la colaboración. Densidad y calidad de interacción. Cohortes contrastadas

8.9.1.1. Densidad de interacción. Cantidad de mensajes en la tarea completa y por etapa 
8.9.1.2. Densidad de interacción. Componentes de los mensajes según su tipo en la tarea completa y por etapa

8.9.1.3. Dimensión individual de la colaboración. Comentarios

8.9.2. Dimensión grupal de la colaboración. Cohortes contrastadas

8.9.2.1. Conexión semántica

8.9.2.2. Cohesión de la comunicación

8.9.2.3. Argumentación

8.9.2.4. Dimensión grupal de la colaboración. Comentarios

8.10. Impacto de la estrategia de mirroring en la cohorte 2016

8.10.1. Acceso a la información sobre el tiempo restante para la entrega del trabajo

8.10.2. Información a la que se accedió según su autoría

8.10.3. Formato de información a la que se accedió

8.10.4. Decisiones de trabajo grupal resultantes del conocimiento de la información del proceso

8.10.5. Consolidación del impacto de la estrategia

8.11. Discusión sobre la eficacia de MetSCIn a partir de los resultados obtenidos

8.11.1. Autoinforme de autorregulación

8.11.2. Densidad de interacción. Análisis cuantitativo

8.11.3. Tipos de mensajes y cohesión

8.11.4. Impacto de la estrategia de mirroring

8.12. Conclusiones del capítulo

\section{Cuestiones éticas}

El estudio de caso ha sido realizado y documentado bajo las normas éticas que rigen las investigaciones académicas:

- L@s estudiantes fueron informados de antemano del propósito de la investigación.

- La información cualitativa y cuantitativa se ha analizado en base a la metodología MetSCIN, ya descripta.

- Los nombres de los estudiantes fueron resguardados tanto en el análisis del aporte individual como en la construcción grupal (fueron removidos y en su lugar fue colocado el número de participante o sus iniciales).

- Los resultados del autoinforme de autorregulación se presentan en porcentajes, sin alusión a respuestas individuales. En las menciones individuales, se identifica a cada estudiante con su número de referencia en el grupo o iniciales, protegiendo su identidad.

- En el análisis de la estrategia de mirroring se hace mención a las respuestas conceptuales, cualitativas, sin mencionar datos de su aut@r. 


\subsection{Introducción}

Una vez validada con los expertos la matriz de indicadores, se trabajó con el estudio de caso para aplicar la metodología MetSCIn completa. El objetivo del estudio de caso fue comprobar la eficacia de la metodología MetSCIn para arrojar resultados confiables en el seguimiento y análisis del trabajo colaborativo.

En este capítulo se presenta la metodología completa utilizada y sus resultados y se avanza hacia la discusión de su eficacia a partir de los resultados obtenidos. Se introduce el estudio de caso: el seminario de "Educación a Distancia" de la Maestría en "Tecnología Informática aplicada en Educación". Se describen los dos grupos de trabajo bajo análisis en cuanto a su constitución y características y se presentan los resultados del trabajo de campo, en cada una de las etapas y según cada uno de los instrumentos mencionados en el capítulo 6:

a. Hallazgos del autoinforme de autorregulación. Análisis de la información contrastando ambas cohortes.

b. Análisis del trabajo colaborativo comparando las cohortes 2015 y 2016: análisis cuantitativo y cualitativo, en las dimensiones individual y grupal. El análisis detallado al interior de cada cohorte y grupo se presenta en el anexo 4.

c. Impacto de la estrategia de mirroring en la cohorte de estudiantes 2016.

\section{Concepto y justificación metodológica del estudio de caso}

\subsection{Definición de la metodología de estudio de caso}

El estudio de caso forma parte de los métodos cualitativos etnográficos y supone un análisis de la realidad desde un contexto particular. Según Elsie Rockwell "el análisis etnográfico es un trabajo especifico que conduce a la construcción de nuevas relaciones, no previstas antes de hacer el análisis" (Rockwell, 1980, pág. 38). La idea clave es la indagación, a partir de preguntas, de problemas o nociones teóricas elaboradas y categorías que tienen conexión con lo empírico. Siguiendo a Cohen \& Manion "al contrario del experimentador que maneja variables para determinar su significación causal o del encuestador que hace preguntas normalizadas a grandes y representativas muestras de individuos, el investigador de estudio de casos observa las características de una unidad individual: un niño, una pandilla, una clase, una escuela o una comunidad. El propósito de tal observación es probar profundamente y analizar intensamente el fenómeno diverso que constituye el ciclo vital de la unidad, con visión para establecer generalizaciones acerca de la más amplia población a la que pertenece tal unidad" (Cohen \& Manion, 1989, págs. 164-165).

La metodología de investigación a seguir es particular, ya que se centra en una situación singular; es descriptiva/cualitativa/heurística, ya que implica la descripción y comprensión de los eventos y es inductiva, ya que se trata de formular conceptualizaciones a partir de una situación particular. 


\subsection{Consideraciones sobre la recolección y análisis de la información en el estudio de caso}

En la metodología de estudio de caso juega un papel muy destacado la recolección de la información y la interpretación de su significado en el escenario en el que el caso tiene lugar y sentido. El análisis de los datos es un aspecto sumamente delicado y complejo, ya que la información fluye en varios sentidos y, en su interpretación, se conjugan diferentes marcos teóricos y contextos. Siguiendo a Stake "el análisis significa esencialmente poner algo aparte. Ponemos aparte nuestras impresiones, nuestras observaciones. [...] Tenemos que separar la nueva impresión, y dar sentido a las partes, a aquéllas que son importantes para nosotros" (Stake, 1998, pág. 93). Por esta razón, el análisis de significado de la información requiere de pasos consecutivos:

a) Planificación sobre qué información recolectar.

b) Selección de datos significativos, a la luz del marco teórico del análisis.

c) Organización y categorización de los datos.

La metodología MetSCIn echó luz sobre qué datos recolectar y cómo analizarlos. Para el estudio de caso en específico se tomaron las decisiones que se presentan en la tabla 32.

\begin{tabular}{|c|c|}
\hline $\begin{array}{l}\text { DECISIONES DE } \\
\text { INVESTIGACION }\end{array}$ & DESCRIPCION EN EL ESTUDIO DE CASO \\
\hline $\begin{array}{l}\text { Planificación sobre } \\
\text { qué información } \\
\text { recolectar }\end{array}$ & $\begin{array}{l}\text { Información completa de la actividad colaborativa de } 18 \text { estudiantes } \\
\text { (divididos en tres grupos) de la cohorte } 2015 \text { y } 11 \text { estudiantes } \\
\text { (divididos en dos grupos) de la cohorte } 2016 \text {. }\end{array}$ \\
\hline $\begin{array}{l}\text { Selección de } \\
\text { información } \\
\text { significativa }\end{array}$ & $\begin{array}{l}\text { Cadena de intercambio de mensajes por la mensajería de WebUNLP y } \\
\text { los foros. Además, el proceso de escritura y de intercambio de } \\
\text { mensajes en la herramienta de GoogleDocs puesta a disposición y las } \\
\text { bitácoras escritas por los propios integrantes de los grupos de trabajo. } \\
\text { En la cohorte } 2015 \text {, la información se ordenó durante su desarrollo y se } \\
\text { analizó después de finalizada la actividad. La posibilidad que brinda la } \\
\text { tecnología de recolectar y guardar la información de los eventos } \\
\text { transcurridos en un tiempo determinado, sumada a su disponibilidad a } \\
\text { posteriori resultó fundamental para este análisis. El análisis se realizó } \\
\text { post mortem, cuando el curso en WebUNLP que había alojado al } \\
\text { seminario de Educación a Distancia del año } 2015 \text { estaba cerrado, } \\
\text { oculto para los estudiantes y sin actividad alguna. } \\
\text { En el año } 2016 \text { la estrategia de mirroring obligó a analizar y publicar la } \\
\text { información durante el desarrollo de la actividad, al finalizar cada } \\
\text { semana. } \\
\text { El resto del análisis (cohesión grupal y argumentación, por ejemplo) se } \\
\text { realizó en las mismas condiciones que en } 2015 \text {. }\end{array}$ \\
\hline $\begin{array}{l}\text { Organización y } \\
\text { categorización }\end{array}$ & $\begin{array}{l}\text { Se dividió la información por grupos y por herramienta. } \\
\text { Se analizó cuantitativamente la cantidad y promedio de intercambios } \\
\text { en general, por etapa del trabajo colaborativo, por integrante y por } \\
\text { tipo de mensaje. } \\
\text { Desde el punto de vista cualitativo, se buscaron unidades de sentido, } \\
\text { como fue explicado en presentación de los indicadores de la matriz y } \\
\text { su operacionalización. }\end{array}$ \\
\hline
\end{tabular}

Tabla 32: Decisiones metodológicas de la recolección de datos en el estudio de caso 


\section{Presentación del caso}

\subsection{Descripción general del caso}

El estudio de caso se instala en el seminario de "Educación a Distancia" de la Maestría en "Tecnología Informática aplicada en Educación” que ofrece la Facultad de Informática de la Universidad Nacional de La Plata desde el año 1999.

Este es uno de los primeros seminarios que se cursan en dicha carrera. El foco de esta asignatura está puesto en la generación de competencias de enseñanza con tecnologías digitales. Se define el término competencia siguiendo a Guy Le Boterf como "la conjunción de saberes conceptuales (conocimiento o meta-conocimiento), procedimentales (acciones o intervenciones) y actitudinales asociado al reconocimiento del contexto especifico para su puesta en acto" (Le Boterf, 2001, pág. 100). La adquisición de estas competencias permitirá a los docentes comprender las modificaciones de los espacios de enseñanza a partir del uso de tecnología digital, por ejemplo, aula extendida, invertida (Lion, 2006; Zangara, 2014) e intervenir en estos espacios, a partir del diseño de propuestas de enseñanza, investigación y desarrollo. En la tabla 33 se describen las competencias a las que se orienta el seminario.

\begin{tabular}{|c|c|}
\hline $\begin{array}{c}\text { COMPETENCIAS QUE SE } \\
\text { DESARROLLAN EN EL SEMINARIO }\end{array}$ & DESCRIPCION \\
\hline Competencias conceptuales & $\begin{array}{l}\text { a.- De entendimiento del rol de la tecnología en } \\
\text { la enseñanza y de los espacios resultantes. } \\
\text { b.- De uso apropiado de terminología (diferencias } \\
\text { conceptuales entre Entornos Virtuales de } \\
\text { Enseñanza y Aprendizaje, campus, plataformas). }\end{array}$ \\
\hline Competencias tecnológicas & $\begin{array}{l}\text { c.- De reconocimiento de los elementos } \\
\text { constitutivos de los medios: soporte, lenguaje y } \\
\text { posibilidades educativas y comprensión del } \\
\text { lenguaje de los diferentes tipos de tecnologías. } \\
\text { d.- De diálogo con los EVEAs en las tareas de } \\
\text { diseño educativo y comunicacional. }\end{array}$ \\
\hline $\begin{array}{l}\text { Competencias de prefiguración o } \\
\text { diseño de situaciones de } \\
\text { enseñanza con tecnología } \\
\text { informática y con EVEAs }\end{array}$ & $\begin{array}{l}\text { De intervención, diseñando situaciones que } \\
\text { incluyan tecnología. }\end{array}$ \\
\hline $\begin{array}{l}\text { Competencias de análisis crítico } \\
\text { de propuestas }\end{array}$ & $\begin{array}{l}\text { De análisis crítico de las ofertas del mercado de } \\
\text { la educación a distancia y de reconocimiento de } \\
\text { los componentes asociados a la calidad de las } \\
\text { propuestas. }\end{array}$ \\
\hline
\end{tabular}

Tabla 33: Competencias a desarrollar en el seminario de Educación a Distancia

El seminario consta de dos módulos de trabajo: "Módulo de conceptos básicos" y "Taller de Entornos Virtuales de Enseñanza y Aprendizaje (EVEAs)". Ambos están integrados para ofrecer una mirada complementaria de las disciplinas que se abordan. Existen actividades particulares de cada uno de los módulos y actividades compartidas, que integran conceptos y competencias trabajadas en particular en cada espacio. 
El seminario dura 6 meses (de Abril a Septiembre) y tiene una serie de encuentros presenciales, que incluye un encuentro final de evaluación. Cada encuentro presencial aborda un eje temático, que atraviesa el Módulo Teórico y el Taller de EVEAs.

Como una actividad integrada, se lleva adelante una e-actividad colaborativa, que en varios años se ha orientado a la escritura colaborativa. Esta actividad se implementa en la 8va. semana (promediando el seminario), luego de una actividad de foro (que también se realiza en grupos pequeños, pero de composición diferente) y antes de la presentación del trabajo final de diseño.

La decisión de conformar un estudio de caso con este seminario estuvo relacionada con su asequibilidad. Siguiendo a Eco (1998), el caso resultó suficientemente asequible para la doctoranda para la implementación de MetSCIn de forma completa, incluyendo la intervención didáctica del mirroring.

\subsubsection{Presentación de la e-actividad de escritura colaborativa}

Siguiendo a Cabero Almenara \& Román Graván (2005) y a Sanz, Zangara \& Manresa-Yee (2012), la actividad de escritura colaborativa que aquí se describe corresponde a una e-actividad, ya que todas sus fases están mediadas a través del entorno virtual de enseñanza y aprendizaje que se utiliza para abordar la propuesta (el entorno WebUNLP) y otras herramientas digitales por fuera de este entorno e integradas al trabajo en la actividad y a su seguimiento.

En el caso del trabajo colaborativo bajo estudio, los estudiantes cuentan con un documento en el EVEA que describe: los objetivos, la conformación de los grupos, la metodología (en fases), las tareas en cada una, los tiempos y los criterios de evaluación. Los alumnos pueden descargarse este documento desde el espacio dispuesto para la distribución de contenidos en WebUNLP ("Información General y Contenidos"). Desde ese momento ya conocen las fechas en que se desarrollará esta experiencia de e-actividad.

En el capítulo 3 se ha avanzado sobre una presentación metodológica de los pasos de diseño didáctico e implementación del trabajo colaborativo, sintetizados en la tabla 6. Asimismo, en la figura 19 se presentan las fases de trabajo de los estudiantes, con la idea de una primera instancia individual, luego el trabajo grupal colaborativo propiamente dicho y el cierre, con las actividades de autoevaluación y evaluación por parte del docente. Se retoman aquí ambos marcos para describir la actividad de trabajo colaborativo en el marco del seminario de "Educación a Distancia".

Paso 1. Determinación de los objetivos didácticos de la actividad de trabajo colaborativo. Se presenta a los estudiantes un documento con los objetivos de la actividad, la idea general de la consigna, sus fases, la conformación de grupos, las herramientas tecnológicas disponibles (dentro y fuera del entorno WebUNLP) y la prefiguración, incluso de los formatos de evaluación. Este documento se distribuye vía WebUNLP antes del tercer encuentro presencial.

Paso 2. Diseño de la consigna en sus fases individual y grupal. En el inicio de la actividad colaborativa se les envía a los alumnos dos materiales:

- La consigna general de la actividad colaborativa, explicada en el paso anterior.

- La consigna individual, correspondiente a la primera fase de la actividad colaborativa.

Cada participante recibe una consigna individual que no es conocida por el resto de sus compañeros. A partir de este momento, las fases por las que transcurre el trabajo colaborativo son las siguientes: 
Primera fase. Trabajo individual. La consigna final es el desarrollo de un libro (sólo el índice y el prefacio), escrito colaborativamente, sobre la tarea docente en los nuevos espacios de enseñanza con nuevas tecnologías informáticas. Como primera fase, cada integrante de cada grupo recibe la información de una fuente relevante y actualizada en este tema. Debe estudiarla y profundizarla, para hacer un mejor aporte a su grupo. Se envía a cada participante una consigna del tipo de la que sigue. Se presenta el ejemplo del participante Nro. $1^{17}$ en la Figura 60.

Ejemplo de una consigna individual
Como primera parte de este trabajo colaborativo, deberá relevar información acerca del
siguiente tema "el valor de la planificación en las buenas prácticas docentes" tomando como
base el trabajo del siguiente autor Ken Bain: "What best teachers do". Deberá:
1. Relevar información de este autor del tema indicado en diferentes fuentes. Pueden tomar
reseñas de sus libros, artículos escritos por el autor, foros de debate al respecto, etc.
2. Realizar un resumen (de no más de una carilla) de las principales ideas que aparecen en
los textos elegidos, siguiendo las recomendaciones vistas para la actividad de pares.
3. Compartir, si lo considera necesario, este resumen antes del día del encuentro presencial.

Figura 60. Ejemplo de consigna individual del trabajo colaborativo en el estudio de caso

Segunda fase. Trabajo grupal colaborativo. Como se anticipó en la primera fase, la consigna grupal consiste en la escritura colaborativa del índice de un libro y el prefacio (o introducción) del mismo, en la que se presente la idea general. El detalle de la consigna grupal se puede ver en la figura 61 .

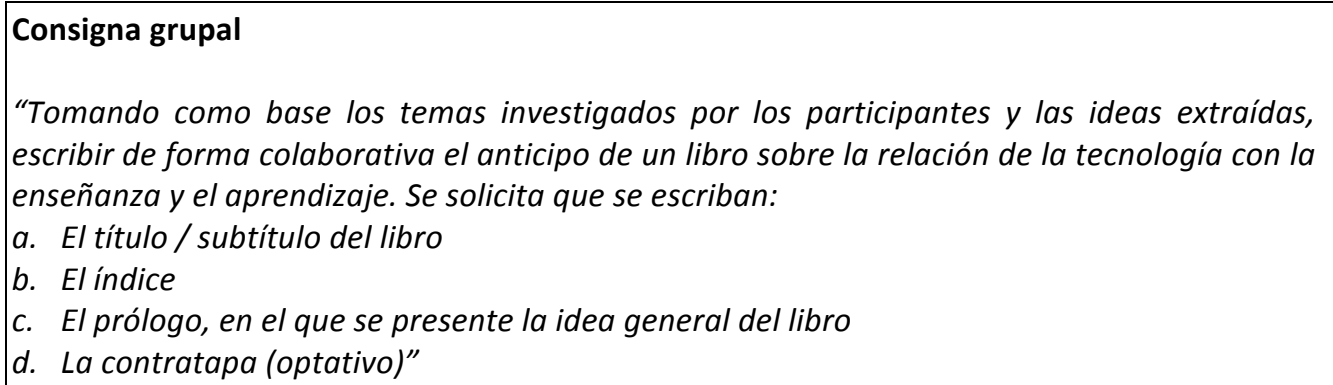

Figura 61. Ejemplo de consigna grupal del trabajo colaborativo en el estudio de caso

Como se trata precisamente de un trabajo colaborativo, no se define en la consigna cuáles deben ser las estrategias de funcionamiento del grupo (roles, tiempos, tareas, estándares de calidad, pre entregables, etc.).

En cuanto a las herramientas, se habilita para cada grupo un espacio en GoogleDocs (creado por los docentes). Además, dentro de WebUNLP, se les ofrece un espacio para compartir archivos, a manera de repositorio (sólo entre los miembros del equipo y los docentes). Esto se realiza a partir de la herramienta de formación de grupos del área de "Trabajo Colaborativo" y también un foro por grupo. Además, los participantes tienen a disposición el uso de la mensajería interna de WebUNLP. Estas herramientas se habilitan pero son optativas para el trabajo.

Tercera fase: Cierre del proceso y autoevaluación. En esta fase, la idea es analizar el desempeño individual y grupal en cuanto a la colaboración. En este caso se les pide que completen una bitácora, con la idea de descripción cuanti-cualitativa del proceso. Existen dos formatos:

\footnotetext{
${ }^{17}$ Es de hacer notar que para acceder a los estudios de Maestría los estudiantes deben saber leer Inglés. Por esta razón, algunos de los textos que sirven de base al trabajo colaborativo están en este idioma.
} 
- Grupo que trabajaron con el modelo A: con una estructura previa de eventos a resaltar y documentar (teniendo en cuenta las bases del trabajo colaborativo).

- Grupos que trabajan con el modelo B: bitácora libre, sin estructura.

Paso 3. Armado de grupos, según criterios que apunten a su grupalidad. En el caso de la actividad de trabajo colaborativo, la conformación de grupos resulta fundamental, ya que parte de la construcción necesaria para responder a la consigna se verá enriquecida por las diferentes miradas, producto de las diferentes profesiones y formaciones específicas. La apuesta del seminario es la construcción de grupos interdisciplinarios. En la Maestría que da contexto al seminario se inscriben anualmente docentes provenientes de diferentes áreas disciplinares, con formación muy disímil (egresados de carreras en Informática, Matemática, Ingeniería, Química, Ciencias de la Educación, Gestión Educativa, etc.). Además, existen otras diversidades tales como, la edad, el lugar de residencia y el contexto de formación (las instituciones a las cuales pertenecen o donde se han formado). Antes del inicio del seminario, se administra una encuesta inicial a los ingresantes, con el objetivo de registrar información personal y profesional básica e identificar conocimientos previos en temas de Tecnología Educativa, Educación a Distancia, trabajo colaborativo y herramientas. Si bien esta encuesta no forma parte del estudio de caso, se presentarán algunos resultados significativos en apartados siguientes. En las decisiones de agrupación basadas en criterios de grupalidad son fundamentadas tanto esta información como en el desempeño que se haya registrado al momento de comenzar la octava semana de trabajo. También la encuesta de autorregulación podría ayudar en la conformación de grupos.

Paso 4. Tareas del docente en cada etapa. En el intento de ser consistentes con la idea de colaboración, los docentes no intervienen. Sólo lo hacen a pedido de los estudiantes, ante consultas específicas, reactivamente ${ }^{18}$. En ese caso, se trata de mantener la comunicación en la esfera privada, y que sea el propio estudiante quien decida qué comunicar al grupo y cuándo hacerlo. Entonces, la tarea consiste en el seguimiento y análisis de las conversaciones y eventos producidos y documentados en cada herramienta. El docente tiene una mirada omnisciente sobre todos los grupos y repositorios de información, que se podría caracterizar como vicaria desde el punto de vista de la interacción (presentado en el capítulo 2, apartado 2.2.1.1. "Tipos de interacciones"), ya que no deja rastros de "haber estado allí".

Paso 5. Autoevaluación del trabajo individual y grupal. La evaluación didáctica que se lleva adelante en el seminario se instala en el seguimiento de la construcción colaborativa. Tiene dos objetos de evaluación definidos: el proceso de trabajo colaborativo y el producto final. En cuanto a la evaluación de proceso, en la consigna inicial está contemplada. Como se adelantó en la tercera fase del paso 2 esta evaluación tiene dos modelos: estructurado y libre. El modelo A (estructurado) contiene, además, la integración de las perspectivas de evaluación individual. Uno de los instrumentos intenta recabar información desde el aporte de cada individuo al grupo y el otro (que deben responder de forma consensuada) recupera la mirada colectiva. La etapa final contempla la evaluación del producto.

Paso 6. Cierre. Análisis del proceso de trabajo y producto. Devolución a los estudiantes. Luego de la entrega del producto final, se realiza una evaluación comparada de producto, de acuerdo con los criterios que se presentan en la figura 62 .

\footnotetext{
${ }^{18}$ Esto significa que el/la docente no toma la iniciativa del contacto con el/la estudiante, sino que lo hace como respuesta a una demanda no iniciada por el/la alumno/a.
} 


\section{CONTENIDO PARTICULAR}

Corrección técnica: que se hayan entendido las ideas provenientes de cada texto o documento presentes en la bibliografía y/o en el repositorio compartido.

\section{CONTENIDO CONSTRUIDO}

Entramado de voces: que las ideas provenientes de las fuentes anteriores estén vinculadas, contrastadas, integradas.

Consistencia: que tenga lógica y orden el trabajo conjunto, desde el punto de vista de los contenidos.

\section{FORMATO}

Formato de la entrega. Adecuación a la consigna

Consideración de los principios de redacción colaborativa

Figura 62: Criterios de evaluación del producto de la actividad de escritura colaborativa

Se realiza una devolución a cada grupo de la calidad de su producto. La información de la evaluación de producto es privada: cada grupo conoce únicamente su informe. El medio utilizado es la mensajería de WebUNLP.

Además, se realiza un informe de proceso, considerando las observaciones que se han realizado y las bitácoras de cada grupo. Se relaciona la información del proceso con los conceptos de trabajo colaborativo presentados desde el inicio. Esta evaluación de proceso es pública y comparativa de los procesos de todos los grupos. Este documento es compartido en el mismo EVEA, dando un marco final a esta e-actividad. El objetivo de estas instancias de evaluación es apuntar al logro de competencias de prefiguración o diseño de situaciones de enseñanza con nuevas tecnologías (presentadas en la tabla 30) y a fortalecer la metacognición y la identidad grupal. Por esta razón, la metodología adquiere una potencialidad modelizante: los estudiantes pueden tomar este modelo para implementar actividades colaborativas en sus espacios docentes.

\subsection{Constitución de los grupos de estudio contrastados}

Se estudiaron dos grupos, que funcionaron como grupos contrastados. Se realizó el trabajo con dos grupos completos, contrastando los estudiantes del año 2015 con los del año 2016. En ambos se trabajó con las mismas condiciones: mismos tiempos, misma e-actividad colaborativa, mismos docentes y misma metodología de seguimiento: MetSCIn, salvo por la implementación de mirroring que sólo se llevó adelante en el 2016. En el grupo de 2016, las condiciones de implementación resultaban adecuadas (por el manejo que los docentes tenían de la actividad, la adecuada cantidad de alumnos -11-y los tiempos de trabajo), y es por ello que se implementó la metodología completa en esta cohorte. Así, se acompañó el trabajo con una estrategia de mirroring, seguida por la indagación de su impacto. Fue posible, entonces, extraer conclusiones específicas en la comparación de ambas cohortes en este sentido.

La razón por la que se tomaron dos grupos completos de estudiantes como universo para contrastarlos (y no la división de un grupo de estudiantes en dos subgrupos, con su contrastación posterior) obedece a la consideración de opiniones presentadas por Anastasi \& Urbina (1997) y Ferrando, Ibáñez \& Martín (1996) con la idea de que el uso de grupos contrastados para probar una innovación (didáctica-tecnológica, en este caso) deja a uno o más de los grupos bajo análisis en una situación de desventaja, ya que no participa de la que sería la "mejor solución" o "mejor escenario de trabajo", según la hipótesis del docente y/o investigador. En este caso, este "mejor escenario" sería la implementación de la metodología completa, con la estrategia de mirroring incluida. Como se ha mencionado en el capítulo 6, la construcción de MetSCin para atender a las preguntas iniciales de esta tesis dio lugar a otras preguntas que, a su vez, fueron atendidas con nuevos componentes de la metodología. Así, la intervención del mirroring permitiría 
comprobar cómo funciona un grupo colaborativo desde las dimensiones individual y grupal si sus miembros van conociendo su desempeño en tiempo real y online. Este es el componente por el que se contrasta a ambos grupos. El estudio de caso completo permitiría, a su vez, conocer la eficacia de la metodología MetSCin para el llevar adelante el seguimiento del trabajo colaborativo mediado por tecnología informática en escenarios educativos.

El estudio de caso de esta tesis quedó conformado como se muestra en la figura 63.

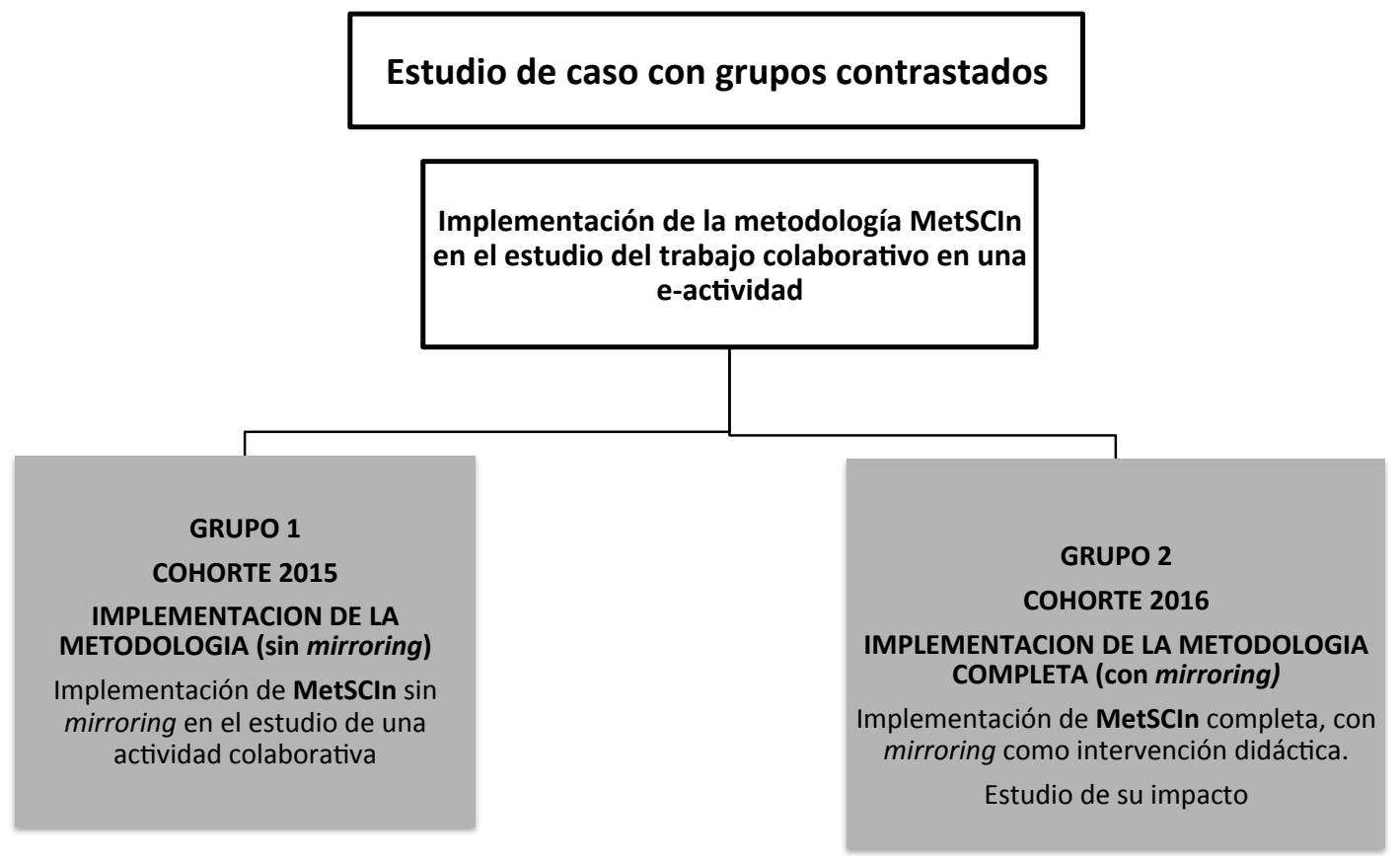

Figura 63: Estructura del estudio de caso de esta tesis

\subsection{Indicadores e instrumentos de MetSCIn para el estudio de caso}

Resulta oportuno recordar el mapa de indicadores, su operacionalización, la unidad de análisis seleccionada en el estudio de caso y el instrumento utilizado para analizar el indicador en la unidad de análisis de MetSCIn. En la tabla 34 están consignadas las unidades de análisis aplicadas al estudio de caso. 


\begin{tabular}{|c|c|c|c|c|}
\hline Teoría & Indicadores & Operacionalización & Unidad de análisis & Instrumento \\
\hline $\begin{array}{l}\text { Wedemeyer en } \\
\text { Moore } \\
(1973,1989,1996, \\
2000,2013) \\
\text { Zimmermann } \\
(1994,1998,2000 \text {, } \\
2001) \\
\text { Shearer en Moore } \\
(2013)\end{array}$ & $\begin{array}{l}\text { a.Motivación - } \\
\text { Sostenimiento de la } \\
\text { motivación } \\
\text { b.Manejo de la } \\
\text { afectividad } \\
\text { c.Gestión del tiempo } \\
\text { d.Concentración } \\
\text { e.Habilidades de } \\
\text { procesamiento de } \\
\text { información } \\
\text { f.Trabajo en equipo }\end{array}$ & $\begin{array}{ll}\text { Existencia de las } \\
\text { habilidades } \\
\text { actividades diarias }\end{array}$ & $\begin{array}{l}\text { Individuo: su } \\
\text { autopercepción }\end{array}$ & $\begin{array}{l}\text { Autoinforme } \\
\text { individual } \\
\text { Formato digital } \\
\text { (GoogleForm) }\end{array}$ \\
\hline $\begin{array}{l}\text { Gunawardena et al. } \\
1997 \\
\text { Ingram \& Hathorn, } \\
2004\end{array}$ & $\begin{array}{l}\text { DIMENSION } \\
\text { INDIVIDUAL } \\
\text { Cantidad y tipos de } \\
\text { mensajes de cada } \\
\text { miembro del grupo }\end{array}$ & $\begin{array}{l}\text { Mensajes por tipo: } \\
\text { organización, } \\
\text { contenido, afectividad. }\end{array}$ & $\begin{array}{l}\text { Análisis de } \\
\text { mensajes } \\
\text { individualmente en } \\
\text { mensajería y foros } \\
\text { de WebUNLP }\end{array}$ & $\begin{array}{l}\text { Análisis cuantitativo } \\
\text { y cualitativo }\end{array}$ \\
\hline $\begin{array}{l}\text { Baker en Spermon } \\
\text { et al., } 2014 \\
\text { Stahl, Koschmann } \\
\text { y Suthers, } 2006\end{array}$ & $\begin{array}{l}\text { DIMENSION GRUPAL } \\
\text { Conexión semántica }\end{array}$ & $\begin{array}{l}\text { Mapas conceptuales } \\
\text { de tópicos abordados }\end{array}$ & $\begin{array}{l}\text { Análisis de la } \\
\text { construcción por } \\
\text { mensajes a través } \\
\text { de la mensajería y } \\
\text { foros de WebUNLP } \\
\text { y GoogleDocs. }\end{array}$ & $\begin{array}{l}\text { Análisis } \\
\text { contenido } \\
\text { (cualitativo) }\end{array}$ \\
\hline $\begin{array}{l}\text { Reyes y } \\
\text { Tchounikine en } \\
\text { Dimitrakopoulou et } \\
\text { al., } 2006 \\
\text { Tuolmin, S. en } \\
\text { Karbach, J. 1987 }\end{array}$ & $\begin{array}{l}\text { Cohesión de la } \\
\text { comunicación }\end{array}$ & $\begin{array}{l}\text { Mensajes on y off } \\
\text { topics } \\
\text { Composición de los } \\
\text { mensajes por líneas } \\
\text { argumentales según } \\
\text { granularidad }\end{array}$ & $\begin{array}{l}\text { Análisis de un } \\
\text { tópico completo en } \\
\text { cada cohorte, en el } \\
\text { foro de WebUNLP. }\end{array}$ & \\
\hline 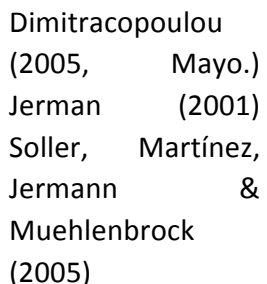 & $\begin{array}{l}\text { Mirroring (sólo en la } \\
\text { cohorte 2016) }\end{array}$ & $\begin{array}{l}\text { Desempeño individual } \\
\text { y grupal a partir del } \\
\text { conocimiento online }\end{array}$ & $\begin{array}{l}\text { Individuo: su } \\
\text { autopercepción }\end{array}$ & $\begin{array}{l}\text { Autoinforme } \\
\text { individual } \\
\text { Formato digital } \\
\text { (GoogleForm) }\end{array}$ \\
\hline
\end{tabular}

Tabla 34: Operacionalización de indicadores de MetSCIn en el estudio de caso

\section{Resultados}

Se presentan los resultados del estudio de caso descripto. La presentación abordará los siguientes apartados:

Por fuera de MetSCIn, correspondiente a la metodología de estudio de caso. 
- Conformación del grupo de estudio. Información de entrada de los estudiantes del seminario de Educación a Distancia, de las cohortes 2015 y 2016. Se presentan en el corpus de la tesis los datos de entrada significativos a la luz de los resultados y conclusiones obtenidas.

\section{Como parte de MetSCIn}

- Resultados comparados de la encuesta de autorregulación. Hallazgos por habilidad. Se presentarán los hallazgos de ambas cohortes en forma comparada.

- Análisis del trabajo colaborativo en los grupos correspondientes a las cohortes 2015 y 2016 en forma comparada" Análisis cuantitativo y cualitativo, en las dimensiones individual y grupal.

- Impacto de la estrategia de mirroring, en la cohorte de estudiantes 2016.

Estos resultados llevarán finalmente a la comprobación de la eficacia de la metodología MetSCIn completa, que representa el objetivo final del estudio de caso. Se volverá sobre este tema en el apartado final de este capítulo y en el siguiente.

\subsection{Conformación del grupo de estudio}

Se presentan las características generales de las dos cohortes de estudiantes que conformaron el caso: 18 personas que siguieron el seminario de "Educación a Distancia" en 2015 y 11 que lo hicieron en 2016. La información recolectada en esta sección tiene como fuentes:

- Los datos de inscripción a la Maestría en general y al seminario en particular, obtenidos por la secretaría de PostGrado de la Facultad.

- La encuesta inicial que se administra a los alumnos del seminario de "Educación a Distancia" previo a su inicio. ${ }^{19}$

Se presenta la información de cada cohorte. En cada una se indica su constitución por género, profesiones y dispersión geográfica según lugar de residencia.

En cuanto a la distribución según género, en la cohorte 2015, de 18 estudiantes, hubo 12 mujeres y 6 varones. En la cohorte 2016, los 11 estudiantes se distribuyeron en 3 mujeres y 8 varones. La composición según profesiones se presenta en la tabla 35.

\begin{tabular}{|l|l|}
\hline \multicolumn{1}{|c|}{ Cohorte 2015: 18 estudiantes } & \multicolumn{1}{c|}{ Cohorte 2016: 11 estudiantes } \\
\hline Licenciatura en Sistemas: 10 & Licenciatura en Sistemas: 5 \\
Ingeniería en Sistemas: 2 & Veterinaria : 2 \\
Licenciatura en Comunicación Social: 2 & Profesorado en Letras: 1 \\
Profesorado en Lengua Inglesa: 2 & Licenciatura en Lengua Inglesa: 1 \\
Diseño en Comunicación Visual: 1 & Ingeniería en sistemas: 1 \\
Licenciatura en Matemáticas: 1 & Profesorado en Informática: 1 \\
\hline
\end{tabular}

Tabla 35: Composición de ambas cohortes según profesiones

\footnotetext{
${ }^{19}$ El protocolo de la encuesta no se incluye en este corpus, por estar fuera de los instrumentos que se crearon ad hoc para esta tesis. Sin embargo, resulta necesario informar que las preguntas son generales, y están vinculadas con:

- $\quad$ datos de identidad y profesión;

- experiencia como docente (presencial o a distancia);

- conocimientos sobre educación a distancia, entornos de enseñanza y aprendizaje y objetos de aprendizaje y

- conceptos previos y valiración del trabajo grupal y colaborativo.
} 
En cuanto a la dispersión geográfica, se considera el lugar de residencia y no de procedencia, ya que para el análisis del trabajo colaborativo resultará significativa esta información. Se presenta en la tabla 36 y, gráficamente, en las figuras 64 y 65.

\begin{tabular}{|l|l|}
\hline \multicolumn{1}{|c|}{ Cohorte 2015 } & \multicolumn{1}{|c|}{ Cohorte 2016} \\
\hline La Plata: 12 estudiantes & La Plata: 4 estudiantes \\
Buenos Aires: 3 estudiantes & Buenos Aires: 2 estudiantes \\
La Pampa: 1 estudiante & Concepción del Uruguay (Entre Ríos): 1 \\
Corrientes: 1 estudiante & estudiante \\
Luján: 1 estudiante & Ushuaia: 1 estudiante \\
& Santiago del Estero: 1 estudiante \\
& Río Negro: 1 estudiante \\
& Lomas de Zamora: 1 estudiante \\
\hline
\end{tabular}

Tabla 36: Composición de ambas cohortes según lugar de residencia

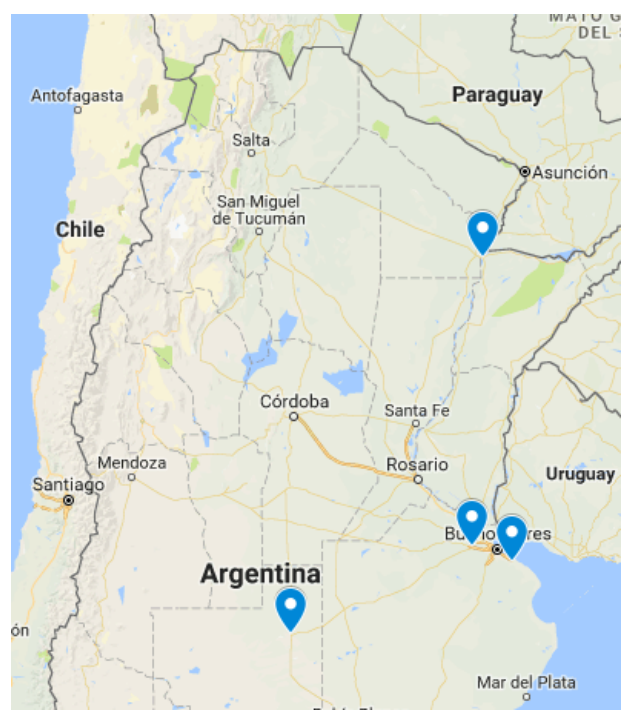

Figura 64: Dispersión geográfica de los estudiantes de la cohorte 2015

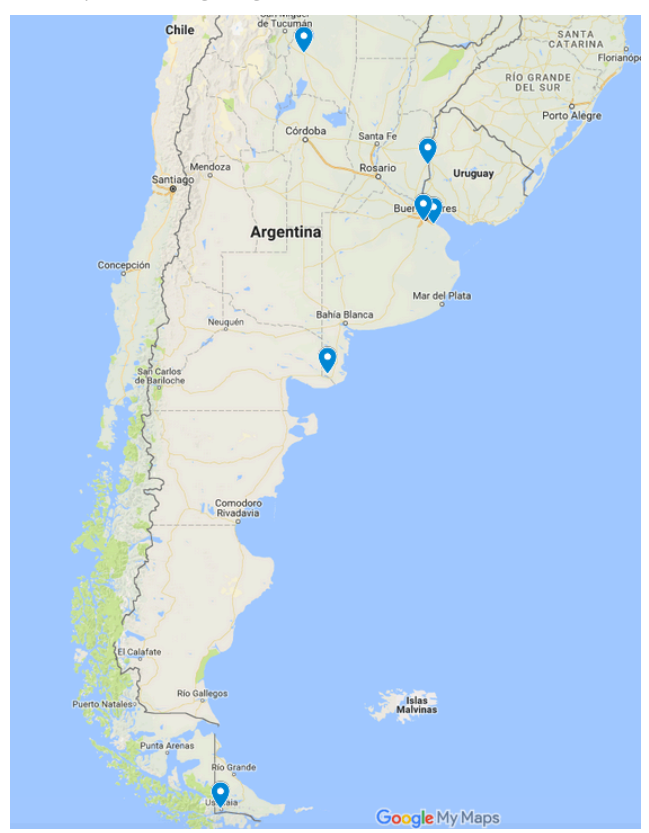

Figura 65: Dispersión geográfica de los estudiantes de la cohorte 2016 


\subsubsection{Otros datos de interés}

En la encuesta inicial se incluye una pregunta de construcción de respuesta en la que se le solicita a los estudiantes que definan el concepto de trabajo colaborativo. La pregunta es: ¿Cómo definirías trabajo colaborativo? Las respuestas mostraron un alto grado de conocimiento y mucha coincidencia con lo que se menciona en la literatura especializada. En la figura 66 se presentan los componentes de trabajo colaborativo mencionados con mayor frecuencia. Aparece el nombre del componente y la cantidad de definiciones en las que se hizo referencia a cada uno.

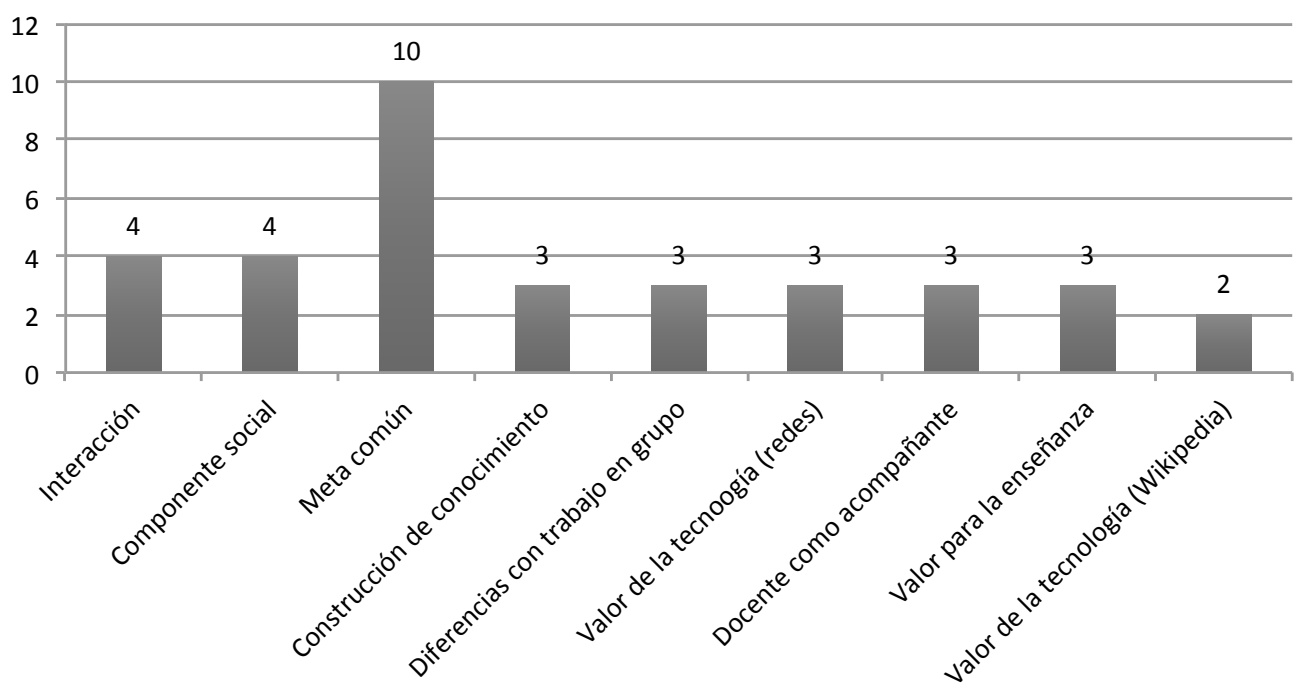

Figura 66: Componentes del concepto de trabajo colaborativo en las respuestas de la encuesta inicial. Ambas cohortes

También se les consulta sobre la relación entre trabajo colaborativo y tecnología digital. Se preguntó: ¿Crees que la tecnología digital puede favorecer el trabajo colaborativo? El 100\% de los encuestados de ambas cohortes dijo que, efectivamente, lo favorece. La siguiente pregunta solicitaba la justificación de esta relación. Los argumentos esgrimidos se presentan en la figura 67. Aparece el nombre del componente y la cantidad de definiciones en las que se lo mencionó.

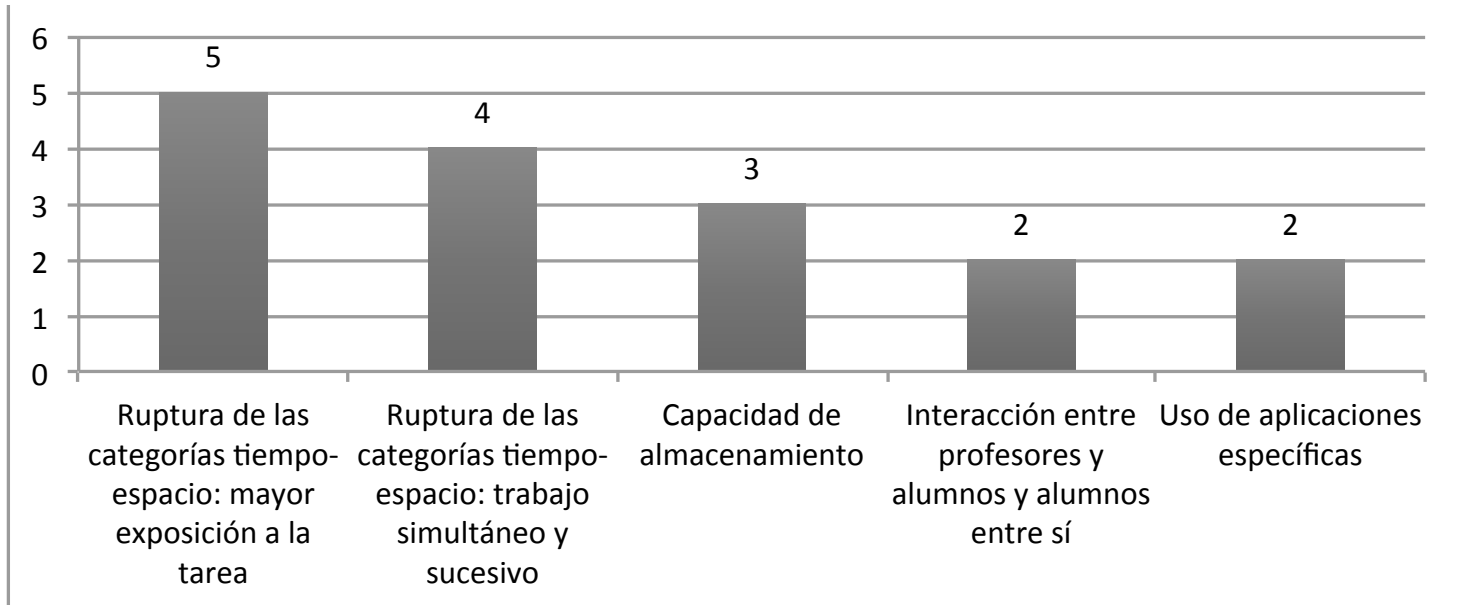

Figura 67: Por qué la tecnología digital puede favorecer el trabajo colaborativo. Justificación. Ambas cohortes 


\subsection{Resultados de la encuesta de autorregulación. Hallazgos por categoría de habilidades}

El primer instrumento de la metodología MetSCIn apunta a la indagación de habilidades de autorregulación. La unidad de análisis estuvo constituida por cada uno de los estudiantes de ambas cohortes, a quienes se indagó individualmente a través de un formulario en formato "e". En este apartado se presentan y comentan los hallazgos más relevantes por cada una de las categorías de indicadores relevadas. Se hará hincapié en aquellas habilidades o concepciones que luego se han visualizado en el trabajo colaborativo. Para la presentación de resultados, en cada una de las habilidades indagadas se presenta:

- la AFIRMACION: la afirmación incluida en el ítem del instrumento de indagación.

- $\quad$ el RESULTADO GRAFICO, comparando las cohortes 2015 y 2016.

- algunos COMENTARIOS sobre la comparación de resultados.

\subsubsection{Motivación}

La primera afirmación presentada en el instrumento fue: "Me motivo fácilmente cuando puedo visualizarme cumpliendo el objetivo de la actividad que me es propuesta". Los resultados obtenidos en ambas cohortes, comparados, se presentan en la figura 68 .

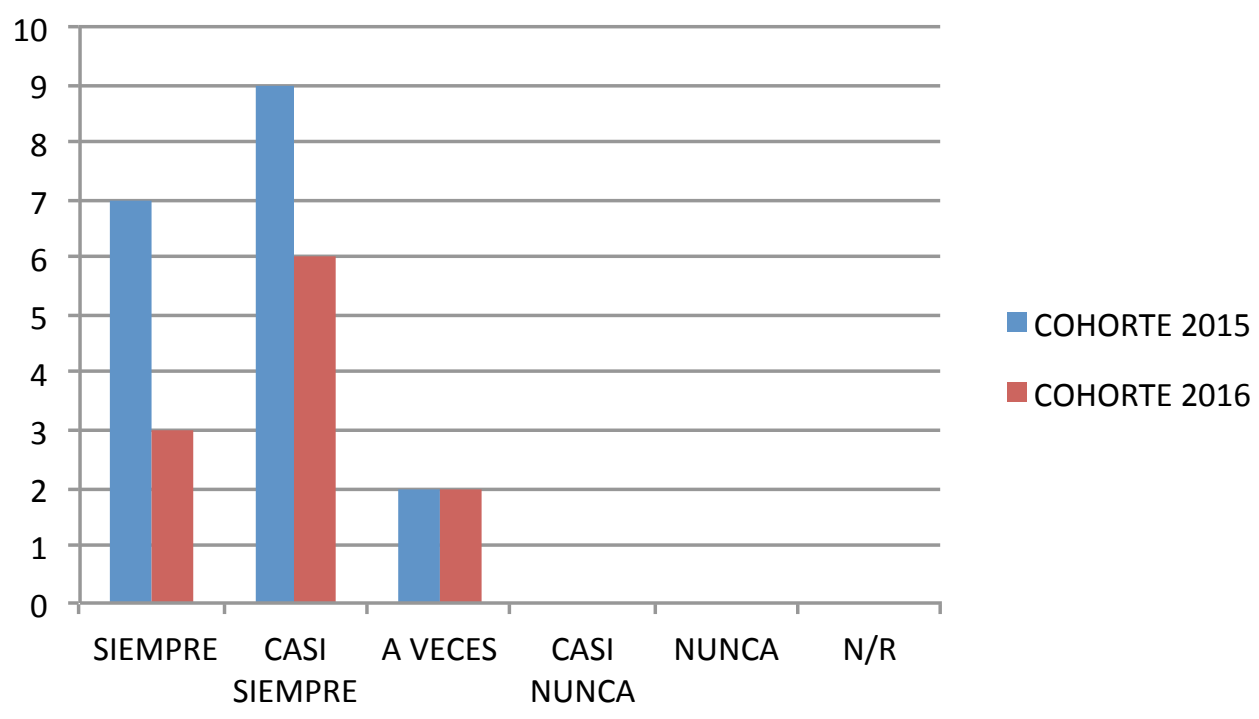

Figura 68: Nivel motivacional en relación con la visualización de la meta a alcanzar

En ambas cohortes las respuestas presentaron relación significativa entre el nivel de motivación y la posibilidad de visualizar la meta a alcanzar. En la cohorte 2015 casi el 89\% de los consultados (16 sobre 18) reconoció que el nivel motivacional se ve incrementado cuando pueden visualizarse llegando a la meta. Siguiendo la misma tendencia, este número alcanzó el $81 \%$ en la cohorte 2016 (9 de 11 estudiantes).

Otra afirmación que vale la pena mencionar, ya que se retomará luego en el análisis del trabajo colaborativo fue la siguiente: "Identifico entre mis compañeros a quién/es podría pedirle ayuda en caso de encontrarme perdido/a". Los resultados se presentan en la figura 69. 


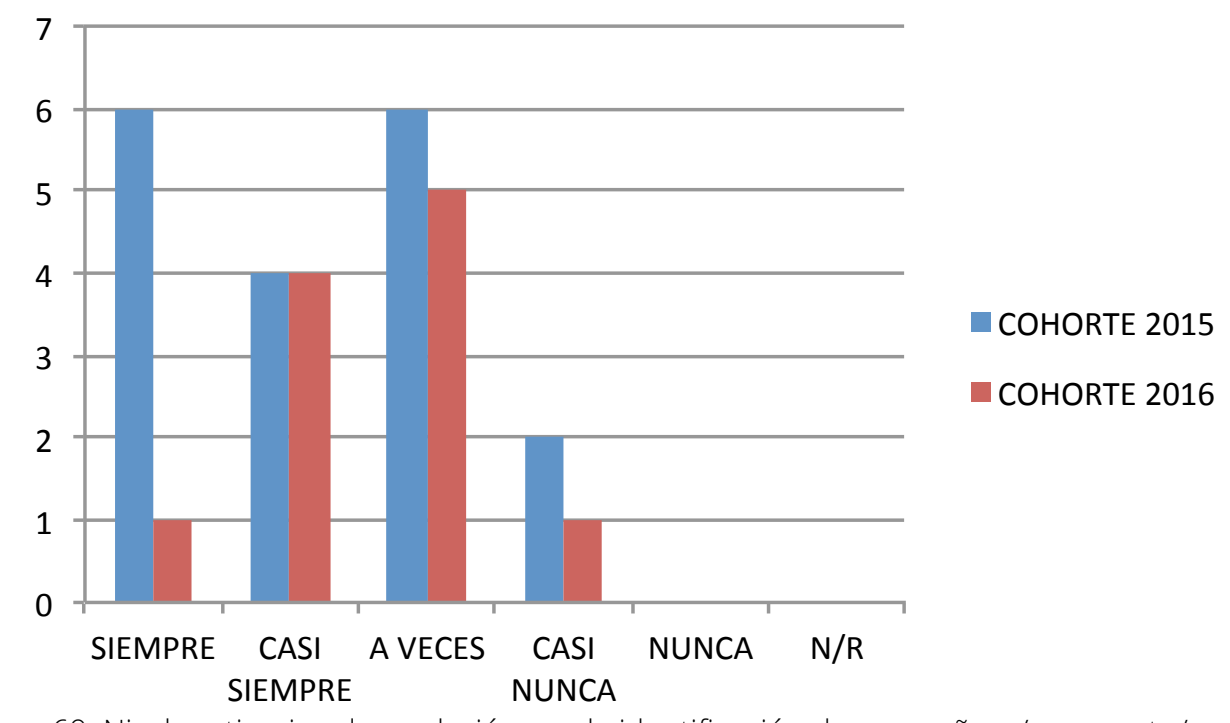

Figura 69: Nivel motivacional en relación con la identificación de compañero/as experto/as

Esta estrategia apareció como relevante en ambas cohortes. En la cohorte 2015, el 55\% de los consultados (10 estudiantes de 18) informó que busca a los pares expertos como una estrategia de aprendizaje (considerando el "Casi Siempre" y "Siempre"). En la cohorte 2016 esta tendencia desciende al $36.6 \%$.

\subsubsection{Manejo de la afectividad}

La primera afirmación significativa en esta categoría es: "Pienso en lo que estoy haciendo (proceso) y no en cómo me saldrá (resultado)". Este tema representa una tensión en la enseñanza y el aprendizaje en todos los niveles educativos. Los resultados obtenidos se presentan en la figura 70 .

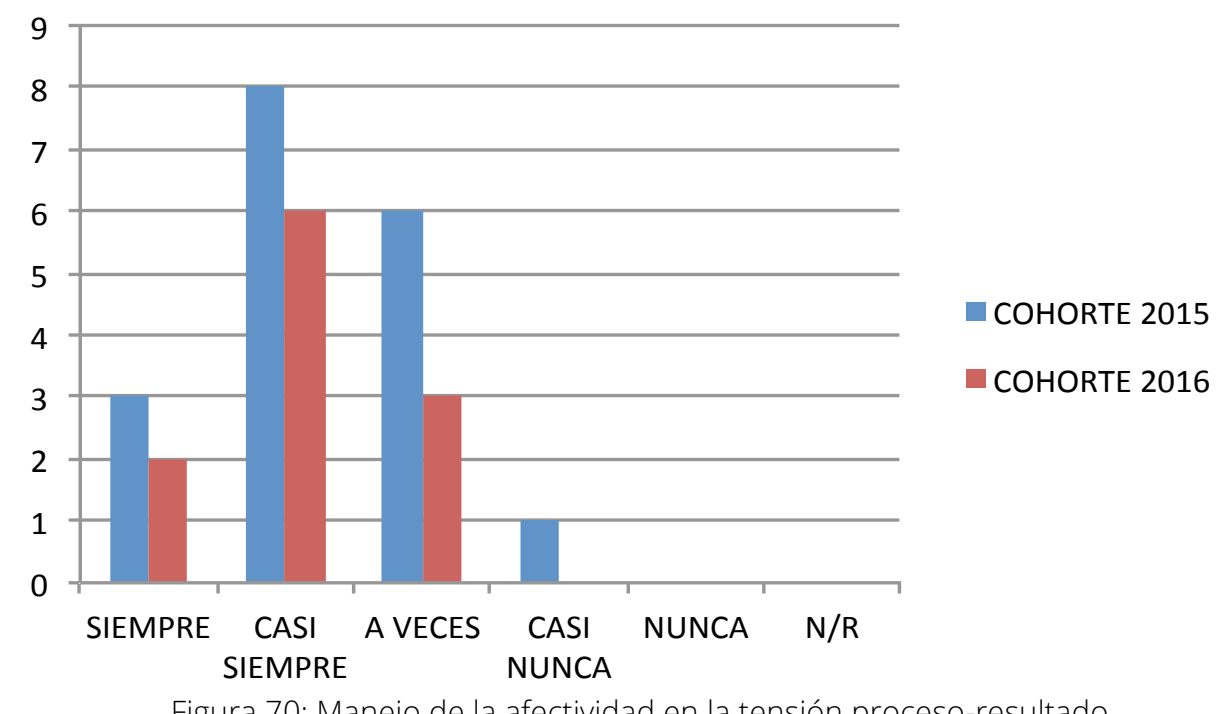

Figura 70: Manejo de la afectividad en la tensión proceso-resultado

En la cohorte 2015, el $61 \%$ de los indagados (11 estudiantes de 18) admitió que puede focalizarse en el proceso de aprender, más que en el resultado. En este punto, es interesante resaltar que comienza a aparecer con frecuencia la categoría "A veces", con un $33 \%$ (6 estudiantes de 18). En la cohorte 2016, el protagonismo del proceso sobre el resultado se acentúa, 
ya que un $72 \%$ de los estudiantes ( 8 de 11) indican que siempre o casi siempre piensan en el proceso más que en el resultado. En esta cohorte, la opción “A Veces" llega a un 27\% (3 estudiantes de 11).

Otra afirmación de gran interés en esta categoría es la relación del aprendizaje con el error. La consulta se realizó en estos términos: "Me preocupa la posibilidad de cometer errores". Los resultados obtenidos se presentan compilados en la figura 71.

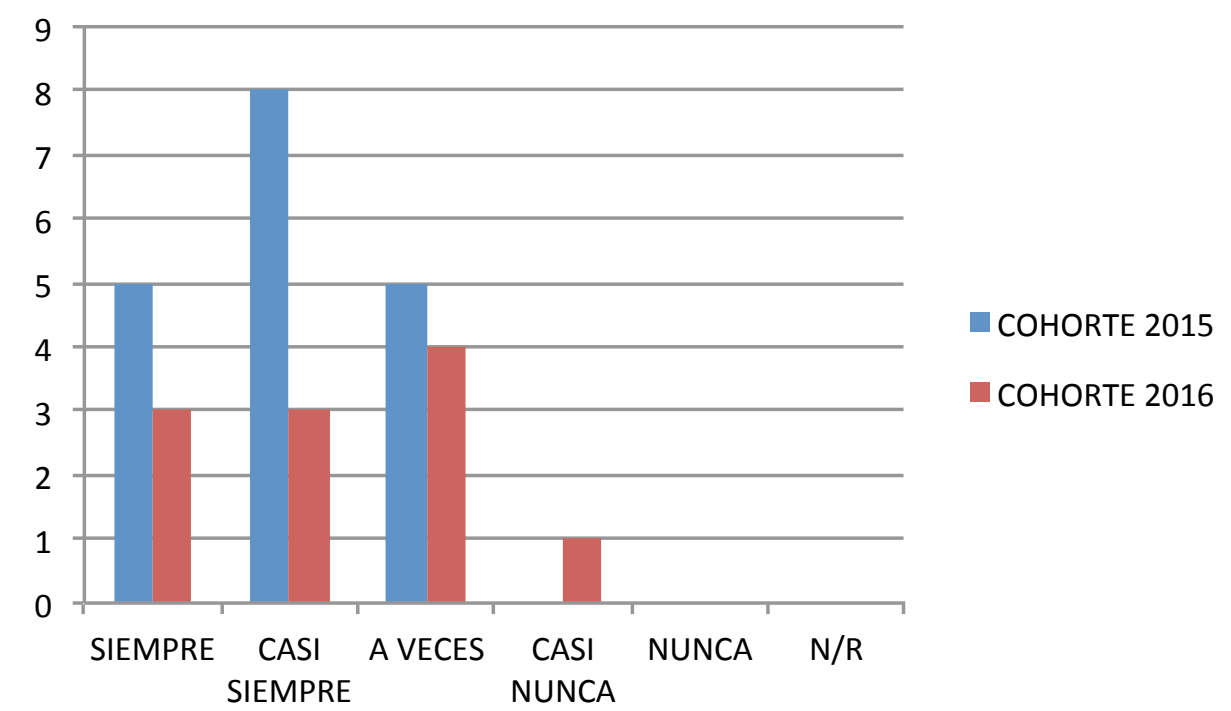

Figura 71: Manejo de la afectividad en relación con la posibilidad de cometer errores

Más allá del esfuerzo de la propuesta de enseñanza por darle sentido al error como parte de la construcción del aprendizaje, la preocupación por este tema aparece fuertemente en los resultados. En la cohorte 2015, las opciones de respuesta "Siempre" y "Casi Siempre" llegan al $72 \%$ (13 respuestas de 18). Si se incluye "A Veces" asciende al 100\%. En la cohorte 2016, un $54 \%$ de los indagados (6 de 11) se preocupan por sus errores siempre o casi siempre. Un $36 \%$ lo hace a veces. Si se consideran las respuestas "Siempre", "Casi Siempre" y "A Veces", la tendencia la preocupación por cometer errores es alta (100\% y 90\%) en ambas cohortes.

\subsubsection{Gestión del tiempo}

La afirmación "Dedico un momento del día a planificar mis actividades" resulta de interés para indagar acerca de la rutina de estudio y trabajo de los encuestados. Los resultados obtenidos se presentan en la figura 72 . 


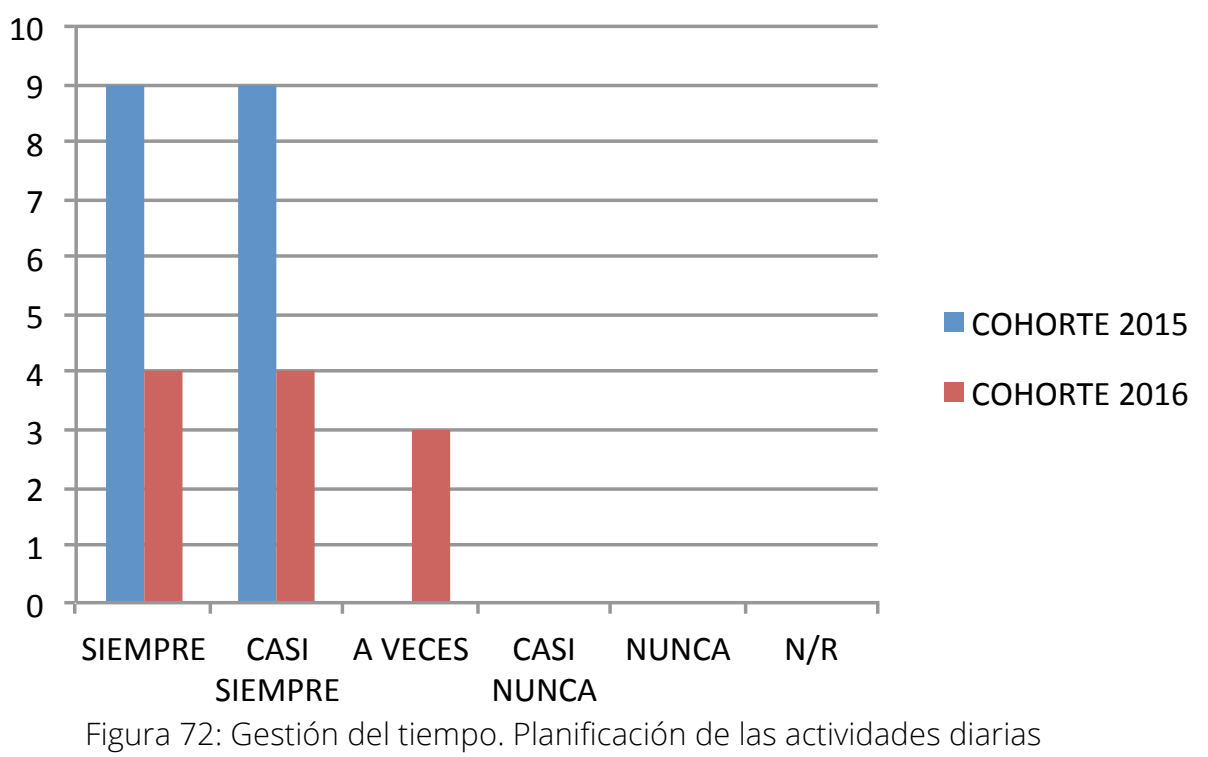

En ambas cohortes se advierte un alto grado de organización de las actividades. En la cohorte 2015, los estudiantes manifestaron hacerlo, ya que las opciones "Siempre" y "Casi Siempre" suman un $100 \%$ de las respuestas. En la cohorte 2016 se notó diferencia ya que el $72 \%$ dijo hacerlo siempre o casi siempre y el $27 \%$ sólo a veces.

La percepción de la tendencia a procrastinar fue indagada con la siguiente afirmación: “Tengo una alta tendencia a procrastinar mis actividades". Se acompañó esta afirmación con la definición del término procrastinar según la Real Academia Española. Las respuestas se presentan en la figura 73 .

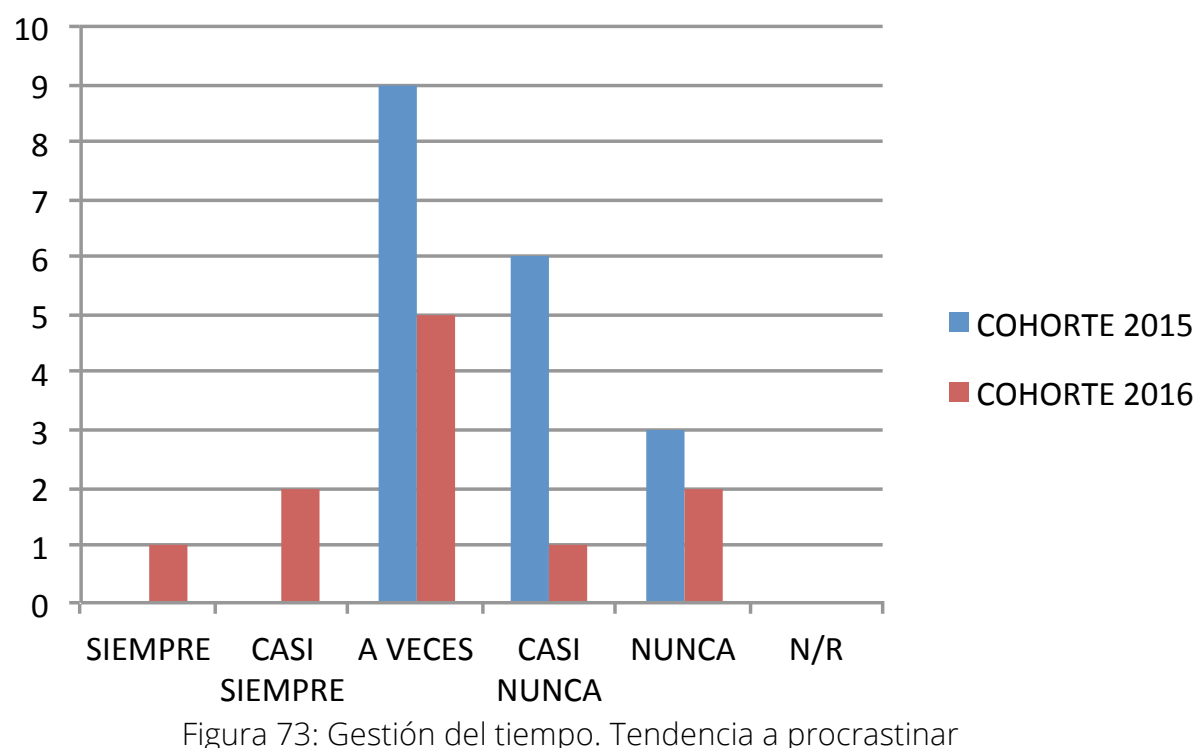

En la cohorte 2015 no se contemplaron las opciones "Siempre" y "Casi Siempre". Sin embargo, fue alta la frecuencia de "A Veces", con un $50 \%$ de las respuestas (9 estudiantes de 18). En la cohorte 2016 , un $72 \%$ de los indagados (8 estudiantes de 11) lo hace siempre, casi siempre o a veces. 


\subsubsection{Concentración}

En ambas cohortes se encontraron altos índices de autopercepción positiva en cuanto a esta categoría. En la cohorte 2015 los encuestados informaron buenas prácticas en la organización de las sesiones de estudio ("Organizo el material / alcance de mi trabajo en función del tiempo que dispongo") con $72 \%$ de "Siempre" y "Casi Siempre"; la organización del espacio ("Busco un lugar acorde para la tarea a realizar: luz, sonido, espacio de trabajo") con $83 \%$ de "Siempre" y "Casi siempre". No parece significativo el índice de distracción en el trabajo. En la afirmación "Me distraigo fácilmente. A los 10" de comenzar un estudio, encuentro algo mejor que hacer y lo dejo" hubo sólo un $27.7 \%$ que manifestó que sólo le sucede "A Veces". A nadie le sucede siempre o casi siempre. Similar situación ocurrió con la cohorte 2016. En la organización de las sesiones de estudio, las respuestas indicaron que un $75 \%$ lo hace siempre o casi siempre; en la organización del espacio, se obtuvieron resultados de un $74 \%$ de las opciones "Siempre" y "Casi Siempre". No parece significativo el índice de distracción en el trabajo, ya que el $42 \%$ de los indagados no se distrae nunca o casi nunca.

\subsubsection{Procesamiento de información}

La percepción de la habilidad de búsqueda de información es alta en ambas cohortes. La afirmación que indagaba acerca de esta cuestión fue: "Me considero eficiente en la búsqueda de información en Internet”. Las respuestas se presentan en la figura 74.

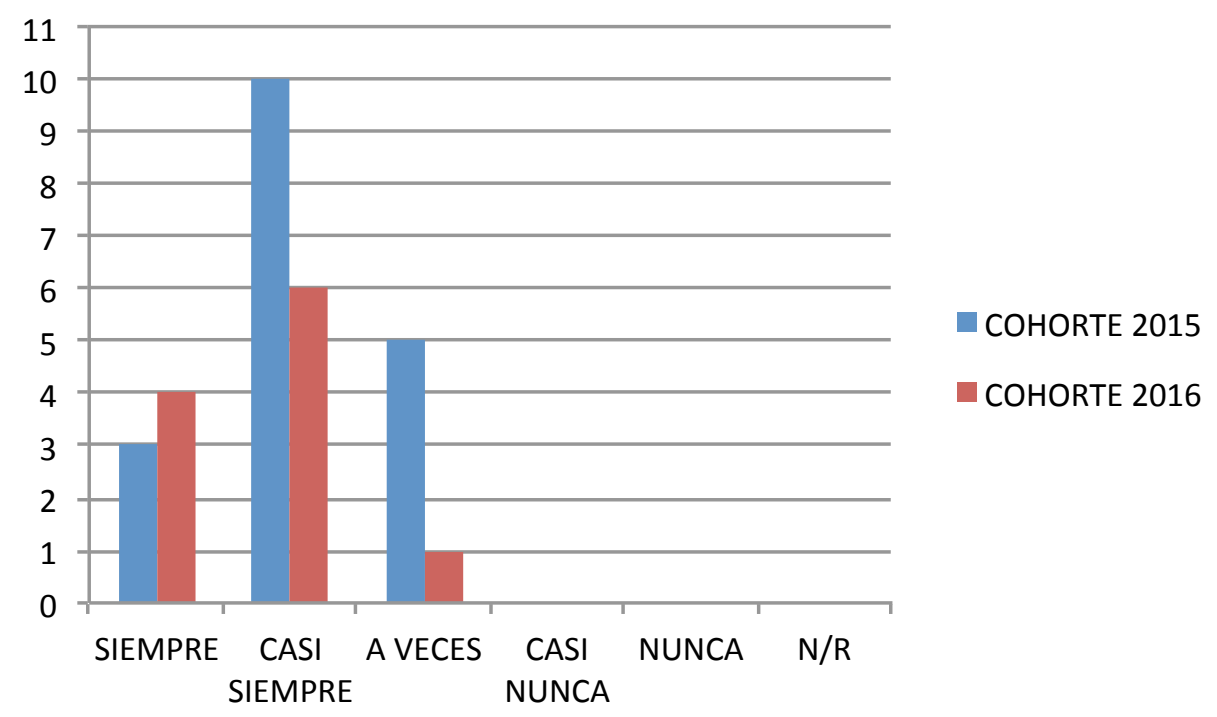

Figura 74: Procesamiento de información. Eficiencia de las estrategias de búsqueda

En la cohorte 2015 las respuestas indicaron un 72\% de "Siempre" y "Casi Siempre" y un $27 \%$ de "A Veces". En la cohorte 2016 son aún más altos los porcentajes de autopercepción sobre la efectividad en la búsqueda: un 90.9\% de "Siempre" y "Casi Siempre" y sólo un 9.09\% (sólo 1 persona) de "A Veces".

Otra afirmación que resulta de interés es la que indaga la interacción vicaria. La afirmación que se presentó fue: "Aprendo de leer los foros y participaciones de mis compañeros en un curso en formato digital. Prefiero eso a participar directamente". Los resultados indicaron que es una práctica común en ambas cohortes. Se presentan los resultados en la figura 75. 


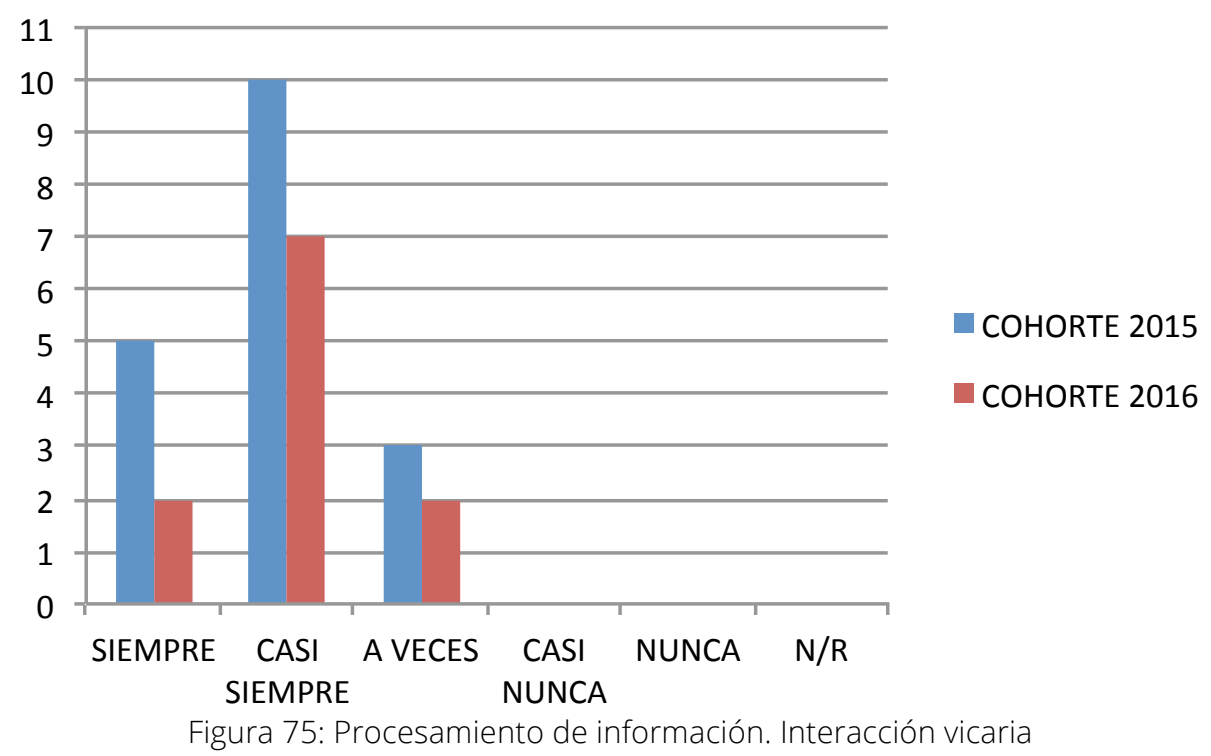

En la cohorte 2015 las respuestas sumaron un 83\% entre las opciones "Siempre" y "Casi Siempre". En la cohorte 2016 permanece casi equivalente, en un $81 \%$. El registro de este tipo de interacción resulta de interés para dar sentido a algunos eventos del trabajo colaborativo que se analizarán más adelante en este capítulo.

\subsubsection{Trabajo en equipo}

Como se ha visto en la presentación del instrumento, eran 15 las afirmaciones que indagaron temas de trabajo grupal (véase la tabla 17 del Capítulo 6 y el anexo 1, con el instrumento completo). Como se ha hecho con las categorías anteriores, se retoman aquí las respuestas más relevantes a la luz del trabajo colaborativo.

La afirmación "Me entusiasma la idea de trabajar con otros sólo si conozco a la gente y sé qué es capaz de hacer cada uno/a" abordó la cuestión de la grupalidad. Las respuestas indicaron que, en general, el conocimiento previo es un requisito importante para ambas cohortes. Se presentan los resultados obtenidos en la figura 76.

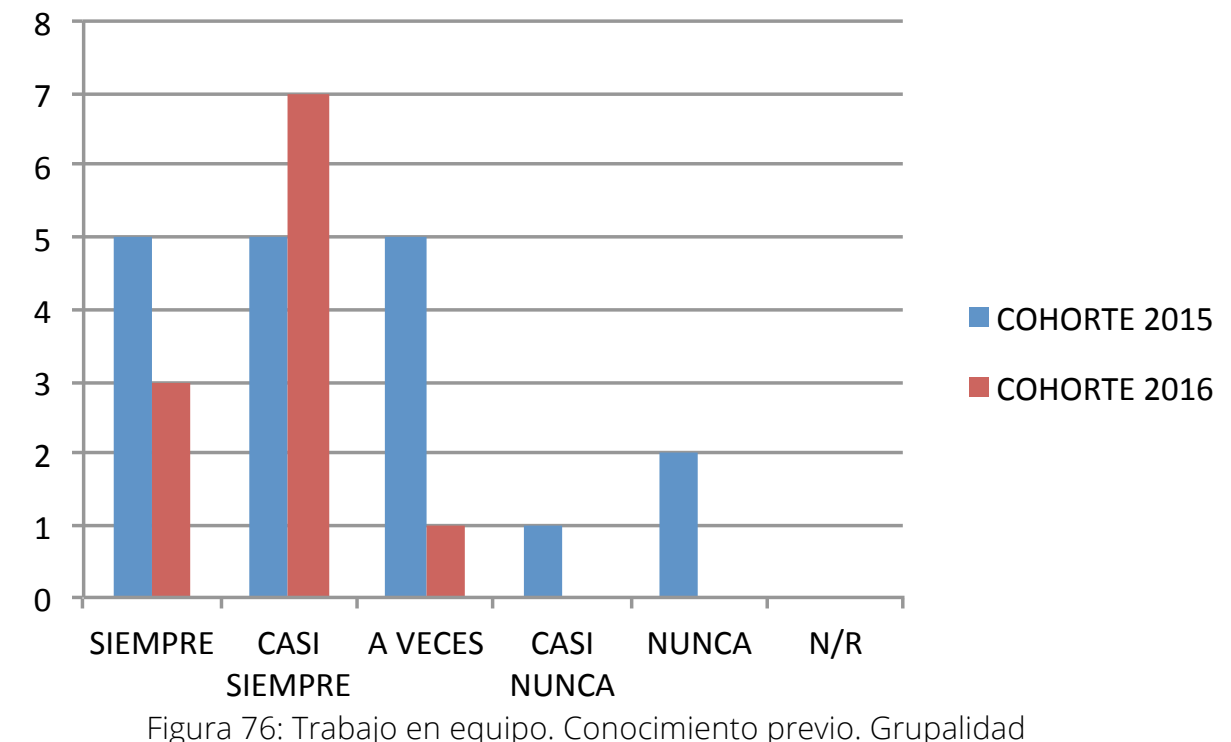


En la cohorte 2015 las opciones "Siempre", "Casi Siempre" y "A Veces" sumaron un 83.3\%. En la cohorte 2016, estas tres opciones completaron el 100\% de las respuestas.

Si bien las tareas grupales fueron altamente valoradas en la encuesta inicial de ambas cohortes (véanse las figuras 70 y 71), las respuestas al autoinforme mostraron inconsistencia entre la valoración manifestada en la encuesta inicial y la autopercepción de la práctica explicitada en el autoinforme. Una prueba de esta inconsistencia puede verse en las respuesta ante la afirmación: "Cuando trabajo en equipo me limito a hacer mi parte: si todos hacemos nuestra parte, el equipo funciona", que se presentan en la figura 77.

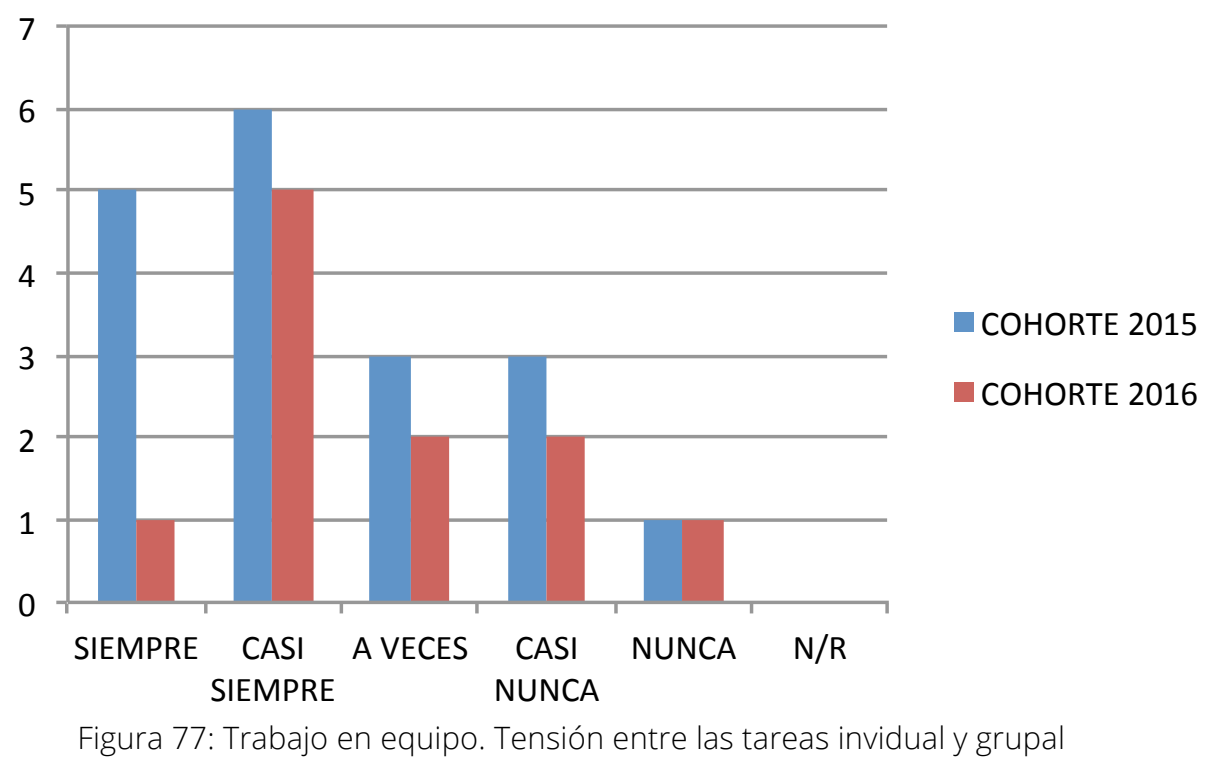

En la cohorte 2015, el 61\% de los encuestados (11 estudiantes de 18) dan cuenta de que trabajan en solitario, con la idea de que el grupo es solamente la suma de las individualidades (este resultado compila las respuestas de "Siempre" y "Casi Siempre"). En la cohorte 2016 la frecuencia de estas respuestas desciende un poco, al $54 \%$. De todas formas, la presencia de la opción "A Veces" da cuenta de que la tensión entre las tareas individual y grupal se mantiene alta.

\subsection{Análisis del trabajo colaborativo en sí}

En este apartado se presenta el análisis del trabajo colaborativo, según los indicadores que propone MetSCIn, contrastando las cohortes 2015 y 2016.

Como la metodología de trabajo colaborativo requiere de la constitución de pequeños grupos, ambas cohortes se dividieron en grupos para la e-actividad de escritura colaborativa. Los 18 estudiantes de 2015 se dividieron en 3 grupos de 6 estudiantes cada uno y los 11 alumnos de 2016 en 2 grupos de 5 y 6 personas.

Los resultados serán presentados, atendiendo a cada indicador de MetSCIn y comparando ambas cohortes en forma completa. Como también puede ser de interés detenerse en el trabajo al interior de cada grupo de cada cohorte, se presentan los resultados con en el anexo 4. 


\subsubsection{Dimensión individual de la colaboración. Densidad y calidad de interacción. Cohortes contrastadas}

Retomando la operacionalización de indicadores presentado en la tabla 34, se comenzará por los resultados de densidad y calidad de interacción. Se presentan: a) cantidad de mensajes enviados durante todo el tiempo de la tarea, incluyendo mensajes en el foro y en la mensajería de WebUNLP y media de mensajes; b) cantidad de mensajes enviados en cada etapa de la resolución de la tarea grupal y media de mensajes y c) algunos comentarios finales. Para refinar estos resultados y anticipar algunas conclusiones, se han dividido los mensajes según las etapas de la tarea colaborativa. La definición de las etapas se ha considerado por:

-Las fechas previstas en la consigna del trabajo colaborativo, en sus etapas individual y grupal y la fecha de entrega del producto final.

-La interpretación de los mensajes de los grupos respecto de cuánto tiempo invirtieron en cada etapa de trabajo. Se consideró como inicio la fecha de la primera interacción de uno de los grupos y como final la fecha de la última interacción. Según este análisis, las etapas del trabajo colaborativo consideradas para ambas cohortes se presentan en la tabla 37.

\begin{tabular}{|c|c|c|c|}
\hline & \multicolumn{2}{|c|}{ Etapas } & Cantidad de días \\
\hline \multirow{5}{*}{$\begin{array}{l}\text { Etapas del } \\
\text { trabajo } \\
\text { colaborativo }\end{array}$} & \multicolumn{2}{|c|}{ Trabajo individual } & 5 días \\
\hline & \multirow{3}{*}{$\begin{array}{l}\text { Trabajo grupal } \\
\text { colaborativo }\end{array}$} & Inicio & 15 días \\
\hline & & Desarrollo & 15 días \\
\hline & & Cierre & 6 días \\
\hline & \multicolumn{2}{|c|}{ Trabajo post entrega } & 5 días \\
\hline
\end{tabular}

Tabla 37: Cantidad de días por etapa en el trabajo colaborativo

\subsubsection{Densidad de interacción. Cantidad de mensajes durante toda la tarea y por etapa}

Un primer análisis comparado consiste en calcular la cantidad de mensajes intercambiados por los estudiantes durante toda la tarea, en cada cohorte. Los resultados se presentan en la figura 78 .

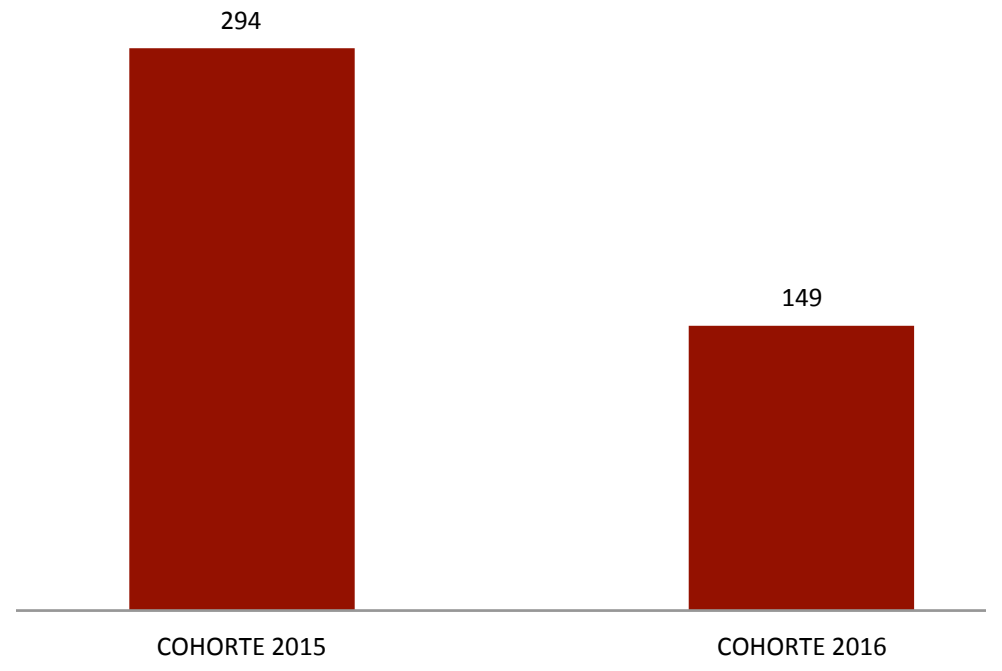

Figura 78: Densidad de interacción en la tarea completa. Ambas cohortes 
Como se observa en la figura anterior, en la cohorte 2015 hubo mayor cantidad de mensajes, aunque también hubo mayor cantidad de participantes y de grupos. Se tomó entonces la media de mensajes por cohorte (cantidad total de mensajes sobre la cantidad total de participantes) para comparar ambas cohortes). Esta comparación arroja el resultado que se muestra en la tabla 38.

\begin{tabular}{|l|c|c|c|}
\hline \multirow{3}{*}{ Media de mensajes } & COHORTE 2015 & COHORTE 2016 & DIFERENCIA \\
\cline { 2 - 4 } & 16.33 & 13.54 & 2.79 (Cohorte 2015) \\
\hline
\end{tabular}

Tabla 38: Media de densidad de interacción en la tarea completa. Ambas cohortes

Extrayendo la media de mensajes se llega a la conclusión de que, con independencia de la cantidad de participantes y grupos, la cohorte 2015 mostró una mayor densidad de interacción, con una media de 16.33 mensajes por participante a lo largo de toda la tarea.

En cuanto a la cantidad de mensajes por etapa, se seguirá la misma lógica: totales y media. La densidad de interacción por etapa, comparando ambas cohortes, arroja los resultados que se presentan en la figura 79 .

\section{- COHORTE $2015 \square$ COHORTE 2016}

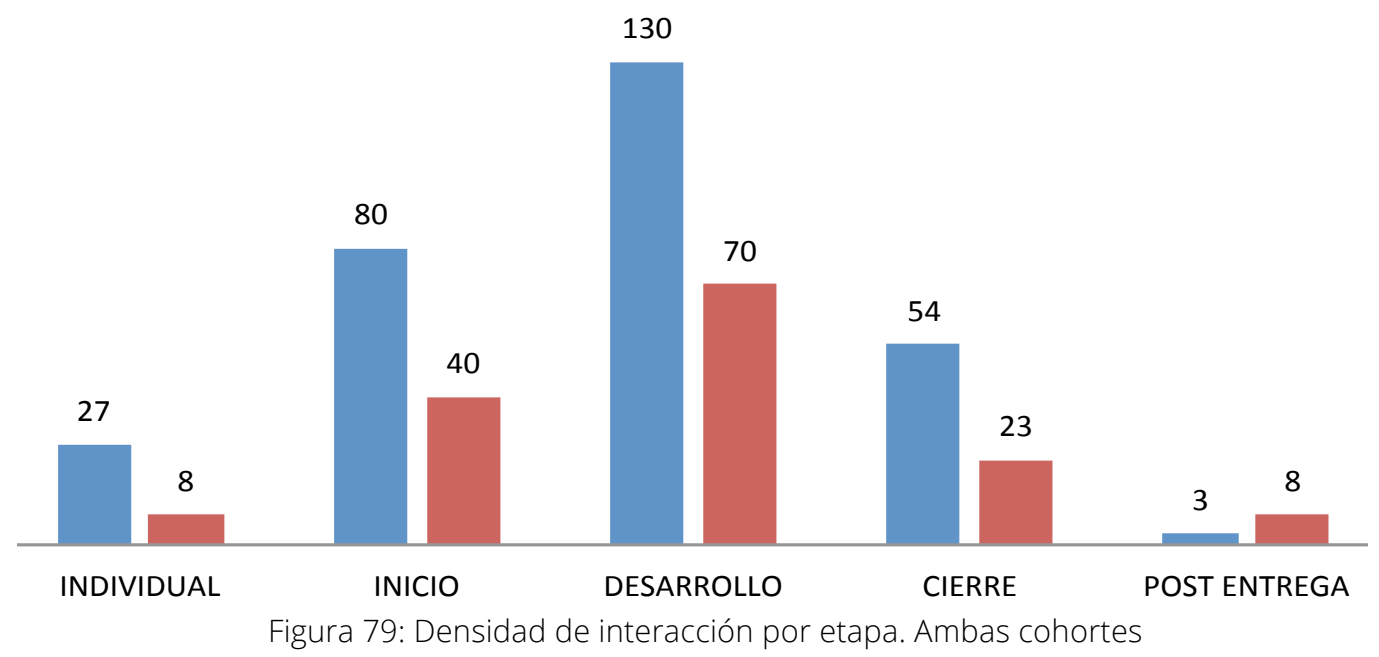

Si consideramos la media de mensajes por etapa se obtienen los resultados que se presentan en la tabla 39.

\begin{tabular}{|l|l|r|r|}
\hline \multicolumn{2}{|c|}{ ETAPAS } & COHORTE 2015 & COHORTE 2016 \\
\hline \multirow{3}{*}{$\begin{array}{l}\text { Trabajo } \\
\text { colaborativo }\end{array}$} & Irabajo individual & 1.5 & 0.72 \\
\cline { 2 - 4 } & Inicio & 4.44 & 3.63 \\
\cline { 2 - 4 } & Desarrollo & 7.22 & 6.36 \\
\cline { 2 - 4 } & Cierre & 3 & 2.09 \\
\hline & Trabajo post entrega & 0.16 & 0.72 \\
\hline
\end{tabular}

Tabla 39: Media de densidad de interacción por etapa. Ambas cohortes

Nuevamente el promedio de mensajes enviados durante el trabajo en la cohorte 2015 supera a la cohorte 2016, salvo en la etapa post entrega. Esto puede deberse a la estrategia de mirroring implementada en 2016, cuyos resultados específicos se presentarán más adelante en este capítulo. 


\subsubsection{Densidad de interacción. Componentes de los mensajes según su tipo en la tarea completa y por etapa}

En cuanto la cantidad de mensajes según su tipo, es de hacer notar que esta cantidad no condice con la cantidad total de mensajes. Esto se debe a que en un mismo mensaje hubo componentes de dos y hasta de las tres categorías. Se presenta la información de los tipos de mensajes por etapa contrastados en la figura 80 .

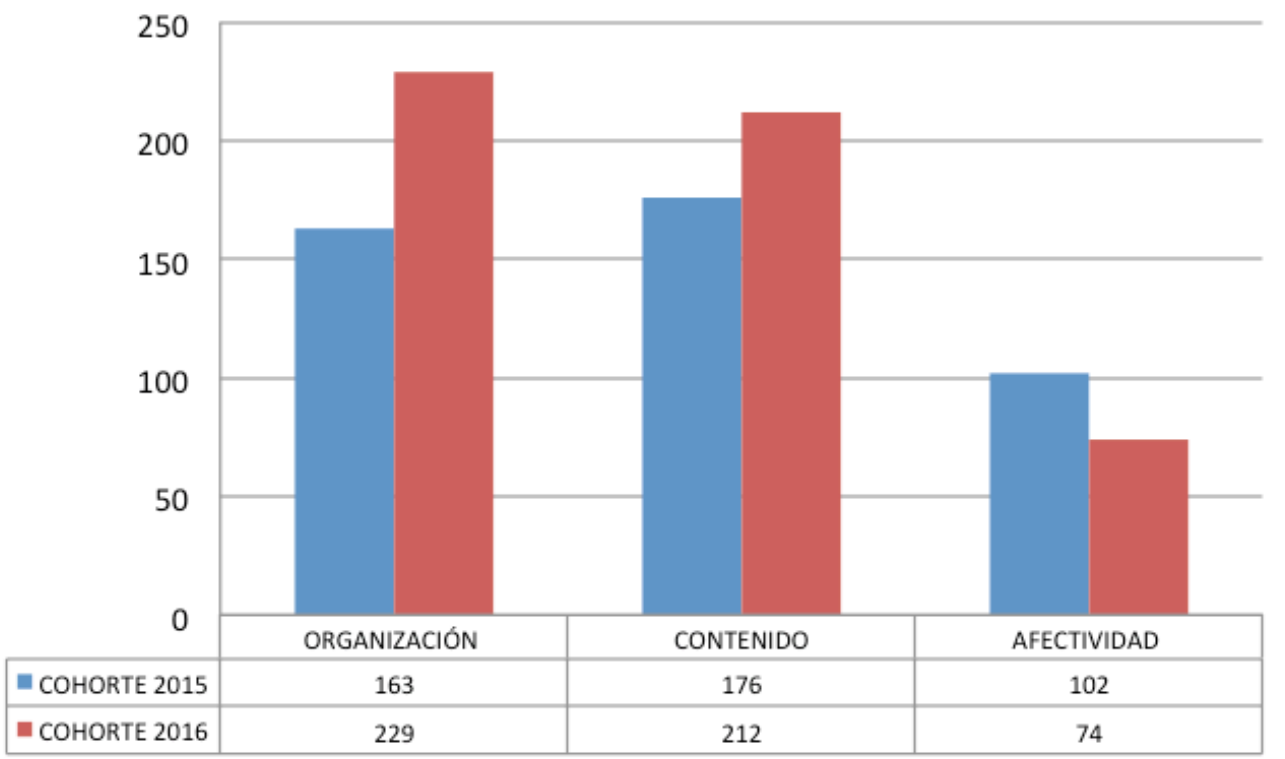

Figura 80: Densidad de interacción por tipo de mensaje en la tarea completa. Ambas cohortes

La media de mensajes por tipo se presenta en la tabla 40 .

\begin{tabular}{|l|c|c|c|c|c|c|}
\hline \multirow{4}{*}{ Media de mensajes } & \multicolumn{3}{|c|}{ COHORTE 2015 } & \multicolumn{3}{c|}{ COHORTE 2016 } \\
\cline { 2 - 8 } & 9.05 & 9.77 & 5.66 & 20.81 & 19.27 & 6.72 \\
\cline { 2 - 8 } \\
\cline { 2 - 8 }
\end{tabular}

Tabla 40: Media de densidad de interacción por tipo de mensaje en la tarea completa. Ambas cohortes

En este análisis puede visualizarse que en la cohorte 2016 hubo más componentes de organización y contenido en los mensajes promedio por participante. En cuanto al componente de organización en los mensajes, de 9.05 en la cohorte 2015 asciende a 20.81 en la cohorte 2016. En los componentes de tratamiento del contenido, va desde 9.77 a 19.27. Este resultado también podría atribuirse a la visualización de indicadores que posibilitó la estrategia de mirroring. En cuanto al componente de afectividad, es el de menor presencia en ambas cohortes.

Finalmente, resta presentar los resultados de tipos de mensaje por etapa en ambas cohortes. Se muestra en la figura 81. 


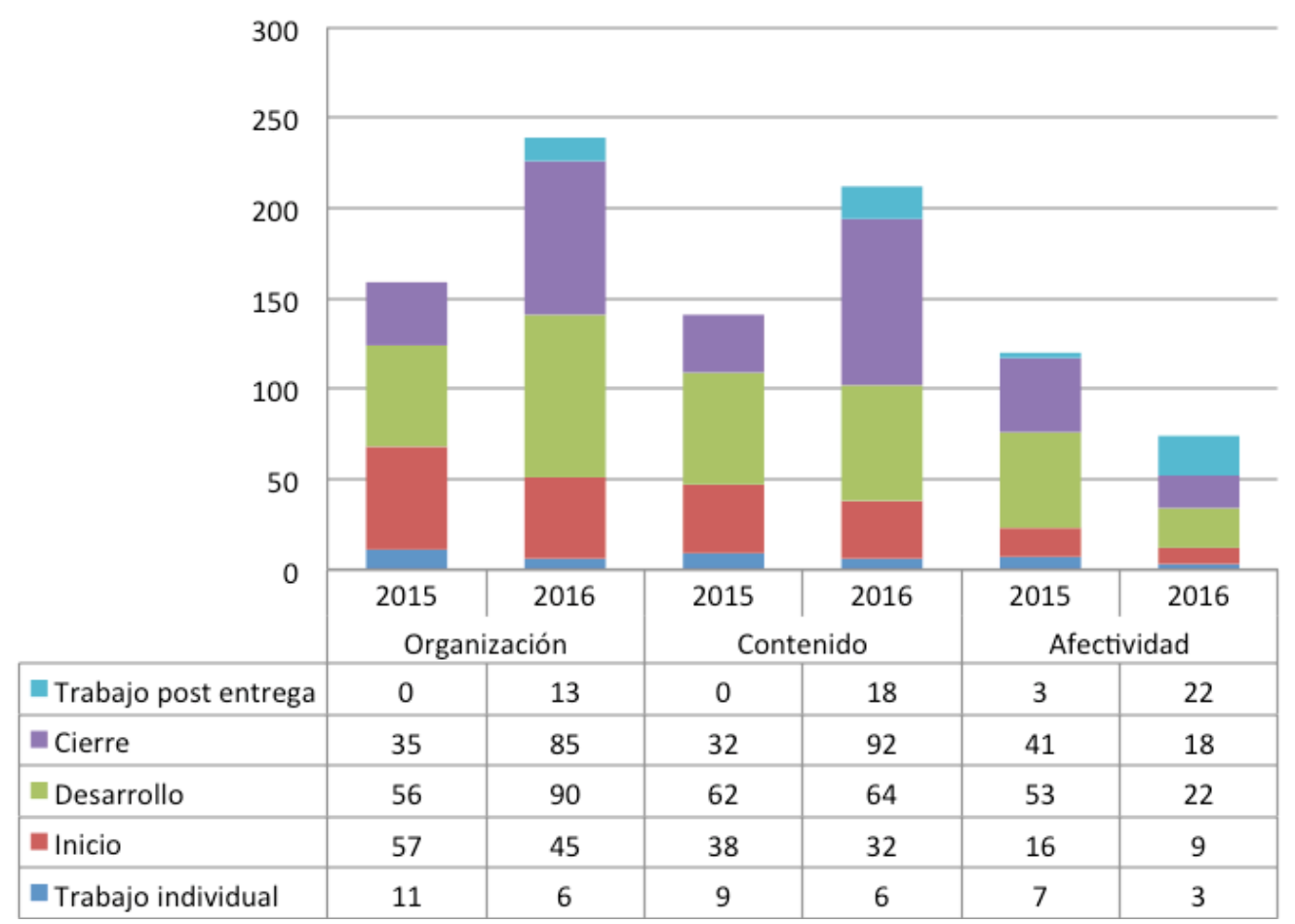

Figura 81: Densidad de interacción por tipo de mensaje por etapa. Ambas cohortes

En coincidencia con el análisis anterior, puede visualizarse en la figura que en la cohorte 2016 hubo más componentes de organización y contenido en los mensajes, especialmente en el desarrollo y cierre de la actividad colaborativa. El componente de afectividad estuvo más presente en la cohorte 2015, sobre todo en la etapa de desarrollo del trabajo colaborativo. Este componente aparece asociado a algún@ de los integrantes del grupo, que ya lo habían manifestado en la encuesta de autorregulación.

\subsubsection{Dimensión individual de la colaboración. Comentarios}

Antes de avanzar en el análisis de la información cualitativa, vale la pena detenerse en algunos comentarios al interior de cada cohorte y en su comparación. De este primer análisis cuantitativo se concluye que los grupos de ambas cohortes presentaron una adecuada densidad de interacción. Considerando que hubo 46 días de trabajo (con las vacaciones de invierno en el medio de la tarea) la media de mensajes resulta de 1 mensaje cada 2 ó 3 días. En cuanto al uso de herramientas, las de WebUNLP fueron usadas de forma complementaria con otras. Se usó el espacio compartido en GoogleDocs (el ofrecido por el seminario) y otro/s creados por los propios estudiantes, sesiones de videoconferencia vía HangOut y hasta reuniones presenciales, en aquellos grupos donde sus integrantes estaban cerca geográficamente (esta fue la situación de la cohorte 2015. Véase figura 68). Si bien la comunicación vía la mensajería y el foro de WebUNLP no son similares, en ambas cohortes se han utilizado de forma homogénea: cuando se iniciaba una cadena de interacción en una herramienta, ese era el camino que se seguía hasta el final del tema y se seguía el hilo de comunicación mediante la herramienta en la que lo habían iniciado. En las restantes herramientas se hacía referencia a la original. Por ejemplo: "Ya en el foro habíamos decidido que el índice lo iniciaríamos con el aporte de [nombre del participante]. Por esta razón avancé sobre esta idea".

En cuanto a los componentes cualitativos en cada mensaje (organización, contenido, afectividad), los porcentajes se mantienen estables en ambas cohortes: menos comunicación al inicio, más densidad en el desarrollo y en el cierre. Respecto al tipo de componente específico, los 
mensajes con componente de contenido (la tarea específica a resolver) dominan la escena, aunque en la cohorte 2016 se nota una referencia creciente en los mensajes de organización. Podría ser atribuido a un cierto impacto intermedio de la estrategia de mirroring, que fue mostrando la organización (o la falta de ésta) a lo largo del proceso. En la cohorte 2016 se visibiliza una gran cantidad de mensajes en la etapa de cierre y post entrega (véase figura 81). Esto puede vincularse con la inactividad de algunos de integrantes de los equipos y la necesidad de comunicarse (sobre todo con mensajes atinentes a la organización y el contenido) para entregar el trabajo solicitado.

Finalmente, los componentes referidos a la afectividad son los menos atendidos. En la cohorte 2015 aparece un promedio alto de este componente (con una media de 3 en la etapa de cierre. Véase tabla 39). Esto se vincula con un integrante que se ocupó de motivar y animar a sus compañer@s para cerrar el trabajo y felicitarlos, una vez concluido. Este integrante ya había mostrado interés en sus respuestas al instrumento de autorregulación, en el componente de "Motivación/Sostenimiento de la motivación". Eso podría indicar que la presencia de este componente en los mensajes está vinculado más específicamente al aspecto individual, de acuerdo a la importancia que cada persona le otorgue la afectividad en el aprendizaje, a las reglas de cortesía (o netiqueta) y sus propias actitudes respecto del trabajo en grupo.

\subsubsection{Dimensión grupal de la colaboración. Cohortes contrastadas}

En esta sección se presenta el análisis cualitativo de la interacción grupal en su componente de conexión semántica. Para la presentación de los resultados de esta sección y de la siguiente se reconstruyó el mapa de tópicos trabajados durante las etapas específicas del trabajo colaborativo a partir del contenido de los mensajes intercambiados.

\subsubsection{Conexión semántica}

Se implementó el análisis de unidades semánticas, intentando seguir el pensamiento colectivo. Se tomaron en cuenta dos componentes fundamentales de los mensajes, según su granularidad (Chi, 1997): mensaje macro y argumentación de la idea central del mensaje, según su composición y palabras clave utilizadas. En el nivel de mensaje macro, el título de cada mensaje (en la mensajería de WebUNLP y en el foro) podría haber resultado una brújula, un organizador anticipante del objetivo y contenido de cada uno. Sin embargo, uno de los problemas encontrados fue la precaria organización de los títulos de los mensajes, lo que conllevó a analizar uno por uno como una unidad de sentido independiente, para luego pensar el entramado. La figura 82 muestra la mensajería de WebUNLP con los títulos de los mensajes, como una prueba de lo descripto. 


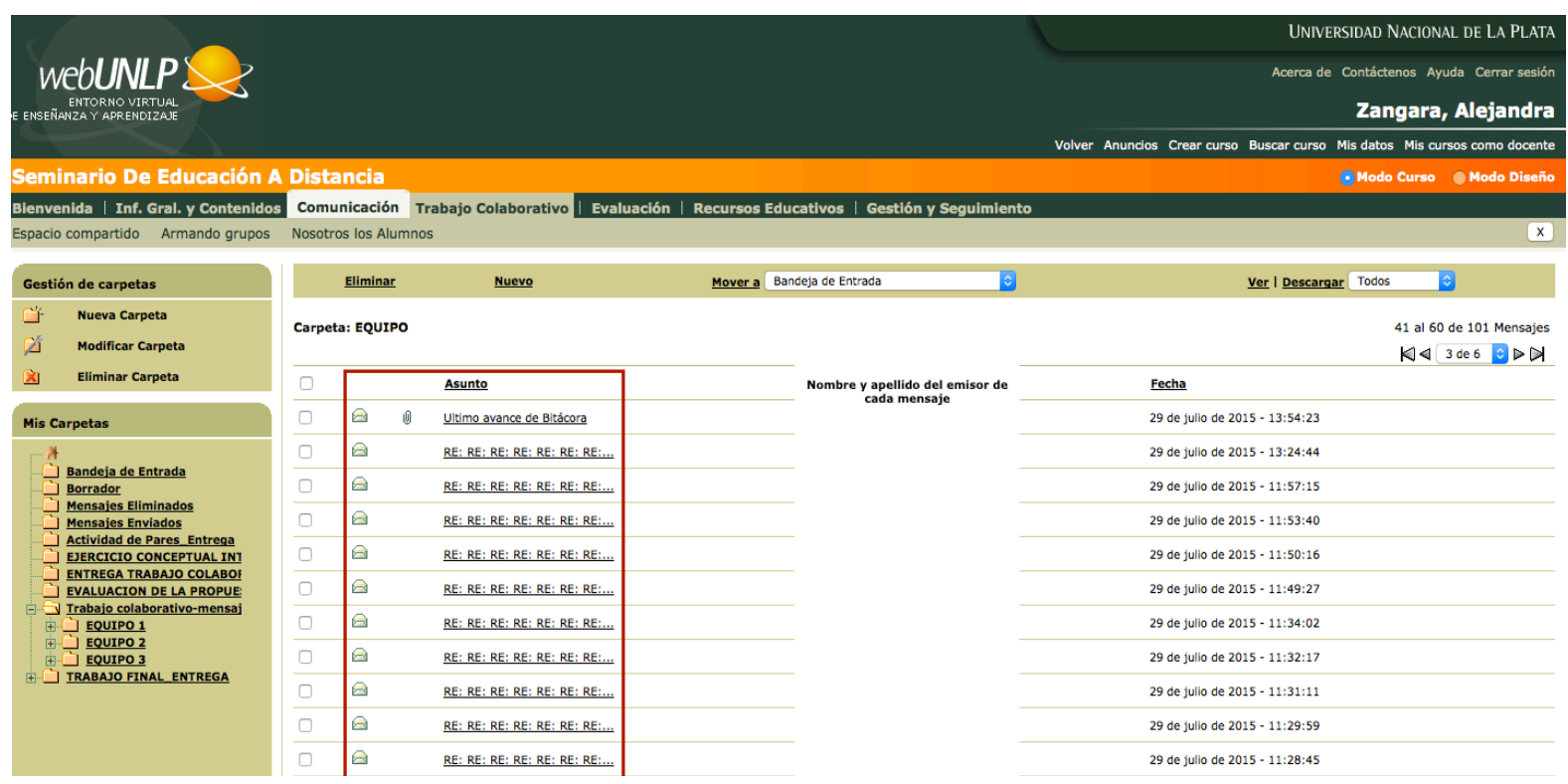

Figura 82: Interface de la mensajería de WebUNLP. Títulos de los mensajes con información irrelevante

En el anexo 4 se presenta el mapa conceptual de tópicos trabajados por cada grupo de cada cohorte. Para facilitar el análisis de las cohortes contrastadas, en este apartado se presentan los tópicos o unidades semánticas abordados por cada cohorte en cada etapa del trabajo colaborativo. Esta información se presenta en la tabla 41. El número que aparece corresponde a la cantidad de cadenas de mensajes que trabajaron ese tema y está considerado el total de cadenas de ambas cohortes en la columna de la derecha.

\begin{tabular}{|c|c|c|c|c|}
\hline \multicolumn{2}{|r|}{ TOPICOS O UNIDADES SEMANTICAS POR ETAPA } & $\begin{array}{c}\text { COHORTE } \\
2015\end{array}$ & $\begin{array}{c}\text { COHORTE } \\
2016\end{array}$ & $\begin{array}{l}\text { CANTIDAD DE } \\
\text { UNIDADES } \\
\text { SEMANTICAS } \\
\text { EN TOTAL } \\
\end{array}$ \\
\hline \multirow[b]{5}{*}{ INICIO } & Trabajos individuales & 3 & 2 & 5 \\
\hline & $\begin{array}{l}\text { Materiales compartidos en el repositorio de } \\
\text { WebUNLP }\end{array}$ & 2 & 2 & 4 \\
\hline & Organización (Vía videoconferencia) & 1 & 1 & 2 \\
\hline & Confección de resúmenes de los textos individuales & 0 & 2 & 2 \\
\hline & Comunicación mediante grupos de WhatsApp & 0 & 1 & 1 \\
\hline \multirow[b]{7}{*}{ DESARROLLO } & Armado de la bitácora & 2 & 1 & 3 \\
\hline & Coordinación & 2 & 1 & 3 \\
\hline & Escritura colaborativa & 3 & 2 & 5 \\
\hline & Calendario & 1 & 0 & 1 \\
\hline & Indice y capítulos & 1 & 1 & 2 \\
\hline & Aviso por vacaciones de invierno & 0 & 1 & 1 \\
\hline & Situación de un participante que dejó el seminario & 0 & 1 & 1 \\
\hline \multirow[b]{4}{*}{ CIERRE } & Formato de tapa y contratapa & 2 & 1 & 3 \\
\hline & Entrega del trabajo final & 3 & 2 & 5 \\
\hline & Control de la información visualizada en el mirroring & 0 & 1 & 1 \\
\hline & $\begin{array}{l}\text { Síntesis de cada paso del estado del trabajo (meta } \\
\text { tarea) }\end{array}$ & 0 & 1 & 1 \\
\hline POST ENTREGA & Control de la información visualizada en el mirroring & 0 & 2 & 2 \\
\hline
\end{tabular}

Tabla 41: Unidades semánticas abordadas en el trabajo colaborativo, por etapas. Ambas cohortes 
Una presentación gráfica se ofrece en la figura 83. El eje "Y" representa cantidad de tópicos o unidades semánticas en cada cohorte y el eje "X" su contenido.

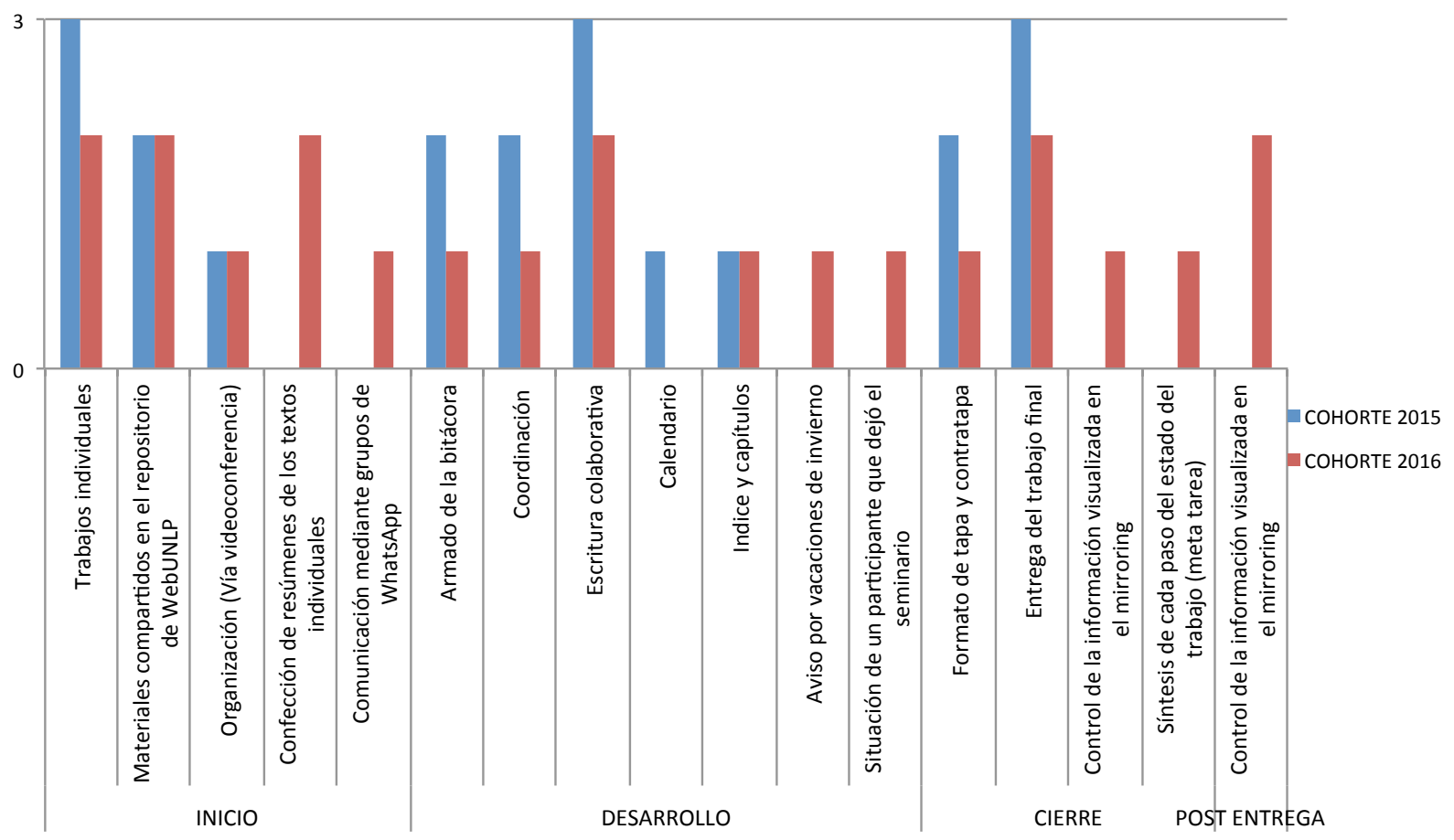

Figura 83: Tópicos o unidades semánticas abordadas en el trabajo colaborativo por etapas. Ambas cohortes. Presentación gráfica

\subsubsection{Cohesión de la comunicación}

El análisis de los mapas conceptuales de las interacciones de los cinco grupos muestra una gran cohesión. Esto se debe a que en las interacciones analizadas no hubo temas off topic (Reyes \& Tchounikine en Dimitrakopoulou et al., 2006) ni off task (Ingram \& Hathorn en Roberts, 2004. Capítulo X, pág. 225). Todos los intercambios fueron en relación con la tarea a resolver. Además, los cinco grupos mostraron un nivel parejo de cantidad y calidad de interacciones. En la figura 84 se muestra una comparativa de la cohesión de la interacción de los cinco grupos, a partir de los mensajes que cada grupo intercambió en cada tópico. 


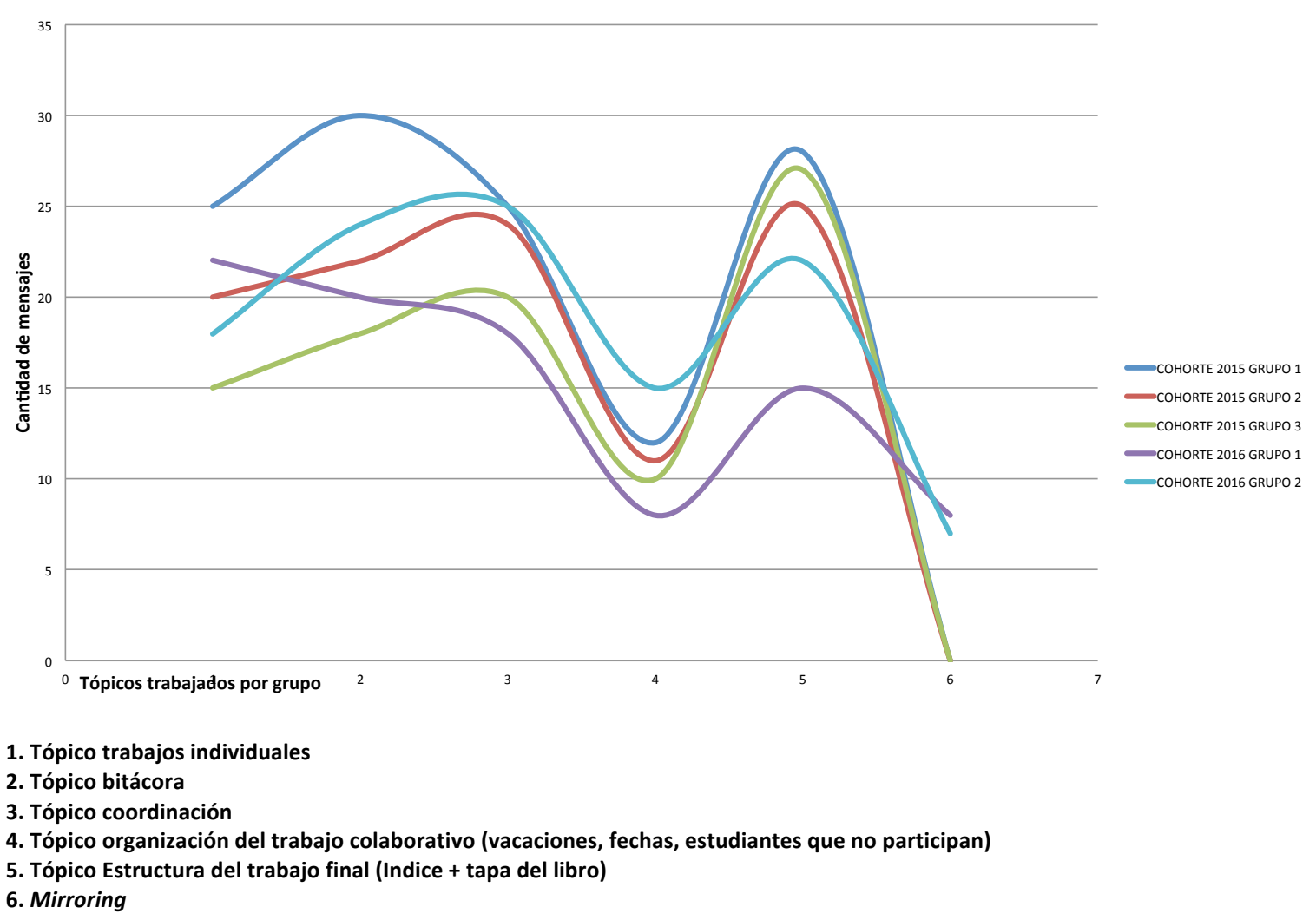

Figura 84: Cohesión de la comunicación. Ambas cohortes

En los dos grupos de la cohorte 2016 hay un tópico que se agrega referido a los comentarios de la estrategia de mirroring implementada.

\subsubsection{Argumentación}

En el capítulo 4, apartado 4.2.3. “Análisis de la conexión semántica en el trabajo colaborativo. Argumentación como idea clave" se ha presentado el concepto de argumentación y su relación con la competencia experta, tanto conocimiento y metaconocimiento. En el capítulo 6 se ha propuesto que la unidad de análisis sea el tratamiento de un tópico completo, que permita analizar el intercambio de mensajes y de componentes argumentativos de todos los participantes que intervienen en el intercambio de mensajes. Se ha seleccionado para su análisis el tratamiento de un tópico que ha estado presente en todos los grupos de las dos cohortes: "Escritura colaborativa" ("Estructura del trabajo final" en la figura 84). Se analizará la conversación en la herramienta mediadora: un foro de la cohorte 2015 y un foro de la cohorte 2016. Se analizará el entramado de argumentaciones de todos los participantes que intervinieron según el modelo de Toulmin (en Karbach, 1987) que fue presentado en los capítulos 4 y 6 . Para realizar este análisis se han tomado los componentes del modelo entendidos de la siguiente forma:

- Argumento: referencias a textos de investigaciones del trabajo individual.

- Evidencia: fundamentación de las propuestas del trabajo colaborativo (Modelo de índice por ejemplo).

- Calificadores: propuestas sobre la construcción colaborativa.

- Refutación: opiniones sobre las tareas que se realizan colaborativamente. 
Se presentan los resultados compilados por tópico (en las dos líneas del foro) a continuación. En el anexo 5 se incluye el análisis de las estrategias de argumentación en un tópico completo, mediado por la herramienta foro de ambas cohortes. Esta información es la base del análisis compilado que se presenta a continuación. En el sitio online: https://sites.google.com/site/trabajocolaborativoead/home/analisis-de-la-argumentacion se puede acceder al corpus completo de ambos foros con el análisis de cada mensaje, según los componentes argumentales mencionados.

Los resultados comparados de la argumentación se presentan inicialmente en una tabla de datos de cada tópico de cada cohorte con la información de cuántos estudiantes participaron y qué tipo de argumentos presentó cada uno y cuántos. En la tabla 42 se presenta la cantidad de argumentos por persona en la cohorte 2015 y en la tabla 43 se hace lo propio con la cohorte 2016.

\begin{tabular}{|l|c|c|c|c|}
\hline \multicolumn{1}{|c|}{ PARTICIPANTE } & \multicolumn{4}{|c|}{$\begin{array}{c}\text { COMPONENTES DE ARGUMENTACION } \\
\text { (Según Toulmin (en Karbach, 1987) }\end{array}$} \\
\hline & ARGUMENTO & EVIDENCIA & CALIFICADORES & REFUTACION \\
\hline NS & 13 & 8 & 5 & 1 \\
\hline PD & 22 & 27 & 8 & 2 \\
\hline GR & 2 & 4 & 3 & 2 \\
\hline FR & 4 & 1 & 2 & 2 \\
\hline PC & 3 & 3 & 2 & 2 \\
\hline Participante 6 & 0 & 0 & 0 & 0 \\
\hline
\end{tabular}

Tabla 42: Componentes de argumentación por participante. Tópico "Escritura colaborativa". Cohorte 2015

\begin{tabular}{|l|c|c|c|c|}
\hline \multicolumn{1}{|c|}{ PARTICIPANTE } & \multicolumn{4}{|c|}{$\begin{array}{c}\text { COMPONENTES DE ARGUMENTACION } \\
\text { (Según Toulmin en Karbach, 1987) }\end{array}$} \\
\hline & ARGUMENTO & EVIDENCIA & CALIFICADORES & REFUTACION \\
\hline MCA & 18 & 10 & 5 & 2 \\
\hline MEC & 11 & 12 & 8 & 3 \\
\hline LR & 3 & 8 & 5 & 2 \\
\hline RP & 8 & 7 & 8 & 3 \\
\hline Participante 5 & 0 & 0 & 0 & 0 \\
\hline
\end{tabular}

Tabla 43: Componentes de argumentación por participante. Tópico "Escritura colaborativa". Cohorte 2016

Cabe aclarar que en ambos foros hubo participantes del grupo que no intervinieron. Están indicados en la tabla con el número de participante, y no con sus iniciales y con un aporte de 0 en cada componente de la argumentación.

Para mostrar el funcionamiento comparado de la argumentación por tipo de componente, la figura 85 muestra una comparación de ambas cohortes por componente de argumentación. Incluye la información de las tablas 42 y 43. 


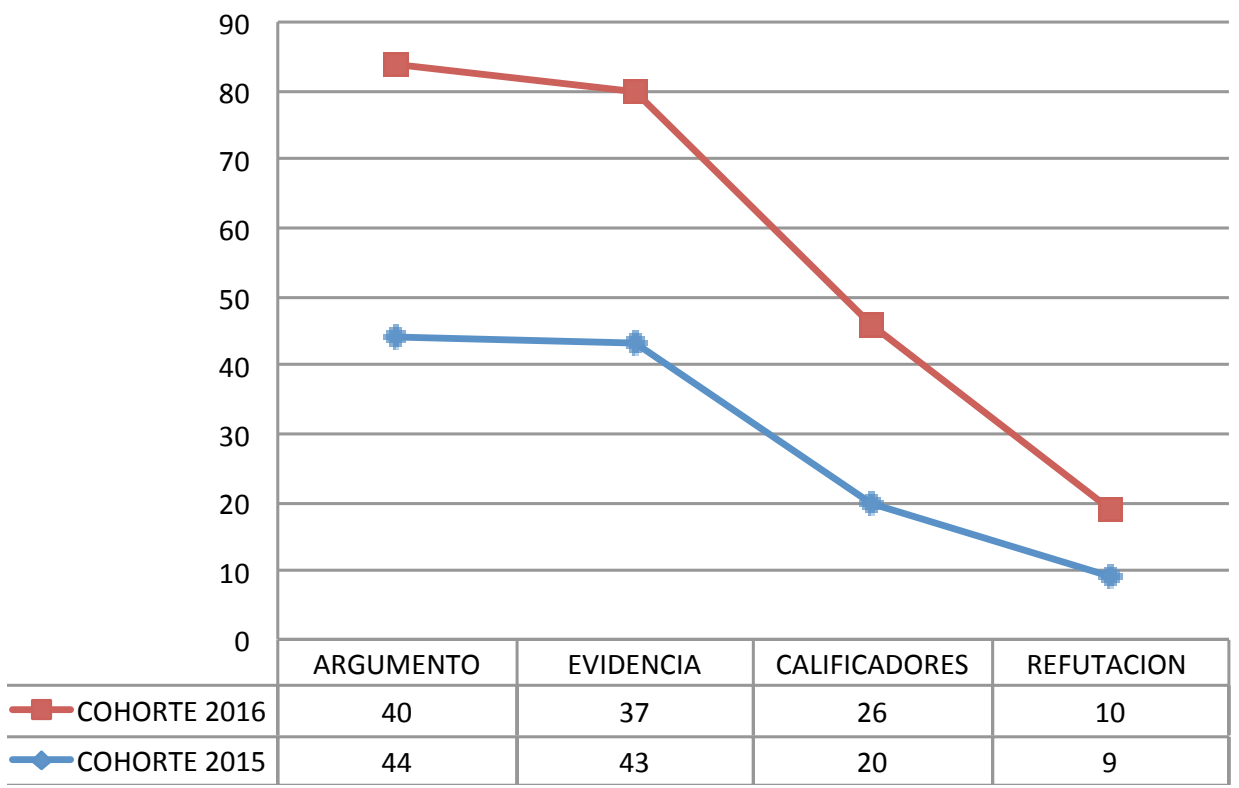

Figura 85: Argumentación según componentes. Ambas cohortes

Para finalizar y como la argumentación es una competencia absolutamente idiosincrásica, que se manifiesta en la relación de 1persona=1mensaje, corresponde buscar un denominador común entre las dos cohortes, ya que cada una contó con cantidad diversa de participantes. En la tabla 44 se presenta la media de componente por mensajes intercambiados en el foro (cantidad de componentes sobre la cantidad de mensajes totales de cada foro).

\begin{tabular}{|l|r|r|}
\hline & $\begin{array}{c}\text { COHORTE 2015 } \\
\text { (25 mensajes) }\end{array}$ & $\begin{array}{c}\text { COHORTE 2016 } \\
\text { (18 mensajes) }\end{array}$ \\
\hline ARGUMENTO & 1.76 & 2.22 \\
\hline EVIDENCIA & 1.72 & 2.05 \\
\hline CALIFICADORES & 0.8 & 1.44 \\
\hline REFUTACION & 0.36 & 0.55 \\
\hline
\end{tabular}

Tabla 44: Media de componentes de argumentación por mensaje. Ambas cohortes

De la figura 85 se desprende claramente que los argumentos y evidencias fueron los componentes más abordados en la interacción. Esto es: presentar una idea para la escritura colaborativa y justificarla desde, por ejemplo, el resumen de los textos insumo de cada autor, que habían sido entregados en la actividad individual. En la tabla 44 se evidencia que en la cohorte 2016 los mensajes contuvieron más componentes de argumentación.

\subsubsection{Dimensión grupal de la colaboración. Comentarios}

Es de hacer notar que en todos los grupos se trabajaron casi los mismos tópicos, vinculados con las etapas presentadas en la consigna: -conocer las consignas individuales por cada uno de los integrantes del grupo; -compartir los trabajos individuales; -definir la estructura del producto resultante; -armar la bitácora; -preparar la entrega, etc. Esto podría establecer una relación primaria entre los tópicos que se trabajan en los grupos y la consigna que se presenta para la actividad. En algunos de los grupos aparecen subtemas, vinculados con eventos específicos, pero los tópicos no se modifican. Por ejemplo, las vacaciones de invierno en el grupo 2 de la cohorte 2016 o la resolución del problema de un integrante que abandonó el seminario en mitad del trabajo colaborativo. Por eso, la figura 84, que muestra la cohesión de la comunicación en ambas cohortes, muestra una fuerte relación entre los temas trabajados por los 5 grupos. En los 
dos grupos de 2016 se muestra un interés manifiesto por la visualización del proceso, tema que será presentado en detalle en secciones posteriores de este capítulo.

En cuanto a la argumentación al interior de los mensajes según el modelo de Toulmin, se han presentado en la figura 85 con la comparación de componentes y la tabla 45 , con la media por mensaje. Tomando solamente la media de argumentos según mensajes puede notarse que hubo intercambio de argumentos iniciales o evidencias, pero no de calificadores o refutación. Una posible explicación de este fenómeno puede ser que no se ha llegado a una argumentación colectiva que permita construir conocimiento colaborativo. Esto significa que los estudiantes que llevaron adelante la coordinación del trabajo colaborativo muchas veces entraron en un soliloquio: o sea que esgrimían sus argumentos y justificaciones, pero las respuestas de sus compañer@s llegaban a destiempo (cuando ya no había disponibilidad de analizar el aporte porque se acercaba la fecha de entrega o se había pasado a otra etapa del trabajo) o, finalmente, no llegaban. Esto puede deberse a:

- las condiciones de entrada de los participantes, ya que la argumentación es una competencia experta y ninguno de los participantes de ninguna de las cohortes tiene como formación de grado alguna disciplina que le hubiera permitido establecer una base de conocimiento suficiente como para construir argumentación;

- a la consigna, ya que está orientada a la construcción de un nuevo discurso, donde la estrategia que usaron los 5 grupos consistió en adherir o sumar información individual, más que refinar el discurso a partir de la argumentación. Prueba de esto es que los 5 índices de los trabajos colaborativos fueron la suma de los textos individuales;

- a la participación algo espasmódica de algunos integrantes del grupo (condición que puede verificarse en el sitio de mirroring del año 2016).

\subsection{Impacto de la estrategia de mirroring en la cohorte 2016}

Se presentan los resultados del impacto del mirroring en el trabajo de la cohorte 2016. Como quedó descripto en el capítulo 6, las preguntas acerca del impacto del mirroring hicieron foco en:

- Frecuencia de acceso al sitio de información de mirroring.

- Acceso a la información sobre el tiempo restante para la entrega del trabajo.

- Información a la que se accedió según su autoría.

- Formato de información a la que se accedió.

- Decisiones de trabajo grupal resultantes del conocimiento de la información del proceso.

- Consolidación del impacto de la estrategia.

En este apartado se presentarán los resultados siguiendo las mismas categorías de las consignas descriptas en el capítulo 6. Cabe recordar que el trabajo colaborativo en el año 2016 fue iniciado por 11 estudiantes y finalizado por 9, ya que dos personas dejaron el seminario promediando este trabajo. Por lo tanto, el universo que ha respondido a este instrumento es de 9 estudiantes, quienes habían completado el trabajo colaborativo. 


\subsubsection{Frecuencia de acceso al sitio de información de mirroring}

La pregunta referida a este tema se formuló de la siguiente forma: “¿Cuántas veces visualizó el sitio de información del proceso colaborativo?" Las opciones de respuesta establecían una escala de frecuencia como la que sigue.

\section{1: NUNCA}

\section{5: DIARIAMENTE}

Las respuestas se contabilizaron según se consigna en la figura 86 .

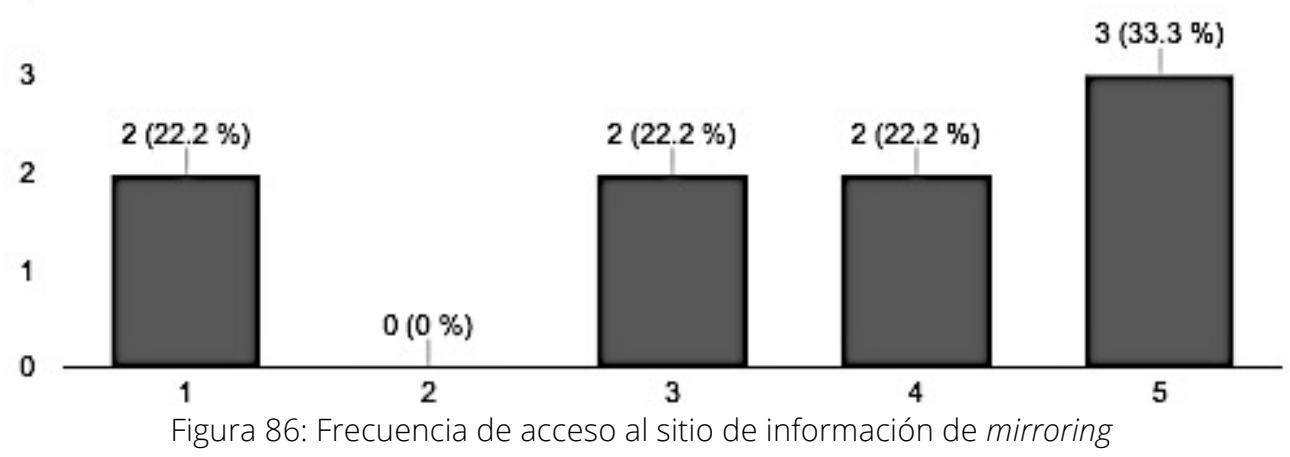

Un primer análisis de las respuestas indican que el sitio fue visitado diariamente por el $30 \%$ de los estudiantes (4 de los 9) y con una alta frecuencia. Dos estudiantes manifestaron no haber ingresado durante las vacaciones de invierno, pero si haberlo hecho una vez reintegrados a sus actividades. En cuanto a las razones del acceso frecuente a esta información, cuestión que se consultó en la pregunta siguiente, los estudiantes manifestaron ideas como las siguientes: "sentí curiosidad del tipo de información que se estaba manejando", "me interesé por saber cómo se mostraba y qué datos se visualizaban sobre las participaciones de los integrantes del grupo" y "me pareció importante saber si lo que se observaba en el trabajo colaborativo de mi grupo estaba reflejado en el sistema”.

También hubo dos estudiantes que no ingresaron a la información del sitio y lo indicaron en este ítem. Adujeron razones personales: "Por cuestiones personales, mi actividad en el trabajo colaborativo fue bastante acotada". Por esta razón, dijeron no haber entrado al sitio para no retrasarse en su trabajo y poder realizar la entrega del trabajo de escritura colaborativa en el tiempo estimado. Así lo manifestaron: "Visualicé [el sitio] una vez terminado el proceso de escritura, le presté más atención al documento compartido nuestro y los aportes del foro" y "Tuve problemas para ingresar al sitio y, como el grueso del trabajo se realizó en la semana final, me concentré en el trabajo grupal".

\subsubsection{Acceso a la información sobre el tiempo restante para la entrega del trabajo}

A partir de este ítem sólo se pedía la respuesta de aquellos estudiantes que habían ingresado a la información del mirroring. Por lo tanto, los dos estudiantes que no lo habían hecho no respondieron. Por esta razón, la cantidad total de personas que respondieron a este instrumento fue de 7 estudiantes.

La pregunta referida a la indicación del tiempo restante se formuló de la siguiente forma: “¿Qué importancia le asignó a la información sobre el tiempo restante para entregar el 
trabajo que apareció en el sitio a partir de la segunda semana (con el reloj en modo 'cuenta regresiva')?". Las opciones de respuesta establecían una escala de frecuencia como la que sigue.

\section{1: NINGUNA}

\section{5: MUCHA}

Las respuestas se contabilizaron como se consigna en la figura 87.

3

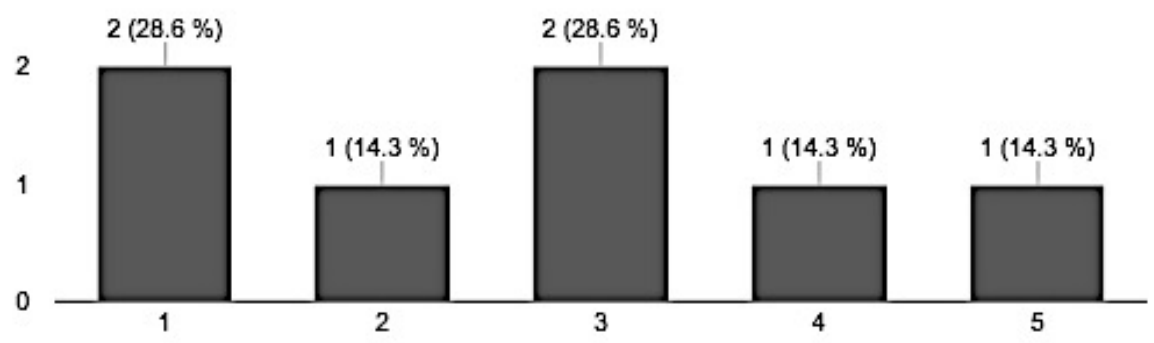

Figura 87: Acceso a la información sobre el tiempo restante para la entrega del trabajo (reloj en formato "cuenta regresiva")

Un primer análisis de las respuestas indica que, para el 57\% de los estudiantes, el manejo del tiempo a través de este tipo de figura (reloj en cuenta regresiva) tuvo importancia. En cuanto a las razones los estudiantes manifestaron, en general que el reloj " $m e$ daba un aviso de avances con respecto al tiempo establecido". No se relevaron respuestas cualitativas que hicieran referencia a algún tipo de presión específica que el reloj en este formato haya ejercido en el trabajo grupal.

\subsubsection{Información a la que se accedió según su autoría}

La intención de estas preguntas fue indagar acerca de qué información había resultado de más interés: la propia individual, la propia grupal o la del otro grupo que estaba trabajando en paralelo. Como en el sitio no se había ocultado información alguna, todos los estudiantes podían ver tanto su información como la de sus compañer@s. Por esta razón, estas preguntas resultaban pertinentes para intentar establecer alguna vinculación con la autorregulación individual en alguna de las categorías indagadas.

La primera pregunta fue: “AA qué indicadores prestó más atención?”, con las siguientes opciones:

- Indicadores individuales.

- Indicadores grupales.

- Ambos por igual.

Los resultados se consignan en la figura 88 . 


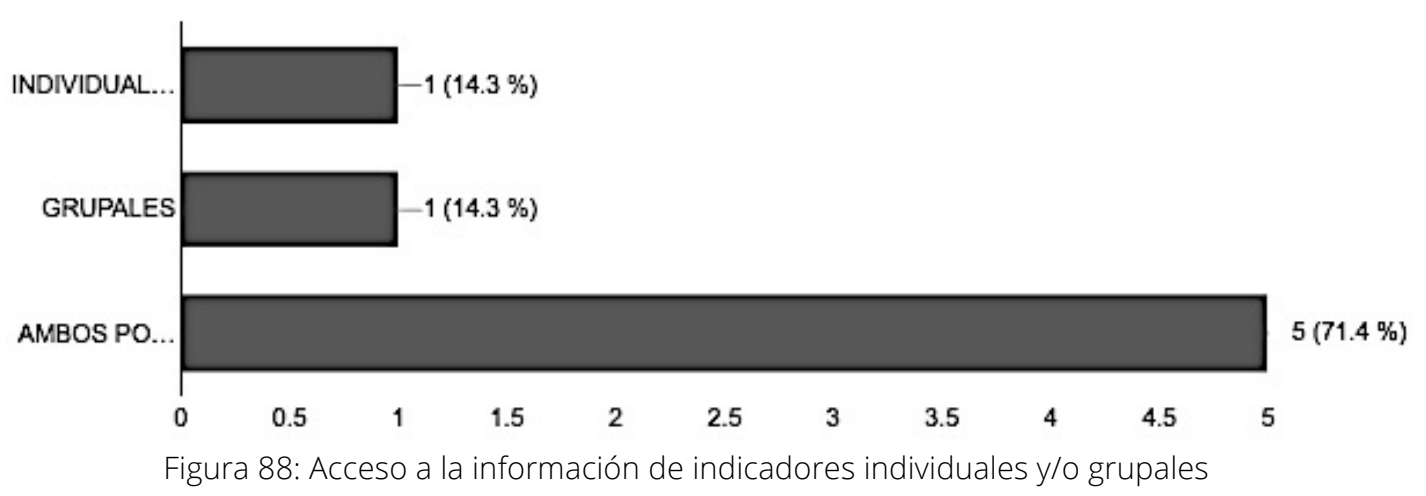

Se notó claramente que un $71.4 \%$ de los indagados estuvo interesado tanto en los indicadores propios como en los de sus compañeros. Esto refuerza la idea de conciencia que genera este tipo de estrategias de mirroring (Erickson \& Kellogg, 2000). Coincidentemente con esta idea, las razones ofrecidas por los mismos estudiantes fueron: "Porque me interesaba ver todos los indicadores"; "Porque da una perspectiva del nivel de avance del trabajo" y "Porque tanto el proceso de desarrollo grupal como individual son importantes".

Además, resulta interesante la presencia de otro concepto presentado por Erickson \& Kellogg: la responsabilidad. Uno de los estudiantes manifestó: "Porque si estamos hablando de un trabajo en forma colaborativa es fundamental prestar atención a si el grupo ha logrado trabajar en forma colaborativa y que no quede sólo en un trabajo grupal en el que cada uno desarrolla el tema asignado" y "Porque me permitió hacer una apreciación diferencial de mi actividad".

Finalmente, uno de los estudiantes manifestó "los miré desde el punto de vista de profesor y evaluador más que el de comportamiento grupal". Es posible que este tema esté relacionado con el tipo de contenidos y competencias que se trabajan en la Maestría y la idea de actividad "modelizante" que subyace a esta propuesta.

La siguiente pregunta avanzó sobre la visualización de la información del propio grupo o del otro grupo que estaba trabajando en forma paralela. Se formuló de la siguiente manera: "Una vez que comenzó a ver la información semanal: ¿A qué tipo de información le prestó más atención?". Las opciones de respuesta fueron:

- Información propia.

- Información de los compañeros de mi grupo.

- Información del otro grupo.

- Todas las informaciones por igual.

- Ninguna información me resulto de interés.

Los resultados gráficos se presenten en la figura 89 . 


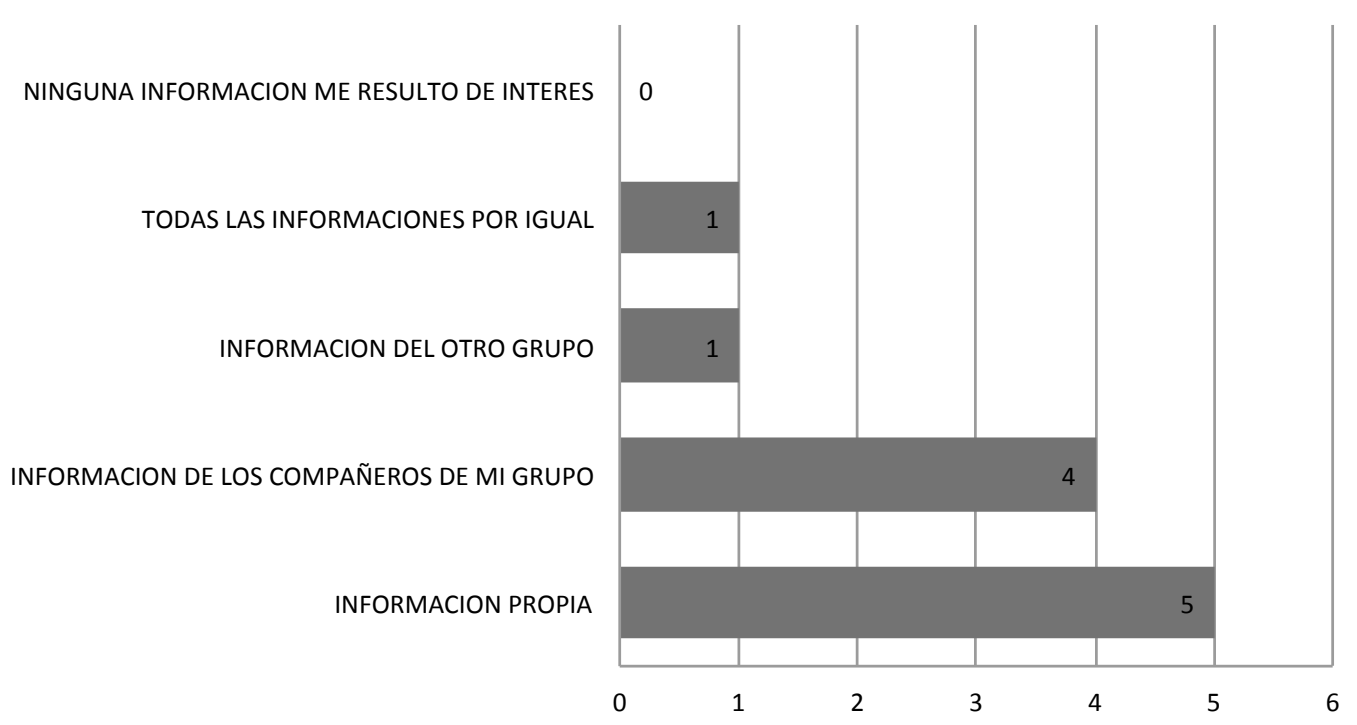

Figura 89: Acceso a la información según autoría (individual o grupal)

Lo primero que debe aclararse es que esta pregunta no requería una única respuesta. Los estudiantes podían indicar una o varias opciones, en coincidencia con el acceso a la información que les ofrecía el sitio. El $71.48 \%$ de los participantes se interesó por la información propia y la de su grupo. Las razones manifestadas fueron: "Me concentré en mi trabajo"; "Me preocupé en intervenir todas las semanas y que eso estuviera visible en el sitio"; "Para que el trabajo colaborativo resulte como tal es importante tanto mi participación como la del resto de los integrantes. Si no tenemos una visión de trabajo colaborativo se pierde el objetivo propuesto". Sólo una persona indicó haber mirado, también, la información del otro grupo. La razón esgrimida fue: "Lo producido por el otro grupo lo miré una sola vez, para ver si andábamos más o menos en lo mismo. En general miraba lo de mi grupo y lo mio".

\subsubsection{Formato de información a la que se accedió}

Este ítem resultó de gran interés, ya que ponía en juego el tipo de indicadores que habían sido construidos y su potencialidad para impactar en el trabajo colaborativo de un grupo. La pregunta fue: “¿Qué tipo de información le resultó de más utilidad?”. Las opciones de respuesta indicaban todos los formatos en los que la información de seguimiento había sido formalizada en el sitio:

- Textos.

- Números.

- Tablas de datos.

- Gráficos de barras de Excel.

- Grafos de trabajo grupal (Realizados con Gephi).

- Imágenes.

- Todos los tipos de información por igual.

- Ninguna información me resulto de interés.

Las respuestas obtenidas se presentan en la figura 90 . 


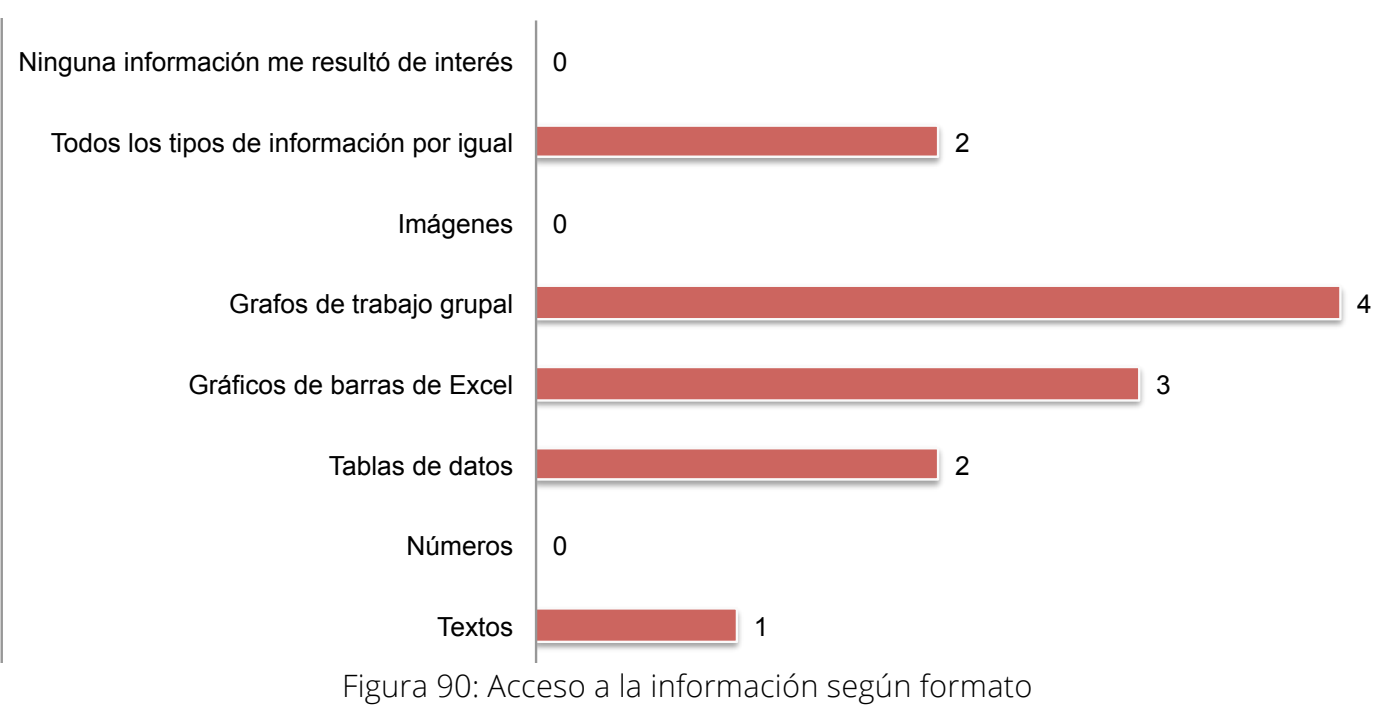

En este ítem podía indicarse más de una opción de respuesta, ya que los tipos de información no resultaban excluyentes. Comenzando por la información que resultó de mayor interés (4 personas) deben resaltarse los grafos de presentación de la actividad tanto individual como grupal. Se utilizaron los grafos como representación gráfica, simbólica de los elementos de un sistema. Como fue adelantado en el capítulo 6, en los grafos cuanto mayor era el tamaño del nodo, mayor participación había tenido la persona en su dimensión individual (más mensajes, más respuestas, etc.) y cuánto más gruesa aparecía la línea de relación entre nodos, más presencia había tenido ese participante en la construcción con sus compañeros: esto permite ver, de una sola vez, tanto el desempeño individual como el de cada estudiante en su contexto. A esta visibilidad del desempeño individual y grupal puede atribuirse la respuesta acerca de la importancia de los grafos en el mirroring. En segundo lugar aparecen los gráficos de barra que mostraron desempeño individual en referencia a la cantidad de mensajes por categoría. Antes de estos gráficos, se incluían las tablas de datos que les habían dado origen. Esta información también fue valorada por los estudiantes. Finalmente, el valor del texto como elemento de integración, explicación y contextualización se apreció como valioso.

Las explicaciones fueron requeridas en la pregunta a continuación. Respecto de los grafos, se rescatan las siguientes: "Los gráficos representan los datos en forma clara y precisa"; "Personalmente, prefiero analizar gráficos a números"; "Prefiero el grafo porque puedo ver la conexión entre los integrantes con las acciones y los tipos de mensajes". También se mencionó la tabla de datos: "Me sirvió el desglose de forma individual de las participaciones y la tabla de datos y sus subdivisiones". Se valoró suficientemente el texto y la integración de diferentes tipos de información en el sitio: "Todos los informes fueron leídos con atención. Los gráficos y tablas y grafos son más fáciles de interpretar, pero siempre viene muy bien la parte de textos" y "Cada elemento enriqueció de manera distinta las estadísticas del proceso y fueron complementarios". Además, los estudiantes valoraron las dos dimensiones en las que se presentó la información, individual y grupal. Esta fue la respuesta que hizo mención a este punto: "Me fue útil ver la actividad individual de cada uno y luego integrados en lo que el grupo iba haciendo".

\subsubsection{Decisiones de trabajo grupal resultantes del conocimiento de la información del proceso}

Este fue otro ítem fundamental, ya que aludía a la transferencia del conocimiento del proceso de trabajo a la propia tarea individual y/o grupal. En el ítem se utilizaron las mismas categorías que se habían utilizado para la presentación de la información en el sitio. Entonces, la pregunta fue: “¿Qué decisiones se modificaron en función de la información mostrada en el sitio?” (se 
dividen las opciones en tres aspectos: afectividad, contenido, organización)". Las respuestas se presentan en la figura 91.

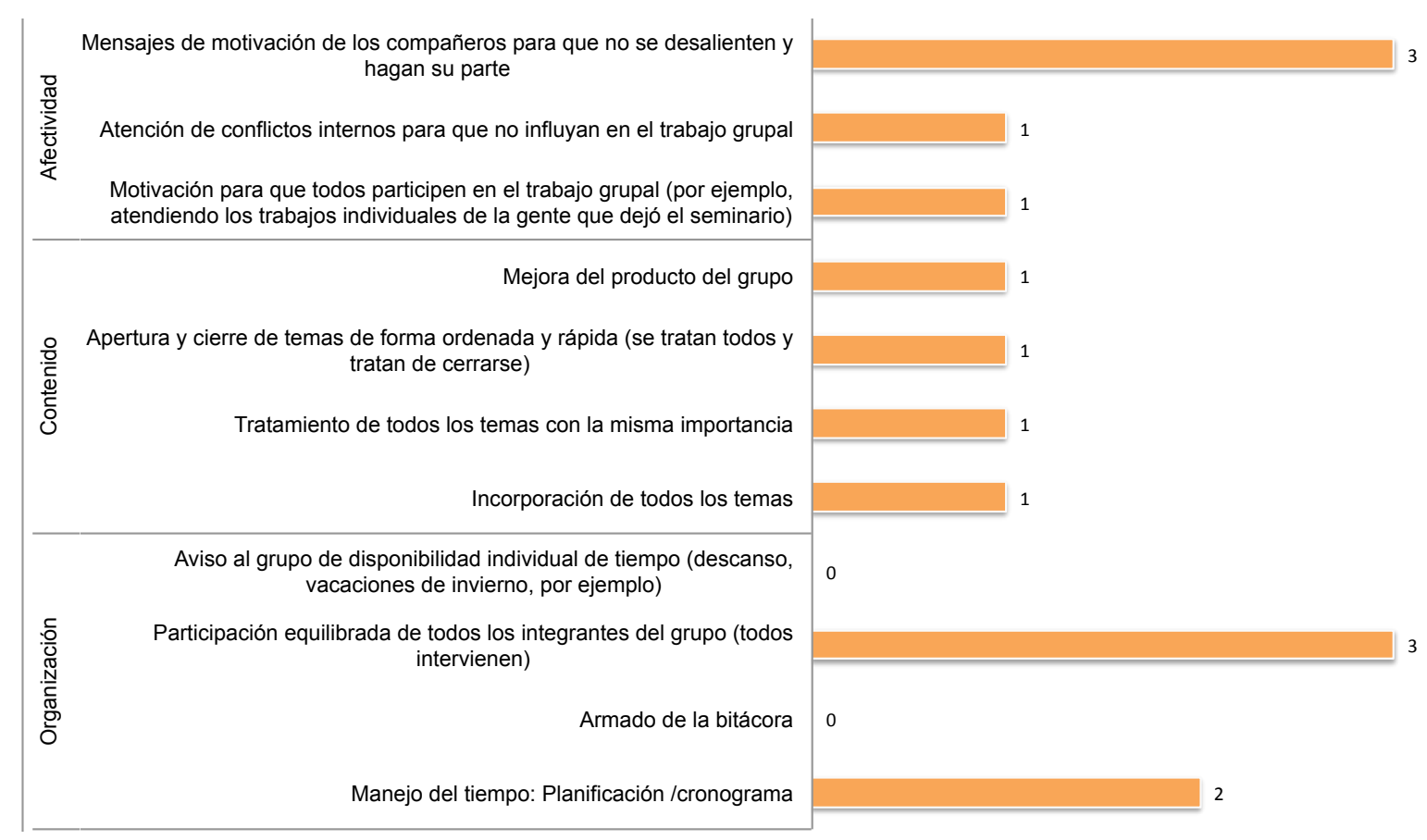

Figura 91: Decisiones tomadas a partir de la información del mirroring

En este caso también podía responderse más de una opción, o incluso todas, si eso hubiera ocurrido. La visualización de un corte por tipo de decisiones (organización, contenido, afectividad) se presenta en la figura 92.

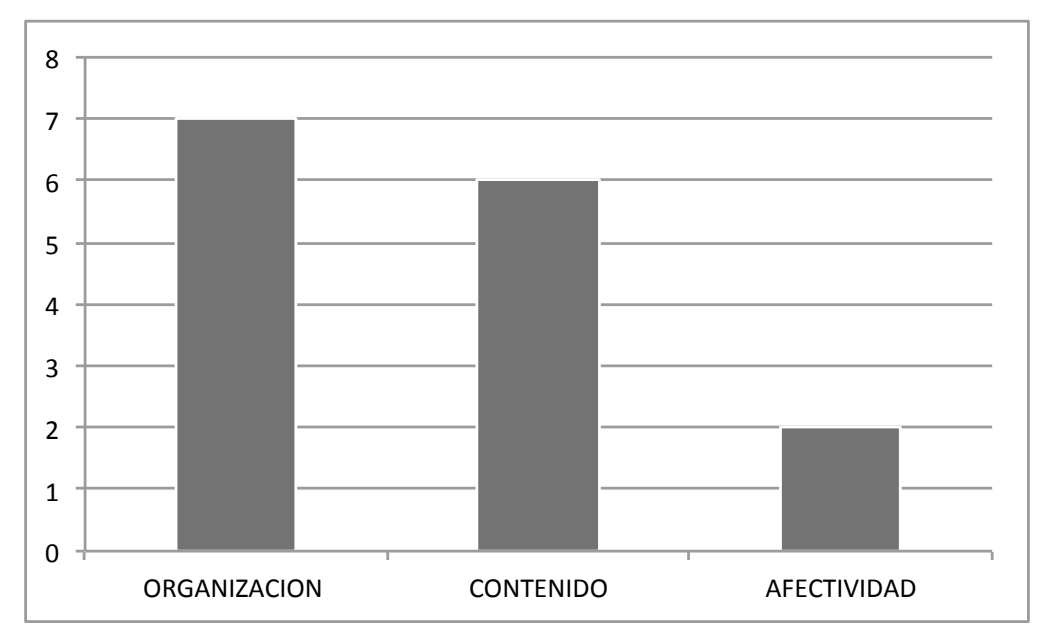

Figura 92: Decisiones tomadas a partir de la información del mirroring. Corte según tipo de decisiones

En la figura anterior se nota claramente que las decisiones de organización fueron las más impactadas por el conocimiento de la información sobre el proceso. Dentro de las decisiones de organización aparecen dos componentes fundamentales: el manejo del tiempo y la participación equilibrada de todos los integrantes del grupo. Así como no fue indicado como un factor de presión el reloj que marcaba el tiempo restante para entregar la tarea, el mirroring si afectó la planificación del tiempo restante. Respecto de la participación de todos, era un requerimiento de la tarea colaborativa encomendada y, al parecer, pudo seguirse a través del sitio el devenir de esa 
participación a través del componente de información individual. En cuanto a las decisiones de contenido, todas fueron indicadas como impactadas por esta estrategia. Las decisiones en el campo de la afectividad que fueron impactadas por la información del mirroring fueron las de motivación: el conocer qué había hecho cada participante ayudó a dirigir los mensajes en función de conseguir un mayor involucramiento y actividad de todos. Lo que indicaron los estudiantes fue lo siguiente: En cuanto a la organización: "Me parece que lo principal fue organizar el tiempo de los integrantes para finalizar cuanto antes con las responsabilidades individuales"; "Permitió organizarnos teniendo en cuenta el tiempo disponible a fin de poder terminar el trabajo en los tiempos previstos. Además se debió tener el cuenta el elaborar una síntesis del tema de una integrante que había abandonado el curso". También sirvió como refuerzo del metaconocimiento acerca de las performances individuales: "Al ver los datos, aprecié en real medida lo baja que había sido mi participación en algunos momentos".

\subsubsection{Consolidación del impacto de la estrategia}

Esta opinión final se indagó a través de dos ítems. En la mitad del instrumento se preguntó: “¿Cuánto le sirvió tener la información de los indicadores que se identificaron para realizar el seguimiento en cada semana del trabajo colaborativo?". Las opciones de respuesta establecían la siguiente escala de frecuencia:

\section{1: NADA}

\section{5: MUCHO}

Las respuestas se presentan en la figura 93.

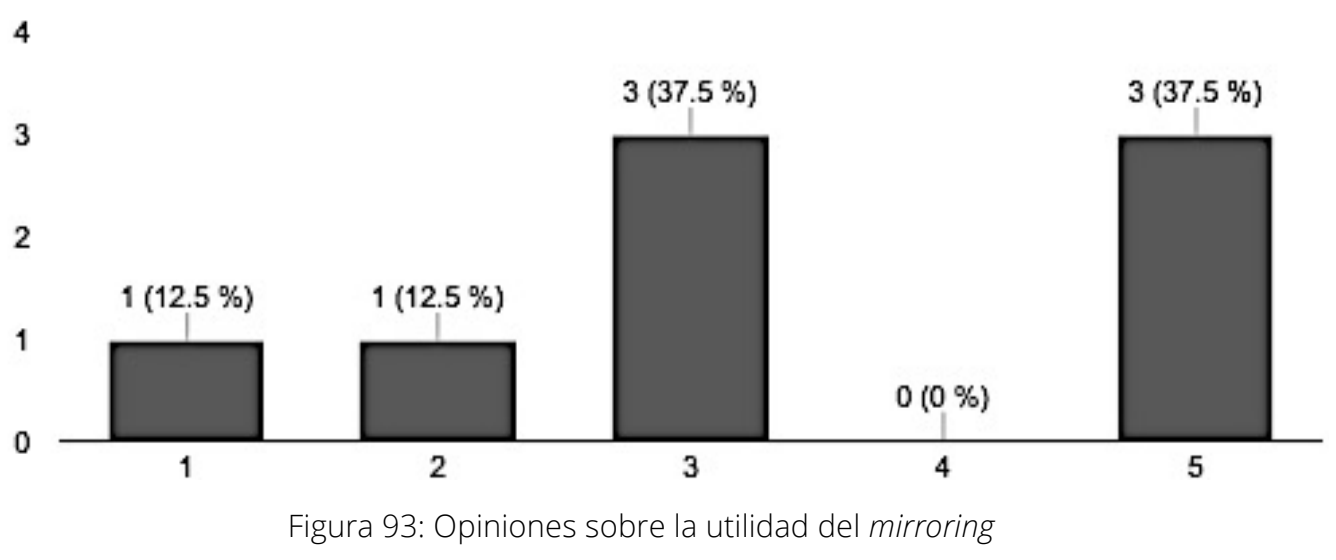

Las respuestas vuelven a consolidar la idea de la importancia que el conocimiento del proceso tiene sobre la organización e implementación de la estrategia individual y grupal (Dimitracopoulou, 2005; Jerman et al., 2001; Soller et al., 2005; Erickson \& Kellogg, 2000). E1 $60 \%$ de los estudiantes aseguran que esta información tiene mucha importancia. Analizando las respuestas cualitativas, se nota la presencia de los componentes de visibilidad ("Por mi parte pude ver cómo fueron decayendo mis aportes a lo largo del trabajo") y conciencia ("me pareció muy interesante, permite sin duda poner el claro los aportes de cada integrante y, al fin, del gruро).

Además, algunos comentarios avanzan sobre un componente de autorregulación central en los escenarios educativos: el del sostenimiento de la motivación. Se ve claramente en este comentario: "Era una manera de motivarme y entender que motivaba al resto. Si bien la información se obtenía de nuestro trabajo y, por lo tanto, era conocida por nosotros, la realidad 
es que tenerla clasificada, graficada y mostrada de la manera que se lo hizo, ponía en claro cómo se desempeñaba el grupo". Avanzando aún más en las posibilidades de intervención didáctica en grupos de trabajo colaborativo, una de las opiniones refuerza la estrategia de mirroring como modelo de decisiones de intervención docente en este tipo de trabajos. El comentario del estudiante fue: "Me sirvió para conocer estrategias de seguimiento y participación en grupos menos numerosos, posibles alumnos de un curso a distancia, y sus respuestas a consignas de trabajo grupal"; "Porque los docentes podían ver cómo estábamos trabajando. En un contexto de trabajo colaborativo, el docente a cargo del grupo debe reducir su intervención en el grupo permitiendo que los integrantes busquen y seleccionen las estrategias que les permitan alcanzar un objetivo".

Finalmente, el último ítem consignaba la una opinión final: "En su opinión ¿cuánto influyó en el trabajo colaborativo tener disponible la información del proceso en forma semanal?". Las opciones de respuesta establecían una escala de frecuencia como la que sigue:

\section{1: NADA}

\section{5: MUCHO}

Las respuestas se presentan en la figura 94.

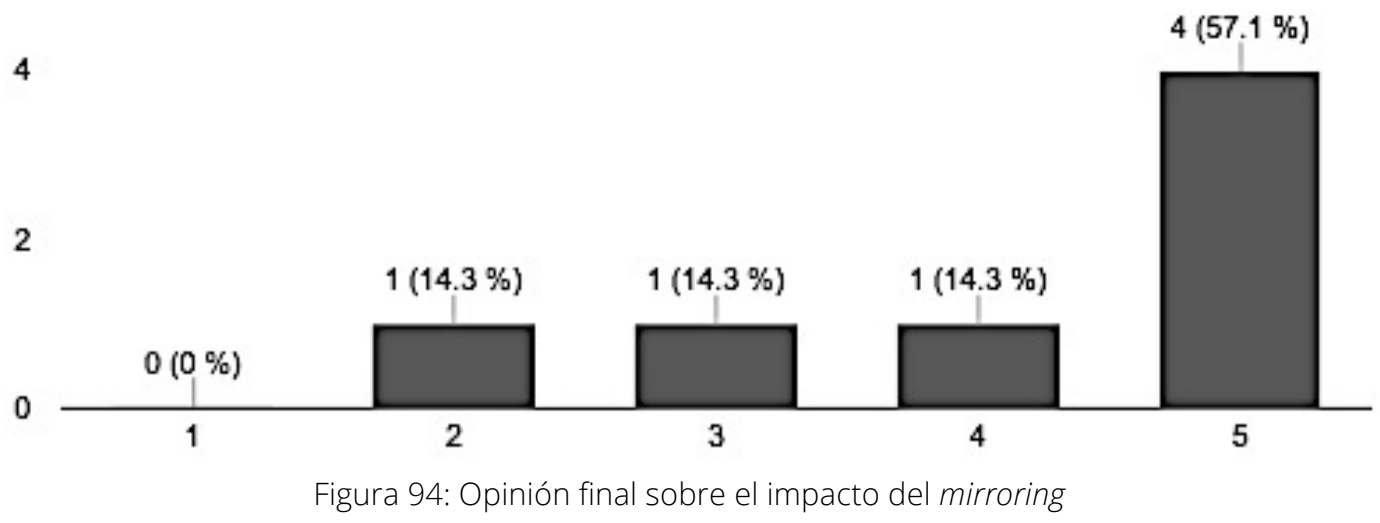

El resultado cuantitativo denota influencia. Un 57\% marcó una influencia alta. Las respuestas cualitativas visibilizan algunas de las categorías de información ya mencionadas. El valor de la disponibilidad de información: "Permite tener rápidamente una idea de cómo está funcionando el equipo en función de aportes". La regulación de la actividad individual para no parecer inactivo: "En mi caso influyó porque no me gusta mostrar falta de actividad". El manejo del tiempo: "Porque me daba un aviso de avances con respecto al tiempo establecido y la organización de las actividades teniendo en cuenta un cronograma". La relación entre el desempeño individual-grupal en el trabajo colaborativo: "En mi caso mucho, fue una forma de medir el esfuerzo de cada integrante".

Finalmente se requirió una reflexión final sobre el seguimiento del mirroring. En general, los comentarios sostienen el valor de tener disponible la información online y la influencia que esta información tiene sobre el trabajo individual y grupal. Hay dos opiniones, que merecen ser mencionadas:

Desde el punto de vista de conocimiento de esta estrategia: "Nunca había abordado este tema en particular, por lo que tenía una visión muy parcial, lo que me llevó a investigar más sobre ésto".

La visibilidad de la información del proceso como motivadora de las actividades del grupo: "El trabajo en equipo, sea mediado por tecnología o no, el trabajo colaborativo más 
aún, es realizado por personas. Cada persona tiene sus ocupaciones, intereses, problemas, compromiso, tiempo. Entonces puede que haya integrantes del grupo que toman mayor protagonismo o responsabilidad y motorizan el trabajo y lo llevan adelante. Eso se ve reflejado en los indicadores de seguimiento, que muestran esta solidaridad individual y el impacto en el grupo. Además, visibiliza la tarea de cada uno".

\subsection{Discusión sobre la eficacia de MetSCIn a partir de los resultados obtenidos}

Esta última sección del capítulo presenta algunas revelaciones que iluminan la discusión acerca de la eficacia de MetSCIn para realizar el seguimiento de actividades colaborativas en escenarios educativos, brindando a estudiantes, docentes y desarrolladores información útil para la toma de decisiones. La estrategia que ha permitido obtener esta información relevante es el eje de la metodología: la matriz de indicadores. La información que ha arrojado MetSCIN y que permite avanzar sobre su eficacia se refiere a: el análisis de la autorregulación a través de un autoinforme; el análisis cuantitativo y cualitativo de la interacción a través de la compilación y análisis de mensajes y la estrategia de mirroring y sus resultados. Se detallan a continuación.

\subsubsection{Autoinforme de autorregulación}

La implementación del autoinforme como primer instrumento de relevamiento permitió obtener información de gran interés. Sin embargo, se debe comenzar con una aclaración. Como se ha descripto en el capítulo 6 de este trabajo, el autoinforme que se administró para relevar las habilidades de autorregulación se manejó en el espectro de la autopercepción: se preguntó a los encuestados acerca de lo que perciben que hacen cuando estudian o se preparan para hacerlo. Este tipo de indagación posibilita la manifestación de algún sesgo de los que suelen aparecer en este tipo de investigaciones: los estudiantes (adultos) se sienten observados y responden según el criterio de "lo correcto", asumiendo el comportamiento que "se supone deberían hacer" ante cada una de las situaciones descriptas. Siguiendo a Manterola \& Otzen, (2015) es posible reconocer este sesgo como "efecto Hawthorne", que ocurre cuando los participantes de un estudio alteran su comportamiento (o sus respuestas en este caso) al saber que están siendo observados. Sin embargo, es posible extraer algunas conclusiones:

Motivación por el trabajo en grupo: la cantidad y calidad de trabajos en grupo que se habían realizado hasta el momento de comenzar el trabajo colaborativo (como fue descripto en este capítulo, apartado 8.4.) parecerían haber servido como escenario motivador, ya que los estudiantes se conocían suficientemente y reconocían a sus pares expertos para realizar la tarea colectiva.

Tensión proceso-producto: la preocupación por cometer errores no aparece como un tema importante en los mapas de tópicos analizados en la interacción, aunque si se manifiesta como una preocupación en los resultados del autoinforme. Una posible interpretación es la calidad de la tarea seleccionada, fuertemente vinculada con el diálogo.

Manejo del tiempo: se considera que el manejo del tiempo fue efectivo, en ambas cohortes. Esto se asocia a la duración de la actividad colaborativa (46 días) y su asincronía, lo que permite una mejor complementación de los tiempos individuales y los del grupo. Se visibiliza una fuerte tracción de los individuos hacia la tarea, al principio y al final de cada etapa. 


\subsubsection{Densidad de interacción. Análisis cuantitativo}

Resulta revelador analizar el diálogo en el trabajo colaborativo, según la propuesta de la metodología desarrollada en esta tesis. A partir de MetSCin pueden extraerse conclusiones interesantes mediante el análisis de este componente. Algunas conclusiones se presentan a continuación. En el caso de la e-actividad colaborativa, los 5 grupos se mostraron cohesionados y tuvieron un diálogo parejo al interior de cada uno. Una posible interpretación de este hallazgo podría ser la característica del seminario que sirve de contexto de la actividad colaborativa, en el que se intenta que todos los estudiantes dialoguen y se contacten entre sí. Ya sea en las actividades presenciales (encuentros mensuales) o en el trabajo mediado por el entorno WebUNLP, el diálogo es constante, no sólo en la interacción entre estudiantes, sino también con las docentes y tutora. Eso se trasluce en la media de densidad de interacción en la tarea completa de ambas cohortes, que se presenta en la tabla 40 de este capítulo. Una primera conclusión podría ser la siguiente: el contexto afecta e influye sobre la actividad colaborativa. Si los grupos se conocen y dialogan, se hace más eficiente la actividad grupal y puede disminuir la posibilidad de turbulencia.

Si la densidad de interacción se analiza por etapas de trabajo, coincide con lo que la literatura marca como hitos en la escritura colaborativa. Sharples et al. (1993) definen tres tipos de tareas en el proceso de escritura colaborativa: 1. tareas de organización, reparto y coordinación del trabajo a realizar; 2. tareas relacionadas con la comunicación entre los miembros del grupo y construcción grupal; y 3. tareas relacionadas con aspectos de la representación y formato del documento final. En los cinco grupos analizados se cumplieron las mismas etapas: en la primera etapa, de organización, hubo dos o tres personas que definieron los pasos a seguir (con pocos mensajes colectivos); en la segunda etapa se incrementaron los mensajes en el nudo de la resolución colaborativa; y en el final volvió a aparecer la presencia de dos o tres integrantes que se ocuparon del formato de la entrega final. Esto puede visualizarse en la figura 79, que muestra la densidad de interacción por etapa de ambas cohortes. Una segunda conclusión: la tarea se inicia en un integrante del grupo (o una díada), luego pasa a ser concerniente al grupo en general, y termina en manos de quien se ocupa de finalizarla y entregarla. El trabajo colaborativo empieza y termina en sus individualidades, pero el individuo que inicia la tarea ya no es el mismo una vez atravesada la experiencia de construcción colaborativa.

$\mathrm{Si}$ estas conclusiones respecto del aporte individual al grupo se relacionan con las habilidades de autorregulación, es consistente el dato de que quienes inician y cierran las cadenas de comunicación y tareas grupales han mostrado mejores estrategias de autorregulación en las entregas de ejercicios individuales, en las prácticas en los entornos virtuales de enseñanza y aprendizaje y en el ejercicio final de diseño. Así, quienes no han participado demasiado en la actividad colaborativa han presentado mayores problemas para terminar el seminario o lo han abandonado hacia el final. Como conclusión, se vislumbra las tareas grupales son iniciadas y finalizadas por los individuos, en función de sus propias estrategias de autorregulación.

\subsubsection{Tipos de mensajes y cohesión}

Siguiendo a MetSCIn, la identificación de categorías de mensajes permitió clasificar los diálogos, para extraer algunas conclusiones de interés. Pudo verse que las estrategias de planificación y de manejo de contenidos superaron (en todos los grupos) los componentes afectivos. En este sentido, los resultados coindicen con los obtenidos por Bacino et al. que en las conclusiones de su trabajo plantea: "se ha comprobado que la manera predominante de expresarse de los estudiantes en el trabajo colaborativo en línea está vinculada con la interdependencia positiva y la construcción de significado, más que con las relaciones psicosociales" (Bacino et al., 2015, pág. 148). 
Tomando en cuenta las etapas del trabajo colaborativo (inicio, desarrollo y cierre) se visualiza que hay muchos mensajes referidos a la planificación-organización al inicio, de contenido en el desarrollo de la tarea colaborativa y vuelven a aparecer mensajes de planificación al final, previo a la entrega. En conclusión, la planificación se entrama con el tratamiento del contenido en la actividad colaborativa. La planificación rodea, organiza, define la tarea y el producto final.

En el análisis de los tópicos trabajados, los cinco grupos se mostraron fuertemente cohesionados. Razones de esto podrían ser las condiciones de la macroactividad: la formación de los grupos (atendiendo a su grupalidad), las etapas del trabajo y las herramientas puestas a disposición. Además, la consigna propiamente dicha de escritura colaborativa, que apuesta a la cohesión. Este tipo de actividades se caracteriza, según Stein, et al. por "el carácter argumentativo, en el que los miembros de un grupo se consideran unos a otros como fuentes de conocimiento". Estos componentes parecen haber favorecido la actividad grupal. (Stein, et al., 1997, pág. 55).

En el anexo 4, donde se desagrega la actividad de cada grupo de cada cohorte, se visualiza cómo cada grupo manejó los temas de interés. En las bitácoras, promovidas por uno o dos participantes en cada grupo, pueden visualizarse las estrategias de autorregulación vinculadas al manejo de información y uso de herramientas. En la distribución de roles se definió quién o quiénes se harían cargo de la tarea de documentar el trabajo grupal. En tres de los cinco fue rotativa (semanalmente), los otros dos fue designado un responsable. En ambos casos, esta tarea fue sostenida por habilidades individuales.

\subsubsection{Impacto de la estrategia de mirroring}

En la metodología MetSCIn ocupa un espacio significativo la estrategia de seguimiento online de avances del grupo denominada mirroring. Los estudiantes de la cohorte 2016 consultados manifestaron que esta estrategia les resultó de gran utilidad. Estas opiniones refuerzan la idea de Erickson \& Kellogg (2000) acerca de la visibilidad, conciencia y responsabilidad que promueve entre los miembros de un grupo el conocimiento de su desempeño. Entre los hallazgos que pudieron relevarse, y que reforzarían la eficacia de la metodología, se encuentran los siguientes:

- Se comprobaron más mensajes asociados a la organización en la cohorte 2016 que en la del año anterior. Si bien no se encuentra un dato preciso acerca de que este evento tenga que ver necesariamente con la estrategia de visibilización, la carencia de mensajes referidos a la organización se mostró en el sitio de mirroring en las primeras semanas, y rápidamente el grupo comenzó a comunicarse en términos de planificación y organización de su tarea.

- Hubo control sobre lo que el sitio mostraba sobre la tarea individual: cada estudiante se aseguró de que el sitio mostrara exactamente lo que había hecho y reclamaron cuando no será así. Por ejemplo, en el grupo 1, en la tercera semana, uno de los estudiantes avisó que había trabajado en la bitácora y que el gráfico de temas abiertos no mostraba sus iniciales. En el grupo 2, en la última semana, un estudiante indicó que había enviado dos mensajes al foro y no se reflejaba en el informe de desempeño individual.

- Sin embargo, no se constató un mejor rendimiento en estos estudiantes, ni en el trabajo colaborativo ni en el trabajo final y cierre del Seminario. Esto condice con los trabajos analizados en la tabla 11 del capítulo 4 (Zumbach, Muehlenbrock, Jansen, Reimann, \& Hoppe, 2002; Jerman, 2004; Nakahara, Kazaru, Shinichi, Yamauchi, 2005; Vassileva, Cheng, Sun, \& Han, 2005) en los que se marcaba que 
los participantes del trabajo colaborativo que podían ver sus resultados traducidos en indicadores, se preocupaban más por la forma (que se vea lo que hicieron, que los cuadros o gráficos indicaran mucha actividad) que por el contenido de la tarea.

Estos puntos permiten visibilizar la cantidad y calidad de información que fue posible recuperar y analizar a partir de la implementación de MetSCIN en cada una de las etapas del trabajo colaborativo. MetSCIn ha permitido echar luz sobre aspectos del trabajo individual y grupal que, en general, quedan ocultos en los espacios de enseñanza. Estos aspectos han podido ser visibilizados y analizados tanto por la implementación de la metodología en sí como por la trazabilidad y reconstrucción de la información que posibilitan las herramientas informáticas.

\subsection{Conclusiones del capítulo}

Este capítulo presenta el estudio de caso que se utilizó para aplicar MetSCIn y valorar su eficacia en el seguimiento del trabajo colaborativo y se adelantaron algunos resultados del trabajo como marco de discusión de la eficacia de la metodología.

En la primera parte, se presentó la justificación metodológica de la elección de la metodología de estudio de caso. Se presentó el contexto de construcción e implementación del estudio de caso en la Maestría de "Tecnología Informática aplicada en Educación" de la Facultad de Informática de la Universidad Nacional de La Plata y se describió la e-actividad colaborativa.

En la segunda parte se presentaron los resultados del estudio de caso, en los siguientes ejes:

- Conformación del grupo de estudio. Información de entrada de los estudiantes del seminario de Educación a Distancia, de las cohortes 2015 y 2016.

- Hallazgos del autoinforme de autorregulación. Análisis de la información contrastando ambas cohortes.

- Análisis del trabajo colaborativo comparando las cohortes 2015 y 2016: análisis cuantitativo y cualitativo, en las dimensiones individual y grupal.

- Impacto de la estrategia de mirroring en la cohorte de estudiantes 2016.

- Discusiones sobre la eficacia de MetSCIn, como metodología de seguimiento del trabajo colaborativo.

En referencia a la conformación del grupo de estudio: antes del inicio del seminario de "Educación a Distancia" se contaba con información significativa respecto del grupo de estudiantes. En este capítulo se ha presentado la composición por género, profesiones, lugar de procedencia y formación y experiencia docente.

Luego se presentó una síntesis de los hallazgos del instrumento de autorregulación individual administrado. Los resultados mostraron regularidad entre las cohortes 2015 y 2016 en los siguientes aspectos:

a. Los estudiantes encuestados manifiestan iniciar las tareas con una alta motivación, pero luego les cuesta mantenerla en el proceso, más aún si existen obstáculos o la tarea parece estar fuera de su zona de confort.

b. En cuanto al proceso de aprendizaje, existe un protagonismo del proceso sobre el resultado, a la vez que un alto porcentaje de ambas cohortes manifiesta que teme cometer errores. 
c. EI manejo del tiempo parece ser efectivo. Sin embargo, la tendencia a procrastinar es alta. Esta conducta se ha notado en el diferimiento de entrega de algunos trabajos intermedios en el seminario, y hasta en la presentación del trabajo final.

d. Un tema de interés para este trabajo, que se retomará en las conclusiones con mayor profundidad, es la autopercepción acerca de los tipos de interacción que se generan durante el proceso de aprender. Un alto porcentaje de los encuestados manifiesta que interactúa sin dejar rastro (lo que Sutton, 2000 en Friesen, 2013 menciona como interacción vicaria y fue presentado en el capítulo 2, sección 2.2.1.1. "Tipos de interacciones"). En los tópicos del trabajo colaborativo pudo corroborarse este tipo de interacción. Se volverá sobre esta relación en las conclusiones de la tesis.

e. Finalmente, aparece una inconsistencia respecto de la valoración que los estudiantes hacen del trabajo grupal y colaborativo en la encuesta inicial (que puede verse en la figura 66, donde la descripción y justificaciones que mencionan coinciden con la teoría en este aspecto) y la práctica como integrantes de un grupo de trabajo. Los estudiantes hacen una alta valoración del trabajo colaborativo. Sin embargo, en la afirmación que sostiene: "Cuando trabajo en equipo me limito a hacer mi parte: si todos hacemos nuestra parte, el equipo funciona", entre el $54 \%$ y el $61 \%$ de las respuestas mostraron que los estudiantes dicen que hacen efectivamente ésto cuando integran un grupo. Más allá de este hallazgo de aparente inconsistencia entre la valoración conceptual del trabajo colaborativo y lo que los encuestados dicen que hacen, la práctica grupal resultó exitosa. Tal vez esta baja valoración de la colaboración en la práctica pueda ser una de las posibles explicaciones de la escasa argumentación que se demostró en la construcción grupal, lo que se corrobora en el promedio de argumentos por mensajes que se presentan en las tablas 42,43 y 44 y en la figura 85.

En cuanto a la descripción del trabajo colaborativo, se analizaron cinco grupos de trabajo: 3 de la cohorte 2015 y 2 de la cohorte 2016. Se presentaron en este capítulo los resultados compilados por cohorte. Los resultados desagregados por grupo se ofrecen en el anexo 4 .

En cuanto a la dimensión individual del estudio, se comenzó el análisis por la densidad de interacción. Más allá de las herramientas que cada grupo utilizó (foro, mensajería o GoogleDocs) se estima equivalente la interacción entre los grupos. La densidad de interacción por sub etapas del trabajo colaborativo fue pareja, con un mismo patrón: pocos mensajes al inicio, muchos e incrementándose en el nudo de la resolución colaborativa y uno o ninguno luego de la entrega, en el momento de recibir los resultados de la evaluación de los docentes. Salvo en la cohorte 2016, que la estrategia de mirroring produjo algunos mensajes con posterioridad a la entrega (en la etapa de post entrega).

Si bien el total de la comunicación no varía significativamente, es interesante visualizar las variaciones cualitativas. Se hizo un corte por tipo de mensajes, dividiendo las interacciones en mensajes de organización, contenido y afectividad. Se notó que los mensajes de planificación se mantienen estables, mientras que en el tratamiento del contenido y componentes afectivos comienza a verse la idiosincrasia de cada grupo, como un sistema de integración de los componentes individuales.

Finalmente, en el análisis de la producción grupal como una unidad, se analizaron y compararon los grupos según de los indicadores propuestos en MetSCIn: conexión semántica, cohesión de la comunicación y argumentación.

En cuanto a la conexión semántica, se tomó como unidad de análisis los mapas de tópicos trabajados por cada grupo. Se verificó que los cinco grupos trabajaron sobre los mismos temas, fuertemente asociados a la consigna a resolver. En este capítulo se ha presentado un análisis completo de cómo funcionó cada tema en cada grupo. Una síntesis podría ser: 
- los tópicos fueron abiertos y cerrados por una persona en particular (incluso, la misma persona abrió más de uno y hasta todos los tópicos).

- la herramienta no tuvo un peso significativo: los temas se abrían y cerraban por cualquiera de las herramientas utilizadas. Aunque se generaba una especie de "espejo" en las herramientas usadas para seguir la cadena de interacción: se hacía algo (por ejemplo en GoogleDocs) y se avisaba al grupo por el foro o mensajería de WebUNLP, explicitando exactamente qué se había hecho. Esto tuvo un aporte significativo en términos de metacognición grupal y se notó en el análisis de las bitácoras de cada grupo.

- se comprobó un uso importante de la herramienta de videoconferencia en el grupo 1 de la cohorte 2015, que tenía la mayor dispersión geográfica (véase la figura 107 del anexo 4). Se reunían semanalmente mediante videoconferencia usando HangOut. Las minutas de cada reunión funcionaron como memoria grupal y formalización de los compromisos asumidos, agenda y registro metacognitivo.

Se notó un alto grado de cohesión en los cinco grupos. Volviendo al análisis de los mapas de los tópicos trabajados, no hubo líneas de interacción off topic (fuera del contenido) ni off task (fuera de la tarea).

El promedio de argumentos por mensajes fue bajo, sobre todo en los tipos de argumentos de calificador (Qualifier) y refutación (Rebuttal). Esta situación muestra una alerta acerca de la construcción colaborativa, en términos de compartir o discutir ideas. Alguien presentaba una idea (Argumento o Claim), con su justificación (Evidencia o Ground) y era aceptada rápidamente, sin mayor contra argumentación.

Finalmente, y como aporte diferencial de la cohorte de 2016, se presentaron los resultados de las opiniones acerca del impacto que la estrategia de visualización de información de proceso tipo mirroring ha tenido sobre los dos grupos de trabajos de 2016. Se detallaron los resultados por cada una de las categorías de indagación. Los comentarios fundamentan el valor la disponibilidad y visibilidad de la información online y la influencia que esta información tiene sobre el trabajo individual y grupal. Se relevaron dos escenarios en los que el conocimiento del proceso resulta de gran impacto para el trabajo: el sostenimiento de la motivación individual y la explicitación de la estrategia grupal como un metaconocimiento del grupo.

En la sección final de este capítulo se reservó un espacio para la discusión sobre la eficacia de MetSCin, haciendo especial referencia al tipo de información que permitió visibilizar, correspondiente a los objetivos de su creación.

Con este capítulo se cierra la segunda parte: "Marco metodológico y trabajo de campo". Se avanza hacia la parte final de este trabajo: "Conclusiones y trabajos futuros". 


\section{Tercera parte: Conclusiones y trabajos futuros}




\section{Capítulo 9: Conclusiones y trabajos futuros}

El presente trabajo ha tenido como objetivo conceptualizar los fenómenos de interacción e interactividad y construir, aplicar y validar una metodología de seguimiento del trabajo colaborativo mediado por tecnología informática en escenarios educativos que se ha denominado MetSCIn.

En el apartado de conclusiones que ha cerrado cada capítulo se han adelantado algunas conclusiones particulares de cada tema. En este capítulo se presentan las conclusiones generales de la tesis y los trabajos futuros que de ellas se desprenden. Para facilitar la lectura se organizan según los compromisos de aporte de valor presentados al inicio de este trabajo. Inicialmente se expone la producción científica y académica vinculada con el desarrollo de este trabajo de tesis. Luego, se presentan las conclusiones divididas en tres bloques: conceptuales (relación entre interacción e interactividad y trabajo colaborativo. Componentes del trabajo colaborativo. Vinculaciones) y metodológicas (comentarios sobre la metodología MetSCIn y el estudio de caso no incluidos en la discusión del capítulo anterior). Finalmente se describen los trabajos futuros derivados del proceso de investigación.

El recorrido conceptual propuesto para este capítulo es el siguiente:

\section{PRODUCCION CIENTIFICA Y ACADEMICA}

9.1. Producción científica y académica en relación con la tesis

II. CONCLUSIONES DESDE EL PUNTO DE VISTA CONCEPTUAL

9.2. Conceptualización de interacción-interactividad

9.3. Componentes del trabajo colaborativo. Vinculaciones

III. CONCLUSIONES DESDE LA PERSPECTIVA METODOLOGICA

9.4. Construcción de indicadores de MetSCIn

9.5. Conclusiones del estudio del caso no incluidas en el capítulo anterior

9.5.1. Uso de herramientas

IV. TRABAJOS FUTUROS

9.6. Avance en el campo de la interacción-interactividad

9.7. Autorregulación individual como pilar de la enseñanza y del seguimiento grupal

9.7.1. Derivaciones de la autorregulación para la enseñanza

9.7.2. Relación entre la autorregulación individual y grupal

9.8. Prototipo de una herramienta de mirroring sobre IDEAS 


\section{Producción científica y académica}

\subsection{Producción científica y académica en relación con la tesis}

Se presentan en esta sección los trabajos científicos y académicos por año y tipo de trabajo, desde el año 2012 al 2016. Se comienza por los más antiguos para mostrar el avance en el tratamiento de los temas.

\section{Año 2012}

Publicaciones en revistas con referato

Artículos en Congresos
Sanz, C. V., \& Zangara, A. (2012). "El desarrollo de los foros en el marco de las e-actividades en una propuesta de educación mediada". TE \& ET. Nro. 7. Págs. 29-35.

Zangara, A. \& Sanz, C. (2012) "Aproximaciones al concepto de interactividad educativa". En Actas jAUTI 2012 | I Jornadas de Difusión y Capacitación de Aplicaciones y Usabilidad de la Televisión Digital Interactiva.

Sanz, C. \& Zangara, A. (2012). "La escritura colaborativa como una eactividad”. En XVIII Congreso Argentino de Ciencias de la Computación.

Sanz, C., Zangara, A., \& Manresa-Yee, C. (2012). "E-activities in teaching processes using ICTS collaborative activity as a case study". EDULEARN12 Proceedings. Págs. 2034-2041.

Cursos, Seminarios, Talleres
Seminario de postgrado intensivo sobre "Clasificación de actividades en propuestas didácticas: las e-actividades" dictado en el primer semestre de 2012 para los docentes de la Facultad de Informática de UNLP.

\section{Año 2013}

Publicaciones en revistas con referato

\section{Artículos en Congresos}

Sanz, C., Zangara, A. (2013) "Las e-actividades en el proceso de enseñanza con TICs. Actividad colaborativa como caso de estudio". En: González, A. y otros: E-book del Programa de Educación a Distancia de la UNLP. Editorial: EUNLP-1a ed. La Plata: Universidad Nacional de La Plata, 2013. E-Book. ISBN 978-950-34-0952-7

Zangara, A., \& Sanz, C. V. (2013). "Aproximaciones al concepto de interactividad educativa". En I Jornadas Iberoamericanas de Difusión y Capacitación sobre Televisión Digital Interactiva.

Zangara, A., \& Sanz, C. "Aproximaciones al concepto de interactividad educativa, en tiempos de la tecnología digital". En $6^{\circ}$ Seminario Internacional de Educación a Distancia "La educación en tiempos de convergencia tecnológica. RUEDA.

Sanz C., Zangara A., Manresa-Yee C. (2013) "La inclusión de e-actividades como estrategia de enseñanza a distancia en un curso de postgrado. Experiencia en el curso "Interfaces avanzadas". En VIII Congreso sobre Tecnología en Educación \& Educación en Tecnología (Santiago del Estero, 2013). 


\section{Año 2014}

Publicaciones en libros

Conferencia
Sanz, C., \& Zangara, A. (2014). "La formación de docentes en el ámbito de la Educación a Distancia: aspectos epistemológicos y metodológicos. Análisis a partir de un caso". Signos Universitarios. Págs. 487-497.

Charla abierta para los docentes de la Universidad de La Plata sobre "Buenas prácticas para la enseñanza y el estudio a distancia", ofrecida desde la Dirección de Educación a Distancia y Tecnologías Informáticas aplicada en Educación de la Facultad de Informática de la UNLP.

\section{Año 2015}

\section{Artículos en} Congresos
Zangara, A., \& Sanz, C. V. (2015). "Importancia de las estrategias de autorregulación en el aprendizaje y sus derivaciones para la enseñanza". En X Congreso sobre Tecnología en Educación \& Educación en Tecnología (Corrientes, 2015). Págs. 79-89.

Zangara, A., Sanz, C. (2015). "Collaborative learning work. Evaluation model using the ethnographic metodologhy of "Analysis of social network”. EDULEARN15. Proceedings. Págs. 5373-5380.

\section{Año 2016}

\section{Artículos en} Congresos
Zangara, A., \& Sanz, C. V. (2016). "Building traceability indicators in collaborative processes using digital technology in educational settings. Presentation and comparison of educational and technological perspectives". En INTED2016. 10th anual International Technology, Education and Development Conference. Valencia (España), 7-8 de Marzo, 2016. Págs. 7428-7437.

Hernández Gallardo, S., Sanz, C., Cano Guzmán, C, Naiouf, M. (Compiladores) (2016) "Aplicación de la tecnología en el aprendizaje Casos de Argentina y México". Editorial de la Universidad de Guadalajara. Capítulo 1: "Interacción tangible. Aplicaciones en el escenario educativo. El caso de ITCOL".

Zangara, A; Sanz, C; Dieser, P. "Modelo de seguimiento de una actividad de foro en la enseñanza universitaria. Aplicación en un estudio de caso." XXII Congreso Argentino de Ciencias de la Computación. San Luis. Octubre de 2016. Págs. 431-440.

\section{Año 2017}

\begin{tabular}{ll}
\hline $\begin{array}{l}\text { Publicaciones en } \\
\text { revistas con }\end{array}$ & Zangara, A. \& Sanz, C. (2017) "Displaying the collaborative process as \\
referato & meta-knowledge. Description of a mirroring strategy and its results". En: \\
& Communications in Computer and Information Science (CCIS) vol. 790. \\
& Springer. En proceso de edición.
\end{tabular}

Artículos en Congresos
Zangara, A., \& Sanz, C. V. (2017). "Visualización del proceso colaborativo como metaconocimiento. Descripción de una estrategia de mirroring y sus resultados". En CACIC 2017. XXIII Congreso Argentino de la Computación. La Plata, Argentina. 9-13 de Octubre 2017. Págs. 475486. 


\section{Conclusiones desde el punto de vista conceptual}

\subsection{Conceptualización de interacción-interactividad}

Como se ha presentado en las conclusiones del capítulo 2, interacción e interactividad tienen un mismo origen: el diálogo. El interés por la conceptualización de ambos términos obedeció a la necesidad de definir sus límites con vistas a una posterior operacionalización en la práctica.

Se definió, en coincidencia con autores significativos en la Ciencias de la Educación (Freire, García Aretio, Litwin y otros), que la interacción es la base de la comunicación. La educación es comunicación y la comunicación es interacción. En su relación con la tecnología, la interacción puede estar mediada por objetos simbólicos (lenguaje, software) o físicos (computadoras u otros artefactos). En el caso de la mediación por un programa y con un soporte artefactual, se la define como interactividad.

La interactividad es, entonces, un subtipo específico de interacción. Se define en este trabajo como interacción mediada por una herramienta y un programa: cuánto más pueda la persona modificar ese programa, mayor será el grado de interactividad que éste muestre. En las situaciones de interactividad también hay interacción (mediada por la interactividad del programa) con los diseñadores, desarrolladores y equipo que está detrás de cada aplicación informática.

\subsection{Componentes del trabajo colaborativo. Vinculaciones}

La presentación del mapa conceptual del epílogo de la primera parte de este trabajo tuvo como objetivo mostrar la complejidad del trabajo colaborativo y sus componentes, vinculados con diferentes disciplinas de abordaje. Desde el punto de vista instruccional, los componentes organizativos de la actividad colaborativa influyen sobre el proceso y resultado de la actividad.

Sería posible decir, entonces, que en el trabajo colaborativo mediado por tecnología informática en escenarios educativos tienen influencia los siguientes componentes ${ }^{20}$ :

- el grado de cooperación-colaboración, retomando el concepto de trabajo colaborativo abordado en el capítulo 2 de esta tesis y los grados de trabajo grupal no colaborativo que se describen;

- la macroestructura de la actividad, vinculada a la cantidad de grupos e integrantes por cada uno y su potencial grupalidad y el tiempo destinado a la actividad;

- la microestructura de la actividad, vinculada al tipo de consigna; y

- las herramientas informáticas puestas a disposición de estudiantes y docentes.

Cada componente tiene su importancia en la definición acerca de qué valorar y cómo. Sin embargo, a la hora de definir qué componente tiene influencia sobre los demás, podría decirse que hay dos componentes que configuran el resto: 1. la macroestructura de la actividad (grado de cooperación-colaboración, formación de grupos según grupalidad, cantidad de grupos y cantidad de integrantes de cada uno, etapas o fases de la actividad, herramientas puestas a disposición o el uso de un entorno virtual diseñado específicamente para la colaboración) y $\mathbf{2}$. la consigna.

${ }^{20}$ El orden de presentación de estos componentes no significa relevancia. Todos tienen influencia. 
En la macroestructura pueden visualizarse grados de tensión:

a. la intervención del docente;

b. los medios de diálogo puestos a disposición (si será libre o estructurado a partir de alguna herramienta);

c. el manejo de los tiempos -sincrónico o asincrónico o ventanas intermedias-; y

d. el grado de libertad con el que cuenten los miembros del grupo en general y la coordinación del trabajo grupal en particular.

La consigna de la actividad pertenece a la microestructura y tiene una gran importancia. En este sentido, se retoma a Dimitracopoulou (2005) en cuanto a la significatividad del tipo de actividad que se pone en juego para que el grupo resuelva. La importancia de la consigna de trabajo es un tema recurrente, no sólo para la actividad colaborativa, sino para la Didáctica en general. Dimitracopoulou (2005) considera dos clases de actividades cooperativas-colaborativas diferentes que, a su vez, modifican el tipo de trabajo a realizar. Estas dos clases de actividades son:

- Actividades orientadas a la acción: se trata de consignas más cerradas, con una o pocas respuestas correctas, en las que el grupo tiene que dialogar para encontrar el camino de la solución. Construye, dialoga, presenta alternativas, maneja variables, pero lo que se espera que haga es que en algún momento cierre esos caminos y presente la o las respuestas correctas. El diálogo en este tipo de consignas, si bien es libre, está enmarcado por la solución unívoca del problema.

- Actividades orientadas al texto: en este tipo de actividades la construcción no está predefinida de antemano. La consigna marca un eje, pero nadie sabe (ni el grupo ni los docentes) dónde se espera que se llegue exactamente. No hay una "respuesta correcta". La e-actividad de escritura colaborativa que se enmarca en el estudio de caso de esta tesis se corresponde con este segundo tipo de consigna.

Así, la consigna o tarea a realizar grupalmente determina: a. el foco de la tarea grupal -la construcción del grupo como protagonista o la tarea como centro-; b. las habilidades cognitivas que se ponen en juego y su vinculación con la tarea grupal.

Este modelo, entonces, representa un eje, una espacie de brújula que orienta a quien esté interesado en valorar el trabajo colaborativo. Para su mejor uso deben tenerse en claro, inicialmente, los componentes de la macroestructura de la actividad y la consigna propiamente dicha. Luego, se debería recorrer cada etapa instruccional del trabajo para revisar qué se quiere valorar y cuál es la mejor forma de llevarlo adelante.

\section{Conclusiones desde la perspectiva metodologica}

\subsection{Construcción de indicadores de MetSCIn}

La construcción de la metodología de seguimiento del trabajo colaborativo fue un compromiso central de este trabajo. En ese sentido, se diseñó MetSCIn, con los componentes que fueron presentados en el capítulo 6: objeto (con sus dimensiones de análisis), etapas, actores, modelo teórico subyacente, indicadores, espacios de construcción colaborativa y seguimiento del 
trabajo, instrumentos y tecnología involucrada. En centro de esta metodología estuvo constituido por la matriz de indicadores de colaboración, que fue sometida al juicio de expertos (desarrollado en detalle en el capítulo 7). Se considera que la matriz resultó válida a la hora de valorar el trabajo colaborativo, ya que:

-Considera e integra lo presentado en el marco conceptual en referencia al estado del arte en el tema de trabajo colaborativo mediado por tecnología informática;

-Fue confirmada por el juicio de un grupo de expertos de diferentes áreas e integró aquellos aspectos que los expertos sugirieron;

-Ha permitido realizar un seguimiento detallado del trabajo colaborativo en dos cohortes contrastadas. La información pertinente a este seguimiento ha formado parte de la discusión final del capítulo anterior en el apartado 8.11. "Discusión sobre la eficacia de MetSCIn a partir de los resultados obtenidos";

-Ha posibilitado obtener información online del proceso, a través de la estrategia de mirroring, que tuvo un impacto positivo en el trabajo colaborativo de los estudiantes y arrojó más y mejor información para la intervención docente.

\subsection{Conclusiones del estudio del caso}

En el apartado final del capítulo anterior se incluyen los resultados más significativos a los que ha permitido arribar MetSCIn. En la sección 8.11. "Discusión sobre la eficacia de MetSCIn a partir de los resultados obtenidos" se abren líneas de discusión sobre los puntos clave que la metodología ha permitido visibilizar:

- análisis de la autorregulación a través de un autoinforme;

- análisis cuantitativo de la interacción (densidad);

- análisis cualitativo de la interacción según tipos de mensajes y cohesión; e

- implementación de mirroring y su impacto.

Además, MetSCIn permitió extraer algunas conclusiones sobre el uso de herramientas informáticas en la construcción colaborativa que se presentan seguidamente.

\subsubsection{Uso de herramientas}

El seguimiento de la colaboración usando MetSCIn posibilitó también analizar el uso de las herramientas informáticas. Permite concluir, una vez más, en la importancia del diálogo como motor de la actividad grupal colaborativa. En los grupos analizados, las herramientas fueron transparentes a este diálogo y su uso diverso no mostró diferencias significativas.

Por ejemplo, en cuanto al uso de repositorios de materiales: en la cohorte 2015, el grupo 1 guardó los documentos producto del trabajo individual previo en la red (usando una carpeta compartida en GoogleDrive, que era conocida sólo por los integrantes del grupo); el grupo 2 usó el repositorio de documentos de WebUNLP, accesible sólo para el grupo; y el grupo 3 no usó ni el repositorio ni la nube: los intercambió por la mensajería de WebUNLP (como archivo adjunto) $\mathrm{y}$, se supone, que cada integrante del grupo los guardó en sus propios dispositivos o en su propia red. En la cohorte 2016, el grupo 1 usó el repositorio del entorno WebUNLP y el grupo 2 usó un repositorio externo (Dropbox). En el trabajo colaborativo no se notaron diferencias en cuanto al manejo de archivos ni problemas en el acceso a esa información. 
Otra cuestión interesante fue el uso de los documentos compartidos en GoogleDocs. Los grupos usaron diferente cantidad de archivos en GoogleDocs con diferentes usos. Todos lo usaron para cumplir con su función específica: escribir juntos en el mismo espacio. Pero, además, dos de los cinco grupos lo usaron para compartir la agenda de trabajo colectivo y dos grupos lo convirtieron en el espacio de diálogo, ya que compartían opiniones (con la forma asuntos abiertos) en el mismo espacio en el que escribían. Más allá de este diferente uso de las herramientas, no se notaron diferencias significativas en relación con la producción final.

Es interesante analizar otra tarea puntual, que dos de los cinco grupos cumplieron al momento de tratar cuestiones previas a la entrega: usar el voto para definir alguna decisión semántica o de diseño gráfico. Uno de los grupos usó la herramienta de Doodle; otro votó por la mensajería y alguien llevó la cuenta (con un método no identificado, que podría haber sido offline, el tradicional método de lápiz y papel). Tampoco se notaron diferencias significativas, tomando en cuenta la calidad del producto final y la recuperación del proceso.

Otra cuestión significativa es el entramado interactividad-interacción que apareció muy marcado en los cinco grupos. Por cada tarea o decisión que se iba tomando en alguno de los espacios comunes, el integrante del grupo que lo había llevado adelante se ocupaba de explicar la tarea o decisión a sus compañeros. Lo hacía mediante el canal de comunicación establecido como espacio de interacción: la mensajería o el foro de WebUNLP, o el documento compartido en GoogleDocs. Esta práctica, como una especie de metatarea fue altamente significativa para el grupo, ya que permitió documentar quién hizo qué, cuándo y para qué. Esta memoria grupal resultó fundamental para la confección de la bitácora. Otro ejemplo de esta memoria colectiva fueron las detalladas minutas que circularon en el grupo 1 de 2015 y 1 de 2016, con posterioridad a cada videoconferencia vía HangOut. Su seguimiento permitió reconstruir el itinerario del grupo. Se describieron acuerdos, desacuerdos y consensos. En cambio, en el grupo 3 de la cohorte 2015, en el que hubo reuniones presenciales entre sus integrantes, las minutas contaban las decisiones, pero no presentaban detalle alguno del intercambio anterior. Sería posible relacionar esta memoria grupal con la dispersión geográfica de cada grupo. El estar lejos geográficamente, y trabajar en diferente tiempo requiere documentar y explicitar los intercambios y las decisiones y eso compone una memoria grupal cuidadosa. El desarrollo de una memoria grupal, producto de la metatarea de explicitación de cada evento realizado individualmente configuró una buena práctica de trabajo colaborativo.

Esta metatarea de construcción de memoria grupal puede relacionarse con un tipo de interacción que se fue presentada en el capítulo 3 y resulta interesante analizar, no sólo para el trabajo colaborativo sino para la enseñanza a distancia en general: la interacción vicaria (Sutton, 2000 en Friesen, 2013). Esta recuperación metacognitiva, producto de la explicitación de cada actividad individual permitió que todos estuvieran al tanto de todo, más allá de los rastros que dejaran en cada espacio grupal que visitaban durante el trabajo. El trabajo grupal requiere comunicar, avisar, explicitar cada cosa que se lleva adelante: esto minimiza las posibilidades de invisibilizar la interacción. Si bien en el autoinforme apareció como una práctica recurrente, el propio trabajo colaborativo lo volvió visible. Se notó claramente quiénes estaban como espectadores, visualizando las decisiones del grupo, pero sin participar en ellas.

Finalmente, las prácticas relevadas darían indicios de que las herramientas no configuran las tareas: más allá de la herramienta con la que se las lleve adelante (digital o no) son las tareas las que configuran el trabajo grupal y prefiguran el uso de la herramienta. En este sentido, y atendiendo a que se trata de una afirmación a otra escala, Manuel Castells, en su paradigmático libro La sociedad red, ya había anticipado "no está demostrado que Internet cambie los comportamientos, sino que se amplifican y potencian [...]. No es Internet lo que cambia el comportamiento, sino que es el comportamiento lo que cambia Internet". (Castells, M., 2005 , pág. 138). En mayor o menor escala, son las personas quienes definen y configuran las herramientas a partir de prácticas de uso concretas y situadas que las resignifican (Wertsch, 1998). 


\section{Trabajos Futuros}

En algunas líneas de trabajo aparecen áreas de vacancia que sería deseable que se continúen. Algunas, incluso, forman parte de proyectos que se están trabajando en la Facultad, como proyectos de investigación o tesis de Maestría. Se describen a continuación.

\subsection{Avance en el campo de la interacción-interactividad}

Como se ha expuesto en las conclusiones de este trabajo, conceptualizar ambos términos es el primer paso para operar sobre ellos. En este sentido, podría avanzarse hacia la definición escalas o grados de interacción e interactividad que permitan, por ejemplo, valorar la calidad de un software o de una propuesta educativa usando tecnología informática.

En este sentido, en los capítulos 2 y 3 de esta tesis se han presentado algunos modelos que operan sobre estos grados. En el capítulo 2 se han descripto el modelo de grados de interacción. Chi (2009) considera la interacción desde una perspectiva individual, como un grado superior de aprendizaje autorregulado, que permite aprender de y con otros. Se describió, también, el modelo que presenta Spermon et al. (2014), tomando de Kahn \& Mentzer (1996). Este modelo demarca cuatro grados, que integran interacción y colaboración. También en el capítulo 2 se destinó un espacio para el tema de niveles de interactividad. Se tomó el modelo de Williams et al. (1998), quienes definen tres niveles de interactividad pedagógica, según la tecnología de soporte utilizada en los materiales: pasivo, moderado y activo. Este modelo toma el soporte y lenguaje como criterio de definición de grados o niveles, asumiendo que todos los usuarios harían un uso más o menos similar de lo que las herramientas ofrecen.

De todas formas, en la literatura analizada no existe una métrica que permita comparar propuestas (educativas, lúdicas, de marketing, etc.) en cuando al grado de interacción e interactividad que propongan. Existen intentos de operar sobre este concepto. Por ejemplo, según Betrián, Hilera \& Pagés-Arévalo (2011), en el estándar IEEE LOM existe un metadato que intenta describir a los materiales digitales en este sentido y el vocabulario que especifica es tipo de interactividad: baja, media y alta. Sin embargo, a la hora de definir este metadado, no existe una métrica que permita explicitar con mayor exactitud dónde estarían los límites de cada categoría. Una razón del área de vacancia en este tema podría argüirse en la complejidad propia de la definición, comenzando por los modelos de comunicación que están en la base de ambos conceptos. En el caso de la interacción, habría que definir grados para medir la interacción en diferentes situaciones, según la comunicación se dé: uno a uno (persona o herramienta), uno a varios, o varios a varios. Los flujos de artefactos simbólicos (lenguajes, mensajes, gestos, etc.) en cada uno de estos escenarios de comunicación son tantos y tan disímiles que la definición de una métrica podría terminar reduciendo la complejidad del fenómeno y, entonces, dejaría de ser útil para su uso generalizado y no permitiría la comparación. En el caso de la interactividad, la relación sería 1 a 1 (persona-herramienta); sin embargo el carácter situado de las prácticas de interactividad (tomando en cuenta las características de la persona, sumadas a las del hardware y software, dentro del contexto) asimilan este fenómeno a la situación anterior: la métrica podría disminuir su complejidad a un nivel tal que se convierta en una medida estéril, con un uso demasiado reducido. 


\subsection{Autorregulación individual como pilar de la enseñanza y del seguimiento grupal}

Como se ha mencionado, la indagación de la autorregulación para mejorar la enseñanza no fue el foco de este trabajo. La idea fue trabajar sobre los criterios de grupalidad y analizar algunas participaciones individuales en el trabajo colaborativo dentro del marco de la distancia transaccional. No obstante, la información obtenida (y posible de obtener en el futuro, ya que el protocolo de autoinforme es uno de los aportes propios de esta tesis), permitiría profundizar en dos aspectos: las derivaciones de la autorregulación para la enseñanza y la relación entre la autorregulación individual y grupal.

\subsubsection{Derivaciones de la autorregulación para la enseñanza}

En este sentido sería necesario, como trabajos futuros:

a. Correlacionar las estrategias de autorregulación que los estudiantes dicen tener con su desempeño. Se han hecho algunos análisis preliminares en la discusión final y en las conclusiones del capítulo 8, pero no se ha profundizado en este sentido. Podría triangularse la información obtenida en la encuesta con indicadores de desempeño individual, en parejas $\mathrm{y}$ en pequeños grupos.

b. Incluir nuevas categorías de habilidades a estudiar: Son menos estudiadas las variables afectivas vinculadas a la resistencia a la frustración, el manejo de la ansiedad, la solidaridad, autoestima, entusiasmo, optimismo y pesimismo. En este caso, es imprescindible acudir a la interdisciplinariedad: contar con un psicólogo es fundamental para entender este rasgo de las personas, definir los conceptos, las métricas y los instrumentos.

\subsubsection{Relación entre la autorregulación individual y grupal}

En este campo, el gran tema es pensar a la autorregulación como una habilidad a nivel de grupo. El trabajo de aquí en más sería indagar cómo funcionan estas individualidades en la construcción grupal. Si bien se han anticipado algunas consideraciones en este trabajo, no se avanza hacia la conceptualización de autorregulación grupal.

\subsection{Implementación de MetSCIn con vistas al análisis de su confiabilidad}

Se ha implementado MetSCIn en dos grupos de estudiantes adultos, de postgrado y se han contrastado sus resultados. Sería deseable, atendiendo al análisis de confiabilidad de esta metodología, que se implemente en diferentes escenarios educativos: con estudiantes de diferentes edades, con diferentes tipos de actividades colaborativas y con diversas herramientas.

\subsection{Prototipo de una herramienta de mirroring sobre IDEAS}

Podría considerarse un trabajo futuro el desarrollo de una aplicación de mirroring en uno de los entornos de enseñanza y aprendizaje que se utilizan en la Facultad de Informática de la UNLP: IDEAS. Podría mostrar la información individual y grupal al interior de cada grupo e información comparada entre grupos e individuos. 
Se presentan algunas funcionalidades generales, según las siguientes líneas orientadoras:

- Qué información se visualizaría

- En qué momento del proceso de trabajo del grupo se visualizaría

- Qué perfiles de usuario se configurarían

- Qué relación habría entre los perfiles de usuario y la información: quién vería qué información.

- Cómo se actualizaría la información.

- De dónde se extraería la información.

- Qué reportes se podrían obtener. 


\section{Bibliografía}

Abascal González, J. (2000). La interacción persona-computador en los próximos 25 años. Novática: Revista de la Asociación de Técnicos de Informática, (145), 24.

Álvarez Ferrando, A., Kuz, A., \& Falco, M. (2013). Gephi: Análisis de Interacciones en un Foro, a través de ARS en el aula. TE \& ET.

Anastasi, A. \& Urbina, S. (1997). Study Guide [to] Psychological Testing. USA: Pearson Education/Prentice Hall.

Andriessen, J., Baker, M., \& Suthers, D. (Eds.). (2013). Arguing to learn: Confronting cognitions in computer-supported collaborative learning environments (Vol. 1). Springer Science \& Business Media.

Anzieu, D., \& Martin, J. Y. (1968). La dynamique des groupes restreints. PUF 12 ème édition Septiembre 2000.

Arango, M. L. (2003). Foros virtuales como estrategia de aprendizaje. Anexo 1. Universidad de los Andes. Departamento de Ingeniería de Sistemas y Computación. LIDIE. Laboratorio de Investigación y Desarrollo sobre Informática en Educación, Bogotá.

Avouris, N., Komis, V., Margaritis, M., \& Fidas, C. (2004, June). ModellingSpace: A tool for synchronous collaborative problem solving. In Proceedings of Int. Conf. on Educational Multimedia \& Telecommunications (pp. 381-386).

Avouris, N., Margaritis, M., \& Komis, V. (2004, August). Modelling interaction during smallgroup synchronous problem-solving activities: The Synergo approach. In Proceedings of ITS 2004 workshop on designing computational models of collaborative learning interaction (pp. 13-18).

Avouris, N., Dimitracopoulou, A., \& Komis, V. (2003). On analysis of collaborative problem solving: An object-oriented approach. Computers in Human Behavior, 19(2), 147-167.

Azuma R. (1997). “A Survey of Augmented Reality”. In Presence: Teleoperators and Virtual Environments. 6, 4 (August 1997),Pág. 355-385.

Bacino, Gustavo, Massa, Stella Maris y Zangara, Ma. Alejandra (2015) Aula extendida en la educación superior en Ingeniería. Una propuesta de aplicación en el área tecnológica básica de electrotecnia. Tesis de la Maestría de "Tecnología Informática aplicada en Educación". Facultad de Informática, Universidad Nacional de La Plata. En: http://sedici.unlp.edu.ar/handle/10915/45476. Consultado en Noviembre de 2017.

Bain, K. (2011). What the best college teachers do. Harvard University Press.

Bandura, A. (1986). Social foundations of thougth and action. USA: Prentice Hall.

Bandura, A. (1997). Self efficacy: the exercise of control. USA: Freeman. 
Barros, B., Verdejo, M. F., Read, T., \& Mizoguchi, R. (2002, April). Applications of a collaborative learning ontology. In Mexican International Conference on Artificial Intelligence (pp. 301-310). Springer Berlin Heidelberg.

Bateson, G. (1984). "El telégrafo y la orquesta". En: Winkin, Y. (Ed.). (1984). La nueva comunicación (Vol. 1). Editorial Kairós.

Beaufait, P., Lavin, R. S., \& Tomei, J. (2008). Online Collaboration: An Overview. En D. Harper (ed.), Education for a Digital World: Advice, Guidelines, and Effective Practice from Around the Globe (pp. 441-460). Vancouver: Commonwealth of Learning.

Betrián, D. P., Hilera, J. R., \& Pagés-Arévalo, C. (2011). ISO/IEC 19788 MLR: Un Nuevo Estándar de Metadatos para Recursos Educativos. IEEE-RITA, 6(3), 140-145.

Benkler, Y., \& Nissenbaum, H. (2006). Commons based Peer Production and Virtue. Journal of Political Philosophy, 14(4), 394-419.

Bertoni, A., Poggi, M. y Teobaldo, M. (1997) Evaluación: Nuevos significados para una práctica compleja. Buenos Aires: Kapelusz.

Blanco, N., Cuello, N., González, G., \& Penco, P. (2016). El discurso en entornos virtuales de aprendizaje: categorías de análisis de los desempeños escritos. En XXII Congreso Argentino de Ciencias de la Computación (CACIC 2016).

Bodemer, D., \& Dehler, J. (2011). Group awareness in CSCL environments. Computers in Human Behavior, 27(3), 1043-1045.

Bratitsis, T., \& Dimitracopoulou, A. (2006). Monitoring and analyzing group interactions in asynchronous discussions with the DIAS system. In Groupware: Design, implementation, and use (pp. 54-61). Springer Berlin Heidelberg.

Brown, J. S., \& Duguid, P. (2000). Social Life of Information. Cambridge, MA Harvard Bussines School Press.

Bruner, J. (1997). Realidad mental y mundos posibles. Madrid: Gedisa.

Burbules, N. C. (1999). El diálogo en la enseñanza. Teoría y práctica. Buenos Aires: Amorrortu.

Burge, E., Campbell Gibson, C. \& Gibson, T. (Eds.). (2011) Flexible pedagogy, flexible practice: notes from the trenches of distance education. Athabasca University Press, Edmonton, 348 pages.

Cabanach, R. G., Valle, A., Gerpe, M. G., Rodríguez, S., Pineiro, I., \& Rosario, P. (2009). Design and Validation of a Motivational Management Questionnaire. Revista de Psicodidáctica, 14(1), 29-47.

Cabero Almenara, J., \& Cejudo, M. D. C. L. (2013). La aplicación del juicio de experto como técnica de evaluación de las tecnologías de la información y comunicación (TIC). Eduweb, $7(2), 11-22$.

Cabero Almenara, J., \& Barroso Osuna, J. B. (2013). La utilización del juicio de experto para la evaluación de TIC: el coeficiente de competencia experta. Bordón. Revista de pedagogía, 65(2), $25-38$ 
Cabero Almenara, J. \& Román Graván, P. (compiladores) (2005) E-actividades: un referente básico para la formación en Internet. Madrid: Eduforma Editores.

Cabrera Murcia, E. P. (2004). Aprendizaje colaborativo soportado por computador (CSCL): su estado actual. Revista Iberoamericana de Educación, 33(6).

Cáceres, P. (2008). Análisis cualitativo de contenido: Una alternativa metodológica alcanzable. Psicoperspectivas. Individuo y Sociedad, 2(1), 53-82.).

Camilloni, A. et al. (2004) Corrientes didácticas contemporáneas. Buenos Aires: Paidós.

Camilloni, A., Celman, S., Litwin, E. Palou de Maté, M. (2000). La evaluación de los aprendizajes en el debate didáctico contemporáneo. Bs.As.: Paidós.

Canós, J. H., Letelier, P., \& Penadés, M. C. (2003). "Metodologías ágiles en el desarrollo de software". Material del Taller realizado en el marco de las VIII Jornadas de Ingeniería de Software y Bases de Datos, JISBD 2003. [En: https://pdfs.semanticscholar.org/f6bf/6501301a0af9ff19ffca080d22e5f1e276e8.pdf].

Consultado en Noviembre de 2017.

Casanova Uribe, M. O. (2008). Aprendizaje Cooperativo en un Contexto Virtual Universitario de Comunicación Asincrónica: Un estudio sobre el proceso de interacción entre iguales a través del análisis del discurso (Tesis de Doctorado). Universidad Autónoma de Barcelona. Barcelona.

Castells, M., Gimeno, C. M., \& Alborés, J. (2005). La sociedad red (Vol. 1). Alianza.

Cenich, G. (2007). Indagación acerca de procesos para compartir y negociar significados en un caso de estudio de aprendizaje colaborativo on line. En II Congreso de Tecnología en Educación y Educación en Tecnología.

Cenich, G., \& Santos, G. (2006). Aprendizaje colaborativo online: Indagación de las estrategias de funcionamiento. Revista TE \& ET. Nro. 1.

Chacón, F. (2003). Mind-Mapping for Web Instruction and Learning. Franciscan University of Steubenville.

Charczuk, N., Rodríguez, D., \& García Martínez, R. (2015). Integración de indicadores sociométricos de dinámicas grupales en ambientes virtuales de trabajo colaborativo orientados a intervenciones didácticas. En XXI Congreso Argentino de Ciencias de la Computación (Junín, 2015).

Cheng, R., \& Vassileva, J. (2005, May). Adaptive Reward Mechanism for Sustainable Online Learning Community. In AIED (pp. 152-159).

Chi, M. T. H. (2009). Active constructive interactive: A conceptual framework for differentiating learning activities. Topics in Cognitive Science, 1(1), 73-105.

Chi, M. T. H. (1997). Quantifying qualitative analyses of verbal data: A practical guide. Journal of the Learning sciences, 6, 271-315.

Chickering, A. W., \& Gamson, Z. F. (1987). Seven principles for good practice in undergraduate education. AAHE bulletin, 3, 7. 
Ciapuscio, H. (1996, mayo). "El conocimiento tecnológico". Revista Redes. Centro de Estudios e Investigaciones. Universidad Nacional de Quilmes. Vol. III, Nro. 6. Buenos Aires.

Clark, G. C., \& Moore, M. G. (Eds.). (1989). Reading in Principles of Distance Education. Pennsylvania State University Press.

Clark, R. (2000). Evaluating Distance Education: Strategies and cautions. Quarterly Review of Distance Education, 1(1), 3-16.

Cohen, L. \& Manion, L. (2002) Métodos de investigación educativa. Madrid: Editorial La Muralla.

Cohen, R. \& Swerdlik, M. (2001). Pruebas y evaluación psicológicas: Introducción a las pruebas y a la medición. (4a ed.). Mexico: Mc Graw Hill.

Coll, C. \& Onrubia, J. (1994). Temporal dimension and interactive processes in teachinglearning activities: A theoretical and methodological challenge. Teaching, learning and interaction, 107-122.

Constantino, G. D. (2010). El Análisis del Discurso Didáctico en entornos presenciales y virtuales: Claves conceptuales para la construcción compartida del conocimiento y la enseñanza multimedia. La renovación de la palabra en el bicentenario de la Argentina, 365-371.

Cook, T. D., \& Reichardt, C. S. (Eds.). (1979). Qualitative and quantitative methods in evaluation research. Beverly Hills, CA: Sage publications.

Corbel, A., Jaillon, P., Serpaggi, X., Baker, M., Quignard, M., Lund, K., \& Séjourné, A. (2003, April). DREW: Un outil Internet pour créer des situations d'apprentissage coopérant. In Desmoulins, Marquet \& Bouhineau (Eds.), EIAH2003 Environnements Informatiques pour l'Apprentissage Humain, Actes de la conférence EIAH (pp. 109-113).

Corral, Y. (2009). Validez y confiabilidad de los instrumentos para la recolección de datos. Revista ciencias de la educación, (33), 228-247. [En: http://servicio.bc.uc.edu.ve/educacion/revista/n33/art12.pdf]. Consultado en Noviembre de 2017.

Correa, L. M. Z. (2013). Aprendizaje colaborativo: una nueva forma de Diálogo Interpersonal y en Red. Revista digital de educación y nuevas tecnologías, (28). [En: http://www.citeulike.org/group/17901/article/12307503] Consultado en Noviembre de 2017.

Crooks, T. J. (1988). The impact of classroom evaluation practices on students. Review of educational research, 58(4), 438-481.

De Bono, E. (1988). Seis sombreros para pensar. Ediciones Granica SA.

De Jong, T., \& Van Joolingen, W. R. (1998). Scientific discovery learning with computer simulations of conceptual domains. Review of educational research, 68(2), 179-201.

Dehler, J., Bodemer, D., Buder, J., \& Hesse, F. W. (2011). Guiding knowledge communication in CSCL via group knowledge awareness. Computers in Human Behavior, 27(3), 1068-1078.

Delling, R. M. (1975). Distant study as an opportunity for learning. The system of distance education, ICCE, 58-59. 
Díaz-Antón, M. G., Pérez, M., Grimmán, A., \& Mendoza, L. (2006). "Propuesta de una metodología de desarrollo de software educativo bajo un enfoque de calidad sistémica". Univ. Simón Bolívar, Caracas, Venezuela. 1, 91. [En: http://www.academiainteractiva.com/doc/ise.pdf]. Consultado en Noviembre de2017.

Díaz Barriga, F. (2005). "Principios de diseño instruccional de entornos de aprendizaje apoyados con TIC: un marco de referencia sociocultural y situado". Tecnología y comunicación educativas, 41, 8-9.

Dillenbourg P. (1999) What do you mean by collaborative leraning? In P. Dillenbourg (Ed) Collaborative-learning: Cognitive and Computational Approaches. (pp.1-19). Oxford: Elsevier. Chapter 1 (Introduction).

Dimitracopoulou, A. (2005, May). Designing collaborative learning systems: current trends \& future research agenda. In Proceedings of th 2005 conference on Computer support for collaborative learning: learning 2005: the next 10 years! (pp. 115-124). International Society of the Learning Sciences.

Dimitrakopoulou, A., Petrou, A., Martinez, A., Marcos, Vassilis Kollias, J. et al. (2006) State of the art of interaction analysis for Metacognitive Support \& Diagnosis. (D31.1.1) EU Sixth Framework programme priority 2, Information society technology, Network of Exc.

Driscoll, M.P. y Vergara, A. (1997). Nuevas Tecnologías y su impacto en la educación del futuro, en Pensamiento Educativo, 21.

Dolina, A. (1996). Crónicas del ángel gris. Buenos Aires: Ediciones Colihue SRL.

Dourish, P., \& Bellotti, V. (1992, December). Awareness and coordination in shared workspaces. In Proceedings of the 1992 ACM conference on Computer-supported cooperative work (pp. 107-114). ACM.

Eco, U. (1998). Cómo se hace una tesis. Madrid: Gedisa.

Erickson, T., Kellogg, W. (2000) Social translucence: an approach to designing systems that support social processes. ACM Transactions on Computer-Human Interaction (TOCHI) Special issue on human-computer interaction in the new millennium, Part 1: Volume 7 Issue 1, March 2000. Publisher: ACM.

Erickson, T., Smith, D. N., Kellogg, W. A., Laff, M., Richards, J. T., \& Bradner, E. (1999, May). Socially translucent systems: social proxies, persistent conversation, and the design of "babble". In Proceedings of the SIGCHI conference on Human Factors in Computing Systems (pp. 72-79). ACM.

Escobar Pérez, J., \& Cuervo-Martínez, A. (2008). Validez de contenido y juicio de expertos: una aproximación a su utilización. Avances en medición, 6, 27-36.

Fainholc, B. (1999). La interactividad en la educación a distancia. Buenos Aires: Paidós.

Felton, M, Garcia-Mila, M, Villarroel, C, \& Gilabert, S. (2015) "Arguing collaboratively: Argumentative discourse types and their potential for knowledge building". British Journal Of Educational Psychology, 85, 3, pp. 372-386

Fernández, Ana María (1989) El campo grupal, notas para una genealogía. Buenos Aires: Nueva Visión. 
Ferrando, MG., Ibáñez, J., Martín, FA. (1996) El análisis de la realidad social: métodos y técnicas de investigación. Madrid: Alianza.

Fessakis, G., \& Dimitracopoulou, A. (2003). Exploitation of data modeling for database design in secondary education learning activities: A case study concerning real stories analysis. In International Workshop ICL 2003-Interactive Computer Aided Learning.

Flavell, J. H. (1971). First's disscusants comments. What is memory development the devolopment of Human Development. 14, 272-278.

Friesen, Norm \& Kuskis, A. (2013). Modes of interaction. Handbook of Distance Education,, 351-371.

Fulford, C.P., \& Zhang, S. (1993). Perceptions of Interaction: The critical predictor in distance education. American Journal of Distance Education, 7(3), 8-21.

García, L., \& Fernández, S. J. (2008). Procedimiento de aplicación del trabajo creativo en grupo de expertos. Ingeniería Energética, 29(2), 46-50.

García Aretio, L. (2011). "La interacción es elemento definitorio del hacer educativo". Entrevista en Revista Learning Review, 27 de Junio. En: http://www.learningreview.com/articulos-y-entrevistas-elearning/3231-la-interaccion-eselemento-definitorio-del-hacer-educativo. Consultado en Noviembre de 2017.

García-Cano, J. M. L. (1988). El diseño modular como marco en la formación permanente del profesorado: modelo de actualización propuesto. Revista interuniversitaria de formación del profesorado. Nro. 2. Págs. 167-176.

Gimeno Sacritán, J. \& Pérez Gómez, A. I (1995) Comprender y transformar la enseñanza. Madrid: Morata.

Gimeno Sacristán, J. y Pérez Gómez, A (1989). La enseñanza: su teoría y su práctica. Madrid: Akal.

Gimeno Sacristán, J. (1981). Teoría de la enseñanza y desarrollo del currículum. Buenos Aires: REI Argentina.

Goodyear P., Jones C., Thompson K. (2014) Computer-Supported Collaborative Learning: Instructional Approaches, Group Processes and Educational Designs. In: Spector J., Merrill M., Elen J., Bishop M. (eds) Handbook of Research on Educational Communications and Technology. Springer, New York, NY.

Gunawardena, C. N., Lowe, C. A. \& Anderson, T. (1997). Analysis of a global online debate and the development of an interaction analysis model for examining social construction of knowledge in computer conferencing. Journal Educational Computing Research, 17(4), 397431.

Heim, S. G. (2008). The Resonant Interface: HCI foundations for interaction design. Pearson/Addison Wesley.

Hernández, Pedro (1989). Diseñar y enseñar. Madrid: Narcea e ICE Universidad de la Laguna.

Hillman, D., Willis, D.J., \& Gunawardena, C. (1994). Learner-Interface Interaction in Distance Education: An extension of contemporary models and strategies for practitioners. The American Journal of Distance Education, 8(2), 30-42. 
Holmberg, B. (1989). Theory and practice of Distance Education. Routledge Studies in Distance Education.

Horton, W. K. (2000). Designing web-based training: How to teach anyone anything anywhere anytime (Vol. 1). New York, NY: Wiley.

Hutchins, E. (1995). Cognition in the Wild. MIT press.

Ingram, A. \& Hathorn L. (2004). Methods for Analyzing Collaboration in Online Communications, en T. Roberts (ed). Online Collaborative Learning: Theory and Practice. USA: Idea Group Inc. 215-241.

Ishii, H. \& Ullmer, B. (1997). Tangible bits: towards seamless interfaces between people, bits and atoms. In Proceedings of the ACM SIGCHI Conference on Human factors in computing systems (pp. 234-241). ACM.

Jaggars, S. S., \& Xu, D. (2016). How do online course design features influence student performance?. Computers \& Education, 95, 270-284.

Janssen, J., Erkens, G., \& Kirschner, P. A. (2011). Group awareness tools: It's what you do with it that matters. Computers in Human Behavior, 27(3), 1046-1058.

Jermann, P., Soller, A. \& Müehlenbrock, M. (2001). From mirroring to guiding: A review of the state of art technology for supporting collaborative learning. In European Conference on Computer-Supported Collaborative Learning EuroCSCL-2001 (pp. 324-331).

John, O. P., \& Srivastava, S. (1999). The Big Five trait taxonomy: History, measurement, and theoretical perspectives. Handbook of personality: Theory and research, 2(1999), 102-138.

Johnson, David W., and Frank P. Johnson. (1997). Joining Together: Group Theory and Group Skills. Needham Heights, MA: Allyn \& Bacon.

Jonassen, D. H. (1999). Designing constructivist learning environments. Instructional design theories and models: A new paradigm of instructional theory. En: Reigeluth, Ch. (Editor) (1999) Instructional-design Theories and Model. A New Paradigm of Instructional Theory. Volume II, 215-239.

Jonassen, D. H., \& Kim, B. (2010). Arguing to learn and learning to argue: Design justifications and guidelines. Educational Technology Research and Development, 58(4), 439-457.

Kahn, K. B., \& Mentzer, J. T. (1996). Logistics and interdepartmental integration. International Journal of Physical Distribution \& Logistics Management, 26(8), 6-14.

Karbach, J. (1987). Using Toulmin's model of argumentation. Journal of Teaching Writing, 6 (1), 81-92.

Kay, J., Yacef, K., \& Reimann, P. (2007, July). Visualisations for team learning: small teams working on long-term projects. In Proceedings of the 8th iternational conference on Computer supported collaborative learning (pp. 354-356). International Society of the Learning Sciences.

Kay, J., Maisonneuve, N., Yacef, K., \& Reimann, P. (2006, June). The big five and visualisations of team work activity. In Intelligent tutoring systems (pp. 197-206). Springer Berlin Heidelberg. 
Keegan, D. (1990). A theory for distance education. Contemporary issues in American distance education, 327-332.

Keegan, D. (1996). Foundations of distance education. Psychology Press.

Keegan, D. J. (1980). On defining distance education. Distance education, 1(1), 13-36.

Kelly, M. J., \& Chapanis, A. (1977). "Limited vocabulary natural language dialogue". International Journal of Man-Machine Studies, 9(4), 479-501.

Kharrufa, A. S. (2010). Digital tabletops and collaborative learning (Doctoral dissertation, Newcastle University).

Köhler, W. (1929). Gestalt psychology.

Konno, T., Morita, J. \& Hashimoto, T. (2012, February). How is pragmatic grounding formed in symbolic communication systems?. In The Evolution of Language: Proceedings of the 9th International Conference (EVOLANG9), Singapore. World Scientific.

Kruh, J., \& Murphy, K. (1990, October). Interaction and Teleconferencing - The key to quality instruction. In Annual Rural and Small Schools Conference. Annual Rural and Small Schools Conference. ERIC Document Reproduction Service, ED 329418.

Kuutti, K. (1995, September). Work processes: Scenarios as a preliminary vocabulary. In Scenario-based design (pp. 19-36). John Wiley \& Sons, Inc.

Landis, J. R., \& Koch, G. en Cerda, J. \& Villarroel, L. (2008). Evaluación de la concordancia inter-observador en investigación pediátrica: Coeficiente de Kappa. Revista chilena de pediatría, 79(1), 54-58.

Latour, Bruno (1992) "Where are the missing masses? The sociology of a few mundane artetifacts", in Bijker and Law (Eds.) Shaping technology/building society: studies in sociotechnical change. Cambridge: MIT Press.

Laurillard, D. (2000). New technologies and the curriculum. In P. Scott. P. (Ed.) Higher Education Reformed (pp. 133-153) London: Falmer Press.

Laurillard, D. (1997). Rethinking University Teaching: A framework for the effective use of educational technology. London: Routledge.

Le Boterf, G. (2001) Ingeniería de las competencias. Editorial Gestión 2000: Madrid, España.

Lewin, K. (1935). A dynamic theory of personality. Mac Graw Hill: USA.

Libedinsky, Marta (2016). “¿Cómo enseñar para la transferencia en aulas en línea de nivel superior?”. Signos Universitarios. Revista de Educación a Distancia. Editorial USAL: Buenos Aires.

Libedinsky, M.; Manso. M.; Pérez, P.; Light, D.; Garzón, M. (2011) “Cap. 2: La colaboración y el trabajo en red con TIC" (En: Las TIC en las aulas. Experiencias latinoamericanas. Buenos Aires: Paidós).

Liddle, D. (1996, Abril). Design of the conceptual model. In Bringing design to software (pp. 17-36). ACM. 
Lion, Carina. (2006). Imaginar con tecnologías. Buenos Aires: La Crujía.

Litwin, E. (2011) El oficio de enseñar: condiciones y contextos. Buenos Aires: Paidós - Voces de la Educación.

Litwin, E. (2005). Tecnologías educativas en tiempos de Internet. Buenos Aires: Amorrortu.

Litwin, E. (2000) Las configuraciones didácticas. Una nueva agenda para la enseñanza superior. Buenos Aires: Paidós Educador.

Lucero, M. M., Chiarani, M. C., \& Pianucci, I. G. (2003). Modelo de Aprendizaje Colaborativo en el ambiente ACI. En IX Congreso Argentino de Ciencias de la Computación.

Malbrán, M. D. C., \& Pérez, V. R. (2013) Interpretación del contenido de la entrevista en profundidad (EP): Herramientas cognitivas.

Maldonado Mahauad, J.; Sanz, C. \& Fernández Pampillón, A. (2014). Desarrollo de un Marco de Análisis para la Selección de Metodologías de Diseño de Objetos de Aprendizaje (OA) basado en criterios de calidad para contextos educativos específicos. Tesis de la Maestría de “Tecnología Informática aplicada en Educación”. Facultad de Informática, Universidad Nacional de La Plata. En: http://sedici.unlp.edu.ar/handle/10915/45063. Consultado en Noviembre de 2017.

Maldonado, C. M., \& Chavarría, A. C. (1991) "Aplicación de la programación no lineal a un simulador de procesos comercial: enfoques en la simulación y optimización de procesos". En: Tecnología y Ciencia. Departamento de Ingeniería Química. Facuñtad de Química. UNAM. México.

Manresa-Yee, C., Abásolo, M. J., Sansó, R. M., \& Vénere, M. (2011). Realidad Virtual, Realidad Aumentada e Interfaces Basadas en Vision. XV Escuela Internacional de Informática, XVII Congreso Argentino de Ciencia de la Computación CACIC.

Manterola, C., \& Otzen, T. (2015). Los sesgos en investigación clínica. International Journal of Morphology, 33(3), 1156-1164.

Martín, E., Celdrán, M., \& Zamarro, J. M. (2009). Colab: Un entorno colaborativo para el aprendizaje investigando. Proyecto Colab-web. Universidad de Murcia. España.

Martínez Maldonado, R. (2014). Analysing, visualising and supporting collaborative learning using interactive tabletops (Doctoral dissertation, The University of Sydney, Australia).

Martínez, R., Kay, J., \& Yacef, K. (2011). Visualisations for longitudinal participation, contribution and progress of a collaborative task at the tabletop (pp. 2-11). School of Information Technologies, University of Sydney.

Martínez Maldonado, R., Kay, J., \& Yacef, K. (2010, November). Collaborative concept mapping at the tabletop. In ACM International Conference on Interactive Tabletops and Surfaces (pp. 207-210). ACM.

Mason, R. (1992). Computer conferencing: The last word. Beach Holme.

Mayer, R. E. (1999). "Diseño educativo para un aprendizaje constructivista." En Reigeluth, Ch . (ed). Diseño de la instrucción. Teorías y Modelos. Madrid. Santillana. 
Mayer, R. E. (2003). "The promise of multimedia learning: using the same instructional design methods across different media". Learning and instruction, 13(2), 125-139.

Mayaute, L. M. E. (1988). Cuantificación de la validez de contenido por criterio de jueces. Revista de Psicología, 6(1-2), 103-111.

McLuhan, M. (1972). La comprensión de los medios como las extensiones del hombre. México: Editorial DIANA.

Mehrabian, A. (1968). Male and female scales of the tendency to achieve. Educational and Psychological Measurement.

Mena, M. Rodríguez, L. \& Diez, M.L. (2005). Diseño de Proyectos de Educación a Distancia. Páginas en Construcción. Buenos Aires. Editorial La Crujía.

Mengual, S. (2011). La importancia percibida por el profesorado y el alumnado sobre la inclusión de la competencia digital en Educación Superior. Alicante: Departamento de Didáctica General y Didácticas específicas de la Facultad de Alicante. España.

Mochizuki, T., Kato, H., Yaegashi, K., Nagata, T., Nishimori, T., Hisamatsu, S. I., ... \& Suzuki, M. (2005, May). Promotion of self-assessment for learners in online discussion using the visualization software. In Proceedings of th 2005 conference on Computer support for collaborative learning: learning 2005: the next 10 years! (pp. 440-449). International Society of the Learning Sciences.

Molina, A., Beristaín, L., Tamés, E., Moska, D., Ramírez, R. \& Romo, M. (2012). Un modelo innovador para el aprendizaje activo. In Tenth LACCEI Latin American and Caribbean Conference. Panama City, Panama. Recuperado de: http://laccei.org/LACCEI2012Panama/RefereedPapers/RP199.pdf. Consultado en Noviembre de 2017.

Molina, M. E., \& Padilla, C. (2013). Argumentar en dos disciplinas universitarias: una aproximación toulminiana a la argumentación académica en Letras y Biología. Logos: Revista de Lingüistica, Filosofia y Literatura, 23(1), 62-79.

Monje Alvarez, C. A. (2011). Metodología de la investigación cualitativa y cuantitativa. Guía Didáctica. Universidad Surcolombiana. Facultad de Ciencias Sociales y Humanas. Programa de Comunicación Social y Periodismo.

Moore, Michael:

a. (Editor) (2013). Handbook of distance education. Routledge.

b. (1996) Distance Education: A Systems View. Wadsworth Publishing Company: USA.

c. (Editor) (1990). Contemporary Issues in American Distance Education. Great Britain: Pergamon Press. BPCC Wheatons Ltd, Exeter.

d. (1990). Recent contributions to the theory of distance education. Open learning, 5(3), 1015.

e. (Editor) (1989) "Readings in Principles of Distance Education (Readings in Distance Education Series No. 1)". American Center for the study of Distance Education. College of Education. Pennsylvania State University.

f. (1973) "Towards a theory of independent learning and teaching". Journal of Higher Education, 44, págs. 661-679. USA. 
g. (1972) "Learning autonomy: the second dimension of independent learning", Conference Fall, págs 76-88. USA.

Moralejo, L., Sanz, C. V., Pesado, P. M., \& Baldassarri Santalucía, S. (2014). Avances en el diseño de una herramienta de autor para la creación de actividades educativas basadas en realidad aumentada. TE\&ET. Número: 12 Páginas: 8-14.

Moreno, J. M. (1999). Paulo Freire: Una propuesta de comunicación para la educación en América Latina. Razón y palabra, 13(5).

Mühlenbrock, M., \& Hoppe, U. (1999, December). Computer supported interaction analysis of group problem solving. In Proceedings of the 1999 conference on Computer support for collaborative learning (p. 50). International Society of the Learning Sciences.

Nakahara, J., Hisamatsu, S., Yaegashi, K. \& Yamauchi, Y. (2003). iTree : The mobile phone software for visualizing the learner's interaction on BBS. In D. Lassner \& C. McNaught (Eds.), Proceedings of EdMedia: World Conference on Educational Media and Technology 2003 (pp. 401-404). Association for the Advancement of Computing in Education (AACE).

Nakahara, J., Hisamatsu, S., Yaegashi, K., \& Yamauchi, Y. (2005, May). iTree: Does the mobile phone encourage learners to be more involved in collaborative learning? In Proceedings of th 2005 conference on Computer support for collaborative learning: learning 2005: the next 10 years! (pp. 470-478). International Society of the Learning Sciences. Network of Exc.

Nardi, B. A. (1996). Context and consciousness: activity theory and human-computer interaction. mit Press.

Novak, J. D. (1990) Teoría y Práctica de la Educación. Madrid: Alianza Universidad.

Ogata, H., \& Yano, Y. (2004). Knowledge awareness map for computer-supported ubiquitous language-learning. In Wireless and Mobile Technologies in Education, 2004. Proceedings. The 2nd IEEE International Workshop on (pp. 19-26). IEEE.

Okamoto, M., Yang, Y., \& Ishida, T. (2001). Wizard of oz method for learning dialog agents. In Cooperative Information Agents V (pp. 20-25). Springer Berlin Heidelberg.

Palacios, A. M., \& Villar, C. M. (1996). El pensamiento del experto como objeto de estudio. Revista de Filosofia y Teoría Politica, (31-32), 228-234.

Panitz, T. (1997). Collaborative versus cooperative learning: A comparison of two concepts which will help us understand the underlying nature of interactive learning. En: http://files.eric.ed.gov/fulltext/ED448443.pdf]. Consultado en Noviembre de 2017.

Pansza, M., Juárez, E. C. P., \& Oviedo, P. M. (1986). Fundamentación de la didáctica (Vol. 1). Buenos Aires: Ediciones Gernika.

Pedersen, E. R., \& Sokoler, T. (1997, March). AROMA: abstract representation of presence supporting mutual awareness. In Proceedings of the ACM SIGCHI Conference on Human factors in computing systems (pp. 51-58). ACM.

Penzo, Fernández, García, Gros, Pagès, Roca,... \& Vendrell, P. (2010). Guía para la elaboración de las actividades de aprendizaje. Cuadernos de docencia universitaria, 15, 1-67. En: https://octaedro.com/appl/botiga/client/img/16515.pdf. Consultado en Noviembre de 2017. 
Pérez, M. M. (2007). El trabajo colaborativo en el aula universitaria. Laurus, 13(23), 263-278.

Peters, O. (1971). Theoretical aspects of correspondence instruction. McKenzie y Christensen. The changing world of correspondence study. Pensylvania State University Presss.

Phielix, C., Prins, F. J., \& Kirschner, P. A. (2010). Awareness of group performance in a CSCL-environment: Effects of peer feedback and reflection. Computers in Human Behavior, 26(2), 151-161.

Pinch, T. J., \& Bijker, W. E. (1984). "The social construction of facts and artefacts: Or how the sociology of science and the sociology of technology might benefit each other". Social studies of science, 14(3), 399-441.

Pintrich, P. R. (1991). A manual for the use of the Motivated Strategies for Learning Questionnaire (MSLQ).

Pisani, Francis \& Piotet, D. (2008) La alquimia de las multitudes. Cómo la web está cambiando el mundo. Buenos Aires: Paidós Comunicación.

Popham, W. J. (1974). Evaluation in Education: Current Applications. USA: Allyn and Bacon.

Preece, J. (1994) Human Computer Interaction. Addison-Wesley Educational Publisher Inc: USA.

Preece, J., Rogers, Y., \& Sharp, H. (2002). Interaction Design: Beyond Human-Computer Interaction. John Wiley \& Sons Inc.

Puente, J. C. T. (2007). Una triple alianza para un aprendizaje universitario de calidad. Universidad Pontificia Comillas.

Quintanilla, Miguel Angel (1988) Tecnología: un enfoque filosófico. Buenos Aires: EUDEBA. Colección Ciencia y Técnica.

Ramírez, J. V., \& Noguera, M. Á. D. (1999). La programación e intervención didáctica en el deporte escolar (II): aportaciones de los diferentes estilos de enseñanza. Apuntes: Educación fisica y deportes, (56), 17-24.

Restrepo, C.; Jiménez, L.; Hurtado, J.; Collazos, C. (2017) "Integrando la ingeniería de la colaboración en los procesos de software: Un enfoque de Análisis Visual" Congreso Interacción 2017: Human Computer Interaction. Cancún, México, 25 al 27 de Septiembre. Proceedings del Congreso.

Rhodes, B. J., Minar, N. \& Weaver, J. (1999). Wearable computing meets ubiquitous computing: Reaping the best of both worlds. In Wearable Computers, 1999. Digest of Papers. The Third International Symposium on (pp. 141-149). IEEE.

Riveiro, J. S., Nieto, D. A., \& Veiga, I. G. (2004). Diferencias diagnósticas en función del género respecto a la utilización de estrategias autorreguladoras en estudiantes universitarios. Revista de Investigación Educativa, 22(1), 245-258.

Roberts, T. S. (Ed.). (2004). Online collaborative learning: Theory and practice. Information Science Publishing: Australia.

Rockwell, E. (1980). Etnografía y teoría en la investigación educativa. Revista Dialogando, Nro. 2. Pág. 29-45. 
Rogers, C. (1982) Libertad y creatividad en la educación. Buenos Aires: PAIDOS.

Roig Vila, R., Rosales Statkus, S.E.: Assessing participation in online discussion forums: A proposal for multidimensional analysis. Píxel-Bit. Revista de Medios y Educación. 40, 137-149 (2012).

Rojas, N., Carrillo, J., Flores, P. (2012). Características para identificar a profesores de matemáticas expertos. En A. Estepa, Á. Contreras, J. Deulofeu, M. C. Penalva, F. J. García y L. Ordóñez (Eds.), Investigación en Educación Matemática XVI (pp. 479 - 485). Jaén: SEIEM. Recuperado de: Repositorio Digital de Documentos en Educación Matemática. Universidad de los Andres, Bogotá, Colombia. http://funes.uniandes.edu.co/2072/1/Rojas\%2CN.Carrillo\%2CJ_y_Flores\%2CP._2012.pdf Consultado en Noviembre de 2017.

Ros, R. G., \& González, F. P. (2014). La gestió dels temps d'estudi. Futura, (28), 5-21.

Rubin, H. J., \& Rubin, I. S. (2011). Qualitative interviewing: The art of hearing data. Sage.

Salinas, J. (2012). La investigación ante los desafíos de los escenarios de aprendizaje futuros. RED. Revista de Educación a Distancia, 11, 32.

Salomon, G. (2001) (Compilador) Cogniciones distribuidas: consideraciones psicológicas y educativas. Buenos Aires: Amorrortu Ediciones. Colección Agenda Educativa.

Salomon, G., Perkins, D. N., \& Globerson, T. (1992). "Coparticipando en el conocimiento: la ampliación de la inteligencia humana con las tecnologías inteligentes". Comunicación, lenguaje y educación, 4(13), 6-22.

Sangin, M., Molinari, G., Nüssli, M. A., \& Dillenbourg, P. (2011). Facilitating peer knowledge modeling: Effects of a knowledge awareness tool on collaborative learning outcomes and processes. Computers in Human Behavior, 27(3), 1059-1067.

Santos Guerra, M. A. (1993). Estrategias para la evaluación interna de los centros educativos (Vol. 9). Ministerio de Educación. Bogotá. Colombia.

Sanz, C., \& Zangara, A. (2014). "La formación de docentes en el ámbito de la Educación a Distancia: aspectos epistemológicos y metodológicos. Análisis a partir de un caso". Signos Universitarios. Revista de Educación a Distancia. Editorial USAL: Buenos Aires.

Sanz, C., Zangara, A., \& Manresa-Yee, C. (2012). E-activities in teaching processes using ICTS collaborative activity as a case study. EDULEARN12 Proceedings, 20342041.

Schmuk, R. A., \& Schmuk, P. A. (1975). Group processes in the classroom.

Schön, D. (1998). El profesional reflexivo. Barcelona: Paidós.

Scriven, M. (1967). The methodology of evaluation (AERA Monograph series on curriculum evaluation, No. 1). New York: Rand Mc Nally.

Seifert, T. L., \& O'Keefe, B. A. (2001). The relationship of work avoidance and learning goals to perceived competence, externality and meaning. British Journal of Educational Psychology, $71(1), 81-92$.

Sewart, D., Keegan, D., \& Holmberg, B. (Eds.). (1983). Distance education: International perspectives. Beckenham, Kent: Croom Helm. 
Sharples, M., Goodlet, J. S., Beck, E. E., Wood, C. C., Easterbrook, S. M., \& Plowman, L. (1993). Research issues in the study of computer supported collaborative writing (pp. 9-28). Springer London.

Shearer, R. L. (2013). Theory to practice in instructional design. Handbook of distance education, 3, 251-267.

Simon, H. (1969) The Artificial Science (En Ciapuscio, H. (1996). "El conocimiento tecnológico". Revista Redes. Centro de Estudios e Investigaciones. Universidad Nacional de Quilmes. Vol. III, Nro. 6. Buenos Aires, mayo. Pág. 182).

Simons, J., Dewitte, S., \& Lens, W. (2004). The role of different types of instrumentality in motivation, study strategies, and performance: Know why you learn, so you'll know what you learn!. British Journal of Educational Psychology, 74(3), 343-360.

Simonson, M., Smaldino, S., Albright, M. \& Zvacek, S. (2006) Teaching and Learning at a Distance: Foundations of Distance Education Upper Saddle River, New Jersey: Merrill. (4th. Edition).

Skinner, B. F. (1938). The behavior of organisms: An experimental analysis.

Skinner, B. F. (1953). Science and human behavior. Simon and Schuster.

Soller, A., Martínez, A., Jermann, P., \& Muehlenbrock, M. (2005). From mirroring to guiding: A review of state of the art technology for supporting collaborative learning. International Journal of Artificial Intelligence in Education, 15(4), 261-290.

Souto, Marta. (1993) Hacia una didáctica de lo grupal. Buenos Aires: Miño y Dávila Editores.

Souto de Asch, Marta (1987) "El grupo de aprendizaje como unidad de operación educativa". En: Revista Argentina de Educación. Año V. Nro. 8.

Spermon, M., Schouten, I., \& van den Hoven, E. (2014). Designing interaction in digital tabletop games to support collaborative learning in children. International Journal of Learning Technology, 9(1), 3-24.

Stahl, G. (2006). Group cognition: Computer support for building collaborative knowledge. Cambridge, MA: MIT Press.

Stahl, G., Koschmann, T., \& Suthers, D. (2006). Computer-supported collaborative learning: An historical perspective. Cambridge handbook of the learning sciences, 2006, 409-426.

Stake, R. E. (1998). Investigación con estudio de casos. Ediciones Morata.

Stein, L.; Bernas, S.; Calicchia, D. (1997) Conflict talk: understanding and resolving arguments. En Giron, T. (Ed.). Conversation: Cognitive, communicative, and social perspectives. Typological studies in language. Vol. 34, (233-267). Amsterdam, The Netherlands: John Benjamins.

Stufflebeam, D y Shinkfield, A (1987). Evaluación Sistemática. Guía teórica y práctica. Barcelona: Paidós.

Surowiecki, J. (2005). The wisdom of crowds. Anchor. 
Tatar, D., Roschelle, J., Vahey, P., \& Penuel, W. R. (2003). Handhelds go to school: Lessons learned. Computer, (9), 30-37.

Thorndike, E. L. (1910). The contribution of psychology to education. Journal of Educational Psychology, l(1), 5.

Tiffin, J., Rajasingham, L. (1995). In Search on The Virtual Class. Education in an information society. New York, USA: Routeledge.

Upton, K., \& Kay, J. (2009). Narcissus: group and individual models to support small group work. In User modeling, adaptation, and personalization (pp. 54-65). Springer Berlin Heidelberg.

van Joolingen, W. R., de Jong, T., Lazonder, A. W., Savelsbergh, E. R., \& Manlove, S. (2005). Co-Lab: research and development of an online learning environment for collaborative scientific discovery learning. Computers in human behavior, 21(4), 671-688.

Vassileva, J., Cheng, R., Sun, L., \& Han, W. (2005). "Designing mechanisms to stimulate contributions in collaborative systems for sharing course-related materials". (En: Kock Ned (2005) Interdisciplinary Perspectives on E-Collaboration: Emerging Trends and Applications: Emerging Trends and Applications. Texas. M\&M Interational University. Hershey. NYC.

Vizcaíno, A. (2005). A simulated student can improve collaborative learning. International Journal of Artificial Intelligence in Education (IJAIED), 15, 3-40.

Vygotsky, L., Hanfmann, E. E., \& Vakar, G. E. (1962). Thought and language.

Watson, J. B. (1913). Psychology as the behaviorist views it. Psychological review, 20(2), 158.

Wedemeyer, C. A. (1973). Characteristics of Open Learning Systems. Report of NAEB Advisory Committee on Open Learning Systems to NAEB Conference (New Orleans, Louisiana, November 1973).

Weinberger, A., \& Fischer, F. (2006). A framework to analyze argumentative knowledge construction in computer supported collaborative learning. Computers and Education. pp.71-95. En: https://hal.archives-ouvertes.fr/hal-00703945/document. Consultado en Noviembre de 2017

Weinstein, C. E., \& Palmer, D. R. (1990). Learning and study strategies inventory-high school version. Clearwater, FL: $H \& H$ Publishing.

Weiser, M. (1991). The computer for the 21 st century. Scientific american, 265(3), 94-104.

Wenger, E. (2001). Supporting communities of practice. A survey of community-oriented technologies.

En:

https://guard.canberra.edu.au/opus/copyright register/repository/53/153/01_03 CP technology survey v3.pdf. Consultado en Noviembre de 2017

Wertheimer, M., \& Riezler, K. (1944). Gestalt theory. Social Research, 78-99.

Wertsch, J. (1998) La mente en acción. Buenos Aires: AIQUE.

Williams, M. L., Paprock, K., \& Covington, B. (1998). Distance learning: The essential guide. Sage Publications. 
Wlodkowski, R. (1985). Enhancing Adult Motivation to Learn. San Francisco, CA: JosseyBass.

Yanacon Atia, D., \& Costaguta, R. (2013). Manifestación de habilidades de colaboración en grupos de aprendizaje síncronos y asíncronos. In XVIII Congreso Argentino de Ciencias de la Computación.

Zabalza, M. A (1987). Diseño y desarrollo curricular. Madrid: Narcea.

Zangara, A., \& Sanz, C. V. (2015). Importancia de las estrategias de autorregulación en el aprendizaje y sus derivaciones para la enseñanza. In X Congreso sobre Tecnología en Educación \& Educación en Tecnología (Corrientes, 2015).

Zangara, A., Sanz, C. (2015). Collaborative learning work. Evaluation model using the ethnographic metodologhy of "Analysis of social network". EDULEARN15. Proceedings, 19871998.

Zimmerman, B. (1989). A social cognitive view of self-regulated academic learning. Journal of Educational Psychology, 81, 329-339.

Zimmerman, B. (1998). Developing self-fulfilling cycles of academic regulation: an analysis of exemplary instructional models. En: D. D. Schunk, \& B. Zimmerman, Self-regulated learning: From teaching to self-reflective practice (págs. 1-19). USA: Guilford Press.

Zimmerman, B. (2000). Attaining Self-regulation. En M. Boekaerts, P. Pintrich, \& M. Zeidner. Handbook of Self-regulation (págs. 13-40). USA, USA: Academic Press.

Zimmerman, B. (2001). Theories of self-regulated learning and academic achievement: an overview and analysis. En B. Zimmerman, \& D. Schunk, Self-regulated learning and academic achievement: theoretical perspectives (págs. 1-37). USA: Laurence Erlbaum Associates Publishers.

Zumbach, J., Muehlenbrock, M., Jansen, M., Reimann, P., \& Hoppe, H. U. (2002, January). Multi-dimensional tracking in virtual learning teams: An exploratory study. En Proceedings of the Conference on Computer Support for Collaborative Learning: Foundations for a CSCL Community (pp. 650-651). International Society of the Learning Sciences.

Zumbach, J., Reimann, P., \& Koch, S. C. (2006). Monitoring students' collaboration in computer-mediated collaborative problem-solving: Applied feedback approaches. Journal of Educational Computing Research, 35(4), 399-424.

Zumbach, J., Reimann, P., \& Schönemann, J. (2005, May). Effects of Resource Distribution and Feedback on Computer-Mediated Collaboration in Dyads. In ICCE (pp. 587-594). 


\section{Anexo 1: Comunicación y protocolo del autoinforme sobre habilidades de autorregulación}

\section{Comunicación de la indagación}

Dentro de la metodología MetSCIn se proponen los siguientes momentos de comunicación:

1er. momento. Desde el inicio de la propuesta de enseñanza debe informarse a los estudiantes que el instrumento será administrado. Puede incluirse en el contrato pedagógico inicial, en la lista de actividades, como actividad obligatoria u optativa, o como se decida dentro de la propuesta pedagógica.

2do. momento. En el momento de inicio de la actividad según el cronograma, se recomienda que se comunique mediante un mensaje grupal, público. Se presenta, a modo de ejemplo en la figura 95, el mensaje enviado a los estudiantes de las cohortes 2015 y 2016 en el caso de estudio que se describe en el capítulo 8.

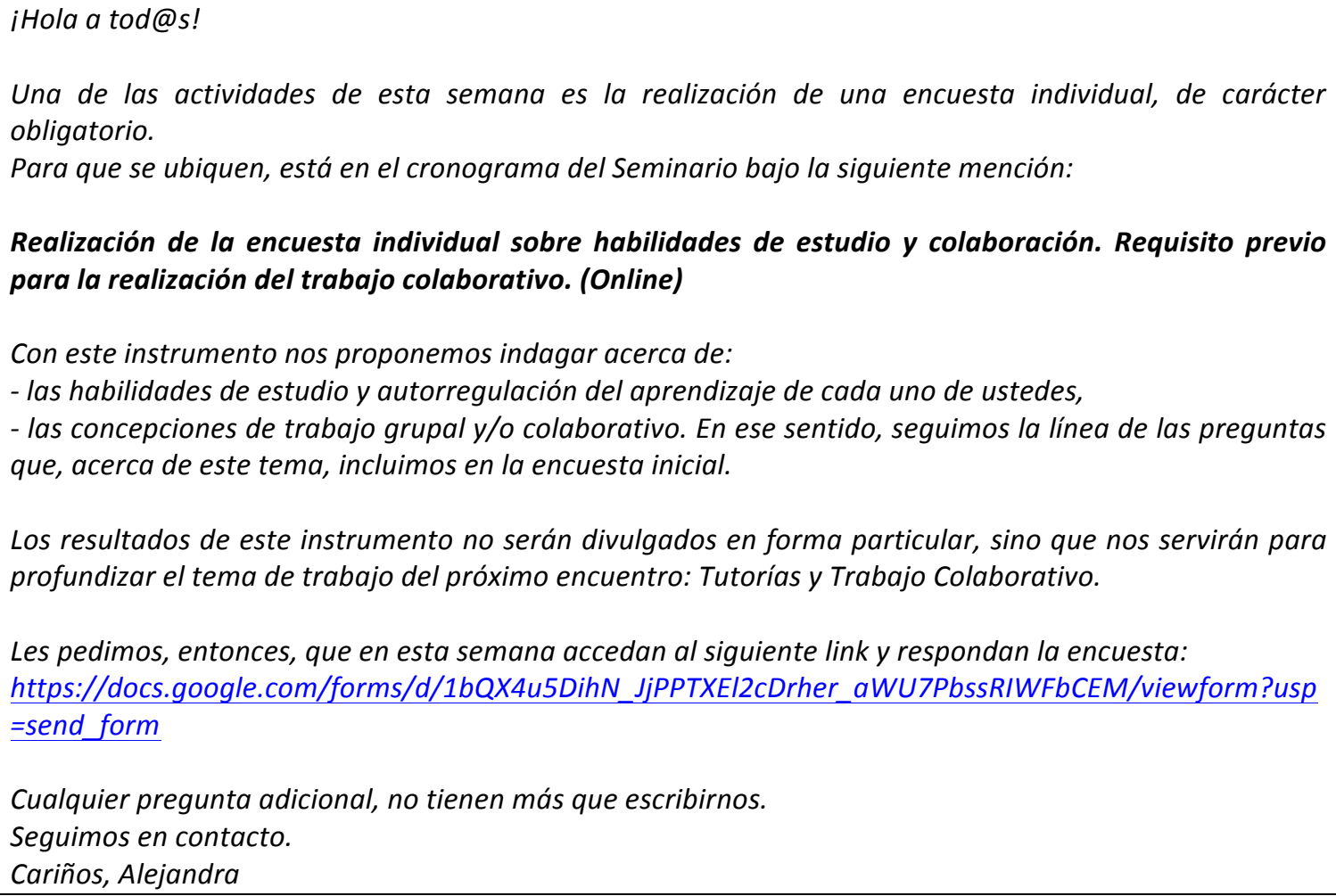

Figura 95: Comunicación de la indagación sobre autorregulación 
3er. momento. En el mensaje se incluye el link al formulario de GoogleForm.

4to. momento. Se recomienda realizar un cuidadoso seguimiento de su completamiento, enviando avisos a los alumnos que no lo completen en tiempo y forma (según el cronograma que se maneje). El seguimiento puede consistir en volver a enviar el mismo mensaje, o variaciones del mensaje, según la casuística: "perdí el link", "me olvidé de hacer la encuesta", "en el momento no la hice y ahora no recuerdo dónde guardé en mensaje con el link", etc. Este mensaje debería repetirse, al menos, una vez por semana en las próximas dos semanas para tener seguridad sobre su realización.

5to. momento. Recopilación y análisis de los resultados.

\section{Protocolo del instrumento}

Este instrumento se propone identificar el repertorio de habilidades de autorregulación en el aprendizaje que podrían favorecer el trabajo colaborativo. Para realizar este relevamiento se han organizado las habilidades en las siguientes categorías (cada una contiene una cantidad diferente de preguntas).

a. Motivación - Sostenimiento de la motivación

b. Manejo de la afectividad

c. Gestión del tiempo

d. Concentración

e. Habilidades de procesamiento de información

f. Trabajo en equipo

¡Gracias por responder!

Nombre y apellido:

\section{Motivación - Sostenimiento de la motivación}

Descripción de la categoría: Se muestra entusiasmado/a ante una nueva tarea por aprender y puede sostener su motivación durante el proceso de logro del objetivo previsto.

1. Me motivo fácilmente cuando puedo visualizarme cumpliendo el objetivo de la actividad que me es propuesta.

$\begin{array}{ll}\circ & \text { SIEMPRE } \\ \circ & \text { CASI SIEMPRE } \\ \circ & \text { A VECES } \\ \circ & \text { CASI NUNCA } \\ \circ & \text { NUNCA } \\ \circ & \text { SIN RESPUESTA }\end{array}$

2. Logro terminar todo lo que inicio.
SIEMPRE
CASI SIEMPRE
A VECES
CASI NUNCA
NUNCA
SIN RESPUESTA 
3. Identifico entre mis compañeros a quién/es podría pedirle ayuda en caso de encontrarme perdido/a.

$\begin{array}{ll}\circ & \text { SIEMPRE } \\ \circ & \text { CASI SIEMPRE } \\ \circ & \text { A VECES } \\ \circ & \text { CASI NUNCA } \\ \circ & \text { NUNCA } \\ \circ & \text { SIN RESPUESTA }\end{array}$

\section{Manejo de la afectividad}

Descripción de la categoría: Demuestra una valoración positiva hacia lo que se aprende. Se dirige hacia un objetivo que valoriza como importante para sí mismo y/o para su contexto.

4. Cuando inicio una tarea, soy consciente de la importencia que eso tiene para mí. Selecciona todas las opciones que correspondan.
- SIEMPRE
- CASI SIEMPRE
- A VECES
- CASI NUNCA
- NUNCA
- SIN RESPUESTA

5. Cuando estudio, pienso en lo que estoy haciendo (proceso) y no en cómo me saldrá (resultado).
- SIEMPRE
- CASI SIEMPRE
- A VECES
- CASI NUNCA
- NUNCA
- SIN RESPUESTA

6. Me preocupa la posibilidad de cometer errores.
- SIEMPRE
- CASI SIEMPRE
- A VECES
- CASI NUNCA
- NUNCA
- SIN RESPUESTA

\section{Gestión del tiempo}

Descripción de la categoría: Entiende que la organización del tiempo es parte importante del aprender. Hace coincidir esa (auto) planificación con los eventos de la enseñanza: encuentros, entrega de ejercicios, exámenes, organización del calendario académico, etc.

7. Dedico un momento del día a planificar mis actividades.

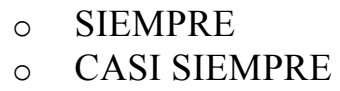



- A VECES
- CASI NUNCA
- NUNCA
- SIN RESPUESTA

8. Tengo una alta tendencia a procrastinar mis actividades. Procrastinar: Diferir, aplazar (Diccionario de la Real Academia Española).
- SIEMPRE
- CASI SIEMPRE
- A VECES
- CASI NUNCA
- NUNCA
- SIN RESPUESTA

9. Dedico unos minutos antes de comenzar a estudiar para organizarme y unos minutos después para cerrar lo realizado en esa sesión.

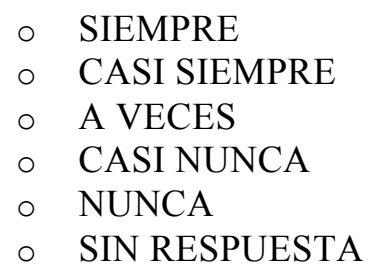

\section{Concentración}

Descripción de la categoría: Organiza la relación entre el objetivo y contenido a aprender y el tiempo disponible y el lugar de estudio. Presta la importancia debida a las tareas de repaso.

10. Organizo el material / alcance de mi trabajo en función del tiempo que dispongo.
- SIEMPRE
- CASI SIEMPRE
- A VECES
- CASI NUNCA
- NUNCA
- SIN RESPUESTA

11. Busco un lugar acorde para la tarea a realizar (luz, sonido, espacio de trabajo).
- SIEMPRE
- CASI SIEMPRE
- A VECES
- CASI NUNCA
- NUNCA
- SIN RESPUESTA

12. Me concentro en cualquier lugar para estudiar/trabajar (tren subte, colectivo).

- SIEMPRE 


\section{- CASI SIEMPRE \\ - A VECES \\ - CASI NUNCA \\ - NUNCA \\ - SIN RESPUESTA}

13. Utilizo la modalidad de estudio móvil (estudiar con material en el celular o tablet).
- SIEMPRE
- CASI SIEMPRE
- A VECES
- CASI NUNCA
- NUNCA
- SIN RESPUESTA

14. Me distraigo fácilmente. A los 10' de comenzar un estudio, encuentro algo mejor que hacer y lo dejo.

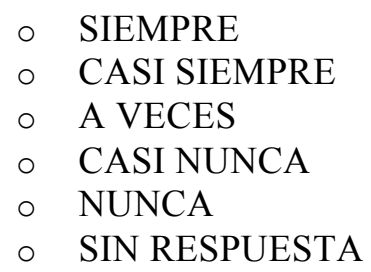

\section{Habilidades de procesamiento de información}

Descripción de la categoría: Cómo es el acceso al conocimiento en diferentes medios y soportes (impresos, multimediales, digitales) y por medio de actividades de interacción e interactividad.

15. Me considero eficiente en la búsqueda de información en Internet.
- SIEMPRE
- CASI SIEMPRE
- A VECES
- CASI NUNCA
- NUNCA
- SIN RESPUESTA

16. Cuando navego una página en Internet, me desvío a otros contenidos o páginas y termino perdiéndome.
- SIEMPRE
- CASI SIEMPRE
- A VECES
- CASI NUNCA
- NUNCA
- SIN RESPUESTA

17. Estoy acostumbrado/a a leer transversalmente (a través de títulos o índice) y así puedo encontrar lo que busco en un documento. 


$\begin{array}{ll}\circ & \text { SIEMPRE } \\ \circ & \text { CASI SIEMPRE } \\ \circ & \text { A VECES } \\ \circ & \text { CASI NUNCA } \\ \circ & \text { NUNCA } \\ \circ & \text { SIN RESPUESTA }\end{array}$

18. Para estudiar, prefiero imágenes o videos antes que textos.
- SIEMPRE
- CASI SIEMPRE
- A VECES
- CASI NUNCA
- NUNCA
- SIN RESPUESTA

19. Aprendo de leer los foros y participaciones de mis compañeros en un curso en formato digital. Prefiero eso a participar directamente.

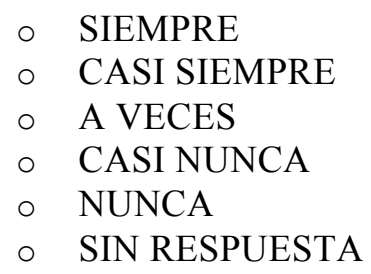

20. Para aprender un contenido, necesito hacer algo (subrayar conceptos básicos, hacer un resumen, mapa conceptual, tabla, gráfico, informe, etc.) para asegurarme de que lo sé.

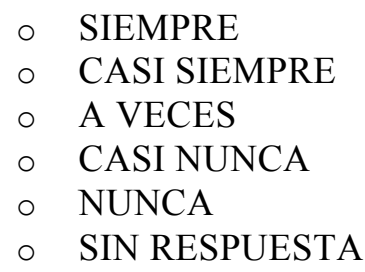

\section{Trabajo en equipo}

Descripción de la categoría: Se consulta sobre diferentes dimensiones del trabajo en equipo: motivación por el trabajo en equipo, aportes individuales en pos de la construcción del mensaje grupal, habilidades para el manejo de conflictos, importancia que le atribuye a la planificación y cómo lleva adelante lo planificado y el uso de la tecnología.

21. Me entusiasma la idea de trabajar con otros sólo si conozco a la gente y sé qué es capaz de hacer cada uno/a.
- SIEMPRE
- CASI SIEMPRE
- A VECES
- CASI NUNCA
- NUNCA
- SIN RESPUESTA 
22. Estoy convencido/a de que planificar es la mayor meta de un equipo: de ahí se desprende el trabajo que puede hacer cada uno/a.

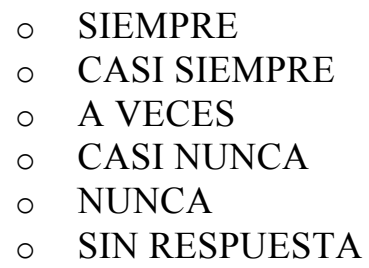

23. Leo los componentes verbales y no verbales en los mensajes generados por los miembros de mi equipo a través de la tecnología: presto atención a signos de puntuación y admiración, palabras clave, uso de emoticones, etc.
- SIEMPRE
- CASI SIEMPRE
- A VECES
- CASI NUNCA
- NUNCA
- SIN RESPUESTA

24. Soy bueno/a para proponer nuevas estrategias en el rumbo de trabajo de mi equipo.
- SIEMPRE
- CASI SIEMPRE
- A VECES
- CASI NUNCA
- NUNCA
- SIN RESPUESTA

25. En la planificación de las tareas del equipo, velo por la confianza: que cada uno cumpla con lo que se compromete a hacer.
- SIEMPRE
- CASI SIEMPRE
- A VECES
- CASI NUNCA
- NUNCA
- SIN RESPUESTA

26. Cuando expreso mis ideas en un equipo, me aseguro de que se me haya entendido.
- SIEMPRE
- CASI SIEMPRE
- A VECES
- CASI NUNCA
- NUNCA
- SIN RESPUESTA

27. Cuando una estrategia definida en el equipo no funciona, me doy cuenta rápidamente y lo hago saber al resto. 

- SIEMPRE
- CASI SIEMPRE
- A VECES
- CASI NUNCA
- NUNCA
- SIN RESPUESTA

28. Estoy convencido/a de esta idea: "entender cómo funciona la tecnología es fundamental para sacarle provecho en un trabajo -mediado- en equipo".
- SIEMPRE
- CASI SIEMPRE
- A VECES
- CASI NUNCA
- NUNCA
- SIN RESPUESTA

29. Cuando trabajo en equipo me limito a hacer mi parte: si todos hacemos nuestra parte, el equipo funciona.
- SIEMPRE
- CASI SIEMPRE
- A VECES
- CASI NUNCA
- NUNCA
- SIN RESPUESTA

30. En un equipo de trabajo, soy el que hace la síntesis y compila la entrega final. Soy muy prolijo/a con las formalidades.
- SIEMPRE
- CASI SIEMPRE
- A VECES
- CASI NUNCA
- NUNCA
- SIN RESPUESTA

31. Me cuesta aceptar cambios de rumbo en la dirección del trabajo en el equipo. Si puedo, sigo haciendo lo mío.
- SIEMPRE
- CASI SIEMPRE
- A VECES
- CASI NUNCA
- NUNCA
- SIN RESPUESTA

32. Me cuesta presentar mis puntos de vista en el trabajo en equipo.
- SIEMPRE
- CASI SIEMPRE 

- A VECES
- CASI NUNCA
- NUNCA
- SIN RESPUESTA

33. Para llevar adelante mi tarea en el equipo necesito mucha interacción con los demás. Si no la tengo, me desanimo y no hago nada.
- SIEMPRE
- CASI SIEMPRE
- A VECES
- CASI NUNCA
- NUNCA
- SIN RESPUESTA

34. Me cuesta lidiar con los caracteres de cada uno de los miembros de un equipo. Soy malo/a para ejercer la coordinación, prefiero que lo haga otro/a.
- SIEMPRE
- CASI SIEMPRE
- A VECES
- CASI NUNCA
- NUNCA
- SIN RESPUESTA

35. Me cuesta aceptar los puntos de vista de los demás si no coinciden con lo que yo pienso.
- SIEMPRE
- CASI SIEMPRE
A VECES
CASI NUNCA
NUNCA
- SIN RESPUESTA 


\section{Anexo 2: Comunicación e instrumento de indagación de impacto de la estrategia de mirroring}

\section{Comunicación de la estrategia de mirroring en MetSCIn}

Como se mencionó en el capítulo 6: "Presentación de la metodología de seguimiento y valoración del trabajo colaborativo (MetSCIn) y avances en su validación”, el primer paso es informar a los interesados sobre la estrategia de mirroring que se implementará. Un mensaje tipo se presenta en la figura 96.

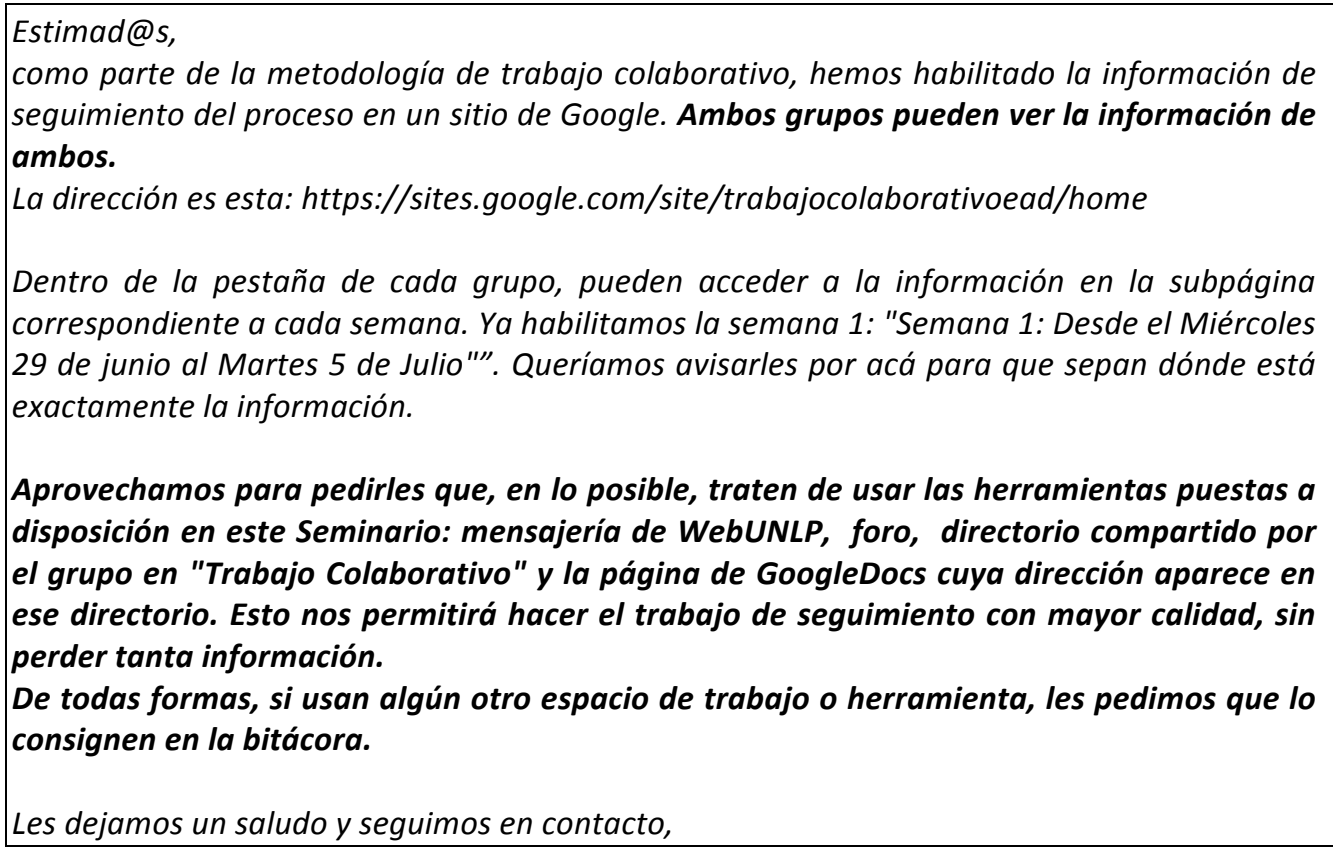

Figura 96: Comunicación inicial de la estrategia de mirroring

Cada semana, se recomienda que se refuerce la publicación de la información en el entorno que se decida con un mensaje público, como el que aparece en la figura 97.

Estimad@s,
les avisamos que ya hemos subido al sitio:
https://sites.google.com/site/trabajocolaborativoead/home la información de seguimiento
de la [tercera semana como ejemplo] del trabajo colaborativo.
Recuerden que deben entrar a la información del su grupo y luego al link de la [tercera]
semana.
Cariños, Alejandra

Figura 97: Comunicación semanal de la estrategia de mirroring 
En la última semana, se recomienda un mensaje de cierre, que aparece en la figura 98.

Estimad@s,
les avisamos que ya hemos subido al $\quad$ sitio:
https://sites.google.com/site/trabajocolaborativoead/home la información de seguimiento
de la [sexta y última] semana del trabajo colaborativo. Recuerden que deben entrar a la
información del su grupo y luego al link de la sexta semana.
Esta vez, además, insertamos en la pestaña "Encuesta individual (en GoogleForm)" la
encuesta final, en la que le pedimos su opinión acerca del trabajo individual, grupal y del
impacto de la información que hemos ido publicando semanalmente en el trabajo de estas
seis semanas.
Les pedimos que, cuando tengan un momento, la respondan. Será de gran utilidad para
nosotros.
iHan hecho un gran trabajo!
iFelicitaciones!

Figura 98: Comunicación final de la estrategia de mirroring

\section{Indagación del impacto del mirroring en el trabajo colaborativo en MetSCIn}

En este formulario le solicitamos que registre su opinión acerca del trabajo colaborativo que acaba de finalizar. Se ha dividido en 5 secciones:

1. Datos personales

2. Trabajo individual

3. Uso de herramientas

4. Trabajo grupal

5. Impacto de la estrategia de mirroring

Desde ya, agradecemos su opinión y comentarios.

Datos personales

Nombre y apellido:

\section{Número de grupo}

GRUPO 1

GRUPO 2

\section{Trabajo individual}

Descripción de la categoría: En esta sección le requerimos información acerca de su aporte individual al trabajo colaborativo.

1. En la primera etapa del trabajo, ¿comprendí correctamente la consigna individual que me encomendaron?

SI

NO 
2. ¿Había trabajado las ideas de los links/textos investigados al momento de conocer la consigna grupal?

SI

NO

2.a. Si no fue así, explique las causas

- No tuve tiempo

- No entendí la consigna

- No supe manejar la tecnología

- No pude discriminar niveles de información significativos en la información obtenida

○ Otros

3. ¿Qué cree que le ha aportado la tecnología a la realización de esta actividad?

4. ¿Cuánto le ha permitido aprender acerca del aprendizaje colaborativo la realización de esta actividad?

\section{Uso de herramientas}

Descripción de la categoría: En el trabajo conjunto ¿qué herramientas utilizaron y para qué? 5. ¿Qué herramientas de WebUNLP utilizaron en el trabajo colaborativo?

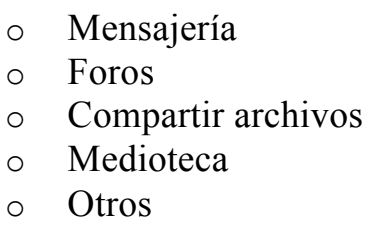

6. ¿Qué herramientas por fuera de WebUNLP utilizaron en el trabajo colaborativo?

- Formulario de GoogleDocs

- Repositorios compartidos en Drive o Dropbox

- Grupos de WhatsApp

- Cuentas de mail particulares

- Mensajes de texto

- Videoconferencia mediante Skype o HangOut

- Llamadas telefónicas (teléfonos fijos o celulares)

- Grupos de Facebook

- Twitter

- Otras redes sociales

- Otras herramientas informáticas en general

○ Otros

6.a Indique cualquier información que pueda resultar de interés acerca de cómo usaron estas herramientas

7. ¿Hicieron reuniones presenciales para realizar parte o toda la tarea colaborativa? (no considere la reunión inicial del encuentro 3, donde se entregó la consigna)

SI

NO

7.a. Si se realizaron reuniones presenciales, indique qué tareas llevaron adelante en esas reuniones 


\section{Trabajo grupal}

Descripción de la categoría: En la escritura colaborativa ¿cómo se completaron las siguientes tareas? Les pedimos que indiquen si consideraron cada uno de estos aspectos de la escritura colaborativa y, si lo hicieron, describa brevemente cómo se dividieron las tareas y las personas en el grupo para llevarlas adelante.

8.a. ¿Abordaron en la tarea grupal la definición de la estructura de lo que se quiere decir? (índice o mapa del libro)

SI

NO

Si lo hicieron, describa brevemente cómo

8.b. ¿Chequearon que todas las voces (las investigaciones previas en la etapa de la consigna individual) estén representadas?

SI

NO

Si lo hicieron, describa brevemente cómo

8.c. ¿Se aseguraron de la "función transaccional" de la escritura, ésto es asegurarse de que se entienda lo que se escribe?

SI

NO

Si lo hicieron, describa brevemente cómo

8.d. ¿Se preocuparon por la cohesión y cierre del texto, que las ideas se entiendan y el texto sea coherente y tenga sentido?

SI

NO

Si lo hicieron, describa brevemente cómo

8.e. ¿Se preocuparon por la "función representativa o ideacional" de la escritura colaborativa?

Esto es asegurarse de que lo que se escribe representa la idea que el grupo quiere transmitir

SI NO

Si lo hicieron, describa brevemente cómo

8.f. ¿Se llevaron adelante estrategias de repaso y emprolijamiento del texto? Cuestiones gramaticales, ortográficas, de organización (márgenes, tipografía, espacios, imágenes, etc.). SI

NO

Si lo hicieron, describa brevemente cómo

8.g. Describa brevemente cómo se preparó la entrega del trabajo: cantidad y nombre de archivos, herramientas utilizadas, responsables, etc.

\section{Impacto de la estrategia de mirroring}

Descripción de la categoría: En esta sección nos interesa conocer su opinión acerca de cómo influyó en el proceso y producto del grupo el conocer, con actualización semanal, los indicadores de trabajo colaborativo que hemos puesto a disposición en el sitio de Google: https://sites.google.com/site/trabajocolaborativoead/home

9. ¿Cuántas veces visualizó el sitio de información del proceso colaborativo? * 


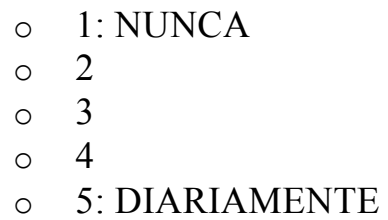

¿Por qué? Explique su respuesta anterior

Sólo debe responder a las preguntas restantes si ha visualizado la estrategia de "mirroring" en el sitio dispuesto para esto. ( $\mathrm{O}$ sea, si ha respondido un número mayor a 1 en la pregunta anterior)

10. ¿Cuánto le sirvió tener la información de los indicadores que se identificaron para realizar el seguimiento en cada semana del trabajo colaborativo?

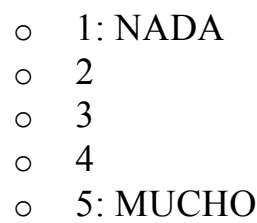

¿Por qué? Explique su respuesta anterior

11. ¿Prestó más atención a los indicadores individuales o a los grupales?

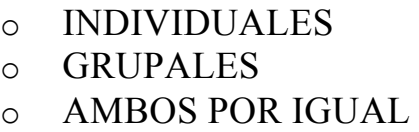

¿Por qué? Explique su respuesta anterior

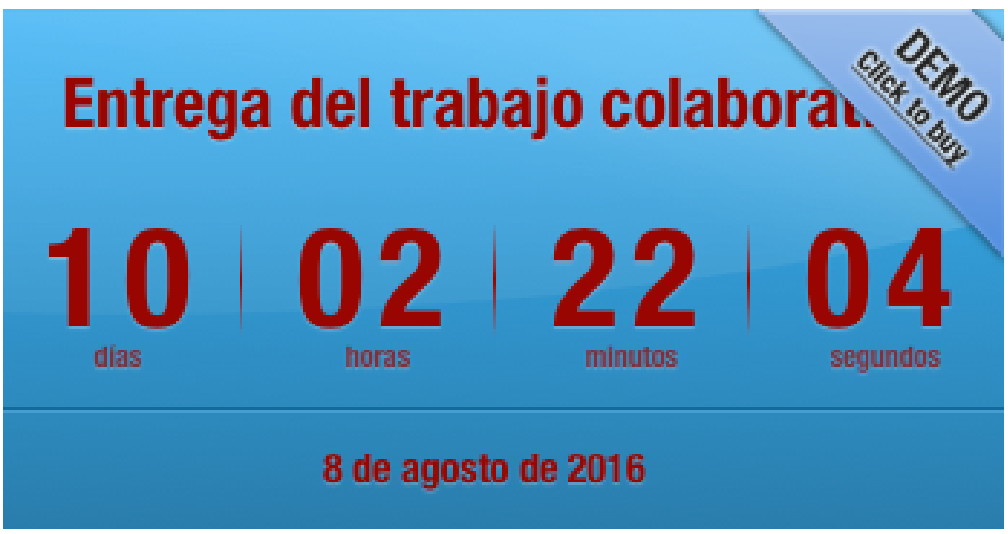

12. ¿Qué importancia le asignó a la información sobre el tiempo restante para entregar el trabajo que apareció en el sitio a partir de la segunda semana (con el reloj en modo "cuenta regresiva" que puede verse arriba)?

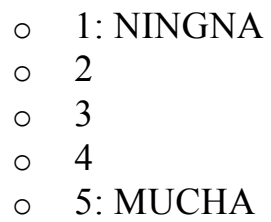


13. Una vez que comenzó a ver la información semanal: ¿Le prestó más atención a: la información propia, la información de lo producido por los compañeros de su grupo o a la información de lo producido por el otro grupo?

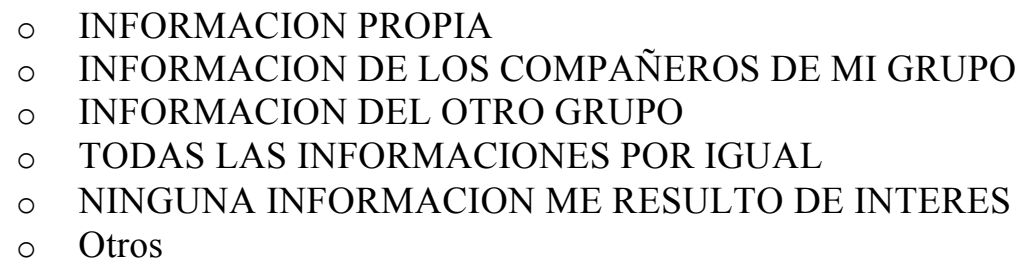

Explique su respuesta anterior

14. ¿Qué tipo de información le resultó de más utilidad?

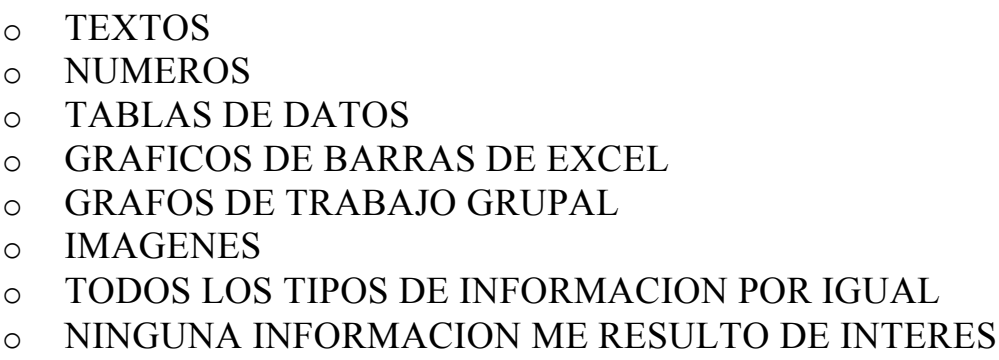

Explique su respuesta anterior

15. ¿Cuál fue la información que le resultó más novedosa o impactante de la que se presentó en el sitio de seguimiento del trabajo colaborativo?

16. ¿Qué decisiones se modificaron en función de la información mostrada en el sitio? (se dividen las opciones en tres aspectos: afectividad, contenido, organización)

- Organización: Manejo del tiempo: Planificación /cronograma

- Organización: Armado de la bitácora

- Organización: Participación equilibrada de todos los integrantes del grupo (todos intervienen)

- Organización: Aviso al grupo de disponibilidad individual de tiempo (descanso, vacaciones de invierno, por ejemplo)

- Contenido: Incorporación de todos los temas

- Contenido: Tratamiento de todos los temas con la misma importancia

- Contenido: Apertura y cierre de temas de forma ordenada y rápida (se tratan todos y tratan de cerrarse)

- Contenido: Mejora del producto del grupo

- Afectividad: Motivación para que todos participen en el trabajo grupal (por ejemplo, atendiendo los trabajos individuales de la gente que dejó el seminario)

- Afectividad: Atención de conflictos internos para que no influyan en el trabajo grupal

- Afectividad: Mensajes de motivación de los compañeros para que no se desalienten y hagan su parte

- Otros

Profundice en cualquier punto que desee de su respuesta anterior 
17. En su opinión ¿cuánto influyó en el trabajo colaborativo tener disponible la información del proceso en forma semanal?

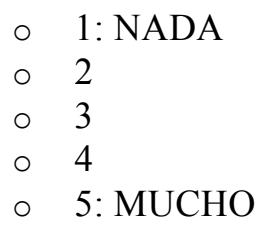

Explique su respuesta anterior

18. Consigne cualquier información de interés que no le haya sido requerida en este formulario, en cualquiera de sus secciones (trabajo invidual, grupal o estrategia de seguimiento) 


\section{Anexo 3: Comunicación e instrumento de indagación del juicio de expertos}

\section{Comunicación de la estrategia de juicio de expertos}

Para informar a los expertos de esta estrategia, y solicitarles su colaboración, se envió un primer mensaje a través de email (con copia oculta a cada uno) con el texto que se presenta en la figura 99.

Estimad@s colegas,
Espero que se encuentren muy bien.

El motivo de este contacto es pedirles su colaboración como parte de un proyecto de investigación que estamos desarrollando en [indicación del proyecto y lugar de desarrollo de este trabajo]. Nos proponemos construir una matriz de indicadores que permitan describir, realizar el seguimiento y evaluar actividades colaborativas.

Para eso, redefinimos el concepto de trabajo colaborativo, con sus componentes y etapas, identificamos posibles indicadores y buscamos formas de operacionalizarlos en una actividad colaborativa particular, que desarrollamos en [caso de estudio]". Este trabajo se está desarrollando en el marco de una tesis de Doctorado [tesis de doctorado donde se enmarca el estudio].

La colaboración que les requerimos consiste en ayudarnos a validar, mediante el juicio de expertos, la matriz de indicadores que hemos construido y su operacionalización. Como profundos conocedores en el área de trabajo grupal y colaborativo desde diferentes disciplinas, sería de gran valor para nosotros contar con su calificada opinión. Luego de la concordancia de las opiniones, le haremos llegar el informe correspondiente.

El formulario de consulta está desarrollado en GoogleForm. Requerimos algunos datos particulares al inicio, que sólo servirán para analizar las respuestas, haciendo un corte por disciplina. La respuesta al formulario le llevará entre 20 y 25'.

Esperamos su conformidad para enviarles el link correspondiente. Luego de ese envío, estimamos un tiempo de dos a tres semanas para recibir las respuestas.

Desde ya quedamos muy agradecidos por esta colaboración.

Un cordial saludo,

Figura 99: Comunicación inicial del juicio de expertos. Grupal

Una vez que cada experto hubo respondido afirmativamente, aceptando colaborar, se envió el link al instrumento y se recordó el tiempo estimado para la realización del trabajo. Este mensaje fue privado y personalizado a cada un@ y se presenta en la figura 100. 


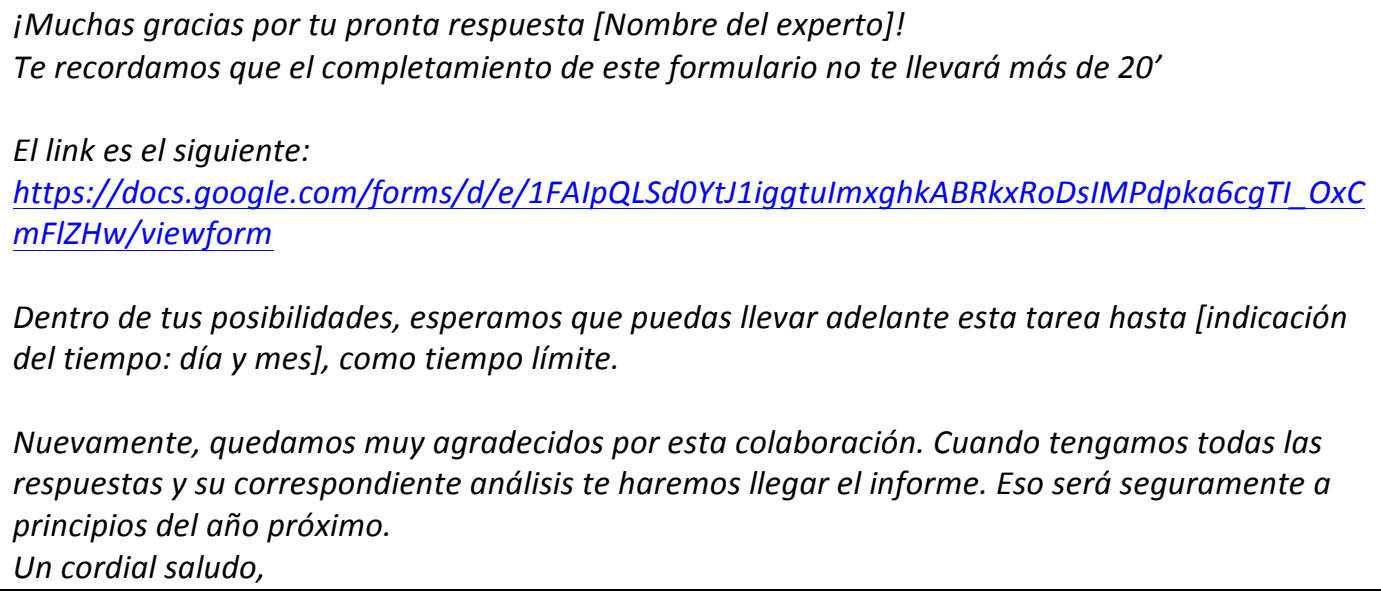

Figura 100: Segunda comunicación del juicio de expertos. Individual

\section{Instrumento de indagación del juicio de expertos}

A continuación se presenta el instrumento, tal como aparece en el sitio de GoogleForm.

\section{Indicadores para la descripción y seguimiento del trabajo colaborativo - Evaluación de validez mediante el juicio de expertos}

Estimado colega:

¡Muchas gracias por colaborar en este trabajo de validación!

Nos interesa conocer su opinión sobre la validez de contenido y de criterio de una matriz de indicadores que hemos construido para describir y realizar el seguimiento de actividades de trabajo colaborativo, cuya resolución requiera de estructuras de comunicación verbal, mediadas por tecnología informática. Nos guía la idea de que la completa definición de estas actividades, a partir de la descripción de los indicadores que aquí se presentan, permitirá describir este tipo de trabajo, avanzar en su seguimiento y realizar intervenciones didácticas oportunas. Este instrumento consta de cinco secciones:

SECCION 1. Datos personales del experto y experiencia en el área de trabajo grupal y colaborativo

SECCION 2. Opinión sobre el concepto de trabajo colaborativo y sus componentes

SECCION 3. Análisis de la dimensión individual - indicadores

SECCION 4. Análisis de la dimensión grupal - indicadores

SECCION 5. Matriz completa de indicadores

Cuando tengamos los resultados de concordancia, nos comunicaremos con ustedes para hacerle llegar las conclusiones de esta indagación.

Le llevará alrededor de 20' responder a este cuestionario.

¡Volvemos a agradecerle su atención!

\section{SECCION 1. Datos personales del experto y experiencia en el área de trabajo grupal y} colaborativo

1. Nombre y apellido

2. Formación académica (Puede indicar título de grado y postgrado) 
3. Area de experiencia profesional

4. Institución donde trabaja (indique la institución donde trabaja más tiempo de la semana)

5. Cargo que desempeña en dicha Institución

6. ¿Qué grado de especialización considera que posee respecto al trabajo en grupos y colaborativo?

NIVEL 1: No es un tema de gran interés para mí, prefiero otros

NIVEL 2: Conozco de este tema, como de otros de mi especialidad

NIVEL 3: Investigo y estudio el tema

NIVEL 4: Investigo y he escrito sobre el tema, con gran influencia en la comunidad científica

7. ¿Qué grado de expertise estima que posee respecto del trabajo colaborativo mediado por tecnología digital?

NIVEL 1: No es un tema de gran interés para mí, prefiero otros

NIVEL 2: Conozco de este tema, como de otros de mi especialidad

NIVEL 3: Investigo y estudio el tema

NIVEL 4: Investigo y he escrito sobre el tema, con gran influencia en la comunidad científica

\section{SECCION 2. Opinión sobre el concepto de trabajo colaborativo y sus componentes}

En esta sección le requerimos su opinión (expresada en grado de acuerdo o desacuerdo) sobre el concepto de trabajo colaborativo y sus componentes conceptuales.

8. ¿En qué grado acuerda con esta definición de trabajo colaborativo? "Es un tipo especial de trabajo en grupo que promueve el desarrollo de habilidades de aprendizaje, personales y sociales, en el que cada miembro expresa compromiso tanto con su propio aprendizaje como con el de los demás miembros de su grupo. Son elementos básicos la interdependencia positiva, la interacción, la contribución individual y la construcción grupal"

GRADO 1: Completo desacuerdo

GRADO 2. Algo en desacuerdo

GRADO 3. Ni acuerdo ni desacuerdo

GRADO 4. Algo de acuerdo

GRADO 5. Completo acuerdo

9. ¿En qué grado acuerda con esta idea? "La interdependiencia positiva es el reconocimiento de los miembros de un grupo y la necesidad mutua en pos de la tarea compartida. Depende del uso de recursos compartidos con actividades compartidas, con contraposición de opiniones, consenso de conocimientos alcanzados y roles diferenciados y complementarios". [Extraído y modificado de Salomon, Perkins \& Globerson, 1992]

GRADO 1: Completo desacuerdo

GRADO 2. Algo en desacuerdo

GRADO 3. Ni acuerdo ni desacuerdo

GRADO 4. Algo de acuerdo

GRADO 5. Completo acuerdo

10. ¿En qué grado acuerda con esta idea? "La interdependiencia positiva, esencial para la colaboración, puede analizarse en la dimensión individual (lo que cada miembro aporta) y grupal (lo que el grupo construye en su interacción y mediante las herramientas tecnológicas". 


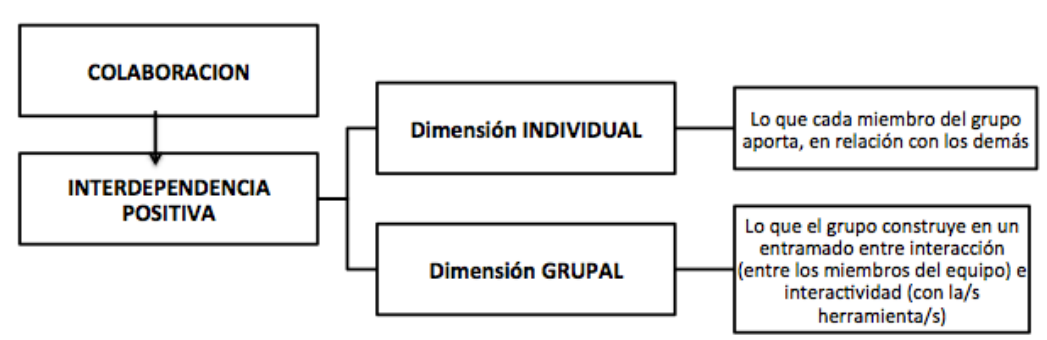

GRADO 1: Completo desacuerdo

GRADO 2. Algo en desacuerdo

GRADO 3. Ni acuerdo ni desacuerdo

GRADO 4. Algo de acuerdo

GRADO 5. Completo acuerdo

\section{SECCION 3. Análisis de la dimensión individual - indicadores}

En esta sección le requerimos su opinión (expresada en grado de acuerdo o desacuerdo) sobre los indicadores construidos para el análisis de la dimensión individual del trabajo colaborativo.

11. ¿En qué grado acuerda con la idea de que los mensajes que un grupo de personas intercambian en la realización de una tarea colaborativa, en un entorno informático (mensajería o foro, por ejemplo) tienen diferentes componentes lingüísticos: organización (de la tarea), tratamiento del contenido y afectividad?

GRADO 1: Completo desacuerdo

GRADO 2. Algo en desacuerdo

GRADO 3. Ni acuerdo ni desacuerdo

GRADO 4. Algo de acuerdo

GRADO 5. Completo acuerdo

12. ¿En qué grado acuerda con esta idea? "Los indicadores de cantidad y tipos de mensajes de cada miembro del grupo pueden dar cuenta de la contribución individual al trabajo, o sea la dimensión individual del concepto de interdependiencia positiva". Nota: Los tipos de mensaje devienen de las dimensiones estructural y social de la comunicación grupal [Gunawardena, 1997; Hatrom, 2004]. Se consideran los tipos de mensajes como referidos a la organización, al contenido y a la afectividad.

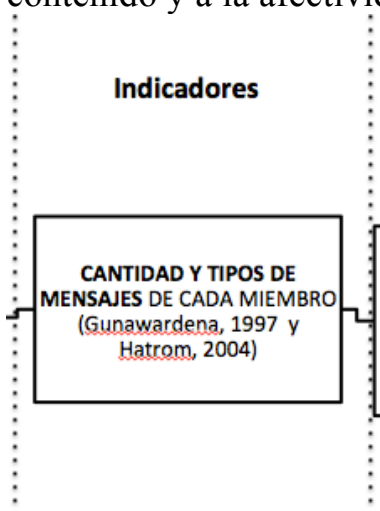

GRADO 1: Completo desacuerdo

GRADO 2. Algo en desacuerdo

GRADO 3. Ni acuerdo ni desacuerdo

GRADO 4. Algo de acuerdo

GRADO 5. Completo acuerdo 
13. ¿En qué grado acuerda con la idea de que la operacionalización de los indicadores de interdependencia podría realizarse mediante el análisis de los mensajes intercambiados por los miembros de un grupo? Esto significa que analizando los tipos de mensajes que se intercambian, se daría cuenta de la interdependencia del grupo.

Operacionalización

MENSAJES POR TIPO:

ORGANIZACIÓN

TRATAMIENTO DEL

CONTENIDO Y

AFECTIVIDAD

GRADO 1: Completo desacuerdo

GRADO 2. Algo en desacuerdo

GRADO 3. Ni acuerdo ni desacuerdo

GRADO 4. Algo de acuerdo

GRADO 5. Completo acuerdo

14. ¿Considera que hay algún otro indicador de la producción individual que no se haya

considerado?

SI

NO

14a. Si respondió "SI" en la pregunta anterior, por favor indique cuál/es (y, si es posible, la fuente de información)

\section{SECCION 4. Análisis de la dimensión grupal - indicadores}

En esta sección le requerimos su opinión (expresada en grado de acuerdo o desacuerdo) sobre los indicadores construidos para el análisis de la dimensión grupal del trabajo colaborativo.

15. ¿En qué grado acuerda con esta idea? "Para que se produzca construcción colaborativa debe haber un entendimiento mutuo desde el punto de vista del significado de lo que se dice o escribe. La colaboración es un proceso de construcción de significados compartidos". [Stahl, Koschmann $\&$ Suthers, 2006 y Baker et al. (en Spermon et al., 2014)]

GRADO 1: Completo desacuerdo

GRADO 2. Algo en desacuerdo

GRADO 3. Ni acuerdo ni desacuerdo

GRADO 4. Algo de acuerdo

GRADO 5. Completo acuerdo

16. ¿En qué grado acuerda con esta idea? "La cohesión de la comunicación representa la difusión de la información en el grupo: cuanto más cohesionada, mejor fluye la información entre todos los miembros del grupo". [Reyes \& Tchounikine en Dimitrakopoulou et al., 2006]

GRADO 1: Completo desacuerdo

GRADO 2. Algo en desacuerdo

GRADO 3. Ni acuerdo ni desacuerdo

GRADO 4. Algo de acuerdo

GRADO 5. Completo acuerdo 
17. ¿En qué grado acuerda con la idea de que la operacionalización de los indicadores de construcción semántica podría realizarse mediante el análisis de las conversaciones de un grupo, que identifiquen los tópicos trabajados y el tiempo de duración de cada uno? Nota: en el gráfico siguiente se muestran, por semana y por colores, los temas de conversación que se trataron en un grupo. Las letras que aparecen en cada recuadro corresponden a los datos de los integrantes del grupo involucrados en esa conversación.

\begin{tabular}{|c|c|c|c|c|c|c|}
\hline $\begin{array}{l}\text { Compartir trabajos } \\
\text { individuales }\end{array}$ & LH & LH - SB & $\begin{array}{l}\text { OC- LH- } \\
\text { OS }\end{array}$ & LH & $\begin{array}{l}\text { LH JMM } \\
\text { (palabra } \\
\text { clave) }\end{array}$ & OC - LH \\
\hline Bitácora & JMM - LH & LH - LH & & & & LH - JMM \\
\hline $\begin{array}{l}\text { Planificación del trabajo } \\
\text { colaborativo }\end{array}$ & & OS - LH & $\begin{array}{l}\text { OC-OS- } \\
\text { LH- JMM }\end{array}$ & os & LH JMM & $\begin{array}{l}\text { OS- LH - } \\
\text { LMM }\end{array}$ \\
\hline $\begin{array}{l}\text { Situación de estudiante que } \\
\text { dejó el Seminario }\end{array}$ & & & os & $\begin{array}{l}\text { LH } \\
\text { (Comparte } \\
\text { trabajo) }\end{array}$ & & \\
\hline Aviso de vacaciones & & & os & & & \\
\hline Titulo del libro & & & & & LH - JMM & \\
\hline Organización del libro & & & & & $\begin{array}{l}\text { JMM (de lo } \\
\text { general a lo } \\
\text { particular) }\end{array}$ & JMM - LH \\
\hline Prólogo del libro & & & & & & $\begin{array}{l}\text { OS - LH- } \\
\text { JMM }\end{array}$ \\
\hline $\begin{array}{l}\text { Diferencia entre } \\
\text { "currículum" y "currícula" }\end{array}$ & & & & & & LH - JMM \\
\hline $\begin{array}{l}\text { Síntesis de estado del } \\
\text { trabajo }\end{array}$ & & & & & & OS- LH \\
\hline Formato de entrega & & & & & & SB - OS \\
\hline \multirow[t]{3}{*}{ Envío } & & & & & & $\begin{array}{l}\text { OS-JMM- } \\
\text { LH }\end{array}$ \\
\hline & $\begin{array}{l}\text { Semana del } \\
29 / 6 \text { al } 5 / 7\end{array}$ & $\begin{array}{c}\text { Semana del } \\
6 \text { al } 12 / 7\end{array}$ & $\begin{array}{c}\text { Semana del } \\
13 \text { al } 19 / 7\end{array}$ & $\begin{array}{l}\text { Semana del } \\
20 \text { al } 26 / 7\end{array}$ & $\begin{array}{l}\text { Semana del } \\
27 / 7 \text { al } 2 / 8\end{array}$ & $\begin{array}{c}\text { Semana de } \\
\quad 3 \text { al } 8 / 7\end{array}$ \\
\hline & 1 & 2 & 3 & 4 & 5 & 6 \\
\hline
\end{tabular}

GRADO 1: Completo desacuerdo

GRADO 2. Algo en desacuerdo

GRADO 3. Ni acuerdo ni desacuerdo

GRADO 4. Algo de acuerdo

GRADO 5. Completo acuerdo

18. ¿En qué grado acuerda con este mapa de indicadores que dan cuenta de la construcción grupal en el trabajo colaborativo? 


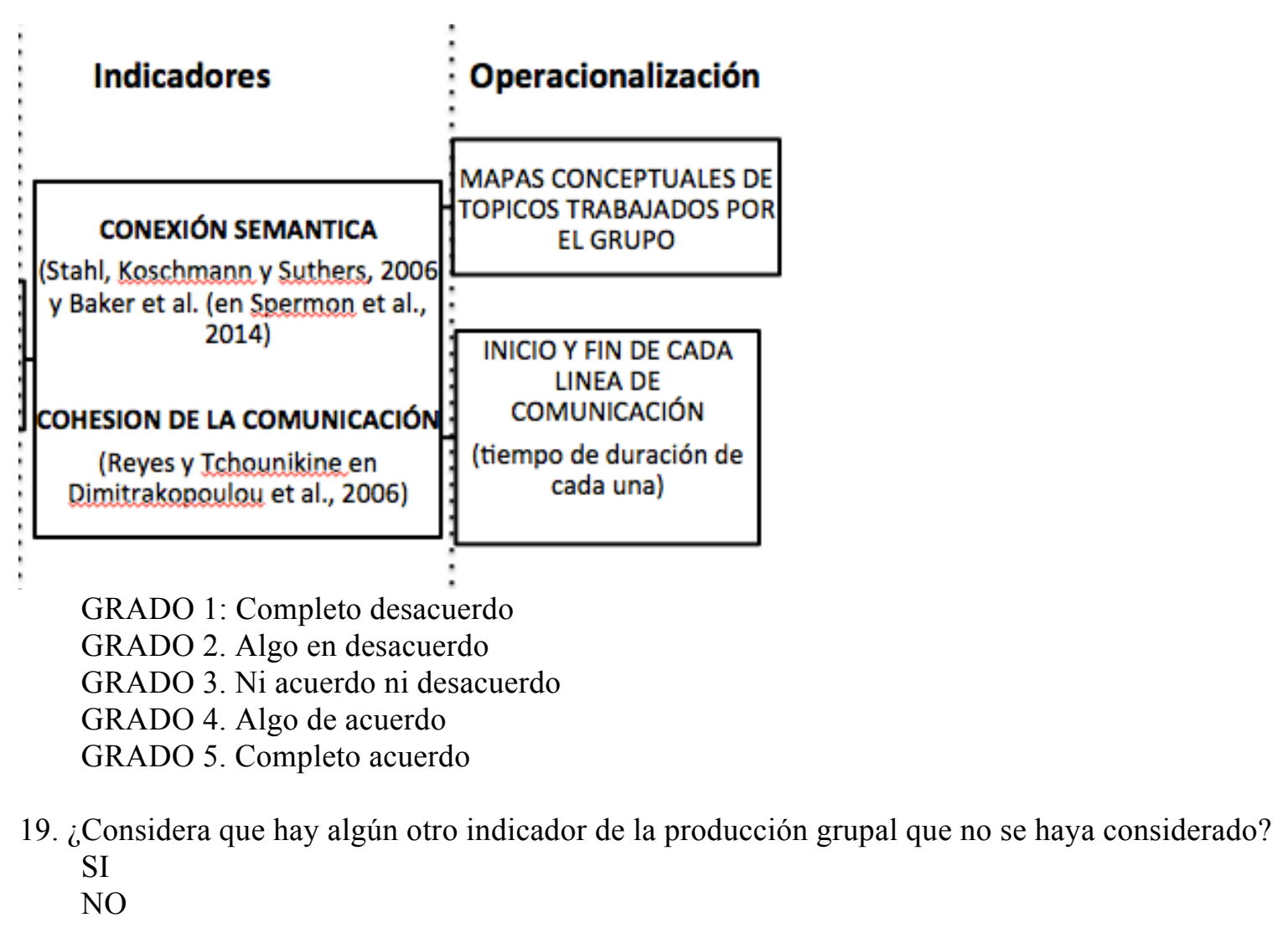

19.a. Si respondió "SI" en la pregunta anterior, por favor indique cuál/es (y, si es posible, la fuente de información)

\section{SECCION 5. Matriz completa de indicadores}

En esta sección le requerimos su opinión (expresada en grado de acuerdo o desacuerdo) la matriz completa y su operacionalización.

20. ¿En qué grado acuerda con la idea completa presentada aquí? a. que la colaboración requiere de la interdependencia positiva; b. que ésta tiene una dimensión individual y otra grupal; c. que la dimensión individual puede analizarse por la cantidad y tipos de mensajes aportados por cada miembro de un grupo; d. que en el análisis de la dimensión grupal debe hacerse foco en la construcción de significados; e. que esta construcción puede seguirse mediante el análisis de los mapas conceptuales de los tópicos tratados; f. que la cohesión semántica de la comunicación da indicios de la consistencia del grupo en tanto inicia y cierra todos los temas tratados y g. que el tiempo que media entre el inicio y cierre de cada tópico da idea de cohesión grupal.

GRADO 1: Completo desacuerdo

GRADO 2. Algo en desacuerdo

GRADO 3. Ni acuerdo ni desacuerdo

GRADO 4. Algo de acuerdo

GRADO 5. Completo acuerdo

\section{Matriz completa de indicadores de descripción y seguimiento del trabajo colaborativo}




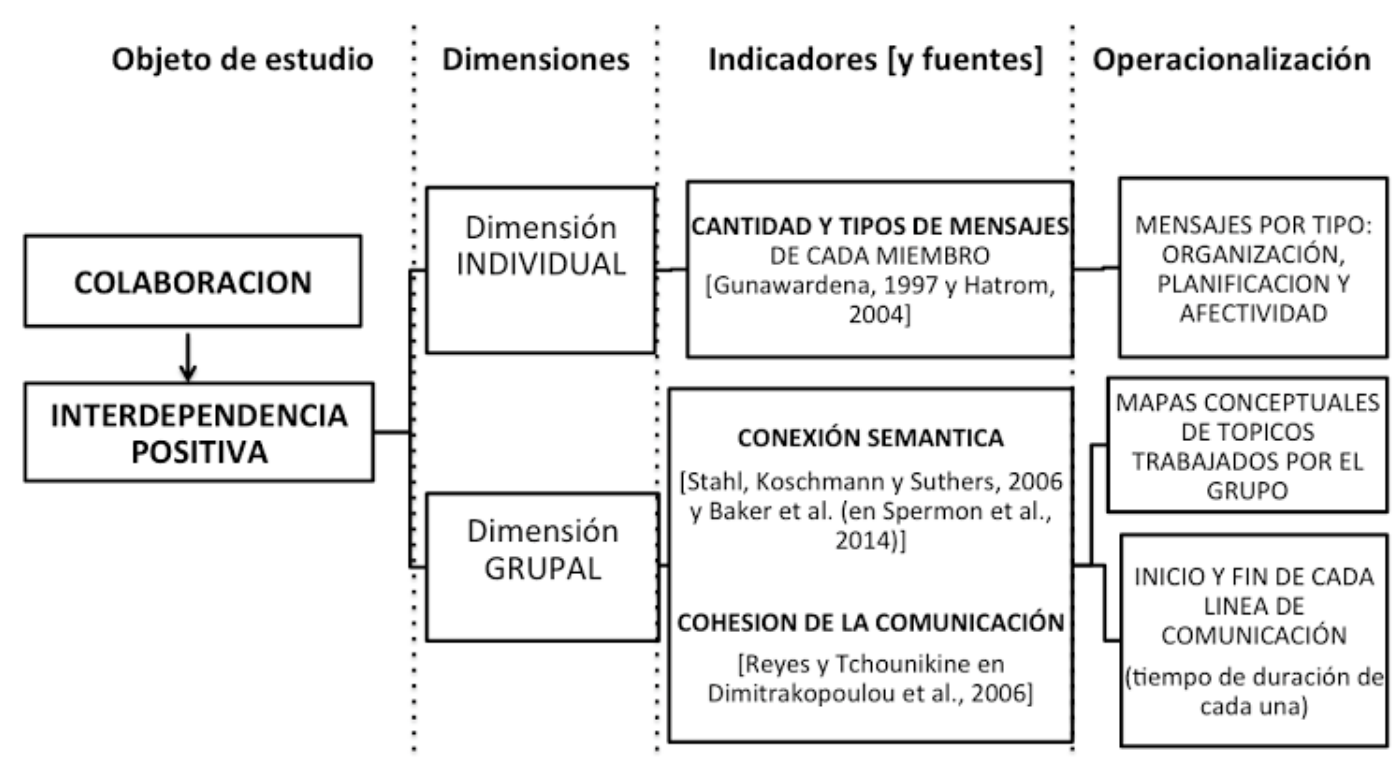

21. ¿En qué grado acuerda con la matriz de indicadores y su operacionalización, presentada en la figura anterior?

GRADO 1: Completo desacuerdo

GRADO 2. Algo en desacuerdo

GRADO 3. Ni acuerdo ni desacuerdo

GRADO 4. Algo de acuerdo

GRADO 5. Completo acuerdo

22. ¿Considera que hay algún otro indicador o relación de indicadores o su operacionalización que no se haya considerado?

SI

NO

22.a. Si respondió "SI" en la pregunta anterior, por favor indique cuál/es (y, si es posible, la fuente de información) 


\section{Anexo 4: Resultados del estudio de caso por cohorte y por grupo}

En este anexo se presentan los resultados al interior de cada grupo en cada cohorte, según la siguiente estructura:

- Conformación de los grupos de trabajo de las cohortes 2015 y cohorte 2016.

- Dimensión individual de la colaboración. Densidad y calidad de la interacción por grupo.

- Dimensión grupal: conexión semántica.

\section{Conformación de los grupos de trabajo}

Se presenta a continuación la información de los integrantes de cada grupo dentro de cada cohorte.

\section{Cohorte 2015}

Los grupos de trabajo colaborativo fueron 3, de 6 personas cada uno. En la figura 101 se presenta su conformación y otros datos de interés.

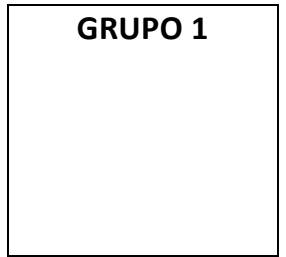

GRUPO 2

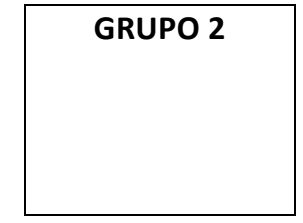

GRUPO 3
4 mujeres, 2 hombres.

4 Informáticos, 1 Licenciada en Comunicación Visual, 1 Licenciada en Matemática.

Experiencia docente ${ }^{21}: 100 \%$ con experiencia.

Lugar de residencia: La Pampa: 1 estudiante; Buenos Aires: 2 estudiantes y La

Plata: 3 estudiantes

4 mujeres, 2 hombres.

5 Informáticos, 1 Licenciada en Comunicación Social.

Experiencia docente: $100 \%$ con experiencia.

Lugar de residencia: La Plata: 3 estudiantes; Corrientes: 1 estudiante y Luján:

1 estudiante

4 mujeres, 2 hombres.

3 Informáticos, 1 Licenciada en Comunicación Social, 2 Profesoras de Lengua y Literatura Inglesa.

Experiencia docente: 5 de los 6 se desempeñan como docentes.

Lugar de residencia: Buenos Aires: 2 estudiantes y La Plata: 4 estudiantes

Figura 101: Datos de entrada de los tres subgrupos de la cohorte 2015

\footnotetext{
${ }^{21}$ Nótese que se hace referencia a la experiencia docente y no a la formación docente sistemática.
} 


\section{Cohorte 2016}

Los grupos de trabajo colaborativo fueron 2, uno de 5 y otro de 6 personas. En la figura 102 se presenta su conformación y otros datos de interés.

\begin{tabular}{|l|}
\hline GRUPO 1 \\
\end{tabular}

2 mujeres, 3 hombres.

3 Informáticos, 1 Licenciada en Lengua Inglesa, 1 Médica Veterinaria.

Experiencia docente: $80 \%$ con experiencia (4 de 5 ).

Lugar de residencia: La Plata: 2 estudiantes; Concepción del Uruguay (Entre

Ríos): 1 estudiante; Ushuaia: 1 estudiante y Santiago del Estero: 1 estudiante

GRUPO 2

1 mujer, 5 hombres.

4 Informáticos, 1 Licenciado en Letras, 1 Médica Veterinaria

Experiencia docente: $100 \%$ con experiencia.

Lugar de residencia: La Plata: 2 estudiantes; Buenos Aires: 2 estudiantes; Río

Negro: 1 estudiante y Lomas de Zamora: 1 estudiante

Figura 102: Datos de entrada de los dos subgrupos de la cohorte 2016

\section{Dimensión individual de la colaboración. Densidad y calidad de la interacción por grupo}

En cada cohorte se presenta, por cada grupo, la densidad de interacción por etapa y la calidad de mensajes por etapa.

\section{Cohorte 2015}

La densidad de interacción por etapa puede visualizarse en la figura 103.

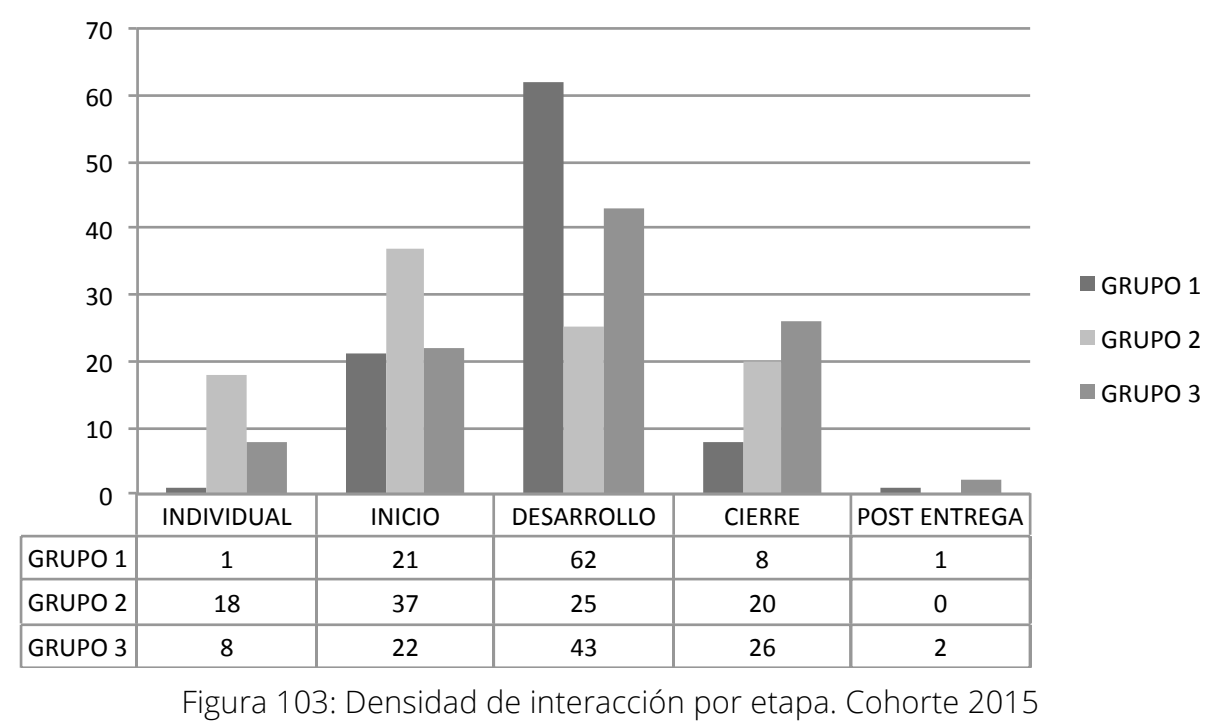

El promedio de mensajes por etapa (cantidad de mensajes sobre la cantidad de días de cada etapa) es el que se presenta en la tabla 45. 


\begin{tabular}{|c|c|c|c|c|}
\hline \multicolumn{2}{|r|}{ ETAPAS } & \multirow{3}{*}{$\begin{array}{r}\text { GRUPO } 1 \\
0.2 \\
\end{array}$} & \multirow{3}{*}{$\begin{aligned} \text { GRUPO } 2 \\
3.6\end{aligned}$} & \multirow{3}{*}{$\begin{array}{r}\text { GRUPO } 3 \\
1.6 \\
\end{array}$} \\
\hline & Trabajo individual & & & \\
\hline & & & & \\
\hline \multirow{4}{*}{$\begin{array}{l}\text { Trabajo } \\
\text { colabor } \\
\text { ativo }\end{array}$} & Inicio & 1.4 & 2.46 & 1.46 \\
\hline & Desarrollo & 4.13 & 1.66 & 1.33 \\
\hline & Cierre & 1.33 & 3.33 & 4.33 \\
\hline & Trabajo post entrega & 0.2 & 0 & 0.4 \\
\hline
\end{tabular}

Tabla 45: Promedio de mensajes por etapa y por grupo. Cohorte 2015

En cuanto la cantidad de mensajes por etapa según su tipo, es de hacer notar que esta cantidad no condice con la cantidad total de mensajes. En un mismo mensaje hubo componentes de dos y hasta de las tres categorías. Puede visualizarse en la figura 104.

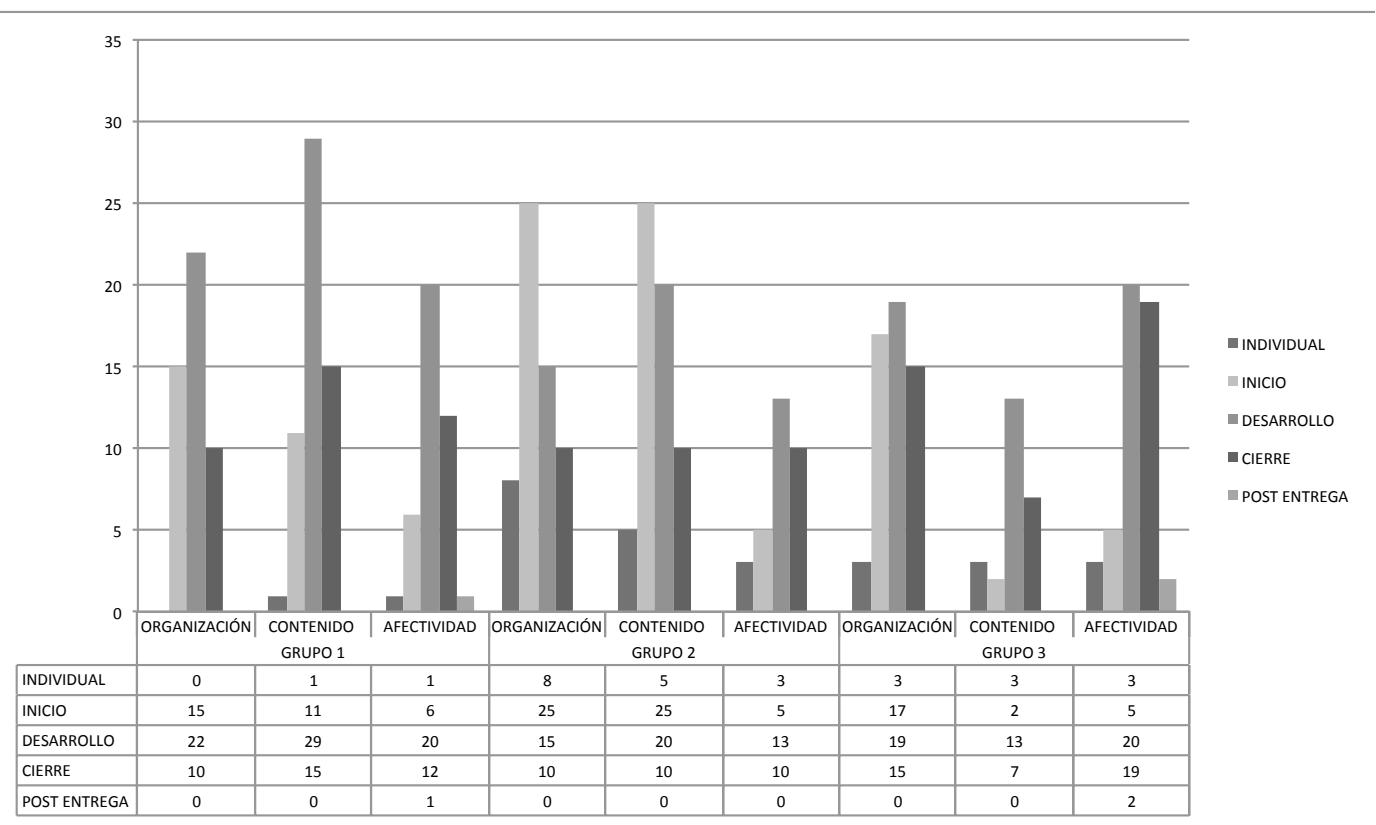

Figura 104: Mensajes por etapa y por tipo. Cohorte 2015

El promedio de cada componente de los mensajes se presenta en la tabla 46.

\begin{tabular}{|l|l|r|r|r|r|r|r|r|r|r|}
\hline & \multicolumn{1}{|c|}{ ETAPAS } & \multicolumn{3}{|c|}{ GRUPO 1 } & \multicolumn{3}{|c|}{ GRUPO 2 } & \multicolumn{3}{|c|}{ GRUPO 3 } \\
\hline & & ORG & CONT & AFEC & ORG & CONT & AFEC & ORG & CONT & AFEC \\
\hline & Individual & 0 & 0.2 & 0.2 & 1.6 & 1 & 0.6 & 0.6 & 0.6 & 0.6 \\
\hline \multirow{2}{*}{$\begin{array}{l}\text { Trabajo } \\
\text { colaborativo }\end{array}$} & Inicio & 1 & 0.73 & 0.4 & 1.6 & 1.6 & 0.33 & 1.13 & 1.13 & 0.33 \\
\cline { 2 - 11 } & Desarrollo & 1.46 & 1.93 & 1.33 & 1 & 1.33 & 0.86 & 1.26 & 1.26 & 1.33 \\
\cline { 2 - 11 } & Cierre & 2 & 2.5 & 2 & 1.6 & 1.6 & 1.6 & 2.5 & 2.5 & 3.16 \\
\hline & Post entrega & 0 & 0 & 0.2 & 0 & 0 & 0 & 0 & 0 & 0.4 \\
\hline
\end{tabular}

Tabla 46: Promedio de mensajes por tipo, por etapa y por grupo. Cohorte 2015

\section{Cohorte 2016}

La densidad de interacción por etapa está representada en la figura 105. 


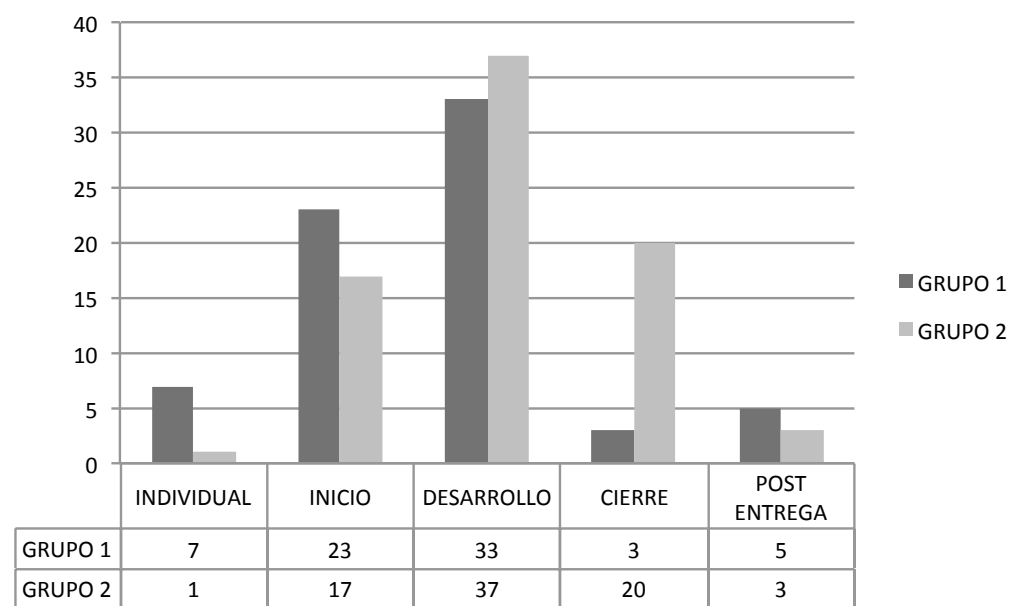

Figura 105: Densidad de interacción por etapa. Cohorte 2016

El promedio de mensajes por etapa se presenta en la tabla 47.

\begin{tabular}{|l|l|r|r|}
\hline \multicolumn{2}{|c|}{ ETAPAS } & GRUPO 1 & \multicolumn{1}{c|}{ GRUPO 2 } \\
\hline \multirow{2}{*}{$\begin{array}{l}\text { Trabajo } \\
\text { colaborativo }\end{array}$} & Trabajo individual & 1.16 & \\
& & 1.76 & 0.16 \\
\cline { 2 - 4 } & Desarrollo & 2.53 & 2.30 \\
\cline { 2 - 4 } & Cierre & 0.6 & 4 \\
\hline & Trabajo post entrega & 2.5 & 1.5 \\
\hline
\end{tabular}

Tabla 47: Promedio de mensajes por etapa y por grupo. Cohorte 2016

Los tipos de mensaje por etapa pueden visualizarse en la figura 106.

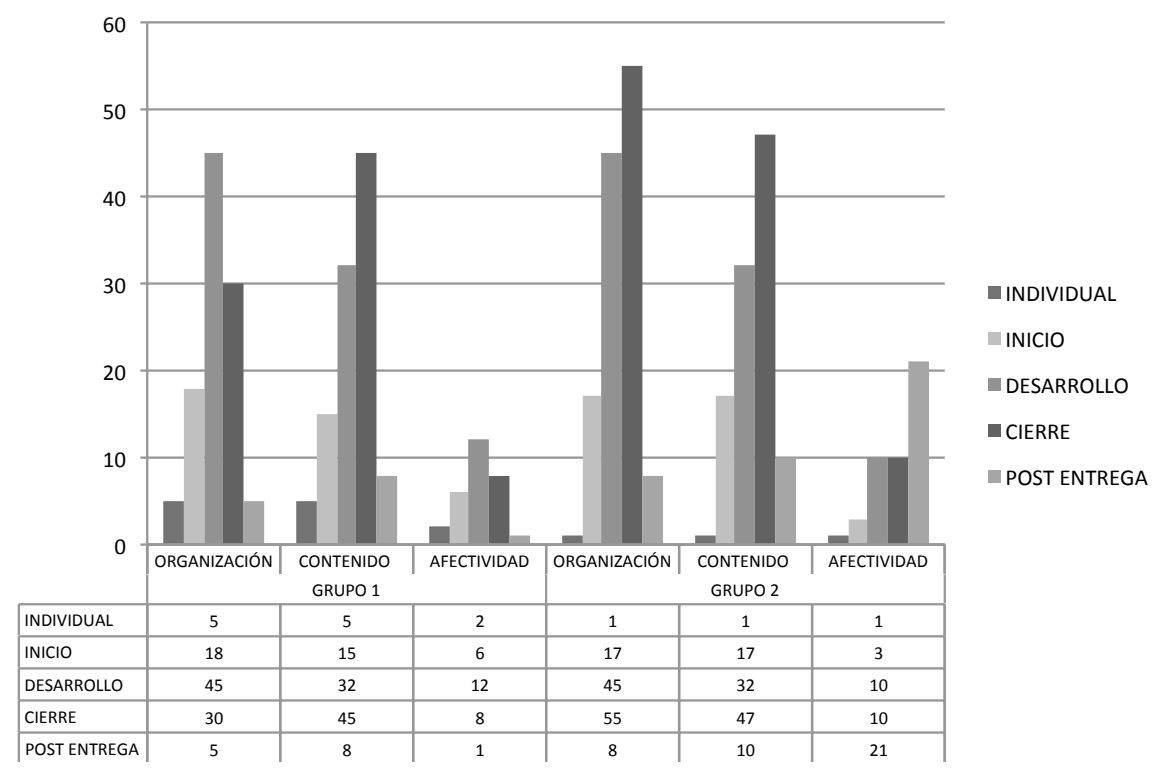

Figura 106: Mensajes por etapa y por tipo. Cohorte 2016 
El promedio de cada componente se presenta en la tabla 48.

\begin{tabular}{|l|l|r|r|r|r|r|r|}
\hline & \multicolumn{1}{|c|}{ ETAPAS } & \multicolumn{3}{|c|}{ GRUPO 1 } & \multicolumn{3}{c|}{ GRUPO 2 } \\
\hline & & \multicolumn{1}{c|}{ ORG } & \multicolumn{1}{c|}{ CONT } & \multicolumn{1}{c|}{ AFEC } & \multicolumn{1}{c|}{ ORG } & \multicolumn{1}{c|}{ CONT } & AFEC \\
\hline & Individual & 0.83 & 0.83 & 0.4 & 1.6 & 1 & 0.6 \\
\hline \multirow{2}{*}{$\begin{array}{l}\text { Trabajo } \\
\text { colaborativo }\end{array}$} & Inicio & 1.38 & 1.15 & 0.46 & 1.6 & 1.6 & 0.33 \\
\cline { 2 - 8 } & Desarrollo & 3.46 & 2.46 & 0.92 & 1 & 1.33 & 0.86 \\
\cline { 2 - 8 } & Cierre & 6 & 9 & 1.6 & 11 & 9.4 & 2 \\
\hline & Post entrega & 2.5 & 4 & 0.5 & 4 & 5 & 10.5 \\
\hline
\end{tabular}

Tabla 48: Promedio de mensajes por tipo, por etapa y por grupo. Cohorte 2016

\section{Dimensión grupal. Conexión semántica}

La forma de presentación de este indicador es el mapa de tópicos de cada grupo. Así se presenta, por cada grupo de cada cohorte, la conexión semántica. La cohorte 2015 se presenta en las figuras 107 a 109 y la cohorte 2016 en las figuras 110 y 111. Se agregan comentarios.

\section{Cohorte 2015}

\section{Grupo 1}

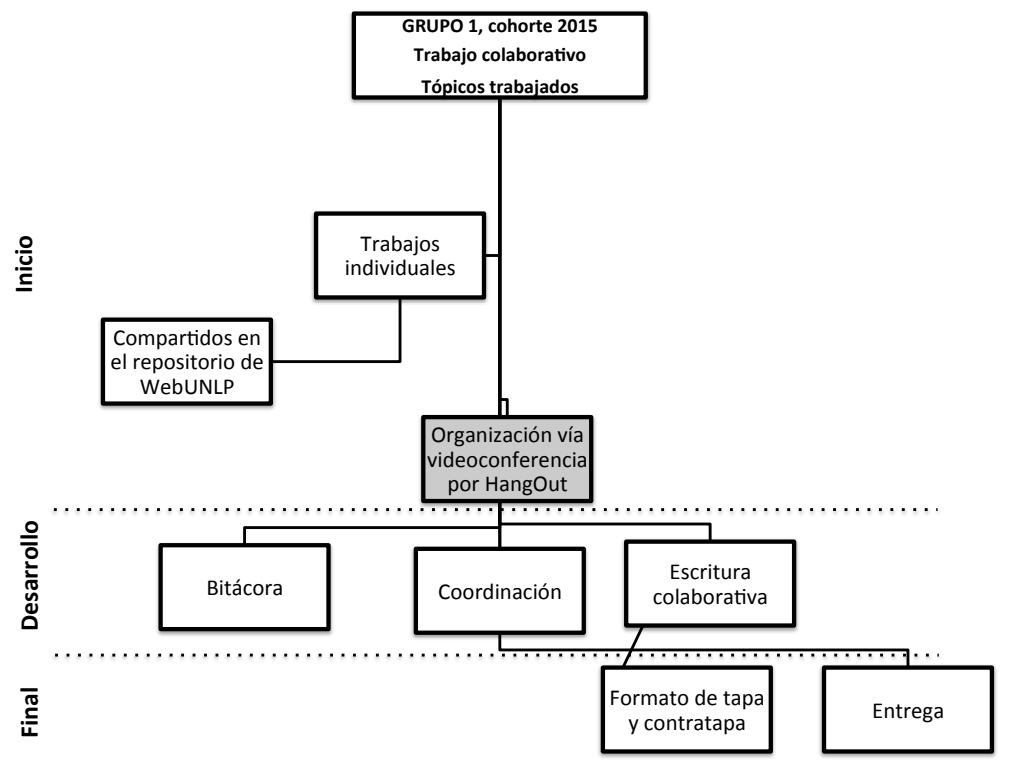

Figura 107: Mapa de tópicos. Conexión semántica. Grupo 1. Cohorte 2015

\section{Comentarios Grupo 1}

- Tópico trabajos individuales: Utilizaron el repositorio de materiales indicados para los grupos de WebUNLP.

- Tópico bitácora: Una persona comienza a hacer la bitácora. Va compartiendo el avance en GoogleDocs. Se distribuyen semanalmente las tareas, sobre la base de la estructura compartida en la primera semana.

- Tópico coordinación: se intercambian minutas de la videoconferencia en la carpeta compartida en GoogleDrive. 
- Tópico entrega: Una persona recopila y se hace cargo de la entrega.

\section{Grupo 2}

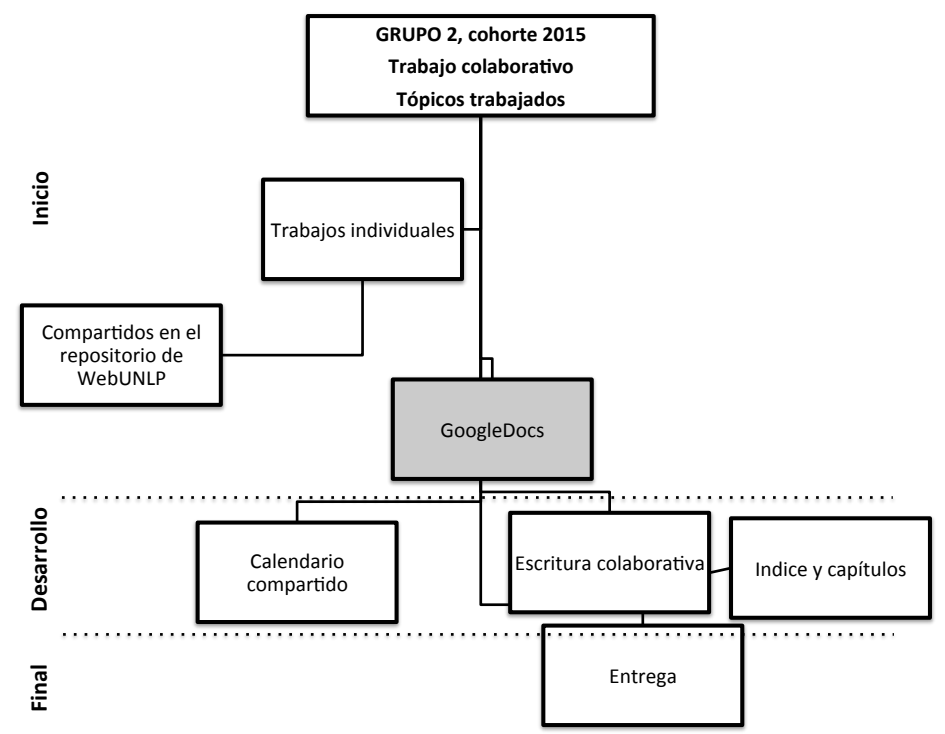

Figura 108: Mapa de tópicos. Conexión semántica. Grupo 2. Cohorte 2015

\section{Comentarios Grupo 2}

- Tópico trabajos individuales: Utilizaron el repositorio de materiales para los grupos de WebUNLP.

- Tópico bitácora: Se define un cronograma de trabajo en GoogleDocs, con tareas compartidas semanalmente y por persona. (Lo define un integrante y todos aceptan). El cronograma y las tareas compartidas ordenan la tarea grupal.

- Tópico entrega: toda la información se trabaja en el GoogleDocs compartido desde el seminario. Luego de la entrega se borran las interacciones y es imposible reconstruir. La reconstrucción fue posible por la repetición en el foro de lo que cada uno iba haciendo en el documento colectivo.

\section{Grupo 3}

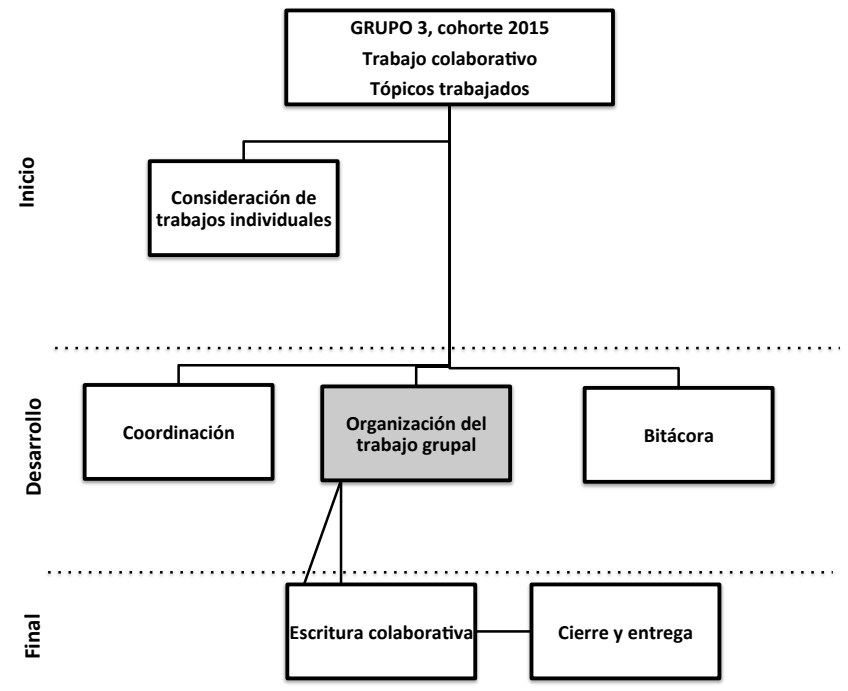




\section{Comentarios Grupo 3}

Figura 109: Mapa de tópicos. Conexión semántica. Grupo 3. Cohorte 2015

- Tópico trabajos individuales: todos habían compartido sus trabajos. Un integrante (ocupado de la coordinación en la primera etapa) lo recordó y todos lo cumplieron.

- Tópico bitácora: una persona comienza a hacer la bitácora. Va compartiendo el avance (como archivo adjunto).

- Tópico coordinación: dos integrantes del grupo se reunieron (presencialmente) y decidieron coordinar juntos.

- Tópico entrega: dos personas recopilan y se hacen cargo de la entrega.

\section{Cohorte 2016}

\section{Grupo 1}

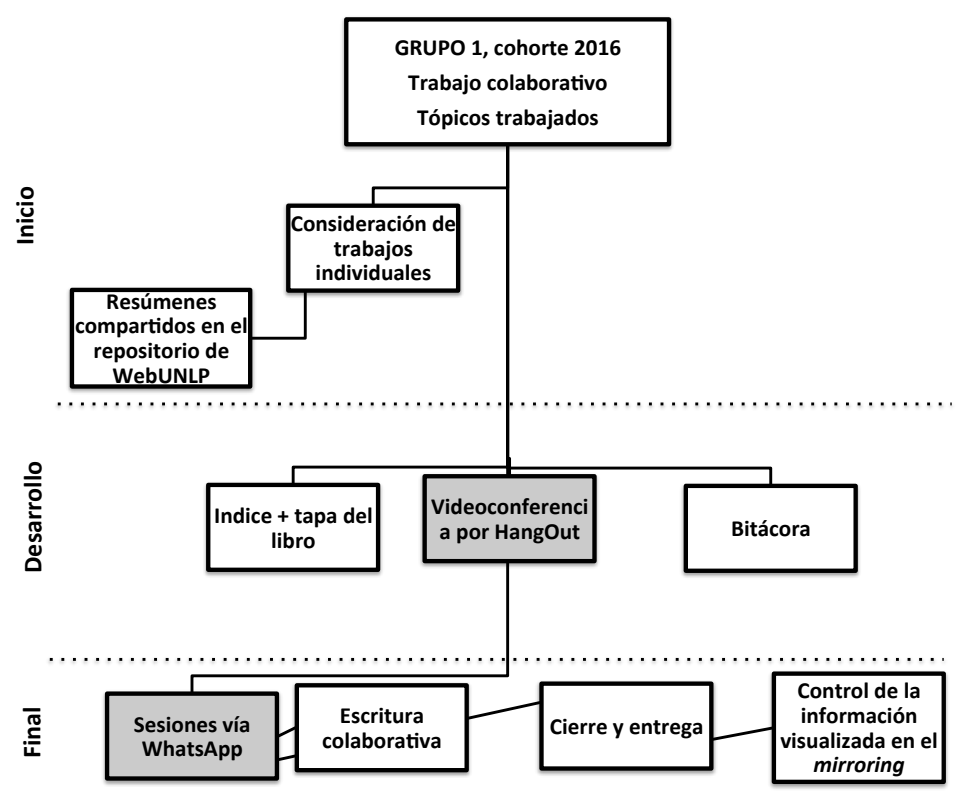

Figura 110: Mapa de tópicos. Conexión semántica. Grupo 1. Cohorte 2016

\section{Comentarios Grupo 1}

- Tópico trabajos individuales: todos comparten un resumen de sus trabajos en el repositorio compartido en WebUNLP. Un integrante se ocupó de recordarlo y ordenar el material.

- Tópico bitácora: dos personas se ocupan del tema. Se avanza mucho en la videoconferencia de la semana 5 y en el proceso de comunicación vía WhatsApp de las semanas 5 y 6 .

- Tópico Indice + tapa del libro: un integrante se ocupa de armar las sucesivas propuestas (que, al no tener demasiados comentarios, es la que se termina entregando)

- Tópico entrega: una persona se ocupa (el mismo integrante del tópico anterior).

- Tópico control de la información visualizada en el mirroring: este tópico nuevo aparece en esta cohorte. Uno de los integrantes del grupo controla que la información publicada en el sitio sobre su participación, sea la correcta. 


\section{Grupo 2}

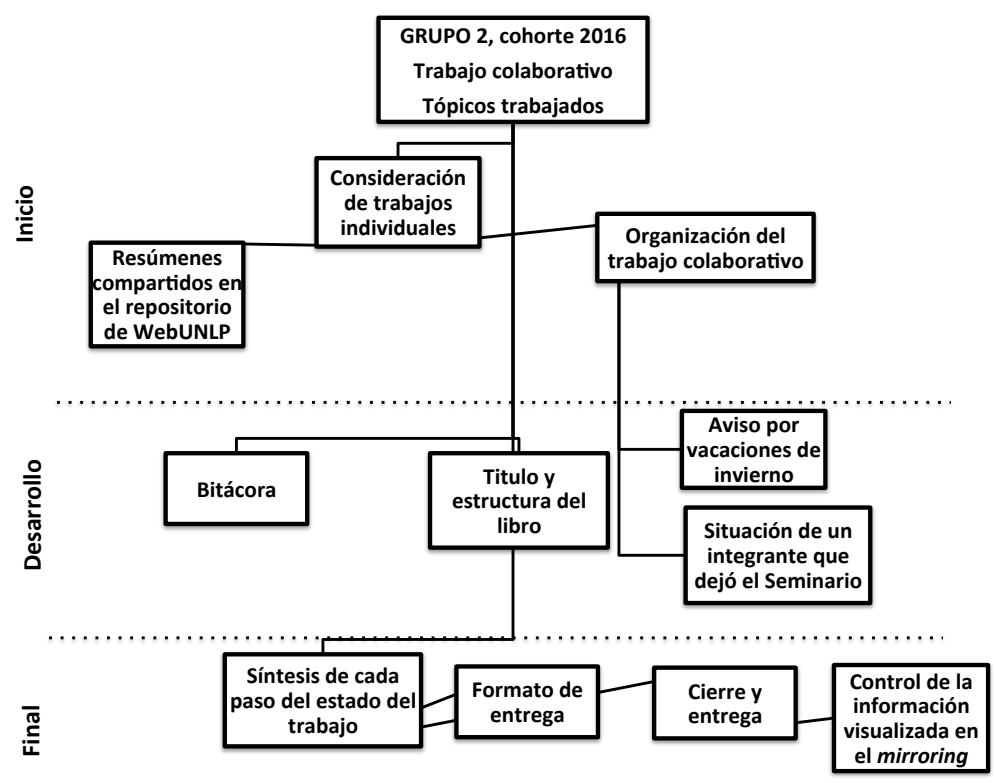

Figura 111: Mapa de tópicos. Conexión semántica. Grupo 2. Cohorte 2016

\section{Comentarios Grupo 2}

- Tópico trabajos individuales: todos comparten un resumen de sus trabajos en el repositorio compartido en WebUNLP. Todos participan en esta tarea

- Tópico bitácora: dos personas se ocupan del tema.

- Tópico organización del trabajo colaborativo: tres personas participan de esta tarea. En este grupo se organizan las vacaciones de invierno de sus integrantes y se planifica el trabajo en función de una integrante del grupo que dejó el seminario en mitad del trabajo colaborativo (se incluye su trabajo individual en la producción final)

- Tópico entrega: dos personas se ocupan.

- Tópico control de la información visualizada en el mirroring: este tópico nuevo aparece en esta cohorte.

Cabe hacer mención de que en esta segunda cohorte, como parte del proceso de mirroring descripto, los integrantes de cada grupo fueron informados semanalmente del desarrollo de los tópicos, así como el grado de participación que cada integrante del grupo tuvo en cada uno. La figura 112 presenta el mapa de tópicos del grupo 2, en la semana 6. 


\begin{tabular}{|c|c|c|c|c|c|c|}
\hline $\begin{array}{l}\text { Compartir trabajos } \\
\text { individuales }\end{array}$ & LH & LH - SB & $\begin{array}{l}\text { OC- } \mathrm{LH}- \\
\text { OS }\end{array}$ & LH & $\begin{array}{l}\text { LH JMM } \\
\text { (palabra } \\
\text { clave) }\end{array}$ & OC - LH \\
\hline Bitácora & JMM - LH & LH - LH & & & & LH - JMM \\
\hline $\begin{array}{l}\text { Planificación del trabajo } \\
\text { colaborativo }\end{array}$ & & OS - LH & $\begin{array}{l}\text { OC-OS- } \\
\text { LH- JMM }\end{array}$ & os & LH JMM & $\begin{array}{l}\text { OS- LH - } \\
\text { LMM }\end{array}$ \\
\hline $\begin{array}{l}\text { Situación de estudiante que } \\
\text { dejó el Seminario }\end{array}$ & & & os & $\begin{array}{l}\text { LH } \\
\text { (Comparte } \\
\text { trabajo) }\end{array}$ & & \\
\hline Aviso de vacaciones & & & os & & & \\
\hline Titulo del libro & & & & & LH - JMM & \\
\hline Organización del libro & & & & & $\begin{array}{l}\text { JMM (de lo } \\
\text { general a lo } \\
\text { particular) }\end{array}$ & JMM - LH \\
\hline Prólogo del libro & & & & & & $\begin{array}{l}\text { OS - LH- } \\
\text { JMM }\end{array}$ \\
\hline $\begin{array}{l}\text { Diferencia entre } \\
\text { "currículum" y "currícula" }\end{array}$ & & & & & & LH - JMM \\
\hline $\begin{array}{l}\text { Síntesis de estado del } \\
\text { trabajo }\end{array}$ & & & & & & OS- LH \\
\hline Formato de entrega & & & & & & SB - OS \\
\hline \multirow[t]{3}{*}{ Envío } & & & & & & $\underset{\text { OH }}{\text { OS - JMM- }}$ \\
\hline & $\begin{array}{l}\text { Semana del } \\
29 / 6 \text { al } 5 / 7\end{array}$ & $\begin{array}{c}\text { Semana del } \\
6 \text { al } 12 / 7\end{array}$ & $\begin{array}{l}\text { Semana del } \\
13 \text { al } 19 / 7\end{array}$ & $\begin{array}{l}\text { Semana del } \\
20 \text { al } 26 / 7\end{array}$ & $\begin{array}{l}\text { Semana del } \\
27 / 7 \text { al } 2 / 8\end{array}$ & $\begin{array}{l}\text { Semana de } \\
\mathbf{3} \text { al } 8 / 7\end{array}$ \\
\hline & 1 & 2 & 3 & 4 & 5 & 6 \\
\hline
\end{tabular}

\section{Semanas}

Figura 112: Tópicos trabajados por semana en la información de mirroring del grupo 2 de la cohorte 2016 


\section{Anexo 5: Sitios de interés construídos especialmente para esta tesis}

\section{Encuesta a expertos para el juicio de expertos}

https://docs.google.com/forms/d/e/1FAIpQLSd0YtJ1iggtuImxghkABRkxRoDsIMPdpka6cgTI_O $\mathrm{xCmFlZHw/viewform}$

Instrumento de autorregulación

https://docs.google.com/forms/d/e/1FAIpQLScNdx9KJHtBeY6nsnik-mRMfzfq4RTjOBPiVv18N4U2EfzFw/viewform

Sitio de seguimiento del trabajo colaborativo para mirroring (en GoogleSites)

https://sites.google.com/site/trabajocolaborativoead/home?previewAsViewer=1

Instrumento de indagación de impacto de la estrategia de mirroring https://docs.google.com/forms/d/e/1FAIpQLScistelIQXiz8gDrQ9rcOiZTcihQ2ZK_f1ntxkVCg16 $\mathrm{NNgDNg}$ /viewform

Análisis de las estrategias de argumentación en un tópico completo, mediado por la herramienta foro. Ambas cohortes

https://sites.google.com/site/trabajocolaborativoead/home/analisis-de-la-argumentacion 